Gallien in Spätantike und Frühmittelalter 


\section{Millennium-Studien}

zu Kultur und Geschichte des ersten Jahrtausends n. Chr.

\section{Millennium Studies}

in the culture and history of the first millennium C.E.

Herausgegeben von / Edited by

Wolfram Brandes, Alexander Demandt, Helmut Krasser, Hartmut Leppin, Peter von Möllendorff, Karla Pollmann

Band 43 


\title{
Gallien in Spätantike und Frühmittelalter
}

Kulturgeschichte einer Region

\author{
Herausgegeben von \\ Steffen Diefenbach \\ und \\ Gernot Michael Müller
}

De Gruyter 
Gedruckt mit Unterstützung der Gesellschaft der Freunde der Universität Augsburg e.V. und des Kompetenzzentrums für Kultur- und Bildungswissenschaft der Universität Augsburg.

Diese Publikation wurde im Rahmen des an der Bayerischen Staatsbibliothek durchgeführten und durch das Bundesministerium für Bildung und Forschung geförderten Vorhabens 16TOA021 - Reihentransformation für die Altertumswissenschaften („Millennium Studien“) mit Mitteln des DFG-geförderten Projekts Fachinformationsdienst Altertumswissenschaften - Propylaeum im Open Access bereitgestellt.

\section{(cc) BY-NC-ND}

Dieses Werk ist lizenziert unter der Creative Commons Attribution-NonCommercial-NoDerivatives 4.0 International Lizenz. Weitere Informationen finden Sie unter http://creativecommons.org/licenses/by-nc-nd/4.0/.

Die Bedingungen der Creative-Commons-Lizenz gelten nur für Originalmaterial. Die Wiederverwenung von Material aus anderen Quellen (gekennzeichnet mit Quellenangabe) wie z.B. Schaubilder, Abbildungen, Fotos und Textauszüge erfordert ggf. weitere Nutzungsgenehmigungen durch den jeweiligen Rechteinhaber.

ISBN 978-3-11-026005-2

e-ISBN 978-3-11-026077-9

ISSN 1862-1139

Library of Congress Cataloging-in-Publication Data

A CIP catalog record for this book has been applied for at the Library of Congress.

Bibliografische Information der Deutschen Nationalbibliothek

Die Deutsche Nationalbibliothek verzeichnet diese Publikation in der Deutschen Nationalbibliografie; detaillierte bibliografische Daten sind im Internet über http://dnb.dnb.de abrufbar.

(C) 2013 Walter de Gruyter GmbH, Berlin/Boston

Druck: Hubert \& Co. GmbH \& Co. KG, Göttingen

(@) Gedruckt auf säurefreiem Papier

Printed in Germany

www.degruyter.com 
Inhaltsverzeichnis

Abkürzungsverzeichnis .................................................................................

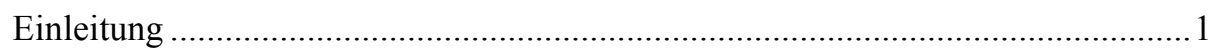

I. RÖMER UND BARBAREN:

POLITISCHE STRUKTUREN DES ZUSAMMENLEBENS

UND STRATEGIEN DER INTEGRATION

Christine Delaplace

Les relations entre les Wisigoths et le pouvoir romain de 411 à 439 :

Comment faut-il interpréter la politique des foedus

et la logique de ses acteurs dans la Gaule

de la première moitié du $\mathrm{V}^{\mathrm{e}}$ siècle ap. J.-C.?

Walter Goffart

Administrative Methods of Barbarian Settlement in the Fifth Century:

The Definitive Account .45

II. RÖMISCHE ELITEN IN GALLIEN:

TRANSFORMATIONEN IDENTITÄRER BEZUGSFELDER

John F. Drinkwater

Un-becoming Roman. The End of Provincial Civilisation in Gaul

Michael Kulikowski

Sundered Aristocracies, New Kingdoms, and the End of the Western Empire

Steffen Diefenbach

„Bischofsherrschaft“. Zur Transformation der politischen Kultur im spätantiken und frühmittelalterlichen Gallien 
III. STÄDTISCHER RAUM UND IDENTITÄT:

URBANER STRUKTURWANDEL IM SPÄTANTIKEN GALLIEN

Christian Witschel

Die spätantiken Städte Galliens:

Transformationen von Stadtbildern

als Ausdruck einer gewandelten Identität?

Jean Guyon

Les chefs-lieux de cités de Gaule méridionale aux $\mathrm{V}^{\mathrm{e}}$ et $\mathrm{VI}^{\mathrm{e}}$ siècles:

Un espace urbain en mutation 201

Simon T. Loseby

Lost cities. The End of the civitas-system in Frankish Gaul

IV. ZWISCHEN AUSSENSEITER UND RÖMISCHEM BÜRGER:

ZUR MODELLIERUNG VON RANDGRUPPEN

IM SPÄTANTIKEN GALLIEN

David Lambert

Salvian and the Bacaudae .255

Philipp von Rummel

Unrömische Römer und römische Barbaren.

Die Fluidität vermeintlich präziser Leitbegriffe der Forschung zum spätantiken Gallien

V. VERFAHREN UND KULTURELlE METHODEN

KOLLEKTIVER IDENTITÄTSSTIFTUNG

IN DEN BARBARISCHEN REGNA

Alexander Callander Murray

So-called Fictitious Trial in the Merovingian Placita 
VI. HeIDNISCHE MOdELlE UND CHRISTLICHE KUltur:

FUNKTIONSFELDER VON TRADITIONSBILDUNG

IN DER SPÄTANTIKEN LITERATUR

Meinolf Vielberg

Picture and Poetry.

Conceptions of the Hereafter and of Court Scenes

in the Works of Ausonius of Bordeaux and Paulinus of Nola......

Antonella Bruzzone

Mito e politica nei Panegyrici di Sidonio Apollinare

Philippe Bruggisser

Un remodelage identitaire.

Enquête sur les concepts de vitae exordium et d'innocentia

dans la Passion des martyrs d'Agaune d'Eucher de Lyon

VII. LITERARISCHE KOMMUNIKATION IM SPÄTANTIKEN GALLIEN

ZWISCHEN UNIVERSALER BILDUNGSTRADITION

UND REGIONALISIERUNG

\section{Ulrich Eigler}

Gallien als Literaturlandschaft.

Zur Dezentralisierung und Differenzierung

lateinischer Literatur im 5. und 6. Jh.

Gernot Michael Müller

Freundschaften wider den Verfall.

Gemeinschaftsbildung und kulturelle Selbstverortung

im Briefwechsel des Ruricius von Limoges

Ralph W. Mathisen

Desiderius of Cahors: Last of the Romans 455

Orts- und Namenregister

Stellenregister 



\section{Abkürzungsverzeichnis}

AASS

CCSL

CSEL

CTh

$\mathrm{CJ}$

FC

GCS

HLL

LCL

MGH

MGH Auct. ant.

MGH Capit.

MGH Epp.

MGH LL

MGH LL nat. Germ. Monumenta Germaniae historica.

Leges nationum Germanicarum

MGH SS

MGH SS rer. Merov. Monumenta Germaniae historica.

Scriptores rerum Merovingicarum

Acta Sanctorum

Corpus Christianorum, series Latina

Corpus scriptorum ecclesiasticorum Latinorum

Codex Theodosianus

Codex Iustinianus

Fontes christiani

Die griechischen christlichen Schriftsteller der ersten drei Jahrhunderte

Handbuch der lateinischen Literatur der Antike

Loeb Classical Library

Monumenta Germaniae historica

Monumenta Germaniae historica. Auctores antiquissimi

Monumenta Germaniae historica.

Capitularia regum Francorum

Monumenta Germaniae historica. Epistolae

Monumenta Germaniae historica. Leges

Monumenta Germaniae historica. Scriptores 
PL

PLRE

$\mathrm{SC}$

TU
Patrologia latina

Prosopography of the Later Roman Empire

Sources chrétiennes

Texte und Untersuchungen zur Geschichte der altchristlichen Literatur 


\section{Einleitung}

I.

Die Zeit zwischen dem frühen 5. und dem ausgehenden 6. Jh. n. Chr. ist im Westen des römischen Reichs gekennzeichnet durch tiefgreifende und epochale Veränderungen, die sich zeitgleich, aber nicht unbedingt synchron auf unterschiedlichen Feldern des politischen, gesellschaftlichen, wirtschaftlichen, religiösen und kulturellen Lebens vollzogen. Unabhängig davon, ob man dieses Phänomen als „Niedergang“ oder als „Transformation“ qualifiziert und welchen historischen Akteuren und strukturellen Faktoren man den maßgeblichen Einfluss auf die damit verbundenen Entwicklungen zuspricht: Man hat es bei den dadurch bedingten Veränderungen nicht mit einem katastrophischen Umschlag der Verhältnisse, sondern vielmehr mit einem Strukturwandel mittlerer Reichweite zu tun, der eine Betrachtung über einen ausgedehnten Zeitraum mehrerer Jahrhunderte erfordert. ${ }^{1}$

Als wesentliche Charakteristika dieses Strukturwandels gelten traditionell sich verändernde Formen der Herrschaftsbildung und der politischen wie kulturellen Vergemeinschaftung, die sich in wesentlichen Aspekten vom Imperium der frühen und hohen Kaiserzeit unterschieden und Regionalisierungstendenzen Vorschub leisteten. So hatte u. a. die Schwächung der monarchischen Spitze im Westen des Imperiums zur Folge, dass die beiden zentralen Trägergruppen einer reichsbezogenen Integration - die römischen Truppen und die senatorische Aristokratie - sich nicht mehr am universalen Ordnungszusammenhang des Imperi-

1 Das letztlich auf Edward Gibbons „Decline and Fall of the Roman Empire“ zurückgehende Niedergangsparadigma ist im Zuge der zunehmenden Etablierung einer primär kultur- und religionsgeschichtlich ausgerichteten Spätantike-Forschung seit den 1960er und 1970er Jahren zugunsten einer neutraleren Transformationsperspektive relativiert worden. Zuletzt haben Heather 2005 und Ward-Perkins 2005 die Kategorie des Niedergangs erneut in die wissenschaftliche Diskussion eingebracht - verbunden mit einer stärkeren Akzentsetzung auf der Geschichte der politischen, administrativen und wirtschaftlichen Strukturen; ähnlich zuletzt Christie 2011 (für eine - wohlwollende - Auseinandersetzung mit diesem Ansatz vgl. Rutenburg/Eckstein 2007; Marcone 2008. Zu den bleibenden Anknüpfungspunkten von Gibbons Werk auch für die aktuelle Forschungsdiskussion vgl. ferner Ando 2009). Wenn im Folgenden der Begriff „Transformation“ bevorzugt wird, ist dies nicht als Positionierung in dieser Debatte zu verstehen, sondern allein dem Umstand geschuldet, dass der Begriff des Niedergangs apriorische Bewertungsmaßstäbe und Kriterien impliziert, die den Blick auf wesentliche Charakteristika dieser Transformationszeit von vornherein zu verstellen drohen. 
ums orientierten. Ferner löste der Zuwachs an staatlicher Durchdringung, insbesondere in ländlichen Gebieten, Gegenreaktionen aus, sich dem Schutz lokaler potentes zu unterstellen. Die kirchliche Organisation brachte ihrerseits eine eigene institutionelle Struktur hervor, die neben der politischen Ordnung des Imperiums existieren konnte und gleichzeitig ihren Führern durch die habituelle Angleichung an das Umfeld der politischen Kultur neue Möglichkeiten in ihrem Streben nach Ehre und Einfluss im lokalen und regionalen Rahmen eröffnete. Auch für die barbarischen gentes erwies sich dieser regionale Bezug als entscheidend: Sie brachen nicht einfach als feste und geschlossene Verbände über das Römische Reich herein, sondern entwickelten sich erst durch die Kooperation mit dem Imperium zu schärfer konturierten Einheiten - ein dynamischer Prozess kollektiver Identitätsstiftung, der auch nach dem Zusammenbruch der römischen Administration nicht abgeschlossen war, sondern anhaltend neue Herausforderungen an die Integrationsfähigkeit ethnischer Identität im jeweiligen regionalen Kontext stellte.

In ähnlicher Weise wie die politische ist auch die literarische Kultur des Untersuchungszeitraums geprägt von vergleichbaren Wandlungs- und Umbruchsprozessen. Dies zeigt sich zum einen in einem kreativen Umgang mit dem traditionellen Gattungsrepertoire und in der Etablierung neuer christlicher Gattungen wie etwa der Hagiographie in Prosa und Vers, welche traditionelle heidnische Texttypen adaptierten und weiterentwickelten. Zum anderen zeichnen sich nicht zuletzt auch diese durch einen teilweise ostentativ inszenierten Traditionsbezug aus, der von der Anspielung über das offensichtliche Zitat bis hin zur centonenhaften Adaptation ganzer Werke reicht. Dieses ambivalente Spannungsfeld zwischen einer zur Hybridbildung neigenden Innovation und einer gleichzeitigen engen Anlehnung an klassische Vorbilder in Sprache und Stil wird in zunehmendem Maße als Ausdruck einer Strategie kultureller Standortbestimmung bei gleichzeitiger Anpassung an neue Bedürfnisse der literarischen Kommunikation begriffen. Diese liegen einerseits in der Integration divergierender politischer und gesellschaftlicher Kräfte über die entweder stilistisch-formale oder inhaltlich-konzeptuelle Betonung eines gemeinsamen kulturellen Erbes sowie generell in der wechselseitigen Vergewisserung ihrer Träger, Garanten für die Fortdauer römischer eruditio zu sein. Besonders deutlich tritt diese Funktion spätantiker Literatur in den elaborierten Briefkorpora der Zeit wie auch in deren Vorliebe für Gelegenheitsdichtungen entgegen, die als Freundschaftsgaben zirkulierten und auf diese Weise der Gemeinschaftsbildung einer sich über ihre Bildung definierenden Elite dienten, deren Vernetzung sich in immer stärkerem Maße regionalisierte.

$\mathrm{Zu}$ diesen Themenbereichen liegt eine ausgedehnte Forschungsliteratur vor, die sowohl hinsichtlich Quellen- und Materialerschließung wie auch in der interpretatorischen Durchdringung ihrer Gegenstände Maßstäbe setzt. ${ }^{2}$ Was diese

2 Im Folgenden eine umfassende Auflistung von Titeln zu einem so stark expandierenden Forschungsfeld wie der spätantiken und frühmittelalterlichen Geschichte präsentieren zu wollen, erübrigt sich von selbst. Wir beschränken uns darauf, auf einige maßgebliche Ar- 
Literatur indes weitgehend charakterisiert, ist die in der Regel separate Behandlung der oben skizzierten Bereiche. Dies gilt nicht nur für jüngere Gesamtdarstellungen zur spätantiken Geschichte, die insgesamt eine ausgeprägtere Hinwendung zur politischen, administrativen und wirtschaftlichen Geschichte erkennen lassen und andere, religions- und kulturgeschichtliche Themen nur am Rande behandeln. ${ }^{3}$ Auch in den zahlreichen Tagungsbänden, die aus dem von der European Science Foundation geförderten Wissenschaftlernetzwerk ${ }^{4}$ und dem am Institut für Mittelalterforschung der Österreichischen Akademie der Wissenschaften angesiedelten Wittgensteinprojekt zur Bildung ethnischer Identitäten im frühmittelalterlichen Europa seit Mitte der 1990er Jahre hervorgegangen sind, dominiert der Versuch, das Thema ,Transformation der römischen Welt" im Westen des römischen Reichs durch die separate Erschließung einzelner Themenbereiche in den Blick zu nehmen. ${ }^{5}$ Für dieses wohl ambitionierteste Projekt der letzten Jahre, einen spätantiken Strukturwandel in umfassender Weise zu konzeptualisieren, ist dabei ferner charakteristisch, dass die Perspektive auf diesen Transformationsprozess sehr stark durch spezifisch mediävistische Interessen geprägt ist. So stehen Fragen der Ethnogenese und der gentilen Herrschaftsstrukturen eindeutig im Vordergrund $;{ }^{6}$ daneben bilden - jedoch deutlich weniger ausgeprägt - die Stadt, ${ }^{7}$ die christliche Sakraltopographie und durch christliche Rituale vermittelte Formen der kollektiven Identitätsstiftung weitere thematische Schwerpunkte. ${ }^{8}$ Aspekte der literarischen Kommunikation und der Poetik finden hingegen deutlich geringere Beachtung.

Für das Gros der jüngeren Literatur ist demnach kennzeichnend, dass sich diese auf einzelne Themenbereiche und Handlungsfelder konzentriert und diese im regionenübergreifenden Vergleich untersucht. ${ }^{9}$ Versuche, diese unterschiedlichen Bereiche und Felder in ihren Interdependenzen zueinander in Beziehung zu

beiten zu verweisen, die nach unserer Einschätzung die Tendenzen und den Stand der Forschung exemplarisch charakterisieren.

3 Mitchell 2007. Für den Westen vgl. Halsall 2007; Börm 2013.

4 Für eine Bilanz des von 1993 bis 1998 von der European Science Foundation (ESF) geförderten Projekts vgl. Wood 1997.

5 Die von der ESF finanzierten Konferenzen sind in der Reihe „Transformation of the Roman World“ (Leiden) veröffentlicht worden und umfassen 14 Tagungsbände (19972004). Die Tagungen des Wittgensteinprojekts (2005-2010) sind in den „Forschungen zur Geschichte des Mittelalters“(Wien) publiziert worden.

6 Pohl/Reimitz 1998; Poh1/Diesenberger 2002; Goetz u.a. 2003; Airlie u.a. 2006; Pohl/Zeller 2012. Zum Thema Ethnizität und Ethnogenese in Spätantike und Frühmittelalter vgl. außerdem Mitchell/Greatrex 2000; Gillett 2002 und Pohl u.a. 2012.

7 Brogiolo/Ward-Perkins 1999; Brogiolo u.a. 2000. Zur Stadt vgl. ferner Liebeschuetz 2001; Bauer/Witschel 2006.

8 De Jong/Theuws 2001; Theuws/Nelson 2000.

9 Diesem Ansatz folgt auch die monumentale Synthese zur frühmittelalterlichen Geschichte von Wickham 2005. Handbücher zur Spätantike verfahren ähnlich; vgl. etwa Demandt 2007; Cameron u.a. 2000. Andere Schwerpunkte und einen geringeren Anspruch auf systematische Geschlossenheit erheben Bowersock u.a. 1999. 
setzen, bilden demgegenüber die Ausnahme. Dies macht sich insbesondere in der eingangs bereits angedeuteten und insbesondere in der englischsprachigen Forschung verbreiteten Tendenz bemerkbar, sich entweder auf kultur- und religionsgeschichtliche Themen oder auf Politik-, Verwaltungs- und Wirtschaftsgeschichte zu konzentrieren. ${ }^{10}$ Als dringliches Desiderat der Forschung ergeben sich demnach Ansätze, die diese Trennung zu überwinden und im Sinne einer umfassenden Kulturgeschichte auch des Politischen zu integrieren versuchen. ${ }^{11}$

Eine Möglichkeit, sich dieser Herausforderung zu stellen, besteht darin, über regionale Studien eine Untersuchung unterschiedlicher Handlungsfelder in vergleichender Perspektive zusammenzuführen und miteinander zu einer integrierenden Kulturgeschichte zu verbinden. Die spätantike und frühmittelalterliche Region Gallien ${ }^{12}$ bietet sich dafür in besonderer Weise an, da sie ein quellenmäBig besonders gut bezeugtes Beispiel für den eingangs skizzierten langfristigen Transformationsprozess darstellt, in dessen Verlauf die Zugehörigkeit zum römischen Imperium einer Regionalisierung wich, in deren Rahmen die traditionellen Bezugsfelder kollektiver Identitätsstiftung grundlegend neu definiert wurden. Regionale Studien zum spätantiken und frühmittelalterlichen Gallien, die diese Transformationszeit zum Gegenstand haben, erschöpfen sich bisher vor allem in Forschungsüberblicken, die eine fundierte Zusammenschau der archäologischen Überlieferung und ihrer Implikationen für die Entwicklung von Siedlungs- und Wirtschaftsräumen bieten. ${ }^{13}$ Deutungen dieser Befunde mit Blick auf die politische Kultur und die damit einhergehenden Wahrnehmungen der historischen Akteure treten jedoch weitgehend in den Hintergrund. Eine bemerkenswerte Ausnahme bildet in dieser Hinsicht ein von John F. Drinkwater und Hugh Elton her-

10 Diese divergierenden Ansätze haben sich in den letzten Jahrzehnten forschungspragmatisch und auch terminologisch verfestigt: Während eine seit etwa zwei Generationen blühende „Spätantike“-Forschung die Religions-, Literatur- und Kulturgeschichte stark in den Vordergrund gerückt hat, ist in den letzten Jahren eine verstärkte Rückkehr zu traditionellen Themen der Politik-, Institutionen- und Wirtschaftsgeschichte zu verzeichnen, die in der Regel aus der Perspektive der Verhältnisse der Hohen Kaiserzeit erfolgt und dementsprechend den Untersuchungszeitraum meist als „spätrömische Geschichte“ versteht (zu „Late Antiquity“ und „Later Roman Empire“ als Leitbegriffen dieser divergierenden Ansätze vgl. Mitchell 2007, 5-9; eine konzise forschungsgeschichtliche Aufarbeitung bietet Marcone 2008. Vgl. auch o., Anm. 1).

11 So auch Cameron u.a. 2000, 980f. als Bilanz des abschließenden Bandes der „Cambridge Ancient History“. In eine ähnliche Richtung argumentiert Ando 2008, bes. 48-51, der für eine stärkere historische Kontextualisierung gerade auch des Phänomens „Kultur“ plädiert. Für einen programmatischen und gelungenen Versuch, Institutionen- und Kulturgeschichte miteinander zu verbinden, vgl. exemplarisch die Studie von Millar 2006. Zum Konzept einer „Kulturgeschichte“ im umfassenden Sinn s. u., S. 5 f.

12 Unter Gallien wird der Bereich der beiden spätantiken Diözesen - Galliae nördlich und Septem Provinciae südlich der Loire - verstanden, auf deren Territorium sich im Laufe des 5. Jh.s die regna der Westgoten, Burgunder und Franken bildeten. Zur Einheit dieser Region im 5. und 6. Jh. vgl. Jones 2009, $7 \mathrm{f}$.

13 Heijmans/Guyon 2006-2007; Gauthier/Picard 1986-2007. 
ausgegebener Sammelband, ${ }^{14}$ der sich allerdings auf das 5 . Jh. beschränkt und damit nur auf die erste Phase eines längerfristigen Strukturwandels, der auf zahlreichen Handlungsfeldern erst an der Wende vom 6. zum 7. Jh. zu einem erkennbaren Abschluss kam. ${ }^{15}$

Diese Aufgabe, die regionale Transformation Galliens als einen umfassenden und langfristigen kulturgeschichtlichen Prozess in den Blick zu nehmen, hat eine internationale Tagung in Angriff genommen, die von 16. bis 19. September 2009 in Augsburg in den historischen Räumen des Augustana-Forums stattgefunden hat. Ihr Ziel war es, die für den Übergang von der Spätantike zum Frühmittelalter charakteristischen Transformationsprozesse mit Blick auf das spätantike Gallien zwischen dem frühen 5. und der Wende vom 6. zum 7. Jh. n. Chr. ${ }^{16} \mathrm{zu}$ analysieren und in ihren regional spezifischen Ausprägungen und Interdependenzen zu erfassen. In methodischer Hinsicht war dieses Vorhaben jüngeren Ansätzen zur Kulturgeschichte verpflichtet, die im Unterschied zu Kulturgeschichten traditionellen Zuschnitts ${ }^{17}$ „Kultur“ nicht als einen bestimmten gesellschaftlichen Sektor neben anderen wie z. B. Politik, Wirtschaft oder Religion, sondern als die Summe mentaler Dispositionen begreifen, die in unterschiedlichen Feldern des gesellschaftlichen Lebens wirksam werden. ${ }^{18}$ Dabei suggeriert der Kulturbegriff weniger eine holistische Geschlossenheit im Sinne einer einheitlichen Kultur ${ }^{19}$ als vielmehr eine methodische Herangehensweise, die nach den Haltungen der historischen Akteure sowie nach den Perspektiven und Wahrnehmungen fragt, die ihr Handeln bestimmen. Einer konsequent kulturwissenschaftlich ausgerichteten Geschichtsforschung geht es dementsprechend weniger um die histoire totale einer Kultur als um die Bildung transdiziplinärer Leitbegriffe, die den Blick auf Sinnstiftungs- und Deutungshorizonte historischer Akteure eröffnen und die aus

14 Drinkwater/Elton 1992.

$15 \mathrm{Zu}$ dieser Periodisierung vgl. die folgende Anm.

16 Der Beginn des Untersuchungszeitraums orientiert sich an den schweren Erschütterungen der Rheingrenze zu Beginn des 5. Jh.s; die untere Zeitgrenze - die Wende vom 6. zum 7. Jh. - trägt dem Umstand Rechnung, dass erst im Laufe des 7. Jh.s zentrale Veränderungen insbesondere in der Elitenbildung und Vergemeinschaftung einsetzten, die auf den Beginn einer neuen Zeit verweisen. Eine vergleichbare Periodisierung liegt auch dem 14. Band der „Cambridge Ancient History“ zugrunde, der den Zeitraum von 425 bis ca. 600 abdeckt.

17 Für das spätantike und frühmittelalterliche Gallien vgl. z. B. Vieillard-Troiekouroff 1976; Weidemann 1982; Beaujard 2000.

18 Vgl. die konzise Standortbestimmung von Gotter 2001. Für eine instruktive, aus den Forschungsdebatten um den Kulturbegriff entwickelte Annäherung an die „neue Kulturgeschichte" vgl. Tschopp/Weber 2007, bes. 72-81.

19 Die Problematik eines holistischen Kulturbegriffs ist in jüngerer Zeit vor allem in den Diskussionen um das kulturelle Gedächtnis, wie es maßgeblich von Jan Assmann (grundlegend in: Assmann ${ }^{5}$ 2005) konzeptualisiert wurde, deutlich geworden: Kritiker des Konzepts - vor allem aus der angloamerikanischen „social memory“-Forschung - haben zu Recht moniert, dass kollektive Identitäten in ihrer Pluralität nicht ohne weiteres durch vereinheitlichende Kategorien wie Kultur oder Mentalität miteinander verbunden werden können (zur Debatte vgl. Diefenbach 2007, 5-12). 
der Perspektive unterschiedlicher Fachdisziplinen in den Blick genommen werden. ${ }^{20}$ In diesem Rahmen nehmen insbesondere Formen kollektiver Identitätsstiftung und die damit verbundenen Integrationsleistungen einen führenden Rang in der kulturwissenschaftlichen Agenda ein. ${ }^{21}$ Im Sinne einer kulturwissenschaftlichen Konzeptualisierung der Tagung kam daher der Interdisziplinarität von Althistorikern und Mediävisten, klassischen und christlichen Archäologen sowie Philologen und Literaturwissenschaftler eine hohe Bedeutung zu. Durch sie sollten nicht nur einzelne inhaltliche Bereiche abgedeckt, sondern vielmehr bestimmte Phänomene wie etwa die Identitätsstiftung von zivilen und klerikalen Eliten, städtischen Gemeinschaften und militärischen Herrschaftsträgern aus unterschiedlichen Perspektiven in den Blick genommen werden.

Der Tagung ging es somit darum, durch die Bezugnahme auf eine bestimmte Region sowie die für diese konstitutiven sozialen Trägergruppen einen langfristig wirksamen Transformationsprozess modellhaft zu erhellen, der einen umfassenden kulturellen Strukturwandel zur Folge hatte. Ihr spezifisches Profil im Kontext der Publikations- und Tagungstätigkeit der letzten Jahre lässt sich wie folgt in Stichworten zusammenfassen:

1. eine regionale Studie, die von einer vergleichenden Perspektive auf unterschiedliche Regionen bewusst absieht und stattdessen unterschiedliche Aspekte kollektiver Identitätsstiftung am Beispiel des Kulturraums Gallien zueinander in Beziehung setzt;

2. ein interdisziplinärer Ansatz, der keine additive Zusammenfügung von Einzelaspekten bietet, sondern das Phänomen einer sich regionalisierenden Reichsaristokratie aus verschiedenen Perspektiven in den Blick nimmt;

3. eine dezidiert altertumswissenschaftliche Perspektive, die die vorwiegend von Mediävisten geprägte Forschungstätigkeit der letzten Jahre ergänzt und erweitert;

4. die Einbeziehung eines breiten Untersuchungszeitraums zwischen dem frühen 5. und dem beginnenden 7. Jh. n. Chr., der die Verwurzelung der identitären Transformationsprozesse im spätantiken Imperium Romanum ebenso verdeutlicht wie die bis weit in das Frühmittelalter hinein wirksamen Beharrungskräfte spätantiker Deutungsmuster sozialer Wirklichkeit.

20 Zum Selbstverständnis der neuen Kulturgeschichte, die unter den Vorzeichen einer transdisziplinären Begriffsbildung die Öffnung der Geschichtswissenschaft hin auf andere Bereiche der Kulturwissenschaften propagiert und die Anschlussfähigkeit über die etablierten Grenzen einzelner Fachdisziplinen hinweg betont, vgl. exemplarisch Daniel 2001, bes. $7-$ 25, wo allerdings die Antike so gut wie vollständig ausgeblendet wird.

$21 \mathrm{Zu}$ „Identität“ als einer zentralen kulturwissenschaftlichen Kategorie vgl. Assmann/Friese 1998, 11-23; Landwehr/Stockhorst 2004. Im 2004 erschienenen dreibändigen „Handbuch der Kulturwissenschaften“ firmiert „Identität“ als kulturwissenschaftlicher Schlüsselbegriff (Jaeger/Liebsch 2004). 
II.

Der vorliegende Sammelband umfasst siebzehn Beiträge, die aus den Vorträgen der soeben skizzierten Tagung zur Kulturgeschichte Galliens in Spätantike und Frühmittelalter hervorgegangen sind. Deren internationaler Ausrichtung entsprechend sind diese in den Sprachen Deutsch, Englisch, Französisch und Italienisch verfasst. $^{22}$ Die Aufsätze sind sieben Kapiteln zugeordnet, welche zum einen den differenten Mustern und Modellen kollektiver Identitätsstiftung gelten und zum anderen die gesellschaftlichen Gruppen zum Thema haben, denen der Wandel der historischen Verhältnisse im spätantiken Gallien Neuorientierungen abverlangte. Zudem zeichnen sich die einzelnen Kapitel durch vergleichbare Fragestellungen oder Quellenkorpora aus. Freilich wollen diese nicht als in sich abgeschlossene Sektionen verstanden werden, sondern vor allem als heuristisch relevante Gliederung. So beziehen die in ihnen versammelten Beiträge in je unterschiedlicher Weise ihre Fragestellungen und Erkenntnisinteressen auf die Leitfragestellung des Sammelbandes und öffnen sich auf diese Weise zu den grundlegenden identitären Transformationsprozessen der jeweils anderen Themenbereiche. Insofern machen sie die von ihnen behandelten und in der Forschung bislang weitgehend unabhängig voneinander erforschten Felder kollektiver Identitätsstiftung als integrale Teilbereiche eines die Kultur Galliens insgesamt prägenden identitären Transformationsprozesses sichtbar und verbinden sich zu einer Kulturgeschichte Galliens im eingangs dargelegten Sinn.

Das erste Kapitel des Sammelbands trägt den Titel „Römer und Barbaren: Politische Strukturen des Zusammenlebens und Strategien der Integration" und beinhaltet die Beiträge von Christine Delaplace (Toulouse) mit dem Titel „Les relations entre les Wisigoths et le pouvoir romain de 411 à 439: Comment faut-il interpréter la politique des foedus et la logique de ses acteurs dans la Gaule de la première moitié du V $\mathrm{e}^{\mathrm{e}}$ siècle ap. J.-C.?" (S. 25-43) und von Walter Goffart (Yale) mit dem Titel „Administrative Methods of Barbarian Settlement in the Fifth Century: The Definitive Account“ (S. 45-56). Beide Aufsätze beschäftigen sich mit den rechtlichen Aspekten des Zusammenlebens von Barbaren und Römern - konkret mit der vieldiskutierten Frage, unter welchen Modalitäten die Ansiedlungen barbarischer gentes (Westgoten, Alanen, Burgunder) seit dem Beginn des 5. Jh.s auf gallischem Boden vorgenommen wurden. Christine Delaplace formuliert in ihrem Beitrag die Ansicht, dass die Westgoten beim foedus des Jahres 416/418 nicht als eine barbarische gens, sondern als römische Auxiliartruppen behandelt worden seien. Der Vertrag habe dementsprechend auch kein völkerrechtliches

22 Um eine leichtere Auffindung der zum Teil entlegenen Quellen zu ermöglichen, findet sich am Ende eines jeden Beitrags ein Verzeichnis nicht nur der Sekundärliteratur, sondern auch der verwendeten Quelleneditionen und Übersetzungen. Bei den weitgehend standardisierten Textausgaben klassischer Autoren wurde in der Regel darauf verzichtet, Hinweise auf Editionen mit aufzunehmen. Verweise auf Autoren wie Vergil oder Plinius finden sich nur dort, wo die Verfasser der Beiträge auf spezifische zweisprachige Ausgaben und Übersetzungen rekurriert haben. 
Signal enthalten, die Westgoten als selbständige, mit Eigentumsrechten am römischen Territorium ausgestattete Ethnie zu begreifen; dementsprechend habe ihnen der Vertrag zwar ein Privat-, aber kein Obereigentum in den von ihnen besiedelten Gebieten zugebilligt. Walter Goffarts Überlegungen gehen hingegen von der entgegengesetzten Voraussetzung aus: Die römischen foedera mit den barbarischen gentes hätten keine realen Gebietsabtretungen zur Folge gehabt, sondern es den barbarischen gentes nur ermöglicht, anstelle des römischen Staates Steuern zu erheben. Gegenstand der Verträge sei dementsprechend ausschließlich das Obereigentum des römischen Staates gewesen, das bereits zu Beginn des 5. Jh.s in die Hände der Westgoten, Alanen und Burgunder übergegangen sei; in privatrechtlicher Hinsicht sei es jedoch nicht zu Eigentumsübertragungen gekommen. Damit setzen sich die Ansätze beider Autoren von der traditionellen Forschungsposition ab, wonach die mit den Barbaren geschlossenen Verträge eine mit einer Ansiedlung verbundene dauerhafte Abtretung römischen Provinzialbodens an die Barbaren vorgesehen hätten, und bieten alternative - und diametral entgegengesetzte - Erklärungsmodelle für die rechtlichen Voraussetzungen des Zusammenlebens von Römern und Barbaren an.

Das zweite Kapitel mit dem Titel „Römische Eliten in Gallien: Transformationen identitärer Bezugsfelder" thematisiert die Reaktionen der römischen Eliten Galliens auf die sich im Laufe des 5. Jh.s rapide ändernden politischen Rahmenbedingungen. John F. Drinkwater (Nottingham) kommt in seinem Beitrag „Unbecoming Roman. The end of provincial civilisation in Gaul" (S. 59-77) zu dem Ergebnis, dass die römische Senatsaristokratie auch unter der zunehmenden Desintegration des weströmischen Imperiums auf Rom und die imperiale Ordnung bezogen blieb. Ein regionales Selbstbewusstsein habe sich innerhalb dieser Schicht nicht ausgebildet: Es gab keine gallische Senatsaristokratie, sondern nur römische Aristokraten in Gallien. Dass diese soziale Gruppe auch nach dem endgültigen Zusammenbruch der imperialen Ordnung in den 470er Jahren in den barbarischen regna und in den civitates eine führende Rolle beibehielt, wird von Drinkwater nicht bestritten; er plädiert jedoch dafür, das Selbstverständnis dieser Elite nicht mit dem Attribut „,römisch“ zu belegen. Die Aufsätze von Michael Kulikowski (Pennsylvania State University) und Steffen Diefenbach (Konstanz) beschäftigen sich mit den beiden Alternativen, die sich für den Senatsadel für eine politische Betätigung jenseits der imperialen Ordnung eröffneten: den barbarischen regna und den civitates. Der Beitrag von Michael Kulikowski (,Sundered Aristocracies, New Kingdoms, and the End of the Western Empire“, S. 79-90) zeichnet den graduellen, sich über hundert Jahre erstreckenden Entwicklungsprozess nach, in dessen Verlauf die barbarischen Truppenführer eine Alternative zur römischen und imperialen Ordnung entwickelten. Dabei hebt er hervor, dass das Verhalten der barbarischen reguli zunächst von einer hohen Bereitschaft geprägt gewesen sei, sich als Klientelkönige und römische Truppenkommandanten in das Imperium zu integrieren - auch die weströmischen Kaiser und magistri militum hatten ein korrespondierendes Interesse daran, sich der barbarischen Truppenkontingente in inneren Auseinandersetzungen zu bedienen. Erst seit den 460er Jahren 
hätten der Zusammenbruch der imperialen Administration und die unklaren Legitimitätsansprüche der weströmischen Kaiser dazu geführt, dass sich nicht nur die Barbaren, sondern zeitgleich auch die römische Senatsaristokratie Galliens von Rom als Ordnungsmacht abgewandt hätten. Steffen Diefenbach beschäftigt sich in seinem Beitrag (,,Bischofsherrschaft‘. Zur Transformation der politischen Kultur im spätantiken und frühmittelalterlichen Gallien“, S. 91-149) mit dem Phänomen, dass seit der Mitte des 5. Jh.s immer mehr Bischofssitze in Gallien mit Angehörigen der römischen Reichsaristokratie besetzt wurden, die ihren traditionellen Führungsanspruch zunehmend durch das Bischofsamt und damit auf der lokalen Ebene der civitas geltend machten. In kritischer Auseinandersetzung mit dem spezifisch deutschsprachigen Konzept der „Bischofsherrschaft“ plädiert Diefenbach dafür, die bischöfliche „Herrschaftsbildung“ als einen Prozess zu verstehen, der ganz wesentlich von der erfolgreichen Durchsetzung neuer kultureller Modelle abhing und von einem grundlegenden Wandel der politischen Kultur im Laufe des 6. Jh. begleitet war. Ähnlich wie Drinkwater kommt damit auch Diefenbach zu dem Schluss, den Zäsurcharakter des ausgehenden 5. Jh. stärker als in der Forschung allgemein üblich zu betonen: Bei aller Fortschreibung traditioneller, kultureller Praktiken und Selbstdeutungen durch die zivilen und klerikalen Eliten begründeten die Bischöfe im Laufe des 6. Jh. einen neuartigen, poströmischen Autoritätstyp von Heiligkeit, der seit dem 7. Jh. verstärkt auch von den fränkischen Führungsschichten aufgegriffen wurde.

Das dritte Kapitel des Sammelbands mit der Überschrift „Städtischer Raum und Identität: Urbaner Strukturwandel im spätantiken Gallien“ versammelt drei Beiträge zur Stadt als identitätsstiftendem Raum und politischer Organisationseinheit im spätantiken Gallien. In seiner Untersuchung zur „Durchschnittsstadt“ im südlichen Gallien („Die spätantiken Städte Galliens: Transformation von Stadtbildern als Ausdruck einer gewandelten Identität?“, S. 153-200) diskutiert Christian Witschel (Heidelberg) eine signifikante, praktisch alle Städte der Region erfassende Entwicklung: die Ummauerung eines vergleichsweise kleinen städtischen Areals und die damit verbundene rapide Schrumpfung der Städte seit dem 3. Jh. Witschel betont, dass es sich dabei um einen längerfristigen Prozess handelt, der nicht monokausal - etwa durch die Barbareneinfälle seit dem 3. Jh. erklärt werden kann. Obwohl sich die Auswirkungen dieser urbanistischen Veränderungen auf das Selbstverständnis der Stadtbewohner in den literarischen Quellen kaum fassen lassen, indizieren die baulichen Veränderungen ein stark gewandeltes Verständnis von Stadt und städtischer Kultur; dabei ist freilich zu bedenken, dass die mit der Romanisierung verbundene Urbanisierung Galliens sich auf die frühe und beginnende hohe Kaiserzeit beschränkte und dementsprechend in der gallischen Gesellschaft weniger tief verwurzelt war als in anderen Regionen des Römischen Reichs. Jean Guyon (Aix-en-Provence) widmet sich in seinem Aufsatz „Les chefs-lieux de cités de Gaule méridionale aux $\mathrm{V}^{\mathrm{e}}$ et $\mathrm{VI}^{\mathrm{e}}$ siècles: Un espace urbain en mutation“ (S. 201-222) daraufhin der Entwicklung der civitas-Hauptorte im südlichen Gallien und stellt in diesem Zusammenhang weitere Indikatoren heraus, die auf einen tiefgreifenden urbanistischen Struktur- 
wandel schließen lassen: die Auflassung öffentlicher Gebäude, die Zunahme an hüttenartigen Behausungen und der Rückgang des Ausstattungsluxus in den städtischen domus aristokratischer Familien. Wesentlicher Bestandteil des städtischen Erscheinungsbilds war seit dem 5. Jh. die Kathedralgruppe aus Bischofskirche(n), Baptisterium und Bischofspalast, die häufig weite Teile des ummauerten Stadtbezirks ausfüllte. Gleichzeitig führte die christliche Sakraltopographie auch zu einer urbanistischen Akzentuierung des unmittelbaren städtischen Umlandes, wo in der Umgebung von Friedhofsbasiliken kleinere Siedlungen und Klöster entstanden, die organisatorisch und liturgisch eng mit der Bischofskirche verbunden blieben und zur Ausbildung eines polyzentrischen, nuklearisierten Stadtbilds beitrugen. Auch unter diesen veränderten christlichen Vorzeichen behielt im Übrigen die Stadt ihre traditionelle Zentralortfunktion bei - zur Ausbildung bedeutender klösterlicher Zentren in größerer Entfernung der Städte sollte es erst seit dem 7. Jh. kommen. Simon T. Loseby (Sheffield) nimmt mit seinem Beitrag „Lost cities. The end of the civitas-system in Frankish Gaul“" (S. 223-252) die Wende vom 6. zum 7. Jh. in den Blick, der er einen historischen Zäsurcharakter zuweist: Die Städte hätten in dieser Zeit ihre traditionelle Eigenständigkeit gegenüber der königlichen Zentralgewalt weitgehend eingebüßt, die sie vor allem während und infolge der rivalisierenden Auseinandersetzungen der merowingischen Könige im Laufe des 6. Jh.s aufgebaut hatten. Konkreten Ausdruck fand dieser Machtverlust in der Privilegierungspolitik der merowingischen Herrscher, die seit dem Beginn des 7. Jh.s landsässige Magnaten mit umfassenden fiskalischen und juridischen Immunitäten auszustatten begannen. Diese Vergabepolitik führte zu einem Verlust nicht nur der königlichen Autorität, sondern auch der Städte, auf die sie sich bis dahin wesentlich gestützt hatte. Davon betroffen waren in erster Linie säkulare Institutionen wie der comes civitatis, der an Einfluss in der Steuererhebung, Rechtsprechung und Rekrutierung von Soldaten verlor. Kirchliche Einrichtungen profitierten zwar von den Privilegierungen, doch kam es auch hier zur Verschiebung von Machtkonzentrationen: Der Schwerpunkt auch der bischöflichen Autorität begann sich nun zunehmend von der Stadt auf das Land zu verlagern; seit dem 7. Jh. vollzog sich der Übergang zum Adelsbischof, der als Magnat über großen Landbesitz verfügte und dort auch in steigendem Maße klösterliche Eigengründungen zu errichten begann.

Die Stellung von Außenseitern der römischen Ordnung und ihre normative Bewertung in zeitgenössischen Identitätsdiskursen des 5. Jh.s bildet den Gegenstand des vierten Kapitels, das den Titel trägt: „Zwischen Außenseiter und römischem Bürger: Zur Modellierung von Randgruppen im spätantiken Gallien“. In diesem untersucht David Lambert (St. Andrews) unter der Überschrift „Salvian and the Bacaudae“" (S. 255-276) die Darstellung, die eine sozialgeschichtlich nur schwer zu fassende Gruppe von Aufrührern, die sog. Bacaudae, bei Salvian von Marseille gefunden hat. Salvian, dem wir die ausführlichste Darstellung der spätantiken Bacaudae verdanken, charakterisiert sie als römische Bürger, die sich aufgrund der drückenden und ungerechten Steuerlast und Rechtsprechung der römischen Administration freiwillig dem Schutz der Barbaren unterstellt und 
damit ihre römische Identität bewusst preisgegeben hätten. Lambert macht in seiner Diskussion der Testimonien zugleich deutlich, warum es problematisch ist, die Aussagen Salvians auf ihren realhistorischen Quellenwert hin zu befragen: Sie stehen im Kontext eines umfassenden Moraldiskurses, mit dem der Christ Salvian den Verfall der römischen Ordnung beklagt und in paradoxer Weise ,unrömische“ Elemente wie die Barbaren und die Bacaudae zu den wahren Hütern der römischen Tradition erklärt. Ausgangs- und Referenzpunkt der Beschreibung des anderen bildet damit das, was Salvian als den Kern der römischen Identität ausmacht; die methodische Schwierigkeit, derartigen Zeugnissen einen historischen Kern jenseits normativer Identitätsdiskurse abzugewinnen, liegt auf der Hand. In vergleichbarer Weise stellt auch Philipp von Rummel (Rom) in seinem Beitrag „Unrömische Römer und römische Barbaren. Die Fluidität vermeintlich präziser Leitbegriffe der Forschung zum spätantiken Gallien“ (S. 277-293) zu „unrömischen Römern“ die Aussagekraft des dichotomischen Begriffspaars „Römer Barbar" auf den Prüfstand. Er kann dabei überzeugend nachweisen, dass die Träger barbarischer Tracht sich durchaus als Römer und Teil der politischen Ordnung Roms begriffen, auch wenn sie vermeintlich unrömische Formen der Selbstdarstellung und -inszenierung wählten: von Rummel erkennt in ihnen die Exponenten einer neuen, bereits seit dem 3. Jh. im sozialen Aufstieg befindlichen Militäraristokratie, die ihre Absetzung von der zivilen Verwaltungselite auch äußerlich markierte.

Das fünfte Kapitel (,Verfahren und kulturelle Modelle kollektiver Identitätsstiftung in den barbarischen regna") nimmt frühmittelalterliche politische Institutionen und Ordnungsbegriffe in den Blick und diskutiert, inwieweit sich in diesen nicht nur neue politische Organisationsformen, sondern - damit unmittelbar verbunden - veränderte Wahrnehmungen und Ordnungskonzepte widerspiegeln. In ihm beschäftigt sich Alexander Callander Murray (Toronto) mit den Urteilen des fränkischen Königsgerichts (placita) und ihrer institutionengeschichtlichen Herleitung aus dem römischen Verfahrensrecht (,So-called Fictitious Trial in the Merovingian Placita“, S. 297-327). Im Unterschied zur etablierten Forschung zieht Murray eine scharfe Grenze zwischen vor dem königlichen Gericht ausgetragenen Prozessen und Eigentumsübertragungen: Letztere seien nicht - wie seit dem 19. Jh. angenommen - als Scheinprozesse zwischen dem Empfänger und dem Überträger des Eigentums inszeniert worden, sondern folgten dem römischen Verfahren der in iure cessio, die ihrerseits nur scheinbare Analogien zu Gerichtsverfahren aufwies. Unter kommunikativen Gesichtspunkten bemerkenswert ist der Umstand, dass die königliche Bestätigung von Eigentumsübertragungen nicht als ein Verwaltungsakt vorgenommen wurde, sondern das persönliche Erscheinen der beteiligten Parteien vor dem König und seinem Hofgericht sowie umfassende protokollarische Akte voraussetzte: Über den rein funktionalen Aspekt der Eigentumsübertragung hinaus wurde hiermit zugleich die politische Ordnung des Königreichs performativ und - in Form der urkundlichen Ausfertigungen, die diese Vorgänge minutiös protokollierten - auch imaginativ sichtbar gemacht. 
Das sechste Kapitel wendet sich als erstes des Sammelbands der Literatur der Epoche zu und trägt die Überschrift „Heidnische Modelle und christliche Kultur: Funktionsfelder von Traditionsbildung in der spätantiken Literatur". Es gilt der Frage nach dem Fortleben klassischer literarischer Modelle im Kontext der christlichen Kultur im spätantiken Gallien. Meinolf Vielberg (Jena) arbeitet in seinem Beitrag „Picture and Poetry. Conceptions of the Hereafter and of Court Scenes in the Works of Ausonius of Bordeaux and Paulinus of Nola“" (S. 331-353) zunächst divergierende Jenseitsvorstellungen bei Ausonius von Bordeaux und seinem später in Kampanien beheimateten - Schüler Paulinus von Nola heraus. Seine Ausführungen, die von der Ekphrasis einer Unterweltsszene bei Ausonius ihren Ausgangspunkt nehmen, verdeutlichen die enge Verbindung von visuellen, taktilen und akustischen Signalen, die der literarischen Gestaltung des Jenseits bei Ausonius einen ausgesprochen plastischen und sinnlich wahrnehmbaren Charakter verleihen. Damit evoziert Ausonius ein grundlegend anderes Bild vom Jenseits als christliche Autoren wie Paulinus: ein Befund, der auf einen mentalen Strukturwandel hindeutet, in dessen Folge der produktive Rückbezug auf klassische Vorbilder seiner Selbstverständlichkeit verlustig geht, ohne innerhalb der literarischen Kommunikation der Spätantike freilich grundlegend an Attraktivität einzubüßen. Dies belegen auf unterschiedliche Weisen die beiden folgenden Fallanalysen, die intertextuelle Bezüge zwischen spätantiken Werken und Hypotexten klassischer Autoren zum Gegenstand haben. Antonella Bruzzone wirft in ihrem Aufsatz mit dem Titel „Mito e politica nei Panegyrici di Sidonio Apollinare“ (S. 355-378) die Frage nach der Funktion des Mythos in den panegyrischen Dichtungen des Sidonius Apollinaris auf und macht deutlich, dass die mythischen exempla keinen religiösen, sondern einen politischen und kulturellen Sinn erfüllten. Der Mythos vergegenwärtigte die römische Geschichte und stellte damit zeitgenössische Ereignisse wie die kriegerischen Auseinandersetzungen mit dem Vandalenherrscher Geiserich in einen spezifischen Deutungshorizont. Indem Sidonius die Kämpfe mit den Vandalen in eine unmittelbare Beziehung zum Antagonismus zwischen Dido und Aeneas und den punischen Kriegen bringt, verleiht er diesen nicht nur eine schicksalhafte myth-historische Dimension, sondern zugleich auch eine Legitimation, die in Anbetracht der verworrenen politischen Verhältnisse in der westlichen Reichshälfte um die Mitte des 5. Jh.s alles andere als evident war: Sidonius' Dichtungen trugen wesentlich dazu bei, dass schwach legitimierte und mit inneren Auseinandersetzungen kämpfende Kaiser wie Avitus, Maiorian und Anthemius sich als Anwälte Roms darstellen konnten - nicht etwa ein Geiserich, der in Anbetracht seiner Verbindungen zum oströmischen Kaiserhof zumindest anfangs ähnliche Ansprüche hätte vorbringen können. Dass für Sidonius insbesondere Vergils Aeneis als bevorzugter intertextueller Referenztext für mythologische Anspielungen fungiert, ist kein Zufall, da bereits in der vergilischen Dichtung Mythos und historische Bezüge auf die römische Geschichte eng ineinander verwoben waren. In seinem Beitrag „Un remodelage identitaire. Enquête sur les concepts de vitae exordium et d'innocentia dans la Passion des martyrs d'Agaune d'Eucher de Lyon“ (S. 379-396) legt Philippe Bruggisser hierauf 
eine minuziöse Untersuchung des Bekenntnisses vor, das Eucherius von Lyon in der von ihm verfassten passio Acaunorum martyrum den Protagonisten dieses Märtyrerberichts in den Mund gelegt hat. Bruggisser kann darin überzeugend darlegen, dass Eucherius gezielt auf klassische Texte wie die lateinische Timaiosübersetzung Ciceros Bezug genommen hat, um auf diese Weise platonische Grundannahmen seines christlichen Weltbilds zu akzentuieren. Somit liefert Eucherius von Lyon den Beleg dafür, dass selbst noch Autoren genuin christlicher Gattungen wie des Märtyrerberichts den Rückgriff auf Werke der heidnischen Antike für ihre Zwecke produktiv zu machen verstanden. Von einer konsequenten Abkehr christlicher Autoren von der ihnen vorangehenden literarischen und geistesgeschichtlichen Tradition kann also bis weit ins 5. Jh. hinein nicht gesprochen werden.

Das siebte und letzte Kapitel des Sammelbands trägt den Titel „Literarische Kommunikation im spätantiken Gallien zwischen universaler Bildungstradition und Regionalisierung“. Sein Gegenstand ist der Befund, dass die auch in der Literatur des spätantiken Gallien zunächst unangefochtene Tradition der Bezugnahme auf einen reichsweit gültigen Kanon vorbildlicher Autoren zunehmende Konkurrenz durch die gegenläufige Tendenz einer sukzessiven Regionalisierung der literarischen Kommunikation erhält. Denn diese manifestiert sich nicht nur in der geographischen Einengung der Rezipientenschaft auf den Raum Gallien, sondern befördert auch das Entstehen einer Literatur, welche den universalen literarischen Bildungskanon als bis dahin selbstverständlichen Referenzrahmen aus den Augen verliert. Freilich zeigen die Beiträge dieser Sektion auch auf, dass der Verzicht auf diesen nicht unbedingt bedeutet, dass damit gleichzeitig das Bewusstsein der Zugehörigkeit zu einer auf römische Traditionen gründenden Bildungselite verlorengehen muss. Ulrich Eigler geht in seinem Beitrag mit dem Titel „Gallien als Literaturlandschaft. Zur Dezentralisierung und Differenzierung lateinischer Literatur im 5. und 6. Jh.“ (S. 399-419) der generellen Frage nach, ob sich Gallien seit der Spätantike zu einer eigenen Literaturlandschaft ausgebildet habe. In einer tour d'horizon skizziert er dabei die wesentlichen Entwicklungen zwischen dem 5. und dem ausgehenden 7. Jh. und kommt dabei zu dem Ergebnis, dass es mit dem Beginn des 5. Jh.s zu einer Ausdifferenzierung gekommen sei: Komplementär zu den Klassikern, die im Römischen Reich durch den Schulunterricht reichsweit bekannt waren und zum allgemeinen Bildungsgut einer Elite gehörten, die ihren Zusammenhalt zu einem erheblichen Teil auf diese verbindende literarische Kultur gründete, sei es zur Ausbildung einer Literatur gekommen, deren kommunikative Reichweite deutlich begrenzter gewesen sei. Dazu rechnet Eigler vor allem die vielfältigen Formen hagiographischer Literatur: Sie seien von wenigen Ausnahmen abgesehen nur in einer regionalen literarischen Öffentlichkeit zirkuliert und hätten zur Ausbildung einer eigenen gallischen Literaturlandschaft maßgeblich beigetragen, während die Tradition einer imperialen Bildungsliteratur mit dem Zusammenbruch des Schulsystems seit dem 6. Jh. zum Erliegen gekommen sei. Erst mit der karolingischen Renaissance sei es unter Anknüpfung an die klassischen Werke der lateinischen Antike wieder zur Ausbildung einer im ganzen 
Karolingerreich verbreiteten Literatur gekommen, die - in vergleichbarer Weise wie in der Spätantike - neben und komplementär zu einer regionalen Literatur bestanden habe. Die beiden folgenden Beiträge gelten daraufhin einem zentralen Feld aristokratischer Identitätsstiftung im spätantiken und frühmittelalterlichen Gallien: der Epistolographie. Gegenstand des Beitrags von Gernot Michael Müller ist die Korrespondenz des Ruricius von Limoges, die an die Wende vom 5. zum 6. Jh. zu datieren ist (,Freundschaften wider den Verfall. Gemeinschaftsbildung und kulturelle Selbstverortung im Briefwechsel des Ruricius von Limoges“, S. 421-454). Ausgangspunkt seiner Überlegungen ist die Beobachtung, dass Ruricius anders als der eine Generation ältere Sidonius Apollinaris, der seine Briefsammlung ostentativ in die Tradition lateinischer Epistolographie seit Cicero und Plinius d. J. einreiht und damit programmatisch zur eigenen kulturellen Selbstverortung verwendet, auf eine solche literarische Kontextualisierung seines epistolographischen Schaffens verzichtet. Dennoch knüpft auch Ruricius inhaltlich wie performativ an die Tradition des aristokratischen Freundschaftsbriefes an, dessen Funktion weniger in der Informationsvermittlung als darin bestand, ein Zeichen freundschaftlicher Wertschätzung zu sein und durch das Medium des Briefes eine persönliche Vergegenwärtigung des Verfassers beim Adressaten zu bewirken. Damit ordnet sich Ruricius in die seit dem 4. Jh. florierende spätantike christliche Epistolographie ein, deren Vertreter zwar kein Interesse zeigen, sich offen in die Tradition heidnischer Briefkultur zu stellen, die aber dennoch bestimmte Aspekte von dieser - unter anderem die briefliche Freundschaftspflege wie selbstverständlich kontinuieren. Freilich zeigt sich Ruricius dahingehend seinem Zeitgenossen Sidonius Apollinaris verwandt, dass er diese epistolare Praxis auf ihre Ursprünge in der heidnischen Antike zurückführt und sich auf diese Weise einmalig ähnlich programmatisch wie dieser als Fortsetzer alter römischer Traditionen inszeniert. Dieser Befund legt den Blick dafür frei, dass mit dem Verzicht auf die Zurschaustellung literarischer Kontinuität nicht gleichzeitig die Zugehörigkeit zur römischen Elitenkultur zur Disposition gestellt wird. Im Gegenteil bezeugt der ostentative Rückbezug auf die Ursprünge des epistolaren Freundschaftsdiskurses im Briefœuvre des Ruricius von Limoges, dass auch in Kreisen, die kein Interesse mehr an jener literarischen Beziehungsstiftung eines Sidonius hatten, das Bedürfnis fortbestand, sich über das Feld bestimmter kultureller Praktiken wie der epistolaren Kommunikation in die Kontinuität römischer Elitenkultur zu stellen und sich auf diese Weise wirksam von einem zunehmend barbarischen Umfeld abzugrenzen. Die Persistenz einer solchen Form aristokratischer Gemeinschaftsbildung durch das Medium Brief bezeugt schließlich Ralph W. Mathisen (Urbana), der sich in seinem Beitrag mit dem Titel „Desiderius of Cahors: Last of the Romans“" (S. 455-469) dem letzten in der Überlieferung fassbaren Vertreter dieser epistolographischen Praxis widmet: Desiderius von Cahors, der am Hof der merowingischen Könige Chlothar II. (584-629) und Dagobert I. (623/629-639) enge Verbindungen zu hohen weltlichen Amtsinhabern, Bischöfen und Klostergründern knüpfte und diese amicitia-Beziehungen durch Freundschaftsbriefe pflegte. Hinsichtlich ihrer Funktion und der performativen Inszenie- 
rung von Nähe entsprechen diese Briefe des Desiderius weitgehend dem, was für das 5. und frühe 6. Jh. an aristokratischer Briefkultur in Gallien bekannt ist. Dennoch ist die Zahl der erhaltenen Briefe deutlich geringer, der Kreis der mit Desiderius über die Praxis des Briefeschreibens verbundenen Standesgenossen vergleichsweise klein. Zu Beginn des 7. Jh.s haben sich die kulturellen Praktiken inneraristokratischer Beziehungen und die damit verbundenen Freundschaftskonzepte bereits stark gewandelt; der noch in einer unmittelbaren Tradition zur Spätantike stehende Habitus des mit seinen Standesgenossen korrespondierenden Aristokraten reduzierte sich auf eine kleine Elite. Unmittelbar nach Desiderius scheint die Epistolographie als kulturelle Praxis ganz zum Erliegen zu kommen. Dies veranlasst Ralph Mathisen dazu, das frühe 7. Jh. als die eigentliche Epochengrenze zwischen Spätantike und Mittelalter anzusetzen. Somit hätte der kontinuierliche identitätsstiftende Rückgriff auf die römische Bildungskultur nach dieser Sichtweise das Ende des Römischen Reichs als politischer Institution um nahezu zweihundert Jahre überlebt.

\section{III.}

Die soeben skizzierten Beiträge des Sammelbands bieten nicht nur ein breites Spektrum von Einblicken in unterschiedliche kommunikative Felder und kulturelle Modelle, durch welche die für das Gallien der Spätantike relevanten Gruppenidentitäten in der kollektiven Wahrnehmung konstituiert und nach außen propagiert wurden. Sie zeigen auch, dass sich identitäre Transformationsprozesse im spätantiken Gallien auf den verschiedenen Beobachtungsfeldern in unterschiedlichen Phasen und mit unterschiedlichen Geschwindigkeiten vollzogen.

Die offensichtlichste Voraussetzung für den damit verbundenen Strukturwandel, der Gegenstand dieses Bandes ist, liegt zweifelsohne in der politischen Entwicklung im Gallien des 5. Jh.s begründet. Zwar war die römische Zentralmacht zunächst bestrebt, die Ansiedlung barbarischer gentes auf dem Boden der gallischen Provinzen über Föderatenverträge zu regeln, wie die Beiträge von Christine Delaplace und Walter Goffart in perspektivisch unterschiedlicher Annäherung an dieses Problemfeld aufzeigen, und damit ein auch anderenorts schon erfolgreich angewandtes Verfahren zu privilegieren, das von veritablen Gebietsabtretungen noch Abstand nahm. Doch führte der sukzessive Zusammenbruch des römischen Herrschaftssystems im Jahre 476 auch in Gallien zur endgültigen Auflösung der dort noch existierenden römischen Verwaltungsstrukturen. Wie John F. Drinkwater und Michael Kulikowski in komplementärer Weise aufzeigen, ging auf diese Weise der bis dahin ununterbrochen auf Rom ausgerichteten gallischen Aristokratie ihr traditionelles Betätigungsfeld verloren, aus dem diese Selbstbestätigung und Prestige bezog. Der damit einhergehenden Desorientierung standen mit der Bischofswürde und kirchlichen Ämtern im Allgemeinen jedoch alternative Karrieremöglichkeiten gegenüber, welche für die lokalen Eliten in Gallien im Verlauf des 5. Jh.s hinweg zunehmend an Attraktivität gewannen. Mit der Bischofsherr- 
schaft wurde jedoch nicht nur ein alternativer Weg der Bewahrung gesellschaftlichen Ansehens und des sozialen Aufstiegs eröffnet, sondern diese begründete auch, wie Steffen Diefenbach betont, einen grundsätzlich neuen Typus von Autorität, der als solcher zudem eigene Kriterien herausbildete, nach denen Eigenbild und Status bemessen wurden.

Dennoch vermochten sich bei den Trägern dieses neuen lokalen Herrschaftstypus grundlegende kulturelle Verhaltensmuster zu erhalten, an welche die römische Aristokratie traditionell ihr Selbstverständnis knüpfte. Hierzu zählt vor allem der Bereich literarischer Interessen, sei es in Form von Bücherbesitz und -austausch oder durch eigene schriftstellerische Praxis. Damit ergibt sich für die Vertreter des höheren Klerus eine komplexe identitäre Struktur, welche sich in der Verbindung jener grundlegend neuen, zur Alternative für bisherige öffentliche Wirkmöglichkeiten gewordenen Formen von Autorität mit traditionellen kulturellen Praktiken artikuliert. Im vorliegenden Sammelband bestätigen diesen Befund gerade jene Beiträge, die der Literatur der Epoche gewidmet sind, wenn Meinolf Vielberg darlegt, dass sich auch christliche Literaten, die sich der Askese verschrieben haben, in ihren Werken des gleichen vorchristlichen literarischen Hintergrunds bedienen können wie jene noch gänzlich in der klassischen Tradition stehenden Autoren, wenn Antonella Bruzzone aufzeigt, dass die heidnische Mythologie in der politischen Dichtung weiterhin wie selbstverständlich ihren Platz hat, und wenn schließlich Philippe Bruggisser nachweist, dass selbst Märtyrerberichte intertextuelle Referenzen auf klassische Autoren sinnstiftend nutzen.

Eine vergleichbar vielschichtige identitäre Lage, wie sie sich bei den zivilen Eliten zeigt, lässt sich auch bei anderen gesellschaftlichen Gruppen im spätantiken Gallien greifen: bei den Unterschichten, die, wie Philipp Lambert am Beispiel der Bacaudae herausarbeitet, bisweilen den Schulterschluss mit den Barbaren bevorzugen, als ihr Dasein in Abhängigkeit von römischen Grundbesitzern zu fristen, oder im Falle militärischer Würdenträger, die Philipp von Rummel zufolge barbarischen Habitus - vor allem in Bezug auf die Kleidung - und römische Identität $\mathrm{zu}$ integrieren und dies erfolgreich für die Etablierung eines eigenen Standesbewusstseins zu nutzen wissen. In einem wesentlichen Kriterium unterscheidet sich der identitäre Befund bei den zivilen und klerikalen Eliten jedoch von jenem der anderen gesellschaftlichen Akteure. Denn bei diesen zielt das traditionelle römische Element ihrer Identität dezidiert auf Bewahrung der mit diesem verbundenen kulturellen Verhaltensmuster und Betätigungsfelder und wird vor diesem Hintergrund immer wieder auch deutlich markiert. In diesen Kontext gehört zum einen der bereits erwähnte Bücherkult, der selbst dann noch eine weit vor das Christentum zurückreichende Praxis kontinuieren will, wenn die Titel, die ausgetauscht werden, ausschließlich christlich geworden sind. Hierher gehört ferner vor allem eine Kultur des brieflichen Austauschs, die bewusst als Kontinuierung einer aristokratischen Praxis mit lange zurückreichender Tradition inszeniert wird, verbunden mit einer ebenso verstandenen Freundschaftspflege, die indes auch von der Heiligen Schrift her als legitimiert gilt, wie Gernot Michael Müller am Beispiel der Korrespondenz des Ruricius von Limoges erkennen lässt. 
Beide Aspekte verweisen auf die hohe Bedeutung, welche neben der Literatur auch die kommunikativen Praktiken für das Fortleben römischer Kultur im Kreise einer intellektuellen Elite im spätantiken Gallien haben. Trotz einer fortexistierenden Briefkultur und der Verbreitung auch hagiographischer Literatur über diese traditionellen Kommunikationsnetzwerke werden die herkömmlichen Formen literarischer Kommunikation, wie Ulrich Eigler für die Übermittlung von Literatur in der hier zur Debatte stehenden Epoche insgesamt konstatieren muss, von einem sich geographisch sukzessive immer stärker verengenden und dabei immer grobmaschiger werdenden Netz von an dieser Form der Selbstdarstellung interessierten Personen gepflegt, bis sie Ralph W. Mathisen zufolge mit Desiderius von Cahors in der Mitte des 7. Jh.s endgültig versiegen. Mag dies daran liegen, dass sich im literarischen Diskurs inzwischen andere, dem Anschluss an die antike literarische Tradition keine Bedeutung mehr abgewinnende Regeln durchgesetzt haben, oder daran, dass der Konsens, der hinter den damit verbundenen gemeinschaftsstiftenden Praktiken stand, bei deren Trägern abhanden gekommen war; jedenfalls scheint mit der merowingischen Expansion ein identitärer Wandel endgültig seinen Abschluss gefunden zu haben, der dazu führen sollte, dass ein Anschluss an römische Traditionen und darauf aufbauende Formen kultureller Selbstmodellierungen im Folgenden nurmehr über den Akt der Rekonstruktion möglich war, wie es ca. eineinhalb Jahrhunderte nach dem Ende des hier analysierten Zeitraums im Zuge der karolingischen Renovatio erstmals im größeren Stile unternommen wurde.

Dieser Befund veranlasst Ralph W. Mathisen dazu, den Protagonisten seines Beitrags, Desiderius von Cahors, als ,last of the Romans“ zu titulieren, um damit $\mathrm{zu}$ bedeuten, dass von einem Ende römischer Kultur erst dann die Rede sein kann, als deren letzte Repräsentanten, mithin also jene, die ihre Identität zumindest in Teilen immer noch aus dieser ableiteten, von der Bühne der Geschichte abgetreten waren. Diese Sichtweise unterscheidet sich deutlich von jener John F. Drinkwaters, der in seinem Beitrag aus der Perspektive der politischen Geschichte dafür plädiert, das Selbstverständnis der gallischen Senatsaristokratie ab dem Zeitpunkt, als diese nach dem Zusammenbruch der imperialen Ordnung ihre Tätigkeitsfelder in den barbarischen regna fanden, nicht mehr als römisch zu bezeichnen. Diese einander auf den ersten Blick diametral widersprechenden Auffassungen sind nicht den jeweiligen thematischen Schwerpunkten der beiden Verfasser geschuldet, sondern primär dadurch bedingt, dass traditionelle kulturelle Modelle und Praktiken zwar auch noch im 6. Jh. Bestand hatten, jedoch dadurch eine grundlegende Transformation erfuhren, dass sie in veränderte Deutungshorizonte eingepasst wurden. Zu diesem Ergebnis kommen auch Steffen Diefenbach und Gernot Michael Müller in ihren Beobachtungen zur politischen Kultur der Bischöfe und zur Selbstmodellierung der zivilen Eliten, die in übereinstimmender Weise einen tiefgreifenden Wandel der politischen Kultur und der amicitia-Konzeptionen an der Wende vom 5. zum 6. Jh. ausmachen. Anstelle einer Alternative zwischen unterschiedlichen Zäsursetzungen scheint es daher sinnvoller, von der Emergenz eines poströmischen Handlungs- und Deutungsrahmens auszugehen und auf diese 
Weise der um 500 einsetzenden Transformation Rechnung zu tragen, ohne damit das Fortbestehen kultureller Praktiken zu negieren.

Diese differenzierende Konzeptualisierung eines poströmischen Handlungsund Deutungsrahmens kann als ein fruchtbares und weiterführendes Ergebnis der Tagung gelten, das unter dem Gesichtspunkt identitären Wandels eine interpretatorische Matrix auch für die Einordnung der übrigen Befunde zu liefern vermag. Die grundsätzliche Berechtigung, mit Blick auf das spätantike und frühmittelalterliche Gallien von einem Zeitalter des Wandels zu sprechen, wird nicht zuletzt von der materiellen Überlieferung der untersuchten Epoche bestätigt. So konstatieren die Beiträge von Christian Witschel und Jean Guyon für das Erscheinungsbild der Städte im spätantiken Gallien ebenfalls einen allmählichen Strukturwandel, der sich neben partiellen Schrumpfungsprozessen vor allem in der Einschreibung der neuen kirchlichen Herrschaftsstrukturen in Gestalt von Kathedralkirchen mit entsprechender baulicher Umgebung in den Stadtraum artikuliert. Ein präzises Ende lässt sich damit - zumindest in topographischer und siedlungsgeographischer Hinsicht - auch für den Bereich urbaner Kultur nicht ausfindig machen. Vielmehr unterliegen auch die Städte langfristigen, auf die anderen hier untersuchten Bereiche des identitären Wandels verweisenden Veränderungen, bis sich in merowingischer Zeit, wie Simon T. Loseby nachweisen kann, eine neue Herrschaftsgeographie etabliert, die ohne die alten römischen Städte auskommt.

Wie eingangs bereits angedeutet, verstehen sich die hier versammelten Aufsätze als spezifisch altertumswissenschaftlicher Beitrag zur Erschließung eines Transformationsprozesses, der bislang weitgehend aus der Perspektive der Mediävistik in den Blick genommen worden ist. Während sich deren Aufmerksamkeit in erster Linie auf die Herausbildung frühmittelalterlicher Ordnungen und Deutungsmuster sozialer Wirklichkeit richtet und in kulturgeschichtlicher Hinsicht somit vor allen Dingen nach den für diese relevanten Akteuren fragt, stand hier in gleichsam umgekehrter Betrachtungsrichtung der Prozess der Ablösung römischer „Kultur“ im Mittelpunkt des Interesses. Immerhin vermag auch Alexander Murray exemplarisch anzudeuten, dass sich selbst noch im merowingischen Recht Reflexe auf Institutionen der römischen Vergangenheit finden. Vor diesem Hintergrund gälte es im Folgenden, die altertumswissenschaftliche und die mediävistische Perspektive aufeinander zu beziehen. War hier die noch lange fortdauernde Attraktivität römischer Kulturtechniken auch nach dem Zusammenbruch der imperialen Ordnung in Gallien zu konstatieren, bliebe diese Beobachtung mit dem komplementären Befund engzuführen, dass sich dennoch neue kulturelle Konfigurationen durchzusetzen vermochten, die römische Paradigmen freilich nicht so vollständig verdrängt haben, dass sich dieses nicht mittelfristig doch wieder als Leitmodell zurückmeldeten. Dies freilich wäre ein anderes und neues Thema, nämlich die im Vorigen skizzierte Transformation erneut aus einer verstärkt mediävistischen Perspektive in den Blick zu nehmen. 
IV.

Die Augsburger Tagung und der aus ihr hervorgegangene Sammelband hätten ohne die mannigfaltige Unterstützung vieler nicht realisiert werden können. Sie sollen hier abschließend dankend Erwähnung finden. Dass die Tagung in den ansprechenden Räumen des Elias-Holl-Baus stattfinden konnte, ist der großzügigen Einladung durch den Leiter des Augustana-Forums, Pfarrer Dr. Nikolaus Hueck, zu verdanken. Er und seine Mitarbeiterinnen haben während der Veranstaltung zudem dafür gesorgt, dass es den Teilnehmerinnen und Teilnehmern der Tagung an nichts gefehlt hat. Besonderen Dank haben die Veranstalter ihren damaligen Augsburger Hilfskräften Mischa Grab und Markus Rinner abzustatten, die die Referentinnen und Referenten während der Tagung betreut haben. Für die großzügige Finanzierung der Tagung sei der Gerda-Henkel-Stiftung, der Forschungskommission der Universität Luzern, dem Kompetenzzentrum für Kulturund Bildungswissenschaft der Universität Augsburg sowie der Gesellschaft der Freunde der Universität Augsburg e.V. gedankt.

Die Drucklegung des vorliegenden Sammelbands haben erneut das Kompetenzzentrum für Kultur- und Bildungswissenschaft der Universität Augsburg sowie die Gesellschaft der Freunde der Universität Augsburg e.V. finanziell unterstützt. Für Unterstützung bei Lektorat und Einrichtung der Beiträge haben die Herausgeber vor allem den Hilfskräften bei der Professur für Klassische Philologie und Wirkungsgeschichte der Antike an der Katholischen Universität EichstättIngolstadt Isabella Brummer, Jasmin Dorner, Madlen Renner und Ferdinand Wurzer zu danken. Diese haben sich auch der beschwerlichen Arbeit der Registererstellung unterzogen. Auch den Konstanzer Hilfskräften Philipp Flaig und Lasse Stodollick sei für ihre Hilfe herzlich gedankt. Für die Aufnahme des Bandes in die Reihe „Millennium-Studien“ gilt herzlicher Dank deren Herausgebern, vor allem Helmut Krasser, Peter von Möllendorff (beide Gießen) und Hartmut Leppin (Frankfurt am Main). Ebenso herzlich haben die Herausgeber schließlich dem Verlag Walter de Gruyter, namentlich Frau Katrin Hofmann und Frau Katharina Legutke, für die hervorragende Zusammenarbeit und professionelle Betreuung des Projekts zu danken.

Konstanz und Eichstätt, im Juni 2013

Steffen Diefenbach

Gernot Michael Müller 


\section{Literaturverzeichnis}

Airlie u.a. (2006): Stuart Airlie, Walter Pohl u. Helmut Reimitz (Hgg.), Staat im frühen Mittelalter, Wien.

Ando (2008): Clifford Ando, „Decline, Fall, and Transformation“, JLA 1, 31-60.

Ando (2009): Clifford Ando, „Narrating Decline and Fall“, in: Philip Rousseau (Hg.), A Companion to Late Antiquity, Malden, 59-76.

Assmann (2005): Jan Assmann, Das kulturelle Gedächtnis. Schrift, Erinnerung und politische Identität in frühen Hochkulturen, München.

Assmann u. Friese (1998): Aleida Assmann u. Heidrun Friese, „Einleitung“, in: Aleida Assmann u. Heidrun Friese (Hgg.), Identitäten. Erinnerung, Geschichte, Identität 3, Frankfurt a. M., 11-23.

Beaujard (2000): Brigitte Beaujard, Le culte des saints en Gaule. Les premiers temps, d'Hilaire de Poitiers à la fin du VI siècle, Paris.

Börm (2013): Henning Börm, Westrom. Von Honorius bis Justinian, Stuttgart.

Brogiolo u.a. (2000): Gian P. Brogiolo, Nancy Gauthier u. Neil Christie (Hgg.), Towns and their Territories between Late Antiquity and the Early Middle Ages, Leiden.

Brogiolo u. Ward-Perkins (1999): Gian P. Brogiolo u. Bryan Ward-Perkins (Hgg.), The Idea and Ideal of the Town between Late Antiquity and the Early Middle Ages, Leiden.

Bowersock u.a. (1999): Glen W. Bowersock, Peter Brown u. Oleg Grabar (Hgg.), Late Antiquity. A Guide to the Postclassical World, Cambridge (Mass.).

Cameron u.a. (2000): Averil Cameron, Bryan Ward-Perkins u. Michael Whitby, „Conclusion", in: Averil Cameron, Bryan Ward-Perkins u. Michael Whitby (Hgg.), The Cambridge Ancient History, Bd. 14: Late Antiquity. Empire and Successors, A. D. 425600, Cambridge, 972-981.

Christie (2011): Neil Christie, The Fall of the Western Roman Empire. An Archaeological and Historical Perspective, London.

Daniel (2001): Ute Daniel, Kompendium Kulturgeschichte. Theorien, Praxis, Schlüsselwörter, Frankfurt a.M.

de Jong u. Theuws (2001): Mayke de Jong u. Frans Theuws (Hgg.), Topographies of Power in the Early Middle Ages, Leiden.

Demandt (2007): Alexander Demandt, Die Spätantike. Römische Geschichte von Diocletian bis Justinian, 284-565 n.Chr., München, 2. Aufl.

Diefenbach (2007): Steffen Diefenbach, Römische Erinnerungsräume. Heiligenmemoria und kollektive Identitäten im Rom des 3. bis 5. Jh., Berlin/New York.

Drinkwater u. Elton (1992): John F. Drinkwater u. Hugh Elton (Hgg.), Fifth-Century Gaul: A Crisis of Identity?, Cambridge.

Gauthier u. Picard (1986-2007): Nancy Gauthier u. Jean-Charles Picard (Hgg.), La topographie chrétienne des cités de la Gaule des origines au milieu du VIIIe siècle, 15 Bde., Paris.

Gillett (2002): Andrew Gillett (Hg.), On Barbarian Identity. Critical Approaches to Ethnicity in the Early Middle Ages, Turnhout.

Goetz u.a. (2003): Hans-Werner Goetz, Jörg Jarnut u. Walter Pohl (Hgg.), Regna and gentes. The Relationship between Late Antique and Early Medieval Peoples and Kingdoms in the Transformation of the Roman World, Leiden/Bosten. 
Gotter (2001): Ulrich Gotter, „Akkulturation“ als Methodenproblem der historischen Wissenschaften“, in: Stefan Altekamp, Mathias R. Hofter u. Michael Krumme (Hgg.), Posthumanistische Klassische Archäologie. Historizität und Wissenschaftlichkeit von Interessen und Methoden (Kolloquium Berlin 1999), München, 255-286.

Halsall (2007): Guy Halsall, Barbarian Migrations and the Roman West, 376-568, Cambridge.

Heather (2005): Peter Heather, The Fall of the Roman Empire: A New History, London.

Heijmans u. Guyon (2006-2007): Marc Heijmans u. Jean Guyon (Hgg.), „Antiquité tardive, haut Moyen Âge et premiers temps chrétiens en Gaule méridionale“, Gallia 63, $1-170$ und $64,1-189$.

Jaeger u. Liebsch (2004): Friedrich Jaeger u. Burkhard Liebsch (Hgg.), Handbuch der Kulturwissenschaften, Bd. 1: Grundlagen und Schlüsselbegriffe, Stuttgart/Weimar, 277-363.

Jones (2009): Allen E. Jones, Social Mobility in Late Antique Gaul: Strategies and Opportunities for the Non-Elite, Cambridge.

Krause u. Witschel (2006): Jens-Uwe Krause u. Christian Witschel (Hgg.), Die Stadt in der Spätantike - Niedergang oder Wandel?, Stuttgart.

Landwehr u. Stockhorst (2004): Achim Landwehr u. Stefanie Stockhorst, Einführung in die Europäische Kulturgeschichte, Paderborn.

Liebeschuetz (2001): John H.W.G. Liebeschuetz, The Decline and Fall of the Roman City, Oxford.

Marcone (2008): Arnaldo Marcone, „A Long Late Antiquity? Considerations on a Controversial Periodization“, JLA 1, 4-19.

Millar (2006): Fergus Millar, A Greek Roman Empire. Power and Belief under Theodosius II (408-450), Berkeley u. a.

Mitchell (2007): Stephen Mitchell, A History of the Later Roman Empire, AD 284-641. The Transformation of the Ancient World, Malden.

Mitchell u. Greatrex (2000): Stephen Mitchell u. Geoffrey Greatrex (Hgg.), Ethnicity and Culture in Late Antiquity, London.

Pohl (1997): Walter Pohl (Hg.), Kingdoms of the Empire. The Integration of Barbarians in Late Antiquity, Leiden.

Pohl u. Diesenberger (2002): Walter Pohl u. Max Diesenberger (Hgg.), Integration und Herrschaft. Ethnische Identitäten und soziale Organisation im Frühmittelalter (Forschungen zur Geschichte des Mittelalters 3), Wien.

Pohl u. Reimitz (1998): Walter Pohl u. Helmut Reimitz (Hgg.), Strategies of Distinction. The Construction of Ethnic Communities, 300-800, Leiden/Köln.

Pohl u.a. (2012): Walter Pohl, Clemens Gantner u. Richard Payne (Hgg.), Visions of Community in the Post-Roman World. The West, Byzantium and the Islamic World, 300-1100, Farnham.

Pohl u. Zeller (2012): Walter Pohl u. Bernhard Zeller (Hgg.), Sprache und Identität, Wien.

Rutenburg u. Eckstein (2007): Jeanne Rutenburg u. Arthur M. Eckstein, „The Return of the Fall of Rome“, The International History Review 29, 109-122.

Theuws u. Nelson (2000): Frans Theuws u. Janet L. Nelson (Hgg.), Rituals of Power. From Late Antiquity to the Early Middle Ages (Transformation of the Roman World 8), Leiden/Köln/New York.

Tschopp u. Weber (2007): Silvia S. Tschopp u. Wolfgang E.J. Weber, Grundfragen der Kulturgeschichte, Darmstadt. 
Vieillard-Troiekouroff (1976): May Vieillard-Troiekouroff, Les monuments religieux de la Gaule d'après les œuvres de Grégoire de Tours, Paris.

Ward-Perkins (2005): Bryan Ward-Perkins, The Fall of Rome and the End of Civilisation, Oxford.

Weidemann (1982): Margarete Weidemann, Kulturgeschichte der Merowingerzeit nach den Werken Gregors von Tours, 2 Bde., Mainz.

Wickham (2005): Chris Wickham, Framing the Early Middle Ages. Europe and the Mediterranean, 400-800, Oxford.

Wood (1997): Ian Wood, „The European Science Foundation's Programme on the Transformation of the Roman World and the Emergence of Early Medieval Europe", Early Medieval Europe 6, 217-227. 
I.

RÖMER UND BARBAREN:

POLITISCHE STRUKTUREN DES ZUSAMMENLEBENS UND STRATEGIEN DER INTEGRATION 



\title{
Les relations entre les Wisigoths et le pouvoir romain de 411 à 439: Comment faut-il interpréter la politique des foedus et la logique de ses acteurs dans la Gaule de la première moitié du $\mathrm{V}^{\mathrm{e}}$ siècle ap. J.-C.?
}

\author{
Christine Delaplace
}

\section{Introduction}

Pour étudier la période 411-439 des relations entre les Wisigoths et le pouvoir impérial romain, je partirai d'un postulat préalable: les Wisigoths d'Alaric et de ses successeurs ne forment pas un peuple (encore moins une nation), mais sont une partie de l'armée romaine, sont l'armée romaine et en conséquence, toutes les relations entre ces fédérés et le pouvoir romain, légal ou illégal, sont des négociations de rapports de force entre troupes fédérées au service d'un pouvoir politique, engagés par lui et payés par lui pour un nombre de services déterminés.

A partir de ce postulat, l'ensemble des événements décrits durant les trois premiers tiers du $\mathrm{V}^{\mathrm{e}}$ siècle entre les Wisigoths et Rome en Gaule du sud et en Espagne, en dépit du vocabulaire traditionnel de la diplomatie romaine et de l'idéologie du pouvoir qu'il véhicule, doivent être réexaminés, ce que j'ai pu entreprendre dans un ouvrage à paraître. ${ }^{1}$ Mais dans cette communication, je m'attarderai seulement sur les deux points suivants:

- $\quad$ Le traité de 416 et son application strictement technique définie en 418

- La réorganisation des services et rémunérations des fédérés wisigoths intervenue en 439 après l'échec de la politique d'Aetius.

II. Le traité de 416 et son application technique de 418

\section{A. 411-416: La stratégie d'Ataulf et les réactions du pouvoir impérial}

Athaulf prit la succession d'Alaric et passa en Gaule en 412 pour rejoindre l'usurpateur Jovinus. Les Goths décidèrent en effet qu'il était inutile de demeurer en Italie, car dans ce cas, ils se retrouveraient rapidement sans contrat militaire et

1 Delaplace à paraître. 
sans approvisionnement alimentaire. Mais désormais, avec ce passage en Gaule, l'évolution de la géostratégie des Goths dépendit de la situation en Espagne.

En effet, le rôle assigné aux Goths, à partir de 416, fut tout entier consacré à la surveillance de la péninsule Ibérique. La géostratégie de ceux que l'historiographie, à partir de Jordanès, appellent les Wisigoths, est dès le départ, tournée vers le contrôle de l'Espagne, d'abord dans le cadre de la mission militaire qui leur est confiée par l'empereur d'Occident jusqu'en 476, ensuite dans le cadre d'une reconnaissance de leur autonomie par Constantinople. Même durant la période gauloise de l'histoire des Wisigoths, l'horizon hispanique est un élément déterminant de la compréhension des événements qui surviennent entre les fédérés goths et le pouvoir impérial.

En 411, il n'y avait pas eu de traité conclu entre Rome et les Barbares installés en Espagne, contrairement à ce que certains historiens ont pu affirmer. Pas plus avec Maximus, l'empereur que s'était choisi Gerontius, qu'avec l'empereur officiel, Honorius. Les peuples barbares parvenus à franchir les Pyrénées, s'établirent seuls dans les différentes régions, s'organisant plus ou moins pour que chaque groupe ne se retrouve lésé par les autres. C'est éventuellement la seule signification que l'on peut accorder au tirage au sort auquel fait allusion Orose (Histoires, Livre VII, 40, 10). Mais en aucun cas, cette organisation ne fut présidée par une autorité romaine. Il est vraiment dommage que nous ne sachions vraiment rien de la situation interne de l'Espagne entre la fin de la première usurpation de Maximus et l'intervention wisigothique en 416. Nos sources contemporaines, Orose et Hydace, ne révèlent aucun événement dramatique. Sans foedus ou accord officiel avec l'Etat romain, les Alains, Suèves et Vandales demeuraient pourtant sans légitimité et étaient vraisemblablement supportés faute de mieux. Dès qu'ils firent montre à nouveau d'agressivité, Rome dépêcha aussitôt en Espagne les Goths. Ces derniers inaugurèrent ainsi leur statut de soldats fédérés, mais surtout de gardiens de la paix transpyrénéenne.

En 411, en dépit du succès remporté avec l'élimination de l'usurpateur Constantin III, les autorités romaines étaient toujours préoccupées de régler la situation de la Gaule. Car celle-ci devint plus complexe avec l'arrivée d'Athaulf et de l'armée gothique auprès du nouvel usurpateur Jovinus. Ce dernier était bien plus redoutable que ne l'avait été Constantin III. En effet, à la différence de ce dernier, il était membre de cette aristocratie provinciale gauloise, parvenue aux hautes fonctions et promue durant le règne de Constantin III. Si l'aristocratie auvergnate était au centre de la rébellion, celle de la Narbonnaise demeura plutôt favorable au pouvoir légitime de Ravenne. Vir Galliarum nobillissimus, Jovinus bénéficiait néanmoins des appuis de personnages importants dans tout le sud de la Gaule, du grand-père de Sidoine Apollinaire à Decimus Rusticus, devenu son préfet du prétoire et à Consentius, rhéteur et philosophe de Narbonne.

Jovinus était le fer de lance d'une grande partie des aristocrates gaulois qui refusaient de voir se réinstaller l'emprise du gouvernement de Ravenne sur la Gaule après la défaite de Constantin III. Il s'entoura bientôt d'alliés comme Goar, le roi des Alains, Gunthiarius, le roi des Burgondes et Athaulf, avec qui il passa 
un accord, vraisemblablement avant même que les Goths ne quittent l'Italie. Il réunissait ainsi, et les forces des barbares du Rhin, et celles des Wisigoths, auxquelles auraient dû même s'ajouter celles de Sarus, si ce dernier n'avait pas fait l'objet de la faid d'Athaulf.

Selon le témoignage d'Olympiodore, Athaulf se détacha assez vite de la coalition. Pour comprendre cette volte-face, il faut prendre en compte le fait que Jovinus ne semblait pas très enclin à prendre en charge une armée affamée. Les Goths lui était peut-être d'ailleurs imposés par l'usurpateur Attale. Ce dernier, décidément toujours sur le devant de la scène politique en dépit de ses échecs en Italie, avait accompagné l'armée d'Ataulf en Gaule et tentait d'y trouver une légitimité. Mais Jovinus refusa de faire de ce dernier un collègue dans l'augustat et préféra choisir pour ce rôle son frère Sebastianus. Athaulf rompit donc rapidement une alliance qui n'avait pas d'intérêt tangible et aucune garantie politique sans un rôle important pour Attale. Ataulf se remit en conséquence au service d'Honorius, sans doute à la fin de l'année 412, en lui proposant de se débarasser des usurpateurs gaulois.

Ces négociations successives d'Athaulf, dans un premier temps avec Jovinus, ensuite avec Dardanus le représentant de Constantius à Arles, enfin avec la cour de Ravenne, sont les conséquences inévitables des incertitudes quant au statut accordé aux Goths dans lesquelles se trouva le successeur d'Alaric dans les mois qui suivirent son départ d'Italie. Mais dès lors qu'il accepta d'être au service d'Honorius, il est fort probable qu'il ait pris la tête des opérations militaires qui aboutirent en 413 à la capture des usurpateurs, Jovinus et Sebastianus, puis à la répression des nobles arvernes. On voit ainsi que les troupes wisigothiques n'étaient efficaces que lorsqu'elles étaient mobilisées dans un combat pour lequel un contrat clair leur avait été signifié. Pour ce faire, Athaulf avait sans doute reçu le titre de général des auxiliaires wisigoths placés sous les ordres du magister peditum Constantius.

La chronologie des années 412-416 est vraiment difficile à établir avec certitude. Si Athaulf a bien reçu un commandement militaire pour combattre les usurpateurs, rien d'illogique dans ce cas à ce que l'on puisse considérer que les Goths ont été cantonnés en Aquitaine Seconde une première fois à la fin de l'année 412 ou en 413 après la mort de Jovinus. Mais il s'avère difficile de comprendre alors pourquoi le problème crucial de l'approvisionnement en vivres signalé par certains auteurs contemporains a pu devenir source de tensions graves avec les autorités impériales, au point d'amener les Goths à venir, durant l'automne 413, attaquer Marseille puis à s'installer à Narbonne où Athaulf épousa une seconde fois selon le rite romain Galla Placidia, le $1^{\mathrm{er}}$ janvier 414.

Si les troupes d'Athaulf étaient des troupes fédérées officielles, elles auraient dû bénéficier dans ce cas du cantonnemment et des approvisionnements alimentaires qu'il était sans doute assez facile de trouver dans une des régions agricoles les plus riches de la Gaule. Pourquoi donc le dispositif qu'il fut possible de mettre en place à partir de 418-419 lorsque les Goths furent définitivement cantonnés en Aquitaine, ne 1'était-il pas en 413-414? Quel désagrément poussa donc Athaulf à 
se servir une seconde fois d'Attale comme d'un bouclier politique en le nommant empereur à Bordeaux?

Beaucoup d'historiens évoquent, comme cause principale à cette nouvelle donne, la révolte d'Héraclianus en Afrique qui bloqua, durant quelques semaines au printemps, les convois de blé à Carthage et donc les approvisionnements militaires des troupes en Occident. Or, Heraclianus tenta ensuite une invasion de l'Italie, au cours de laquelle il fut vaincu sur la route le menant vers Ravenne. Il s'enfuit en Afrique et y fut décapité durant l'été $413 .^{2}$ Le retard du blé africain fut donc très limité dans le temps et les bateaux annonaires ont dû pouvoir quitter Carthage avant l'automne. Si c'est là l'argument invoqué par nos sources, il corrobore l'hypothèse d'annones versées aux fédérés goths et constituées d'approvisionnement alimentaire d'origine extérieure à la région de cantonnement.

Ce ne fut sans doute point la seule cause au différend entre les Goths d'Athaulf et Honorius, mais nous sommes ici tributaires des informations données par Olympiodore qui se focalise essentiellement sur le chantage que pouvait exercer Athaulf auprès d'Honorius et Constantius, en voulant échanger Galla Placidia contre des vivres (Olympiodore, Frag. 22, 1-2). Mais le chantage était des deux côtés, puisque Constantius "leur ayant principalement interdit et coupé tout approvisionnement par mer et le commerce avec les étrangers" 3 à Narbonne, les Goths retournèrent donc assez vite dans l'année 414 à Bordeaux puis évacuèrent la ville et on les retrouve, assiégeant la ville de Bazas en compagnie d'un groupe d'Alains, sans doute entre le printemps et l'automne 414.

Le conflit entre Honorius et Athaulf ne doit donc pas se situer uniquement dans la négociation pour la libération de Galla Placidia, libération pour laquelle Athaulf et Constantius exercent mutuellement un chantage somme toute habituel aux négociations diplomatiques de l'Antiquité. Celles-ci comportaient toujours des clauses concernant des otages, souvent de haute naissance.

Le conflit politique me semble contenu plutôt dans le refus de l'empereur de cantonner une troupe fédérée sans affectation militaire claire et précise. Or, après l'exécution des usurpateurs Jovinus et Sébastianus, Athaulf semble inutile, voire nuisible en Gaule. Il tente de se rendre incontournable par son mariage avec Galla Placidia et de se protéger en remettant en selle l'usurpateur Attale. Mais Honorius et Constantius n'ont pas, dans l'immédiat, de service à lui affecter dans la réorganisation de la Gaule et n'entendent visiblement pas lui en donner. On peut s'en convaincre facilement en considérant que ce sont les Alains et non pas les Goths que l'on va cantonner en 414 en Aquitaine. Après l'offre de paix que les Alains proposèrent à l'issue du siège de Bazas, le pouvoir impérial s'en servit immé-

2 Oros. hist. 7, 42, 12: [...] aliquamdiu Africana annona extra ordinem detenta [...], cf. Soz. 9, 8, 7 qui indique la famine à Rome occasionnée par le blocage d'Héraclien; voir Oros. hist. 7, 42, 14, Hyd. chron. 56 pour la fin d'Héraclien et son échec en Italie.

3 Oros. hist. 7, 43, 1: [...] interdicto praecipue atque intercluso omni commeatu navium et peregrinorum usu commerciorum. 
diatement. ${ }^{4}$ Ce ne fut pas le cas des Goths d'Athaulf qui quittèrent alors la Gaule pour l'Espagne.

Les sources contemporaines et les historiens qui s'en inspirent sans discussion, considèrent ce départ comme étant un départ volontaire, un choix émanant d'Athaulf, mais il y a de fortes présomptions pour que Constantius ait considéré les Alains moins dangereux que les Goths d'Athaulf. Il préféra contraindre ces derniers à passer en Espagne où il escomptait sans doute dès 414 les utiliser pour contrôler les différents peuples barbares qui s'y étaient installés depuis 409. Leur intégration dans l'administration militaire et civile de l'Empire était donc décidée par Constantius, selon les modalités déterminées par ce dernier et non pas selon le bon vouloir des Goths. Il dut vouloir contraindre les Goths dans leur ensemble plutôt que le seul Athaulf, car il faut sans doute prendre en considération les divisions internes du peuple goth qui devaient limiter la légitimité d'Ataulf au sein même de son armée. Mais de ces divisions internes, nous n'avons malheureusement aucun témoignage direct, si ce n'est leur conséquence ultime: l'assassinat d'Athaulf et la crise politique qui s'en suivit.

On peut néanmoins se persuader que ce passage en Espagne fut marchandé par Athaulf car ce dernier n'hésita pas alors à se débarasser d'Attale qui fut bientôt capturé par Constantius. C'est donc qu'il avait reçu quelque assurance de la part du gouvernement impérial pour juger l'usurpateur désormais totalement inutile.

En tenant compte de cette double perspective, - les luttes internes au clan gothique et la faiblesse du pouvoir d'Athaulf d'une part, la volonté de Constantius de se servir des Goths en Espagne dès 413 d'autre part -, je crois que l'on peut saisir la logique des événements qui demeuraient jusqu'à présent obscurs et contradictoires dans l'interprétation historiographique ancienne, même si celle-ci a été récemment révisée par la chronologie proposée par Maria Cesa. ${ }^{5}$

\section{B. L'accord de 416: le véritable et seul foedus entre Rome et les Wisigoths}

Avant la signature de l'accord de 416, le pouvoir impérial attendit donc que les Goths règlent leurs querelles internes, éventuellement en jouant de leurs divisions et en les contraignant à accepter de partir en Espagne en maintenant le blocus alimentaire et l'absence de perspectives en Gaule. Ces quelques mois d'expectative mutuelle peuvent également s'expliquer par des facteurs externes à la situation des Goths. Il y a tout lieu de penser que de 411 à 416, la situation en Espagne ait été calme et ne nécessitait aucune intervention militaire impériale, donc aucun envoi de troupes d'intervention sur le terrain.

\footnotetext{
4 Perevalov 2000.

5 Cesa 1992/1993.
} 
L'accord de 416 nous est rapporté par plusieurs témoignages. Orose en fait la conséquence directe de l'échec de l'expédition maritime des Goths dans le détroit de Gadès:

Donc, terrifié surtout par le jugement de Dieu, du fait que l'année précédente, alors qu'une grande troupe de Goths, [...] avait péri d'une fin misérable, se souvenant également de ce fameux désastre essuyé sous Alaric, quand les Goths s'étaient efforcés de passer en Sicile [...] Vallia conclut avec l'empereur Honorius une excellente paix, en donnant des otages du plus haut rang; Placidia, la sœur de l'empereur, qui avait été traitée chez lui avec honneur et respect, fut rendue à son frère; Vallia s'offrit au danger pour la sécurité de Rome, si bien qu'il combattait à ses risques et vainquait pour les Romains les autres peuples qui s'étaient établis à travers les Espagnes. ${ }^{6}$

La chronique d'Hydace est plus laconique: "Vallia lui succède; après avoir conclu une paix avec le patrice Constance, il se dresse contre les Alains et les Vandales Silings, établis en Lusitanie et en Bétique."7

Le témoignage d'Olympiodore donne quelques précisions sur le contexte de discussion diplomatique de cet accord, mais oblitère toute clause traitant des obligations de service des Goths:

L'agens in rebus Euplutius fut envoyé auprès de Wallia qui venait d'être proclamé chef tribal des Goths, pour négocier un traité de paix et le retour de Placidia. Il fut rapidement cellé et lorsque 600.000 mesures de grains furent fournies, Placidia fut libre et fut rendue à son frère, Honorius. ${ }^{8}$

Prosper, dans sa Chronique écrite vers 433, fonde la paix sur la nécessité certes de rendre Galla Placidia à son frère, mais surtout à Constantius, à qui elle avait été promise, vraisemblablement dès 414 . C'est pour lui le seul élément de la transaction à retenir car le but de sa chronique est, ici, de mettre en valeur Constantius, héros de la Restauratio imperii:

6 Oros. hist. 7, 43, 11-12, p. 130: Hic igitur, territus maxime iudicio Dei quia cum magna superiore abhinc anno Gothorum manus [...] miserabili exitu perierat; memor etiam illius acceptae sub Alarico cladis, cum in Siciliam Gothi transire conati, [...] pacem optimam cum Honorio imperatore, datis lectissimis obsidibus, pepigit; Placidiam imperatoris sororem honorifice apud se honesteque habitam fratri reddidit; Romanae securitati periculum suum obtulit, ut adversum ceteras gentes quae per Hispanias consedissent, sibi pugnaret et Romanis vinceret.

7 Hyd. Chron. 60, p. 120 [...] Cui succedens Vallia in regno cum patricio Constantio pace mox facta Alanis et Vandalis Silingis in Lusitania et Baetica sedentibus adversatur.

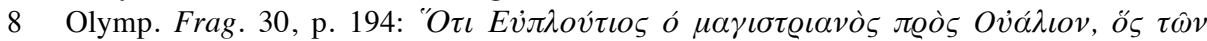

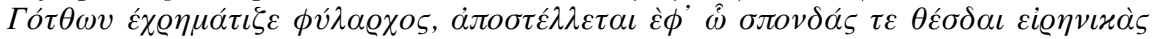

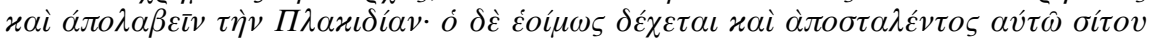

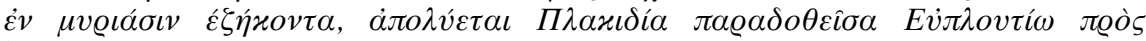

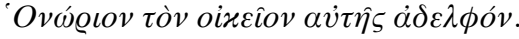


Wallia rendit Placidia qui avait été promise en mariage à Constantius; Placidia, la fille de l'empereur Théodose que les Goths avaient enlevée aux Romains et qu'Athaulf avait épousée, fut rendue par Wallia à Honorius en échange d'une paix. Elle était en effet promise en mariage à Constantius. ${ }^{9}$

Jordanès, un siècle plus tard, centre également les termes de l'accord sur la promesse d'un mariage entre Constantius et Galla Placidia, promesse faite par Honorius à son général devenu patrice:

164. [...] Il (Honorius) craignait que Valia lui-même ne bafouât le traité jadis conclu avec Athaulf et n'ourdit à nouveau quelque piège contre l'Empire, maintenant que ses voisins avaient été repoussés. En même temps, il désirait libérer sa sœur Placidia de la situation infamante de sujétion où elle se trouvait. Il conclut un marché avec Constantius: si, par les armes ou pacifiquement, ou par n'importe quel moyen, il pouvait la ramener dans son empire, il la lui donnerait en mariage. ${ }^{10}$

Le passage rédigé par Jordanes dans ses Romana est plus laconique:

"Valia, le roi des Wisigoths ayant fait la paix avec Honorius, lui rendit sa sœur Placidia. Celle-ci fut unie par mariage au patrice Constantius qui la ramena."

Les chroniqueurs byzantins ultérieurs tireront de ce dernier témoignage une version très romanesque.

L’interpétation des événements proposée par Jordanès amène plusieurs commentaires. La chronologie est particulierement mise à mal dans les Getica. En effet, Jordanès attribue à Athaulf, dans le chapitre XXXI qui précède le passage présenté ci-dessus, des campagnes en Espagne contre les Vandales, "et trois ans après avoir soumis les Gaules et les Espagnes, il mourut." Ce qui situerait ces événements entre 412 et 415 . Manifestement, Jordanès confond ici la situation avec celle qui se mit en place lentement après 418. En revanche, dans les lignes qui suivent immédiatement celles que nous avons reproduites, Jordanès parle de l'usurpation de Constantin III, plaçant ainsi les événements espagnols qui nous intéressent avant 407.

Si la chronologie s'avère totalement erronée chez Jordanès, on peut cependant noter que le résultat d'ensemble de sa présentation de la géostratégie des Goths

9 Prosp. chron., 1259 A. 416, p. 468: Wallia Placidiam reddit, cuius nuptias Constantius promeretur. Placidiam Theodosii imperatoris filiam, quam Romae Gothi ceperant quamque Athaulfus coniugem habuerat, Wallia pacem Honorii expetens reddit eiusque nuptias Constantius promeretur.

10 Iord. Get. 32, 164-165, p. 100-101: [...] ne foedus dudum cum Athaulfo inito ipse turbaret et aliquas rursus in re publica insidias moliretur vicinas sibi gentes expluses, simulque desiderans germanam suam Placidiam subiectionis obprobrio liberare, paciscens cum Constantio, ut, aut bello aut pace vel quo modo si eam potuisset ad suum regnum reducere, ei eam in matrimonio sociaret.

11 Iord. Rom. 326, p. 42: Valia rex Vesegotharum facta pace cum Honorio Placidiam sororem eius reddidit quam Constantio patricio qui eam revocaverat, in matrimonio iungens. 
est exact: ils combattent d'abord en Gaule, en tant que fédérés, Constantin III et Jovinus en 411-412, puis ensuite, ils combattent en Espagne les Vandales en 416 et ils eurent sous leur contrôle militaire une partie des Gaules et de l'Espagne à partir de 418 et plus encore dans les décennies qui suivirent l'accord de 418 .

Dans cette présentation, Jordanès ignore toutefois la série d'accords passés entre 411 et 418 , soit parce qu'il ignore l'existence de ces différentes étapes de la transaction entre Constantius et l'armée gothique. Soit parce qu'il estime que cela n'a pas d'importance: seul compte le résultat final, la création d'une armée fédérée et la place des Wisigoths dans l'Empire romain, pour la postérité dont Jordanès est le premier jalon à Constantinople pour ce milieu du $\mathrm{VI}^{\mathrm{e}}$ siècle auquel il appartient.

Mais le plus troublant dans son témoignage consiste plutôt dans la mise en scène, dans le paragraphe suivant des Getica, d'un traité officiel, conclu entre deux délégations d'ambassadeurs venant chacune du camp des deux armées royales ayant convergé l'une et l'autre en grande pompe jusqu'aux claustra Pyrenei:

Constantius applaudit à cet accord. Il gagne l'Espagne avec une troupe nombreuse de combattants et un apparat presque royal déjà. Valia, roi des Goths, avec un dispositif non moins impressionnant, se porte à sa rencontre aux portes des Pyrénées. Là, les deux camps dépêchent une ambassade et Valia souscrit à l'accord suivant: il rendrait la sœur du prince, Placidia, et il ne refuserait pas d'apporter son aide à l'état romain, lorsque le besoin s'en ferait sentir [...]. ${ }^{12}$

Cette mention géographique explicite situe donc la rencontre diplomatique à l'un des lieux où se matérialisa la "frontière" pyrénéenne à partir de la réforme augustéenne, c'est-à-dire au col de Panissars (près du Perthus actuel). Ce point de contrôle du passage des Pyrénées, sans doute essentiellement douanier, se déplaça un peu plus en aval de la voie domitienne, aux Cluses (claustra ou clausurae), toponyme signifiant à la fois "portes" et "forteresses". Ce déplacement est peutêtre effectif dès l'époque tétrarchique, d'après des témoins archéologiques retrouvés lors de la fouille du site, ou bien a eu lieu en 352-353 lors de la révolte de Magnence, selon 1'hypothèse d'Émilienne Demougeot. ${ }^{13}$ En tout cas, il faut accepter le terminus ante quem de 408. La céramique qui y a été retrouvée aux cours des fouilles plaide de toute manière en faveur de l'occupation des forteresses des cluses durant les $\mathrm{IV}^{\mathrm{e}}$ et $\mathrm{V}^{\mathrm{e}}$ siècles, sinon dès le $\mathrm{III}^{\mathrm{e}}$ siècle. L'ensemble des textes connus pour cette période et pour la période carolingienne confirment

12 Iord. Get. 32, 165, p. 101: Quo placito Constantius obans cum copia armatorum et pene iam regio apparatu Spanias petit. Cui Vallias rex Gothorum non cum minori procinetu ad claustra Pyrenei occurit: ubi ab utraque parte legatione directa ita convenit pacisci ut Placidiam sororem principis redderet suaque solacia Romanae rei publicae, ubi usus exegerit, non denegaret.

13 Demougeot 1974, 109, note 72. 
bien à cet endroit l'emplacement durable de la zone-frontière pyrénéenne entre les provinces de Narbonnaise et de Tarraconnaise. ${ }^{14}$

Cette belle reconstitution littéraire d'un "Camp du drap d'or" avant la lettre pouvait magnifier l'accord ainsi intervenu entre les Goths et Rome et constitue, dans la rédaction des événements menée par Jordanes, le seul "traité": il n'y a ensuite aucune allusion à l'accord de 418. Pour l'historien du milieu du $\mathrm{VI}^{\mathrm{e}}$ siècle qu'est Jordanès, l'accord de 416 devint le traité fondateur du royaume wisigothique de Toulouse et d'Espagne.

Pourtant nos autres sources, antérieures à Jordanès et situées dans le temps de manière plus proche des événements, ne font absolument aucune allusion à un accord qui aurait une telle mise en scène diplomatique, en dépit du fait que quantitativement et qualitativement, les témoignages le concernant sont plus importants que pour l'accord de 418.

Deux hypothèses peuvent en partie proposer des solutions à cette patente contradiction des sources. La première consiste à avancer que Jordanès disposait de sources orales ou bien même d'archives diplomatiques à Constantinople qui faisaient défaut à Orose et Hydace, ce qui lui permit de connaître avec précision le déroulement du cérémonial diplomatique. C'est tout à fait probable. Mais on peut toutefois nous objecter que, si une telle mise en scène avait eu lieu à la frontière pyrénéenne, il y a de fortes chances que les auteurs ci-dessus cités, tous deux espagnols et contemporains des faits, aient été au courant d'un événement d'une telle ampleur.

Il faut donc proposer une seconde hypothèse plus paradoxale: Jordanès invente de toute pièce la cérémonie. Si c'est le cas, c'est très révélateur de sa volonté d'inscrire l'histoire diplomatique des Goths dans la tradition impériale des grands traités, à l'image de ceux de 380 et 382 conclus dans le passé par les chefs goths avec l'empereur Théodose et à l'image de ceux que signe à son époque Constantinople avec ses voisins.

Dans l'un et l'autre cas de figure, Jordanès assigne au traité de 416 une importance historique qu'il ne concède nullement à l'accord de 418 puisqu'il le passe totalement sous silence. On peut donc conclure que ce dernier n'était qu'une clause supplémentaire déterminée par le départ d'Espagne des troupes gothiques et par leur installation en Aquitaine, mais qu'il n'eut pas, surtout à Constantinople, le caractère déterminant d'un accord diplomatique de première importance.

C'est le débat historiographique autour de l'installation des Barbares en Occident qui a contribué à exagérer la signification réelle de l'accord de 418. Il suffit de revenir sur le témoignage des sources disponibles à son sujet pour s'en convaincre. La Chronique d'Hydace ne fait référence à aucun nouveau traité, mais signale simplement que: "69. Les Goths, ayant interrompu les combats qu'ils menaient, furent appelés par Constance en Gaule; ils reçurent des terres en

14 Constant (thèse inédite). 
Aquitaine, depuis Toulouse jusqu'à l'Océan."15 La Chronique de Prosper précise bien que "le Patrice Constantius confirma la paix faite avec Wallia en lui attribuant pour s'établir l'Aquitaine seconde et quelques cités aux confins de ces provinces. ${ }^{" 16}$ La Chronica Gallica, 73, signale seulement que 1'Aquitania Gothis tradita et Philostorge dans son Histoire ecclésiastique, XII, 4, semble considérer qu'un seul traité permit aux Goths de recevoir une quantité de grains (clause du traité de 416) et un district en Gaule pour s'y installer (clause de 418) en échange de la rétrocession de Placidia et d'Attale. ${ }^{17}$

Ce rappel des textes à notre disposition appelle une seule conclusion: aucune source contemporaine ne signale un nouveau traité en 418. Les témoignages font simplement écho d'une installation des Goths en Aquitaine et il est donc préférable de penser que le traité de 416 était toujours valable et qu'en 418 , seul un accord d'intendance militaire fut discuté puis validé, entre Constantius ou ses représentants et les Goths.

Il faut donc séparer cette question de celle de l'installation matérielle voire foncière des Wisigoths en Aquitaine. Seule est fiable, pour comprendre la causalité événementielle, la méthode de travail proposée ici: relier les événements d'Espagne à cette implantation en Gaule du sud, donc envisager conjointement les intérêts du pouvoir romain dans les deux zones géographiques qui font l'objet de la réorganisation politique, administrative et militaire menée par Constantius depuis 411 .

\section{Une oeuvre impériale qui ne laisse place à aucun Regnum Wisigothorum}

J'ai proposé, dans plusieurs publications récentes, ${ }^{18}$ de mettre fin à l'usage abusif de formules totalement anachroniques et institutionnellement erronées, mais qui sont pourtant encore communément utilisées comme regnum Wisigothorum ou bien regnum Tolosanum.

Car la situation dans le premier tiers du $\mathrm{V}^{\mathrm{e}}$ siècle en Gaule, et à mon sens au moins jusqu'en 476, demeure celle d'une Gaule contrôlée par Arles et par Ravenne, y compris dans la zone où se sont installées les troupes wisigothiques, car les rois goths n'ont jamais détenu de commandements militaires officiels: ils sont les reges de leur peuple, mais en aucun cas, ils n'ont le rang de magister militum ou ne possèdent d'autres hauts commandements militaires au sein de

15 Hyd. chron. 69, p. 122: Gothi, intermisso certamine quod agebant per Constantium ad Gallias revocati, sedes in Aquitanica a Tolosa usque ad Oceanum acceperunt.

16 Prosp. chron. 1271, A. 419, p. 469: Constantius patricius pacem firmat cum Wallia data ei ad inhabitandum secunda Aquitanica et quibusdam civitatibus confinum provinciarum.

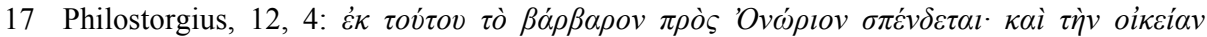

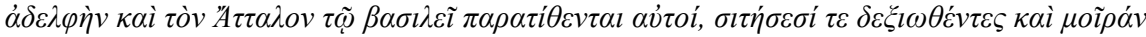

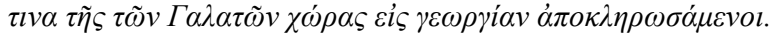

18 Delaplace 2009a, 87-89; Delaplace 2010, 15. 
l'armée romaine qui leur auraient permis d'intervenir dans le contrôle administratif local. Est-ce en fait pour cette raison enfin que les rois wisigoths tentèrent dans les décennies qui suivirent, de remédier aux carences de cet accord? Nous essayerons plus loin de le démontrer.

En ce sens, on peut accepter très largement la proposition faite récemment par A. Gillett qui suggère de voir dans le système imposé par Constantius aux Wisigoths une forme renouvelée du royaume client du Principat, tout à la fois réservoir humain et zone-tampon, le rex $\mathrm{du} \mathrm{V}^{\mathrm{e}}$ siècle demeurant un rex socius et amicus et la terminologie avant tout une terminologie latine. ${ }^{19}$

Constantius avait donc imposé un habile compromis, nettement moins favorable aux Wisigoths qu'on ne le croit. Ils demeuraient des soldats auxiliaires et n'étaient pas mieux lotis que les Alains, Suèves et Vandales qu'on leur demandait de surveiller. Cet accord marquait en revanche un des succès les plus tangibles de la politique de Constantius, puisqu'il avait réussi à empêcher les barbares installés en Espagne de nuire à la paix en Gaule et en Italie. La "marche wisigothique de l'Aquitaine" était protégée par un dispositif défensif que renforçaient les constructions de fortifications urbaines entreprises dans les Pyrénées, notamment à Saint-Bertrand-de-Comminges et à Saint-Lizier. ${ }^{20}$

L'historiographie a longtemps considéré qu'Aetius avait, dans la décennie suivante, repris en main les destinées de l'Occident romain et qu'il était le véritable défenseur de la grandeur de l'Empire au début du $\mathrm{V}^{\mathrm{e}}$ siècle. ${ }^{21} \mathrm{Il}$ est grand temps de réfuter ce portrait laudatif du "dernier des Romains". La stratégie de Constantius mettait la frontière aux Pyrénées et amorçait un recentrage sur l'Italie et l'Espagne et sur la défense de l'Afrique: elle s'affirmait comme une "Realpolitik" qu'il fallait, peut-être par la force, faire admettre à l'aristocratie gallo-romaine, mais c'était une politique qui innovait et qui faisait le deuil de la stratégie de la défense du Rhin. Aetius, au contraire fut en partie responsable des conséquences néfastes d'une politique obsolète qui aboutit à la perte de l'Afrique et à l'exaspération des Wisigoths.

\section{Des relations néfastes avec les Wisigoths jusqu'à la renégociation de l'accord en 439}

La tradition historiographique des Grandes Invasions s'est posée, à propos des Wisigoths, une seule et unique question: quand les Wisigoths avaient-ils dénoncé le foedus de 418 pour devenir un royaume indépendant? Pratiquement, toutes les solutions ont été envisagées: dès 418 , en $425,430,439,451$ et finalement en 469 avec l'avènement d'Euric, terminus post quem sur lequel s'accordent en définitive tous les historiens. Jamais autrefois les historiens n'ont pu envisager l'histoire des

19 Gillett 2002, 118.

20 Delaplace 2009b.

21 Zecchini 1983. 
relations entre les barbares et l'Empire autrement qu'en terme de menaces et de conquêtes. Il ne pouvait donc y avoir ni relations pacifiques ni négociations lorsque des tensions survenaient parce que les Goths étaient considérées comme des hordes barbares hostiles aux Romains et aux habitants des régions où ils s'installaient en envahisseurs.

En 418, les Wisigoths obtinrent seulement un statut d'auxiliaires et non pas de fédérés. Les relations conflictuelles qu'ils entretinrent avec l'autorité romaine jusqu'en 439 sont donc la conséquence de la volonté d'Aetius de ne pas leur accorder un rôle primordial dans sa stratégie défensive de l'Occident. L'ombre des contingents huns utilisés par Aetius plane sur cette situation conflictuelle, car les Wisigoths ne pouvaient supporter de voir ainsi leur ennemi héréditaire obtenir les mêmes conditions dans l'armée romaine d'Occident.

De ce fait, les expéditions vers Arles n'eurent pas pour but de dénoncer un traité passé qui n'avait jamais existé dans les termes que l'historiographie a retenus, mais au contraire d'obtenir un statut plus intéressant que celui de troupes auxiliaires, tant sur le plan de l'assise territoriale octroyée que sur celui de la reconnaissance définitive de leur valeur guerrière et de leur légitimité au sein de l'armée romaine. Le pouvoir impérial et ses représentants en Gaule comprirent l'intérêt de cette reconnaissance seulement après l'échec de la politique d'Aetius et consentirent alors au traité de 439.

Car les tensions effectives des années précédentes ne me paraissent cependant pas avoir abouti à la signature d'un quelconque traité. Ce sont pourtant des épisodes qui ont été abondamment commentés par la tradition historiographique ancienne. Ainsi en 425, alors que les Wisigoths avaient eu la prudence de pas reconnaître l'usurpateur Jean, ils assiégèrent Arles où peu de temps auparavant, le préfet du prétoire des Gaules avait été assassiné par la garnison qui s'était mutinée. Comment interpréter ce fait d'armes? Était-ce un acte de conquête et d'indépendance, comme le soutient la tradition historique ou bien tentèrent-ils ainsi plus subtilement de profiter d'une situation de grand désordre politique pour se faire reconnaître par le pouvoir impérial que représentait encore difficilement Galla Placidia?

Cinq ans plus tard, en 430, un chef goth, Anaolsus, conduisit un raid sur Arles, mais sans que l'on sache s'il agissait pour son propre compte ou s'il était mandaté par le roi Théodoric $\mathrm{I}^{\mathrm{er}}$. L'analyse des décennies précédentes de l'histoire des Goths nous a en effet habitué à prendre en compte le fait que les nobles goths ont bien souvent pratiqué des politiques indépendantes voire rivales de celles des reges qu'ils élisaient à leur tête. Rien donc ne s'oppose ici à considérer cet épisode comme sans réelle conséquence, car les auteurs contemporains de l'événement, que cela soit Prosper, Hydace ou bien l'auteur anonyme de la Chronica Gallica de 452, demeurent dans le vague, ce qui ne sera pas le cas de leurs récits ultérieurs des événements de 439.

Ces derniers ont été précédés par la "guerre gothique" (436-439), formule emphatique que l'on retrouve chez tous les historiens modernes favorables à Aetius qui magnifient ainsi leur héros en lui opposant un farouche adversaire. Faut-il 
rappeler que l'on a affaire seulement à quatre épisodes guerriers, étalés tout le long de quatre années mais dont deux d'entre eux demeurent totalement hypothétiques:

- le siège de Narbonne en 436, suivi par sa libération quelques mois plus tard ou l'année suivante;

- $\quad$ une bataille dite du Mons Colubianus, mentionnée uniquement dans le panégyrique de Mérobaudes en l'honneur d'Aetius et de datation incertaine, mais que certains historiens ont évidemment rapprochée d'une bataille qui se serait soldée par la défaite des Wisigoths et par la perte de 8000 d'entre eux, signalée quant à elle, par Hydace pour l'année 438 et attribuée par lui à Aetius, alors qu'il y a de fortes présomptions qu'elle soit due à l'action de Litorius;

- $\quad$ une bataille près de Toulouse et la défaite de Litorius qui s'en suivit en 439;

- $\quad$ rien ne permet de penser qu'une autre bataille, dirigée par Aetius aurait eu lieu ensuite et puisse correspondre, comme le pensaient André Loyen et Guiseppe Zecchini, aux "anticipis pugnae" de Prosper et au récit tout aussi elliptique de Jordanès. ${ }^{22}$

Il ne suffit pas de parler de "guerre gothique", encore faut-il comprendre comment et pourquoi les relations se sont-elles à ce point détériorées entre le pouvoir impérial, représenté conjointement sur le terrain militaire en Gaule par Aetius et Litorius, et les auxiliaires goths de l'armée romaine.

En fait, la "guerre gothique" n'est que le versant militaire d'une crise politique, bien trop complexe pour l'étudier ici en elle-même, ${ }^{23}$ mais qui fait resurgir les luttes de pouvoir des années précédentes. Chez les généraux romains, il s'agit de celles qui furent si intenses entre Boniface et Aetius, et du côté des Goths, celles entre Bérimond et Théodoric $\mathrm{I}^{\mathrm{er}}$, mais durant la "guerre gothique", ces luttes se déroulent désormais par personnages interposés: le comte Sebastianus et un certain Vitericus, peut-être le futur père d'Eutharic qui, dans la Chronique de Prosper, apparaît curieusement dans le paragraphe qui précède celui où est consignée la paix de $439 .^{24}$

22 Prosp. chron. 1338, p. 377: Pax cum Gothis facta, cum eam post ancipitis pugnae lacrimabile experimentum humilius quam [umquam] antea poposcissent. Contra Loyen 1934, 412 et Zecchini 1983, 221 qui rapprochent indûment deux éléments très éloignés du texte de Jordanès. Au contraire, dans ce dernier, c'est Litorius qui commande l'armée romaine durant cette bataille, Iord. Get. 34, 177: Hunnis quoque auxiliariis Litorio ductante contra Gothos Romanus exercitus movit procinctum, diuque ex utraque parte acies ordinatae cum utrique fortes et neuter infirmior esset, datis dextris in pristina concordia redierunt, foedusque firmatum ab alterutrum fida pace peracta recessit uterque.

23 Delaplace à paraître.

24 Prosp. chron. 1337, p. 477: Per idem tempus Vitericus rei publicae nostrae fidelis et multis documentis bellicis clarus hababatur; idem, 1338, p. 377: Pax cum Gothis facta, [...]. 
Manifestement, Ravenne ou Aetius, ont voulu faire naître une crise dynastique chez les Wisigoths afin de pouvoir mettre sur le trône un rex à leur convenance. Étant devenu plus libre de sa politique après s'être enfin assuré sa survie politique à la cour après sa nomination, en tant que magister utriusque militiae et patrice, nomination consentie par Galla Placidia le 5 septembre 435, on peut donc subodorer qu'Aetius fit des choix diplomatiques et militaires qui allaient lui permettre d'acculer les Wisigoths à la faute, donc à la guerre. La paix avec les Vandales, signée le 11 février 435, rendait vaines dans le court terme toutes les aides militaires que les Wisigoths avaient apportées en Espagne pour combattre ces mêmes Vandales. Ce mépris des accords et des combats communs du passé, comme la crainte d'un renversement total d'alliances, ne devaient pas être sans poids dans la décision prise par le roi Théodoric $\mathrm{I}^{\mathrm{er}}$ de s'engager dans le siège de Narbonne. Le statut octroyé en 418 devenait de plus en plus inadapté et les Wisigoths ne devaient plus se considérer à égalité de traitement avec les Vandales et bientôt avec les Burgondes.

Pour affirmer leur capacité de nuisance, les Goths entreprirent donc le siège de Narbonne, au moment où Aetius était retenu sur le Rhin par les Burgondes. Considérée par certains historiens comme une véritable rupture de foedus, cette manœuvre qui ressemble fort aux épisodes précédents de 425 et 430, était moins une déclaration de guerre qu'un appel à la négociation.

La responsabilité de la libération de Narbonne, qui eut lieu en 436 selon Prosper et seulement en 437 selon Hydace, est attribuée par Prosper à Litorius et à sa cavalerie hunnique, par Sidoine Apollinaire à Avitus. Ces divergences d'interprétation sont à mon avis bien intéressantes et reflètent les idéologies en place à l'époque. D'un côté, on interprète l'événement comme une libération par la force, ce qui convient bien au discours de la "guerre gothique" des auteurs favorables à Aetius, de l'autre, Sidoine Apollinaire présente une libération par la diplomatie, menée par un Romain, futur proche collaborateur de Théodoric $1^{\mathrm{er}}$, Avitus, répondant donc à cet appel à la négociation. On a souvent reproché à Sidoine Apollinaire de se complaire dans une laudatio sans réalisme à l'égard de son beaupère, mais les événements tels qu'ils se déroulent en 436, ou 436-437, peuvent parfaitement, dans un premier temps, avoir effectivement abouti à un accord à l'amiable.

Si l'on est convaincu que les Wisigoths n'avaient pas la volonté de faire la guerre aux Romains, mais seulement, par cette action spectaculaire, celle de montrer leur force et de faire du butin (ce que signale d'ailleurs Sidoine Apollinaire: iam tristis propriae credebat defore praedae si clausus fortasse perit), ${ }^{25}$ nous sommes dans un cadre, assez habituel depuis plusieurs décennies, de relations entre troupes gothiques et pouvoir romain qui aboutissent en effet à cette solution satisfaisante pour chaque camp. Les choses auraient dû en rester là.

On doit donc penser que c'est le climat politique du côté romain qui changea à partir de 438, lorsque l'empereur Valentinien III et les Caeonii-Decii qui domi-

25 Sidon. carm. 7, $478 \mathrm{f}$. 
naient alors les factions à la Cour, considérèrent qu'il fallait être plus ferme et mettre en place une guerre totale contre les Barbares. Cette interprétation permet de mieux comprendre l'enlisement du conflit et son évolution. Alors que l'intervention d'Avitus à Narbonne avait peut-être ramené la paix entre les deux parties, les 8000 morts de la bataille de 438 signalée par Hydace et l'intervention des auxiliaires huns honnis par les Wisigoths, enfin la bataille de Toulouse dont l'issue se retourna finalement contre Litorius et l'armée romaine, semblent ressortir d'une politique de guerre à outrance, particulièrement excessive par rapport au casus belli de départ. L'acharnement de Litorius contraste en effet avec la solution diplomatique engagée par le roi Théodoric $\mathrm{I}^{\mathrm{er}}$ et s'explique par sa rivalité avec Aetius. Selon Salvien, Litorius, jaloux de la gloire d'Aetius, renvoya imprudemment l'ambassade envoyée par Théodoric qui se jugeait peut-être perdu et décida l'assaut en comptant surtout sur ses cavaliers huns qui infligèrent de lourdes pertes aux Wisigoths. Mais ces derniers se ressaisirent, peut-être grâce aux soldats goths du comte Sebastianus présents à Toulouse. Litorius fut blessé, emprisonné et peu après mis à mort.

Pour mettre fin de manière définitive au conflit, le pouvoir romain, mais sans doute plutôt l'aristocratie gauloise mieux avisée, jugea sans doute avec raison que la voie diplomatique était désormais la seule possible. Avitus, devenu alors préfet du prétoire des Gaules, fut nommé pour résoudre la crise de 439. Si les auteurs des chroniques restent très elliptiques en signalant simplement qu'une paix fut décidée, Sidoine Apollinaire n'hésite pas à mettre longuement en évidence le rôle d'Avitus à l'issue de ces quatre années de conflit entre le pouvoir romain et ses alliés goths:

Comme il ne restait nulle part de garnison ni aucun moyen d'action à tes chefs, ô Rome, tu renouvelles, Avitus, le traité: la lecture d'une page de toi soumet un roi furieux; il suffit que tu aies ordonné ce que sollicite le monde. Les nations, les peuples de l'avenir le croiront-ils jamais? Une lettre d'un Romain annule tes victoires, ô Barbare...C'est ainsi qu'Avitus géra la Préfecture du Prétoire, et il était juste en effet que celui qui devait un jour faire les lois en fût d'abord le défenseur; que l'homme qui était promis aux peuples comme souverain, chef, empereur, César et Auguste, n'eût pas seulement l'expérience des combats cruels. ${ }^{26}$

Le terme foedus est utilisé par Sidoine Apollinaire, ce qui n'est pas le cas des autres écrivains contemporains qui n'utilisent que le terme pax, à la seule exception de Jordanès qui, on le voit encore ici, avait une compréhension a posteriori des événements particulièrement judicieuse. L'allusion à un texte écrit, faite ici

26 Sidon. carm. 7, 306-315: [...] Postquam undique nullum / praesidium ducibusque tuis nil, Roma, relictum est, / foedus, Avite, nouas; saeuum tua pagina regem / lecta domat; iussisse sat est te quod rogat orbis. / Credent hoc umquam gentes populique futuri? / Littera Romani cassat quod, barbare, vincis. / Iura igitur rexit; namque hoc quoque par fuit, ut tum / assertor fieret legum qui nunc erit auctor, / ne dandus populis princeps, caput, induperator, / Caesar et Augustus solum fera proelia nosset. 
par Sidoine Apollinaire, correspond davantage aux tractations entreprises par Avitus qu'au document final du traité dont le contenu nous est malheureusement inconnu. Jordanès en avait-il pour sa part une copie, archivée par la chancellerie de Constantinople, qu'il puisse donc ainsi parler si facilement d'un traité? En tout cas, il ne fait aucun doute que le foedus de 416 fut renouvelé, même si nous restons dans le domaine des hypothèses pour cerner ses clauses exactes.

On peut néanmoins déduire d'un certain nombre de faits qu'une tractation serrée, entre Théodoric $\mathrm{I}^{\mathrm{er}}$ et Aetius ou ses agents, aboutit à résoudre la crise politique dont nous avons résumé plus haut l'intensité, de la manière la moins attendue qui soit. Le malheureux comte Sebastianus fut sommé de quitter Toulouse, expulsé par Théodoric $\mathrm{I}^{\mathrm{er}}$ qui le laissa partir un temps en Espagne où les sources contemporaines le situent à Barcelone. Sans doute peu en sécurité dans une zone contrôlée à la fois par Rome et les Wisigoths, il s'enfuit en Afrique. L'autre protagoniste de la crise, Vitericus, connut lui aussi vraisemblablement un exil obligatoire, car nous n'entendons plus guère parler de lui. Les deux éventuels futurs gendres de Théodoric $\mathrm{I}^{\text {er }}$ et futurs prétendants au trône wisigothique furent donc sacrifiés l'un et l'autre sur l'autel de la réconciliation romano-wisigothique! ${ }^{27}$

Celle-ci fut parachevée et fortement mise en scène par le mariage d'Aetius avec la fille de Théodoric I ${ }^{\mathrm{er}}$. Aetius prit soin de répudier sa première épouse, l'Amale Pelagia. Les Wisigoths avaient obtenu plus qu'ils ne l'espéraient: le foe$d u s$ était scellé par une union matrimoniale entre le puissant généralissime et une fille du roi, ce qui ne pouvait que protéger l'avenir et peut-être même favoriser une alliance à long terme. Cette alliance n'avait plus le caractère aléatoire des décisions militaires arrêtées en 416 et en 418/419 et il est donc possible que les clauses de l'organisation des divisions de terres aient été prises à ce moment-là, en 439 .

\section{Conclusion}

Le tournant des relations entre le pouvoir romain et les fédérés se situerait donc en 439 et non pas vingt ans plus tôt, mais il n'aboutit en aucun cas à une indépendance conquise de force par les Wisigoths. Ce changement de politique impériale fut rendu obligatoire par l'impact décisif de deux bouleversements essentiels du rapport des forces stratégiques en Occident: d'une part l'arrêt définitif des apports de contingents hunniques sur lesquels Aetius avait construit sa fragile suprématie militaire et politique; d'autre part, la prise de Carthage par Geiseric en octobre 439 , signe d'un basculement total des modes de relations entre un chef barbare et Ravenne. L'incapacité de récupérer l'Afrique avant la Reconquête justinienne un siècle plus tard, témoigne assez de l'ampleur de la catastrophe.

Il ne s'agit donc pas d'un changement politique en faveur d'un assouplissement des relations guerrières entre Ravenne et le roi wisigoth, comme le laissait

27 Delaplace à paraître. 
autrefois penser la logique d'une hostilité chronique entre deux états rivaux, mais d'une realpolitik largement imposée par la situation internationale du moment et les rapports de force, désormais favorables aux Wisigoths.

Cette interprétation me semble confortée par l'installation des Burgondes en Sapaudia qui pourrait avoir succédé très rapidement à leur défaite contre les Huns, dès 438 et donc avoir précédé ou bien être concomitante du foedus de 439 avec les Wisigoths. ${ }^{28}$ Le pouvoir impérial aurait, dans l'un et l'autre cas, inauguré une nouvelle formule de relations avec ses armées barbares qu'il aurait appliqué, dans un laps de temps assez court, d'une part aux Alains de l'Orléanais placés là pour juguler la Bagaude en Armorique, d'autre part aux Burgondes et aux Alains de Valence installés dans la Sapaudia pour défendre la Gaule de la menace des Alamans. L'installation des Burgondes en Sapaudia ne se situe donc plus après les hostilités romaines contre les Wisigoths et le traité de 439, mais avant et n'a donc plus à être interprétée comme une solution géniale faisant partie intégrante de la réorganisation de la politique romaine qu'aurait décidée Aetius. En plus d'une nouvelle lecture des relations entre les Wisigoths et l'Empire, un mythe historiographique tenace, celui d'Aetius, "le Dernier des Romains", disparaît donc avec cette nouvelle interprétation.

\section{Bibliographie}

\section{Sources primaires}

Hydatius, Chronicon:

Hydace, Chronique, Tome I: introduction, texte critique, traduction, Tome II: commentaire et index par Alain Tranoy (SC 218/219), Paris 1974.

The ,Chronicle of Hydatius' and the ,Consularia Constantinopolitana': two contemporary accounts of the final years of the Roman Empire. Edited with an English Translation by Richard W. Burgess, Oxford 1993.

Jordanès, De origine et actibus Gothorum:

Jordanès, Histoire des Goths, introduction, traduction et notes par Olivier Devillers, Paris ${ }^{2} 2000$.

Iordanis Romana et Getica, rec. Theodor Mommsen (MGH Auct. ant. 5, 1), Berlin 1882, 1-138.

Jordanès, De summa temporum vel origine actibusque gentis Romanorum: Iordanis Romana et Getica, rec.Theodor Mommsen (MGH Auct. ant. 5, 1), Berlin 1882, 1-52.

Olympiodorus, Fragmenta: Roger C. Blockley, The Fragmentary Classicising Historians of the Later Roman Empire. Eunapius, Olympiodorus, Priscus and Malchus, Tome I: Introduction, Liverpool 1981, Tome II: Text, Translations and historiographical Notes, Liverpool 1983, 152-209.

Orosius, Historia adversus paganos: Orose, Histoires (Contre les Païens). Texte établi et trad. par Marie-Pierre Arnaud-Lindet, Paris 1990-1991.

28 Sharf 1996, 44 et Wood 1987, 255. 
Philostorgios, Historia ecclesiastica: Philostorgius, Kirchengeschichte. Mit dem Leben des Lucian von Antiochien und den Fragmenten eines arianischen Historiographen, hg. von Joseph Bidez, Leipzig 1913, 3., bearbeitete Auflage von Friedhelm Winkelmann (GCS 21), Berlin 1981.

Prosperus Tiro Aquitaniensis, Epitoma chronicon et addimenta in Prosperi Textum inserta: Chronica minora saeculi IV, V, VI, VII, rec. Theodor Mommsen (MGH Auct. ant. 9), Berlin 1892, 341-499.

Sidonius Apollinaris, Carmina: Sidoine Apollinaire, Euvres, Tome I: Poèmes, Texte établi et traduit par André Loyen, Paris 1960.

Sozomenos, Historia ecclesiastica: Sozomène, Histoire ecclésiastique, Tome IV: Livres VII-IX: texte grec de l'édition J. Bidez - G. C. Hansen (GCS), traduction par AndréJean Festugière et Bernard Grillet (SC 516), Paris 2008.

\section{Littérature secondaire}

Cesa (1992/1993): Maria Cesa, „Il matrimonio di Placidia e Ataulfo sullo sfondo dei rapporti tra ravenna e I Visigoti“, Romanobarbarica 12, 23-53.

Constant (thèse inédite): André Constant, Du castrum à la seigneurie: pouvoirs et occupation du sol dans le massif des Albères et ses marges (IIIe-XIIe siècles) (thèse de l'Université de Toulouse-II sous la direction de B. Cursente, soutenue en mars 2005).

Delaplace (2009a): Christine Delaplace, „Les Wisigoths en Septimanie à travers les sources", El tiempo de los ,Barbaros'. Pervivencia y transformación en Gallia e Hispania (ss V-VI d.c), Zona Arqueologica, 87-95.

Delaplace (2009b): Christine Delaplace, „Le dispositif défensif de l'Aquitaine wisigothique et franque. L', affaire Gondovald' et le siège de Saint-Bertrand-de-Comminges (Haute-Garonne) à la lumière de recherches récentes sur les fortifications pyrénéennes dans l'Antiquité tardive“, Aquitania 25, 199-211.

Delaplace (2010): Christine Delaplace, „Wisigoths et Ostrogoths en Gaule et en Espagne (411-534)“, in: Luc Bourgeois (ed.), Autour de la Bataille de Vouillé: Francs et Wisigoths (507-2007) XXVIII ${ }^{\mathrm{e}}$ Journées Internationales d'Archéologie Mérovingiennes, (Vouillé-Poitiers, 28-30 septembre 2007), Saint-Germain-en-Laye (Mémoires de 1'Association française d'Archéologie Mérovingienne XXII), 15-18.

Delaplace (à paraître): Christine Delaplace, La géostratégie des Wisigoths. Les relations entre les Wisigoths et l'Empire romain de la seconde moitié du IV siècle à 534, Turnhout.

Demougeot (1974): Émilienne Demougeot, „Constantin III, l'empereur d'Arles“, in: Hommage à André Dupont, Montpellier, 83-125 (repris in: L'Empire romain et les barbares d'Occident (IV $V^{e}$-VII siècle) Scripta varia, Paris 1988, 171-214).

Gillett (2002): Andrew Gillett, „Was Ethnicity Politicized in the Earliest Medieval Kingdoms?", in: Andrew Gillett (ed.), On Barbarian Identity: Critical Approaches to Ethnicity in the Early Middle Ages, Turnhout (Studies in the Early Middle Ages 4), 85121.

Loyen (1934): André Loyen, „Les débuts du royaume wisigoth de Toulouse“, Revue des Etudes Latines 44, 406-15.

Perevalov (2000): S.M. Perevalov, „Bazas, 414: la rupture de l'alliance alano-gothique“, Dialogues d'Histoire Ancienne 26, 1, 175-193. 
Scharf (1996): Ralf Scharf, „Die ,Gallische Chronik von 452‘, der Fall Karthagos und die Andsiedlung der Burgunder“, in: Spätrömische Studien. Prosopographische Studien und quellenkundliche Untersuchungen zur Geschichte des 5. Jahrhunderts nach Christus, Mannheim, 37-47.

Wood (1987): Ian Wood, „The Fall of the Western Empire and the End of Roman Britain“, Britannia 18, 251-262.

Zecchini (1983): Guiseppe Zecchini, Aezio: l'ultima difesa dell'Occidente romano, Rome. 



\title{
Administrative Methods of Barbarian Settlement in the Fifth Century: The Definitive Account
}

\author{
Walter Goffart
}

The settlements in question here form a group defined by a small corpus of evidence, perhaps five pages in all of modern print; the main problem is to interpret this corpus coherently. The settlements affected the Goths and Burgundians of Gaul, the Vandals of North Africa, and, in Italy, Odoacer and his army, then the Goths of Theoderic. A book of 1844 by Ernst-Theodor Gaupp set in motion efforts to construct a sophisticated interpretation of these Ansiedlungen, and, amazingly, Gaupp's reasoning remained dominant until 1980. In that year I published Barbarians and Romans, 419-584: The Techniques of Accommodation, in which a different theory was proposed. ${ }^{1}$

I have not stopped working on this topic since my book of thirty years ago. After 1980 my interests moved to other subjects, but in 2001 I reopened my barbarian settlement file and, in 2006, published Barbarian Tides, whose sixth chapter and an appendix offer eighty new pages on the subject. ${ }^{2}$ Barbarian Tides reaffirms my original argument, but presents the subject in a better way. For example, I no longer put the Ostrogothic case at the head of the discussion; the Visigothic case takes priority in the book; and I draw special attention to the multiple meanings of "land". In addition to Barbarian Tides, my reawakened interest was expressed, in 2008, in "Frankish Military Duty and the Fate of Roman Taxation", in which I established a strong likelihood that the technique of settlement used for the Goths and Burgundians was also applied to the Franks. ${ }^{3}$ Here, I shall add comments about the Vandals, who are a new interest, and make it clear (as I may not have before) that the barbarian sors was a package of landed property rights. In my recent publications, the basic positions have not changed, but they have widened and their presentation has improved.

Among the writings on this subject by others, I single out the review of Barbarians and Romans by Maria Cesa in Archivo storico italiano for 1982. This

1 Gaupp 1844; Goffart 1980.

2 Goffart 2006, 119-186, 311-329, 257-262.

3 Goffart 2008. See now also Goffart 2010. Special pains are taken here to correct the misapprehensions, especially about property, evident in Halsall 2010 (but by no means his alone). I am grateful to him for highlighting the points of my argument in need of further clarification. 
was a very early review, and although my book did not convince Cesa, I admire her for having really understood its argument. She set a model of accuracy and discernment that, alas, was not followed by later critics. ${ }^{4}$ I refer particularly to the English ones - Barnish, Heather, Wood, Wickham, and Liebeschuetz. Their writings about my scheme are more notable for firm resistance to new ideas than for contributing anything that advances the problem beyond the hospitalitas theory of Gaupp. 5

But there is better news out of England. In 2007, Guy Halsall of the University of York published Barbarian Migrations and the Roman West, which contains twenty-five pages on "Administered Settlement: the Hospitalitas Question". 6 Two features of Halsall's account stand out. For one thing, he shows that the many dissents by his British confrères have neither disproved my proposal nor swept it into a dustbin. Halsall's main conclusion also seems important; he says: "Whether or not one accepts [Goffart's] detailed replacement thesis, [he] irreparably torpedoed the idea that the Roman system of hospitalitas had anything to do with land or property and thus served as the basis for landed settlement". I In other words, Gaupp's theory about military billeting is dead and buried; good-bye to hospitalitas in connection with these fifth-century settlements. (This negative conclusion was already reached in 1987 by Jochen Martin, thus twenty years before Halsall. $)^{8}$ We can no longer speak of barbarian settlement as though Gaupp provided a comfortable, secure alternative to my scheme. Halsall puts the matter succinctly: a return to the status quo ante Goffartum is not possible. What I offer here is the up-to-date and succinctly spelled out interpretatio Goffartiana. ${ }^{9}$

My account begins with an observation that seems central to this subject, namely that the administered settlement of Goths and others was calm and peaceful. It is very hard to deny this fact. Although the argument is e silentio, it is extraordinarily strong. In Gaul and Italy and even in North Africa, there are no indications of "shock, outrage or opposition" by the affected populations at the time when allotments, sortes, were given to the barbarian troops. ${ }^{10}$ We also know that, later on, in the countryside of Gaul and Italy, barbarians and Romans lived as neighbors without bitterness, hostility, and resentment. Cassiodorus is our most

4 Cesa 1982. The refutation of Goffart 1980 that has won greatest attention is Barnish 1986, which lacks Cesa's virtues.

5 The authors mentioned are fully cited in Goffart 2006, 313 n. 14. Add Wickham 2005, 84 86. The longest critique of my book is Krieger 1991.

6 Halsall 2007, 422-447.

7 Ibid., 435.

8 Martin 1987, 165: "Die Ansiedlung der Germanen [ist] wieder ein offenes Problem."

9 My account here is abridged in order to facilitate understanding. I omit many points discussed in Goffart 1980, Goffart 2006 and Goffart 2010.

10 The quotation is from Halsall 2007, 423. For my comments on the subject, see Goffart 1980, 58; Goffart 2006, 138, 166-167, 319 n. 70 (recording the protests of Liebeschuetz, Heather, and Wood). 
eloquent source; everyone, he tells us, was happy and content. It is as though the barbarians had been quietly absorbed in an orderly way. ${ }^{11}$

This astonishing feature of the barbarian Landnahme is not paradoxical or amazing; there is a very simple reason for it. No one protested because the settlement was carried out at the expense of the state, and exclusively of the state. The cultivation of the soil stayed in the hands of the farmers who collected the harvests. The ownership of the land by private Roman proprietors was also unaffected; even in North Africa, ordinary lay owners were not expropriated. ${ }^{12}$ The change took place at the uppermost legal stratum of land, namely, the government's records of land valuation and payment. The settlement of barbarians involved only the public register of taxpayers and property assessments, that is, the cadastre. The asset allocated to the barbarian troops was a hereditary proprietary package consisting of a bounded fraction of the cadastre, along with the taxes arising from it. (I shall explain this process in a moment.) ${ }^{13}$ Because that official record of property and the tax revenue that it generated pertained only to the government, the loss incurred was felt nowhere else than in the public treasury. In Italy, over the vain protests of the patrician Orestes, the government lost one-third

11 Cassiod. var. 2, 16, 5 (a text that is very prominent in both my own and my critics' discussion of "accommodation"): Iuvat nos referre quemadmodum in tertiarum deputatione Gothorum Romanorumque et possessiones iunxit et animos. Nam cum se homines soleant de vicinitate collidere, istis praediorum communio causam videtur praestitisse concordiae: sic enim contigit, ut utraque natio, dum communiter vivit, ad unum velle convenerit. En factum novum et omnino laudabili: gratia dominorum de cespitis divisione coniuncta est; amicitiae populis per damna creverunt et parte agri defensor adquisitus est, ut substantiae securitas integra servaretur. Una lex illos et aequabilis disciplina complectitur. Necesse est enim, ut inter eos suavis crescat affectus, qui servant iugiter terminos constitutos. This letter is usually interpreted as though it recorded a division of Roman private property. A wholly different reading results if the letter is understood to show that the ownership of land (retained by the Romans) was detached from the property assessment yielding a fiscal revenue (given, sors by sors, to the Goths). One cannot help noticing that Cassiodorus's tone is positive, rejoicing in the harmony that the division produced; see in this sense, e.g., Jones 1964, 251. Incidentally, the damna alluded to by Cassiodorus are likely to be the costly Gothic conquest of Italy rather anything having to do specifically with land. For friction between barbarian and Roman landowners after the settlement, see the comprehensive rundown of the six cases in Goffart 2006, 183-186; none of them explicitly concerns sortes.

12 On the continuity of (abundant) Roman landownership in Vandal Africa, see Courtois 1955, 276-278. The allegation of Procopius (in the 550s) that a robbery of land took place in connection with the distribution of sortes is disproved by the much earlier, and natively North African, testimony of Victor of Vita, quoted below (see n. 24).

13 The term "cadastre", derived from Byzantine fiscality (kata stychon), entered western usage via Italy in the late Middle Ages. It is now well defined as "A public record, survey, or map of the value, extent, and ownership of land as a basis of taxation" (American Heritage Dictionary of the English Language). I use it here, as others have, as a convenient shorthand term for late Roman public registers of taxpayers, property assessments, and (often) tax payments (cf. Déléage 1933). For a discussion of such public records, see Goffart 1982. 
of its tax base. ${ }^{14}$ The population at large was unmoved by this irrevocable loss. No one was going to cry and be upset if the cost of the barbarian settlement was borne entirely by the government.

Let me follow this introduction with comments about land. Almost all my critics claim that I have challenged an old, sane, land-based explanation (Gaupp's) with a foolhardy tax-based hypothesis. This emphatic contrast of land versus tax made counterarguments very simple. One might say, how can Goffart talk about taxes when all the primary sources speak of land? As was put by Barnish and Liebeschuetz, the "surface" and "natural" meaning of the evidence incontestably refutes the Goffart system. ${ }^{15}$ I am glad to see that Halsall rejects this facile opposition of land to tax.

The crux of the problem is the meaning of land. (One might refer to "property" instead, but the pitfalls of this term should be avoided, at least for the time being. Besides, the sources speak of terra.) My critics, without exception, have presupposed that land is simple and self-explanatory, with a clear and obvious meaning; one of them assures us that "terra $[\ldots]$ is unambiguous". ${ }^{16}$ Land, in their view, is just private property. And so, when sources speak of division and partition, they must be understood to mean that private property was taken away from some people and given to other people. It seems as though the barbarian immigrants each received an exact fraction of the assets of a resigned Roman proprietor. To almost all commentators, Roman land was both private and easily expropriated.

One more preliminary remark is needed. In each case of settlement, Halsall, like many others as said above, requires that the Romans should lose a large part of their property. This approach should properly be called "expropriationist". If the terra involved in these transactions were private, then massive and wholly illegal dispossessions of landowners (one-third of all private land in Italy! twothirds in Gaul!) are unavoidable. The extent of these robberies can be limited only by arbitrary softenings lacking any documentary basis (e.g., lands of large proprietors only, or state lands). ${ }^{17}$ And these pitiless expropriations, even if imaginatively softened, appear to have taken place without any murmur of anguish or remonstrance from the victims. The alternative to my explanation is fatally flawed by the indispensability of expropriations, and the absence of protests.

The narrow meaning of land presupposed by the "expropriationists" - that land is private property, period - is simplistic. Land has multiple meanings ("property" is not univocal either). In the Dictionnaire Robert, under "terre", we find five and a half columns of definitions and examples of usage. In the (unabridged) Oxford English Dictionary, under "land", we find nine main headings

14 Procop. bell. Goth. 1, 1, 4-5.

15 See the passages of Barnish and Liebeschuetz cited in Goffart 2006, 122, 314 n. 17, $321 \mathrm{n}$. 90.

16 Innes 2006, 52.

17 Since their presentation by Hans Delbrück and Ferdinand Lot, such arbitrary qualifications have been widely resorted to. 
with fifteen subdivisions. Among these choices, "land" as "private property" obviously exists but is hardly unique.

I suggest that, for purposes of the present subject, land should be understood in three ways: (i) occupancy and cultivation; (ii) ownership, that is, private property; (iii) governmental property-assessment yielding a fiscal revenue. ${ }^{18}$ (As we have already seen, such state valuations, often with their tax charges, were registered in the public records that moderns commonly call cadastres.) Each person with any of these three rights could refer to "his land", meaning the particular rights to land that he possessed. For a tenant farmer, "his land" comprised occupancy and cultivation, subject to a rent. For an owner, "his land" meant legal prerogatives such as sale, exchange, lease, and bequest, as well as subjection to taxes. For the state, "its land" involved valuation, registry, and tax imposition and collection. All three senses of land could be cumulated in one person: he could own land, cultivate and occupy it, and be excused the taxes on it by the state. Normally, the three senses were distributed in two or three ways. One more thing: It will not do to call the state assessments of land "abstract" by comparison with a supposed "concreteness" of private property. Cultivators and agronomists deal with concrete land, but ownership is distant from the soil; the purchase, bequest, and division of land are abstract operations (one may measure the difference in concreteness by substituting meat or a bolt of cloth for land). On the other hand, the collection of state revenue from a taxpayer is just as palpable as the collection of rent from a tenant.

It needs to be understood that, in most cases where I say "land", the term "property" could be substituted. (Not using that term is meant to avoid confusion.) Property is not a discrete "thing"; it consists of bundles of rights - such as those referred to above as the separate "senses of land". Property can take various forms, typically, as said above, the rights of tenants and of owners. The humblest example would be a late Roman peasant tenant's rights of permanent tenure and stability of rental, as well as of residence and cultivation. These rights are proprietary. The essential point is that "private property" is not a privileged entity; it consists of a bundle of rights coexisting with other, just as proprietary, bundles of rights.

My threefold ordering of land is not a Roman peculiarity; it calls for commonplace distinctions that exist today. One may, for example, own a house that one occupies, leases, or leaves vacant; it is registered in the records of its municipality and, on the basis of its official appraisal, one pays taxes when called on to do so. Every time land is spoken of in connection with the barbarians, the sense or senses that it is meant in should be specified. I suggest that the settlements of barbarians affected only land in its third meaning. This cadastral sense of land allowed the Roman state to marshal the landed assets of its provincials without confiscating them. Its technique was the most original and creative aspect of the

18 At least two additional (here irrelevant) senses come to mind: land as sovereignty (e.g., Switzerland) or as the soil, dealt with by chemists and agronomists. 
fifth-century barbarian settlements: by the allotments (sortes) to barbarians, the government brought into existence a new, singular kind of property.

I assume - correctly, I think - that the Roman territories in which Goths, Burgundians, and Vandals were settled had public records listing owners, rating their properties, and indicating the taxes arising from them. ${ }^{19}$ What resources could the patrician Constantius mobilize in 418 when he had to settle the Visigoths in Aquitaine ? $^{20}$ The answer is plain: he could not legally touch the peasants; he could not legally touch the landowners; but he did have the state's official registers of taxable property. Out of this cadastre, without outcry or disturbance, he could provide a revenue for the Visigoths, a revenue that was securely backed by registered land declarations. The government did not detach its taxes from the property assessment ("land") on whose account they were paid. What the barbarian beneficiary received, his sors, was a package of cadastred land and its revenue, not revenue apart from land.

The process that Constantius (or whoever else was responsible) resorted to is not beyond our abilities to reconstruct. It worked somewhat like this: the total tax registry of a territory was divided between the Gothic king and his army; one part of the total stayed with the king or government (one-third in Gaul, two-thirds in Italy); the other part was allocated to the troops. This is the division into thirds that we notice in the sources. The fractions do not refer to individual Roman properties, but relate to something global and abstract, namely, the cadastre. Out of the part of it reserved for the barbarian troops, hereditary allotments, sortes, were provided for each barbarian soldier, carved out piece by piece from the cadastre into roughly equal segments. The details of this allotment may have been as follows: each soldier received a list, extracted from the public records, of the Roman properties whose fiscal proceeds were given hereditarily to him (he could refer to this cadastral extract as "his land" or, if one wishes, his property). With this document in hand, the sors-receiver would hereafter collect his annual stipend - equal to the tax formerly paid to the state - from the person or persons whose assessed land was subject to this payment. A Roman making a payment to the sors-receiver did not turn into the barbarian's tenant; both parties were private owners, the Roman of his fundus, the barbarian of his sors. The sortes were hereditary property, given by the government once and for all, irrevocably, to individual soldiers and their descendants.

19 About the coupling of property declarations with fixed tax charges, see Goffart 1989, 239241. An important indicator is a law of 412 (CTh 13, 11, 13): Loca, quae praestationem suam implere non possunt, praecipimus adaequari, ut, quid praestare possint, mera fide et integra veritate scribatur, id vero quod impossibile est a vasariis publicis auferatur.

20 I am speaking hypothetically, not asserting as fact that Constantius himself used this method of settlement or that the distribution of state resources occurred in 418 rather than later. (The sources are uncommunicative on these subjects.) Regardless of who the official was, or when he acted, he availed himself of Roman bureaucrats and the tax machinery. For the circumstances of 418, see Heather 1991, 219-224. What he says of hospitalitas (i.e., the Gaupp system) is outdated in the light of Halsall's mise au point (n. 7, above). 
The barbarian's distinct bundle of rights was just as much "property" as a tenant's rental land or an owner's prerogatives of sale, lease, division, etc. It was a layer of ownership coinciding with the boundaries of the private-law ownership of the Romans affected. The revenue arising from a sors was packaged with the land (in its cadastral sense) on whose account it was paid, just as it had been when in the state's possession. Revenue and land were not separate "things" awarded at different times to the beneficiary.

Like other proprietors, the beneficiaries of sortes had costly obligations; barbarian allotments were not free. Although not taxed in money or goods by the government, the sortes nevertheless entailed an expensive functio publica. The barbarian beneficiaries owed military service to the king whenever summoned. In Gaul this service was unpaid; soldiers furnished their own rations and equipment. In Italy, allowance was made for some remuneration. ${ }^{21}$ The importance of this requirement of military service can hardly be exaggerated. It shows, for one thing, that governments did not simply relinquish a large share of the tax base; in return for their concession they imposed a costly and valuable functio publica on the sortes. The requirement also shows something new of far-reaching significance: the creation of a landed basis for military service in the successor kingdoms. Might this be the birth of Beneficialwesen? I shall return to this subject.

Finally, each barbarian sors is likely to have been much larger - to have had much more extended boundaries - than an average Roman property (fundus). It must be kept in mind that tax revenue from land is a mere fraction of its rental revenue. Because the sors owner collected only the tax charge of Roman property, it follows that, in order to equal the rental income of a single Roman property, he needed the fiscal returns of several fundi. ${ }^{22}$ This consideration has implications for barbarian occupation of the soil that one hopes will be explored.

I should like now to present some texts that, to my mind, document the scheme I have described. I begin with the Vandals. Chris Wickham, in his magnum opus of 2005, chides me for not producing a "single text" clearly supporting my proposed method of settlement. ${ }^{23}$ I suggest that the single text Wickham calls for is found in a few lines of Victor of Vita's Historia persecutionis Africanae provinciae. I quote my translation:

21 About payment (annonae) in Italy for actively serving troops, see Cassiod. var. 2, 5; 3, 42; 4,$13 ; 5,9 ; 13,16 ; 6,22 ; 10,18$. This may be what is referred to from a somewhat different standpoint as exercituales expensae: ibid., 3, 40; 5, 26. The continued resort to military payments by the government was why the Italian sortes affected only one-third of the "land", as contrasted to the two-thirds awarded in territories where military service was unpaid.

22 E.g., an imaginary Roman farm, rental revenue 100 solidi, tax 25 solidi; the barbarian had to be given the taxes of three of these Roman farms in order to equal the net revenue of a single one. (This example is purely hypothetical. I have made no attempt to approximate realistic figures of revenue and tax.)

23 Wickham 2005, 85. 
Setting in order (disponens) each of the provinces, [Geiseric] kept Byzacena, Abaritana, Gaetulia, and part of Numidia for himself; and he divided the [...] Proconsular province into hereditary lots [1 Chron. 16:18] for the army. ${ }^{24}$

Victor substantiates the essentials of what I described a moment ago. Step one: the cadastre of these provinces - the main asset of the government in all Africa was divided into two parts, of which one was kept by Geiseric's government. Step two: the other part of the cadastre - here, the province of Proconsularis - was allocated globally to the Vandal troops. Step three: the army's allocation was divided into individual hereditary bounded property packages, bundles of (formerly tax) revenue and (formerly cadastred) land, for each soldier. These individual allotments were collectively called the sortes Vandalorum. No step of this operation required the expropriation of Roman landowners. We know that, although much land of notables was confiscated by the Vandal régime, ordinary Roman landownership continued in Africa. ${ }^{25}$ The payments by Romans to sorsbeneficiaries prolonged the Romans' former payments to the state. The charges did not constitute a form of tenancy or imply a diminution of personal status.

For a second proof, I refer to the case of the Visigoths, the earliest of these regulated settlements. As a starting point, CE 277 speaks of sortes Gothorum and tertias Romanorum: What do these collective terms mean? Tertias Romanorum should be considered first. According to LVisig 10, 1, 16, tertia was land that paid its taxes to the royal fisc; it was cultivated and owned by Romans (thus called "Roman" rather than "royal"), but it was "royal" from the standpoint of its fiscal revenue. LVisig 10, 1, 8 confirms that tertia Romanorum was "royal land". ${ }^{26}$ It says that a Goth was forbidden to have tertia Romanorum unless the king had given it to him, nisi [...] a nostra forsitan ei fuerit largitate donatum. This royal gift did not consist of ownership, which Romans retained; no expropriation was involved. What the beneficiary received was a package of hereditary proprietary rights consisting of bounded land-assessment yielding revenue - thus

24 Vict. Vit. 1, 13: Disponens [Geisericus] quoque singulas quasque provincias, sibi Byzacenam, Abaritanam atque Getuliam et partem Numidiae reservavit, exercitui vero Zeugitanam vel proconsularem funiculo hereditatis divisit. Vict. Vit. 1, 22: Aquae regiones palatio tributa pendebant; a contrast is implied between provinces paying their taxes to the king and the one paying its tributa to sors-beneficiaries. The (biblical) term funiculus in the quotation is a synonym for sors, a portion or allotment; Bible translations bear this out.

25 See n. 12, above. The hereditary character of the army's sortes shows that they were the private property of the beneficiaries. They were demonstrably alienable in the Burgundian kingdom. Their subjection to a functio publica did not make the award precarious.

26 Cod. Eur. 277: Sortes Gothicae et tertias Romanorum [are subject to a 50-year prescription] [...] alias omnes causas [are terminated in 30 years]; LVisig 10, 1, 16: Ut, si Goti de Romanorum tertiam quippiam tulerint, iudice insistente Romanis cuncta reforment. Iudices [...] tertias Romanorum ab illis, qui occupatas tenent, auferent et Romanis [...] sine aliqua dilatione restituant, ut nihil fisco debeat deperire [...]. Because cultivated and owned by Romans, the sortes Gothicae were just as "Roman" as the lands paying their taxes to the king. 
private land from the fiscal standpoint, publicly registered and at the king's disposal to keep for himself or to give away as an individual soldier's property, a sors. In neither case was the title of the Roman owner(s) subverted.

These findings about tertia allow the sortes Gothorum to be explained. LVisig 10, 1, 8 contrasts the duas partes Goti to the tertia Romani. ${ }^{27}$ Because we know that tertia is royal land forming a part of a cadastre, we can infer with near certainty that "the two parts of the Goth" are its equally cadastred complement. When taken together, tertia and partes Goti allow us to conjure up the total tax base of the territory occupied by the Goths: one-third of it was retained by the king; the remaining duas partes were allocated collectively to the Gothic soldiers; and this soldiers' share was sliced into roughly equal hereditary holdings - the sortes. The sors awarded to each Goth did not include either the cultivation of the soil or its private-law ownership (both of which stayed with Romans); it was a bundle of hereditary proprietary rights composed of public property-assessment whose fiscal proceeds went hereafter to the beneficiary of the sors. The sors had definite boundaries. ${ }^{28}$ They coincided with those of the Roman properties listed in the beneficiary's cadastre-extract; this was his land, a negotiable commodity.

I hope these two demonstrations suffice as examples. Both of them bear out that the barbarian soldiers were given "land", but land in its governmental sense a fraction of the official cadastre. We are entitled to say that this share of public property, and the revenue from it, were privatized. And, just as Roman private property owed taxes to the public fisc, so the soldier-beneficiary of a sors was subject to the expensive functio publica of military service. Of course I leave aside much documentation, such as that from Ostrogothic Italy. Most of all, I pass over the rich evidence found among the laws of the Burgundians. These texts and other matters are pursued at length in chapter six of my Barbarian Tides; that is the place to look for further clarification. ${ }^{29}$ Without dealing with additional texts, I shall sum up.

We know of six cases of administered barbarian settlement; I listed them at the start: Visigoths in Gaul and Spain, Vandals in Africa, Burgundians in Gaul, Odoacer's troops in Italy, Theodoric's Ostrogoths again in Italy, and probably Clovis's Franks in Gaul. In all six cases, the clearly articulated Roman system of

27 LVisig 10, 1, 8, De divisione terrarum: [...] ne de duabus partibus Goti aliquid sibi Romanus presumat [...], aut de tertia Romani Gotus sibi aliquid audeat usurpare [...] nisi quod a nostra forsitan ei fuerit largitate donatum [...]. (It is important to notice that, in this law, Gotus and Romanus are used synechdochically, pars pro toto, thus land of "the" Roman, not of "a" Roman. We know this to be the case because "de tertia Romani" has already been shown to refer to royal land as a whole, and not to one-third of an individual Roman's property.

28 This would explain a text such as Cod. Eur. 276.

29 About the Burgundian case, Goffart 2006, 143-162, 257-262. My words, or anyone else's, on this difficult evidence are not definitive. It is not surprising that the Burgundian texts have probably received more attention from scholars than any other material on the barbarian sortes. One is well advised not to use them as the point of departure in interpretations of the settlements. 
settlement, based on public resources, that I have described was applied. It did not matter whether the part of the cadastre allocated by the government to the troops was two-thirds (as in Gaul) or one-third (as in Italy) or one province (as in Africa); the technique remained the same. With minimum disturbance and friction, the barbarian soldiers were given a permanent landed settlement, a hereditary bounded bundle of rights of their own, assuring them a stream of revenue. Simultaneously, the kings gained a paid-for army. In each territory, the overall settlement - the creation of soldiers' sortes - brought into existence an additional layer of proprietary rights in the countryside, intertwined with the bundle of proprietary rights of Roman landowners and of tenant farmers.

The question of barbarian settlement has been mired in controversy ever since Gaupp and his appeal to the Roman law of billeting. Everywhere, it is presented, not as settled doctrine, but as a troubled debate. The same corpus of evidence has been wrestled with for more than 160 years. ${ }^{30}$ I hope that the details of the settlement that I have set out can bring this controversy to an end. I should like to think that these Roman procedures, already outlined by me in 1980, will now be accepted as being well-grounded facts, and that the "expropriationist" theses will be abandoned as untenable. The cadastre-based method of settlement - the creation of a new type of private property - was the gift that the Roman state and its tax system made to all the western kingdoms to which it handed over the machinery of rule. I have always been a fan of the continuity of Roman institutions into the Middle Ages. I think this is one such case of creative adaptation and possibly the farthest-reaching of them all.

From the point of view of taxation, the creation and distribution of sortes constituted a large-scale adaeratio, a commutation or exchange of taxation from one functio publica to a different one. The payment by some lands of taxation in money or goods was exchanged for a different functio, namely, the performance of unpaid military service. Of course, the service was not cost-free; it was rewarded, but irrevocably, by a division of the cadastre and the establishment of each individual permanent sors. Historians hardly need to be reminded that the exchange of a revenue for military service was a feature of medieval society. It seems to me as though we see it being first instituted here. And not without governmental resistance. Procopius tells how in Italy this change was considered outrageous and repugnant when it was first proposed; the patrician Orestes paid with his life for digging in his heels and refusing the army's demand for a onethird share of the state's landed assessment (cadastre). ${ }^{31}$ It certainly mattered to royal governments that a large fraction of their potential revenue was permanently assigned to a hereditary, landed, military, social stratum. The sors subject to military service was hereditary; it was awarded once and for all, and not subject to

30 For a good example of the long, inconclusive debate, see Musset 1965, 284-288, translated in Musset 1975, 214-218; and compare Jones 1964, 249-253.

31 For the beginnings of Odoacer's régime and the attendant award to the soldiery, see n. 14, above. 
curtailment or confiscation for failure to answer the royal summons to war. A monetary fine was the only sanction. The creation of these sortes gave birth to a markedly changed military system; it also had proprietary implications, as we have seen.

To conclude. As I returned to hospitalitas in the early $2000 \mathrm{~s}$, it seemed to me that, after a few decades of attention, a level of exhaustion had been reached among the historians concerned. It was not that everything had been said, but that the controversy had petered out, and new blood was not being recruited. My fear when publishing Barbarian Tides was that the audience had melted away. ${ }^{32}$ Hardly any reviewer had the energy and interest to navigate my sixth chapter; no one did enough homework to understand what they were reading. So I was heartened by Halsall's conclusions in Barbarian Migrations and very much welcomed this Augsburg conference as an occasion to reanimate an ostensibly tired discussion. Perhaps the subject can now be definitely settled.

\section{Bibliography}

\section{Primary sources}

Cassiodorus, Variae: Cassiodori senatoris variae, rec. Theodor Mommsen, Berlin 1894 (MGH Auct. ant. 12), 1-385.

Legum codicis Euriciani fragmenta: Leges Visigothorum, ed. Karl Zeumer (MGH LL nat. Germ. 1), Hanover/Leipzig 1902, 1-32.

Codex Theodosianus: Theodosiani libri XVI cum constitutionibus Sirmondianis et leges novellae ad Theodosianum pertinentes, 3 vol., ed. Theodor Mommsen and Paul M. Meyer, Berlin ${ }^{4} 1970$.

Leges Visigothorum, ed. Karl Zeumer (MGH LL nat. Germ. 1), Hanover/Leipzig 1902.

Procopius, Bellum Gothorum: Procopius. With an English Translation by Henry B. Dewing, vol. 3-5 (LCL), Cambridge (Mass.)/London 1962-1968.

Victor Vitensis, Historia persecutionis Africanae proviciae sub Geiserico et Hunirico regibus Wandalorum, rec. Karl Halm, Berlin 1879 (MGH Auct. ant. 3, 1), 1-58.

\section{Secondary sources}

American Heritage Dictionary of the English Language (4th ed. revised, 2003), Boston.

Barnish (1986): Sam J. B. Barnish, "Taxation, Land and Barbarian Settlements in the Western Empire", Papers of the British School at Rome 54, 170-95.

Cesa (1982): Maria Cesa, "Hospitalità e altro techniques of accomodation [sic]? A proposito di un libro recente", Archivo storico italiano 140, 539-52.

Courtois (1955): Chrétien Courtois, Les Vandales et l'Afrique, Paris.

Déléage (1933): André Déléage, "Les cadastres antiques jusqu'à Dioclétien”, Études de papyrologie 2, 73-228.

32 This fear has turned out to be unfounded. Enough hard cover copies have been sold to warrant the publisher's issuance of a paperback edition. 
Gaupp (1844): Ernst-Theodor Gaupp, Die germanischen Ansiedlungen und Landtheilungen in den Provinzen des römischen Weltreiches, Breslau.

Goffart (1980): Walter Goffart, Barbarians and Romans, A.D. 418-584: The Techniques of Accommodation, Princeton.

Goffart (1989): Walter Goffart, "Merovingian Polyptychs: Reflections on Two Recent Publications", in: Walter Goffart, Rome's Fall and After, London, 233-253.

Goffart (1989a): Walter Goffart, Rome's Fall and After, London.

Goffart (2006): Walter Goffart, Barbarian Tides: The Migration Age and the Later Roman Empire, Philadelphia.

Goffart (2008): Walter Goffart, "Frankish Military Duty and the Fate of Roman Taxation", Early Medieval Europe 16, 166-190.

Goffart (2010): Walter Goffart, "The Technique of Barbarian Settlement in the Fifth Century: A Personal, Streamlined Account with Ten Additional Comments", Journal of Late Antiquity 3, 65-98.

Halsall (2007): Guy Halsall, Barbarian Migrations and the Roman West, 376-568, Cambridge.

Halsall (2010): Guy Halsall, "The Technique of Barbarian Settlement in the Fifth Century: A Reply to Walter Goffart", Journal of Late Antiquity 3, 99-112.

Heather (1991): Peter Heather, Goths and Romans, 332-489, Oxford.

Innes (2006): Matthew Innes, "Land, Freedom and the Making of the Medieval West", Transactions of the Royal Historical Society, 6th ser., 16, 39-74.

Jones (1964): Arnold H. M. Jones, The Later Roman Empire, Norman, Oklahoma.

Krieger (1991): Rommel Krieger, Untersuchungen und Hypothese zur Ansiedlung der Westgoten, Burgunden und Ostgoten, Bern.

Martin (1987): Jochen Martin, Spätantike und Völkerwanderung, Munich.

Musset (1965): Lucien Musset, Les invasions. Les vagues germaniques, Paris

Musset (1975): Lucien Musset, The Germanic Invasions, E. and C. James (trs.), Pennsylvania.

Wickham (2005): Chris Wickham, Framing the Early Middle Ages: Europe and the Mediterranean 400-800, Oxford. 
II.

RÖMISCHE ELITEN IN GALLIEN:

TRANSFORMATIONEN IDENTITÄRER BEZUGSFELDER 



\title{
Un-becoming Roman
}

\author{
The end of provincial civilisation in Gaul
}

\author{
John F. Drinkwater
}

In a paper published in $2001 \mathrm{I}$ referred to 'the peculiar rarity and lateness of the late antique Gallic warlord'. ${ }^{1}$ My aim here is to explain and extend my thinking in this respect.

The Late Empire saw the appearance of a number of local Gallic leaders. Rutilius Namatianus and Zosimus both suggest the establishment of some sort of local power in northern Gaul from the early fifth century; ${ }^{2}$ and in the later fifth century this area produced Riothamus, leader of the Bretons. ${ }^{3}$ Furthermore, however one explains it, the late fifth century also saw some sort of regional Roman power being exercised in northern Gaul by men such as Syagrius, Paul and Arbogast. ${ }^{4}$ More widely in Gaul, throughout this century, as imperial power weakened and retreated, local leaders of all sorts, from gentry to bandits, took power into their own hands, possibly under the general label of 'Bagaudae'. 5 So there were, I concede, a number of what may loosely be called Gallic 'warlords'. But most of these were not what I had in mind when I remarked upon 'the peculiar rarity and lateness of the late antique Gallic warlord'. None was successful in the sense that none established any long-standing sub-Roman state that was directly founded on Roman imperial and provincial administrative structures and practice. What I have in mind as 'warlords' are, rather, local Roman - not barbarian - leaders who, though no longer properly part of the imperial structure and relying for their initial authority on force more than office, nonetheless managed to acquire some Roman title, continued Roman imperial and provincial administrative structures and practices, and so may be seen as local inheritors of Roman power.

\footnotetext{
1 Drinkwater 2001, 143.

2 Rut. Nam. 1, 213-216; Zos. 6, 5, 2-3.

3 Sidon. epist. 3, 9. Stevens 1933, 94; Wood 2000, 507f.; MacGeorge 2002, 74.

4 PLRE 2, 1041f.; 851f.; 128f.

5 Drinkwater 1992; cf. Wood 2000, 504.
} 
It may be argued that possible examples of these are Aegidius and Syagrius, who may have created a sub-Roman state in the Soissons/Paris basin. ${ }^{6}$ But this state is historically obscure. If it ever existed, it was hardly permanent. Roman communities survived only in the gaps between expanding barbarian kingdoms. As these grew larger, the interstices grew smaller and eventually disappeared. ${ }^{7}$ Instead of a 'post-colonial' Gallo-Roman state there was a Germanic takeover or, as far as one can see, in Brittany a reversion to Celtic type. ${ }^{8}$ This is odd in view of the absence of imperial usurpers commanding the whole of Gaul after the fall of Constantine III which, as I have hypothesised elsewhere, should have allowed both barbarian kingdoms and warlords. ${ }^{9}$ What I am asking, therefore, I guess, is why were there no Romano-Gallic diadochoi, no Gallic Ambrosius Aurelianus. ${ }^{10}$ Bluntly, why did the Gallo-Roman aristocracy fail to put up protracted armed resistance to the invaders? In Mathisen's key study of the Gallic aristocratic response to the changing conditions of the fifth century the choices are: flight; alternative careers in the Church; immersion in Classical culture; or collaboration with Germani to the point of treachery. In other words, imperial defeat and Germanic victory are taken for granted, and analysis developed on this basis. Mathisen mentions armed resistance, but only in passing, as sporadic, localised phenomena, before moving on to examine the wider, passive response. ${ }^{11}$ I believe that these are valid questions, and have been gratified to find that at least some aspects of them have been touched on by recent commentators, in particular Halsall.

Much of their validity lies in the fact that there were surely sufficient martial skills and spirit in Gaul to resist the, at first relatively few, Germanic incomers. As Halsall says, the standard view of western provincials as 'usually passive, indeed apathetic, cowardly observers of the movements of armies and the transfers of political power' must be unfair. ${ }^{12}$ In my 2001 article I questioned the notion that the Germanic takeover of the Gallic provinces in the fifth century was explicable in terms of local leaders having gone 'soft'. I observed that most aristocratic Gallic males preserved and practised martial strength and skills in the complex and dangerous, but ever popular, country-pursuit of hunting. In this they trained both themselves and their dependants for the hardships of war. ${ }^{13}$ The bestknown practical demonstration of their mastery of such skills is the defence of Clermont by Ecdicius, son of the emperor Avitus and brother-in-law of Sidonius Apollinaris, and his followers in the period 471-474, in the closing days of Ro-

\footnotetext{
PLRE 2, 11f.; Wood 2000, 497, 508; MacGeorge 2002, 75-164.

Cf. MacGeorge 2002, 73f.

Brittany: Wood 2000, 497; MacGeorge 2002, 74.

9 Drinkwater 1998, 296.

10 Cf. Wood 2000, 508; Halsall 2007, 520-526.

11 Mathisen 1993, 31, 56f.

12 Halsall 2007, 10 (disputing Jones 1964, 1059-1062).

13 Drinkwater 2001, 136f., $142 \mathrm{f}$.
} 
man rule in the Auvergne. ${ }^{14}$ Ward-Perkins, indeed, sees Ecdicius' actions as one of the earliest manifestations of militarisation of the later Roman aristocracy. ${ }^{15}$ Gallo-Roman military ability was also shown soon afterwards by Arborius, Vincentius, Victorius, Calminius and Namatius, and later by Apollinaris, son of Sidonius Apollinaris, who served as officers in Visigothic land and sea forces. ${ }^{16}$ As Loseby observes elsewhere in this volume, by the mid-sixth century, local comites in the Frankish kingdom recruited Gallic other ranks for service in the royal armies as a matter of course. ${ }^{17}$ However, the martial instincts of GalloRoman aristocrats had been revealed even earlier by their construction and use of defensible sites. Best known are Dardanus' 'Theopolis' and 'Burgus', the fortified villa of Pontius Leontius. To these we may add, for example, bishop Lupus of Troyes' ordering the reoccupation of a hill-fort against the Huns in $451 ;^{18}$ and in this volume Diefenbach notes continuing episcopal control of troops and building of strong-points into the sixth century. ${ }^{19}$ As Mathisen remarks, ' $[\ldots]$ unlike their more timid cousins to the south, the aristocrats of Gaul had always affected something of a military bearing. ${ }^{20}$ And again to quote Halsall: 'The common ideas that the Romans needed barbarians for military protection and that the Britons were the only provincials to take up arms are in serious need of revision. ${ }^{21}$ So, if Wood is right to see the failure of the imperial military as the key to the end of the Roman world, ${ }^{22}$ it is reasonable to ask why Gallo-Roman leaders did not copy the Romano-British of the early-fifth century in establishing their own forces, comprising both native dependants and, if they could pay for them, Germanic federates. Returning to Mathisen's 'strategies', was the Gallic choice really just 'Empire or Barbarians'?

Recruitment of both Gauls and federates would, of course, have required money, and so taxation, which brings us to the next requirement for a successful Gallo-Roman successor state, a strong political and administrative infrastructure. Gaul had such a structure, and its basis was the civitas. This had survived from the Iron Age, had been developed by Rome and, despite the disruption of the fifth century, survived into the post-Roman period, being made great use of by the Church and by Germanic kings. As a fundamental element in the Roman fiscal system, civitas-authorities had passed tax receipts up the line of imperial administration to the regional Praetorian Prefect, for disbursement by the comes sacrum

14 Sidon. epist. 3, 3, 3-6; PLRE 2, 383f.; Harries 1994, 229; Sivonen 2006, 153 f.

15 Ward-Perkins 2005, 48 (with Sivonen 2006, 154 n. 64).

16 Apollinaris the younger: Greg. Tur. Franc. 2, 37. Mathisen 1993, 125-127; Drinkwater 2001, 143; Sivonen 2006, 157; Halsall 2007, 495 (though cf. 475f.: the lack of leading Gauls in Frankish service).

17 Below p. 235.

18 Mathisen 1993, 55, 99f., 125; Wood 2000, 511.

19 Below p. 98.

20 Mathisen 1993, 56f.

21 Halsall 2007, 496; cf. Whittaker 1994, 263-270.

22 Wood 2000, 504-506. 
largitionum. Now they were free to retain these for themselves. ${ }^{23}$ And, in addition, following fourth century decentralisation of the imperial administration, they would have been in a position to appropriate local state resources in the shape of treasuries, factories, and land. Gauls still clearly identified themselves by their civitas, native or adopted, which, as in the case of Sidonius Apollinaris's defence of Clermont, will have stiffened martial resolve. ${ }^{24}$ But it must also have encouraged the payment of what was due to the civitas, in cash or kind. All this would, at least in principle, have made independent civitas-actions, political or military, perfectly viable.

I stress 'civitas'. Some wider 'Gallic' identity had been fostered by Rome, ideologically through the definition and separation of 'Galli' from the rest, especially from Germani, and practically, at least in part, through the establishment of centres of the imperial cult at Lyon and Narbonne. Gaul had historical experience of independent action, verging on separatism, within the Roman Empire in the third century, in the shape of Postumus' 'Gallic Empire'. In the fourth it had seen legitimate emperors resident in Trier, and been given its own praetorian prefecture. In the early fifth century, the Council of the Seven Provinces was established at Arles. In the late Roman period, indeed, Gallic identity appears to have reached such a state that Gaul won the reputation of being especially troublesome: of having its own interests and desiring its own emperors. ${ }^{25}$ Its particular views and grievances were, of course, most dramatically expressed by Sidonius Apollinaris in the mid-fifth century, in his panegyrics of Avitus, Majorian and Anthemius. ${ }^{26}$ This Mathisen describes as indicating the evolution of a Gallic 'sense of regional identity', a 'Gallic self-consciousness', which 'would have tended not only to unify the Gauls but also to separate them all the more from their aristocratic brethren elsewhere in the empire'. ${ }^{27}$ But here one needs to tread very carefully. To the end of the fourth century, 'Gallic' troublemaking had been not so much of the Gauls of Gaul, but of the military in Gaul, still based on the Rhine frontier, and was, therefore, at heart still imperial, Roman, troublemaking. In the fifth century, Gauls of Gaul were concerned not to leave the Roman Empire, but to get from it what they wanted of its rewards, albeit on their own terms: office; ac-

23 On the enduring strength of the Gallic civitas and its access to local resources see in this volume, Kulikowski, p. 84; Diefenbach, p. 98; Witschel, p. 154; Loseby, p. 222, 231-232, and Murray, p. 307-308. Elsewhere see, for example, Mathisen 1993, 81; Harries 1994, 126; Lewis 2000, 73-75, 77; Wood 2000, 520f.; MacGeorge 2002, 120; Halsall 2007, 480f., 432-435 (supporting Goffart: cf. above p. 45-55), 476; Brunaux 2008, 74.

24 Cf. Loseby in this volume, below p. 232: "The city communities themselves had their identities repeatedly reinforced in moments of collective spiritual, military, or political action..." He also notes that such action sometimes took place as a civitas-, not a royal, initiative. Elsewhere: Harries 1994, 35, 246f.; Sivonen 2006, 66-68; Halsall 2007, 482.

25 Mathisen 1993, 17-20, 24-6; cf. Halsall 2007, 19, 34, on imperial regionalism in general, and the breakdown of links between periphery and centre as creating a political vacuum that was filled, not created by barbarians.

26 E.g. Sidon. carm. 5, 354-363 (to Majorian, in 458); and below p. 64, n. 41.

27 Mathisen 1993, 20; cf. Harries 1994, 89f. 
ceptance of equality by Italians; the ability to continue to be closely involved in Gallic, i.e. primarily civitas, affairs; and, above all, continued Roman commitment to the defence of Gaul - as in the age of Aëtius, and which men like Sidonius Apollinaris hoped would be reinstated under Majorian and Anthemius. ${ }^{28}$ In short, Gaul was too big, and a strictly Gallic identity too weak, for separate action on a grand scale. ${ }^{29}$ In other words, here I am not concerned with the absence of the emergence of a new 'Gallic Empire', but with that of independent political and military action by, say, a major civitas and its dependencies, about the size of an early Germanic proto-kingdom. ${ }^{30}$

So what prevented this? As in most things, explanation boils down to consideration of 'attitude' and 'opportunity'. As far as 'attitude' is concerned, it seems clear that by the fifth century most leading Gauls, constrained by a long-ingrained 'imperial habit', would not, as already observed, have desired a break from Rome. Previously, the Gauls' relationship with the Empire had been uneven. They had embraced it to the later first century; had kept it (or had been kept by it) at arm'slength to the later third century; had, thanks to a local imperial presence at Trier, begun to warm to it again from the later third century; and had, with the emergence of a new, imperially-minded, Gallic aristocracy, begun fully to embrace it from the later fourth century. By the early fifth century, despite the problems of the age and the imperial retreat from the north, they were fully integrated, espousing imperial ambitions and craving imperial office - as long, that is, in an attitude that went back to their third-century re-awakening, these did not take them too far from their Gallic interests and responsibilities. ${ }^{31}$ This 'Gallic attitude' to the Roman Empire has been much studied, most recently by Sivonen, who emphasises Gallic integration into Roman aristocratic - basically old Republican customs and values to such an extent that he prefers to speak not of 'Gallic aristocrats' but rather of 'Roman aristocrats living in Gaul', who adopted no 'specific Gallic attitude towards the Empire'. ${ }^{32}$ Again, one has to be careful. As Wood has pointed out, and as is touched upon by Sivonen, this interpretation is derived from the writings of a coterie of authors, so the extent to which it is generalisable is open to question. ${ }^{33}$ The same writers acknowledged the fact that there were members of their social circle who were much less keen on imperial office. ${ }^{34}$ And even some of those who were keen may have wanted Roman office for selfish, practical ends - wealth, power, self-protection - not feelings of traditional Roman duty

28 For a negative, precisely because it was so Gaul-centred, assessment of Aëtius' policy, see Delaplace, above p. 35.

29 As Sivonen 2006, 16f., 68, 76, 78, $103 \mathrm{f}$.

30 See Witschel, below p. 155, for the extraordinary size of many Gallic civitates (in the original sense of the word, as territoria, not just civitas-capitals). For 'proto-' see below p. 68 on the fluid nature of Germanic kingship and kingdoms at this time.

31 Drinkwater 1989, 141-145; cf. Mathisen 1993, 17-26, Harries 1994, 89-91.

32 Sivonen 2006, 10, 130f.; cf. Drinkwater 1989, 151f.

33 Wood 1992, 10; Sivonen 2006, 64.

34 Mathisen 1993, 20; Harries 1994, 25f.; Sivonen 2006, 56-58, 61, 136-138. 
or Republican pride. However, the people we know about seem to have been among the major 'movers and shakers' of late imperial Romano-Gallic politics. If they had wished to pursue a different policy vis-à-vis the Empire, they would have done so. But they did not: local power was apparently simply unthinkable no substitute for imperial. As Halsall says, 'There were enormous brakes, cultural and socio-economic as well as political, upon the abandonment of Romanness'; and, '[...] it was not easy to respond to the Empire's political decay simply by setting out to rule independently. The Empire was so deeply ingrained into ideas of all aspects of social and political action that simple 'rejection' of Rome was not an option. ${ }^{35}$ Rutilius Namatianus was unshakeable in his belief in Rome's power, and in his conviction that she would defeat her enemies. ${ }^{36}$

This brings us to opportunity, and the observation that, even if there had been a significant desire for a breakaway state, pragmatically there was never really a right time for its creation. When might this have occurred? Under Constantine III, from 407? But Constantine was set on controlling Italy, and through this the whole of the western Empire, and perhaps beyond. ${ }^{37}$ Under his successor, Jovinus, from 411? As a local leader, Jovinus looked promising, but he was ephemeral, no match for Athaulf's Goths. ${ }^{38}$ Under Avitus, from 455? But Avitus, like Constantine III, was set on gaining Italy to restore the west: Gaul would save the Empire, not just itself. ${ }^{39}$ Immediately after Avitus, in the awkward interregnum from October 456 to the accession of Majorian in April 457? But, despite some feeling of alienation from Italy and unrest in Gaul, this moment too was lost, as most Gallic aristocrats showed themselves willing to follow Majorian on the old terms. ${ }^{40}$ After the fall of Majorian in 461? The situation now, for the first time, becomes really promising, since we have the non-cooperation of Aegidius. But the Gallic aristocrats living in residual imperial territories remained steadfastly loyal to the Empire, ${ }^{41}$ and, as far as can be seen, Aegidius nursed fundamentally imperial, not Gallic, ambitions. ${ }^{42}$ This leaves only the period of the end-game, from the late-460s to the mid-470s, as rising barbarian power and increasing imperial weakness, accelerated by the failure of the great Vandal campaign of $468,{ }^{43}$ will have made it ever more evident that there was nothing to be hoped for from Rome. This was, after all, the time of the 'conspiracies' - probably better, realistic attempts to come to terms with barbarian leaders - of Arvandus (condemned in

35 Halsall 2007, 470, 368.

36 Rut. Nam. 1, 141-154; Sivonen 2006, 33f.

37 Drinkwater 1998, 281.

38 Cf. Delaplace, above p. 27.

39 Sidon. carm. 7, 585-598; Sivonen 2006, 75f.

40 Harries 1994, 82-84, 90f.; Sivonen 2006, 77f.

41 Sidon. carm. 2 (panegyric on Anthemius).

42 Harries 1994, 96; MacGeorge 2002, 90-93, 296.

43 Harries 1994, 224f.; MacGeorge 2002, 241. 
469) and Seronatus (in the early 470s). ${ }^{44}$ It was also that of the brave exploits of Ecdicius in the defence of Clermont. Could Ecdicius, as a Gallic Ambrose, have created a Gallo-Roman successor-state? As Wood says, 'Ecdicius showed what a man with military experience and a private following could manage in central Gaul'; ${ }^{45}$ and in a famous but obscure passage of a letter concerning the crimes of Seronatus, Sidonius Apollinaris even hints that Ecdicius might become some sort of local leader. ${ }^{46}$ But in 474, just before the surrender of the Auvergne, Ecdicius abandoned Clermont to serve as magister militum under Julius Nepos, first in Gaul but then, in line with the imperial mind-set of his class, in Italy.

This litany of missed opportunities is, indeed, in part the concrete manifestation of the 'imperial habit'. It also reflects the consequence of the transformation of what had once been a great imperial strength into a debilitating weakness. Political centripetalism, which had held the Empire together in the worst times of the third-century 'Crisis', now undermined the position of the West. ${ }^{48}$ But behind this there were other situations and forces. There was no event that suddenly forced people to take sides. Things happened slowly, and in a complex and confusing fashion. ${ }^{49}$ The rump western Empire, commanding Italy, remained strong; and when it received help from the East it was still a superpower. Roman emperors interfered in Gallic affairs to the very end. ${ }^{50}$ Contemporaries could not know the future. Seeing the Empire's residual strength, they might well imagine that its current weakness was only temporary, and that it would eventually strike back and re-establish its power. Down to the 470 s there was a run of major players Constantius III, Aëtius, Ricimer - who, whatever their particular failings, managed to hold things together. A brilliant successor might yet be able to do more. In particular, if Rome managed to recover Africa (which, as Justinian was to show, was not an impossibility), Italy would be safe and resources would be available for a return to the traditional policy of defending the peninsula from over the Alps, and a return of serious imperial attention to Gaul. ${ }^{51}$ As Halsall says, 'Different outcomes to some of the high-level political events of the fifth century could have changed many of the details or even reaffirmed the fourth-

44 Teitler 1992; Mathisen 1993, 83-85 also noting Agrippinus, in the late 450s: cf. MacGeorge 2002, 88-92, 119.

45 Wood 2000, 507 (Harries 1994, 229, is rather more negative about Ecdicius).

46 Sidon. epist 2, 1, 4; Mathisen 1993, 89.

47 MacGeorge 2002, 275f.

48 Drinkwater 1989, 152: 'it was the maintenance of this Empire, not the establishment of a strong Gaul, that diverted and wasted [Gallic] strength for most of the fifth century.' Cf. Drinkwater 2005, 62f.

49 Cf. Mathisen 1993, 19, 67, 72.

50 As Harries 1994, 142, 148, 225 suggests, even the appointment of Anthemius, a renowned soldier, with an adult heir and strong eastern military backing, was more than mere gesture politics.

51 Cf. MacGeorge 2002, 268: Ricimer concentrated on Italy. 
century supremacy of Romanness. ${ }^{52}$ And, less positively, if people believed that Rome might return, they would avoid putting themselves in a position where they could be subject to harsh punishment for showing disloyalty. Again to quote Halsall, 'The Empire came close several times to restoring its authority in the West and, when on the offensive, it showed remarkably little tolerance for those who, it felt, had usurped its authority. ${ }^{, 53}$ So why not stay with it, and its offices and rewards, as did both Avitus and Sidonius Apollinaris, i.e. why not practise "pragmatism'? This had wide implications. Acceptance of office and rewards brought with it obedience: if you recognised imperial authority but your civitas was then effectively handed over to a Germanic king by your emperor, you stayed ceded, and did not argue the toss by making a unilateral declaration of independence. And even before this stage you accepted imperial compromising of your position. The Empire relatively quickly accepted the Visigoths as part of the landscape.$^{54}$ There was no thought of removing them, as there was no thought of removing any barbarians except the Huns. ${ }^{55}$ A vigorous barbarian kingdom in Aquitania or even, as Delaplace argues in this volume, a powerful allied 'Visigothic Army On the Garonne, ${ }^{56}$ strengthened by the long reigns of Theoderic I and II and Euric,${ }^{57}$ totally distorted Gallo-Roman politics, since policy-makers grew used to taking into account the views of Toulouse. In practical terms this put an end to the history of the 'old' Roman Gaul, created by the establishment of the imperial frontier on the Rhine. And the stronger the Visigoths became, the more their neighbours would feel that they needed imperial, not just local, resources, to counter their influence. In short, the process will have sapped local political initiative.

'Attitude' and 'opportunity' are not exclusive categories, and other forces will also have been at work, of which I note two. First, where might an autonomous Gallo-Roman state have been based? By the fifth century, to continue the Roman tradition there was no absolute need for the old Rome. The Empire was by now sufficiently Romanised for the City of Rome to be dispensable, which explains the rise of Constantinople. So was another 'new Rome' possible in Gaul? Perhaps yes: in 402, Honorius may have considered a move to Lyon. ${ }^{58}$ But more likely no: though old Rome was dispensable, it was relatively close to Gaul and, though probably little visited, was much revered there. ${ }^{59}$ It would have been very difficult for Gauls to make the break. And, even if they had, where might they have gone instead? Of the cities that had seen resident emperors, Trier, Rheims and Paris were too far to the troubled north and so soon effectively out of the running; and by the mid-fifth century, Lyon was too close to the Burgundians, and Vienne was

52 Halsall 2007, 482.

53 Halsall 2007, 368f.

54 Kulikowski, below p. 84: no later than the 430s/440s.

55 Mathisen 1993, 56.

56 Delaplace, above p. 38.

57 Respectively: 418-451; 453-466; 466-484.

58 Drinkwater 1998, 274.

59 Cf. Sivonen 2006, 34, 36, 43, 73, $107 f$. 
too close to Lyon. This left Arles, exposed to attack from Italy, and Africa. ${ }^{60}$ Of the rest, Clermont was a possibility, but this was threatened by Visigoths and Burgundians; and the choice of a civitas other than one of the traditional imperial residencies may well have generated local rivalries. Second, and which would perhaps repay closer attention, is the Church. In this respect I am not thinking of Christian criticism of Roman values and behaviour, or even of the establishment of a higher loyalty, beyond the state, dealt with below. Rather, I have in mind more immediate local considerations. For example, overt Church backing of a Romano-Gallic Christian state might have vexed neighbouring Germanic rulers, and so compromised Christians and Church influence in their realms. In addition, in a successful Romano-Gallic Christian state, an able and influential courtbishop might well have provoked papal jealousy and, as was already happening, papal alliance with Germanic kings. ${ }^{61}$ Overall, the situation was hardly propitious for the emergence of a breakaway state.

Those who are familiar with the period will know most of the material presented so far, if not the arguments I derive from it. However, for the remainder of this paper I will pursue two related aspects of 'attitude' and 'opportunity' that have received less attention. These move discussion from 'warlords' to 'the end of Roman provincial civilisation in Gaul' of my title, and are, I believe, of particular relevance to the topic of this volume.

The first aspect may be categorised as 'constitutional'. If a sub-Roman Gallic state had come into being, what would have been the title of its leader? Burned deep into the Roman - and probably, given the long history of civitasgovernment, into the Gallic - political psyche was the close association of executive power with legitimate office, not brute control of people and resources. Someone who set himself up as a local leader, without Roman office or title, would be seen as illegitimate, no more than a 'brigand' ${ }^{62}$ True Romans would have been uncomfortable in supporting such a man. As cronies of a bandit-chief, a man without the imperial diadem or the purple,$^{63}$ they were themselves bandits. As outlaws, they would have no lawful access to local imperial resources, and be unable to deal with conventional Roman communities. On the other hand, as the Roman people under arms, they had a right to name an imperator; ${ }^{64}$ and in fact the sole recourse for an individual leading such an enterprise, and one that was much resorted to over the centuries, was to have his backers salute him as imperator and Augustus. However, the traditional expectations and ambitions of the imperial political nation, now intensified by Christian monotheism, and the con-

60 Cf. Harries 1993, 137; Wood 2000, 518.

61 Harries 1993, 135-138.

62 Sivonen 2006, 27, 45, 62f., touches on these points, but fails to develop them.

63 Cf. Sivonen 2006, 108-10, 127.

64 Pabst 1997, 54-66. 
viction that rival rulers could not all be God's vicegerents, ${ }^{65}$ put huge pressure on a local leader to make for the centre of power, which in the later Roman West meant moving into Italy. In the meantime, the sitting incumbent, anticipating such a move, would have condemned him as a 'tyrant', and be preparing to destroy him. Emperors never tolerated outsiders, even when these (e.g., from the late third to the early fifth centuries, Carausius, Magnentius, Vetranio, Magnus Maximus, Constantine III) might have helped share the burdens of office. The result was civil war. If the challenger won, he would become responsible for the whole of the Empire. He could not use his victory simply to confirm his breakaway state: the Empire was not for partitioning. It was never allowed to break up into smaller, self-governing 'mini-empires', which in the West was probably its best means of long-term survival.

Apart from imperator and Augustus, the only titles that allowed legitimate local action were, as in the case of Aegidius, that of free-lance magister militum, or, as in the case of Syagrius, that of rex. But the former led nowhere, and the latter had its own problems. ${ }^{66}$ There was, of course, already the ancient Roman prejudice against kingship; and in the contemporary context the title of rex was demeaning because it put a Roman on the same level as a Germanic king, which was not particularly high. As Halsall and others have commented, in this period Germanic kingship and Germanic kingdoms were evolving under Roman influence. By the end of the sixth century these institutions had become accepted centres of power, breaking Rome's monopoly. ${ }^{67}$ In the fifth century, however, they were still in flux: 'there were more kings than there were kingdoms'. ${ }^{68}$ At this date, indeed, as in the days of Crocus, rex probably retained connotations of 'princeling' or 'mercenary captain', which helps explain Germanic regard for, and Roman provincial obedience to, supplementary imperial office. ${ }^{69}$ A Gallo-Roman 'king' would have been severely lacking in political clout. And, to return to my previous point, any emperor faced by a local Roman leader must always have feared that he would ultimately declare himself imperator and make a bid for the

65 Fowden 1993, 88: 'one god, one empire, one emperor.' Fowden elsewhere (106) notices that the doctrine of the Trinity permitted some voluntary sharing of imperial power, particularly among family-members. But this could hardly have been extended to a multiplicity of autonomous rulers.

66 PLRE 2, 12; cf. MacGeorge 2002, 93f., 108, on Aegidius' fighting still in the name of Rome. Fanning 1992, observes that, since it had long been possible to call Roman emperors 'kings', some - in particular, Gregory of Tours - who describe them as 'kings' may have regarded Aegidius and Syagrius as emperors. However, at 296f. he concedes, 'It would be extremely rash to suggest that Aegidius and Syagrius were in fact Roman emperors.'

67 Halsall 2007, 491, 515, 517; Delaplace (above p. 33-35), Kulikowski (abelow p. 80-81), Loseby (below p. 288).

68 Kulikowski, below p. 80.

69 Drinkwater 2009, 190; cf. Harries 1994, 137, 224; Delaplace, above p. 27, 34; Kulikowski, below p. 86. For a much earlier precedent, cf. also Hartmann 2008, 354f.: in 263, Odenaethus was both corrector totius Orientis and dux Romanorum and rex and rex regum. 
Empire as a whole. No emperor could tolerate a potential usurper, and must always seek to break him, if necessary, as in the case of Aegidius, by getting barbarian reges to do the job for him. But here an emperor faced another danger: that, as in the cases of Attalus and Avitus, a Germanic king might himself turn a local Roman leader into an imperial usurper in order to exploit his authority. Overall, Roman emperors could not have treated local Roman leaders in the same way that they handled Germanic federates, and so could not have included them in any formal partitioning of the provinces. And even a Roman rex who found imperial favour would have been subordinate to the emperor and to his whims and fancies: though Syagrius may have put himself under Zeno, Zeno appears to have favoured Odovacer. ${ }^{70}$

The second aspect leads from the first, and may be classed as 'ideological'. A Roman rex and his subjects would also be weak, and so despicable, creatures because they would be outside the framework of Roman history. What did it mean to be Roman? Romanitas surely amounted to more than membership of $a$ state that happened to have a Roman background and character. To be truly Roman one had to be a citizen of the Roman state, the manifest destiny of which was perpetual hegemony of the known world, with the power, as Virgil put it, 'to establish peace, give pardon to the conquered, and bring the mighty low'. ${ }^{71}$ Virgil's Aeneid was the foundation myth of the Augustan Empire, as the story of Romulus and Remus was that of the Republic. It marked 'the end of history' as the Roman Empire at last, as divinely ordained, came into the charge of the Julio-Claudian dynasty. By a deft sleight of hand, the inheritance and destiny envisaged for the house of Caesar and Augustus was appropriated by subsequent dynasties, and became the birth-right of every educated Roman, including late Roman Gauls. As far as these are concerned, their belief in Rome's eternal triumph is even more significant than the 'imperial habit' or 'pragmatism' discussed so far. The integrated late Roman Gauls we know best - Ausonius, Rutilius Namatianus, Sidonius Apollinaris - fully identified themselves with it. For them, the holding of Roman office was more than just a matter of noblesse oblige, or the price of ambition. $^{72}$ Rather, such office made them part of a living legend, that ran from oldest antiquity and would last for ever. The huge power of the Virgilian, pagan, myth is vividly illustrated in this volume, in Bruzzone's analysis of Sidonius Apollinaris' panegyrics to Avitus, Majorian and Anthemius. Here, direct allusions to the Aeneid, in particular (in the context of the Vandal threat) to the tragedy of Dido of Carthage, are used to articulate pressing contemporary political and military concerns, and to put the best possible 'spin' on the characters and policies of

70 MacGeorge 2002, $115 \mathrm{f}$.

71 Verg. Aen. 1, 278-279: [Jupiter] his ego nec metas rerum nec tempora pono: / imperium sine fine dedi; 6, 852-853: [Anchises] pacique imponere morem, / parcere subiectis et debellare superbos.

72 Thus contra Sivonen 2006, 64, 78 (though cf. 80: office-holding emphasised one's Roman identity). 
current leaders. ${ }^{73}$ In this belief-structure, local, Gallic, 'native', history was simply forgotten. ${ }^{74}$ For educated Gauls, the exempla maiorum, both good and bad, were those of the great Greeks and Romans of old, especially Romans of the Republic. $^{75}$ Though such beliefs may seem hackneyed and derivative to us, they were sincerely held by Gallo-Roman aristocrats because they explained their world, that of the Roman Empire, and justified their privileged position within it. ${ }^{76}$ These convictions were, therefore, enormously resistant to alteration or abandonment, and indeed they necessitated significant denials of reality.

As Guyon, Loseby and Witschel indicate in this volume, one denial concerned the built environment. From perhaps as early as the late-second century, Gallo-Roman cities became less imposing in size and appearance as the rich increasingly resorted to their country villas to practise and demonstrate their paideia, as poorer urban dwellers reverted to older forms of living and, finally, as new curtain-walls cropped the old urban centres. However, the upper-classes continued to vaunt their home-cities as the political, religious and cultural hubs of their lives. ${ }^{77}$ This is apparent in Ausonius' descriptions of his beloved Bordeaux. In these, those who know what they are looking for may dimly discern the reduced, fortified late-Roman city; but the uninitiated will see a place comparable to first-century Rome. ${ }^{78}$ Another sort of everyday denial, examined by von Rummel here, concerns dress. Fashion changed. Male dress and armament were very different from those of the Republic and the Early Empire, but fairly uniform across the political nation. However, upper-class Gallo-Romans, viscerally opposed to Germanic integration, were quick to categorise a man's costume as 'Roman' or 'barbarian' depending on his ethnic background, not his style of dress. As with everything else, they saw the world as they wanted to see it, not as it was.

This could not last. Flat denial was no way of coping with change. Belief in Rome's divinely ordained superiority was like an electrical battery: it had to be recharged regularly by victories over foreign enemies. From the later fourth century, the Empire suffered ever-more frequent defeats by outsiders. The battery began to run down. Romans would soon have to face their real destiny. But this was not all. From the fourth century, the Virgilian destiny was significantly challenged from within, as the result of Constantine's conversion to Christianity. To some extent, the Virgilian, pagan, destiny of Rome could be replaced by a new, Christian destiny. In the spirit of Christ's 'render unto Caesar' and St. Paul's 'let

73 Bruzzone, below p. 360-368.

74 So Sidon. carm. 7, 139-140: on the Latin blood of the Arverni; cf. Drinkwater 1987, 243 and n. 24; Harries 1994, 188; Sivonen 2004, 74-76.

75 Sivonen 2004, 86f., 96f.; Bruzzone, below p. 355.

76 Cf. Sivonen 42, 45, 56, 104 (" [...] these ideals accounted for the success of the Roman Empire and gave the Romans - at least in their own minds - a good reason for their empire").

77 Witschel, below p. 177.

78 Auson. ordo urb. nob. 20; epist. 6 [4: Green], 19-28; Sivan 1993, 38-44. 
every soul be subject unto the higher powers', the Church had never opposed the Empire as such; ${ }^{79}$ and from no later than the early third century, some Christians had openly appreciated this Empire as the providential vessel for the reception of Christ and the instrument for broadcasting His teaching. To those who believed in such providence, the conversion of Constantine will have seemed both the proof and the culmination of the intimate relationship between God and the Roman Empire. ${ }^{80}$ However, unlike Virgilian prophecy, divine providence did not guarantee that the interests of Church and state would continue to be identical. Christianity had other perspectives and priorities which soon manifested themselves, and caused tension between it and its new partner. Constantine I himself, in claiming to be 'bishop of those outside', quickly demonstrated that he saw the implications of the fact that Empire and Christianity were not coterminous. ${ }^{81}$ Closer to home, the repertoire and modes of expression of Classical culture were anyway bound to cause strain; and in the fourth century there arose a strong Christian ascetic movement, diverting Romans of both sexes and every age and class from their traditional aspirations and activities. Three contributors to this volume show how Romans and Christians moved apart in Gaul in the decades around 400. Vielberg points up the vast difference between pagan and Christian conceptions of the underworld and, more specific but equally significant, the likely embarrassment caused by Ausonius' irreverent depiction of even a pagan god undergoing extreme torture, in his Cupido cruciatus. ${ }^{82}$ Diefenbach considers the new, Christian, intepretation of merita, based on asceticism and giving deserving aristocrats honor in the next world, i.e. in a heavenly patria wholly different from the traditional earthly community of their ancestors. ${ }^{83}$ And Bruggisser presents Eucherius of Lyon arguing that in certain circumstances it was legitimate for Roman soldiers, by appealing to a higher allegiance, to God, to ignore the orders of their emperor. ${ }^{84}$ Elsewhere, in similar vein, Matthews has recently shown how the grand funerary commemorations of both pagan and Christian aristocrats in fourthcentury Rome reflect a common cultural ground, subsequently destroyed by ascetic hard-liners such as Jerome. ${ }^{85}$ Likewise, Traina has drawn attention to how, in the same period, John Cassian bitterly lamented the way in which thoughts of the 'trifling fables' of his Classical education were interfering with his prayers. ${ }^{86}$

The split between Roman and Christian identity became a canyon as chronic civil strife and barbarian insubordination cruelly exposed the systemic weaknesses of the Empire in the West, and finally exhausted the battery of Roman superiority. Pagans claimed that it was the abandonment of the old gods that had led to

79 Matthew 22, 21; Romans 13, 1; cf. Tert. apol. 30, 4-5.

80 Orig. Cels. 2, 30; Eus. HE 9, 8, 15-9, 1. Fowden 1993, 89.

81 Fowden 1993, 91.

82 Vielberg, below p. 348-349.

83 Diefenbach, below p. 130-131.

84 Brugisser, below p. 389.

85 Matthews 2009.

86 Cassian. conf. 14, 12; Traina 2009, 72. 
disaster. This goaded Christians into rebutting the charge, often in radically new terms. Thus, as Lambert shows in this volume, Salvian presents the barbarian invasions as God's punishment of wicked Romans. Salvian destroys the comfort of Virgilian prophecy by arguing that Roman mischance is the result of the Christian God's direct involvement in world affairs. His interpretation turns the world upside down: barbarians are morally Roman and Romans are morally barbaric. ${ }^{87}$ It is a total subversion of traditional Roman certainty that the City's success lay in its, first pagan then Christian, pious maintenance of the pax deorum. Most famously, of course, such consideration led Augustine to discover a loyalty that completely transcended Rome: not to the material and historical, but to the spiritual and eternal city, the civitas Dei. In the East, the state was protected by strategic advantage and continuing economic and fiscal strength, and was bound up with the Church through the rise of Caesaropapism, in which the 'one emperor' could make contact with the 'One God' through a 'holy intermediary' ${ }^{88}$ In the West, however, strategic vulnerability with fiscal weakness, political instability, and military defeat continued to invalidate the notion of Rome's divine destiny as the eternal hegemonic power; and the bishop of Rome interposed himself ever more between the emperor and the ear of God. By the middle of the fifth century, a generation or so after Augustine, Prosper of Aquitaine was still placing hope in the providential mission of the Empire, but even he had to concede its division and the failing strength of Rome in the West. ${ }^{89}$ The contraction of imperial frontiers and the rise of the papacy maintained and accelerated western divergence. To be a Christian in Gaul one did not have to be - indeed, eventually one could no longer be - a loyal citizen of the Empire.

This takes us to a final, crucial, question: whether an individual or community in the West could remain 'Roman' outside the Empire. Greg Woolf, in his rightly influential Becoming Roman. The Origins of Provincial Civilization in Gaul, asks if a viable Roman cultural unity could exist without Roman political unity. With regard to the Republic and Early Empire, he answers no; but for the Late Empire he is much more positive:

At some point in the fifth century AD Roman cultural identity became finally dissociated from any particular political membership, and the ethnic 'Roman' came to refer to a people scattered throughout a series of barbarian kingdoms, rarely in positions of power but maintaining, for a time, separate legal and educational systems, and distinguished by their own language, religion (now Catholic Christianity) and literature. ${ }^{90}$

87 Lambert, below p. 260.

88 Fowden 1993, 14, 89, 173.

89 Ps. Prosp. vocat. gent. 2, 16; Traina 2009, 42f.

90 Woolf 1998, 249. 
This view is widespread; it is, for example, supported by Halsall. ${ }^{91}$ But I am sure that it is mistaken - hence the title of my paper, which reverses that of Woolf's book.

For Gallo-Roman aristocrats of the fifth century, the present and the future were not in line with what they had been led to expect from the past. What was desperately needed is what I term a 'realignment of expectation'. 92 Such a realignment had occurred in the late-first century B.C., with the second 'foundationmyth'. This myth had become an integral part of Roman paideia, generating the, to us lumbering and embarrassing, patriotic versifications of writers such as Ausonius and, as we have seen, Sidonius Apollinaris, but giving Roman identity and confidence an enormous strength. Other realignments followed; the Roman Empire could not have survived without them. The most important were, without doubt, the conversion of Constantine I and the foundation of what became literally a 'New Rome' in Constantinople. ${ }^{93}$ But nothing outstripped the Augustan 'ideology of victory', 94 and its success prevented another when it was required - one that might have allowed Romans to live in a world where the Roman Empire was no longer all-powerful, in a separate state that was Roman but had no pretensions of a special destiny. For a Roman, to live in a regnum Romanorum outside the main body of the Empire or in a Germanic kingdom could mean only the painful surrender of an ancient identity. As Lambert also observes in this volume, Salvian, describing people forced to flee the rapacity of imperial officials, makes the point that these lose their Romanness not only if they choose to flee to barbarians but also if they choose to flee to communities of former subjects of the Empire living within its nominal frontiers, the Bagaudae. In short, Salvian believes that it is impossible to be Roman outside the Empire. As ever, one has to be careful with a tendentious source. Salvian has an axe to grind, and in his desire to show a world turned upside down he also argues that those who stay within the Empire as coloni, helpless dependants of the rich, are equally deprived of their birthright. However, what he says about refugees is in line with the established legal concept of postliminium, and suggests that the Romans themselves never believed that one could be truly Roman when compelled to live outside Roman borders.

To abandon the notion of perpetual hegemony, to be no longer part of the great enterprise, i.e. to be a citizen of something that was less than the Empire, was indeed to lose one's essential Romanness. It may be argued that Romans living under barbarian kings might, for a while, have continued to believe in the Roman myth, because such kings were still at least nominally subordinate to the eastern emperor, and the Empire might still return to take control of their lands. But even these would eventually have to accept the realities of the new world.

91 Halsall 2007, 482: “[...] people were able to separate the political aspects of imperial Roman identity from the cultural."

92 I owe this idea to the work of my student, Ahamed Osman, on the application of Bourdieu's concept of habitus to Roman history.

93 See now Bowersock 2009.

94 Lee 2007, 37. 
What is the significance of Woolf's 'cultural identity [...] finally dissociated from any particular political membership'? The second letter of Book 8 of Sidonius' collection, to Johannes, contains the sentiment: 'with the removal of the ranks of office, the only means by which the best men can be distinguished from their inferiors, hereafter the only mark of nobility, will be knowledge of letters'. Harries calls it 'the most significant single remark made by any contemporary western author on the end of Roman rule'. ${ }^{95}$ It appears, indeed, to be the earliest, and clearest, contemporary expression of 'cultural identity [...] finally dissociated from any particular political membership'. However, its early date requires that it be treated with caution. Sidonius and the other Gallo-Roman aristocrats of his generation had been subjects of Rome. They had lived in another, imperial, world, and had held high office there. But this world had vanished; as Sidonius puts it in the same place, the current ruling power is unconquerable, but it is no longer Roman. ${ }^{96}$ So they turned to learning for escape. ${ }^{97}$ In short, they were not forging a new cultural identity, but retreating into an old one. Later generations, with no direct memory of the Empire, were able to use the Classical heritage in a wholly different way, which did not distance them from their own societies.

Does speaking and writing in the Queen's English in modern India make one culturally British? Did speaking and writing in good Latin in sixth-century Gaul make one culturally Roman? Along with Sidonius, much has been made of Gregory of Tours as a Roman living long after the disappearance of the Empire in the West; and in this volume Mathisen pushes the survival of Romanitas two generations later in arguing for Desiderius of Cahors to be recognised as 'the last of the Romans ${ }^{98}$ But elsewhere Müller shows that the acutely self-aware literary letterwriting tradition - the product and advertisement of the Classical paideia that distinguished Roman from barbarian - which permits such a claim was being rejected as early as the lifetime of its greatest Gallo-Roman exponent, Sidonius Apollinarius. In addition, what we know of Desiderius' literary interests and activities suggest that these were very much a court-phenomenon, the artefact of a relatively small and preciously self-conscious coterie of self-professed intellectuals, self-referencing themselves in terms of the past. It is no wonder that they had no successors. And, ideologically, Gregory and Desiderius were hardly 'Roman'. In Gregory we see someone who is clearly a product of the Gallo-Roman cultural legacy, but who is totally integrated into Merovingian society and politics, and looking not backwards, into history, but forwards, to the Christian Day of Judgement. He is, indeed, profoundly uninterested in the Roman imperial past, displaying no curiosity in, or nostalgia for, the passing of the western Empire. Desiderius, a long-time intimate of king Dagobert, was even more of a Merovingian

95 Sidon. epist. 8, 2, 2: nam iam remotis gradibus dignitatum, per quas solebat ultimo a quoque summus quisque discerni, solum erit posthac nobilitatis indicium litteras nosse, trans. Harries; Harries 1994, 16.

96 Sidon. epist. 8, 2, 2: iam sinu in medio sic gentis invictae, quod tamen alienae.

97 Cf. Harries 1994, 242.

98 Mathisen, below p. 455, 464. 
courtier than Gregory, in a world where, as Mathisen notes, there was no indication of any basic divide, cultural or social, between Romans and barbarians. ${ }^{99}$ Unlike Sidonius, both men had Roman veneers, but no essential Romanness.

One could not be truly Roman outside the Roman Empire. My contention is, therefore, that authentic Roman 'provincial civilisation in Gaul' ended relatively early, in the late fifth and early sixth century, as the last generation of imperial subjects died off. This is crucial for 'Gaul in Late Antiquity and the Early Middle Ages'. If new polities and identities were to emerge, the old had to make way for them - and the sooner and more complete the disappearance of the old, the more successful would be the growth of the new. Authentic Roman identity was strong but brittle. It quickly shattered and was soon cleared away, ready for the appearance of wholly different outlooks and identities.

\section{Bibliography}

\section{Primary sources}

Ausonius, Decimus Magnus, Opera, rec. Roger P. H. Green, Oxford 1999.

Eusebius, Historia Ecclesiastica: Eusebius, The ecclesiastical history, 2 Vol., with an Engl. transl. by Kirsopp Lake and John E. Oulton, ed. by Hugh J. Lawlor (LCL 153/265), London 1980.

Gregorius Turonensis, Libri historiarum X (=Historia Francorum): Gregorii episcopi Turonensis libri historiarum X, ed. Bruno Krusch and Wilhelm Levison (MGH SS rer. Merov. 1, 1), Hanover ${ }^{2} 1951$.

Origines, Contra Celsum libri VIII, ed. Miroslav Marcovich (Supplements to Vigiliae Christianae 54), Leiden 2001.

Prosperus Tiro Aquitaniensis, De vocatione omnium gentium, ed. Roland J. Teske and Dorothea Weber (CSEL 97), Wien 2009.

Quintus Septimius Florens Tertullianus, Apologeticum: Quinti Septimi Florentis Tertulliani Apologeticum, ed. Heinrich Hoppe (CSEL 69), Wien/Leipzig 1939.

Rutilius Namatianus, De reditu suo: Rutilius Namatianus, Sur son retour, texte établi et trad. par Étienne Wolff, Paris 2007.

Sidonius Apollinaris, Carmina: Sidoine Apollinaire, Cuvres, vol. I: Poèmes, texte établi et trad. par André Loyen, Paris 1960.

Sidonius Apollinaris, Epistulae: Sidoine Apollinaire, Euvres, vol. 2-3: Lettres, texte établi et trad. par André Loyen, Paris 1970.

Zosimos, Historia nova: Zosimus, New History. A Translation with Commentary by Ronald T. Ridley (Byzantina Australiensia 29), Canberra 1984.

99 Cf. Mathisen 1993, 105-116, 135f., 145. 


\section{Secondary sources}

Bowersock (2009): Glen W. Bowersock, „Old and New Rome in the Late Antique Near East", in: Philip Rousseau and Manolis Papoutsakis (eds.), Transformations of Late Antiquity. Essays for Peter Brown, Farnham, 37-49.

Brunaux (2008): Jean-Louis Brunaux, Nos ancêtres les Gaulois, Paris.

Drinkwater (1987): John F. Drinkwater, The Gallic Empire. Separatism and Continuity in the North-Western Provinces of the Roman Empire A.D. 260-274, Stuttgart (Historia Einzelschriften 52).

Drinkwater (1989): John F. Drinkwater, „Gallic attitudes to the Roman Empire in the fourth century A.D.: continuity or change?“, in: Heinz E. Herzig and Regula FreiStolba (eds.), Labor Omnibus Unus. Gerold Walser zum 70. Geburtstag, Stuttgart (Historia Einzelschriften 60), 136-153.

Drinkwater (1992): John F. Drinkwater, „The Bacaudae of fifth-century Gaul“, in: John F. Drinkwater and Hugh Elton (eds.), Fifth-century Gaul: a Crisis of Identity?, Cambridge, 208-217.

Drinkwater (1998): John F. Drinkwater, „The usurpers Constantine III (407-411) and Jovinus (411-413)“, Britannia 29, 269-298.

Drinkwater (2001): John F. Drinkwater, „Women and Horses and Power and War“, in: Thomas. S. Burns and John W. Eadie (eds.), Urban Centers and Rural Contexts in Late Antiquity, East Lansing MI, 135-146.

Drinkwater (2005): John F. Drinkwater, „Maximinus to Diocletian and the 'Crisis'“, in: Alan K. Bowman, Peter Garnsey and Averil Cameron (eds.), Cambridge Ancient History XII. The Crisis of Empire A.D. 193-337 (2nd edition), Cambridge, 28-66.

Drinkwater (2009): John F. Drinkwater, „Crocus, 'king of the Alamanni'“, Britannia 40, $185-195$.

Fanning (1992): Steven Fanning, „Emperors and empires in fifth-century Gaul“, in: John F. Drinkwater and Hugh Elton (eds.), Fifth-century Gaul: a Crisis of Identity? Cambridge, 288-297.

Fowden (1993): Garth Fowden, Empire to Commonwealth. Consequences of Monotheism in Late Antiquity, Princeton NJ.

Halsall (2007): Guy Halsall, Barbarian Migrations and the Roman West 376-568, Cambridge.

Harries (1994): Jill Harries, Sidonius Apollinaris and the Fall of Rome AD 407-485, Oxford.

Hartmann (2008): Udo Hartmann, „Das palmyrenische Teilreich“, in: Klaus-Peter Johne, Udo Hartmann and Thomas Gerhardt (eds.), Die Zeit der Soldatenkaiser, 2 vols., Berlin, 343-378.

Jones (1964): A. Hugh M. Jones, The Later Roman Empire 284-602 (3 vols.), Oxford.

Lee (2007): A. Doug Lee, War in Late Antiquity, Oxford.

Lewis (2000): Catrina M. Lewis, „Gallic identity and the Gallic civitas from Caesar to Gregory of Tours“, in: Stephen Mitchell and Geoffrey Greatrex (eds.), Ethnicity and Culture in Late Antiquity, London/Cardiff, 69-81.

MacGeorge (2002): Penelope MacGeorge, Late Roman Warlords, Oxford.

Mathisen (1993): Ralph W. Mathisen, Roman Aristocrats in Barbarian Gaul, Austin TX.

Matthews (2009): John F. Matthews, „Four funerals and a wedding: this world and the next in fourth-century Rome“, in: Philip Rousseau and Manolis Papoutsakis (eds.), Transformations of Late Antiquity. Essays for Peter Brown, Farnham, 129-146. 
Pabst (1997): Angela Pabst, Comitia imperii. Ideelle Grundlagen des römischen Kaisertums, Darmstadt.

Sivan (1993): Hagith Sivan, Ausonius of Bordeaux. Genesis of a Gallic Aristocracy, London.

Sivonen (2006): Pauli Sivonen, Being a Roman Magistrate. Office-holding and Roman Identity in Late Antique Gaul, Helsinki.

Stevens (1933): Courtenay E. Stevens, Sidonius Apollinaris and his Age, Oxford.

Teitler (1992): Hans C. Teitler, „Un-Roman activities in late antique Gaul: the cases of Arvandus and Seronatus“, in: John F. Drinkwater and Hugh Elton (eds.), Fifthcentury Gaul: a Crisis of Identity? Cambridge, 309-317.

Traina (2009): Giusto Traina, 428 AD, Princeton NJ.

Ward-Perkins (2005): Bryan Ward-Perkins, The Fall of Rome and the End of Civilization, Oxford.

Whittaker (1994): C. Richard Whittaker, Frontiers of the Roman Empire. A Social and Economic Study, Baltimore MA/London.

Wood (1992): Ian N. Wood, „Continuity or calamity? The constraints of literary models“, in: John F. Drinkwater and Hugh Elton (eds.), Fifth-century Gaul: a Crisis of Identity? Cambridge, 9-18.

Wood (2000): Ian N. Wood, „The north-western provinces“, in: Averil Cameron, Bryan Ward-Perkins and Michael Whitby (eds.), Cambridge Ancient History XIV: Late Antiqu- ity: Empire and Successors, A.D. 425-600, Cambridge, 497-524.

Woolf (1998): Greg Woolf, Becoming Roman. The Origins of Provincial Civilization in Gaul, Cambridge. 



\title{
Sundered Aristocracies, New Kingdoms, and the End of the Western Empire
}

\author{
Michael Kulikowski
}

That the Gallic aristocracy of the fifth century grew increasingly removed from its Italian counterparts has long been known. ${ }^{1}$ A number of socio-political explanations help account for this separation of two senatorial aristocracies: the impact of usurpation and civil war from the 380s, the progressive withdrawal of Rhineland defences, and the parallel withdrawal from imperial residences north of the Alps, so that both Trier and Lyon lost the importance they had had in the fourth and earlier centuries. ${ }^{2}$ These various factors, some accidental, all historically contingent, provided the Gauls with the experience of limited self-government. Thereafter, the creation of a new concilium Galliarum, which was meant to meet annually at Arles from 417 forward, may have accelerated the process by which the Gauls learnt to manage their own affairs without treating the Italian centre as the primary focus of their interests. Finally, the settlement of new, functionally independent powers on Spanish and Gallic soil provided still further incentives for Gallic aristocrats to pay less attention to Italy.

The prosopographical foundations on which these conclusions rest have been thoroughly worked over, the broad outlines of aristocratic behavior and ecclesiastical politics are well understood, and there is not a great deal new to be said on either front. ${ }^{3}$ On the other hand, the normal modern interpretative framework takes insufficient account of the way new power groupings on Gallic soil behaved as indigenous political actors, rather than as alien bodies within the Gallic provinces. That is to say, even those commentators who do not adopt a catastrophist approach nevertheless still tend to see the Goths in Aquitania, and emerging military powers elsewhere in the region, whether Burgundian, Frankish or otherwise, as external impositions on a Roman body politic - even though the evidence sug-

1 Sundwall 1919; Stroheker 1948 remain fundamental.

2 Matthews 1975.

3 Recently on aristocrats: Mathisen 1993. Ecclesiastical politics: Langgärtner 1964; Griffe 1964-1966; Heinzelmann 1976; Mathisen 1989; Baumgart 1995. 
gests that they were very much integral parts of the local scene. ${ }^{4}$ So it is that, when we try to treat these figures as something other than foreign military threats, we begin to see a process of localization - even "re-focalization" - of politics to a more limited Gallic sphere of activity, a process that gradually made the old Italian centre unnecessary and brought the first barbarian kingdoms into being on provincial soil. The process by which the aristocracies of Italy, Gaul and Spain came to be sundered one from another, and the process by which uncertain and accidental beginnings brought about the creation of barbarian kingdoms on imperial soil, are parallel. One illuminates the other, and while inter-aristocratic aspects have been much studied and are well understood, the formation of the Gallic kingdoms has not yet been treated with sufficient nuance.

The present article offers a schematic analysis of how barbarian kingdoms came into being on Gallic territory that had previously been administered by Roman magistrates, an analysis that attempts to take Gallic events according to their own dynamic, rather than as an episode in a grander narrative of barbarian invasion and Roman collapse. At the outset it is important to distinguish between kings and kingdoms, because for much of the fifth century, we are generally dealing with the former and not the latter. The Roman empire could certainly claim to rule over administered territory as well as over people, and so too could the developed kingdoms of the early Middle Ages, though perhaps to a lesser extent. By comparison with either of those standards, however, there were many more kings than there were kingdoms in the fifth century, and the same holds true for much of the sixth century as well. Before then, the western kingdoms were polities made up of the people a king ruled. Because that was always an open question, contingent on momentary circumstance, very few late antique kings specified quite what it was they were king of. ${ }^{5}$ There was a good reason for that, because they could often not be entirely sure themselves: their royal status depended upon a shifting relationship with an imperial government. For that reason late antique reges cannot be treated as embryonic versions of early medieval kings of Francia, Lombard Italy, or seventh-century Spain. On the contrary, fifth-century reges have to be understood in the same way as the client kings that Roman emperors had always cultivated along the imperial frontier. From the Roman perspective, client kings supplied a measure of stability, since families and familial prestige provided continuity, but they were also usefully unsettled and could be maintained in state of perpetual weakness and uncertainty, meaning that they rarely challenged the empire effectively. ${ }^{6}$ What client kings on the frontiers actually ruled over always depended on what an emperor was prepared to let them rule, something that could vary over time, often quite dramatically and suddenly - the

4 Ward-Perkins 2005 and especially Heather 2005 and Heather 2009 are standard bearers of this revenant catastrophist approach, but some of their assumptions are shared by more nuanced work like Drinkwater 2007.

5 Gillett 2002 demonstrates this beyond dispute.

6 Braund 1984; Pitts 1989; Sullivan 1990. 
royal authority of these border reges was real, and their followers recognized and depended upon it, but it was at the same time insecurely linked to any particular territory, and still less to any institutionalized control over that territory.

Beginning in the early fifth century, however, this model of client kingship was transferred from the frontiers into the imperial interior, in what we can think of as a frontier diaspora. ${ }^{8}$ That is to say, the regna of the fifth-century West were at first simply client kingdoms transposed onto imperial soil, and operated as such. Only after the reach of imperial government was irreparably diminished did one or two late antique kings manage to create territorial kingdoms, as a way of compensating for imperial absence. It is worth stressing that latter point: not one fifth-century king set out to deliberately create a territorial kingdom as a polity with which to replace imperial government. That was an unimaginable goal, and one point on which catastrophist interpretations of the period misread it entirely. Just because many people did in fact experience the fifth-century breakdown of the western empire as a catastrophe, and just because barbarian kings did eventually replace the Roman emperor in providing whatever government existed, these kings did not necessarily want to create their own kingdoms in opposition to the empire. ${ }^{9}$ Conquest and royal ambition did not will the territorial kingdoms of the late fifth and the sixth centuries into existence. ${ }^{10}$ They were, rather, the products of failure, the failure of imperial governance and the failure of various reges and reguli to find a place within the imperial structure. This was a failure that affected provincial senators as well, and it was the reason so many senators became inadvertently complicit in the dissolution of imperial authority in Gaul. Fifth-century kings and fifth-century senators all wanted more or less the same thing: a functional Roman empire, in which reges could have a recognizable place as clients of the empire and participants in its affairs. ${ }^{11}$ Only when that prospect became hopeless did they create territorial kingdoms, as a distinctly second-best alternative: before that, to be a king was to be a loser in a world where to be a Roman officer was to win. ${ }^{12}$

Comparison with an earlier stage of Roman history can help us understand how a very few among the large number of kings in the fifth-century West, many of whose regna were hardly defined, developed territorial kingdoms at the end of the century - the analogy with the mid and late Republican transformation in the meaning of the word provincia and the fifth-century changes to the significance

7 Hedeager 1992; Storgaard 2001; Magnus 2001.

8 The phrase is used in a sense borrowed from post-colonial diaspora studies, with the implications of a recreated, but imaginary, original homeland, which is in fact only loosely linked to the reality of the place from which any individual member of the diaspora might have come: Lionnet and Shih 2005; Kirshenblatt-Gimblett 1994; Hayes Edwards 2001.

9 This narrative drives the otherwise barely compatible approaches of Wolfram 1988 and Heather 2005; Heather 2009.

10 Gillett 1999; Halsall 2007.

11 Harries 1994 recognizes this.

12 Halsall 2007. 
of regnum is quite precise. In the Republican period, a provincia never lacked a territorial component, but for centuries the territorial element was secondary to the primary definition as the sphere within which a pro-magistrate had imperi$u m .{ }^{13}$ In much the same way, fourth- and fifth-century regna always had a territorial aspect, but until at least the end of the fifth century, the territorial component was secondary, gaining ground only when the traditional loosely-defined role of a client king ceased to be viable. We can distinguish four stages leading up to that point, and they will occupy us in the remainder of this discussion.

The first stage was the actual movement of reges and reguli from frontier to imperial interior, that is to say, the movements of population that we normally describe as barbarian invasions. ${ }^{14}$ The second stage was the generalized acceptance of that fait accompli, so that, from the $420 \mathrm{~s}$ and 430 s, the existence of reguli inside the imperial frontiers came to be tolerated as normal, even if not necessarily desirable. The third stage was the recognition that the western empire could no longer administer areas of its former territory from its own shrinking resources, which meant that it was sensible to cede effective control of imperial lands to the reges who were now a permanent part of the landscape, although this de facto cession of control did not necessarily imply that these lands had ceased to be part of the empire conceptually. The fourth and final stage emerged slowly and without most people noticing what had happened until it had done so: left to their own devices for long enough, both the western reges and the provincial population living beside or under them lost the habit of waiting for the empire to again take up its proper function. In those circumstances, the kings started to do what the empire had once done, thus finally turning abstract and ambiguous regna into territorial polities on imperial soil.

The starting point of this historical process is, then, the invasions and invitations that brought foreigners onto imperial soil in large numbers. The Roman empire had always been happy to invite large numbers of barbarian neighbours into the imperial provinces, usually with a view to replacing some deficit in the population, military, agricultural or fiscal. The imperial capacity for receptio was almost infinite, but several accidents complicated matters in the late fourth and early fifth century. ${ }^{15}$ Two civil wars in quick succession, followed by imperial minorities and the cold wars of successive regents, meant that Alaric's Goths became an active force in imperial politics, only tenuously linked to the imperial center, however much Alaric wanted and tried to be a Roman general on the traditional model. ${ }^{16}$ When combined with the invasions of Radagaisus and the Alans, Vandals and Sueves between 405 and 407, there emerged a large quantity of uncooperative soldiers, inside the empire but with no links to the imperial govern-

13 Richardson 1986.

14 Goffart 2007 summarizes the fifth-century evidence. Bury 1923 remains the most immediately accessible narrative.

15 Horn 1930; Scharf 2001.

16 Demougeot 1951 for the basic narrative; Kulikowski 2007, 154-84 for Alaric. 
ment save through the negotiating tactics of their commanders. ${ }^{17}$ All the same, the leaders of these invaders behaved much more like the fourth-century frontier reguli than the monarchs of later in the century, as is made clear time and again in the chaotic circumstances of the 410s. The Rhine invaders were kept in check and managed by Constantine III just as frontier client kings always had been; they only penetrated into the south of Gaul and Spain after Constantine's regime itself fractured into civil conflict. ${ }^{18}$ Similarly, rival claimants to the Gothic client kingship - Alaric, Athaulf, Sarus, Sigeric and perhaps others - both validated their authority and prosecuted their feuds through their relationships to the Roman government, which in turn relied upon the mixture of authority and the insecurity caused by dynastic rivalry to manage clients and to prosecute imperial civil conflict where doing so was useful. The only thing that had changed was the location, transporting the prosecution of these conflicts onto the soil of the empire, and particularly Gaul, so that not just the rivalry, but the actual military conflict as well took place there.

One could add further such parallels between the fourth-century frontier kings and the reges and reguli on western provincial soil in the 400s and 410s, but let us instead note the extent to which these reges were managed and handled by the imperial government, and likewise the degree to which Stilicho and thereafter Constantius fought to reduce the power of any such reges as declined to knuckle under and behave themselves as good clients should. ${ }^{19}$ There was never any intention of allowing these newcomers to operate on their own terms and all those who tried to do so were ruthlessly eliminated. Even when the existence of certain reges was tolerated - as the Sueves and part of the Vandals were allowed to prosper in Gallaecia between 418 to 421 - they were tolerated only on imperial terms and at the edge of a not very important province. ${ }^{20}$ The Gothic settlement in Aquitania might look like a stark exception to this rule, but at its inception the Gothic settlement was in perfect conformity with previous norms: Wallia and Theoderic's Goths were treated as the Alamanni of Vadomarius had been seven decades earlier, as provisionally loyal clients of imperial government, available for the chastisement of internal enemies. ${ }^{21}$ Aquitania was not ceded to the Goths; no Gothic territorial polity was created; imperial government was envisaged as continuing in the regions where the settlement took place; and the Gallic aristocracy, whether or not it actually liked the settlement, was brought into the compact and given its

17 Drinkwater 1998; Kulikowski 2000a.

18 Kulikowski 2000a; Birley 2005, 455-460 correctly challenges the date of the Rhine crossing in the foregoing, but not the extent and chronology of Constantine III's achievement: there is no evidence that the invaders of 406 moved south of the Loire until 409 and all the southern Gallic testimony to their destructiveness belongs to a relatively restricted part of that year.

19 Demougeot 1951; Mazzarino 1942; Lütkenhaus 1998.

20 Kulikowski 2000b; Kulikowski 2004, 173-175.

21 Kulikowski 2001; for Vadomarius, PLRE 1, 928 (Vadomarius). 
own concilium at Arles as a sop to the region's centrifugal tendencies. ${ }^{22}$ We can never be sure of just what Constantius had hoped to achieve with the Gothic settlement, but it was clearly the only such expedient that enjoyed official approval and toleration, and we ought to make no assumptions about any permanence it might or might not have been intended to have at the time it was conceived. Then, however, and as had happened so frequently since the 380 s, internal politics at the imperial and senatorial levels conspired to push dealings with barbarians to a secondary level of concern.

That is to say, if the existence of client reges on Gallic soil was a product of the $400 \mathrm{~s}$ and $410 \mathrm{~s}$, their normalization in the provincial landscape was fundamentally a product of the $420 \mathrm{~s}$ and $430 \mathrm{~s}$ - and that normalization was the result of instability at the imperial centre. At first, when Constantius died, his policies seem to have been continued, for instance by the general Castinus. ${ }^{23}$ But when Honorius rapidly followed his co-ruler to the grave, the western empire fell apart in one of its periodic bouts of civil war, and barbarian reges became useful tools for rival magistri more than they seemed threats to imperial power: where Constantius had been able to follow a consistent policy of pushing reges and their followers to extinction, or into marginal positions where they could do little harm, for Felix, Boniface, Aëtius and the other rival soldiers of the 420s and 430s, suppressing the reges altogether was undesirable - they were far too useful. That, in turn, meant the de facto tolerance of semi-independent rulers with their own followers on Roman soil. One says semi-independent, because Roman government always retained the initiative in these decades, vis-à-vis both the reges and provincial subjects. The $420 \mathrm{~s}$ and $430 \mathrm{~s}$ certainly did not witness the creation of actual independent kingdoms on imperial soil, the cession of land to client reges, or the recognition of any barbarian rex as an equal of the empire. Instead, these two decades saw the acceptance of old fashioned reges as internal players in the politics of controlling the West and the governmental apparatus of its underwhelming emperor Valentinian. The utility of the Gothic, Burgundian and other reges, in a perpetual state of uncertainty as to their own security and anxious to improve their individual conditions, was enormous so long as Aëtius' hold on power remained insecure. This meant that, by the time Aëtius' rivals had disappeared - as they did after Valentinian came into his own and the formidable Galla Placidia faded into the background in the early 440s - the barbarian kings were a permanent feature of the Gallic landscape. ${ }^{24}$

That is because local Roman powers - imperial, ecclesiastical, curial and aristocratic - had found their own uses for the reges, whether or not those coincided with the wishes or interests of the court. In this respect, one may think of the way the Gothic prince Frederic found his way into papal correspondence on the back

22 Epist. Arelatenses 8.

23 PLRE 2, 269-270 (Castinus 2).

24 In general, for Galla, Oost 1968. 
of Gallic ecclesiastical disputes, though there are many other possible examples. ${ }^{25}$ As it happened, these shifting local alliances had the effect of making regional powers less amenable to imperial control. This was a problem undoubtedly compounded by the fact that the emperors, far away in Italy, could do less and less of what their Gallic subjects had once expected them to do, and also by the fact that links between Gallic and Italian aristocracies were more limited than they had been even two or three decades before. The existence of rival sources of power, though not yet of authority, in the shape of barbarian reges, meant that Gallic strongmen and aristocrats had much greater latitude within which to ignore the imperial government, and thus that by the time Aëtius was in control of the central government, the sway of that government was both narrower and shallower than it had ever been in the past. ${ }^{26}$

It was in these circumstance that the third stage in the construction of the western kingdoms began, one in which the imperial government recognized the right of reges to rule not just in the ambiguous and provisional manner of oldfashioned client kings, but as the territorial governors of parts of imperial provinces. The change seems to have been implicit in the treaty between Theoderic and Aëtius of $439 .{ }^{27}$ Surrounding circumstances are obscure and we should not assume that Aëtius was compelled to make peace against his will after Theoderic had badly beaten Litorius and his Huns. ${ }^{28}$ By 439, given his recent successes, Litorius was certainly in a position to threaten Aëtius, something to which Prosper clearly alludes. ${ }^{29}$ Though it would be rash to suggest that Theoderic was acting on the patrician's orders, Aëtius cannot have found the death of Litorius unwelcome. That is to say, the Gothic treaty of 439 may have reflected Aëtius' dawning recognition that the Goths were better "partners for peace" than were overmighty subordinates in his own ranks. Regardless, territory was not being ceded irrevocably, any more than northern Gaul had been consciously given up just because contemporary authors tended to treat everything north of the Loire Gallia Ulterior - as a foreign land. ${ }^{30}$ Cessions were always provisional. But the treaties of the late $430 \mathrm{~s}$ and 440 s made no pretence of active imperial administration, leaving that task to the local reges. ${ }^{31}$ That is something new, and it meant that if the government were never to get around to reasserting its control over such lands, the foundations for a territorial regnum had been laid. ${ }^{32}$

All the same, these treaties did not suddenly create territorial polities for barbarian reges to rule; their significance is obvious mainly in retrospect. Until the

25 Hilarus, epist. 8 (Thiel); PLRE 2, 484 (Fredericus 2).

26 Stickler 2002 puts the chronology of Aëtius on a firm footing.

27 Prosp. chron. 1338.

28 That is the default assumption of Wolfram 1988, 176; Heather 2005, 287-288.

29 PLRE 2, 684 (Litorius).

30 Gallia Ulterior: Chron. Gall. a. 452: 117, 127.

31 That is, by contrast with the settlements of the 410 s and 420 s, Roman officials are invisible at the time of, and even more so after, these later treaties.

32 The evidence is surveyed, without adequate analysis, in Barnwell 1992. 
460 s, the western reges generally continued to behave like old-fashioned client kings. We can see this in the way that Aëtius and his less competent successors were able to play members of various regal families off one another, or alternatively to adjudicate the familial arguments of client rulers, as in the incipient civil war between Theoderic II and Frederic that Avitus prevented just before he was raised to the purple at Toulouse. ${ }^{33}$ We should also take note of how western reges behaved at times of imperial regime change. Theoderic had been a loyal client of Avitus, and consequently showed no liking for Majorian, in fact testing imperial strength on the battlefield. Nevertheless, after Majorian was murdered, Theoderic hesitated, backing no candidate for the throne and taking no action, hostile or otherwise. We look in vain for any desire on his part to conduct himself without reference to imperial authority. While Theoderic's power was distant enough from the shrinking imperial centre that he could to all intents and purposes do whatever he liked, most of the reges of this third period preferred to act not in their royal capacities, but rather as Roman magistri militum. That role was much easier to explain, whether to themselves or to the Gallic aristocrats who were now their chief interlocutors. ${ }^{34}$ There is no shortage of examples: the Burgundian king Gundioc was by preference magister militum per Gallias. Thereafter, his son Gundobad cultivated a similar position as magister militum. ${ }^{35}$ After Ricimer, who had been Gundobad's patron, died, Gundobad added the rank of patricius to his magisterium - claiming a greater place inside the imperial structure, but not in the least claiming to go outside it. Only when both Olybrius and Glycerius proved short-lived and incapable did he decide that no western emperor could any longer hope to hold both Gaul and Italy. ${ }^{36}$ At that point, because a magisterium no longer meant much of anything, he finally chose Burgundian kingship, and the provincial Gallic supporters on whom he could rely. ${ }^{37}$

The integration of reges into imperial politics, which the example of Gundobad illustrates, offered both opportunities and difficult challenges to provincial aristocrats. These aristocrats were used to manœuvring for authority and power in the aftermath of an imperial death, and those in Gaul, in particular, had quite often pursued their own interests in opposition to the Italian center - not least because, with the late fourth-century retreat of emperors from Gallic to Italian residences, the access of Gallic nobles to the court became attenuated. ${ }^{38}$ The centrifugal tendencies of the Gauls were certainly restrained after the crisis of the $400 \mathrm{~s}$ and $410 \mathrm{~s}$, not least thanks to the Gothic settlement; in the long run, however, that and the other settlements created alternative centres of power which became more attractive as successive imperial regimes suffered crises of legitimacy. The impossibility of definitively settling on the legitimacy of any given emperor after

33 Kulikowski 2008.

34 Coville 1928 contains pertinent observations.

35 PLRE 2, 523-524 (Gundiocus); 2, 524-525 (Gundobadus 1).

36 This is a major insight of Halsall 2007.

37 From the later 470s, see Favrod 1997.

38 Stroheker 1948. 
the death of Majorian made the possibility of working with alternative, regal sources of power both attractive and simultaneously fraught with danger. ${ }^{39}$ Majorian, by dint of careful diplomacy, had won the recognition of every western interest group save the Vandals, but his death meant that every Roman army in the West had the choice of going its own way, and neither armies nor aristocrats had any firm grounds on which to determine where their loyalties should lie.

This utter confusion of legitimacy makes the 450s, and particularly the $460 \mathrm{~s}$, very difficult for modern scholars to read, and contemporaries were deeply uncertain themselves. Whereas the participation of men like Theoderic and Frederic in local politics had been no more than a normal part of the provincial landscape, the boundaries of legitimate alliance and illegitimate, contemnible behavior now became impossible to discern. Part of the reason that the "treason" of the Gallic praetorian prefect Arvandus seemed so appalling, and so embarrassed Sidonius as the urban prefect who should have tried him, was that Arvandus' alliance with Euric could be portrayed as a betrayal of the emperor and his fellow citizens, whereas other aristocrats' dealings with the Gothic king could be construed as legitimate. ${ }^{40}$ Sidonius' long-term friend, and perhaps cousin, Avitus, could negotiate with the Visigoths without any aspersions being cast on his motives; Leo "of Narbonne", who claimed descent from Fronto, the great orator and tutor of Marcus Aurelius, could move from an imperial career in which he had achieved spectabilis rank to the courts of Euric and Alaric without anyone holding it against him. ${ }^{41}$ The difficulty was in telling which uses of the barbarian reges were understood to be perfectly all right in the game of imperial competition, and which were not. As Arvandus' case shows, correspondence that might be acceptable in a man with a good deal of friendly local support - which is what had happened when Avitus bid for imperial office with the backing of Theoderic was unacceptable and thoroughly unsafe for a man who had a lot of local enemies.

The tottering late reign of Anthemius, and the ephemeral reigns that followed, increasingly made such ambiguities an irrelevance, given that an emperor like Anthemius, who had won the grudging acknowledgement of most of the regional powers in the West, could nonetheless achieve next to nothing his aristocratic subjects might desire of him, even in large parts of Italy. Usurpation and the installation of a new regime would have been the old-fashioned way of dealing with an unsatisfying emperor, but that option looked less and less attractive as the examples of Severus, Glycerius, and Olybrius demonstrated that the imperial title, legitimate or not, guaranteed the control of almost nothing. So it was that the West reached the fourth and final stage in the process we are considering here, one which involved the taking on of formerly imperial powers of administration and legal authority by barbarian rulers. More than any of the previous ones, this

39 Harries 1994, 82-102.

40 PLRE 2, 157-158 (Arvandus); Teitler 1992.

41 PLRE 2, 662-663 (Leo 5). 
final stage of regnal formation required the active participation of Roman aristocrats. Some had of course hitched their stars to barbarian reges from the beginning, but it was only in this later period, from the 460s and 470s onwards, that the service of barbarian kings came to seem not an occasional alternative to, but rather a replacement for, the sort of political and magisterial career that the empire could no longer provide. Thus it was the vir spectabilis Anianus who edited and authenticated copies of Alaric's II Breviarium, and the comes Timotheus to whom our manuscript of the code is dedicated. ${ }^{42}$ The same thing happened in almost every region where the command of territory had shifted definitively out of imperial hands, and where it will have looked to most residents as if the change would be permanent. This sort of service penetrated quite deeply down the social scale and although the scale of different regnal administrations differed, it was often quite considerable. South of the Loire river, the infrastructure of imperial government was all still in place at the end of the fifth century, though the extent to which it survived in northern Gaul and along the Rhine-Danube frontier is much harder to determine. In both cases, however, new rulers and local aristocrats shared an interest in attempting to replicate the old imperial system on whatever scale they could. Of course, given the diminished territories of these new regna by comparison to the old empire, the distance between ruler and ruled shrank at the same time that the political distance between pieces of what had once been a single empire gaped much wider. And so it was that the final sundering of the Gallic aristocracy from the other provincial aristocracies of the empire came because Gallic aristocrats, like everyone in the West, had been forced to do without an effective emperor for so long that they turned to other, closer substitutes, however imperfect those were.

\section{Bibliography}

\section{Primary sources}

Chronica Gallica: Chronica minora saeculi IV, V, VI, VII, rec. Theodor Mommsen (MGH Auct. ant. 9), Berlin 1892, 615-666.

Epistolae Arelatenses: Epistolae Merowingici et Karolini aevi, vol. 1, ed. Ernst Dümmler (MGH Epp. 3), Berlin 1892, 1-83 (ed. Wilhelm Gundlach).

Hilarus, Epistulae: Epistolae Romanorum pontificum genuinae et quae ad eos scriptae sunt a S. Hilaro usque ad Pelagium II, rec. et ed. Andreas Thiel, vol. 1, Hildesheim 1974 (Nachdruck der Ausgabe Braunsberg 1867-1868), 126-170.

Prosperus Tiro Aquitaniensis, Epitoma chronicon et addimenta in Prosperi Textum inserta: Chronica minora saeculi IV, V, VI, VII, rec. Theodor Mommsen (MGH Auct. ant. 9), Berlin 1892, 341-499.

42 PLRE 2, 90 (Anianus 2); PLRE 2, 1121 (Timotheus 4). 


\section{Secondary sources}

Barnwell (1992): P. S. Barnwell, Emperor, Prefects, and Kings: The Roman West, 395565, Chapel Hill.

Baumgart (1995): Susanne Baumgart, Die Bischofsherrschaft im Gallien des 5. Jahrhunderts, Munich.

Birley (2005): Anthony R. Birley, The Roman Government of Britain, Oxford.

Braund (1984): David Braund, Rome and the Friendly King: The Character of Client Kingship, London.

Bury (1923): J. B. Bury, History of the Later Roman Empire, AD 395-565, London.

Coville (1928): Alfred Coville, Recherches sur l'histoire de Lyon du Vme au IXme siècle (450-800), Paris.

Demougeot (1951): Emilienne Demougeot, De l'unité a la division de l'empire romain, 395-410, Paris.

Drinkwater (1998): John F. Drinkwater, „The usurpers Constantine III (407-411) and Jovinus (411-413)“, Britannia 29, 269-98.

Drinkwater (2007): John F. Drinkwater, The Alamanni and Rome, 213-496, Oxford.

Favrod (1997): Justin Favrod, Histoire politique du royaume burgonde (443-534), Vaud.

Gillett (1999): Andrew Gillett, „The accession of Euric“, Francia 26.1, 1-40.

Gillett (2002): Andrew Gillett, „Was ethnicity politicized in the earliest medieval kingdoms?", in: Andrew Gillett (ed.), On Barbarian Identity: Critical Approaches to Ethnicity in the Early Middle Ages, Turnhout, 84-121.

Goffart (2007): Walter Goffart, Barbarian Tides, Princeton.

Griffe (1964-1966): Élie Griffe, La Gaule chrétienne à l'époque romain, 3 vols., Paris.

Hayes Edwards (2001): Brent Hayes Edwards, „The uses of diaspora“, Social Text 19, $45-72$.

Heather (2005): Peter Heather, The Fall of the Roman Empire. A New History of Rome and the Barbarians, New York.

Heather (2009): Peter Heather, Empires and Barbarians. The Fall of Rome and Birth of Europe, New York.

Hedeager (1992): Lotte Hedeager, Iron Age Societies. From Tribe to State in Northern Europe, Oxford.

Heinzelmann (1976): Martin Heinzelmann, Bischofsherrschaft in Gallien, München (Beihefte der Francia 5).

Horn (1930): Heinrich Horn, Foederati. Untersuchungen zur Geschichte ihrer Rechtsstellung im Zeitalter der römischen Republik und des frühen Principats, Berlin.

Kirshenblatt-Gimblett (1994): Barbara Kirshenblatt-Gimblett, „Spaces of dispersal“, Cultural Anthropology 9, 339-344.

Kulikowski (2000a): Michael Kulikowski, „Barbarians in Gaul, Usurpers in Britain“, Britannia 31, 325-345.

Kulikowski (2000b): Michael Kulikowski, „The Career of the Comes Hispaniarum Asterius“, Phoenix 54, 124-141.

Kulikowski (2001): Michael Kulikowski, „The Visigothic Settlement: The Imperial Perspective," in: Ralph W. Mathisen and Danuta Shanzer (eds.), Society and Culture in Late Antique Gaul: Revisiting the Sources, Aldershot, Hants., 26-38.

Kulikowski (2007): Michael Kulikowski, Rome's Gothic Wars from the Third Century to Alaric, Cambridge. 
Kulikowski (2008): Michael Kulikowski, „Sidonius Carmen VII and a Hitherto Unnoticed Gothic Civil War", Journal of Late Antiquity 1, 335-352.

Langgärtner (1964): Georg Langgärtner, Die Gallienpolitik der Päpste im 5. und 6. Jahrhundert, Bonn.

Lionnet \& Shih (2005): Françoise Lionnet and Shu-mei Shih (eds.), Minor Transnationalism, Durham, NC.

Lütkenhaus (1998): Werner Lütkenhaus, Constantius III. Studien zu seiner Tätigkeit und Stellung im Westreich 411-421, Bonn.

Magnus (2001): Bente Magnus (ed.), Roman Gold and the Development of the Early Germanic Kingdoms, Stockholm.

Mathisen (1989): Ralph W. Mathisen, Ecclesiastical Factionalism and Religious Controversy in Fifth-Century Gaul, Washington, DC.

Mathisen (1993): Ralph W. Mathisen, Roman Aristocrats in Barbarian Gaul: Strategies for Survival in an Age of Transition, Austin.

Mazzarino (1942): Santo Mazzarino, Stilicone: La crisi imperiale dopo Teodosio, Mailand.

Oost (1969): S.I. Oost, Galla Placidia Augusta, Chicago.

Pitts (1989): L.F. Pitts, „Rome and the German 'Kings' on the Middle Danube“, Journal of Roman Studies 79, 45-58.

Scharf (2001): Rolf Scharf, Foederati: von der völkerrechtlichen Kategorie zur byzantinischen Truppengattung, Vienna.

Stickler (2002): Timo Stickler, Aëtius: Gestaltungsspielräume eines Heermeisters im ausgehenden Weströmischen Reich, Munich.

Storgaard (2001): Birger Storgaard (ed.), Military Aspects of the Aristocracy in Barbaricum in the Roman and Early Migration Periods, Copenhagen.

Sullivan (1990): Richard D. Sullivan, Near Eastern Royalty and Rome, 100-30 B.C., Toronto.

Teitler (1992): H.C. Teitler, „Un-Roman activities in late antique Gaul: the cases of Arvandus and Seronatus“, in: John F. Drinkwater and Hugh Elton (eds.), Fifth Century Gaul: A Crisis of Identity?, Cambridge, 309-17.

Ward-Perkins (2005): Bryan Ward-Perkins, The Fall of Rome and the End of Civilization, Oxford. 


\title{
„Bischofsherrschaft“ \\ Zur Transformation der politischen Kultur im spätantiken und frühmittelalterlichen Gallien
}

\author{
Steffen Diefenbach
}

Vermutlich im Jahr 470 wandte sich Sidonius Apollinaris, der erst kurze Zeit zuvor nach einer glänzenden zivilen Ämterkarriere das Bischofsamt der Stadt Clermont-Ferrand übernommen hatte, mit einer Rede in der Kathedrale von Bourges an die dort versammelte Gemeinde. ${ }^{1}$ Der Anlass waren die anstehenden Bischofswahlen, zu denen sich zahlreiche Bewerber eingefunden hatten - Sidonius spricht davon, dass die Kandidaten mehr als zwei Reihen der Kathedrale gefüllt hätten. Das Bewerberfeld war zudem hochkarätig besetzt. Mindestens drei der Anwärter zählten zu den höchsten Rangklassen der spätrömischen Aristokratie: Sidonius erwähnt zwei illustres sowie einen spectabilis namens Simplicius, den Sidonius als den geeigneten Kandidaten ansah und auch unterstützte. Der großen Zahl an einflussreichen und sozial angesehenen Bewerbern entsprechend war es offenbar bereits im Vorfeld der Wahl zu rivalisierenden Faktionsbildungen gekommen. Sidonius, der von der Gemeinde von Bourges gebeten wurde, in dieser Situation eine Wahlempfehlung auszusprechen, entschied sich dabei mit Simplicius für einen Mann, der sich nach Sidonius' Worten sowohl für die res publica als auch für die ecclesia, sowohl für die politische als auch für die kirchliche Gemeinde von Bourges, als eine geeignete Wahl herausstellen würde. Unter Simplicius' Vorfahren, so Sidonius, befänden sich sowohl Präfekten als auch Bischöfe; Simplicius selbst habe sich bereits in der zivilen Administration bewährt und sei nun der geeignete Kandidat, um auch das Bischofsamt in Bourges zu übernehmen. ${ }^{2}$ Dass Simplicius keine klerikale Ämterlaufbahn durchlaufen hatte und zum Zeitpunkt der Bischofswahl nicht einmal über einen niederen Weihegrad verfügte, stellte aus Sicht des Sidonius hingegen keinen ernsthaften Hinderungsgrund dar - auch Sidonius selbst war ja im Jahr 469 nach Ableistung der

1 Zum Folgenden Sidon. epist. 7, 9.

2 Ebd., 16f.: Simplicius [...] ita utrique parti vel actu vel professione respondet, ut et respublica in eo quod admiretur et ecclesia possit invenire quod diligat. si natalibus servanda reverentia est [...]: parentes ipsius aut cathedris aut tribunalibus praesederunt. 
römischen Stadtpräfektur per saltum zum Bischof von Clermont-Ferrand geweiht worden. ${ }^{3}$

Beispiele wie das eben genannte gelten in der Forschung seit geraumer Zeit als exemplarische Hinweise auf einen tiefgreifenden politischen Strukturwandel im spätantiken Gallien. Seit dem 5. Jh. hätten, so die „communis opinio“, die dort ansässigen Angehörigen der römischen Reichsaristokratie zunehmend das kirchliche Leitungsamt als ein neues Betätigungsfeld genutzt, um ihre politischen Ambitionen und ihren traditionellen gesellschaftlichen Führungsanspruch aufrechtzuerhalten. ${ }^{4}$ Wie die eingangs zitierten Bemerkungen des Sidonius zur Bischofswahl in Bourges nahelegten, habe das Bischofsamt zumindest für Teile der Reichselite nahezu gleichberechtigt neben den hohen zivilen Ämtern rangiert, auf deren Bekleidung das Prestige dieser sozialen Gruppe traditionell beruhte. Im Unterschied $\mathrm{zu}$ den übrigen Regionen des Imperiums, wo das Amt des christlichen Gemeindeleiters seit dem 4. Jh. vor allem für die Kurialen interessant wurde, weil die gesetzliche Privilegierung eine Abschüttelung der von dieser Gruppe eingeforderten Leistungen ermöglichte und zugleich auch einer sozialen Aufwertung des Bischofs im lokalen Kontext der städtischen Gemeinden Vorschub leistete, habe in Gallien der Episkopat die Aufmerksamkeit nicht allein der munizipalen Eliten auf sich gezogen. ${ }^{5}$ Vielmehr hätten die besonderen Voraussetzungen der gallischen Städte mit ihren vergleichsweise großen civitas-Territorien ${ }^{6}$ dazu geführt, dass die ausgesprochen selbstbewusste, sich zuweilen als Gegenpol zu der in Italien ansässigen kaiserlichen Zentrale verstehende gallische Aristokratie in Ermangelung geeigneter politischer Betätigungsmöglichkeiten in der Reichsverwaltung seit dem ersten Drittel des 5. Jh. verstärkt auf die Bischofssitze drängte. Sie hätte damit eine - auch prosopographisch fassbare ${ }^{7}$ - Entwicklung eingeleitet, in deren Verlauf sich das Bischofsamt zunehmend zu einer Domäne der senatorischen Aristokratie entwickelt und damit zugleich den institutionellen Garant für das Fortbestehen ihrer gesellschaftlichen Leitungsposition gebildet habe.

3 Sidonius spielt in dem genannten Schreiben selbst darauf an (ebd., 14). Zum historischen Kontext vgl. Harries 1994, 169-179, die in Sidonius' politischer Isolierung nach dem Arvandusprozess den entscheidenden Grund für seine Übernahme des Bischofsamts erkennt und betont, dass die Bekleidung des kirchlichen Amts eher notgedrungen und aus Mangel an Alternativen erfolgte.

4 Für das Folgende vgl. u.a. die Resümees von Prinz 1988a, 47-55; Baumgart 1995, $193-$ 196; Jussen 1995, bes. 675f.; dems. 1998, bes. 78f.; Wiesheu 2001, 6-9. Diesem Deutungsansatz sind auch die u., S. 94-96 angeführten Studien verpflichtet. Zur forschungsgeschichtlichen Einordnung dieses Ansatzes, der verstärkt seit den 1950er Jahren florierte, vgl. Brown 2000b, 322.

5 Zu dieser für Gallien spezifischen Entwicklung vgl. Rapp 2005, 183-192.

6 Als ein Alleinstellungsmerkmal der städtischen Territorien und damit der kirchlichen Bistümer in Gallien herausgestellt von Eck 1978, 583. Zur großen Ausdehnung der civitasTerritorien im spätantiken Gallien vgl. auch den Beitrag von Christian Witschel in diesem Band.

7 Grundlegend Stroheker 1948; in Fortführung Heinzelmann 1976, bes. 211-232. 
Im Folgenden soll dieses Paradigma, das in der deutschsprachigen Literatur für gewöhnlich unter der Bezeichnung einer spätantiken „Bischofsherrschaft“ oder „,bischöflichen Stadtherrschaft“ firmiert, einer näheren Betrachtung unterzogen werden. Als Grundlage wird zunächst in einem ersten Schritt die Forschungslage rekapituliert, um auf diese Weise einen Ausgangspunkt für die offenen Fragen und Probleme zu gewinnen, die sich in den aktuellen Diskussionen mit diesem Konzept verbinden.

I.

Bereits ein summarischer Blick auf die einschlägige Literatur erweckt den Eindruck, dass das oben skizzierte Modell bischöflicher Herrschaft im spätantiken Gallien stark durch nationale Forschungstraditionen geprägt ist. Begriffe wie „Bischofsherrschaft“ oder „bischöfliche Stadtherrschaft“" begegnen vorzugsweise in der deutschen Forschung. Bezeichnenderweise findet sich dafür kein englischsprachiges Pendant, etwa ,episcopal rule“ oder vergleichbare Wendungen. Vielmehr wird auch in englisch- und französischsprachigen Publikationen der deutsche Ausdruck „Bischofs-“ bzw. „bischöfliche Stadtherrschaft“" gleichsam als eine Art „terminus technicus“ verwendet. ${ }^{8}$ Diese spezifisch deutsche Rede von einer gallischen „Bischofsherrschaft ${ }^{“ 9}$ hat zu einem erheblichen Teil forschungsgeschichtliche Gründe, die mit der Stellung der Bischöfe im spätantiken und frühmittelalterlichen Gallien nicht unmittelbar etwas zu tun haben: Der Begriff geht auf die für das deutsche Reich eigentümliche Stellung der Bischöfe als Herrschaftsträger in spätkarolingischer und ottonischer Zeit zurück und ist von dort ausgehend im Rückblick auf die merowingischen und spätantiken Verhältnisse bezogen worden, um auf diesem Wege die entwicklungsgeschichtlichen Grundlagen für eine erst im Hochmittelalter voll ausgeprägte Form der Bischofsherrschaft $\mathrm{zu}$ eruieren. ${ }^{10}$ Dieser Ansatz birgt in mehrfacher Hinsicht Risiken in sich: zum einen, weil auf diese Weise anachronistischen Rückprojektionen hochmittelal-

8 Vgl. etwa zuletzt Claudia Rapp in ihrer Monographie zu den spätantiken Bischöfen (Rapp 2005, 11) oder Peter Brown in einer jüngeren Studie zu Gregor v. Tours (Brown 2002a, 12). Für die französischsprachige Forschung s. z.B. van Uytfanghe 2001a, 216.

9 So auch explizit - und in dezidiert kritischer Distanzierung von diesem Sprachgebrauch Wood 1983, 34; ähnlich Loseby 2006, 92; Brown 2012, 506. Vgl. ferner Heinzelmann 1994, 166.

10 Die von der Mediävistik ausgehende Perspektive spiegelt sich beispielsweise in den Arbeiten von Prinz 1973a und Kaiser 1981 wider: Beide beurteilen die spätantiken Verhältnisse unter dem Gesichtspunkt, inwieweit sie als Vorstufe bischöflicher Herrschaft im späten 9. und 10. Jh. aufgefasst werden können (vgl. Prinz 1973a, 32; Kaiser 1981, 66). Zum mediävistischen Forschungsinteresse an den spätantiken Wurzeln hochmittelalterlicher Bischofsherrschaft vgl. auch Anton 1996, 467-473; Kaiser 2004, 75f., 129. Davon angeregt hat das Paradigma der ,spätantiken Bischofsherrschaft" in Gallien auch Eingang in die althistorische Forschung gefunden (vgl. z.B. die Studien von Heinzelmann 1976 und Baumgart 1995). 
terlicher Bischofsherrschaft der Weg eröffnet wird, zum anderen, weil damit zugleich auch eine spezifische Konzeptualisierung der von den Bischöfen ausgeübten „Herrschaft“" verbunden ist, die die bischöfliche Autorität als Erscheinungsform einer im Wesentlichen politisch definierten Herrschaftsstellung begreift. Um dies zu verdeutlichen, erscheint es sinnvoll, sich kurz einige mit diesem Konzept der „Bischofsherrschaft“ im spätantiken und frühmerowingischen Gallien verbundene Grundannahmen zu vergegenwärtigen. Zwei charakteristische Aspekte verdienen dabei besondere Beachtung:

1. Bei der Positionsbestimmung der Bischöfe als Herrschaftsträger steht generell nicht primär die Frage nach der bischöflichen Autorität über die Gemeinde im Vordergrund, sondern das Verhältnis der Bischöfe zu einer in der Regel als „staatlich“ bezeichneten zentralen Herrschaftsgewalt - im 5. Jh. verkörpert durch den römischen Kaiser und die römische Administration, seit dem 6. Jh. durch die barbarischen Könige. Anders gewendet: Das Konzept der „Bischofsherrschaft“ operiert nicht mit einem soziologischen Herrschaftsbegriff, sondern mit einem institutionell-verfassungsrechtlichen. Es bezeichnet den Grad, in dem Bischöfe als kirchliche Gemeindeleiter an einer allgemeinen politischen bzw. „staatlichen“ Herrschaftsgewalt partizipierten und sich bestimmte Kompetenzen zu sichern in der Lage waren.

Dies vorausgesetzt, haben sich die Auseinandersetzungen der Forschung vorzugsweise darauf konzentriert, ob die Bischöfe in der Ausübung dieser Herrschaftsrechte als Agenten der politischen Zentralgewalt handelten oder aber sich ihre Befugnisse ohne das Zutun oder gar gegen den Willen der Zentrale aneigneten - eine Debatte, die zugleich eng mit der Frage nach der Kontinuität römischer Verwaltungsstrukturen und Institutionen verbunden ist. ${ }^{11}$ So unterschiedlich diese

11 So sind Forscher wie Martin Heinzelmann oder vor allem Jean Durliat, die von einem Fortbestand wesentlicher Strukturen der römischen Fiskal- und Munizipaladministration bis weit über das 6. Jh. hinaus ausgehen, der Auffassung, dass die Bischöfe bereits seit der konstantinischen Wende von der kaiserlichen Zentrale in ihrer Funktion als lokale Herrschaftsträger kontinuierlich gestärkt worden seien und die frühmittelalterliche Bischofsherrschaft auf den institutionellen Grundlagen einer derartigen Einbeziehung der Bischöfe in die Administration des römischen Imperiums basiert habe (zu dieser Perspektive auf die Bischöfe als staatlich delegierte Herrschaftsträger vgl. Heinzelmann 1988; Durliat 1996; ähnlich auch Baumgart 1995, bes. 17-39; Elm 2003, 22-24). Für den weiteren Kontext das Fortbestehen institutioneller Strukturen der spätantiken Verwaltung in der Merowingerzeit - vgl. Durliat 1990 (Übernahme der römischen Fiskaladministration durch die fränkischen Könige); Heinzelmann 1990 (institutionelle Aufrechterhaltung des öffentlichen Schulwesens durch die Städte). Zum Fortleben eines für die senatorischen Eliten charakteristischen Amtsverständnisses im Bischofsamt und, damit einhergehend, zu den Bischöfen als Trägern einer auch unter den Merowingern fortbestehenden spätantiken „Staatlichkeit“ vgl. Heinzelmann 1976, bes. 243-245. Die gegenteilige Ansicht, wie sie u.a. maßgeblich von Friedrich Prinz vertreten wird, beruht demgegenüber auf der Annahme, dass die Bischöfe seit dem 5. Jh. zunehmend herrschaftliche Rechte und Befugnisse usurpiert hätten bzw. in das Vakuum einer immer brüchiger werdenden zivilen Administration eingerückt seien (Prinz 1971, 37-72; ders. 1973a; ders. 1981, bes. 108-113). Als konstitutiv für den faktischen Machtzuwachs der Bischöfe seit der Mitte des 5. Jh.s wird 
beiden Bewertungen auch sind, ${ }^{12}$ liegt ihnen doch ein vergleichbares Verständnis des Phänomens - nicht nur bischöflicher - Herrschaft zugrunde. Letztlich unabhängig von der Frage ihrer Delegation oder Usurpation ist die bischöfliche Herrschaftsbildung nach dieser Vorstellung definiert durch die Partizipation an bestimmten Rechten oder administrativen Kompetenzen: Die Macht des Bischofs entfaltet sich innerhalb eines weitgehend homogen strukturierten Rahmens von Herrschaft, der in Ermangelung einer geeigneten Terminologie meist als ,öffentlich“ oder „staatlich“ charakterisiert wird ${ }^{13}$ und damit zugleich den Zuschnitt und Charakter dessen, was bischöfliche Herrschaft sein soll, maßgeblich bestimmt. ${ }^{14}$ Dies wird zugleich, wie schon erwähnt, zum Anlass genommen, einen Begriff der „Stadtherrschaft“, der eigentlich mit Blick auf die hochmittelalterlichen Verhältnisse der spätkarolingischen und ottonischen Reichskirche geprägt wurde, strukturell bis auf die spätantiken Verhältnisse zurückzubeziehen und die Wurzeln

dabei allgemein die Bedrohung der Städte durch außenpolitische Krisensituationen angesehen: Die Bischöfe hätten sich als erfolgreiche Vermittler zwischen der römischen Administration und den barbarischen Königen profiliert und elementare Schutzfunktionen und damit einhergehende „Kompetenzen“ übernommen (Prinz 1988b, 5-7; Anton 1996, 463; ähnlich auch Beaujard 1991; dies. 2000, 117-141).

12 Von der erkenntnisleitenden Frage nach der Alternative zwischen Delegation oder Usurpation von Herrschaftsrechten ist auch der Beitrag von Durliat 1996 bestimmt. Zur Anatomie dieser Debatte vgl. Esders 1993, 97; Jussen 1995, 677-679; Kaiser 2004, 75f.; Patzold 2010, $121 \mathrm{f}$.

13 Diese Sicht besteht, wie erwähnt, unabhängig von der Einschätzung, ob die Bischöfe ihre Macht mit oder gegen den Willen der römischen Administration bzw. der merowingischen Könige begründeten. Exemplarisch für die letztere Auffassung z.B. Scheibelreiter 1983, 172f. („Arrogierung ,öffentlicher' Befugnisse, die [...] aus Gründen der starken Stellung in der civitas oder einfach aus der Notwendigkeit des Augenblicks heraus beansprucht wurden“); Prinz 1988a, 324 (Übernahme „staatlicher Funktionen“); ders. 1988b, 7 (die Entstehung bischöflicher Macht in Räumen mit schwacher Königsmacht wird verstanden als Ausfüllen eines „machtpolitischen Vakuums“); Anton 1996, 463, 469 (noch keine umfassende „Usurpation staatlicher Kompetenzen“ durch die Bischöfe im 5. Jh., aber Wahrnehmung „klarer öffentlicher Aufgaben“ seit dem 6. Jh.). Naturgemäß wird diese Sichtweise noch ausgeprägter von denjenigen Forschern vertreten, die den Delegationscharakter bischöflicher Herrschaft stärker betonen; vgl. z.B. Heinzelmann 1988, 26 über die spätantike kaiserliche Gesetzgebung (,,von der Staatsgewalt geförderte Ausstattung der Kirchenvorsteher mit öffentlichen Kompetenzen“; „Delegation öffentlicher Tätigkeitsbereiche durch die oberste Staatsgewalt - also Kaiser oder König“) oder Kaiser 1988, 88f. über die Immunitätsprivilegien merowingischer Könige („Umverteilung von Macht und Herrschaftsbefugnissen, die beide als öffentliche angesehen wurden"). Zur Komplementarität königlicher und bischöflicher Herrschaft als Kern des von Gregor v. Tours entwickelten Gesellschafts- und Herrschaftskonzepts vgl. Heinzelmann 1994, bes. 181-184; ähnlich Breukelaar 1994, 227-267.

14 Als typische, in der Literatur immer wieder aufgeführte Beispiele für derartige Herrschaftsbefugnisse begegnen die für das 5. und 6. Jh. gelegentlich bezeugte Verfügung von Bischöfen über bewaffnete Gefolgschaften, die Errichtung von Mauern und Kastellen und vor allem fiskalische und juridische Kompetenzen. 
dieser hoheitlichen „Herrschaftsrechte“ in der spätantiken und frühmittelalterlichen Entwicklung des Bischofsamts zu suchen. ${ }^{15}$

2. Die soziale Schicht, die als maßgeblicher Träger dieser Entwicklung hin zur Bischofsherrschaft ausgemacht wird, erscheint als eine weitgehend homogene Gruppe mit uniformer Ausrichtung. Meist ist die Rede von „dem“ senatorischen Adel des spätantiken Gallien im Sinne einer einheitlichen Herrschaftsschicht, die die kollektive Aneignung des Bischofsamts während des Zusammenbruchs der römischen Administration im Laufe des 5. Jh.s maßgeblich vorangetrieben habe. ${ }^{16}$ Unmittelbar damit einher geht die komplementäre Vorstellung, dass das Bischofsamt für die traditionellen Eliten als der alleinige institutionelle Fokus von Herrschaftsausübung verblieben sei: Nach dem Wegfall der römischen Verwaltungsstrukturen habe sich den Angehörigen der Senatsaristokratie nur noch das Bischofsamt als geeignetes Betätigungsfeld geboten, um ihren Führungsanspruch, der nach dem Selbstverständnis dieser Schicht in elementarer Weise auf der Bekleidung von politischen Ämtern gründete, aufrechtzuerhalten. ${ }^{17}$ Zwar wird durchaus betont, dass über lange Jahrzehnte des 5. Jh.s hinweg ein Nebeneinander und Zusammenwirken von zivilen und kirchlichen Verwaltungsträgern, häufig auch in Form von adligen Faktionsbildungen, charakteristisch gewesen sei. ${ }^{18}$ Das Ergebnis der historischen Entwicklung erscheint davon jedoch unberührt: Insgesamt geht man in der Forschung weitgehend davon aus, dass sich der Bischof in der Zeit bis etwa 500 zum alleinigen politisch-administrativen Herrschaftsträger in den civitates Galliens entwickelt habe. ${ }^{19}$

Diese für das Konzept einer spätantiken und frühmerowingischen „Bischofsherrschaft" in Gallien charakteristischen Grundannahmen sind in den letzten Jah-

15 Besondere Aufmerksamkeit gilt dabei den Immunitätsprivilegien, die traditionell als die zentrale Voraussetzung für die Entfaltung ,voller“ bischöflicher Herrschaft im 9. und 10. Jh. angesehen werden (vgl. Kaiser 1981, 624; Anton 1996, 468; Patzold 2008, 24f.). In jüngerer Zeit werden die merowingischen Immunitätsprivilegien freilich nicht mehr als „Ausverkauf" königlicher Herrschaftsansprüche aufgefasst (vgl. Murray 1994; Rosenwein 1999, bes. 74-96).

16 In dieser Hinsicht besteht weitgehender Konsens auch zwischen den Vertretern der „Delegations-“ bzw. „Usurpationsthese“. Jussen 1995, ders. 1998 spricht wahlweise von Reichsaristokratie oder senatorischer Aristokratie, um die sozialen Träger der Entwicklung zu bezeichnen. Auch dass das Bischofsamt auf diese Weise zu einer regelrechten Domäne der gallischen Senatsaristokratie geworden sei, ist nahezu „,communis opinio“ der Forschung; vgl. z.B. Scheibelreiter 1983, 45-49; van Dam 1985, 141-156; Jussen 1995, 686; Gauthier 2000, 195-199.

$17 \mathrm{Zu}$ dieser uniformen Ausrichtung auf das Bischofsamt vgl. Jussen 1995, 688f.

18 Heinzelmann 1976, 73-84; grundlegend Mathisen 1989.

19 Exemplarisch die Einschätzungen von Jussen 1998, 79 („um 400 war kein Bischof Stadtherr, und kaum ein Aristokrat hat sich für dieses Amt interessiert. Hundert Jahre später, um 500, saßen die Aristokraten auf den Bischofsstühlen und waren die Bischöfe zugleich Stadtherren“) oder Gauthier 2000, 173 (,dans la Gaule du haut Moyen-Âge, l'évêque est véritablement le pivot de la vie sociale“) und 182 („le pouvoir de l'évêque à l'intérieur de son diocèse est, au moins théoriquement, incontesté“"). 
ren zunehmend kritisch hinterfragt worden, in Details ebenso wie im Grundsätzlichen.

So hat man vor allem in der angloamerikanischen Forschung zu Recht darauf hingewiesen, dass die Bischöfe in den gallischen civitates keineswegs eine politische Monopolstellung besaßen, die es rechtfertigen würde, ein Konzept mittelalterlicher Bischofsherrschaft bereits auf die spätantiken und frühmerowingischen Verhältnisse zurückzubeziehen. ${ }^{20}$ Abgesehen davon, dass die Bischöfe bis mindestens zu Beginn des 7. Jh.s offenbar große Schwierigkeiten hatten, ihre Autorität auch außerhalb der Städte in den weitläufigen civitas-Territorien Galliens zur Geltung zu bringen, ${ }^{21}$ war die bischöfliche Macht selbst in den städtischen Zentren des Rhoneraums, der Provence, der Tourraine und Aquitaniens ${ }^{22}$ alles andere als unumstritten. Hier lässt sich bis zum ausgehenden 6. Jh. neben Bischof und Klerus eine nichtklerikale und einflussreiche stadtsässige Elite fassen, die bei Gregor v. Tours unspezifisch als cives honorati, senatores, nobiles oder in ähnlicher Bezeichnung erscheint. ${ }^{23}$ Neben diesen lokalen Eliten formierte sich ein

20 Vorbehalte bezüglich einer zu starken Akzentuierung der Stellung der Bischöfe des 6. Jh.s als Herrschaftsträger bereits bei Beck 1950, 317f. Ähnlich (und in expliziter Auseinandersetzung mit den Arbeiten von Friedrich Prinz) auch Brown 1976 (1982), 193f.; ders. 1977 (1982), 246f. mit Anm. 98. Aus jüngerer Zeit vgl. die ähnlich skeptischen Einschätzungen von Wood 1983, 34; Brennan 1992, 117-119; Fouracre 1999, 147; Coates 2000, 1131f.; Liebeschuetz 2001, 161-167.

21 In der kirchlichen Gesetzgebung der gallischen Synoden des 6. Jh.s finden sich wiederholt Regelungen, die wenigstens an den Hochfesten wie Ostern, Pfingsten und Weihnachten die Teilnahme aller civitas-Bewohner am bischöflichen Gottesdienst in der Kathedrale des civitas-Hauptortes einschärfen und dabei explizit gegen die Tendenz, diese Gottesdienste in ländlichen villae zu feiern, Stellung beziehen (eine Zusammenstellung und Diskussion der einschlägigen Belege bei Beck 1950, 73-76; Godding 2001, 255-260; vgl. auch Bailey 2003, 22f.). Zu den Villen im spätantiken und frühmerowingischen Gallien vgl. van Ossel 1992; Ripoll/Arce 2000; Stirling 2007 und u., Anm. 56.

22 Zur geographischen Konzentration von spätantik-frühmerowingischen „Bischofsherrschaften“ auf diesen geographischen Raum südlich der Loire vgl. Ewig 1976 (1955), 416f., 432f.; Prinz 1981, 112.

23 Der Grad ihrer institutionellen oder organisatorischen Verfestigung lässt sich nur schwer bestimmen. Zwar deuten dokumentarische Quellen, wie Formelsammlungen und Testamente, darauf hin, dass diese honorati zumindest partiell mit Amtsbezeichnungen und -funktionen der spätrömischen Munizipalverfassung belegt wurden, die neben dem Bischofsamt fortexistierten, doch beruhte der Einfluss dieser Gruppe im Wesentlichen nicht auf institutionellen Grundlagen, sondern umgekehrt auf dem Umstand, dass die honorati in der Lage waren, sich selbst und ihre Klienten dem Zugriff der staatlichen Verwaltung zu entziehen (vgl. die Diskussion der Zeugnisse bei Müller 2003, 6-81, der das institutionelle Gewicht der Amtsbezeichnungen und des ordo decurionum als gering einstuft; anders z.B. Durliat 1996, 273f.). Zum wachsenden Einfluss der honorati, die seit der Wende vom 4. zum 5. Jh. das politische Geschehen in den spätantiken Städten zu bestimmen begannen, vgl. allgemein Liebeschuetz 2001, 104-136. Für die soziale Bestimmung dieser senatores s. die divergierenden Einschätzungen von Gilliard 1979 (rein ökonomische Kriterien) und Brennan 1985 (Abstammung). Gregor v. Tours' Sprachgebrauch von senatores und nobiles im Sinne einer geburtsständisch abgegrenzten Elite hat dabei allerdings sicher idiosynkratische Züge, da in der merowingischen Gesellschaft ausgeprägte Aufstiegschancen 
Gegengewicht zum Bischof insbesondere in der Person des comes civitatis, der im Auftrag der merowingischen Könige die Erhebung von Steuern und Truppen koordinierte und in dieser Funktion nicht selten in Konflikt mit den Bischöfen geriet. ${ }^{24}$ In dem Maße, in dem die civitates in den merowingischen regna als administrative Zentren fungierten, in denen unabhängig von der kirchlichen Verwaltung Steuern erhoben, Truppen ausgehoben, Recht gesprochen und Besitzübertragungen archiviert wurden, ${ }^{25}$ blieben demnach zentrale fiskalische und juridische „Kompetenzen“ in den Händen von Gruppen und Amtsträgern, die neben und zum Teil in Konkurrenz zu den Bischöfen agierten. Auch dass Bischöfe des 5. und 6. Jh.s zum Teil über bewaffnete Anhängerschaften verfügten, kann nicht - wie insbesondere in der älteren Forschung teilweise noch üblich ${ }^{26}$-als ein Hinweis auf den Bischof als militärischen Stadtherrn verstanden werden. Zwar war das Selbstverständnis der gallischen Aristokratie, der diese Bischöfe entstammten, deutlich stärker militärisch geprägt, als man lange Zeit angenommen hat. ${ }^{27}$ Doch hat sich daraus - zumindest bis zum Ende des 6. Jh.s - nicht die Leitvorstellung vom Bischof als eines kriegführenden Adligen entwickelt: ${ }^{28}$ Der Bischof als Kriegsherr - das war habituell keine reguläre Option, allenfalls eine im Übrigen bis zum Ende des 6. Jh.s nur sehr selten bezeugte - Ausnahme.

Was die Bekleidung des Bischofsamts und seine Monopolisierung durch Angehörige der römischen Reichsaristokratie betrifft, ist in jüngerer Zeit verstärkt darauf hingewiesen worden, dass die prosopographisch gesicherten Angaben zur

bis in führende Positionen hinein bestanden (s. zuletzt Jones 2009, 82f., 94f.). Weitere Überlegungen zur demographischen Stabilität aristokratischer Familien im Gallien des 5. und 6. Jh.s bei Pietri 1986; Barnish 1988.

24 Anders als etwa von Prinz 1973a, 23f. behauptet, wurde dieser comes civitatis nicht schon im Laufe des 6. Jh.s durch die Bischöfe „,mediatisiert“, sondern büßte erst seit dem 7. Jh. in steigendem Maße an Bedeutung ein. Anlass für diese Entwicklung waren die königlichen Immunitätsprivilegien und die gezielte Vergabe von Bistümern und vor allem Klöstern an einflussreiche Adlige (so bereits Ewig 1979 [1954], 209-218; Claude 1964, 26-29; vgl. auch den Beitrag von Simon T. Loseby in diesem Band). Zuletzt ist die einflussreiche Stellung des comes civitatis im ausgehenden 6. Jh. erneut betont worden von Müller 2003, 6780. Loseby 2006, 86f. schätzt die Macht des comes bereits für diese Zeit zurückhaltender ein, da er zwischen den beiden Fronten der Bischöfe und der merowingischen Herrscher habe agieren müssen.

25 Zur Bedeutung der civitates als administrative Einheiten s. allgemein Loseby 1998, 245249; dens. 2006, 84-93 und seinen Beitrag in diesem Band. Zur Archivierung von Rechtsdokumenten in den gesta municipalia vgl. zuletzt Wickham 2005, 110f.; Rio 2008, 255258.

26 Prinz 1971, 37-72; kritisch bereits Heinzelmann 1976, 82.

27 Vgl. den Beitrag von John F. Drinkwater in diesem Band.

28 Gregor v. Tours perhorresziert die Vorstellung von einem kriegführenden Bischof nachdrücklich: Das bischöfliche Brüderpaar Salonius v. Embrun und Sagittarius v. Gap tadelt er scharf dafür, dass sie ,nicht das himmlische Kreuz als Waffe führten, sondern die weltlichen Waffen, Helm und Harnisch, und, was schlimmer ist, viele mit eigenen Händen getötet haben sollen" (Greg. Tur. hist. 4, 42: non cruce caelesti moniti, sed galea ac lurica saeculari armati, multos manibus propriis, quod peius est, interfecisse referuntur). 
Besetzung gallischer Bischofssitze nicht ausreichen, um eine so weitreichende Schlussfolgerung zu ziehen. ${ }^{29}$ Selbst wenn man von den Gebieten nördlich der Loire absieht, in denen man mit tiefgreifenden Umbrüchen der gesellschaftlichen Strukturen zu rechnen hat, ${ }^{30}$ können einzelne belegte Fälle von regelrechten Bischofsdynastien $^{31}$ nicht ohne weiteres zu der Hypothese verallgemeinert werden, dass das Bischofsamt in Gallien zur erblichen Domäne einer ständisch weitgehend geschlossenen Senatsaristokratie geworden sei. ${ }^{32}$ Komplementär dazu ist zu betonen, dass sich den traditionellen Anwärtern auf Posten innerhalb der Reichsaristokratie seit dem 5. Jh. neben dem Episkopat durchaus alternative Möglichkeiten dafür boten, ihren sozialen Status aufrechtzuerhalten. ${ }^{33}$ Im zivilen Bereich eröffneten die barbarischen regna auch weiterhin traditionelle Betätigungsfelder, ${ }^{34}$ während im militärischen Sektor mit einem deutlich breiteren Engagement durch römische Eliten zu rechnen ist, als es die Quellen suggerieren. ${ }^{35}$ Von einem

29 So schon Harries 1994, 170-172; zuletzt Patzold 2010.

30 Halsall 1995, bes. 249-261.

31 Etwa im Fall des Gregor v. Tours, der väter- wie mütterlicherseits zahlreiche Bischöfe zu seinen Vorfahren rechnete (zum Stammbaum Gregors vgl. ausführlich Heinzelmann 1994, 10-21).

32 Sichere prosopographische Nachweise lassen sich nur für vergleichsweise wenige Bischöfe führen (vgl. Patzold 2010). Problematisch ist vor allem die soziale Unschärfe des Senatorenbegriffs, der bereits in der Spätantike ausgesprochen diffus ist: Obwohl sich eine Zugehörigkeit prinzipiell aus der Bekleidung von Ämtern der Reichsverwaltung ergab, war der Senatorenstand sozial ausgesprochen heterogen und die Grenze insbesondere gegenüber den Kurialen, die sich durch Patronagebeziehungen kontinuierlich Zugang zum ordo senatorius verschafften, durchlässig (Eck 1978, 569-571; Näf 1995, 5-8). Inwieweit bei Autoren des 6. Jh.s, wie bei Gregor v. Tours, die Bezeichnung senatores auf eine geschlossenere Elite verweist, ist mehr als umstritten (s. o., Anm. 23). Dass die verbreitete Rede von der gallischen Senatsaristokratie die sozialen Realia hinter der Begrifflichkeit weitgehend ausblendet, ist daher zu Recht zu kritisieren (vgl. Patzold 2010, 125). Freilich wird man auch weiterhin daran festhalten müssen, dass insbesondere südlich der Loire das Bischofsamt in überdurchschnittlichem Maße von Angehörigen der Reichselite bekleidet wurde (zu dieser regionalen Differenzierung vgl. Gassmann 1977, 35-71; s. auch o., Anm. 22).

33 Zu den unterschiedlichen Optionen s. allgemein Mathisen 1993, bes. 132-143; vgl. ferner Jones 2009, 74-128.

34 Heather 1994, 187-197.

35 Halsall 2007, 494-497. Gerade in diesem Punkt wird deutlich, wie sehr das landläufige Bild von „der“ römischen Senatsaristokratie im spätantiken Gallien der spezifischen Selbstmodellierung von Aristokraten wie Sidonius Apollinaris geschuldet ist, die sich vermittels spezifischer kultureller Praktiken von militärisch geprägten Eliten abzugrenzen suchten: Was auf den ersten Blick als eine klare Dichotomie zwischen Römern und Barbaren erscheint, erweist sich bei näherem Hinsehen als ein innerrömischer Elitendiskurs. Dass es sich bei den vermeintlichen „Barbaren“ nicht selten um Römer handelt, die in gleicher Weise der Senatsaristokratie zuzuordnen sind wie der togatus Sidonius, wird in seinen Äußerungen zuweilen diskursiv nur unzureichend verdeckt; vgl. z.B. die abschätzigen Bemerkungen des Sidonius über die „barbarische“ Aufmachung des spectabilis Germanicus (Sidon. epist. 4, 13, 1). Zur Deutung barbarischer Kleidung nicht als Stam- 
Fortleben der alten Eliten in den kirchlichen Institutionen der Merowingerreiche wird man nach all dem nur unter Vorbehalt sprechen können: Die von der Forschung präsentierten Kronzeugen für diesen Transformationsprozess bilden nur einen kleinen Ausschnitt einer sozialen Schicht, die zwar das Bischofsbild im spätantiken und frühmittelalterlichen Gallien entscheidend geprägt hat, vermutlich jedoch weit davon entfernt war, die bischöflichen Leitungsämter für sich zu monopolisieren.

All dies sind fraglos wichtige Einzelbeobachtungen, die die Dimension sozialer Kontinuitäten relativieren, vor allem aber das Ausmaß bischöflicher Macht in den spätantiken und frühmerowingischen Städten deutlich einschränken und zugleich die impliziten Gefahren anachronistischer Rückprojektionen verdeutlichen, die die Verwendung eines an den hochmittelalterlichen Verhältnissen entwickelten Konzepts mit sich bringt. Grundsätzlich bleiben aber auch die Kritiker einer Bischofsherrschaft im spätantiken Gallien im Wesentlichen demselben Beurteilungsmaßstab verhaftet wie die Befürworter. Ob Bischöfe Herrschaft besaßen oder nicht, orientiert sich auch in der angloamerikanischen Forschung in erster Linie an ihrer Fähigkeit, ihre Führungsansprüche innerhalb eines gleichförmig strukturierten Rahmens von Herrschaftsbildung erfolgreich zur Geltung zu bringen, ohne dabei die Frage aufzuwerfen, inwieweit die institutionellen Grundlagen des Bischofsamts spezifische Möglichkeiten eröffneten, neuartige Herrschaftsansprüche zu formulieren und durchzusetzen.

Modifikationen grundsätzlicherer Art, die das oben skizzierte Konzept der Bischofsherrschaft als solches betreffen, hat demgegenüber in jüngerer Zeit der Mediävist Bernhard Jussen formuliert. ${ }^{36}$ Das Weiterführende seines Ansatzes besteht darin, dass er die Veränderungen des institutionellen Rahmens, in dem Herrschaft entsteht, in seine Überlegungen miteinbezieht und den Bischof in Gallien als einen neuartigen Autoritätstyp begreift, der sich nicht in den Rahmen der überkommenen institutionellen und politischen Ordnung habe einordnen lassen. Entscheidend für die Autorität, die Bischöfe in Gallien im Laufe des 5. Jh.s erlangt hätten, war nach Jussen, dass das Bischofsamt in dieser Zeit in einer spezifischen Weise modelliert wurde - und zwar von eben der aristokratischen Führungsschicht, die uns bereits eingangs bei der Wahl des Bischofs von Bourges als prominente Anwärterschaft auf den Episkopat begegnet ist. Die Senatsaristokratie habe Elemente der traditionellen Statusrepräsentation in die habituelle Selbstdarstellung des Bischofs - insbesondere in der Prozessionsliturgie und der liturgischen Gewandung - übernommen und sich damit gegen konkurrierende Auffassungen vom Bischofsamt durchgesetzt, die, verkörpert etwa in Martin v. Tours, eine rigide Askese und die immer wieder erneuerte charismatische Bewährung als

mestrachten, sondern als Distinktionsmerkmal spätrömischer Militäreliten vgl. zuletzt von Rummel 2007, bes. 401-406. S. auch u., S. 118.

36 Für das Folgende vgl. Jussen 1995; dens. 1998. 
Voraussetzung für seine Übernahme einforderten. ${ }^{37}$ Durch den Rekurs auf die Liturgie sei es den Bischöfen ferner gelungen, mittelfristig neue gesellschaftliche Ordnungsvorstellungen durchzusetzen und damit auch neuartige Vorstellungen von Herrschaft im Rahmen veränderter gesellschaftlicher Bedingungen zu vermitteln. $^{38}$

Da Jussens Überlegungen insbesondere auch in der angelsächsischen Forschung und der jüngeren deutschen Mediävistik großen Anklang gefunden haben, ${ }^{39}$ können sie gleichsam als „state of the art“ zur spätantiken Bischofsherrschaft in Gallien und zugleich als Ausgangspunkt für eine kritische Auseinandersetzung dienen. Trotz der neuen und weiterführenden Perspektiven, die sein Modell auf ein vermeintlich bekanntes Phänomen eröffnet, erscheint es in wesentlichen Punkten zu undifferenziert und korrektur- bzw. ergänzungsbedürftig. Dies betrifft vor allem drei Aspekte:

1. Die These, dass im frühen 5. Jh. eine spezifisch aristokratische Modellierung des Bischofsamts den Typ eines asketischen Charismatikers auf dem Bischofssitz, wie er in Martin v. Tours begegnet, verdrängt habe. Löst man sich von einer oberflächlichen Lektüre der sulpicischen Martinsschriften und bezieht stärker den historischen Kontext mit ein, in dem sie entstanden sind, wird umgekehrt hinter dem Bischof von Tours ein dezidiert aristokratisches Konzept religiös begründeter Autorität fassbar, das auch die Selbstdarstellung der gallischen Bischöfe noch bis zum ausgehenden 5. Jh. maßgeblich bestimmt hat. Erst mit dem Übergang zum 6. Jh. kam es hier zu habituellen Veränderungen, die eine aristokratische Prägung das Bischofsamts in dem von Jussen skizzierten Sinn zur Folge hatten.

2. Die Durchsetzung eines neuen bischöflichen Autoritätstyps. Bei aller Bedeutung einer gesellschaftlichen Umordnung durch das Medium liturgischer Prozessionen scheint die Frage, auf welche Weise die gallischen Bischöfe einen neuartigen Autoritätstyp konstruierten und durchsetzten, damit nur unzureichend beantwortet zu sein. Die Autorität der Bischöfe beruhte vielmehr auf einer umfassenden Transformation der politischen Kultur, in der unterschiedliche kulturelle Praktiken und Medien zusammenwirkten, um ein spezifisches Wissen vom Bischof zu erzeugen, das seine Evidenz aus der Umdeutung traditioneller Führungsansprüche und Kommunikationsformen sowie aus der engen symbolischen Vernetzung unterschiedlicher bischöflicher Leitungsrollen bezog.

37 Jussen 1995, 682-684, 693f., 699-706. Exemplarisch ders. 1998, 91f.: Martin v. Tours sei als „Modell des asketischen Bischofs [...] im ganzen unterlegen gegenüber jenen Konzeptionen, die den Bischof mit den Attributen der bestehenden sozialen Ordnung nach dem Modell aristokratischer dignitas definierten“.

38 Jussen 1995, 713-717; ders. 1998, 81-85, 105-122.

39 Eine zusammenfassende Darstellung seiner Position in englischer Sprache hat Jussen 2001 vorgelegt. Für die wohlwollende Rezeption seines Ansatzes im angloamerikanischen Raum vgl. exemplarisch Brown 2002a, 13; Rapp 2005, 14. Für die deutsche Mediävistik vgl. die entsprechende Einschätzung von Patzold 2008, 24-26; für die Ur- und Frühgeschichte s. Fehr 2010, 694-696. 
3. Die fehlende Rückbindung an den Herrschaftsbegriff. Mit der Diagnostizierung eines neuen bischöflichen Autoritätstyps ist zugleich ein Ausgangspunkt gewonnen, um die oben skizzierte Debatte um die Existenz einer spätantiken Bischofsherrschaft erneut aufzunehmen. ${ }^{40}$ Eine konsequent soziologische Definition des Herrschaftsbegriffs und eine damit einhergehende Differenzierung zwischen Macht und Herrschaft schärft den Blick dafür, dass sich unter den Händen der gallischen Bischöfe des 6. Jh.s die herkömmliche Macht der Heiligen zu etwas Neuem, einer Herrschaft der Heiligen, wandelte.

II.

Wenden wir uns damit zunächst der Frage zu, inwieweit im Laufe des 5. Jh.s konkurrierende Auffassungen des Bischofsamts in Gallien begegnen. Bei näherem Hinsehen wird deutlich, dass die Trennung zwischen einer martinischen und einer aristokratischen Prägung des Bischofsamts in dieser Form nicht aufrechtzuerhalten ist. Obwohl Martin v. Tours selbst nicht aus der Senatsaristokratie stammte, verkörperte er einen Heiligentyp, der ausgerechnet von Aristokraten in besonderer Weise propagiert wurde. Hier ist neben Sulpicius Severus, dem Verfasser der Martinsvita, vor allem Paulinus v. Nola zu nennen, der mit Sulpicius in engem Kontakt stand und für eine Verbreitung von dessen Martinsschriften außerhalb von Gallien sorgte. ${ }^{41}$ Beide Männer waren Teil eines ausgedehnten Netzwerkes von Angehörigen einer Reichselite, die über den wechselseitigen Austausch von Briefen, Schriften und Geschenken intensive Freundschaftsbeziehungen pflegten und sich zugleich auf diesem Wege ihrer kollektiven Zugehörigkeit zu den Kreisen der höchsten Aristokratie vergewisserten. ${ }^{42}$ Wirft man demnach einen Blick hinter die Kulissen und fragt, wer eigentlich an einer Verehrung Martins ein ge-

40 Jussen setzt sich in seinen Beiträgen zur Bischofsherrschaft in Gallien zwar ausführlich mit der deutschen Forschungsdiskussion auseinander, verzichtet aber darauf, die Distanz insbesondere der englischsprachigen Forschung zu diesem Begriff zu problematisieren.

41 Paulinus sorgte für die Verbreitung der Martinsvita in Rom (Sulp. Sev. dial. 1, 23, 4) und brachte sie Melania d.Ä., Nicetas v. Remesiana und namentlich nicht näher genannten plurimi dei sancti bei einer Lesung in Nola zu Gehör (Paul. Nol. epist. 29, 6 u. 14). Nach Sulpicius' eigenen Worten trug Paulinus damit unmittelbar zur Kenntnis der Schrift in Italien und im Illyricum - der Heimat des Bischofs Nicetas - bei (Sulp. Sev. dial. 3, 17, 4). Dass die Schrift auch in Nordafrika und Ägypten gelesen wurde (Sulp. Sev. dial. 1, 23, 5f.), dürfte ebenfalls ganz wesentlich mit den aristokratischen Netzwerken zusammenhängen, innerhalb derer die Schrift zirkulierte (zu Paulinus' Rolle als Vermittler der sulpicischen Martinsschriften vgl. Fontaine 1967-1969, Bd. 1, 49-51; Stancliffe 1983, 33f.; Mratschek 2002, 457-464).

42 Zum Korrespondentenkreis des Paulinus s. zuletzt ausführlich Mratschek 2002. Zur spätantiken Briefkultur und der zentralen Rolle von Briefen als wechselseitigen Gaben, über die amicitia, sozialer Status und die kollektive Zugehörigkeit zu aristokratischen Netzwerken signalisiert wurden, vgl. grundlegend die Studie von Bruggisser 1993 und zuletzt Ebbeler 2009. Für das spätantike und frühmittelalterliche Gallien s. u., S. 132f. 
steigertes Interesse zeigte, wird man kaum in der Lage sein, in ihm den Gegenpol $\mathrm{zu}$ einer aristokratischen Konzeption des Bischofsamts zu erkennen. Vielmehr verkörperte Martin v. Tours ein spezifisches Heiligenideal, das mit Blick auf seine Unterstützer und Anhänger durchaus nicht weniger aristokratisch genannt werden kann als die Formen asketischer Selbstheiligung, die wenige Jahre später in Lérins von Angehörigen der gallischen Senatsaristokratie praktiziert wurden.

Es fällt des Weiteren nicht ganz leicht, mit Jussen in Martin v. Tours den mehr oder weniger idealtypischen Gegenpol zu einer aristokratischen Prägung des Bischofsamts zu sehen. Dass Martin ein gespanntes Verhältnis zu zahlreichen seiner bischöflichen Amtsgenossen hatte und eine relativ isolierte Stellung innerhalb des gallischen Episkopats einnahm, erscheint nach den Zeugnissen seines Biographen Severus und der erstaunlich geringen Spuren, die Martin in der Überlieferung des 5. Jh.s hinterlassen hat, zwar unbestreitbar. ${ }^{43} \mathrm{Ob}$ dies freilich primär auf sein asketisches Verständnis vom Bischofsamt zurückzuführen ist, darf bezweifelt werden. So ist bemerkenswert, dass Martin ganz offenkundig keine programmatische Reform des bischöflichen Klerus angestrebt hat, mithin auch nicht das Bischofsamt einer asketischen Reform unterziehen wollte. Anders als die etwa zeitgleichen Bemühungen um eine asketische Regulierung des Klerus in Norditalien und Nordafrika, ${ }^{44}$ anders aber auch als die monastische Bewegung von Lérins, die sich etwa eine Generation nach Martin zur regelrechten „Pflanzschule" für die Besetzung gallischer Bischofssitze entwickelte ${ }^{45}$ und die Entstehung städtischer Klöster beförderte, ${ }^{46}$ hat Martin den Kathedralklerus von Tours

43 Sulp. Sev. Vita Mart. 9, 3; 20, 1; 27, 3; dial. 1, 24, 3. Trotz gegenteiliger Versicherungen seines Biographen (Sulp. Sev. Vita Mart. 10, 8f.) hielt sich die Zahl der von Schülern und Anhängern Martins übernommenen Bischofssitze offenbar in Grenzen (s. u., Anm. 45). Zur vergleichsweise geringen Nachwirkung Martins, der erst seit Chlodwig eine überregionale Bedeutung als gallischer Heiliger zu erlangen begann, s. allgemein Prinz 1988a, 19 $46,88-94$.

44 Zum Klerikerkloster des Eusebius v. Vercelli (ca. 344-371) aus dem zweiten Drittel des 4. Jh.s. vgl. Jenal 1995, Bd. 1, 12-15; für das Bischofskloster, das Augustinus in Hippo nach seiner Bischofsweihe 395 errichtete, s. Zumkeller 1968, 81-88.

45 Vgl. bereits Euch. de laude erem. 42; Caes. Arel. serm. 236, 1. Zur Bedeutung von Lérins für die Besetzung von Bischofssitzen im südlichen Gallien vgl. Prinz 1988a, 59-62; Mathisen 1989, 85-92 und u., Anm. 62. Vergleichbares lässt sich von Marmoutier nicht sagen: Die Behauptung des Sulpicius Severus, von dort seien zahlreiche spätere Bischöfe hervorgegangen (Sulp. Sev. Vita Mart. 10, 8f.) wird von Fontaine 1967-1969, Bd. 2, 684 zu Recht als „excès de son enthousiasme apologétique“ und Übertreibung zurückgewiesen; anders Rapp 2005, 151. Dass vergleichsweise wenige Schüler Martins auf gallischen Bischofssitzen begegnen, kann auch mit den politischen Verwerfungen des frühen 5. Jh.s zusammenhängen: Martinsschüler wie Heros v. Arles und Lazarus v. Aix unterhielten enge Beziehungen zum Usurpator Constantinus III. und teilten sein politisches Schicksal, indem sie nach dem Sturz des Constantinus im Jahr 411 abgesetzt wurden (Mathisen 1989, 28-37 und u., Anm. 125).

46 Hilarius v. Arles gründete ein Kloster mitten in der Stadt, das vermutlich auch den in Arles lebenden Klerus miteinbezog (Vita Hil. 7; 10 mit Brunert 1994, 222-228). Ähnlich auch Germanus v. Auxerre, der nach seiner Bischofsweihe (vor 429, möglicherweise 418) ein 
in seine monastische Gründung Marmoutier nicht miteinbezogen: Vielmehr baute er Marmoutier zu einem asketischen Zentrum aus, das in einiger Entfernung vom Bischofssitz in Tours lag ${ }^{47}$ und damit die Distanz zu den Aufgaben des Weltklerus ganz bewusst markierte. ${ }^{48}$ Nicht zuletzt auch Martin selbst evozierte erkennbar das Bild eines Bischofs, der eigentlich keiner sein wollte: Er missionierte auf dem Land, mied die Stadt, soweit dies möglich war, und wenn er nach Tours kam, um dort die Liturgie zu feiern, zog er sich in das secretarium der Kathedrale zurück, um die bischöfliche Schiedsgerichtsbarkeit nicht wahrnehmen zu müssen. ${ }^{49}$

Dieser Umstand gibt Anlass zu der Vermutung, dass der von Sulpicius Severus thematisierte Konflikt zwischen Martin und dem übrigen gallischen Episkopat möglicherweise nur vordergründig eine Auseinandersetzung um die richtige Auffassung vom Bischofsamt war. Dieser Eindruck bestätigt sich, wenn man den Blick nochmals auf die aristokratischen Kreise richtet, die die Verehrung Martins erkennbar gefördert haben. Wie bereits erwähnt, war es neben Sulpicius Severus vor allem Paulinus v. Nola, der Martin eine weit über die Grenzen Galliens hinausreichende Reputation verschaffte und im kampanischen Nola eine asketische Gemeinschaft ins Leben rief, die in ähnlicher Weise dem Kult des Heiligen Felix verpflichtet war wie die in Primuliacum angesiedelte Gemeinschaft des Sulpicius Severus dem Andenken des heiligen Martin. Bemerkenswert ist, dass es sich bei beiden Männern zwar um Angehörige der Senatsaristokratie handelte, die jedoch eine gewisse Distanz zum kirchlichen Amt pflegten: Sulpicius ist vermutlich zwar zum Presbyter ordiniert worden, wird aber in seiner Korrespondenz niemals als solcher angesprochen. ${ }^{50}$ Dasselbe gilt auch für Paulinus v. Nola: Seine Ernennung

Kloster gründete, das zwar im Suburbium der Stadt Auxerre lag, dabei jedoch, anders als Marmoutier, nicht als ein persönlicher Rückzugsraum des Bischofs aus der Gemeinde fungierte, sondern umgekehrt pastoralen Zwecken diente und damit auf die Stadt als Tätigkeitsfeld bezogen war (Const. Vita Germ. 6 mit Brunert 1994, 245-252, die ebd., 249f. die Differenz zur martinischen Gründung Marmoutiers herausstellt). Ein direkter Einfluss von Lérins auf die Gründung des Germanus (so Prinz 1988a, 64) lässt sich zwar nicht zeigen (Atsma 1983, 52-55); angesichts der engen Beziehungen des Germanus v. Auxerre zu Hilarius v. Arles (s. u., Anm. 62) ist aber zu erwägen, ob nicht beide - etwa zeitgleich vorgenommenen - Klostergründungen ähnlichen Vorstellungen folgten.

47 Laut Sulp. Sev. Vita Mart. 10, 3; dial. 3, 6, 2 lag Marmoutier zwar nur zwei Meilen von Tours entfernt, war jedoch nur über einen schmalen, zwischen der Loire und einer Felswand verlaufenden Weg zu erreichen, was die Unzugänglichkeit des Ortes und seine Distanz zur Stadt betonte (Sulp. Sev. Vita Mart. 10, 4).

48 Dies hebt auch von der Nahmer 1987, 5 hervor. Anders Brunert 1994, 166, die die Topik des Textzeugnisses und die Nähe des Klosters zur Stadt betont, gleichzeitig aber einräumt, dass Martin mit dieser Klostergründung die Distanz zur städtischen Siedlung markieren wollte (vgl. ebd., 173f.).

49 Sulp. Sev. Vita Mart. 12-15; dial. 2, 1, 2; vgl. Müller 1999, 146-149. Bezeichnend ist auch die Bemerkung des Sulpicius, wonach Martins thaumaturgische Kräfte nach seiner Ernennung zum Bischof abgenommen hätten (Sulp. Sev. dial. 2, 4, 1).

50 Gennad. vir. ill. 19 ist der einzige Beleg dafür, dass Sulpicius Presbyter war. Entweder wurde er erst gegen Ende seines Lebens ordiniert oder er und seine Korrespondenten maßen diesem Umstand keine größere Bedeutung bei - beide Varianten stimmen dahinge- 
zum Presbyter in Barcelona wurde von ihm als eine reine Dovotionsweihe betrachtet, die ihn nicht daran hinderte, seine Gemeinde zu verlassen und nach Kampanien zu ziehen. ${ }^{51}$ Zum Bischof von Nola wurde Paulinus erst vergleichsweise spät geweiht, und er nahm dies nicht erkennbar zum Anlass, etwas an seinem Lebensstil zu ändern, etwa seinen Aufenthalt vom Felixgrab in Cimitile nach Nola, in seine Gemeinde, zu verlagern. ${ }^{52}$ In dieselbe Richtung weisen auch die deutlich erkennbaren Sympathien, die Sulpicius Severus für den Priszillianismus hegte und die darin begründet lagen, dass die Anhänger Priszillians ähnliche asketische Lebensformen praktizierten, wie sie Sulpicius seinem Protagonisten Martin zuschreibt. ${ }^{53}$ Wiewohl Priszillian selbst es bis zum Bischof von Avila gebracht hatte, waren seine Anhänger in Spanien und Aquitanien vor allem unter aristokratischen Laien zu finden, die auf ihren ländlichen villae ein asketisches und weltabgewandtes Leben führten. ${ }^{54}$ Auch die von Sulpicius ins Leben gerufene Gründung einer Asketengemeinschaft in Primuliacum trägt deutliche Züge eines aristokratischen Zirkels, in dem der asketische Rückzug auf das Land eine enge Verbindung mit dem aristokratischen Lebensideal eines otium cum dignitate ein-

hend überein, dass Sulpicius die Übernahme des kirchlichen Amts nicht sonderlich wichtig gewesen zu sein scheint.

$51 \mathrm{Zu}$ dieser Form einer reinen Devotionsweihe, der sich in derselben Zeit beispielsweise auch Hieronymus unterzog, vgl. König 1985, 64-66. Instruktiv ist in diesem Zusammenhang der 395 verfasste Brief des Hieronymus an Paulinus v. Nola, in dem sich Hieronymus kritisch mit dessen Priesterweihe auseinandersetzt: Das an den presbyter Paulinus gerichtete Schreiben ergeht sich in Warnungen an Paulinus, die mit dem Priesteramt verbundene Bindung an eine Gemeinde und das städtische Leben aufzunehmen, und propagiert den asketischen Rückzug in die Einsamkeit (Hier. epist. 58).

52 Trout 1999, 162f. deutet zu Recht an, dass Paulinus mit seiner auch als Bischof beibehaltenen Ansiedlung beim Felixgrab ,in the suburbs of Nola, aloof from the urban cathedra“ eine für einen bischöflichen Gemeindeleiter außergewöhnlich stadtferne Position bezog. Die von Teilen der archäologischen Forschung vertretene Auffassung, wonach die Bischöfe von Nola bereits vor Paulinus ihren Sitz in Cimitile gehabt hätten (Lehmann 2004, 51), ist stark umstritten (s. Ebanista 2005, 337-344 mit ausführlicher Forschungsbilanz). Eine Lokalisierung des Bischofssitzes von Nola in Cimitile wäre für das 4. Jh. in der Tat sehr ungewöhnlich. Nicht einmal in Rom, wo die Gräber von Petrus und Paulus prestigeträchtige und mit eindrucksvollen Basilikalbauten ausgestattete kirchliche Zentren außerhalb der Stadt bildeten, kam es zu einer derartigen Verlagerung: Bei Konflikten um das Bischofsamt im ausgehenden 4. und frühen 5. Jh. konkurrierten die rivalisierenden Protagonisten immer um die Bischofskirche innerhalb der Stadt, nicht um die apostolischen Grablegen (dazu und zur räumlichen Bindung des Bischofs an die Stadt, die dem elementaren Verständnis vom Bischof als Hirt seiner Herde entsprach, vgl. Diefenbach 2007, 224-251, 276-289, 303-307).

53 Sulp. Sev. dial. 3, 11, 5; chron. 2, 50, 1. Zur Haltung des Sulpicius gegenüber dem Priszillianismus vgl. Stancliffe 1983, 265-296; Frank 1997, $26 f$.

54 In der Forschung gilt es mittlerweile als ausgemacht, dass der Vorwurf des Priszillianismus sich weit weniger gegen gnostische Tendenzen als gegen den asketischen Lebensstil der Anhänger Priszillians richtete (vgl. in diesem Sinne Stancliffe 1983, 278-296; van Dam 1985, 88-11; Rebenich 1992, 211-219). 
ging. ${ }^{55}$ Das dort entstandene Kultzentrum für Martin ordnet sich in vergleichbar ausgestattete aristokratische Landsitze mit Oratorien ein, für die sich in Südfrankreich und Spanien zahlreiche archäologische Spuren erhalten haben ${ }^{56}$ und ist seinerseits in engem Zusammenhang mit Martins Gründung Marmoutier zu sehen, die für die Gründung des Sulpicius das - reale oder imaginäre - Vorbild abgegeben hat. ${ }^{57}$

Von einem Konflikt um das Bischofsamt wird man nach dieser Ausgangslage kaum sprechen können. Zwar hatte die Akzentuierung von Askese als Leitbild unweigerlich zur Folge, dass aus der Perspektive eines Sulpicius Severus und Paulinus v. Nola auch das kirchliche Amt unter asketischen Bewährungsdruck geriet: Wie es die Vita Martini geradezu idealtypisch formulierte, musste auch ein Bischof wie ein Asket leben, um seine geistliche Autorität geltend machen zu können. ${ }^{58}$ Eine konkurrierende Auffassung vom Bischofsamt als Institution ist daraus dennoch nicht erwachsen, weil diese Asketen nicht aktiv in das Bischofsamt hineindrängten: ${ }^{59}$ Sie lehnten die Übernahme eines Klerikeramts zwar nicht kategorisch ab, betrachteten es jedoch als mögliche Quelle einer mit ihrem asketischen Selbstverständnis nicht zu vereinbarenden Selbstüberhöhung und als potentielle Gefährdung ihres Strebens nach Armut und Enthaltsamkeit. ${ }^{60}$ Asketisch lebende Aristokraten, die für die überregionale Verbreitung der Vita Martini eine entscheidende Rolle spielten und deren Protagonisten zum Leitbild erhoben, ${ }^{61}$ beanspruchten vielmehr eine spirituelle Autorität, die ihnen eine eigenständige

55 Fontaine 1973, 100; zurückhaltender von der Nahmer 1987, 17. Bemerkenswert ist in diesem Zusammenhang, dass in der aristokratischen Selbststilisierung der spätantiken zivilen Eliten das otium gegenüber der Bewährung im politischen Amt allgemein an Bedeutung gewann (dazu Matthews 1990, 1-31).

56 Bowes 2008, 179-187. Zu den villae im spätantiken und frühmittelalterlichen Gallien vgl. auch o., Anm. 21.

$57 \mathrm{Zu}$ den Anregungen, die von Marmoutier für Primuliacum ausgingen, und zu den Verbindungslinien zwischen Marmoutier, Primuliacum und Cimitile vgl. Stancliffe 1983, 31, 319. Anders von der Nahmer 1987, 16-19, der die Differenzen zwischen dem martinischen Mönchtum auf der einen und der asketischen Lebensweise eines Sulpicius Severus und Paulinus v. Nola auf der anderen Seite stärker herausstellt.

58 Für die mögliche Verbindung von Askese und Klerikeramt, das allerdings nur unter der Voraussetzung asketischer Vervollkommnung übernommen werden dürfe, vgl. Hier. epist. 52 und 125. Der sulpicische Martin v. Tours steht für eben diese Verbindung, vgl. exemplarisch Sulp. Sev. Vita Mart. 10, 2: inplebat episcopi dignitatem, ut non tamen propositum monachi virtutemque desereret.

59 Bezeichnend ist das Bild, das Paulinus v. Nola von „seinem“ Heiligen Felix entwarf, dessen Kult er in Cimitile nach Kräften förderte: Der Presbyter Felix verzichtet nach dem Ende der Verfolgungen darauf, Bischof von Nola zu werden, und zieht es stattdessen vor, in freiwilliger Armut auf einem kleinen Stück Land zu leben (zur Zeichnung des Felix v. Nola in den paulinischen carmina natalicia 15 und 16 vgl. Evenepoel 1989).

$60 \mathrm{Zu}$ den beiden zentralen Herausforderungen, die die Übernahme eines kirchlichen Amts bedeutete - Verlust von Demut und freiwilliger Armut - vgl. exemplarisch Hier. epist. $125,20$.

61 Zur Publikation und Verbreitung der Vita Martini s. o., Anm. 41. 
Stellung neben der kirchlichen Hierarchie und dem bischöflichen Leitungsamt verschaffte.

Eine aristokratische Prägung des Bischofsamts in Gallien lässt sich erst etwa eine Generation nach Martin fassen, als - ausgehend von Lérins - verstärkt Angehörige der Senatsaristokratie auf die Bischofsstühle im südlichen Gallien, vorzugsweise im Rhoneraum, zu drängen begannen. ${ }^{62}$ Erst jetzt kann man von einer beginnenden und folgenreichen Verbindung von kirchlichem Amt und aristokratischem Status in Gallien sprechen, zwar nicht im Sinne einer Monopolisierung des Bischofsamts, ${ }^{63}$ wohl aber in dem Sinne, dass alternative Entwürfe aristokratischer Autoritätsbildung, wie sie noch im frühen 5. Jh. für Sulpicius Severus und Paulinus v. Nola bestanden, von da an praktisch keine Bedeutung mehr hatten. ${ }^{64}$ Von einer grundsätzlichen Distanz des Asketen zum kirchlichen Amt ist seitdem kaum noch etwas zu spüren, im Gegenteil: Das Bischofsamt wurde nun, anders als noch bei Martin v. Tours, nicht mehr als potentielles Hindernis asketischer perfectio aufgefasst, sondern als folgerichtiges Ziel eines nach Vollendung strebenden Lebens. ${ }^{65}$ Diese Verankerung asketisch begründeter Autorität im Amt ist dabei auch für Bischöfe wie Sidonius Apollinaris kennzeichnend, der Laien, die in asketischer Vollendung lebten, eine hohe Wertschätzung zubilligte, indem er den mit Tugenden begabten vir sacerdotalis höher schätzte als den sacerdos

62 Für Übersichten vgl. Prinz 1988a, 47-58; Mathisen 1989, 76-85. Der Gründer von Lérins, Honoratus, seit 427 Bischof von Arles, stammte aus einer konsularischen Familie; sein Nachfolger im Bischofsamt, Hilarius v. Arles, war mit Honoratus verwandt und von ihm nach Lérins geholt worden, bevor er 430 Bischof von Arles wurde. Lupus v. Troyes, der 426/7 zum Bischof geweiht wurde, war Schwager des Hilarius und hatte sich vor seiner Bischofsweihe ebenfalls in Lérins aufgehalten. Zur ersten Generation von Lérins zählte ferner Eucherius v. Lyon, der ebenfalls aristokratischer Herkunft war und nach 432 zum Bischof geweiht wurde; seine beiden Söhne, Salonius und Veranus, wurden um die Mitte des 5. Jh.s Bischöfe von Genf und Vence. Für Germanus v. Auxerre, der nach Ausweis seiner Vita ebenfalls aristokratischer Abstammung war und vor seiner Bischofsweihe (vor 429, möglicherweise 418) eine zivile Karriere begonnen hatte, lässt sich keine unmittelbare Verbindung zu Lérins nachweisen; er unterhielt jedoch enge Verbindungen zu Lupus v. Troyes, Hilarius v. Arles und Eucherius v. Lyon. Für das ausgehende 5. Jh. ist auf Caesarius v. Arles zu verweisen, der nach mehrjährigem Aufenthalt in Lérins in den Klerus von Arles aufgenommen und zum Leiter des dortigen Klosters ernannt wurde, bevor er 502 zum Bischof gewählt wurde (die historischen Daten orientieren sich an Heinzelmann 1982, ergänzt durch Mathisen 1989, 279-291; Gillett 2003, 278-282 [Germanus v. Auxerre]; Klingshirn 1994, 18-32, 82-87 [Caesarius v. Arles]).

63 S. o., Anm. 32.

64 Zum historischen Kontext dieser Entwicklung s. ausführlicher u., S. 120-122.

65 Exemplarisch sichtbar in der Vita des Hilarius v. Arles (zur Datierung s. u., Anm. 77), wo die Verleihung der Bischofswürde an Hilarius als die folgerichtige Konsequenz dessen aufgefasst wird, dass ihn seine asketischen Tugenden bereits zuvor „geweiht" und zum Bischof prädestiniert hätten (Vita Hil. 10: consecratur in sacerdotio iam diu virtutum meritis consecratus [...] effectus nomine sacerdos, qui iam pridem erat virtutum decoratus insignibus; ähnlich ebd. 25, 4; vgl. in diesem Sinne auch bereits Hil. Vita Hon. 9, 4). Zur konträren Auffassung der Martinsvita in diesem Punkt s. o., Anm. 58. 
selbst. ${ }^{66}$ Bezeichnenderweise galt nämlich auch für Sidonius ein Vollendeter, selbst wenn er nicht den Rang eines Bischofs einnahm, als ein vir sacerdotalis, als ein bischöflicher Mann: Der Bischof, nicht etwa der unabhängig vom Amt nach Perfektion Strebende, gab somit den ideellen Fluchtpunkt eines asketisch ausgerichteten und heiligen Lebens ab. ${ }^{67}$

Dieser Tendenz widerspricht auch nicht, dass die Äbte einzelner gallischer Klöster im 5. und 6. Jh. neben und zum Teil auch in offener Auseinandersetzung mit den Ortsbischöfen eine vergleichsweise unabhängige Stellung behaupten konnten. ${ }^{68}$ Bei diesen Klöstern handelte es sich nicht mehr um asketische Gemeinschaften, wie sie im ausgehenden 4. und frühen 5. Jh. in Primuliacum, Cimitile oder Marmoutier bestanden hatten: Die zunehmende Verfestigung monastischer Strukturen und die mit dem 5. Jh. einsetzende Regulierung des Mönchtums hatten zur Folge, dass asketische Gemeinschaften sich nicht mehr um einzelne Leiter formten, sondern umgekehrt die Klöster als Institutionen transpersonale Leitungsämter ausformten, die mit Äbten besetzt wurden. ${ }^{69}$ Die vergleichsweise unabhängigen Äbte in Gallien sind damit ebenfalls ein Beleg für die These vom „Aufsaugen“ der Askese durch das Amt, wie es Jochen Martin in treffender Weise als Kennzeichen der Entwicklung im spätantiken Gallien und im Westen des Römischen Reichs insgesamt diagnostiziert hat. ${ }^{70}$

Bemerkenswert ist, dass dieser Prozess einer zunehmenden Besetzung von Bischofssitzen durch Aristokraten unter dezidiert asketischen Vorzeichen erfolgte

66 So Sidonius am Schluss eines Briefes, in dem er sich über die Tugenden des vir illustris Vettius auslässt: plus ego admiror sacerdotalem virum quam sacerdotem (Sidon. epist. 4, 9, 5). Rousseau 1976, 366 erkennt in Sidonius' Äußerung den Anspruch auf eine ,potential sanctity of laymen“; ähnlich auch Heinzelmann 1976, 207 und Mathisen 1994, 213 zu dieser Stelle.

67 Dass das Konzept einer „Laienheiligkeit“ nicht überzeugend ist, betont auch Heinzelmann 1977, 745f. Unter dieser Voraussetzung ist auch die Bemerkung des Sidonius zu lesen, dass Faustus v. Riez, zunächst Abt in Lérins und seit ca. 460 Bischof von Riez, als Bischof nichts von seiner Qualität als Mönch und Abt eingebüßt habe (Sidon. epist. 9, 3, 4). Was auf den ersten Blick aussieht wie eine Paraphrase der sulpicischen Vita Martini (s. o., Anm. 58), erfährt bei Sidonius jedoch eine andere Gewichtung: Für ihn rangierte das Bischofsamt gleichrangig neben dem Kloster als ein asketischer Übungsplatz (Sidon. epist. 9, $9,13)$.

68 Hervorgehoben von Mathisen 1994, bes. 217-219. Sichtbar wird dies u.a. im Konflikt zwischen dem Abt Maximus v. Lérins und dem Bischof Theodor v. Fréjus um die Aufsicht über die in Lérins beheimateten Kleriker, der auf einer eigens einberufenen Synode in Arles zwischen 449 und 461 verhandelt wurde (Conc. Galliae, Bd. 1, 131-134). Zu der verglichen mit den etwa zeitgleich auf dem Konzil von Chalkedon getroffenen Regelungen - unabhängigeren Stellung der Klöster in Gallien vgl. auch Ewig 1979 (1968), 411-414, der die Situation für das 6. Jh. allerdings deutlich zurückhaltender beurteilt.

69 Dass Lérins über eine Regel verfügte, spielte in der erfolgreichen Auseinandersetzung mit dem Bischof von Fréjus eine wichtige Rolle (vgl. Kasper 1991, 32f.). Zur Entwicklung von Klosterregeln im spätantiken und frühmittelalterlichen Gallien vgl. allgemein Diem 2005, 131-154.

70 Martin 1990, 455. 
und zunächst nicht dazu geführt hat, der bischöflichen Repräsentation und Selbstdarstellung einen spezifisch aristokratischen Anstrich zu verleihen. Es war durchaus nicht so, dass in habitueller Hinsicht Konzeptionen Einzug hielten, die „den Bischof mit den Attributen der bestehenden sozialen Ordnung nach dem Modell aristokratischer dignitas definierten". ${ }^{71}$ Exemplarisch fassbar wird dies in einem im Juli 428 verfassten Schreiben des römischen Bischofs Caelestinus, in dem er gallische Bischöfe dafür kritisierte, dass sie nach ihrer Weihe ihren früheren monastischen Habitus beibehalten hätten, um auf diese Weise die Fortführung ihres asketischen Lebenswandels zu demonstrieren. ${ }^{72}$ Diese Kritik, die auch die Warnung davor miteinschloss, Fremde und Auswärtige anstelle bewährter Kleriker aus den jeweiligen Gemeinden zum Bischof zu weihen, ${ }^{73}$ richtete sich nicht etwa gegen umherziehende Wanderasketen, die durch ihre Kleidung die Würde eines zunehmend von Aristokraten geprägten Bischofsamts bedrohten. ${ }^{74}$ Der historische Kontext des Schreibens legt vielmehr nahe, dass Caelestins Ausführungen in Verbindung mit dem Gründer von Lérins, Honoratus, stehen, der erst kurz zuvor zum Bischof von Arles geweiht worden war. ${ }^{75}$ Folgt man dieser Deutung, dann zielte die Polemik gegen die Bischöfe im Mönchsgewand nicht auf namenlose Gyrovagen, sondern vielmehr ins Zentrum einer sich abzeichnenden Verbindung von Aristokratie und Bischofsamt in Gallien, die, wie bereits erwähnt, in Lérins ihren Ursprung hatte.

Dieser Eindruck wird bestätigt, wenn man diejenigen Zeugnisse miteinbezieht, die das Selbstbild aristokratischer Bischöfe im Gallien des 5. Jh.s maßgeblich mitbestimmt haben, nämlich die Vitenliteratur und die Grabinschriften. ${ }^{76}$ Nichts deutet darauf hin, dass asketisch lebende Bischöfen aristokratischer Abstammung wie etwa Hilarius v. Arles, Germanus v. Auxerre oder Lupus v. Troyes einen spezifischen Habitus an den Tag legten, der sie erkennbar von einem Martin v. Tours unterschieden hätte. Es ist keineswegs so, dass sich diese Bischöfe allein auf standesgemäße Formen der Askese wie den Verzicht auf Nahrung, Schlaf, Sexualität und Bildung beschränkten: In der asketischen Stilisierung, die Hilarius v. Arles und andere aristokratische Bischöfe des 5. Jh.s erfuhren, wurde regelmäßig auch auf ihre ärmliche Kleidung und äußere Erscheinung, auf ihre Barfüßig-

71 So aber Jussen 1998, 91f. (s. o., Anm. 37).

72 Caelest. epist. 4, 2 vom 25. Juli 428, adressiert an die Bischöfe der Narbonensis und Viennensis.

73 Caelest. epist. $4,7$.

74 In diesem Sinne Jussen 1995, 684, für den sich Caelestins Bemerkungen gegen eine „anonyme Bewegung von Bischöfen, die um 420 ihre Amtsbrüder durch auffällig ,arme“ Kleidung provozierten“, richteten; vgl. auch ebd., 703f.; dens. 1998, 89f.

75 So übereinstimmend Pietri 1976, Bd. 2, 1029-1031; Mathisen 1989, 97-100; Markus 1990, 200; Kasper 1991, 80; Heinzelmann 1992, 245f.; de Vogüé 2003, 197. Ähnlich auch Prinz 1988a, 48.

76 Dazu grundlegend die Studie von Heinzelmann 1976. 
keit und die nichtstandesgemäße körperliche Arbeit verwiesen, der sie sich unterzogen. $^{77}$

Dass Bischöfe adliger Herkunft in Opposition zu Martin v. Tours dem Bischofsamt einen spezifisch aristokratischen, herrschaftlichen Anstrich verliehen hätten, lässt sich demnach nicht zeigen. Anders als zuletzt von Jussen vertreten, kann auch die Liturgie nicht ohne weiteres als ein Feld angesprochen werden, auf dem sich eine derartige Prägung vollzogen hätte. Zwar ist es richtig, dass die gallischen Bischöfe bereits seit dem frühen 5. Jh. insbesondere im Prozessionswesen gezielt auf Elemente des adventus-Zeremoniells und damit auf traditionelle Kommunikations- und Interaktionsformen zurückgriffen, vermittels derer Machtverhältnisse und soziale Abstufungen innerhalb der Bürgerschaft sichtbar gemacht wurden. ${ }^{78}$ Der pauschale Verweis auf Prozessionen als Möglichkeit, Hierarchien zu visualisieren, verlangt jedoch nach Differenzierung: Ein Bischofsoder Reliquienadventus hatte in dieser Hinsicht ganz andere semantische Konnotationen als Bußprozessionen (letaniae), wie die von Mamertus v. Vienne um 470 eingerichteten rogationes, die sich in Gallien großer Beliebtheit erfreuten und nach dem Vorbild des Mamertus weite Verbreitung fanden. ${ }^{79}$ Als Bußübungen beruhten diese Prozessionen nicht auf der Sichtbarmachung sozialer Differenzierungen, sondern umgekehrt auf deren performativer Überschreibung in Form gemeinschaftlich praktizierter humilitas - ein Gestus kollektiver Verdemütigung,

77 Unter den asketischen Übungen, denen sich Hilarius v. Arles unterwarf, hebt der Verfasser der Hilariusvita das Tragen eines härenen Gewands (cilicium) und die Barfüßigkeit auch im Winter hervor (Vita Hil. 18). Ferner unterzog sich Hilarius nach Ausweis seiner Vita und des auf ihn verfassten Grabepigramms körperlichen Arbeiten (s. u., Anm. 83). Von Germanus v. Auxerre heißt es in dessen Vita, er habe nur über ein Unter- und Obergewand verfügt, zu jeder Jahres- und Tageszeit dieselbe Kleidung getragen und sei wegen seiner ärmlichen Aufmachung kaum als Bischof zu erkennen gewesen (Const. Vita Germ. 4; 32). Lupus v. Troyes unterzog sich einer 25-jährigen Askese, die auch dezidiert sein äußeres Erscheinungsbild bestimmte (Vita Lup. 7: Tragen des cilicium; Benutzung nur einer einzigen Tunika). Zum Stellenwert der Askese für die Lupusvita vgl. die Einschätzung von Ewig 2009 (1978), 16: „es könnte scheinen, daß der Asket und Wundertäter den Autor mehr interessierte als der Bischof Lupus“. Alle drei Viten sind noch im 5. Jh. entstanden: Die Vita des Germanus v. Auxerre wurde zwischen ca. 475 und 480 von Constantius v. Lyon verfasst (van Egmond 2006, 26-30). Bei der Vita des Hilarius v. Arles ist die Verfasserfrage umstritten; davon unabhängig wird sie in etwa dieselbe Zeit datiert wie die Germanusvita (Berschin 1986, 245f.; Jacob 1995 [Einleitung zur Vita Hilarii], 11-13; 19-22: ca. 475-480). Die Vita Lupi datiert Heinzelmann 1976, 110 noch ins ausgehende 5. Jh. (vgl. auch dens. 2010, 59). Gillett 2003, 283 erwägt sogar die Möglichkeit, dass Sidonius Apollinaris in epist. 8, 15, 1 Bezug auf eine Vita des Lupus v. Troyes nimmt; nach dieser Hypothese müsste die Vita Lupi unmittelbar nach Lupus' Tod (478) entstanden sein, da Sidonius sein achtes Briefbuch zwischen 477 und 481 publizierte (vgl. Harries 1994, 8f.).

78 Vgl. Jussen 1995, 689-698; 700f., 708-710; dens. 1998, 105-122, der insbesondere Prozessionen und liturgischen Kommunikationsformen große Bedeutung für eine aristokratische Prägung des Bischofsamts im spätantiken Gallien beimisst. Ähnlich bereits Brown 1981, 98f.

79 Zu den rogationes und ihrer Verbreitung im spätantiken Gallien vgl. neben Jussen 1998, 110f. vor allem Beck 1950, 104-106 und Nathan 1998. 
der auch den Gemeindeleitern selbst wenig Möglichkeiten bot, an traditionelle Zeichensysteme und Muster sozialer Hierarchiebildung anzuschließen, ${ }^{80}$ und bei dem auch die Gestaltungsspielräume von Bischöfen wie Mamertus im Übrigen nicht überschätzt werden dürfen. ${ }^{81}$

Mit Blick auf Martin v. Tours und den gallischen Episkopat das 5. Jh. eine habituelle Differenzierung vornehmen zu wollen und dies mit einer Aristokratisierung des Bischofsamts im 5. Jh. zu verbinden, erscheint dementsprechend problematisch. Rein äußerlich bestanden keine erkennbaren Unterschiede zwischen einem Martin v. Tours in seiner schmutzigen Kleidung und einem Germanus v. Auxerre, der sich als Büßer kleidete und sein Gewand trug, bis es ihm in Lumpen vom Leib fiel. Hier zwischen einem martinischen und einem aristokratischen Habitus unterscheiden $\mathrm{zu}$ wollen, führt nicht weiter. So wurde etwa in Marmoutier, Martins asketischer Niederlassung bei Tours, keine Handarbeit praktiziert, was der dort lebenden Asketengemeinschaft ein ausgesprochen aristokratisches Gepräge verlieh. ${ }^{82}$ Umgekehrt wird von Hilarius v. Arles, der im „Aris-

80 Zum Charakter der rogationes als letaniae und kollektive Bußrituale s. Nathan 1998, 284292; Bailey 2010, 50. Baldovin 1987, 234-238 hat zuletzt mit Blick auf die antiken und spätantiken Bitt- und Bußprozessionen deren kollektiven, die gesamte Gemeinde einbindenden Charakter betont und sie dem Typ einer ,participatory procession“ zugeordnet, im Unterschied zur ,personage-centered procession“", die auf eine bestimmte Person ausgerichtet gewesen sei. Bei einer solchen Differenzierung ist freilich zu berücksichtigen, dass auch ,participatory processions“ in dem Sinne personenzentriert waren, dass in ihnen zentrale Leitfiguren wie Kaiser oder Bischof eine führende Rolle spielten und dabei - im Fall von spätantiken Bußprozessionen - auf Repräsentations- und Kommunikationsformen rekurrierten, die ihre Demut und Bußbereitschaft gezielt zum Ausdruck bringen sollten (wie etwa Barfüßigkeit, das Ablegen von Insignien, Prostrationen u.Ä.). Bußprozessionen waren damit gerade nicht der Ort, an dem soziale Führungsansprüche durch den Rekurs auf traditionelle Muster und Zeichen gesellschaftlicher Statusdistinktion performativ aufrechterhalten wurden. Zur Rolle der gallischen Bischöfe, die in ihrer Funktion als Gemeindeleiter die von der gesamten Gemeinde erwarteten Bußpraktiken und Demutsbezeugungen exemplarisch vorlebten, vgl. Nathan 1998, 288-292. Das Spannungsverhältnis zwischen den auf Bußprozessionen praktizierten Gesten der humilitas und den traditionellen Verhaltenserwartungen an soziale Rollen lässt sich auch in anderen spätantiken Kontexten fassen, etwa mit Blick auf den Kaiser in Konstantinopel im 5. Jh. (vgl. dazu Diefenbach 2002).

81 Herausgestellt von Brown 2000b, 344f., der darauf verweist, dass die Sanktimoniale Genovefa in Paris anlässlich der Belagerung der Stadt durch die Hunnen bereits eine Generation vor Mamertus v. Vienne vergleichbare kollektive Bittgebete organisierte (Vita Genov. 12; zur Datierung der frühesten Redaktion des Textes auf die Zeit um 520 vgl. Heinzelmann/Poulin 1986, bes. 8, 51-57, 115-145, 175-178). Auch Sidonius deutet an, dass Mamertus die rogationes nicht neu ins Leben rief (Sidon. epist. 5, 14, 2 mit Beck 1950, 104).

82 Sulp. Sev. Vita Mart. 10, 6 (ars ibi, exceptis scriptoribus, nulla habebatur); als Alleinstellungsmerkmal des martinischen Mönchtums hervorgehoben von Frank 1997, 38; den aristokratischen Charakter dieses asketischen Lebensstils betont von der Nahmer 1987, 7. Für die Gemeinschaft des Sulpicius Severus in Primuliacum, die sich wohl an dem Vorbild Marmoutiers orientierte (s. o., Anm. 57), können ähnliche Verhältnisse vorausgesetzt werden (van Dam 1985, 135: ,an aristocratic spa“). Auch in Cimitile spielte Handarbeit keine wichtige Rolle (Lienhard 1977, 78). 
tokratenkloster" von Lérins sozialisiert wurde, erwähnt, dass er sich der erniedrigenden, seinen aristokratischen Status sichtbar infrage stellenden körperlichen Landarbeit unterworfen habe. ${ }^{83}$

Bemerkenswerterweise legten demnach gerade auch Bischöfe aristokratischer Herkunft, wie Hilarius v. Arles und Germanus v. Auxerre, eine habituelle Betonung bischöflicher humilitas an den Tag. Diese - nicht nur, aber insbesondere in den Viten fassbare Tendenz als rein genrebedingte und damit unhistorische Topik hagiographischer Stilisierung abzutun ${ }^{84}$ greift in mehrfacher Hinsicht zu kurz. Zum einen spielten die gallischen Bischofsviten für die Formierung eines kollektiven Selbstbildes, das die gallischen Bischöfe von sich entwarfen, eine wesentliche Rolle. ${ }^{85}$ Zum anderen weist die Beobachtung, dass es auch und sogar in erster Linie Aristokraten waren, die dieses bischöfliche Leitbild vorantrieben, zugleich einen Weg zum Verständnis des Phänomens. Was den Soldaten Martin v. Tours und den Aristokraten Germanus v. Auxerre voneinander unterschied, waren nicht die äußeren Formen asketischer Praktiken, sondern deren Wahrnehmung. ${ }^{86}$ Was auch immer die wahren Gründe für die Konflikte Martins mit großen Teilen des gallischen Episkopats waren, entscheidend für die Formulierung der Kritik an Martin war, dass man nicht bereit war, in seiner asketischen Armut eine freiwillige Verzichtleistung zu erkennen. Martin v. Tours, der selbst nicht aus der Oberschicht stammte, wurde von seinen Amtskollegen in seiner schmutzigen Kleidung als mittellos und verächtlich wahrgenommen; dass Germanus v. Auxerre sich als Büßer kleidete, tat demgegenüber seiner Würde keinen Abbruch. ${ }^{87}$

Auch für die habituelle Selbstinszenierung der gallischen Bischöfe bewahrheitet sich damit die Regel, dass Zeichen und Symbole nicht für sich allein stehen, sondern in ihrem Kontext zu sehen sind. Dürftige Kleidung und ungepflegtes Haar durften nicht als Zeichen ökonomischer Armut gelten, sondern mussten als Demonstrationen von humilitas und freiwilliger Armut erkennbar sein. Dementsprechend betonen die Viten des 5. Jh.s auch übereinstimmend, dass es den Bi-

83 Vita Hil. 11 (fatigaretur laboribus, manuum quoque operibus continuis vexaretur) und 15 (quemadmodum salinas expetens automata propriis manibus et sudore confecerit [...] nec antiquorum posset explicare facundia); vgl. ferner Gennad. vir. ill. 70 (corporis sui labore sollicitus). Auch das Epitaph des Hilarius betont, er habe bäuerliche Arbeiten mit der Dienstbereitschaft eines Sklaven ausgeführt (ILCV 1062b = Le Blant 516, 9f.: rustica quin etiam pro Christo munia sumens / servile obsequium non dedignatus adire). Zur Betonung körperlicher Arbeit in den gallischen Bischofsviten s. auch u., Anm. 95. Von den hier angesprochenen Formen schwerer körperlicher Arbeit zu unterscheiden sind Formen der Handarbeit, die eher spirituelle Funktion im Sinne einer Vermeidung von Müßiggang hatten, so z.B. das ununterbrochene Knüpfen von Netzen, das auch mit geistigen Betätigungen verbunden werden konnte (Vita Hil. 15 und 19).

84 Vgl. etwa Brunert 1994, 245; Kritzinger 2009, 201.

85 Vgl. dazu u., S. 132-134.

86 Ähnlich auch Müller 1999, $162 \mathrm{f}$.

87 Const. Vita Germ. 32: licet habitu despicabilis videretur, vultus tamen dignitate cognoscitur (vgl. auch die folgende Anm.). 
schöfen gelungen sei, hinter dem Gestus der Verdemütigung ihre wahre Herkunft zu zeigen. ${ }^{88}$ In letzter Konsequenz bedeutet dies aber auch, dass das „Modell des asketischen Bischofs ${ }^{\text {" } 89}$ nicht nur nicht inkompatibel mit aristokratischer Herkunft war, sondern seine Wirksamkeit geradezu erst aus dieser Voraussetzung bezog: Eine besonders effektive Darstellung von humilitas und Demut war nur im Spannungsverhältnis zwischen sozialem Status und seiner Infragestellung möglich.

Die von Lérins ausgehende Bewegung ist sicher nicht ohne weiteres mit „dem“ gallischen Episkopat im 5. Jh. schlechthin gleichzusetzen. Auch erschöpften sich die Möglichkeiten bischöflicher Selbstdarstellung und Kommunikation nicht in der Zurschaustellung rigoristischer Askese. Ein Bischof wie Sidonius Apollinaris etwa, der gemeinhin als das Paradebeispiel für die nahezu bruchlose Übernahme traditioneller Elitenkultur durch die gallischen Bischöfe aristokratischer Herkunft gilt, setzte andere Akzente und verstand unter Askese durchaus etwas anderes, als es die gallischen Bischofsviten evozieren. ${ }^{90}$ Dennoch bestand auch für Sidonius ein elementarer Zusammenhang von Askese und bischöflicher Autorität, der eine unmittelbare Folge der aristokratischen Prägung des Bischofsamts war ${ }^{91}$ und in diskursiver Hinsicht bestimmend wurde: Die asketische Stilisierung der gallischen Bischöfe war mehr als nur eine ,institutionelle Schwachstelle“92. Sie war

88 Ausweis ihrer aristokratischen Herkunft ist das „edle Antlitz“ der Protagonisten, das als Motiv in der gallischen Vitenliteratur des 5. Jh.s auffällig häufig erscheint; vgl. Hil. Vita Hon. 8; Const. Vita Germ. 24, 32; Vita Hil. 10 mit Kolon 1925, 43f.; Vita Caes. 1, 46; 2, 35. Zum Einzugsbereich der gallischen Bischofsviten kann auch noch Ennod. Vita Epiph. 13f. gezählt werden (Levison 1904, 144f.; Gillett 2003, 169).

89 S. o., Anm. 37.

90 Mathisen 1994, 211 spricht von quasiasketischem Lebensstil. Ein griffiges Beispiel dafür ist Sidonius' Beschreibung der neuen Lebensweise seines Freundes Maximus nach dessen Weihe zum Priester (Sidon. epist. 4, 24, 3f.).

91 Diesen Zusammenhang von Askese und aristokratischer Verdienstethik hat Heinzelmann 1976, 185-211 überzeugend herausgearbeitet. Dass Sidonius damit unmittelbar an Lériner Traditionen anschloss, macht auch Rousseau 1976, 358 deutlich. Bezeichnenderweise kann Sidonius in dem in der vorigen Anmerkung zitierten Schreiben aus der Lebensweise des Maximus nicht erkennen, ob er Mönch, Kleriker oder Büßer geworden ist (Sidon. epist. 4, 24, 4: clam percontor adstantes, quod genus vitae de tribus arripuisset ordinibus, monachum ageret an clericum paenitentemve). Anders Consolino 1979, 170, die die Differenzen zwischen der asketisch-monastischen Bewegung in Lérins und Sidonius Apollinaris stark herausstellt. Bei derartigen Gegenüberstellungen ist zu berücksichtigen, dass die erhaltenen Quellengattungen immer nur selektive Einblicke in „die“ bischöfliche Selbstdarstellung eröffnen - im Wesentlichen Viten und Homilien bei den Lériner Protagonisten, Briefe und Gedichte bei Sidonius Apollinaris. Daraus auf grundlegend unterschiedliche Repräsentationsmuster zu schließen, ist methodisch nicht unproblematisch. Umso wichtiger ist es, Differenzen und Veränderungen innerhalb von Gattungstraditionen herauszuarbeiten (vgl. dazu u., S. 114-116).

92 Jussen 1998, 95. 
vielmehr für die Stilisierung und das Selbstverständnis der Bischöfe von zentraler Bedeutung. ${ }^{93}$

Dieses Bild beginnt sich erst im Laufe des 6. Jh.s zu ändern. Ein sicherer Indikator dafür sind die Bischofsviten, weil hier Veränderungen innerhalb desselben Genres fassbar werden. ${ }^{94}$ Bei der Lektüre der Viten wird deutlich, dass Formen rigoristischer Askese, die das Bild des Bischofs im 5. Jh. prägten, zunehmend an Bedeutung verloren. Während gallische Bischofsviten, die noch dem ausgehenden 5. und frühen 6. Jh. zugerechnet werden können, weiterhin asketische Praktiken hervorheben, die den sozialen Status der Protagonisten sichtbar infrage stellten, ${ }^{95}$ schwächt sich diese Tendenz in der Folgezeit spürbar ab. Zum Teil kommen Viten nun gänzlich ohne asketische Stilisierung aus. ${ }^{96}$ Auch dort, wo die Askese eines Bischofs noch ausführlicher thematisiert wird, wie etwa bei Gregorius v. Langres oder in den beiden Viten des Nicetius v. Lyon, tritt die Betonung der humilitas in den Hintergrund: Die heiligmäßige Vollendung fand ihren Ausdruck in Enthaltsamkeit, Almosen und Gebet, nicht aber in der öffentlichen Zurschaustellung von Demut. ${ }^{97}$ Die Bischofsviten des 6. Jh.s setzten stattdessen er-

$93 \mathrm{Zu}$ Recht betont von Baumgart 1995, 169-176.

94 Eine ähnliche Tendenz wie die Viten zeigen auch die Grabinschriften, doch ist das Quellenmaterial hier deutlich begrenzter. Immerhin ist auffällig, dass von den nur wenigen erhaltenen Inschriften des 5. Jh.s immerhin zwei die körperliche Arbeit betonen (Hilarius v. Arles; Eutropius v. Orange), während im 6. Jh. dieser Aspekt und die humilitas im Allgemeinen praktisch keine Rolle mehr spielen (vgl. Heinzelmann 1976, 169f).

95 In der Vita des Bischofs Eutropius v. Orange kommt insbesondere die harte körperliche Arbeit des Protagonisten ausführlich zur Sprache; vgl. Vita Eutr. (Varin 1849, S. 56f.). Das Grabepigramm des Eutropius stellt dessen Kleidungsaskese heraus (vgl. ILCV $1065=$ Le Blant 503, 10). Von Vivianus v. Saintes berichtet die Vita, er habe sich in ärmlicher Kleidung (humilis habitu) an den Hof von Toulouse begeben (Vita Viv. 4). Die Vita des Caesarius v. Arles zählt zu den letzten Zeugnissen, in denen das Motiv des Lumpen tragenden Bischofs nochmals begegnet (Vita Caes. 2, 42). Die Vita Eutropii wurde kurz nach dessen Tod (ca. 500) von seinem Nachfolger im Bischofsamt, Verus, verfasst (Godding 2001, XXIX). Zur Datierung der Vita Viviani (ca. 520/530) vgl. Dolbeau 1983, 108. Die Vita Caesarii wurde in der Zeit zwischen dessen Tod (542) und dem Jahr 549 geschrieben (Klingshirn 1994, 7).

96 So etwa die Vita des Apollinaris v. Valence (gest. 520/523), die nach dessen Tod vermutlich von einem Zeitgenossen verfasst wurde (Heinzelmann 2010, 57f.). Auch für sämtliche Viten des Venantius Fortunatus (530/540-kurz nach 600) gilt, dass in ihnen der Askese kein besonderer Stellenwert zugemessen wird (Collins 1981, 115; ebenso Coates 2000, 1124f. mit einer Einordnung des hagiographischen CEuvres des Venantius in die Tradition der gallischen Viten).

97 Gregor v. Langres ist bei Greg. Tur. vit. patr. 7, prol. zwar ein vir egregiae sanctitatis, der sich durch eine außerordentliche humilitas auszeichnet. Diese Demut äußert sich jedoch nicht in einer zeichenhaften Infragestellung von sozialem Status wie Kleidungsaskese, Barfüßigkeit oder körperlicher Arbeit, sondern in Fasten, Almosen, Gebet und Nachtwachen (ebd. 2). Von Nicetius v. Lyon berichtet dessen 589 verfasste Vita, er habe anderen die Füße gewaschen (Vita Nic. 4); Gregor v. Tours ergänzt, Nicetius habe auch nach seiner Priesterweihe gemeinsam mit den Sklaven körperliche Arbeiten verrichtet (Greg. Tur. vit. patr. 8, 2). Allerdings fehlen in beiden Viten Hinweise auf Kleidungsaskese; Heinzelmann 
kennbar andere Akzente. Für Venantius Fortunatus und Gregor v. Tours bemaß sich die sanctitas eines Bischofs weniger an der Vollkommenheit seiner asketischen Lebensführung als vielmehr an der Macht, die der Heilige durch seine Wunder unter Beweis stellte, ${ }^{98}$ eine Macht, die nicht selten auch unmittelbar gegenüber weltlichen Machthabern demonstriert wurde. ${ }^{99}$ Anders als in den Viten des 5. Jh.s bezogen die Protagonisten der hagiographischen Literatur im ausgehenden 6. Jh. ihr Ansehen demnach nicht aus der (wenn auch nur vordergründigen) Negierung von sozialem Status, sondern aus der Fähigkeit, diesen Status sichtbar zur Geltung zu bringen. ${ }^{100}$

Insbesondere der Rekurs auf die Liturgie spielte in diesem Zusammenhang eine sehr wichtige Rolle. Dies zeigen vor allem die Heilwunder, die von den Protagonisten der Bischofsviten und libelli miraculorum ${ }^{101} \mathrm{zu}$ ihren Lebzeiten und vor allem nach ihrem Tod gewirkt wurden, und die im Rahmen der hagiographischen Wundererzählungen einen besonders breiten Raum einnehmen. ${ }^{102}$ Zum einen boten die kirchlichen Festtage und die an ihnen gefeierte Liturgie einen äußeren Rahmen, innerhalb dessen sich zahlreiche dieser Wunderberichte ereigneten. ${ }^{103}$ Zum anderen nahmen die Heilungen performativ Bezug auf liturgische Handlungen und Rollen des Bischofs und brachten damit ein regelrechtes „reenactment“" bischöflicher Tätigkeiten im Rahmen der Liturgie zur Auffüh-

1976, 168-170 wertet dies als Indiz dafür, dass „für das 6. Jahrhundert gewisse Veränderungen der asketischen Konzeption anzunehmen sind“. In der ca. 585 von Dynamius verfassten Vita des Maximus v. Riez wird die härene Tunika nur noch als Untergewand getragen (Dynam. Vita Maxim. 15; ähnlich auch schon Const. Vita Germ. 4, wo aber der asketische Gesamthabitus deutlich stärker betont wird); in den Viten des 7. und 8. Jh.s. verschwindet das cilicium dann unter der Purpurrobe, die Bischöfe wie Eligius v. Noyon oder Audoin v. Rouen als Zeichen ihrer weltlichen Würde tragen (Vita Elig. 1, 12; Vita Aud. 3).

$98 \mathrm{Zu}$ Recht hervorgehoben von Consolino 1979, 79f.

99 Zur vielschichtigen Rolle dieser bischöflichen Strafwunder s. u., S. 127-129.

100 Diese Tendenz findet ihre Fortsetzung in den Viten des 7. und 8. Jh.s, die den sozialen Status der Protagonisten in noch deutlicherer Form thematisierten (s. u., Anm. 130).

101 Sammlungen von Wundern, die sich während der Feste an den Gräbern der Heiligen ereigneten, wurden in Gallien nachweislich seit dem ausgehenden 5. Jh. angelegt. Sie wurden nur selten als eigenständige libelli miraculorum publiziert, fanden aber Eingang in die zahlreichen Viten, die in merowingischer Zeit verfasst wurden (vgl. Heinzelmann 1981; zur umfangreichen Vitenproduktion s. u., Anm. 173).

102 Zur Prominenz der Heilwunder im hagiographischen Euvre Gregors v. Tours vgl. Graus 1965, 51 und die Übersicht bei Weidemann 1982, Bd. 2, 195-197.

103 Besonders deutlich ist dies in den libelli miraculorum des Gregor v. Tours fassbar; vgl. allgemein Brown 1981, 100; van Dam 1993, 90. Ausführlich Heinzelmann 1981, 239f., der auf der Grundlage der Bücher 2 bis 4 der virtutes Martini des Gregor v. Tours eine Aufschlüsselung der Wunder vornimmt, die sich zwischen 574 und 593 anlässlich der einzelnen Kirchenfeste in Tours ereigneten und protokolliert wurden. Die an Festtagen und während der Liturgie bewirkten Heilwunder nehmen auch in der hagiographischen Überlieferung der Bischofsviten breiten Raum ein; vgl. die allgemeine Bemerkung in Greg. Tur. glor. conf. 88; für weitere Beispiele vgl. z.B. Vita Caes. 2, 16f., 20f., 29; Dynam. Vita Maxim. 16; Greg. Tur. vit. patr. 8, 4; glor. conf. 28; 93; 94. 
rung. ${ }^{104}$ In deutlich stärkerem Maße, als es bei den Wundererzählungen in der hagiographischen Literatur des 5. Jh.s der Fall ist, gewannen die Heilwunder damit eine spezifisch liturgische Färbung. ${ }^{105}$ Auch für diese liturgische Färbung ist dabei charakteristisch, dass die Demonstration von humilitas aus ihr zwar nicht verschwindet, ${ }^{106}$ aber doch in den Hintergrund tritt: Die Wunderberichte akzentuierten vielmehr die Rolle des Bischofs als Richter über Büßer und Besessene ${ }^{107}$ und die Integration und Wiederherstellung der Gemeinde, die sich immer wieder neu um ihren bischöflichen Leiter formierte. ${ }^{108}$

Der Hinweis auf die Liturgie und auf die Heiligenfeste, die den äußeren Handlungsrahmen für die Krankenheilungen bildeten (und an denen auch die Viten verlesen wurden, die die Erinnerung an das Wirken der Heiligen lebendig hielten), ${ }^{109}$ lenkt den Blick von den Texten bereits auf den historischen Kontext, innerhalb dessen sich diese charakteristischen Veränderungen innerhalb eines so toposbeladenen und konservativen Genres wie der Hagiographie vollzogen. Auch wenn die Quellen in die Entwicklung der Liturgie im spätantiken Gallien nur sehr selektive Einblicke gewähren, ${ }^{110}$ deutet vieles darauf hin, dass der Wandel des hagiographischen Leitbildes etwa in dieselbe Zeit fällt, in der auch eine Durch-

104 Dazu treffend Collins 1981, 112-114, der mit Blick auf die Heilungen von einem „constant process of liturgical initiation or re-initiation into the community“" spricht (ebd., 113). Zustimmend Coates 2000, 1129. Vgl. auch u., Anm. 157.

105 Auch in der Vita Martini oder der Vita Germani begegnen zahlreiche Wunderberichte, sie sind dort aber in narrative Zusammenhänge eingebunden, die die Bewährung des Protagonisten in der Auseinandersetzung mit dem teuflischen Widersacher thematisieren (Vita Martini) oder seinen Erfolg in länger andauernden Verhandlungen (Vita Germani). Schon die libelli miraculorum lösten derartige narrative Zusammenhänge auf, indem sie serielle Wunderreihen aneinanderfügten, die nicht biographisch oder historisch eingebettet waren, sondern allein durch den Ort, an dem sie erfolgten, miteinander verbunden wurden (s. o., Anm. 103). Zur Serialität und Austauschbarkeit der Wunder in der hagiographischen Literatur des 6. Jh.s vgl. auch die Bemerkungen von Consolino 1979, 74f. über das 2. Buch der Vita Caesarii, das eine stereotype Auflistung von Wunderberichten enthält.

106 Vgl. z.B. Ven. Fort. Vita Germ. Paris. 6.; Ven. Fort. Vita Hil. 12 (44f.). Die dort geschilderte prostratio der Protagonisten verweist auf den Kontext der Bußliturgie, in deren Verlauf auch der leitende Liturge Prostrationsgesten vollzog, die die Bußfertigkeit der Paenitenten unterstützten (s. Poschmann 1928, 16f., 94), letztlich jedoch als Richter über den Büßer fungierte und damit eine dezidiert hierarchische Position einnahm (vgl. auch u., Anm. 162).

107 Brown 1981, 108f. Vgl. dazu auch u., S. 128f.

$108 \mathrm{Zu}$ diesem Aspekt vgl. die überzeugende Deutung von Brown 1977 (1982), 235-249, der auf die durch die Dämonenaustreibungen und Krankenheilungen bewirkte Wiedereingliederung der Besessenen und Kranken in die Gemeinde verweist und diesen Vorgang als ein „reenactment" des consensus universorum deutet, der bei der Wahl des Bischofs erstmals in ritualisierter Form zur Aufführung gekommen war. Zur fortbestehenden Beteiligung des populus an der Bischofserhebung auch in merowingischer Zeit vgl. Müller 2003, 279-284.

109 Zur liturgischen Lesung von Märtyrerakten und Heiligenviten in Gallien vgl. grundlegend de Gaiffier 1954, 145-151; weitere Belege stellt van Uytfanghe 1985, 59f.; ders. 2005, $171-176$ zusammen.

110 Immer noch grundlegend Beck 1950, 93-154; vgl. ferner Hen 1995. 
dringung der sozialen Zeit durch die Liturgie zunehmend vorangetrieben wurde. Als Gradmesser für eine derartige Durchdringung kann, mehr noch als die wachsende Zahl von Heiligenfesten innerhalb des liturgischen Jahreszyklus, die täglich an den Kirchen und Märtyrerbasiliken gefeierte Stundenliturgie dienen. Sie hatte nicht nur eine immer stärkere Einbindung der Heiligenverehrung in die Liturgie und eine entsprechende Kontrolle der Kultstätten durch den Klerus zur Folge, ${ }^{111}$ sondern ließ den Kleriker auch in der allgemeinen Wahrnehmung mehr und mehr als Liturgen und Kultdiener erscheinen ${ }^{112}$ und trug dazu bei, die Liturgie als Zeichensystem innerhalb der öffentlichen Kommunikation zu verankern. ${ }^{113}$ Wesentliche Impulse gingen hier von Caesarius v. Arles aus, der nicht nur mit Blick auf seine eigene Gemeinde einen Ausbau der kirchlichen Stundenliturgie betrieb, sondern auf der Synode von Agde (506) auch umfassende kirchenpolitische Initiativen ergriff, um eine Vereinheitlichung der Liturgie im westgotischen Gallien zu erreichen. 114

Bemerkenswert ist in diesem Zusammenhang, dass diese Liturgisierung nicht mit einer habituellen Ausdifferenzierung des Klerus einherging: Die Kleriker verfügten über keine spezifische Kleidung, die sie in der öffentlichen Wahrnehmung deutlich sichtbar von Mönchen unterschieden hätte. ${ }^{115}$ Die Synodalbeschlüsse der gallischen Synoden wirkten einzig darauf hin, den Kleiderluxus des Klerus einzudämmen und eine asketische Grundhaltung zu verdeutlichen. ${ }^{116}$ Die

111 Um die Mitte des 5. Jh.s hatte die Sanktimoniale Genovefa noch ungestört Exorzismen in der von ihr gestifteten Dionysiusbasilika vorgenommen (Vita Genov. 30).

112 Diefenbach 2007, 418-424.

113 So auch van Dam 1985, 277-300, der hinsichtlich der Frage, in welcher Weise die Liturgie den Deutungs- und Wahrnehmungshorizont der historischen Akteure beeinflusste, der liturgischen Strukturierung des Tages hohe Bedeutung zumisst. Hen 1995, 71-74 schränkt relativierend ein, dass das Gros der Bevölkerung nur an hohen Festtagen am Gottesdienst teilgenommen habe. Die kollektive Wahrnehmung einer liturgischen Rhythmisierung der Zeit blieb davon jedoch unberührt, etwa durch den Umstand, dass seit dem 6. Jh. Glocken den Beginn der liturgischen Feiern anzeigten und damit die Zeit für alle hörbar einer liturgischen Struktur unterwarfen (vgl. Greg. Tur. hist. 6, 25 mit van Dam 1985, 299).

114 Zu Caesarius' Initiativen vgl. Klingshirn 1994, 92f., $101 \mathrm{f}$.

115 Vgl. Lutterbach 1995, 118-122, der darauf hinweist, dass entsprechende Abgrenzungsversuche erst seit dem ausgehenden 8. Jh. unternommen wurden. Dies betrifft wohlgemerkt nur die außerhalb der Liturgie getragene Kleidung der Kleriker. Die liturgische Gewandung selbst begann sich in dieser Zeit stärker auszudifferenzieren, auch wenn diese Entwicklung nicht überbetont werden sollte. Von einigen spezifischen liturgischen Abzeichen abgesehen, entsprachen die Grundformen (Albe und casula) gängigen spätantiken Gewandtypen (langärmlige Talartunika und paenula), wie sie von den Klerikern auch außerhalb der Liturgie getragen wurden (Braun 1907, 774f.; zur spätrömischen Alltagskleidung von Rummel 2007, 89-92). Gegen Kritzinger 2009, 195-228 ist damit an einem engen Zusammenhang zwischen liturgischer und außerliturgischer Kleidung des Klerus festzuhalten.

116 Nach den Statuta Ecclesiae antiqua, die - vermutlich um 475 verfasst - die ältesten gallischen Synodalregelungen zur Klerikerkleidung enthalten, sollten die Kleidung des Klerus und die Tonsur der professio der Kleriker entsprechen - ein Ausdruck, der in dieser Zeit in gleicher Weise auch auf das Gelübde von Mönchen oder Paenitenten bezogen werden 
Askese verschwand also nicht, wurde aber habituell gleichsam domestiziert. Als regelrechtes Standesabzeichen des Klerus und der Religiosen im weiteren Sinne verlor sie den Charakter, den die Askese in den Bischofsviten des 5. Jh.s hatte: Ein asketischer Habitus war nun keine zeichenhafte Herausforderung der sozialen Ordnung mehr, sondern das Attribut einer neuen Ordnung, in der die Askese nicht mehr als Ausdruck einer individuellen Bewährung, sondern als kollektives Kennzeichen einer Gruppe fungierte.

Am Ende des 6. Jh.s war diese Entwicklung, deren Anfänge sich bis in das letzte Viertel des 5. Jh.s zurückverfolgen lassen, ${ }^{117}$ wohl weitgehend vollzogen. Als König Chilperich I. im Jahr 576 seinen Sohn Merowech politisch kaltstellte und in ein Kloster verbannte, verordnete er ihm zuvor die Tonsur und die „Kleider, die der Klerus gewöhnlich trägt“". ${ }^{118}$ Bemerkenswert ist, dass die Kleidung der Kleriker hier und auch in anderen zeitgleichen Zeugnissen ${ }^{119}$ zugleich als ein „ethnischer“ Marker fungiert bzw., wie die Forschungen der letzten Jahrzehnte klargemacht haben, die Abgrenzung von einem militärisch geprägten habitus barbarus betont, der bereits seit dem 5. Jh. das Kennzeichen einer neuen Oberschicht in Gallien wurde. ${ }^{120}$ Das gibt Anlass, nochmals nach dem weiteren kulturellen Rahmen der Umprägung des Bischofsamts zu fragen: Warum dominierte in der hagiographischen Literatur des 6. Jh.s nicht mehr der bischöfliche Asket, der sich durch seine rigorose Askese auszeichnete, sondern eine Konzeption von Heiligkeit, die eine Sichtbarmachung von sozialem Status betonte, dies durch den

konnte (Stat. Eccl. Ant. 25f. [XLIVf.] = Conc. Galliae, Bd. 1, 171. Zur professio s. Uhalde 2008, 100). Ähnliches gilt auch von der religio, die 506 auf der Synode von Agde als Maßstab für die Kleidung der Kleriker bemüht wurde (Conc. Agath., c. $20=$ Conc. Galli$a e, \mathrm{Bd} .1$, 202). Bezeichnenderweise sah sich Sidonius etwa zur selben Zeit, in der die Statuta Ecclesiae antiqua zusammengestellt wurden, anhand der äußeren Erscheinung seines Freundes Maximus nicht in der Lage zu entscheiden, ob er einen Kleriker, Mönch oder Büßer vor sich hatte (s. o., Anm. 91).

117 Vgl. die vorige Anm.

118 Greg. Tur. hist. 5, 14: Merovechus [...] tunsoratus est, mutataque veste, qua clericis uti mos est, presbiter ordenatur.

119 Auf der Synode von Mâcon (581/583) wurde den Klerikern verboten, einen Feldherrnmantel (sagum) sowie weltliche Kleidung und Schuhwerk zu tragen (Conc. Mat. I, c. $5=$ Conc. Galliae, Bd. 2, 224). Mit dem sagum wird auf den habitus barbarus Bezug genommen, die Kleidung der Militäreliten und barbarischen Könige im spätantiken Gallien (vgl. auch die folgende Anm.). Zum sagum als militärischem Kleidungsattribut vgl. Kritzinger 2009, $209 f$.

120 Zum „barbarischen“ Habitus der spätantiken Militäreliten s. zuletzt von Rummel 2007, bes. 401-409 und seinen Beitrag in diesem Band. Die Ansätze, den habitus barbarus nicht als Ausdruck ethnischer Identität, sondern als Statuszeichen einer neuen Elite zu verstehen, reichen bis in die späten 1970er Jahre zurück (zur Forschungsgeschichte vgl. Fehr 2010, 646-657). Für die klerikale Kleidung als Distinktionsmerkmal gegenüber einer nichtzivilen Elite vgl. auch Trichet 1986, 37-41, der darin allerdings die Gegensätze zwischen der „römischen“ Kleidung des Klerus und der „barbarischen“ Tracht der germanischen Eroberer hervorhebt. Sieht man von dieser ethnischen Zuordnung und dem damit implizierten Verständnis von einer Auflösung des Imperiums durch barbarische Einfälle ab, erscheint mir die Einschätzung im Kern zutreffend. 
verstärkten Rekurs auf liturgische Kommunikationsformen zum Ausdruck brachte und die Askese habituell weitgehend domestizierte?

Die Erklärung dafür dürfte in den sozialen und habituellen Umbrüchen zu suchen sein, die sich im spätantiken Gallien vollzogen. Die gestische Erniedrigung der eigenen Person, aus der die öffentliche Artikulation von humilitas ihre Wirkung erzielte, war zugleich ein prekäres Spiel mit sozialen Rollen und Verhaltenserwartungen, das nur funktionierte, wenn das Zeichenhafte der Demut unmittelbar einsichtig und die soziale Position des Betreffenden nicht hinterfragt war. Die Voraussetzungen dafür dürften spätestens seit dem ausgehenden 5. Jh. in mehrfacher Hinsicht deutlich brüchiger geworden sein. In dieser Zeit verschwanden die letzten Optionen, eine politische Zugehörigkeit zum römischen Imperium, an der weite Teile der gallischen Oberschicht bis zuletzt festgehalten $\mathrm{zu}$ haben scheinen, aufrechtzuerhalten. ${ }^{121}$ Unmittelbar damit einhergehend verloren auch habituelle Zeichen, die auf eine römische Identität verwiesen, ihre kanonische Geltung: ${ }^{122}$ Es setzten sich nun rasch neue Stile durch, die in anderer Weise den Anspruch auf sozialen Status artikulierten. ${ }^{123}$

Paradoxerweise hatten diese Vorgänge Konsequenzen nicht nur für die habituelle Demonstration von Status, sondern auch für dessen Infragestellung. In einer Zeit, in der der politische und soziale Führungsanspruch der traditionellen Eliten ebenso auf dem Prüfstein stand wie die traditionellen habituellen Muster, mit denen dieser Führungsanspruch artikuliert wurde, war es keine Option mehr, Heiligkeit durch eine radikale Demonstration von humilitas und eine (wenn auch nur vordergründige) Negierung von sozialem Prestige unter Beweis zu stellen. In dem Maße, in dem die Zuweisung von Status keine Selbstverständlichkeit mehr war, bestand die Gefahr, damit eine Sprache zu sprechen, die missverständlich war - bezeichnenderweise kam es in dieser Umbruchssituation insgesamt zu einem verstärkten Rekurs auf Zeichen, die besonders geeignet waren, sozialen Status auf eher plakative Weise durch Zurschaustellung von Reichtum zu demonstrieren. ${ }^{124}$ Auch die Liturgisierung des Klerus und die Umprägung der Askese von einem Kennzeichen individueller Verdemütigung zu einem Amtsattribut sind in diesem Kontext zu sehen. Es kam darauf an, sich in einer gesellschaftlichen Stellung zu behaupten und dies auch habituell durchzusetzen.

Blicken wir damit nochmals zurück auf die eingangs skizzierte Auffassung, wonach in Gallien seit dem 5. Jh. ein dezidiert aristokratisches Bischofsbild ge-

121 Zur Schärfe dieser historischen Zäsur und zu ihren habituellen Konsequenzen für eine Aufrechterhaltung von „Romanness“ vgl. den Beitrag von John F. Drinkwater in diesem Band.

122 Auf diesen Aspekt weist auch Jussen 1995, 698f., 710-712; ders. 1998, 129f. hin.

123 S. o., Anm. 35.

124 Darauf macht von Rummel 2007, 382f. unter Verweis auf reich ausgestattete Prunkgräber aufmerksam. Ähnlich auch Halsall 1995, 250f., der im nördlichen Gallien eine signifikante Zunahme von kostbaren und militärischen Status demonstrierenden Grabbeigaben seit dem 5. Jh. verzeichnet; Effros 2003, 118. 
genüber rigoros asketischen Entwürfen eines bischöflichen Habitus durchgesetzt worden sei, das im Verlauf des 6. Jh.s die Grundlage für eine konzeptionelle Neuordnung der Gesellschaft durch die Liturgie gebildet habe. Es sollte deutlich geworden sein, dass diese Auffassung der spezifischen Konfiguration von Askese, Liturgie, Bischofsamt und aristokratischem Selbstverständnis im spätantiken Gallien nicht gerecht wird. Vielmehr bietet es sich an, diese Parameter in ein alternatives Koordinatensystem zu bringen, das eher geeignet ist, die historische Entwicklung in dieser Transformationszeit zu erfassen.

Grundsätzlich trifft zu, was bereits Friedrich Prinz in seiner grundlegenden Studie zum Mönchtum in Gallien herausgearbeitet hat: Das martinische Mönchtum und die von Lérins ausgehende asketische Bewegung bildeten voneinander weitgehend unabhängige Strömungen, hinter denen auch unterschiedliche Konzepte asketischer Autorität standen. ${ }^{125}$ Freilich haben wir es nicht etwa mit einem Konflikt zwischen aristokratischen und nichtaristokratischen, sondern vielmehr mit divergierenden aristokratischen Konzeptionen im Verhältnis von Askese und Autorität zu tun. Auf der einen Seite standen asketisch lebende Aristokraten ohne eine enge Bindung an das kirchliche Amt wie Sulpicius Severus oder Paulinus v. Nola, auf der anderen Seite Angehörige der Senatsaristokratie, für die ein asketisches Leben mit einer stärkeren Integration in den Klerus verbunden war und seine Vollendung in der Erlangung des Bischofsamts fand, wie z.B. diejenigen Bischöfe, die aus der asketischen Gemeinschaft von Lérins hervorgingen. ${ }^{126}$

Aus der durch Personen wie Sulpicius, Paulinus, aber auch den frühen Augustinus ${ }^{127}$ repräsentierten asketischen Bewegung entwickelte sich keine echte Konkurrenz zum Bischofsamt. Die Genannten stehen vielmehr exemplarisch für eine vergleichsweise kurze Phase im ausgehenden 4. und frühen 5. Jh., in der - in den Worten von Peter Brown - ,gebildete christliche Laien mehr Einfluss als zu jeder früheren Zeit ausübten“. ${ }^{28}$ Unter entwicklungsgeschichtlichen Gesichtspunkten erwies sich jedoch nicht diese Form asketischer Autorität, sondern deren

125 Auf die Unterschiede zwischen martinischem und Rhone-Mönchtum hat nachdrücklich Prinz 1988a, 19-117 aufmerksam gemacht, der allerdings zu stark von regelrechten Gegensätzen ausgeht. Man wird beiden Richtungen eher dadurch gerecht, dass man sie als unterschiedliche Entwicklungsphasen der asketisch-monastischen Strömung im spätantiken Gallien versteht; in diesem Sinne Fontaine 1973, 105-113; Heinzelmann 1976, 193 199. Die Unterschiede stellen auch Brunert 1994, 178-180; Kasper 1991, 211; Frank 2010, 43 heraus. Atsma 1983, 72; Beaujard 2000, 114f. sehen hingegen keine größeren Differenzen zwischen martinischem und lerinischem Mönchtum. Ähnlich auch Mathisen 1989, der hinter den unterschiedlichen personalen Konstellationen um Martin v. Tours und die Bischöfe von Lérins weniger divergierende Konzepte von Askese und Autorität vermutet als vielmehr rivalisierende Netzwerke aristokratischer Faktionen.

126 S. o., Anm. 45 und 62. Zu der für Gallien eigentümlichen Bereitschaft von Mönchen, sich zu Klerikern weihen zu lassen, vgl. auch Mathisen 1994, 213-216.

$127 \mathrm{Zu}$ Augustinus' früher Hinwendung zur Askese und dem damit verbundenen gemeinschaftlichen Leben auf dem Landgut von Augustinus' Freund Verecundus in Cassiciacum vgl. Zumkeller 1968, 42-51.

128 Brown 2000a, 299. 
in Lérins praktizierte Bindung an das Amt als zukunftweisend. In Paulinus v. Nola den ,ersten Adelsheiligen“ Europas zu sehen, ${ }^{129}$ ist dementsprechend verfehlt. Abgesehen davon, dass der Begriff des „Adelsheiligen“ ein hagiographisches Leitbild des 7. Jh.s bezeichnet und nicht einfach auf jede beliebige Erscheinungsform aristokratischer Selbstheiligung übertragen werden sollte, ${ }^{130}$ suggeriert er - darin dem Begriff der ,Bischofsherrschaft' vergleichbar - irreführende historische Kontinuitätslinien. Historisch waren Aristokraten wie Paulinus und Sulpicius Severus, die in der Lage waren, eine asketische Autorität außerhalb des Bischofsamts zu begründen, durchaus keine zukunftsweisende Erscheinung, sondern ein Auslaufmodell. Sie waren das Produkt einer intensiven, aber vergleichsweise kurzlebigen asketischen Bewegung, die im Westen des Römischen Reichs zu einer Reihe von spektakulären Konversionen in den höchsten Kreisen der römischen Reichsaristokratie führte, intensive Debatten über Formen und Wert der Askese zur Folge hatte und außer mit Sulpicius und Paulinus auch mit Namen wie Melania d.Ä., Hieronymus oder Rufinus verbunden ist.

Dass dieser Bewegung in Gallien keine Zukunft beschieden war, lag an den veränderten Ausrichtungen und Strategien der Oberschicht, die seit den 420er Jahren mit der verstärkten Übernahme des Bischofsamts - zumindest in Teilen von Gallien $^{131}$ - auch Formen der rigorosen Askese in das bischöfliche Leitbild integrierte. Diese Hinwendung der Aristokratie zum Bischofsamt war im Wesentlichen das Ergebnis sich wandelnder historischer Rahmenbedingungen: ${ }^{132}$ Die

129 So Mratschek 2002, 598-602 als Bilanz ihrer Monographie zu Paulinus v. Nola.

130 Dies kann als das Ergebnis langer Diskussionen um den maßgeblich von Karl Bosl und Friedrich Prinz geprägten Begriff des „Adelsheiligen“ gelten. Bosl 1965 und Prinz 1973b hatten die in den Bischofsviten des 7. Jh.s regelmäßig hervorgehobene adlige Herkunft der Protagonisten als ein Charakteristikum der späten Merowingerzeit aufgefasst und als Aufrechterhaltung einer germanischen „Geblütsheiligkeit“ unter christlichen Vorzeichen gedeutet. Das Konzept ist - abgesehen von grundsätzlichen Vorbehalten gegen die Existenz einer germanischen Geblütsheiligkeit - vor allem in zweierlei Hinsicht kritisiert worden: Zum einen begegnet der Verweis auf die adlige Herkunft keineswegs erst in den spätmerowingischen Viten, sondern ist bereits seit dem 5. Jh. für die gallische Vitenliteratur charakteristisch (Heinzelmann 1976, 185f.; ders. 1990, 117f.; van Uytfanghe 2007, 46); zum anderen kann eine Verbindung von Vitenproduktion und Selbstheiligung bereits für das 6. Jh. vorausgesetzt werden (Brown 1976 [1982], 187; Wood 2000, 422). Dennoch bleibt festzuhalten, dass in den spätmerowingischen Viten seit dem 7. Jh. die Protagonisten ihre Zugehörigkeit zur herrschenden Schicht auch habituell offen zu erkennen geben: Sie tragen keine ärmlichen Kleider bzw. verbergen sie, wie Eligius v. Noyon, unter kostbaren weltlichen Gewändern (s. o., Anm. 97), nehmen umfassende Bauprogramme vor und sind in weltliche Auseinandersetzungen und Machtkämpfe verwickelt (vgl. dazu Fouracre 1990). In diesem Sinne kann der Begriff des merowingischen „Adelsheiligen“ auch weiterhin verwendet werden - als Ausdruck eines gewandelten hagiographischen Leitbildes, das für das 7. und 8. Jh. spezifisch und aus ebenso spezifischen historischen Voraussetzungen heraus erwachsen ist (vgl. die revidierenden Bemerkungen von Prinz 1988a, 656f.; ähnlich auch Fouracre/Gerberding 1996, 48f.).

$131 \mathrm{Zu}$ den Einschränkungen s. o., Anm. 32.

132 In diesem Zusammenhang sei auch nochmals betont, dass die asketische Bewegung im Umfeld von Martin v. Tours und die von Lérins ausgehende Bindung der Askese an das 
politischen Umwälzungen seit dem Beginn des 5. Jh.s hatten erhebliche Auswirkungen auch auf die politischen Optionen der gallischen Aristokratie. Deren Ambitionen wurzelten - wie John F. Drinkwater zeigt - fest in der civitas und begriffen das römische Gallien allenfalls als eine Projektionsfläche, nicht jedoch als eigenständige politische Handlungseinheit. ${ }^{133}$ Ausschlaggebend für das zunehmende Interesse der Aristokraten am Bischofsamt war, dass es einen institutionellen Rahmen bildete, der diesem Horizont entsprach: Es verankerte den Amtsinhaber gleichzeitig in der civitas und band ihn - durch die synodalen Strukturen zugleich in regionale Netzwerke ein. ${ }^{134}$ Durch diese spezifische Verbindung von lokaler Autorität und regionaler Vernetzung, die sich auch in den Kommunikationsbeziehungen dieser klerikalen Elite widerspiegelt, ${ }^{135}$ bot das Bischofsamt solchen Ambitionen auf eine weitgehend unabhängige lokale Herrschaftsstellung in einem regionalen Kontext ein Idiom, das in der traditionellen politischen Sprache römischer imperialer Ordnung so gar nicht verfügbar war. ${ }^{136}$

Freilich darf man deren zähe Beharrungskräfte nicht unterschätzen. Erst im ausgehenden 5. Jh. erloschen die letzten Bemühungen gallischer Aristokraten, Karrieren in der römischen Administration zu machen. Und erst jetzt, in einer Umbruchszeit, in der ein jahrhundertealtes Zeichensystem sozialer Ordnung seine Evidenz verlor, mehren sich die Anzeichen dafür, dass auch mit Blick auf das Bischofsamt habituelle Umprägungen einsetzten. Die Askese wandelte sich von einer individuellen Auszeichnung zu einem kollektiven Standesattribut des Klerus

Amt keine grundsätzlichen Gegensätze darstellen, sondern eher als komplementär anzusehen sind (s. auch o., Anm. 125).

133 Vgl. den Beitrag von John F. Drinkwater in diesem Band.

134 Diese beiden Aspekte werden in der Forschung meist unabhängig voneinander gesehen, machen jedoch erst in ihrem Zusammenspiel das Spezifikum aus. Zum Gesichtspunkt der regionalen (und auch überregionalen) Verflechtung und Identitätsstiftung vgl. Brown 1981, 89-91, 93-95; Jussen 1995, 688f. Die lokale Verortung der Bischöfe betonen stärker Beaujard 1991; Fouracre 1999, 155f.; Bailey 2003.

135 Die Vita Martini des Sulpicius Severus war ein Text, der im gesamten Mittelmeerraum zirkulierte (s. o., Anm. 41 und Uran. epist. ob. Paul. 3 mit der Feststellung, dass die Vita Martini ab omnibus legitur. Van Uytfanghe 2005, 166 möchte darin einen Hinweis darauf erkennen, dass die Vita nicht nur von einem gebildeten Publikum, sondern von breiten Schichten gelesen wurde; gemeint ist jedoch die universale geographische Verbreitung der Vita). Im Unterschied zur Vita Martini richteten sich die Bischofsviten des späteren 5. und des 6. Jh.s an ein regionales Publikum (Müller 1999, 146; zur Regionalisierung der gallischen Epistolographie im 5. Jh. und der vergleichsweise engen Begrenztheit der kommunikativen Netzwerke vgl. Mathisen 1981, bes. 106). Diese zunehmende Regionalisierung der literarischen Öffentlichkeit schlägt sich auch in den hagiographischen Texten selbst nieder: Die beiden einzigen gallischen Viten, die von einer Reise der Protagonisten in den Osten berichten (Vita Iust. 2-5; Hil. Vita Hon. 12-14), sind noch in der ersten Hälfte des 5. Jh.s entstanden (zur Vita Iusti vgl. Beaujard 2000, 105f.; der sermo de vita Honorati wurde 430 oder 431 gehalten [van Uytfanghe 2001b, 1287]).

136 Auf das Fehlen eines regionalen, gallischen Konkurrenzfeldes innerhalb der imperialen politischen Ordnung weist zu Recht Jussen 1998, 81 hin; ebenso John F. Drinkwater in seinem Beitrag in diesem Band. Anders Mathisen 1993, 17-20, 24-26. 
wie auch des Mönchtums und verlor damit zugleich den semantischen Charakter einer zeichenhaften Herausforderung der sozialen Ordnung, den sie bis dahin gehabt hatte. Damit einhergehend verbreitete die hagiographische Literatur ein bischöfliches Leitbild, das durch die signifikante Zunahme an seriellen Wunderberichten zunehmend die Akzentuierung von Status und Macht in den Vordergrund stellte. Ihre Wirkung jenseits der Texte bezogen diese Wunderberichte aus dem Umstand, dass die Liturgie als ein außertextueller Handlungs- und symbolischer Referenzrahmen fungierte, in den diese Wunder eingeschrieben waren: Die Wunder verwiesen damit nicht allein auf die Macht des Heiligen, der sie bewirkte, sondern auch auf die des Bischofs, dessen zeremoniell-liturgische Rollen als Gemeindeleiter und Richter durch diese Wunderberichte performativ reaktualisiert wurden.

Die Liturgie erweist sich damit als einer der Transmissionsriemen, über die, verstärkt seit der Wende vom 5. zum 6. Jh., eine effektive Neustrukturierung sozialer Beziehungen im spätantiken Gallien erfolgte. Der Akzent scheint dabei allerdings weniger auf einer gesellschaftlichen Umordnung durch Prozessionsrituale gelegen zu haben - eine Praxis, die sich im Übrigen nicht vor dem Ende des 6. Jh.s nachweisen lässt und bis dahin allenfalls auf der Ebene normativer Aussagen fassbar wird. ${ }^{137}$ Ausschlaggebend war vielmehr eine neue Begründung bischöflicher Autorität, die durch das interdependente Zusammenspiel von Text und Liturgie, Deutungen und Praktiken bewirkt wurde und die man als tiefgreifenden Wandel in der politischen Kultur ${ }^{138}$ ansprechen kann.

III.

Schlagen wir damit abschließend nochmals den Bogen zurück zum Ausgangspunkt: Welche Auswirkungen hatten die Veränderungen der politischen Kultur auf die politisch-soziale Stellung der Bischöfe im spätantiken und frühmittelalterlichen Gallien? Und inwieweit ist es sinnvoll, mit Blick auf diese Stellung der Bischöfe von einer regelrechten Bischofsherrschaft zu sprechen? Ich möchte abschließend einige Überlegungen und Hypothesen formulieren, die m.E. geeignet sind, die künftige Richtung in der Beschäftigung mit diesen Fragen zu weisen.

Von den divergierenden nationalen Forschungstraditionen zur spätantiken und frühmittelalterlichen Bischofsherrschaft einmal abgesehen, stellt bekanntlich bereits der deutsche Begriff „Herrschaft“ selbst vor fundamentale Verständigungsprobleme, da es für ihn in anderen modernen Sprachen kein passendes Äquivalent gibt. ${ }^{139}$ Umso wichtiger erscheint es, zunächst eine konzeptionelle Übereinkunft in den Grundlagen der Begriffsbildung zu erzielen, um den Herrschaftsbegriff als erkenntnisbildendes Instrument in der wissenschaftlichen Dis-

137 Dies konzediert auch Jussen 1995, 694-698; ders. 1998, 117.

138 Zum Begriff der „politischen Kultur“ s. u., S. 126f.

139 Zum Befund vgl. zuletzt Gotter 2008, bes. 180-182; Becher 2009, 163. 
kussion weiter handhabbar zu erhalten. Als Ausgangspunkt dafür kann Max Webers klassische Unterscheidung von Herrschaft und Macht dienen, die auch in den aktuellen Überlegungen zur Herrschaftsbildung im Frühmittelalter nach wie vor eine grundlegende Rolle spielt. ${ }^{140}$ Bekanntlich differenziert Weber zwischen Herrschaft und Macht, um eine klare Unterscheidung zwischen der Möglichkeit der punktuellen Durchsetzung des eigenen Willens (Macht) und einer regelhaften, auf Freiwilligkeit beruhenden Akzeptanz von Anordnungen (Herrschaft) zu treffen. ${ }^{141}$

Der heuristische Wert dieser Differenzierung dürfte nicht nur allgemein, sondern gerade auch mit Blick auf die Stellung der Bischöfe im spätantiken und frühmittelalterlichen Gallien außer Frage stehen:

Erstens ist sie geeignet, eine insbesondere in der Tradition der deutschen Mittelalterforschung verbreitete Tendenz aufzubrechen, bischöfliche Herrschaft im Kontext einer einheitlich strukturierten Herrschaftsbildung zu verorten: ${ }^{142}$ Eine konsequent soziologische, rein auf dem Kriterium der Akzeptanz beruhende Konzeptualisierung von Herrschaft gibt den Blick frei auf das, was die althistorische Forschung bereits seit längerer Zeit herausstellt, dass nämlich die Reichweite und Begründung bischöflicher Autorität in der Spätantike nicht primär auf den institutionellen Vorgaben und Rahmenbedingungen der römischen Administration beruhten, sondern auf andersartigen Voraussetzungen. ${ }^{143}$ Auch in Gallien passten sich die Bischöfe weder in die administrativen Lücken und Kompetenzen ein, die

140 Zum bleibenden Stellenwert von Webers Definition für die aktuellen Diskussionen zur frühmittelalterlichen Staats- und Herrschaftsbildung vgl. Pohl 1999, 443. Ähnlich Gotter 2008, 182 mit Blick auf die antike Geschichte.

141 Weber 1972, 28f.: „Macht bedeutet jede Chance, innerhalb einer sozialen Beziehung den eigenen Willen durchzusetzen, gleichviel worauf diese Chance beruht. Herrschaft soll heiBen die Chance, für einen Befehl bestimmten Inhalts bei angebbaren Personen Gehorsam zu finden [...]. Der Begriff ,Macht“ ist soziologisch amorph. Alle denkbaren Qualitäten eines Menschen und alle denkbaren Konstellationen können jemand in die Lage versetzen, seinen Willen in einer gegebenen Situation durchzusetzen. Der soziologische Begriff der ,Herrschaft' muß daher ein präziserer sein und kann nur die Chance bedeuten: für einen Befehl Fügsamkeit zu finden.“

142 Vgl. in diesem Zusammenhang die kritischen Bemerkungen von Pohl 1999, 444 und 446f. über die insbesondere in der Tradition der deutschsprachigen Mittelalterforschung verbreitete Tendenz, Herrschaft nach einem einförmigen Modell zu konstruieren und von einem unveränderlichen „Wesen“ von Herrschaft auszugehen.

143 So auch zuletzt Rapp 2005, bes. 235-273, die betont, dass mit der staatlichen Privilegierung der Bischöfe seit dem 4. Jh. keine Einpassung bischöflicher Autorität in den Rahmen bestehender administrativer Kompetenzen erfolgte. Diese Frage ist in den letzten Jahren insbesondere mit Blick auf die bischöfliche Gerichtsbarkeit intensiv diskutiert worden: Obwohl sie als eine modifizierte Form der Schiedsgerichtsbarkeit prinzipiell an ein Institut des römischen Zivilrechts anschloss (Harries 1999, 191-211), partizipierten die Bischöfe damit nicht an einem staatlichen Hoheitsrecht (vgl. Humfress 2011, bes. 377f., 395f.). Versuche von staatlicher Seite, die Felder der bischöflichen Gerichtsbarkeit im Kontext der römischen Administration zu systematisieren, lassen sich erst um die Mitte des 5. Jh.s fassen (ebd., 391-395) und haben wohl nur geringe Auswirkungen auf die bischöfliche persona als Richter im spätantiken und poströmischen Gallien gehabt (s. auch u., S. 128f.). 
mit der zunehmenden Desintegration der römischen Herrschaft in Gallien frei wurden, noch lässt sich eine gallische Bischofsherrschaft komplementär zu Formen der Herrschaftsbildung in den fränkischen regna des 6 . Jh.s verstehen. Wie schon im spätantiken Imperium Romanum ${ }^{144}$ entwickelten die Bischöfe auch im merowingischen Gallien eigenständige Formen, soziale Wirklichkeit zu deuten und Autorität innerhalb dieser sozialen Ordnung zu beanspruchen, und lassen sich daher auch nicht in ein gleichförmiges Modell frühmittelalterlicher Herrschaftsbildung einordnen. ${ }^{145}$

Zweitens relativiert die webersche Unterscheidung von Herrschaft und Macht auch die Vorbehalte gegenüber einer bischöflichen Herrschaftsbildung, die insbesondere in der englischsprachigen Forschung mit Blick auf das spätantike und frühmittelalterliche Gallien begegnen. Wie bereits eingangs angedeutet, stehen vor allem angloamerikanische Forscher der Vorstellung von einer „Bischofsherrschaft" im spätantiken und frühmittelalterlichen Gallien distanziert gegenüber. Die gallischen Bischöfe seien in dieser Zeit allenfalls als Aushandelnde tätig gewesen, hätten jedoch über keine wirksamen Sanktionsmöglichkeiten verfügt, um ihre Ansprüche im Konfliktfall auch wirklich geltend zu machen. Erst seit dem 7. Jh. habe sich dies geändert, weil nun die merowingischen Könige und der fränkische Adel, die über weitreichende ökonomische Ressourcen und Machtmittel verfügten, durch Klostergründungen, die Verleihung von Immunitäten und die verstärkte Übernahme des Bischofsamts umfassend in diesen neuen bischöflichen Autoritätstyp investiert hätten. ${ }^{146}$

An dieser Deutung irritiert vor allem der Umstand, dass die Kriterien für die Existenz einer Bischofsherrschaft sich - webersch gesprochen - im Grunde nicht an Herrschafts-, sondern primär an Machtfragen festmachen. Denn den wesentlichen Maßstab dafür, Bischöfen im 6. Jh. „Herrschaft“ zu- bzw. abzusprechen, bildet nach der oben skizzierten Auffassung letztlich das, was für Weber nicht Herrschaft, sondern Macht charakterisiert, nämlich die Fähigkeit, den eigenen Willen gegen äußere Widerstände zu erzwingen, und die Verfügung über die entsprechenden Ressourcen, um diesen Willen zur Geltung zu bringen. ${ }^{147}$

144 Dass die spätantiken Bischöfe bereits seit dem 4. Jh. begonnen hätten, aktiv einen gesellschaftlichen Führungsanspruch in den spätantiken Städten durchzusetzen, betont Brown 1992, 71-117. Eine andere Auffassung vertritt Liebeschuetz 2001, 137-168, der davon ausgeht, dass sich ein Aufstieg der Bischöfe erst im Laufe des 5. Jh.s infolge einer allgemeinen Desintegration der kurialen Administration vollzog. Obwohl nach dieser Auffassung die Bischöfe in die frei werdenden Lücken einer nicht mehr funktionierenden lokalen Administration einrückten, betont Liebeschuetz, dass die Bischöfe nicht einfach die traditionellen Kompetenzen übernahmen, sondern rechnet mit einer grundlegenden „Desäkularisierung des sozialen Lebens" (ebd., 137), selbst dort, wo die Bischöfe - wie im oströmischen Reich - in die administrativen Strukturen des Imperiums eingebunden blieben.

145 Für das kirchliche Asyl im poströmischen Gallien hat dies Esders 1993 nachdrücklich herausgearbeitet.

146 Vgl. exemplarisch Fouracre 1999.

147 Dass es dabei nicht um Herrschaft, sondern um Macht geht, wird implizit auch bei Fouracre 1999, 147 deutlich, der in Zweifel zieht, dass in ,the sixth century bishops wiel- 
Damit aber stellt sich die Frage nach den Bedingungen bischöflicher Herrschaft auch schon vor dem 7. Jh. neu. Es kommt darauf an, die Stellung der gallischen Bischöfe in einem Kontext alternativer - zum Teil auch konkurrierender Herrschaftsbildung zu verorten. Ausschlaggebend für die Rede von einer gallischen Bischofsherrschaft kann dabei nicht primär das Maß sein, in dem die Bischöfe in der Lage waren, ihren Willen gegen konkurrierende Bemühungen, Herrschaft auszuüben, durchzusetzen und auf diese Weise ihre eigene Macht zu demonstrieren. Entscheidend erscheint vielmehr, inwieweit es den Bischöfen gelang, stabile und „präzise“"148 Autoritätsverhältnisse zu etablieren, die nicht auf der punktuellen Durchsetzung des bischöflichen Willens (Macht) beruhten, sondern auf der regelhaften Akzeptanz derer, die die Autorität der Bischöfe anerkannten (Herrschaft).

Eine solche, aus der kategorialen Unterscheidung zwischen Macht und Herrschaft gewonnene Differenzierung kommt allerdings nicht ohne Modifikationen des weberschen Herrschaftsbegriffs aus. Herrschaftsbeziehungen in Form eines Verhältnisses von Befehl und Gehorsam zu definieren, wie es Weber tut, ist sicher nicht adäquat, um die soziale Stellung der Bischöfe im poströmischen Gallien zu erfassen. Die Erkenntnis, dass eben dieser Aspekt eine grundsätzliche „Schwachstelle“ des weberschen Herrschaftsbegriffs markiert, da er zu sehr an der Ausbildung von Herrschaftsverhältnissen im Rahmen der frühneuzeitlichen Staatsbildung orientiert und aus diesem Grund nicht ohne weiteres auf andere historische Verhältnisse übertragbar ist, ist dabei durchaus nicht neu. ${ }^{149}$ Die Differenzierungskraft des weberschen Herrschaftsparadigmas als solche ist davon freilich nicht tangiert. Will man im Sinne Webers an einer kategorialen und universalisierbaren Unterscheidung zwischen Macht und Herrschaft festhalten - und die obigen Beobachtungen zeigen, dass dies kein inhaltsleerer Streit um Begriffe und kein Selbstzweck einer sich verselbständigenden Weberexegese ist -, erscheint es daher notwendig, die für Herrschaft charakteristische Regelhaftigkeit stabiler Akzeptanzbeziehungen zum Ausgangspunkt zu machen und die Modalitäten von Herrschaftsbeziehungen nicht auf ein Befehl-Gehorsams-Verhältnis zu reduzieren. ${ }^{150}$

Ausgehend von diesen Gesichtspunkten der Regelhaftigkeit und Akzeptanz sollen im Folgenden einige Tendenzen skizziert werden, die auf eine Transformation der politischen Kultur hindeuten, unter deren Vorzeichen sich seit dem 6. Jh. die soziale Stellung der gallischen Bischöfe zu wandeln begann. Die Rede von

ded the same degree of power, through relics or otherwise, as did their later counterparts". Ähnlich die Bemerkungen von Brown 2012, 505-507 über eine „soft pastoral power“ der Bischöfe, die im Zweifelsfall eines Konflikts mit der „wordly power“ der fränkischen Machthaber unterlegen gewesen sei.

$148 \mathrm{Zu}$ diesem elementaren Kriterium von Herrschaft im Unterschied zum soziologisch amorphen Machtbegriff s. o., Anm. 141.

149 Vgl. z.B. die entsprechende Kritik bei Winterling 2001, bes. 628; ähnlich Epp 1999, 3-5.

150 An diesem Gesichtspunkt der Regelhaftigkeit setzen auch aktuelle Überlegungen zur Staatlichkeit und Herrschaftsbildung im Frühmittelalter an (vgl. Pohl 2006, 35f.). 
einer ,ppolitischen Kultur“ steht dabei nicht allein für veränderte Deutungen von Autorität und sozialer Wirklichkeit, sondern auch dafür, in welcher Weise diese Deutungen kommuniziert und durchgesetzt wurden. Wie die folgenden Bemerkungen zu zeigen versuchen, waren die gallischen Bischöfe außerordentlich erfolgreich darin, durch das Ineinandergreifen von Texten, regelhaften Praktiken und literarischer Kommunikation ein Bild vom Bischof zu erzeugen, das bis tief in die alläglichen Lebensvollzüge hinein ein Wissen von der Autorität des Bischofs in der öffentlichen Wahrnehmung verankerte. ${ }^{151}$ Auch wenn die Bischöfe des 6. Jh.s sich unter Machtgesichtspunkten nicht immer gegen Konkurrenten behaupten mochten, legten sie in dieser Zeit ein herrschaftssoziologisches Fundament, auf dem dann die Machteliten des 7. Jh.s aufbauten und neuartige Herrschaftsbeziehungen zu errichten begannen.

Wie bereits im vorigen Abschnitt angedeutet, spricht vieles dafür, dass sich während des 6. Jh.s mit Blick auf den gallischen Episkopat tiefgreifende Veränderungen vollzogen - und zwar nicht allein im hagiographischen Leitbild der Bischöfe, sondern auch in der politischen Kultur, vermittels derer die gewandelten Auffassungen vom Bischof kommuniziert wurden. Als zwei wesentliche Charakteristika dieser Transformation können zum einen der Wandel bischöflicher Heiligkeit von einem individuellen Attribut zu einem kollektiven Merkmal des gallischen Episkopats und zum anderen die damit einhergehende Demonstration von Status und Autorität gelten, die sich praxeologisch wie auch diskursiv in der Betonung von Heilwundern und Exorzismen und in der Funktion des Bischofs als Richter und Wiederhersteller der gemeindlichen Einheit manifestierte. ${ }^{152}$ Diese Wandlungen in der bischöflichen imago deuten zugleich auch eine Richtung an, in der vielversprechende Ansätze für eine präzisere Bestimmung dieses sich neu formierenden Herrschaftstyps und eine umfassendere Sondierung der Grundlagen, auf denen er beruhte, liegen und die im Folgenden schlaglichtartig skizziert werden soll.

Die in den Heilwundern und Exorzismen akzentuierte Befreiungssymbolik fand ihre nahtlose motivische Fortsetzung in bischöflichen Gefangenenbefreiungen $^{153}$ und zum Teil in den mit ihnen verbundenen Strafwundern, die in der galli-

151 Dass diesem Aspekt in herrschaftssoziologischer Bedeutung eine zentrale Rolle zuzusprechen ist, wird in jüngerer Zeit auch mit Blick auf die Bischofsherrschaft der Karolingerzeit betont (vgl. Patzold 2008). Auch unter rechtssoziologischen Gesichtspunkten kommt dem Wissen um gerechtes Handeln und den damit verbundenen Verhaltenserwartungen eine grundlegende Bedeutung zu (für eine instruktive Anwendung dieses Ansatzes auf das spätantike Gallien vgl. Esders 1993, bes. 99-107, 115-123).

152 S. o., S. $115 f$.

153 Eine umfassende Zusammenstellung der Gefangenenbefreiungen in der merowingischen Hagiographie bietet Graus 1961. Das Abfallen von Ketten findet in gleicher Weise für die Loslösung von Gefangenen wie für die Befreiung Besessener von den Dämonen Verwendung - eine explizite Verbindung stellt Greg. Tur. glor. conf. 86 her. Zur Lösung der Ketten beim Exorzismus und Krankenheilungen s. z.B. Greg. Tur. virt. Iul. 9; virt. Mart. 4, 20; 
schen Hagiographie einen prominenten Platz einnehmen und den Bischof als Widerpart weltlicher Machthaber präsentierten. ${ }^{154}$ Das Bild vom Bischof als Richter, der über Büßer und Kranke ${ }^{155}$ urteilte, und als Garant der sozialen Ordnung, der die Geheilten erneut in die menschliche Gemeinschaft eingliederte, wurde damit um eine weitere Dimension bischöflicher Autorität erweitert - unterschiedliche Facetten einer übergreifenden Symbolik, die vielfältige Rollen bischöflicher Autorität miteinander vernetzte. Umgekehrt bedeutet dies auch, dass Gefangenenbefreiungen und Strafwunder nicht als vereinzelte und "nach außen“ gerichtete politische Machtdemonstrationen bewertet werden sollten. ${ }^{156}$ Ihre autoritätssteigernde und herrschaftsgenerierende Wirkung bezogen diese Erzählungen nicht allein und möglicherweise nicht einmal in erster Linie aus dem Umstand, dass in ihnen Bischöfe äußeren Konkurrenten Paroli boten, sondern aus ihrer Einbindung in ein weitgespanntes und dichtes Geflecht aus symbolischen Referenzen: Gefangenenbefreiungen und Strafwunder vindizierten nicht allein bischöfliche Durchsetzungsfähigkeit und Macht gegenüber anderen Herrschaftsträgern und Machthabern, sondern verstärkten die bischöfliche Autorität nach innen, indem sie sich motivisch mit stabilen und regelhaft ausgeübten Leitungsfunktionen verbanden, die der Bischof gegenüber seiner Gemeinde geltend machte. ${ }^{157}$

Dieses Agieren des Bischofs als Richter, Exorzist und Befreier schloss dezidiert nicht an Traditionen spätrömischer Bischofsgerichtsbarkeit an, auf die in der Forschung immer wieder verwiesen wird, um den spätantiken und frühmittelalterlichen Bischöfen herrschaftliche Kompetenzen zuzusprechen. ${ }^{158}$ Abgesehen davon, dass die episcopalis audientia als eine Form der Schiedsgerichtsbarkeit auch in römischer Zeit niemals ein staatliches Herrschaftsrecht gewesen war, ${ }^{159}$

glor. conf. 93; zuweilen wird beim Exorzismus auch der Dämon selbst vom Heiligen in Ketten gelegt (z.B. Vita Hil. 16). Zur Verbindung der Bilderwelten von Gefangenenbefreiungen und Dämonenaustreibungen s. Brown 1981, 100; Jones 2009, $189 \mathrm{f}$.

$154 \mathrm{Zu}$ diesem Typ von Befreiungswundern vgl. das Dossier von Graus 1961, 106-119.

155 Körperliche Gebrechen und Krankheiten wurden ebenfalls in der Regel religiös gedeutet und als Folge von sündhaften Verfehlungen aufgefasst (van Dam 1993, 87-89; Jones 2009, 188-191). Konsequenterweise wird die Buße zuweilen auch mit der Heilung von körperlichen Gebrechen verbunden (vgl. z.B. Vita Hil. 16: Eine Frau, der Hilarius anlässlich der Buße die Hand auflegt, wird von Blindheit geheilt).

156 Dieser Aspekt wird in der Deutung häufig zu einseitig herausgestellt; vgl. Graus 1961, 124f.; Collins 1981, 116-118; James 1983, 31f.; Breukelaar 1994, 257-261; Coates 2000, 1129f.; Wiesheu 2001.

157 In diesem Zusammenhang sei daran erinnert, dass die öffentliche Buße im 5. und 6. Jh., anders als lange angenommen, kein archaisches Ritual war, das liturgisch praktisch kaum noch in Gebrauch war (de Jong 2000, bes. 185-190; Uhalde 2008, bes. 101-108). Hilarius v. Arles erteilte offenbar jeden Sonntag die Buße, um im Rahmen dieses Rituals Krankenheilungen vorzunehmen und damit seine wundertätige Kraft unter Beweis zu stellen (Vita Hil. 16; zur Episode s. o., Anm. 153).

158 Vgl. die Bemerkungen von James 1983, 27f.; Beaujard 2000, 36; Gauthier 2000, 188-190.

159 S. o., Anm. 143. 
waren die Begründungen, Maßstäbe und auch Dimensionen richterlichen Handelns in poströmischer Zeit vollkommen andere. ${ }^{160}$ Der Bischof agierte nicht mehr als ein Schiedsrichter zwischen den Prozessparteien, der weitgehend an das römische Zivilrecht gebunden und auf Ausgleich bedacht war, ${ }^{161}$ sondern in einer wesentlich enthobeneren Richterrolle, die eschatologische Anklänge an den iudex des Jüngsten Gerichts enthielt, ${ }^{162}$ sich wesentlich an moralischen Maßstäben orientierte und in dem Maße, in dem auch ökonomische Armut und Krankheit religiös, nämlich als Ausdruck moralischer Verworfenheit und Sündhaftigkeit gedeutet wurden, ${ }^{163}$ zugleich auch eine wesentliche Erweiterung erfuhr. Ähnliches gilt auch für Verhandlungen gallischer Bischöfe mit Machthabern und Herrschaftsträgern, die nach der Darstellung der hagiographischen Quellen zunehmend nicht mehr auf paideia und rhetorischem Geschick und damit auf innerweltlichen Handlungsbegründungen basierten, sondern auf Strafwundern, einem an der alttestamentlichen Prophetenimago orientierten furchtlosen Auftreten des von Gott gesandten Bischofs vor dem weltlichen Machthaber und auf einer von jeglicher Rhetorik abstrahierenden Überzeugungskraft geisterfüllter Rede. ${ }^{164}$

$160 \mathrm{Zu}$ Recht herausgestellt von Hartmann 1995, bes. 836f.

161 Der Charakter der episcopalis audientia als Schiedsgerichtsbarkeit eröffnete dem Bischof Entscheidungsspielräume, die er nutzen konnte, um auf eine karitative Milderung hinzuwirken (Kuhn 2009). Wie das Beispiel des Augustinus zeigt, orientierten sich die spätantiken Bischöfe in der Urteilsfindung jedoch offenbar stark am römischen Recht (Aug. epist. 24*; vgl. auch Haensch 2007, 164f.).

$162 \mathrm{Im}$ Exorzismus nahm der Bischof die Rolle eines Richters ein, der das Urteil über die Dämonen sprach und darin das Jüngste Gericht vorwegnahm (vgl. Sulp. Sev. dial. 3, 6, 2, wo Martin v. Tours von den Besessenen quasi adveniente iudice empfangen wird; ähnliche eschatologische Konnotationen finden sich z.B. in Vita Hil. 16: quis ita futuri iudicii monstravit examen? Quis ita tenebrosum terribiliter intimavit incendium?). Zur Richterrolle bei der Buße, die zum Teil auch dem Büßer selbst zugewiesen wurde, vgl. auch Bailey 2010, 94f. Die im Exorzismus und Bußritual akzentuierte Enthobenheit und Distanzierung des bischöflichen Richters war möglicherweise bereits ein Kennzeichen der spätantiken audientia episcopalis (vgl. Brown 2002b, 67-70, 86-88; Kuhn [i. Druck]). Für die Frage nach einer Bischofsherrschaft im spätantiken Gallien wäre noch systematischer in den Blick zu nehmen, wie stark diese Tendenzen das Auftreten der Bischöfe gegenüber ihren Gemeinden und gegenüber konkurrierenden Gerichtsbarkeiten bestimmt haben (vgl. die Ansätze dazu bei James 1983; Uhalde 1999). So bemühten sich die Bischöfe seit dem beginnenden 6. Jh. darum, die Buße als einen Ersatz auch für weltliche Strafen zu akzeptieren (vgl. Rur. Lim. epist. 2, 12; Vita Caes. 1, 24); für das spätere 6. Jh. vgl. Greg. Tur. virt. Mart. 3, 53 mit Uhalde 2008, 97f.). Seit dem ausgehenden 6. Jh. nahm die nunmehr nicht mehr freiwillig übernommene Buße auch formal den Charakter einer Strafe an (vgl. Vogel 1952, 157f.).

163 S. o., Anm. 155.

$164 \mathrm{Zu}$ Strafwundern in der gallischen Hagiographie s. allgemein Graus 1965, 387f.; Collins 1981, 115f. Zur Prominenz der Prophetenimago bei Gregor v. Tours vgl. Graus 1965, 381f.; van Uytfanghe 1987, 205; Heinzelmann 1994, 42-69; zu alttestamentlichen Deutungsschemata bei Gregor insgesamt s. Esders 1993, 118. In der gallischen Hagiographie des 5. Jh.s findet die Prophetenimago deutlich geringere Anwendung: Zwar rekurriert Sulpicius Severus bei der Begegnung zwischen Martin und dem Usurpator Magnus Maximus 
Ähnliches zeigt sich auch in weiteren Handlungsfeldern, in denen eine vergleichbare hierarchische Distanzierung der Bischöfe aus innerweltlichen Handlungszusammenhängen und sozialen Handlungsbegründungen wirksam wurde. Ich habe bereits an anderer Stelle zu zeigen versucht, dass materiellen Leistungen der spätantiken Bischöfe für ihre Gemeinden, die von der Forschung überwiegend als eine nahtlose Fortführung traditioneller euergetischer Praktiken im christlichen Gewand gesehen werden, in einem gewandelten Deutungs- und Begründungszusammenhang standen: ${ }^{165}$ Mit Investitionen in Arme, Kranke und christliche Baustiftungen änderten sich nicht nur die Bezugsgruppen und Gegenstände des Gebens, sondern vor allem auch die damit verbundenen Handlungsbegründungen. Karitative Aktivitäten, Baustiftungen, Befreiungen von Abgaben und vergleichbare Leistungen für die Gemeinde ${ }^{166}$ erfolgten nicht mehr im Rahmen eines herkömmlichen euergetischen Gabentauschs, bei dem materielle Aufwendungen und Leistungen für die Bürgerschaft im Rahmen eines innerweltlichen Handlungszusammenhangs durch Anerkennung und Ehrungen beantwortet wurden. Die Gabe begründete nunmehr eine Verpflichtung zum Gebetsgedenken, das Geber wie Empfänger über die Grenze des Todes hinweg in einen imaginären Handlungszusammenhang brachte, zugleich aber auch innerweltlich die traditionelle soziale Bindungskraft der memoria schwächte, da im Diesseits nur bestimmte Gruppen in der Lage waren, eine wirkungsvolle Gebetsfürbitte zu leisten. ${ }^{167}$

Diese Veränderungen der Memorialkultur hatten Implikationen für die Beziehungen der Bischöfe zu ihren Gemeinden und für die Besitz- und Abhängigkeitsverhältnisse im spätantiken und frühmittelalterlichen Gallien. Obwohl gerade auch in Gallien die bischöfliche Selbstdarstellung stark von traditionellen diskursiven Elementen geprägt blieb, indem sie die bischöflichen Verdienste (merita) in herkömmlicher Manier herausstellte, tendierte diese traditionelle Verdienstethik deutlich erkennbar dazu, sich aus menschlichen Handlungsbeziehungen zu lösen: Ihre eigentliche Anerkennung wurde den merita nicht mehr in dieser Welt zuteil, sondern im Jenseits, wo die praemia für das tugendhafte und verdienstvolle Handeln bereitstanden. Während die merita nach traditioneller Vorstellung den irdi-

auf das Modell des Propheten (Sulp. Sev. Vita Mart. 20), doch in der Vita Germani, in der häufig Begegnungen zwischen dem Protagonisten und weltlichen Machthabern zur Sprache kommen, wird der Bezug auf das Bild des Propheten dezidiert vermieden (vgl. Gillett 2003, 123). Das Zurücktreten der paideia, die in den Bischofsviten des 5. Jh.s noch eine wichtige Rolle als Verhandlungsgrundlage spielt (vgl. etwa die Vita Epiphanii des Ennodius), wäre noch eingehender zu untersuchen.

165 Diefenbach 2007, 508-538.

166 Als ein Beispiel für das Spektrum „,verdienstvoller“ Leistungen vgl. die merita, die Venantius Fortunatus in seinem Gedicht auf Nicetius v. Trier (526-nach 561) aufführt (Ven. Fort. carm. 3, 11): Armenfürsorge, Gefangenenbefreiungen, Aufnahme von Verbannten, Schutz der Gemeinde, Erneuerung von Kirchenbauten.

167 Diefenbach 2007, 520-536. 
schen Ruhm dessen, der sich verdient gemacht hatte, steigerten, ${ }^{168}$ fanden die Verdienste der gallischen Bischöfe ihr Ziel nicht mehr im diesseitigen (Nach-)Ruhm: Das Ansehen, das sie vermittelten, verschaffte den Bischöfen eine Ehrenstellung - und damit einhergehende Interzessionsmöglichkeiten für ihre Gemeinden und Anhänger - im Himmel. ${ }^{169}$ Dabei waren es nun bezeichnenderweise die bereits verstorbenen, ,vollendeten“ Heiligen, die das besondere Ansehen, das die merita den Bischöfen vermittelten, garantierten: Die Verdienste eines Bischofs mochten zwar in karitativen und pastoralen Leistungen für seine Gemeinde bestehen; über das daraus resultierende Ansehen entschied jedoch nicht die Gemeinde, sondern der Heilige, der die merita honorierte und dadurch eine Gemeinschaft zwischen den lebenden Bischöfen und den bereits vollendeten Heiligen stärkte. ${ }^{170}$ Der „,christliche Euergetismus “' ${ }^{171}$ der gallischen Bischöfe verankerte sie also nicht in der irdischen, sondern in der himmlischen patria - mit den entsprechenden Folgen, die das für die Wahrnehmung und Begründung bischöflicher Autorität innerhalb der Stadt hatte: Der diskursive Bezugspunkt des bischöflichen Gebens war nicht die politische Gemeinschaft, die diese Leistung einforderte und den Geber zugleich verpflichtete und dafür ehrte, sondern der

168 Beispiele bei Heinzelmann 1976, 48, 53-56.

169 Exemplarisch für diese Umprägung äußert sich Hilarius v. Arles in seinem sermo auf den verstorbenen Vorgänger Honoratus (Hil. Vita Hon. 37): „Dir (scil. Honoratus) war es eine größere Freude, dass Gott deine Verdienste und Tugenden verzeichnete, als dass Menschen deren äußere Zeichen (scil. in Form von Wundern, die der Heilige wirkte) zur Kenntnis nahmen" (maiusque tibi gaudium erat, quod merita et virtutes tuas Deus scriberet, quam quod signa homines notarent). An weiteren Beispielen vgl. allein für das 5. Jh. z.B. Const. Vita Germ. 12; Eus. Gall. 51 (60), 9; 72 (72), 2. Die Vorstellung von einer durch die merita vermittelten Ehrenstellung im Himmel findet sich nicht nur in der Hagiographie, sondern auch in Grabinschriften (vgl. Heinzelmann 1976, 87, 202) und Gedichten (Sidon. epist. 7, 17, 2; für Venantius Fortunatus vgl. die folgende Anm.). Dass die merita und das damit einhergehende Ansehen bei Gott wirksame Interzessionsmöglichkeiten eröffneten, ist ein Aspekt, der sich bereits zu Beginn des 5. Jh.s findet; vgl. z.B. Hier. epist. 123, 15 über Exsuperius v. Toulouse, der seine Stadt 407/408 durch seine merita von einer Belagerung durch die Vandalen befreite; Paul. Med. Vita Ambr. 1, 3 (412/413 oder 422 geschrieben) über die Fürbitten und merita des Ambrosius, die den Verfasser seiner Vita bei deren Abfassung unterstützen sollen.

170 Treffend Brown 1977 (1982), 240f. über den gallischen Episkopat zur Zeit Gregors v. Tours: „We are in a world of men, whose personal status, whose merita, depend on a highly personalized and intense dialogue with such Ideal Companions (scil. the saints)." Für diesen Zusammenhang vgl. exemplarisch die drei Gedichte, die Venantius Fortunatus auf den Bischof Eufronius v. Tours verfasste und in denen das Verhältnis des Eufronius zu seinem heiligen Vorgänger Martin v. Tours ausführlich thematisiert wird: Die Gemeinschaft zwischen Eufronius und Martin beruhte auf den merita des Bischofs Eufronius (Ven. Fort. carm. 3, 1, 3) und die merita des Eufronius waren es, die ihm - jeweils auf die Interzession Martins hin - nicht nur einen Platz Himmel sicherten (Ven. Fort. carm. 3, 2, 5), sondern auch den Bischofssitz von Tours (Ven. Fort. carm. 3, 3, 23f.: Martinus meritis hac vos in sede locavit / dignus eras heres qui sua iussa colis).

171 Auf die konzeptionelle Problematik des Begriffs weist zu Recht auch Müller 2003, 362425 nachdrücklich hin. 
Himmel, wo sich der bischöfliche Geber durch sein verdienstvolles Handeln in die Schar der bereits vollendeten Heiligen einreihte.

In dieser Denkfigur, die die Gemeinschaftsstiftung der Bischöfe mit den vollendeten Heiligen betonte, wird eine Tendenz zu einer kollektiven bischöflichen Selbstheiligung sichtbar, die im spätantiken und frühmittelalterlichen Gallien vor allem durch die Hagiographie vorangetrieben wurde. ${ }^{172}$ Bereits ein kursorischer Blick auf die hagiographische Überlieferung Galliens verdeutlicht, dass sie, verglichen mit den anderen Regionen des Römischen Reichs, überdurchschnittlich viele Bischofsviten enthält. ${ }^{173}$ Dieser schon für sich genommen signifikante Umstand gewinnt seine volle Bedeutung allerdings erst vor dem Hintergrund der kommunikativen Kontexte dieser Literatur. Während sich die Forschung unter Rezeptionsgesichtspunkten bisher vorwiegend auf die Breitenwirkung der Viten als liturgische Lesetexte oder als private Lektüre monastischer Leserkreise konzentriert hat ${ }^{174}$ eröffnet insbesondere die Frage nach ihrer Einbettung in die literarische Kultur neue Perspektiven auf diese Texte. So deutet vieles darauf hin, dass die gallischen Bischofsviten, die nicht selten auf die Initiative von Nachfolgern und befreundeten Bischöfen hin verfasst wurden, ${ }^{175}$ zugleich in einen umfassenderen Kontext kultureller Praktiken und Selbstdeutungen gehören, vermittels derer die Angehörigen einer - das Bischofsamt im spätantiken Gallien maßgeb-

172 Zur Verbindung von Hagiographie und bischöflicher Selbstheiligung s. auch die o., Anm. 130 zitierte Literatur. Im Unterschied zu den dort aufgeführten Studien sollen im Folgenden primär die literarische Öffentlichkeit der gallischen Hagiographie und ihre literatursoziologische Verortung in die Überlegungen miteinbezogen werden.

173 Zur Statistik des Befundes vgl. zuletzt Philippart/Trigalet 2008. Ausgezeichnete Dossiers der merowingischen Hagiographie bietet Heinzelmann 2007; ders. 2010. Eine Übersicht über die Editionen der wichtigsten Texte findet sich bei Godding 2001, XXII-XXXIX.

174 Vgl. Collins 1981; van Uytfanghe 1985; dens. 2001a, bes. 215-217; dens. 2005, bes. $164-$ 177.

175 Besonders aufschlussreich ist die Vita des Germanus v. Auxerre: Zu ihr sind in der Überlieferung zwei Begleitschreiben an bischöfliche Auftraggeber erhalten, die exemplarisch Hinweise auf die unterschiedlichen Verbreitungswege des Textes geben (van Egmond 2006, 29-33; zum Niederschlag in der kodikologischen Überlieferung vgl. Levison 1904, 111f.; Dolbeau 2010, 110). Die Zahl der Beispiele lässt sich unschwer weiter vermehren: Sidonius Apollinaris machte sich auf die Bitte des Bischofs Prosper v. Orléans daran, eine Vita von dessen Vorgänger, Anianus, zu verfassen (Sidon. epist. 8, 15). Venantius Fortunatus schrieb drei seiner Bischofsviten auf den Wunsch von Bischöfen, die später die jeweiligen Bischofssitze innehatten (die Vita Albini für Domitianus v. Angers, die Vita Hilarii für Pascentius v. Poitiers und die Vita Marcelli für Germanus v. Paris). Dynamius v. Marseille überarbeitete eine ältere Vita des Maximus v. Riez auf Veranlassung des Bischofs Urbicus v. Riez. Für die politischen Implikationen dieser Vorgänge vgl. etwa die Vita des Nicetius v. Lyon (gest. 573), nach dessen Tod es zu Auseinandersetzungen um die bischöfliche Nachfolge zwischen zwei Kandidaten, Priscus und Aetherius, kam: Nachdem sich zunächst Priscus durchgesetzt hatte, gelang es Aetherius schließlich, 586 die Bischofswürde zu erlangen. Um seine Legitimität gegenüber den Anhängern des Priscus zu betonen, förderte Aetherius die Verehrung des Nicetius und gab die Abfassung der Vita Nicetii in Auftrag (zu den Vorgängen vgl. Heinzelmann 1976, 175-179; Brown 1977 [1982], 245). 
lich prägenden - gesellschaftlichen Elite sich untereinander vernetzten, sich ihrer kulturellen Identität versicherten und ihren sozialen Führungsanspruch zu bewahren versuchten. ${ }^{176}$ Als exemplarisches Beispiel mag die Vita des Eutropius v. Orange (gest. nach 475) dienen, die von dessen Nachfolger, Verus v. Orange, auf Bitten eines befreundeten Bischofs verfasst wurde. Im Prolog betont der Verfasser der Vita Eutropii die freundschaftliche Gefälligkeit (officium), die er dem Auftraggeber durch die Abfassung seines Textes erwies, und hebt zugleich die durch die Vita bewirkte Vergegenwärtigung des Eutropius beim Auftraggeber und die Überwindung der körperlichen und räumlichen Trennung durch das hagiographische Lebensbild hervor. ${ }^{177}$ Diese aus der Tradition des antiken Freundschaftsbriefs hinlänglich vertrauten Topoi ${ }^{178}$ legen es nahe, dass auch die Hagiographie - komplementär zur Epistolographie, deren identitätsstiftende Bedeutung als Kommunikationsmittel einer gallischen Elitenkultur in der Forschung traditionell sehr ausführlich gewürdigt wird ${ }^{179}$ - einen wesentlichen Beitrag zur Vernetzung und damit auch zur oben skizzierten kollektiven Selbstheiligung der gallischen Bischöfe leistete: In ähnlicher Weise wie Freundschaftsbriefe dienten auch hagiographische Texte zugleich als Zeichen gegenseitiger Wertschätzung und Verbundenheit und als Medien einer performativen Vergegenwärtigung, die die Protagonisten der Viten in der literarischen Öffentlichkeit präsent hielt.

Freilich erfuhr dieses traditionelle Motiv aristokratischer Gemeinschaftsstiftung - ebenso wie das Konzept der amicitia selbst ${ }^{180}$ - dabei eine wesentliche Transformation: Da nach christlicher Vorstellung die Verstorbenen Teil eines die

$176 \mathrm{Zu}$ dieser von intensiven Kontakten unter den aristokratischen Peers geprägten Elitenkultur, die durch brieflichen Austausch, Gastmähler und literarische Patronage gepflegt wurde, vgl. u.a. Brennan 1992; Mathisen 1993, 13-15 sowie die u., Anm. 179 aufgeführte Literatur zur Epistolographie.

177 Vita Eutr. (Varin 1849, 52f.): diu est quod serviri tibi officio digni laboris exposcis; sed miror quod pondus imperati operis non expendis. iniungis ut vitam Sancti Eutropie episcopi, diligentissime perquesitam, ac evidentium testium relatione firmatam, enocleate conscribam, illumque tibi gestis vitae suae resuscitem, cui te absentem solo constat consortio corporis, non plenitudine caritatis: „Schon lange forderst du von mir, ich solle dir durch die Gefälligkeit (officium) einer würdigen Unternehmung einen Dienst erweisen, doch wundere ich mich, dass du das Gewicht des mir aufgetragenen Werkes nicht abwägst. Du erlegst mir auf, das Leben des Bischofs und Heiligen Eutropius, sorgfältigst erforscht und durch die Berichte von erwiesenen Zeugen bekräftigt, erschöpfend zu beschreiben und dir jenen durch seine Taten erneut zum Leben zu erwecken, der von dir einzig körperlich, nicht aber in der Fülle der Liebe getrennt ist."

178 Vgl. dazu Bruggisser 1993, 4-16 (Ableistung eines officium). Zu der durch den Brief bewirkten Vergegenwärtigung und der Vorstellung von einer darin aktualisierten Einigkeit im Geiste und in der Liebe, die durch die körperliche Trennung nicht aufgehoben werden kann, vgl. Thraede 1970, 39-47 und 146-161 sowie 109-146.

179 Mathisen 1981; Le Jan 2004; vgl. auch die Beiträge von Ralph W. Mathisen und Gernot Michael Müller in diesem Band. Für den weiteren historischen Kontext einer bildungsbezogenen Fortführung epistolarer Briefkultur unter christlichen Vorzeichen vgl. Gemeinhardt 2007, 184-244.

180 Vgl. dazu den Beitrag von Gernot Michael Müller in diesem Band. 
Grenze des Todes überspannenden Kommunikations- und Handlungszusammenhangs blieben ${ }^{181}$ und da die in der Epistolographie und Hagiographie bewirkte Vergegenwärtigung von Briefpartnern und Protagonisten um den Aspekt des fürbittenden Gebetgedenkens erweitert wurde, vermittelte diese Vernetzung nicht nur Anteil an Bildung, sondern auch an Heiligkeit, die nun zu einem leitenden Merkmal kollektiver Identitätsstiftung avancierte. ${ }^{182}$ Durch den ideellen Einschluss verstorbener Bischöfe, die durch Viten kommemoriert wurden und damit als vollendete Heilige galten, ${ }^{183}$ in die amicitia-Beziehungen der Lebenden beschritten die Bischöfe den Weg einer kollektiven Selbstheiligung, die sich komplementär zur Liturgisierung des Bischofsbildes und zu dem damit verbundenen Wandel der sanctitas von einem individuellen zu einem kollektiven Merkmal vollzog. ${ }^{184}$ Der enge Zusammenhang von lebenden und vollendeten Heiligen wird nicht zuletzt darin sichtbar, dass er auch das Bild vom interzessorischen Wirken der vollendeten Heiligen bestimmte: Die Art und Weise, in der sie etwa ihren Städten im Jenseits Schutz bei Belagerungen und drohendem Unheil zuteil werden ließen, wirkt wie eine Fortsetzung ihrer irdischen bischöflichen Tätigkeit im Himmel - eine „Pastoralisierung“ des Heiligenbildes, ${ }^{185}$ die zugleich deutlich macht, wie stark die Heiligkeit der lebenden und toten Bischöfe wechselseitig aufeinander verwies. ${ }^{186}$

Sicher bedürften die genannten Tendenzen und Beobachtungen, wie bereits betont, einer systematischeren Aufarbeitung, um die Dimensionen des Wandels

181 S. o., S. $130 f$.

182 Vgl. in diesem Zusammenhang z.B. Ven. Fort. carm. 3, 1, 3, wo Venantius Fortunatus an Bischof Eufronius v. Tours die Bitte richtet, er möge ihn bei Martin v. Tours, mit dem Eufronius Gemeinschaft halte, in Erinnerung bringen: rogo per ispum domnum Martinum, cuius frueris participato consortio, ut apud eum memorari praecipias me famulum et devotum. Zur Deutung des Zeugnisses vgl. Beaujard 2009, 72.

183 Ähnliches gilt für die literarischen Epitaphien, die Venantius Fortunatus auf verstorbene Bischöfe verfasste und sie damit in eine Gemeinschaft der Heiligen eingliederte - auch wenn sie gar nicht Empfänger eines offiziellen Heiligenkultes waren (vgl. Heinzelmann 2007, 161f., der allerdings darauf hinweist, dass sich diese Einreihung unter die Heiligen nicht allein auf Bischöfe beschränkte).

184 Vgl. dazu o., S. 114-118.

185 Ähnlich Orselli 1965, 113.

186 Vgl. Vita Eutr. (Varin 1849, S. 64): Eutropius vereinigt sein Gebet für die bedrohte Stadt mit dem der Bewohner; wie noch zu seinen Lebzeiten treibt Eutropius die Bewohner bei drohendem Unheil zu Almosen, Gebeten, Fasten und Tränen an, um die Fürbitte weiterer Heiliger zu erreichen. Ähnlich auch Hil. Vita Hon. 39, 2, wo der verstorbene Honoratus zum „Übersetzer der Gebete der Gemeinde“ (orationum nostrarum interpres) erklärt wird. In Erinnerungen an das Wirken der Heiligen zu ihren Lebzeiten wird dementsprechend häufig darauf verwiesen, dass sie durch die Feier der Liturgie oder das Gebet ihre Städte vor Belagerungen oder Bränden gerettet hätten (Avit. hom. 6; Greg. Tur. glor. mart. 12). Diese spezifische „Pastoralisierung“ der Heiligen erschließt sich durch den Vergleich mit östlichen Beispielen: Dort dominieren beim Schutz der Städte epiphanieartige Erscheinungen und Machtdemonstrationen, die ihrerseits eng an pagane Vorläufer anschließen (vgl. z.B. Thdt. hist. rel. 1, 11; Euagr. hist. eccl. 4, 28; Cameron 1979, 5 und Zos. hist. 5, 6, 1f.). 
auszuloten und die darin wirksame Veränderungsdynamik in der historischen Entwicklung präziser zu erfassen. Dennoch ist m.E. bereits aus den hier nur in breiten Zügen angedeuteten Linien erkennbar, dass sie für mehr stehen als nur für eine sozial amorphe „Macht der Heiligen“, die sich punktuell an ihren Gräbern oder in ihren Reliquien manifestierte. ${ }^{187}$ Vielmehr wirkten Texte, Liturgie und literarische Kommunikation zu einer umfassenden Transformation der politischen Kultur im poströmischen Gallien zusammen, die seit dem 6. Jh. das Bild und Ansehen des Bischofs erkennbar veränderte. Bei allen Kontinuitäten kultureller Praktiken und Selbstdeutungen, die die aktuellen Perspektiven der Forschung auf den gallischen Episkopat bis zum beginnenden 7. Jh. maßgeblich bestimmen, ${ }^{188}$ ist unübersehbar, dass sich schon seit dem frühen 6. Jh. im Bischof ein neuer, poströmischer Autoritätstyp zu etablieren begann. Er beruhte im Kern auf der Heiligkeit der bischöflichen Herrschaftsträger und ihrer damit einhergehenden Distanzierung aus innerweltlichen Handlungs- und Begründungszusammenhängen, einer Heiligkeit, die sich im Unterschied zu anderen Regionen des Römischen Reichs zunehmend von einer ,personal holiness“ zu einem allgemeinen Attribut des bischöflichen Klerus entwickelte und damit in umfassender Weise bischöfliche Rollen und Tätigkeitsfelder integrierte. ${ }^{189}$

Dieser Paradigmenwechsel nahm vieles von dem vorweg, was dann seit dem 7. Jh. als „Kultur der Heiligkeit“"190 und Herrschaftsgrundlage einer neuen fränkischen Führungsschicht erscheint - bis hin zu präzisen institutionellen Aspekten der Vergemeinschaftung und Herrschaftsbildung, deren Wurzeln bereits im 6. Jh. liegen. ${ }^{191}$ Die bischöfliche Heiligkeit in dieser poströmischen Zeit als eine nur

187 Zur „Macht“ der Heiligen in diesem Sinne vgl. Martin 1990.

$188 \mathrm{Zu}$ dieser Einschätzung vgl. allgemein Wickham 2005, 81f. Gemeinhin gelten die Dichtungen des Venantius Fortunatus (530/540-kurz nach 600), der zahlreiche Gedichte für seine bischöflichen Auftraggeber verfasste, als letzter Außenposten dieser spätrömischen Elitenkultur. In der Epistolographie lassen sich Traditionen ausmachen, die noch bis in das 7. Jh. reichen; zu den aristokratischen Netzwerken um Desiderius v. Cahors (ca. 590-655) und der von diesem Zirkel gepflegten Briefkultur vgl. den Beitrag von Ralph W. Mathisen in diesem Band.

189 Anders Rapp 2005, bes. 16-18, die zwar ebenfalls Heiligkeit als den Autoritätskern des spätantiken Bischofs ausmacht, sie jedoch als eine ,personal holiness“ des asketisch lebenden Bischofs versteht. Mit Blick nicht nur auf Gallien, sondern auf den Westen insgesamt muss man von anderen Voraussetzungen ausgehen, da Heiligkeit dort in stärkerem $\mathrm{Maße}$ als ein allgemeines, mit dem klerikalen Amt verbundenes Attribut gilt und auf anderen Handlungsfeldern wirksam wird (vgl. Sterk 2004, 8f.; s. auch van Uytfanghe 2001b, 1135).

190 In Anlehnung an Fouracre 1999, der bilanzierend von einer „burgeoning culture of sanctity“ seit dem 7. Jh. spricht.

191 So wurzelt etwa das für merowingische Immunitäten charakteristische Introitusverbot, das allgemein als zentrale institutionelle Voraussetzung einer „effektiven“ bischöflichen Herrschaftsbildung angesehen wird (s. o., Anm. 15), letztlich in den bischöflichen Bemühungen schon des frühen 6. Jh.s, durch die Einrichtung von äußeren Einflüssen abgeriegelter Gebetsgemeinschaften die Sicherung der eigenen Memoria und damit die Zugehörigkeit zur kollektiven Elite der vollendeten Heiligen sicherzustellen (Diem 2005, 176-180 über 
äußerlich aufgesetzte, glatte Marmorfassade ${ }^{192}$ zu bezeichnen, die den Blick auf die in Wahrheit äußerst prekäre Lage der in interne und äußere Konflikte verstrickten Bischöfe verstelle, wird diesem Phänomen demnach nicht gerecht. Trotz aller machtpolitischen Auseinandersetzungen um konkrete Herrschaftspositionen stellten die Bischöfe im poströmischen Gallien Autorität und Herrschaft auf eine neue Grundlage. Die Stabilität dieses Fundaments zeigt sich schon allein darin, dass die fränkischen Eliten des 7. Jh.s scheinbar voraussetzungslos darauf aufbauen konnten. Hinter der vermeintlich hohlen Fassade lag die ganze Tragkraft einer politischen Kultur, vermittels derer die gallischen Bischöfe im Laufe des 6 . Jh.s aus der Macht der Heiligen etwas grundlegend Neues - eine Herrschaft der Heiligen - formten.

\section{Literaturverzeichnis}

\section{Quelleneditionen}

Augustinus, epistulae*: Sancti Aureli Augustini opera II 6: Epistolae ex duobus codicibus nuper in lucem prolatae, rec. Johannes Divjak (CSEL 88), Wien 1981.

Avitus v. Vienne, homiliae, in: Alcimi Ecdicii Aviti Viennensis episcopi opera quae supersunt, ed. Rudolf Peiper (MGH Auct. ant. 6, 2), Berlin 1883, 103-157.

Caelestinus, epistulae: Joannis Cassiani opera omnia, accurante Jacques-Paul Migne, Bd. 2 (PL 50), Paris 1846, 417-558 (ed. Pierre Coustant).

Caesarius v. Arles, sermones: Sancti Caesarii Arelatensis sermones recogniti studio et diligentia Germain Morin, 2 Bde. (CCSL 103-104), Turnhout 1953, 2. Aufl.

Concilia Galliae: Bd. 1: A. 314-A. 506, cura et studio Charles Munier; Bd. 2: A. 511-A. 695, cura et studio Charles de Clercq (CCSL 148-148A), Turnhout 1963.

Constantius v. Lyon, Vita Germani: Constance de Lyon, Vie de Saint Germain d'Auxerre. Introduction, traduction, texte critique et notes par René Borius (SC 112), Paris 1965.

das Nonnenkloster des Caesarius v. Arles; zur Herleitung des Introitusverbots, das in den merowingischen Immunitäten allerdings erst seit der Mitte des 7. Jh.s nachweisbar ist [Brühl 1995], vgl. Rosenwein 1999, 25-58). Die für die Selbstheiligung der bischöflichen Elite kennzeichnende Transformation traditioneller amicitia-Beziehungen durch das Motiv des Gebetsgedenkens schuf eine wesentliche Grundlage für die Bildung von Gebetsbünden, die erst in karolingischer Zeit florierten, in Ansätzen jedoch bereits im 6. Jh. vorgebildet waren (vgl. etwa Epist. Austr. 5 aus dem Jahr 551/552). Dass diese sich unter den Vorzeichen einer kollektiven sanctitas vollziehende Gemeinschaftsbildung auch die vollendeten Heiligen miteinschloss, denen man nach ihrem Tod im Diesseits effektive Rechtsansprüche zubilligte, führte ferner zu neuartigen Vorstellungen transpersonaler Besitz- und Abhängigkeitsverhältnisse, die traditionelle rechtliche Konzepte zum Teil radikal transformierten (Borgolte 1988) und schon seit dem späten 6. Jh. begegnen (zum Heiligen als Eigentümer bei Gregor v. Tours s. Hen 1995, 117f.). Darauf, dass kirchliche Vorstellungen vom Gottesurteil bereits im 6. Jh. Eingang in die burgundische und fränkische Gesetzgebung fanden, weist James 1983, 32f. hin.

192 Vgl. die Bemerkung von Brown 1977 (1982), 245 über die ,febrile and insecure accumulation and dispersal or reputation that went to make up what too often strikes the unwary as the marmoreal facade of Gallo-Roman episcopal sanctity." 
Dynamius, Vita Maximi episcopi Reiensis: Dinamii Vita Sancti Maximi episcopi Reiensis, Fausti Reiensis sermo de sancto Maximo episcopo et abbate, rec. Salvatore Gennaro, Catania 1966, 9-36, 63-127.

Ennodius, Vita Epiphanii episcopi Ticinensis: Magni Felicis Ennodi opera, rec. Friedrich Vogel (MGH Auct. ant. 7), Berlin 1885, 84-109.

Epistolae Austrasicae: Il Liber epistolarum della cancelleria austrasica (sec. V-VI), a cura di Elena Malaspina, Rom 2001.

Euagrios Scholastikos, historia ecclesiastica: Euagrius Scholasticus, Historia ecclesiastica. Kirchengeschichte, übers. u. eingel. von Adelheid Hübner. Abdruck des griechischen Textes von J. Bidez/L. Parmentier, The Ecclesiastical History of Evagrius, Amsterdam 1964 (FC 57), Turnhout 2007.

Eucherius, de laude eremi: Eucherii de laude eremi, rec., apparatu critico et indicibus instr. Salvatore Pricoco, Catania 1965.

Eusebius Gallicanus, collectio homiliarum, ed. Francisco Glorie, 3 Bde. (CCSL 101101B), Turnhout 1970-1971.

Gennadius, de viris illustribus: Hieronymus, liber de viris inlustribus, Gennadius, liber de viris inlustribus, hg. von Ernest C. Richardson (TU 14, 1), Leipzig 1896.

Gregor v. Tours, historiae: Gregor v. Tours, Historiarum libri decem - Zehn Bücher Geschichten. Auf Grund der Übersetzung W. Giesebrechts neu bearbeitet von Rudolf Buchner, Darmstadt 1955-1956.

Gregor v. Tours, liber de passione et virtutibus sancti Iuliani martyris: Gregorii episcopi Turonensis miracula et opera minora, ed. Bruno Krusch (MGH SS rer. Merov. 1, 2), Hannover 1885, 112-134.

Gregor v. Tours, libri IV de virtutibus sancti Martini episcopi: Gregorii episcopi Turonensis miracula et opera minora, ed. Bruno Krusch (MGH SS rer. Merov. 1, 2), Hannover $1885,134-211$.

Gregor v. Tours, liber vitae patrum: Gregorii episcopi Turonensis miracula et opera minora, ed. Bruno Krusch (MGH SS rer. Merov. 1, 2), Hannover 1885, 211-294.

Gregor v. Tours, liber in gloria confessorum: Gregorii episcopi Turonensis miracula et opera minora, ed. Bruno Krusch (MGH SS rer. Merov. 1, 2), Hannover 1885, 294 370.

Hieronymus, epistulae: Saint Jérôme, Lettres. Texte établi et traduit par Jérôme Labourt, 8 Bde., Paris 1949-1963.

Hilarius v. Arles, sermo de vita Honorati: Hilaire d'Arles, Vie de Saint Honorat. Introduction, traduction, texte critique et notes par Marie-Denise Valentin (SC 235), Paris 1977.

Paulinus v. Mailand, Vita Ambrosii: Vite dei santi, Bd. 3: Vita di Cipriano, Vita di Ambrogio, Vita di Agostino. Introduzione di Christine Mohrmann, testo critico e commento a.c.d. Antoon A.R. Bastiaensen, traduzioni di Luca Carnali e Carlo Carena, Verona $1975,54-125$.

Paulinus v. Nola, epistulae: Paulinus v. Nola, Epistulae - Briefe, übers. u. eingel. von Matthias Skeb, 3 Bde. (FC 25, 1-3), Freiburg i.Br. 1998.

Ruricius v. Limoges, epistulae: Foebadius, Victricius, Leporius, Vincentius Lerinensis, Evagrius, Ruricius, cura et studio Roland Demeulenaere (CCSL 64), Turnhout 1985, 303-415.

Sidonius Apollinaris, epistulae: Sidoine Apollinaire, Euvres, Bd. 2-3: Lettres. Texte établi et traduit par André Loyen, 2 Bde., Paris 1970. 
Sulpicius Severus, Chronica: Sulpice Sévère, Chroniques. Introduction, texte critique, traduction et commentaire par Ghislaine de Senneville-Grave (SC 441), Paris 1999.

Sulpicius Severus, Vita Martini: Sulpice Sévère, Vie de Saint Martin. Introduction, texte, traduction et commentaire par Jacques Fontaine, 3 Bde. (SC 133-135), Paris 19671969.

Sulpicius Severus, dialogi: Sulpice Sévère, Gallus. Dialogues sur les „vertus“ de saint Martin. Introduction, traduction, texte critique et notes par Jacques Fontaine (SC 510), Paris 2006.

Theodoret v. Kyrrhos, Historia religiosa: Théodoret de Cyr, Histoire des moines de Syrie. „Histoire Philothée“. Introduction, texte, traduction et notes par Pierre Canivet et Alice Leroy-Molinghen, 2 Bde. (SC 234, 257), Paris 1977-1979.

Uranius, epistula de obitu Paulini: Salviani Massilienis presbyteri, S. Patricii, Hibernorum apostoli, Arnobii iunioris, Mamerti Claudiani opera omnia, accurante et denuo recognoscente Jacques-Paul Migne (PL 53), Paris 1847, 859-865 (ed. Laurentius Surius).

Venantius Fortunatus, carmina: Venance Fortunat, Poèmes. Texte établi et traduit par Marc Reydellet, 3 Bde., Paris 1994-2004.

Venantius Fortunatus, Vita Germani episcopi Parisiensis: Passiones vitaeque sanctorum aevi Merovingici 5, ed. Bruno Krusch und Wilhelm Levison (MGH SS rer. Merov. 7), Hannover 1920, 372-418.

Venantius Fortunatus, Vita Hilarii episcopi Pictavensis: Venanti Honori Clementiani Fortunati presbyteri Italici Opera pedestrian, rec. Bruno Krusch (MGH Auct. ant. 4, 2), Berlin 1885, 1-11.

Vita Audoini episcopi Rotomagensis: Passiones vitaeque sanctorum aevi Merovingici 3, ed. Bruno Krusch und Wilhelm Levison (MGH SS rer. Merov. 5), Hannover 1910, 536-567.

Vita Caesarii episcopi Arelatensis: Sancti Caesarii episcopi Arelatensis opera omnia, Bd. 2: Opera varia, studio et diligentia Germain Morin, Maredsous 1942, 291-345.

Vita Eligii episcopi Noviomagensis: Passiones vitaeque sanctorum aevi Merovingici 2, ed. Bruno Krusch (MGH SS rer. Merov. 4), Hannover 1902, 634-741

Vita Eutropii episcopi Arausicani: Varin, Pierre-Joseph, Vie de saint Eutrope, évêque d'Orange, par Verus, son sucesseur, in: Bulletin du comité des monuments historiques écrits de l'histoire de France 1, 1849, 51-64.

Vita Genovefae virginis Parisiensis: Passiones vitaeque sanctorum aevi Merovingici et antiquiorum aliquot, ed. Bruno Krusch (MGH SS rer. Merov. 3), Hannover 1896, 204-238, 685f.

Vita Hilarii episcopi Arelatensis: Honorat de Marseille, Vie d'Hilaire d'Arles. Texte latin de Samuel Cavallin. Introduction, traduction et notes par Paul-André Jacob (SC 404), Paris 1995.

Vita Iusti episcopi Lugdunensis: AASS Sept. 1, 373f. (ed. Johannes Stilting).

Vita Lupi episcopi Trecensis: Passiones vitaeque sanctorum aevi Merovingici 5, ed. Bruno Krusch und Wilhelm Levison (MGH SS rer. Merov. 7), Hannover 1920, 284-302.

Vita Nicetii episcopi Lugdunensis: Passiones vitaeque sanctorum aevi Merovingici et antiquiorum aliquot, ed. Bruno Krusch (MGH SS rer. Merov. 3), Hannover 1896, 521-524.

Vita Viviani episcopi Santonensis: Passiones vitaeque sanctorum aevi Merovingici et antiquiorum aliquot, ed. Bruno Krusch (MGH SS rer. Merov. 3), Hannover 1896, 94 100; Passiones vitaeque sanctorum aevi Merovingici 5, ed. Bruno Krusch und Wilhelm Levison (MGH SS rer. Merov. 7), Hannover 1920, 806-810. 
Zosimos, historia nova: Zosime, Histoire nouvelle. Texte établi et traduit par François Paschoud, Paris 1971 (2. Aufl. 2003)-1989.

\section{Inschriftencorpora}

ILCV: Inscriptiones latinae christinae veteres, Bd. 1-3 ed. Ernst Diehl, Berlin 1925-1931; Bd. 4 ed. Jacques Moreau u. Henri-Irénée Marrou, Berlin 1972.

Le Blant: Inscriptions chrétiennes de la Gaule antérieures au VIII ${ }^{\mathrm{e}}$ siècle, réunies et annotées par Edmond Le Blant, 2 Bde., Paris 1856-1865.

\section{Sekundärliteratur}

Anton (1996): Hans H. Anton, „,Bischofsherrschaften“ und ,Bischofsstaaten“ in Spätantike und Frühmittelalter. Reflexionen zu ihrer Genese, Struktur und Typologie“, in: Friedhelm Burgard, Christoph Cluse u. Alfred Haverkamp (Hgg.), Liber amicorum necnon et amicarum für Alfred Heit. Beiträge zur mittelalterlichen Geschichte und geschichtlichen Landeskunde, Trier, 461-473.

Atsma (1983): Hartmut Atsma, ,Klöster und Mönchtum im Bistum Auxerre bis zum Ende des 6. Jahrhunderts“, Francia 11, 1-96.

Bailey (2003): Lisa K. Bailey, „Building Urban Christian Communities: Sermons on Local Saints in the Eusebius Gallicanus Collection", EME 12, 1-24.

Bailey (2010): Lisa K. Bailey, Christianity's Quiet Success. The Eusebius Gallicanus Collection and the Power of the Church in Late Antique Gaul, Notre Dame.

Baldovin (1987): John F. Baldovin, The Urban Character of Christian Worship. The Origins, Development, and Meaning of Stational Liturgy, Rom.

Barnish (1988): Samuel J.B. Barnish, „Transformation and Survival in the Western Senatorial Aristocracy, c. A.D. 400-700“, PBSR 56, 120-155.

Baumgart (1995): Susanne Baumgart, Die Bischofsherrschaft im Gallien des 5. Jahrhunderts. Eine Untersuchung zu den Gründen und Anfängen weltlicher Herrschaft der Kirche, München.

Beaujard (1991): Brigitte Beaujard, „Cités, évêques et martyrs en Gaule à la fin de l'époque romain“, in: Les fonctions des saints dans le monde occidental (IIIe-XIIIe siècle), Rom, 175-191.

Beaujard (2000): Brigitte Beaujard, Le culte des saints en Gaule. Les premiers temps. D'Hilaire de Poitiers à la fin du VIe siècle, Paris.

Beaujard (2009): Brigitte Beaujard, „Le culte des saints évêques“, in: Isabelle Cartron (Hg.), Autour de Saint-Seurin: lieu, mémoire, pouvoir. Des premiers temps chrétiens à la fin du Moyen Âge, Bordeaux, 71-77.

Becher (2009): Matthias Becher, „Herrschaft‘ im Übergang von der Spätantike zum Frühmittelalter", in: Theo Kölzer u. Rudolf Schieffer (Hgg.), Von der Spätantike zum frühen Mittelalter: Kontinuitäten und Brüche, Konzeptionen und Befunde (Vorträge und Forschungen 70), Ostfildern, 163-188.

Beck (1950): Henry J.G. Beck, The Pastoral Care of Souls in South-East France during the Sixth Century, Rom.

Berschin (1986): Walter Berschin, Biographie und Epochenstil im lateinischen Mittelalter, Bd. 1: Von der Passio Perpetuae zu den Dialogi Gregors des Großen, Stuttgart. 
Borgolte (1988): Michael Borgolte, „Die Stiftungen des Mittelalters in rechts- und sozialhistorischer Sicht", ZRG Kan. Abt. 74, 71-94.

Bosl (1965): Karl Bosl, „Der ,Adelsheilige‘. Idealtypus und Wirklichkeit, Gesellschaft und Kultur im merowingerzeitlichen Bayern des 7. und 8. Jahrhunderts“, in: Clemens Bauer u.a. (Hgg.), Speculum historiale. Geschichte im Spiegel von Geschichtsschreibung und Geschichtsdeutung. Festschrift Johannes Spörl zum 60. Geburtstag, Freiburg/München, 167-187.

Bowes (2008): Kim Bowes, Private Worship, Public Values, and Religious Change in Late Antiquity, Cambridge.

Braun (1907): Joseph Braun, Die liturgische Gewandung im Occident und Orient nach Ursprung und Entwicklung, Verwendung und Symbolik, Freiburg.

Brennan (1985): Brian Brennan, „Senators and Social Mobility in Sixth-Century Gaul“, $J M H ~ 11,145-161$.

Brennan (1992): Brian Brennan, „The Image of the Merovingian Bishop in the Poetry of Venantius Fortunatus“, JMH 18, 115-139.

Breukelaar 1994: Adriaan H.B. Breukelaar, Historiography and Episcopal Authority in Sixth-Century Gaul: The Histories of Gregory of Tours interpreted in Their Historical Context, Göttingen.

Brown (1976 [1982]): Peter Brown, „Eastern and Western Christendom in Late Antiquity: A Parting of the Ways“, in: Derek Baker (Hg.), The Orthodox Churches and the West (Studies in Church History 13), Oxford, 1-24 (aktualisierter ND in: ders., Society and the Holy in Late Antiquity, Berkeley/Los Angeles 1982, 166-195).

Brown (1977 [1982]): Peter Brown, Relics and Social Status in the Age of Gregory of Tours, Reading (aktualisierter ND in: ders., Society and the Holy in Late Antiquity, Berkeley/Los Angeles 1982, 222-250).

Brown (1981): Peter Brown, The Cult of the Saints. Its Rise and Function in Latin Christianity, Chicago.

Brown (1992): Peter Brown, Power and Persuasion in Late Antiquity. Towards a Christian Empire, Madison.

Brown (2000a): Peter Brown, Augustinus von Hippo. Eine Biographie, München, 2. Aufl.

Brown (2000b): Peter Brown, „The Study of Elites in Late Antiquity“, Arethusa 33, 321 346.

Brown (2002a): Peter Brown, „Gregory of Tours: Introduction“, in: Kathleen Mitchell u. Ian Wood (Hgg.), The World of Gregory of Tours, Leiden u.a., 1-28.

Brown (2002b): Peter Brown, Poverty and Leadership in the Later Roman Empire, Hanover.

Brown (2012): Peter Brown, Through the Eye of a Needle. Wealth, the Fall of Rome, and the Making of Christianity in the West, 350-550 AD, Princeton.

Bruggisser (1993): Philippe Bruggisser, Symmaque ou le rituel épistolaire de l'amitié littéraire. Recherches sur le premier livre de la correspondence, Fribourg.

Brühl (1995): Carlrichard Brühl, „Die merowingische Immunität“, in: Chiesa e mondo feudale nei secoli $X-X I I$ (Atti della dodicesima Settimana internazionale di studio Mendola, 24-28 agosto 1992), Mailand, 27-44.

Brunert (1994): Maria-Elisabeth Brunert, Das Ideal der Wüstenaskese und seine Rezeption in Gallien bis zum Ende des 6. Jahrhunderts, Münster.

Cameron (1979): Averil Cameron, „Images of Authority: Elites and Icons in Late SixthCentury Byzantium“, Past and Present 34, 3-35. 
Claude (1964): Dietrich Claude, „Untersuchungen zum frühfränkischen Comitat“, $Z R G$ Germ. Abt. 81, 1-79.

Coates (2000): Simon Coates, „Venantius Fortunatus and the Image of Episcopal Authority in Late Antique and Early Merovingian Gaul", EHR 115, 1109-1137.

Collins (1981): Richard Collins, „Observations on the Form, Language and Public of the Prose Biographies of Venantius Fortunatus in the Hagiography of Merovingian Gaul", in: Mary Brennan u. Howard B. Clarke (Hgg.), Columbanus and Merovingian Monasticism, Oxford, 105-131.

Consolino (1979): Franca E. Consolino, Ascesi e mondanità nella Gallia tardoantica. Studi sulla figura del Vescovo nei secoli IV-VI, Neapel.

De Gaiffier (1954): Baudouin de Gaiffier, „La lecture des actes des martyrs dans la prière liturgique en Occident", $A B$ 72, 134-166.

De Jong (2000): Mayke de Jong, „Transformations of Penance“, in: Frans Theuws u. Janet L. Nelson (Hgg.), Rituals of Power. From Late Antiquity to the Early Middle Ages, Leiden, 185-224.

De Vogüé (2003): Adalbert de Vogüé, Histoire littéraire du mouvement monastique dans l'antiquité, Bd. 7: L'essor de la littérature lérinienne et les écrits contemporains (410500), Paris.

Diefenbach (2002): Steffen Diefenbach, „Zwischen Liturgie und civilitas. Konstantinopel im 5. Jahrhundert und die Etablierung eines städtischen Kaisertums“, in: Rainer Warland (Hg.), Bildlichkeit und Bildort von Liturgie. Schauplätze in Spätantike, Byzanz und Mittelalter, Wiesbaden, 21-49.

Diefenbach (2007): Steffen Diefenbach, Römische Erinnerungsräume. Heiligenmemoria und kollektive Identitäten im Rom des 3. bis 5. Jahrhunderts $n$. Chr., Berlin/New York.

Diem (2005): Albrecht Diem, Das monastische Experiment. Die Rolle der Keuschheit bei der Entstehung des westlichen Klosterwesens, Münster.

Dolbeau (1983): François Dolbeau, „La vie en prose de saint Marcel, évêque de Die. Histoire du texte et édition critique", Francia 11, 97-130.

Dolbeau (2010): François Dolbeau, „Transformations des prologues hagiographiques, dues aux réécritures“, in: Monique Goullet, Martin Heinzelmann u. Christiane Veyrard-Cosme (Hgg.), L’hagiographie mérovingienne à travers ses réécritures, Ostfildern, 103-119.

Durliat (1990): Jean Durliat, Les finances publiques de Diocletien aux Carolingiens (284889), Sigmaringen.

Durliat (1996): Jean Durliat, „Évêque et administration municipale au VIIe siècle“, in: Claude Lepelley (Hg.), La fin de la cité antique et le début de la cité médiévale: de la fin du IIIe siècle à l'avènement de Charlemagne, Bari, 273-286.

Ebanista (2005): Carlo Ebanista, „Il ruolo del santuario martiriale di Cimitile nella trasformazione del tessuto urbano di Nola“, in: Giovanni Vitolo (Hg.), Le città campane fra tarda antichità e alto medioevo, Salerno, 313-377.

Ebbeler (2009): Jennifer Ebbeler, „Tradition, Innovation, and Epistolary Mores“, in: Philip Rousseau (Hg.), A Companion to Late Antiquity, Malden, 270-284.

Eck (1978): Werner Eck, „Der Einfluß der konstantinischen Wende auf die Auswahl der Bischöfe im 4. und 5. Jahrhundert", Chiron 8, 561-585.

Effros (2003): Bonnie Effros, Merovingian Mortuary Archaeology and the Making of the Early Middle Ages, Berkeley u.a. 
Elm (2003): Eva Elm, Die Macht der Weisheit. Das Bild des Bischofs in der Vita Augustini des Possidius und anderen spätantiken und frühmittelalterlichen Bischofsviten, Leiden.

Epp (1999): Verena Epp, Amicitia. Zur Geschichte personaler, sozialer, politischer und geistlicher Beziehungen im frühen Mittelalter, Stuttgart.

Esders (1993): Stefan Esders, „Rechtsdenken und Traditionsbewußtsein in der gallischen Kirche zwischen Spätantike und Frühmittelalter. Zur Anwendbarkeit soziologischer Rechtsbegriffe am Beispiel des kirchlichen Asylrechts im 6. Jahrhundert", Francia 20/1, 97-125.

Evenepoel (1989): Willy Evenepoel, „The Vita Felicis of Paulinus Nolanus and the Beginnings of Latin Hagiography“, in: Antoon A.R. Bastiaensen, Antonius Hilhorst u. Corneille H. Kneepkens (Hgg.), Fructus centesimus. Mélanges offerts à Gerard J.M. Bartelink à l'occasion de son soixante-cinquième anniversaire, Steenbrugge, 167176.

Ewig (1976 [1955]): Eugen Ewig, „Das Fortleben römischer Institutionen in Gallien und Germanien“, in: X Congresso Internazionale di Scienze Storiche, Relazioni, Bd. 6, Florenz 1955, 561-598 (ND in ders., Spätantikes und fränkisches Gallien. Gesammelte Schriften (1952-1973), Bd. 1, München, 409-434).

Ewig (1979 [1954]): Eugen Ewig, „Milo et eiusmodi similes“, in: Sankt Bonifatius. Gedenkgabe zum 1200. Todestag, Fulda 1954, 412-440 (ND in ders., Spätantikes und fränkisches Gallien. Gesammelte Schriften (1952-1973), Bd. 2, München, 189-219).

Ewig (1979 [1968]): Eugen Ewig, „Beobachtungen zu den Klosterprivilegien des 7. und frühen 8. Jahrhunderts“, in: Josef Fleckenstein u.a. (Hgg.), Adel und Kirche. Gerd Tellenbach zum 65. Geburtstag dargebracht von Freunden und Schülern, Freiburg i.Br. u.a. 1968, 52-65 (ND in ders., Spätantikes und fränkisches Gallien. Gesammelte Schriften (1952-1973), Bd. 2, München, 411-426).

Ewig (2009 [1978]): Eugen Ewig, „Bemerkungen zur Vita des Bischofs Lupus von Troyes“, in: Karl Hauck u. Hubert Mordek (Hgg.), Geschichtsschreibung und geistiges Leben im Mittelalter. Festschrift für Heinz Löwe zum 65. Geburtstag, Köln u.a. 1978, 14-26 (ND in ders., Spätantikes und fränkisches Gallien. Gesammelte Schriften (1974-2007), Bd. 3, Ostfildern, 505-517.

Fehr (2010): Hubert Fehr, Germanen und Romanen im Merowingerreich. Frühgeschichtliche Archäologie zwischen Wissenschaft und Zeitgeschehen, Berlin/New York.

Fontaine (1967-1969): Jacques Fontaine, Sulpice Sévère, Vie de saint Martin. Introduction, texte, traduction et commentaire, 3 Bde., Paris.

Fontaine (1973): Jacques Fontaine, „L'ascétisme chrétien dans la literature gallo-romaine d'Hilaire à Cassien“, in: Atti del colloquio sul tema: La Gallia Romana, Rom, 87115 .

Fouracre (1990): Paul Fouracre, „Merovingian History and Merovingian Hagiography“, Past and Present 127, 3-38.

Fouracre (1999): Paul Fouracre, „The Origins of the Carolingian Attempt to regulate the Cult of Saints", in: James Howard-Johnston (Hg.), The Cult of Saints in Late Antiquity and the Middle Ages. Essays on the Contribution of Peter Brown, Oxford, 143-165.

Fouracre u. Gerberding (1996): Paul Fouracre u. Richard A. Gerberding, Late Merovingian France. History and Hagiography 640-720, Manchester.

Frank (1997): Karl S. Frank, „Martin von Tours und die Anfänge seiner Verehrung“, in: Werner Groß u. Wolfgang Urban (Hgg.), Martin von Tours. Ein Heiliger Europas, Ostfildern, 21-62. 
Frank (2010): Karl S. Frank, Geschichte des christlichen Mönchtums, Darmstadt, 6. Aufl. Gassmann (1977): Peter Gassmann, Der Episkopat in Gallien im 5. Jahrhundert, Diss. Bonn.

Gauthier (2000): Nancy Gauthier, „Le réseau de pouvoirs de l'évêque dans la Gaule du haut Moyen Âge“, in: Gian P. Brogiolo, Neil Christie u. Nancy Gauthier (Hgg.), Towns and Their Territories between Late Antiquity and the Early Middle Ages, Leiden, 173-207.

Gemeinhardt (2007): Peter Gemeinhardt, Das lateinische Christentum und die antike pagane Bildung, Tübingen.

Gillett (2003): Andrew Gillett, Envoys and Political Communication in the Late Antique West, 411-533, Cambridge.

Gilliard (1979): Frank D. Gilliard, „The Senators of Sixth-Century Gaul“, Speculum 54, 685-697.

Godding (2001): Robert Godding, Prêtres en Gaule mérovingienne, Brüssel.

Gotter (2008): Ulrich Gotter, „Cultural Differences and Cross-Cultural Contact. Greek and Roman Concepts of Power", HSCP 104, 179-230.

Graus (1961): František Graus, „Die Gewalt bei den Anfängen des Feudalismus und die ,Gefangenenbefreiungen" der merowingischen Hagiographie", Jahrbuch für Wirtschaftsgeschichte, 61-156.

Graus (1965): František Graus, Volk, Herrscher und Heiliger im Reich der Merowinger. Studien zur Hagiographie der Merowingerzeit, Prag.

Haensch (2007): Rudolf Haensch, „Die Rolle der Bischöfe im 4. Jahrhundert: Neue Anforderungen und neue Antworten“, Chiron 37, 153-181.

Halsall (1995): Guy Halsall, Settlement and Social Organization. The Merovingian Region of Metz, Cambridge.

Halsall (2007): Guy Halsall, Barbarian Migrations and the Roman West, 376-568, Cambridge.

Harries (1994): Jill Harries, Sidonius Apollinaris and the Fall of Rome AD 407-485, Oxford.

Harries (1999): Jill Harries, Law and Empire in Late Antiquity, Cambridge.

Hartmann (1995): Wilfried Hartmann, „Der Bischof als Richter nach den kirchenrechtlichen Quellen des 4. bis 7. Jahrhunderts", in: La giustizia nell'alto medioevo (secoli VVIII) (Settimane di studio del centro italiano di studi sull'alto medioevo 42), Bd. 2, Spoleto, 805-842.

Heather (1994): Peter Heather, „Literacy and Power in the Migration Period“, in: Alan K. Bowman u. Greg Woolf (Hgg.), Literacy and Power in the Ancient World, Cambridge, 177-197.

Heinzelmann (1976): Martin Heinzelmann, Bischofsherrschaft in Gallien. Zur Kontinuität römischer Führungsschichten vom 4. bis zum 7. Jahrhundert. Soziale, prosopographische und bildungsgeschichtliche Aspekte, München.

Heinzelmann (1977): Martin Heinzelmann, „Sanctitas und ,Tugendadel“. Zu Konzeptionen von ,Heiligkeit“ im 5. und 10. Jahrhundert“, Francia 5, 741-752.

Heinzelmann (1981): Martin Heinzelmann, „Une source de base de la littérature hagiographique latine: le recueil de miracles", in: Hagiographie. Cultures et societies. IVeXIIe siècles, Paris, 235-259.

Heinzelmann (1982): Martin Heinzelmann, „Gallische Prosopographie, 260-527“, Francia 10, 531-718. 
Heinzelmann (1988): Martin Heinzelmann, „Bischof und Herrschaft vom spätantiken Gallien bis zu den karolingischen Hausmeiern. Die institutionellen Grundlagen“, in: Friedrich Prinz (Hg.), Herrschaft und Kirche. Beiträge zur Entstehung und Wirkungsweise episkopaler und monastischer Organisationsformen, Stuttgart, 23-82.

Heinzelmann (1990): Martin Heinzelmann, „Studia sanctorum. Éducation, milieux d'instruction et valeurs éducatives dans l'hagiographie en Gaule jusqu'à la fin de l'époque mérovingienne“, in: Claude Lepelley u.a. (Hgg.), Haut Moyen-Âge. Culture, éducation et société. Études offertes à Pierre Riché, Paris, 105-138.

Heinzelmann (1992): Martin Heinzelmann, „The ,Affair‘ of Hilary of Arles (445) and Gallo-Roman Identity in the Fifth Century“, in: John F. Drinkwater u. Hugh Elton (Hgg.), Fifth-Century Gaul: A Crisis of Identity?, Cambridge, 239-251.

Heinzelmann (1994): Martin Heinzelmann, Gregor von Tours (538-594) „Zehn Bücher Geschichte". Historiographie und Gesellschaftskonzept im 6. Jahrhundert, Darmstadt.

Heinzelmann (2007): Martin Heinzelmann, „Grégoire de Tours et l'hagiographie mérovingienne“", in: Antonella degl'Innocenti u.a. (Hgg.), Gregorio Magno e l'agiografia fra IV e VII secolo (Atti dell'incontro di studio delle Università di Verona e Trento, Verona, 10-11 dicembre 2004), Florenz, 155-192.

Heinzelmann (2010): Martin Heinzelmann, „L’hagiographie mérovingienne: panorama des documents potentiels“, in: Monique Goullet, Martin Heinzelmann u. Christiane Veyrard-Cosme (Hgg.), L’hagiographie mérovingienne à travers ses réécritures, Ostfildern, 27-82.

Heinzelmann u. Poulin (1986): Martin Heinzelmann u. Joseph-Claude Poulin, Les vies anciennes de sainte Geneviève de Paris. Études critiques, Paris/Genf.

Hen (1995): Yitzhak Hen, Culture and Religion in Merovingian Gaul A.D. 481-751, Leiden u.a.

Humfress (2011): Caroline Humfress, „Bishops and Law Courts in Late Antiquity: How (Not) to Make Sense of the Legal Evidence“, JECS 19, 375-400.

James (1983): Edward James, „Beati pacifici: Bishops and the Law in Sixth-Century Gaul“, in: John Bossy (Hg.), Disputes and Settlements: Law and Human Relations in the West, Cambridge, 25-46.

Jenal (1995): Georg Jenal, Italia ascetica atque monastica. Das Asketen- und Mönchtum in Italien von den Anfängen bis zur Zeit der Langobarden (ca. 150/250-604), 2 Bde., Stuttgart.

Jones (2009): Allen E. Jones, Social Mobility in Late Antique Gaul: Strategies and Opportunities for the Non-Elite, Cambridge.

Jussen (1995): Bernhard Jussen, „Über ,Bischofsherrschaften“ und die Prozeduren politisch-sozialer Umordnung in Gallien zwischen ,Antike“ und ,Mittelalter“", $H Z$ 260, $673-718$.

Jussen (1998): Bernhard Jussen, „Liturgie und Legitimation, oder: Wie die Gallo-Romanen das Römische Reich beendeten“, in: Reinhard Blänkner u. Bernhard Jussen (Hgg.), Institutionen und Ereignis. Über historische Praktiken und Vorstellungen gesellschaftlichen Ordnens, Göttingen, 75-136.

Jussen (2001): Bernhard Jussen, „Liturgy and Legitimation, or How the Gallo-Romans Ended the Roman Empire“, in: Bernhard Jussen (Hg.), Ordering Medieval Society. Perspectives on Intellectual and Practical Modes of Shaping Social Relations, Philadelphia, 147-199. 
Kaiser (1981): Reinhold Kaiser, Bischofsherrschaft zwischen Königtum und Fürstenmacht. Studien zur bischöflichen Stadtherrschaft im westfränkisch-französischen Reich im frühen und hohen Mittelalter, Bonn.

Kaiser (1988): Reinhold Kaiser, „Königtum und Bischofsherrschaft im frühmittelalterlichen Neustrien“, in: Friedrich Prinz (Hg.), Herrschaft und Kirche. Beiträge zur Entstehung und Wirkungsweise episkopaler und monastischer Organisationsformen, Stuttgart, 83-108.

Kaiser (2004): Reinhold Kaiser, Das römische Erbe und das Merowingerreich, München, 3. Aufl.

Kasper (1991): Clemens M. Kasper, Theologie und Askese. Die Spiritualität des Inselmönchtums von Lérins im 5. Jahrhundert, Münster.

Klingshirn (1994): William E. Klingshirn, Caesarius of Arles. The Making of a Christian Community in Late Antique Gaul, Cambridge.

Kolon (1925): Benedikt Kolon, Die Vita S. Hilarii Arelatensis. Eine eidographische Studie, Paderborn.

König (1985): Dorothee König, Amt und Askese in der frühen Kirche. Priesteramt und Mönchtum bei den lateinischen Kirchenvätern der vorbenediktinischen Zeit, St. Ottilien.

Kritzinger (2009): Peter Kritzinger, Bischöfliche Repräsentation. Ursprung und Entwicklung bis zum Niedergang des weströmischen Reiches, Diss. Jena.

Kuhn (2009): Eva-Maria Kuhn, „Rechtsprechung durch den Bischofsrichter. Augustin und die Umsetzung der göttlichen Gerechtigkeit in der Praxis“, in: Johannes Hellebrand (Hg.), Augustinus als Richter, Würzburg, 106-155.

Kuhn (i. Druck): Eva-Maria Kuhn, „Listening to the Bishop. A Note on the Construction of Judicial Authority in Confessions 6, 3-5“, erscheint in: Studia Patristica.

Le Jan (2004): Régine Le Jan, „Le lien social entre Antiquité et haut Moyen Âge: l'amitié dans les collections de lettres gauloises“, in: Dieter Hägermann, Wolfgang Haubrichs u. Jörg Jarnut (Hgg.), Akkulturation. Probleme einer germanisch-romanischen Kultursynthese in Spätantike und frühem Mittelalter, Berlin, 528-546.

Lehmann (2004): Tomas Lehmann, Paulinus Nolanus und die Basilica Nova in Cimitile/Nola. Studien zu einem zentralen Denkmal der spätantik-frühchristlichen Architektur, Wiesbaden.

Levison (1904): Wilhelm Levison, „Bischof Germanus von Auxerre und die Quellen zu seiner Geschichte“, Neues Archiv 29, 95-175.

Liebeschuetz (2001): John H.W.G. Liebeschuetz, Decline and Fall of the Roman City, Oxford.

Lienhard (1977): Joseph T. Lienhard, Paulinus of Nola and Early Western Monasticism. With a Study of the Chronology of His Works and an Annotated Bibliography, 18791976, Köln/Bonn.

Loseby (1998): Simon T. Loseby, „Gregory's Cities: Urban Functions in Sixth-Century Gaul", in: Ian Wood (Hg.), Franks and Alemanni in the Merovingian Period. An Ethnographic Perspective, Woodbridge, 239-270.

Loseby (2006): Simon T. Loseby, „Decline and Change in the Cities of Late Antique Gaul“, in: Jens-Uwe Krause u. Christian Witschel (Hgg.), Die Stadt in der Spätantike - Niedergang oder Wandel?, Stuttgart, 67-104.

Lutterbach (1995): Hubertus Lutterbach, Monachus factus est. Die Mönchwerdung im frühen Mittelalter. Zugleich ein Beitrag zur Frömmigkeits- und Liturgiegeschichte, Münster. 
Markus (1990): Robert A. Markus, The End of Ancient Christianity, Cambridge.

Martin (1990): Jochen Martin, „Die Macht der Heiligen“, in: Jochen Martin u. Barbara Quint (Hgg.), Christentum und antike Gesellschaft, Darmstadt, 440-474.

Mathisen (1981): Ralph W. Mathisen, „Epistolography, Literary Circles and Family Ties in Late Roman Gaul“, TAPA 111, 95-109.

Mathisen (1989): Ralph W. Mathisen, Ecclesiastical Factionalism and Religious Controversy in Fifth-Century Gaul, Washington D.C.

Mathisen (1993): Ralph W. Mathisen, Roman Aristocrats in Barbarian Gaul. Strategies of Survival in an Age of Transition, Austin.

Mathisen (1994): Ralph W. Mathisen, „The Ideology of Monastic and Aristocratic Community in Late Roman Gaul", Polis 6, 203-220.

Matthews (1990): John Matthews, Western Aristocracies and Imperial Court AD 364425, Oxford, 2. Aufl.

Mratschek (2002): Sigrid Mratschek, Der Briefwechsel des Paulinus von Nola. Kommunikation und soziale Kontakte zwischen christlichen Intellektuellen, Göttingen.

Müller (1999): Christoph Müller, „Der untypische Bischof. Martin von Tours und die Funktionen des Bischofs im spätantiken Gallien“, Rottenburger Jahrbuch für Kirchengeschichte 18, 141-165.

Müller (2003): Christoph Müller, Kurialen und Bischof, Bürger und Gemeinde. Untersuchungen zur Kontinuität von Ämtern, Funktionen und Formen der ,Kommunikation“ in der gallischen Stadt des 4.-6. Jahrhunderts, Diss. Freiburg.

Murray (1994): Alexander C. Murray, „Immunity, Nobility, and the Edict of Paris“, Speculum 69, 18-39.

Näf (1995): Beat Näf, Senatorisches Standesbewusstsein in spätrömischer Zeit, Fribourg.

Nathan (1998): Geoffrey S. Nathan, „The Rogation Ceremonies of Late Antique Gaul: Creation, Transmission and the Role of the Bishop“, Classica et Mediaevalia 49, 275-303.

Orselli (1965): Alba M. Orselli, L'idea e il culto del santo patrono cittadino nella letteratura latina cristiana, Bologna.

Patzold (2008): Steffen Patzold, Episcopus. Wissen über Bischöfe im Frankenreich des späten 8. bis frühen 10. Jahrhunderts, Ostfildern.

Patzold (2010): Steffen Patzold, „Zur Sozialstruktur des Episkopats und zur Ausbildung bischöflicher Herrschaft in Gallien zwischen Spätantike und Frühmittelalter", in: Matthias Becher u. Stefanie Dick (Hgg.), Völker, Reiche und Namen im frühen Mittelalter, München, 121-140.

Philippart u. Trigalet (2008): Guy Philippart u. Michel Trigalet, „Latin Hagiography before the Ninth Century: A Synoptic View“, in: Jennifer R. Davis u. Michael McCormick (Hgg.), The Long Morning of Medieval Europe. New Directions in Early Medieval Studies, Aldershot, 111-129.

Pietri (1976): Charles Pietri, Roma christiana. Recherches sur l'Église de Rome, son organisation, sa politique, son idéologie de Miltiade à Sixte III (311-440), 2 Bde., Rom.

Pietri (1986): Luce Pietri, „L'ordine senatorio in Gallia del 476 al fine del VI secolo“, in: Andrea Giradina (Hg.), Società romana e Impero tardoantico, Bd. 1, Rom/Bari, 307323.

Pohl (1999): Walter Pohl, „Herrschaft“, $R G A$ 14, 443-457.

Pohl (2006): Walter Pohl, „Staat und Herrschaft im Frühmittelalter: Überlegungen zum Forschungsstand“, in: Stuart Airlie, Walter Pohl u. Helmut Reimitz (Hgg.), Staat im frühen Mittelalter, Wien, 9-38. 
Poschmann (1928): Bernhard Poschmann, Die abendländische Kirchenbuße am Ausgang des christlichen Altertums, München.

Prinz (1971): Friedrich Prinz, Klerus und Krieg im frühen Mittelalter. Untersuchungen zur Rolle der Kirche beim Aufbau der Königsherrschaft, Stuttgart.

Prinz (1973a): Friedrich Prinz, „Die bischöfliche Stadtherrschaft im Frankenreich vom 5. bis zum 7. Jahrhundert“, $H Z$ 217, 1-35.

Prinz (1973b): Friedrich Prinz, „Gesellschaftsgeschichtliche Aspekte frühmittelalterlicher Hagiographie“, Zeitschrift für Literaturwissenschaft und Linguistik 3, 17-36.

Prinz (1981): Friedrich Prinz, „Der fränkische Episkopat zwischen Merowinger- und Karolingerzeit", in: Nascita dell'Europa ed Europa Carolingia: Un'equazione da verificare (Settimane di studio del centro italiano di studi sull'alto medioevo 27), Bd. 1, Spoleto, 101-133.

Prinz (1988a): Friedrich Prinz, Frühes Mönchtum im Frankenreich. Kultur und Gesellschaft in Gallien, den Rheinlanden und Bayern am Beispiel der monastischen Entwicklung (4. bis 8. Jahrhundert), München, 2. Aufl.

Prinz (1988b): Friedrich Prinz, „Herrschaftsformen der Kirche vom Ausgang der Spätantike bis zum Ende der Karolingerzeit. Zur Einführung ins Thema“, in: Friedrich Prinz (Hg.), Herrschaft und Kirche. Beiträge zur Entstehung und Wirkungsweise episkopaler und monastischer Organisationsformen, Stuttgart, 1-21.

Rapp (2005): Claudia Rapp, Holy Bishops in Late Antiquity. The Nature of Christian Leadership in an Age of Transition, Berkeley u.a.

Rebenich (1992): Stefan Rebenich, Hieronymus und sein Kreis. Prosopographische und sozialgeschichtliche Untersuchungen, Stuttgart.

Rio (2008): Alice Rio, The Formularies of Angers and Marculf. Two Merovingian Legal Handbooks, Liverpool.

Ripoll u. Arce (2000): Gisela Ripoll u. Javier Arce, „The Transformation and End of Roman villae in the West (Fourth-Seventh Centuries): Problems and Perspectives", in: Gian P. Brogiolo, Neil Christie u. Nancy Gauthier (Hgg.), Towns and Their Territories between Late Antiquity and the Early Middle Ages, Leiden, 63-114.

Rosenwein (1999): Barbara H. Rosenwein, Negotiating Space. Power, Restraint, and Privileges of Immunity in Early Medieval Europe, Manchester.

Rousseau (1976): Philip Rousseau, „In Search of Sidonius the Bishop“, Historia 25, 356377.

Scheibelreiter (1983): Georg Scheibelreiter, Der Bischof in merowingischer Zeit, Wien u.a.

Stancliffe (1983): Clare Stancliffe, St. Martin and His Hagiographer. History and Miracle in Sulpicius Severus, Oxford.

Sterk (2004): Andrea Sterk, Renouncing the World and Leading the Church. The MonkBishop in Late Antiquity, Cambridge (Mass.).

Stirling (2007): Lea M. Stirling, „Statuary Collecting and Display in Late Antique Villas of Gaul and Spain: A Comparative Study“, in: Franz A. Bauer u. Christian Witschel (Hgg.), Statuen in der Spätantike, Wiesbaden, 307-321.

Stroheker (1948): Karl F. Stroheker, Der senatorische Adel im spätantiken Gallien, Tübingen.

Thraede (1970): Klaus Thraede, Grundzüge griechisch-römischer Brieftopik, München.

Trichet (1986): Louis Trichet, La costume du clergé. Ses origines et son évolution en France d'après les reglements de l'Église, Paris.

Trout (1999): Dennis E. Trout, Paulinus of Nola. Life, Letters, and Poems, Berkeley. 
Uhalde (1999): Kevin Uhalde, „Proof and Reproof: The Judicial Component of Episcopal Confrontation“, EME 8, 1-11.

Uhalde (2008): Kevin Uhalde, „Juridical Administration in the Church and Pastoral Care in Late Antiquity“, in: Abigail Firey (Hg.), A New History of Penance, Leiden, 97120.

Van Dam (1985): Raymond van Dam, Leadership and Community in Late Antique Gaul, Berkeley/Los Angeles.

Van Dam (1993): Raymond van Dam, Saints and Their Miracles in Late Antique Gaul, Princeton.

Van Egmond (2006): Wolfert S. van Egmond, Conversing with the Saints. Communication in Pre-Carolingian Hagiography from Auxerre, Turnhout.

Van Ossel (1992): Paul van Ossel, Établissements ruraux de l'antiquité tardive dans le nord de la Gaule, Paris.

Van Uytfanghe (1985): Marc van Uytfanghe, „L'hagiographie et son public à l'époque mérovingienne“, Studia Patristica 16, 54-62

Van Uytfanghe (1987): Marc van Uytfanghe, Stylisation biblique et condition humaine dans l'hagiographie mérovingienne (600-750), Brüssel.

Van Uytfanghe (2001a): Marc van Uytfanghe, „L'hagiographie antique tardive: une littérature populaire?", AntTard 9, 201-218.

Van Uytfanghe (2001b): Marc van Uytfanghe, s. v. „Biographie II (spirituelle)“, in: RAC, suppl. 1, 1088-1364.

Van Uytfanghe (2005): Marc van Uytfanghe, „L'audience de l'hagiographie au VIe siècle en Gaule“, in: Étienne Renard u.a. (Hgg.), „Scribere sanctorum gesta“. Recueil d'études d'hagiographie médiévale offert à Guy Philippart, Turnhout, 157-177.

Van Uytfanghe (2007): Marc van Uytfanghe, „L'hagiographie en Occident de la Vita Antonii aux Dialogues de Grégoire le Grand: genèse et occupation du terrain“, in: Antonella degl'Innocenti u.a. (Hgg.), Gregorio Magno e l'agiografia fra IV e VII secolo (Atti dell'incontro di studio delle Università di Verona e Trento, Verona, 10-11 dicembre 2004), Florenz, 3-51.

Vogel (1952): Cyrille Vogel, La discipline pénitentielle en Gaule. Des origines à la fin du VIIe siècle, Paris.

Von der Nahmer (1987): Dieter von der Nahmer, „Martin von Tours: sein Mönchtum seine Wirkung“, Francia 15, 1-41.

Von Rummel (2007): Philipp von Rummel, Habitus barbarus. Kleidung und Repräsentation spätantiker Eliten im 4. und 5. Jahrhundert, Berlin/New York.

Weber (1972): Max Weber, Wirtschaft und Gesellschaft. Grundriß der verstehenden Soziologie, hrsg. von Johannes Winckelmann, Tübingen, 5. Aufl.

Weidemann (1982): Margarete Weidemann, Kulturgeschichte der Merowingerzeit nach den Werken Gregors von Tours, 2 Bde., Mainz.

Wickham (2005): Chris Wickham, Framing the Early Middle Ages. Europe and the Mediterranean, 400-800, Oxford.

Wiesheu (2001): Annette Wiesheu, „Bischof und Gefängnis. Zur Interpretation der Kerkerbefreiungswunder in der merowingischen Hagiographie", Historisches Jahrbuch $121,1-23$.

Winterling (2001): Aloys Winterling, „Die römische Republik im Werk Max Webers. Rekonstruktion - Kritik - Aktualität“, $H Z$ 273, 595-635.

Wood (1983): Ian Wood, „The Ecclesiastical Politics of Merovingian Clermont“, in: Donald Bullough, Roger Collins u. Patrick Wormald (Hgg.), Ideal and Reality in 
Frankish and Anglo-Saxon Society. Studies presented to J.M. Wallace-Hadrill, Oxford, 34-57.

Wood (2000): Ian Wood, „Family and Friendship in the West“, in: Averil Cameron u.a. (Hgg.), The Cambridge Ancient History, Bd. 14: Late Antiquity: Empire and Successors, A.D. 425-600, Cambridge, 416-436.

Zumkeller (1968): Adolar Zumkeller, Das Mönchtum des heiligen Augustinus, Würzburg, 2. Aufl. 



\section{III.}

STÄDTISCHER RAUM UND IDENTITÄT:

URBANER STRUKTURWANDEL IM SPÄTANTIKEN GALLIEN 



\title{
Die spätantiken Städte Galliens: Transformationen von Stadtbildern als Ausdruck einer gewandelten Identität?
}

\author{
Christian Witschel
}

Die Städte Galliens haben im Laufe der Spätantike einen intensiven Transformationsprozess erlebt. ${ }^{1}$ So lassen sich in Bezug auf die gesamte Städtelandschaft, insbesondere aber mit Blick auf die Topographie einzelner Ort zahlreiche Umwandlungen ausmachen. Es stellt sich daher die Frage, ob diese Veränderungen in der gebauten Umgebung der Menschen, also in der täglich erfahrbaren Lebenswelt der Städte, Auswirkungen auf die Identität und Mentalität der Bewohner des spätantiken Gallien gehabt haben bzw. ob ein solcher Mentalitätswandel eine der Voraussetzungen dafür war, dass es zu der genannten Umstrukturierung der Stadtbilder gekommen ist.

Die folgenden Beobachtungen konzentrieren sich auf den von Caesar eroberten Teil Galliens, der unter Augustus als Tres Galliae neu strukturiert wurde. ${ }^{2}$ Ein besonderes Augenmerk gilt dabei Südwestgallien, also der augusteischen Provinz Aquitania, die zu Beginn der Spätantike in die drei Provinzen Aquitania I und II sowie Novempopulana aufgeteilt wurde. ${ }^{3}$ Zudem geht es mir vornehmlich um die gallische ,Normalstadt ${ }^{4}$ und nicht um die großen Metropolen wie Trier, Arles und Toulouse, die - im gesamtgallischen Kontext gesehen - während der Spätan-

1 Zum spätantiken Städtewesen in Gallien vgl. die Überblicke von Février 1980 und Loseby 2006.

2 Auf die Städte Südostgalliens, also diejenigen im Bereich der Gallia Narbonensis, gehe ich hingegen nur am Rande ein; vgl. hierzu den Beitrag von Jean Guyon in diesem Band.

3 Zur kaiserzeitlichen und spätantiken Stadtentwicklung in Aquitanien vgl. die Beiträge in Maurin 1992a und Maurin/Pailler 1998 sowie die drei einschlägigen Bände der Reihe Topographie chrétienne des cités de la Gaule: Prévot/Barral i Altet 1989 zu Aquitania I; Maurin u.a. 1998 zu Aquitania II und Maurin u.a. 2004 zur Provinz Novempopulana.

4 Das bedeutet auch, dass die unterschiedlichen Rhythmen, in denen die spätantike Stadtentwicklung an den einzelnen Orten verlief, hier zu einem gewissen Maße ausgeblendet werden, um eher die gemeinsamen Trends herauszuarbeiten. Für einige Differenzierungen vgl. aber u. Anm. 10, 38 und 40. 
tike als Residenzen von Kaisern, hohen Reichsbeamten und später germanischen Königen eine eher exzeptionelle Entwicklung durchmachten. ${ }^{5}$

\section{Die Stabilität des römischen Städtenetzes in Gallien}

Bevor auf die angesprochenen Veränderungen eingegangen wird, soll jedoch auf einige Elemente der Kontinuität verwiesen werden, die das spätantike Städtewesen in Gallien durchaus (auch) prägten. ${ }^{6}$ Dabei ist zunächst festzuhalten, dass sich das von der römischen Verwaltung eingerichtete, aber bereits auf keltischen Wurzeln aufbauende Netz von sich selbst verwaltenden Gebietskörperschaften (civitates) in Gallien auf lange Sicht als erstaunlich stabil erwiesen hat. ${ }^{7}$ Das lässt sich vor allem daran erkennen, dass die Zahl ,gescheiterter' städtischer Gemeinwesen in Gallien - gerade auch im Vergleich zu anderen Regionen des Westens - eher gering war. ${ }^{8}$ Vielmehr wurden noch bis in das 4 . Jh. hinein immer wieder neue civitates eingerichtet. ${ }^{9}$ Trotz einiger Verlagerungen ihrer Zentralorte haben die

$5 \mathrm{Zu}$ Trier vgl. Kaiserresidenz und Bischofssitz 1984; Witschel 2004/05; Demandt/Engemann 2007, 304-341. Zu Arles vgl. Loseby 1996 und Heijmans 2004; zu Toulouse Guyon 2000 und Pailler 2002.

6 Wichtigste Quelle für die Konstanz des Städtenetzes und der damit verbundenen politischadministrativen Funktionen im spätantiken Gallien ist die um 400 n. Chr. entstandene Notitia Galliarum; vgl. zu dieser Harries 1978. Für das 5. und 6. Jh. lassen sich ferner die Angaben zu den Teilnehmern verschiedener gallischer Synoden in den jeweiligen Konzilsakten heranziehen, die aufzeigen können, welche civitates zu dieser Zeit als eigenständige Bischofssitze fungierten; s. hierzu Munier 1963 und Gaudemet/Basdevant 1989 sowie Loseby 1992, 144-149. Zahlreiche weitere Angaben sind schließlich dem Werk des Gregor von Tours zu entnehmen; vgl. dazu die Beiträge in Gauthier/Galinié 1997 und Mitchell/Wood 2002 sowie u. Anm. 19.

7 Zu den Anfängen und zur Entwicklung des römischen Städtewesens in Gallien während der frühen Kaiserzeit vgl. allgemein Bedon 1999 sowie die Beiträge in Duby 1980 und Goudineau/Rebourg 1991. Zur Raumgliederung und zu den Stadtrechtsformen im römischen Gallien vgl. ferner Wolff 1976 und Wolff 1989.

8 Vgl. hierzu die eingehende Analyse von Loseby 2000, bes. 75-79 (Übersichtstabelle), 80f. (Karte), sowie Beaujard/Prévot 2004, bes. 34 fig. 1. Allerdings kam es durchaus auch in Gallien vor, dass einzelne civitates im Laufe der Zeit als Verwaltungseinheiten gänzlich aufgelöst wurden (dies blieb jedoch die Ausnahme) oder sich innerhalb einer civitas eine Verlagerung der Zentralortfunktionen von einer Siedlung zu einer anderen ergab, was dann häufig - aber nicht immer - für Erstere einen starken Bedeutungsverlust und einen entsprechenden Niedergang bedeutete. Vgl. zu diesen ,capitales éphémères' den umfassenden Überblick sowie die Aufsätze und Katalogeinträge in Ferdière 2004; ferner Guyon 2006, 106-108. Dennoch blieb dies in Gallien im Vergleich zu anderen Regionen des Westens, etwa zu Italien, ein quantitativ eher unbedeutendes Phänomen; dazu Witschel 2008, 32-47.

9 Für die Tres Galliae ergeben sich dabei folgende Zahlen (jeweils in der Reihenfolge: Anzahl der civitates in der hohen Kaiserzeit - Anzahl der civitates in der Notitia Galliarum - Anzahl der Bischofssitze im 5./6. Jh.): Aquitania (Aquitania I und II sowie Novempopulana - gerade hier ist die Situation kompliziert; vgl. Esmonde Cleary 2004): 19/21 - 26 - 25. Gallia Lugdunensis (Lugdunensis I-III, Lugdunensis Senonia): 27 - 27 - 
meisten der in römischer Zeit begründeten Stadtgemeinden bis in das Mittelalter bzw. sogar bis heute überlebt - was im Übrigen bisweilen gewisse Probleme bereitet, weil wegen der dichten mittelalterlichen und modernen Überbauung des antiken Stadtgebiets fast kein urbanes Zentrum flächendeckend archäologisch untersucht werden konnte. ${ }^{10}$

Eine gallische Eigentümlichkeit war der oft sehr große Umfang der civitates, so dass der städtisch verdichtete Zentralort (also die ,Stadt" im siedlungsgeographischen Sinne, um die es im Folgenden vornehmlich gehen soll) ${ }^{11}$ in vielen Fällen von einem ausgedehnten Territorium umgeben war, was den ländlichen Regionen ein gewisses Übergewicht verschaffen konnte. Dennoch hat in den meisten gallischen civitates allem Anschein nach der urbane Mittelpunkt seine Zentralortfunktion vor allem in politischer, administrativer und religiöser (weniger in wirtschaftlicher) Hinsicht über lange Zeit hinweg beibehalten - und das galt auch noch für die Spätantike. Dass bei zahlreichen der civitas-Hauptorte im Laufe des 3. oder frühen 4. Jh.s ein Namenswechsel erfolgte, bei dem der frühkaiserzeitliche, oft künstlich gebildete Ortsname durch die (traditionelle) Bezeichnung der

26. Belgica (Belgica I und II): 13 - 16 - 16. Insgesamt stehen somit den ca. 60 civitates in der hohen Kaiserzeit 69 in der Notitia Galliarum aufgeführte und 67 im 5./6. Jh. als Bischofssitz belegte gegenüber.

10 Eine Ausnahme hiervon stellt die Situation der antiken Stadt Lugdunum (Convenarum) in der Provinz Novempopulana dar, da diese von der kleinen mittelalterlichen Ortschaft Saint-Bertrand-de-Comminges kaum überbaut worden ist, so dass hier großflächige Ausgrabungen möglich waren. Diese haben gezeigt, dass die Siedlung eine komplexe und längerfristige Entwicklung durchlief, welche nur partiell von äußeren Faktoren beeinflusst wurde; vgl. dazu Guyon/Sablayrolles 1991; Aupert/Monturet 1996; Maurin u.a. 2004, 58 80. So tritt in Lugdunum die Epoche des späteren 3. Jh.s, deren Bedeutung als vermeintlich entscheidende Zäsur für das gallische Städteleben in der modernen Forschung so stark betont worden ist, nicht als größerer Einschnitt hervor (s. dazu Guyon/Sablayrolles 1991, 92, 94), denn das monumentale Zentrum der Stadt wurde bis weit in das 4. Jh. hinein instand gehalten. Das Siedlungsgebiet scheint im 3. und 4. Jh. nicht wesentlich geschrumpft zu sein, und es wurde auch nicht von einem Mauerring umgeben. Ein solcher wurde erst im frühen 5. Jh. auf einem benachbarten Hügel errichtet (vgl. Esmonde Cleary u.a. 1998 sowie u. Anm. 39), was zusammen mit einer etwa gleichzeitig einsetzenden Auflassung von öffentlichen Gebäuden in der Unterstadt eine erhebliche Veränderung in der Siedlungsstruktur bewirkte (s. dazu auch Greg. Tur. HF 7, 34-35). Dies führte jedoch nicht zu einer sofortigen und völligen Aufgabe der Unterstadt, da hier auch im 5. Jh. noch eine gewisse Besiedlung fortbestand (vgl. etwa Mousseaux/Robin 2011, 98 zu den Badegebäuden) und im Bereich mehrerer ausgedehnter domus sogar eine größere christliche Basilika errichtet wurde, die offenbar nicht nur zu funerären Zwecken genutzt wurde, sondern zumindest anfänglich auch als Gemeindekirche diente; vgl. hierzu Pulchra imago 1991; Premiers monuments chrétiens 1996, 177-189; Guyon 2006, 117.

$11 \mathrm{Zu}$ der Forschungsdiskussion um den Stadtbegriff in der Antike vgl. etwa Kolb 1984, $11-$ 17; Whittaker 1995a und Zimmermann 1999/2000. Mehrheitlich wird ein siedlungsgeographischer Interpretationsansatz bevorzugt und dabei auf die Zentralortfunktion bestimmter Siedlungen sowie auf deren urbanistische Gestaltung abgehoben. Dabei scheint mir jedoch bisweilen der politisch-administrative Aspekt, der für das Verständnis der Zeitgenossen von einer civitas konstitutiv war (und dies auch noch im 6. Jh.; vgl. u. Anm. 81), etwas zu sehr in den Hintergrund zu treten. 
civitas ersetzt wurde, ${ }^{12}$ ist wohl nicht als Verdrängung des Stadtmodells durch den Stammesgedanken im Zuge einer späten ,keltischen Renaissance' zu erklären, sondern vielmehr als endgültige Durchsetzung des Primats des urbanen Mittelpunkts, der nun auch in seinem Namen die gesamte civitas repräsentierte, zu verstehen. ${ }^{13}$

Die politisch-administrativen Strukturen der gallischen civitates und deren munizipalen Einrichtungen wie die Curia sowie die städtischen Magistraturen ${ }^{14}$ haben allem Anschein nach in der Spätantike fortbestanden, obwohl die diesbezügliche Quellenlage zumeist recht dünn ist. ${ }^{15}$ Das gilt wohl auch noch für das spätere 5. und 6. Jh., als der Bischof eine immer dominantere Rolle in vielen Stadtgemeinden Galliens einnahm, ${ }^{16}$ ohne aber die etablierten Institutionen und ihre Träger, die städtischen Eliten, völlig verdrängen zu können. ${ }^{17}$ Gerade der

12 So wurde beispielsweise aus Augustoritum, dem Hauptort der civitas Lemovicum, im Laufe der Zeit die urbs Lemovica, das heutige Limoges; s. dazu die entsprechenden Belege bei Prévot/Barral i Altet 1989, 71f.

13 Vgl. zu diesem Phänomen die Überlegungen von Bost/Fabre 1983.

14 Allerdings lassen sich hierbei auch einige regionalspezifische Besonderheiten ausmachen. So wurde der defensor civitatis, der in den anderen Gebieten des Reiches ab dem späten 4. Jh. zum dominierenden städtischen Magistraten aufstieg, in Gallien im Laufe des 5. Jh.s zunehmend vom comes civitatis und insbesondere vom Bischof (vgl. u. Anm. 16) in den Hintergrund gedrängt, obwohl es dieses Amt noch im 6. Jh. gab (s. etwa Ven. Fort. carm. 10, 19: Burdigalensis eras et, cum defensor, amator); vgl. dazu Schmidt-Hofner (im Druck).

15 Für einige Quellenbelege zur Kontinuität munizipaler Institutionen im spätantiken Gallien s. Witschel 2004/05, 250f. mit Anm. 153. So sind etwa für Köln, also die colonia Agrippinensis bzw. die civitas Agrippinensium, im 4. Jh. sowohl die Existenz eines Stadtrates (s. Cod. Theod. 16, 8, 3 aus dem Jahr 321, ein Erlass gerichtet an decurionibus Agrippiniensibus) als auch die Fortdauer einer städtischen Ämterlaufbahn bezeugt (s. die Grabinschrift CIL XIII 7918 = ILS 7069 aus dem Jahr 352 für einen dec(urioni) c(oloniae) A(grippinensis), aedilicio, du(u)mvirali, curatoricio, sacerdotali et ex comitibus). Eine ähnlich günstige Quellenlage ist bei den meisten anderen gallischen civitates nicht gegeben, aber es spricht nichts dagegen, dass hier ähnliche Verhältnisse herrschten wie in Köln (vgl. etwa Balmelle 2001, 48f. zu Aquitanien). Aus manchen gallischen Städten liegen sogar noch für eine erheblich spätere Zeit Belege für eine fortdauernde Existenz der Curien bzw. für ein Vorhandensein von curiales vor, so etwa für Poitiers im 6. und 7. Jh.; dazu Maurin u.a. 1998, 76. Allerdings waren sie in dieser Epoche in der innerstädtischen Politik nur noch von untergeordneter Bedeutung, da die Führungs- und Leitungsfunktionen inzwischen - wie auch anderswo im Imperium Romanum bzw. in dessen Nachfolgestaaten - von einer informeller zusammengesetzten Gruppe von Notablen übernommen worden waren. Vgl. zu diesem sog. ,post-curial government` allgemein Liebeschuetz 2001, 104 136.

16 Die ,Bischofsherrschaften', die sich im Laufe des (späteren) 5. Jh.s ausgebildet hatten, stellten in dieser Form ein weiteres Charakteristikum der gallischen Städte am Ende der Spätantike dar. Dieses Phänomen ist in den letzten Jahren intensiv diskutiert worden; vgl. hierzu nur Jussen 1995; Beaujard 1996; Liebeschuetz 2001, 137-168 sowie insbesondere den Beitrag von Steffen Diefenbach in diesem Band.

17 Vgl. zu diesem Aspekt Loseby 2006, 89-92. In den Quellen des 5. und 6. Jh.s werden mehrfach einzelne Personen oder Gruppierungen erwähnt, die als seniores, honorati, principes, magnifici viri, proceres o. ä. bezeichnet werden und zusammen mit dem 
Bischof und generell die Kirche haben durch ihre starke Bezogenheit auf die alten städtischen Zentren zudem erheblich dazu beigetragen, dass deren Zentralortfunktionen erhalten blieben. ${ }^{18}$

Generell lässt sich somit festhalten, dass noch im fränkischen Gallien des 6. Jh.s die civitates und ihre urbanen Mittelpunkte eine wichtige Bezugsgröße darstellten. ${ }^{19}$ Insofern hat sich das von Rom etablierte Städtenetz längerfristig als äußerst stabil und lebensfähig erwiesen. Dieser gewiss nicht zu vernachlässigende Aspekt soll aber im Folgenden nicht im Zentrum der Betrachtungen stehen. Vielmehr ist auf ein anderes Phänomen einzugehen, das sich parallel zu der beschriebenen Langlebigkeit der politisch-administrativen Strukturen in der gallischen Städtewelt ausprägte, nämlich auf den starken Wandel in der gebauten und damit physisch erfahrbaren Umwelt der Menschen, also im Bereich der ,Stadtbilder'. Für diese Entwicklung kann, um es gleich vorweg zu sagen, keine allgemein gültige Erklärung angeboten werden, aber zumindest einige vielleicht nicht ganz unwichtige Beobachtungen sollen hier zur Diskussion gestellt werden.

\section{Der Wandel der Stadtbilder im spätantiken Gallien}

Dabei kann die Betrachtung allerdings keineswegs erst mit dem 5. Jh. beginnen, sondern muss viel früher ansetzen, denn der Wandel der Stadtbilder in Gallien war allem Anschein nach ein langwieriger Prozess, dessen Wurzeln bis in das 2. und 3. Jh. zurückreichten. In der frühen Kaiserzeit, also im 1. und früheren 2. Jh., hatten die lokalen, rasch mit dem römischen Bürgerrecht versehenen Eliten der Tres Galliae vielerorts das mediterrane Stadtmodell mit Begeisterung übernommen und durch ihre Stiftungen dafür gesorgt, dass die - häufig erst unter römischer Ägide begründeten - civitas-Hauptorte monumentalisiert und mit allen

Bischof, bisweilen aber auch gegen ihn agierten. Bei diesen handelte es sich augenscheinlich um die weltliche Elite der Städte (in den loseren Formen des ,post-curial government', das sich während des 5. Jh.s durchgesetzt hatte; dazu o. Anm. 15), welche durchaus noch ein Eigengewicht neben dem Bischof (und dem vom König eingesetzten comes civitatis) besaß.

18 Allerdings hat gerade die Christianisierung der ländlichen Regionen Galliens auf längere Sicht zu einer stärkeren Abtrennung von den städtischen Zentralorten geführt, da sich die dortige Bevölkerung zunehmend an dem lokalen Klerus und nicht mehr am Bischof ausrichtete. Dieser Prozess gewann im Laufe des 6. Jh.s an Dynamik und trug mit dazu bei, dass sich die für die antike civitas so charakteristische Einheit von urbanem Mittelpunkt und umliegendem Territorium langsam aufzulösen begann. Vgl. dazu die Beobachtungen von Krause 2006.

19 Gut erkennbar ist dies bei Gregor von Tours, für den die civitates immer noch einen zentralen Bezugspunkt seiner Lebenswelt darstellten, der auch für die fränkischen Könige von Bedeutung war; dazu Loseby 1998. Zum Ende dieser noch spätantik geprägten Struktur von civitates im fränkischen Gallien während des frühen 7. Jh.s vgl. den Beitrag von Simon T. Loseby in diesem Band. 
äußeren Abzeichen der romanitas versehen wurden. ${ }^{20}$ So entstanden nach einem mehr oder minder standardisierten urbanistischen Kanon großzügig dimensionierte Stadtanlagen, die sich oftmals über erhebliche Flächen von 100 bis 200 ha ausdehnten (Abb. 1). ${ }^{21}$

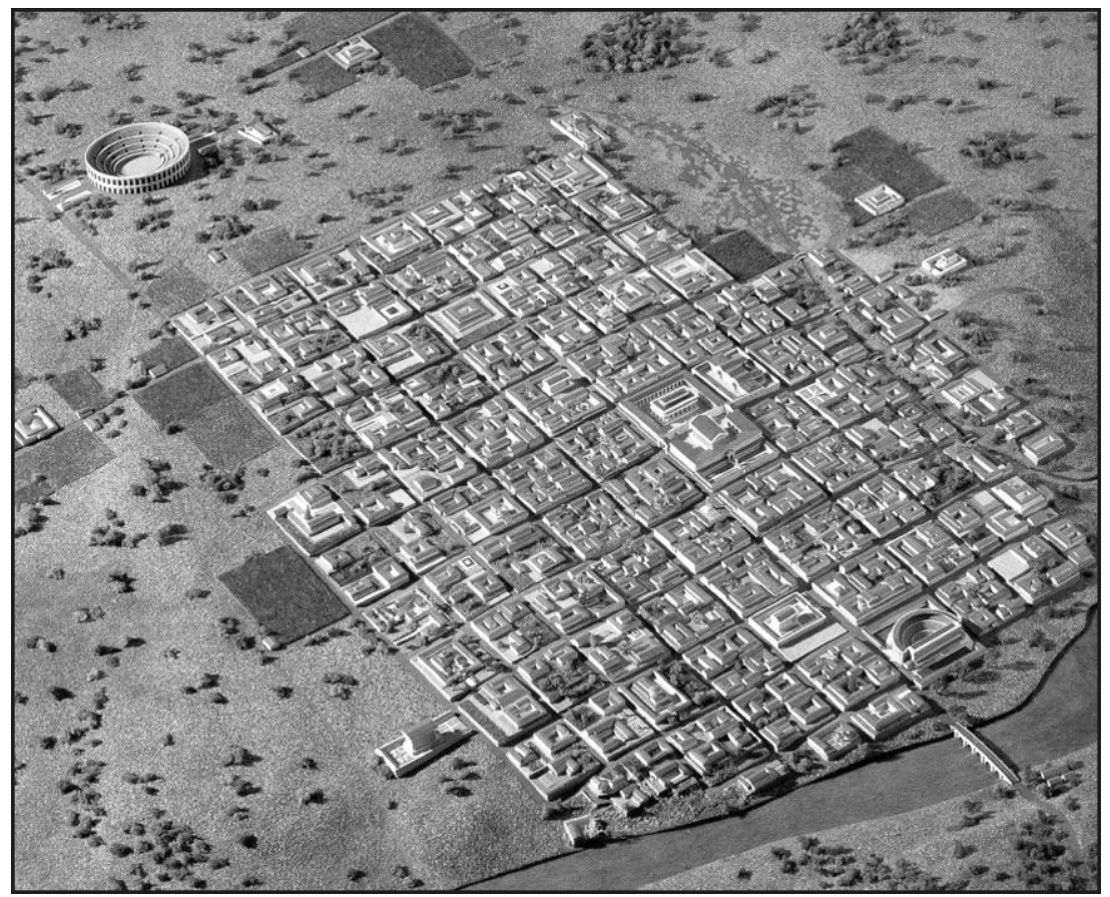

Abb. 1: Rekonstruktionszeichnung des Stadtgebiets von Limoges in der hohen Kaiserzeit.

20 Ein gutes Beispiel hierfür bietet der Ausbau von Mediolanum (Saintes), des Hauptortes der civitas Santonum in Aquitanien. Dieser wurde nach Ausweis der vor Ort gefundenen Inschriften im Laufe des 1. Jh.s n. Chr. im Wesentlichen von der lokalen Elite vorangetrieben, welche aus romanisierten Bürgern (Caii Iulii) mit einheimischen, keltischen Wurzeln bestand; s. Maurin 1994, Nr. 7-9, 18, 20; dazu Maurin 1978, 147-180; Maurin/Thauré 1994 sowie zum gesamtgallischen Kontext Bedon 1999, bes. 211-218, 227f., 235.

21 Dies zeigt sich etwa an der Entwicklung von Augustoritum (Limoges): Bei dem Zentralort der civitas Lemovicum handelte es sich offenbar um eine Neugründung der augusteischen Zeit, die sich über ein ausgedehntes Terrain erstreckte. Dieses wurde - nach erheblichen Terrassierungsarbeiten - durch ein orthogonales Straßennetz erschlossen. Dominiert wurde das Stadtgebiet von einigen großen öffentlichen Anlagen wie dem Forum, einem Thermengebäude, einem Theater und einem Amphitheater; vgl. Prévot/Barral i Altet 1989, 71f.; Desbordes/Loustaud 1991 sowie Perrier 1993, 79-142. In ähnlicher Weise wurden vielerorts auch in Mittel- und Nordgallien in der Zeit zwischen Augustus und der Mitte des 1. Jh.s n. Chr. neue und planmäßig angelegte Stadtprospekte entwickelt, so in Samarobriva (Amiens); dazu Bayard 2007. Vgl. zu diesem Phänomen zusammenfassend Woolf 1998, $112-126$. 
Bei genauerem Hinsehen ist allerdings zu fragen, wie tief dieser Urbanismus nach römischem Vorbild im gallischen Raum tatsächlich verwurzelt war. ${ }^{22}$ Bei einigen Zentralorten von civitates fällt nämlich auf, dass die bebaute Fläche weitgehend von öffentlichen Gebäuden, Platzanlagen und einigen reich ausgestatteten domus eingenommen wurde, während die Gesamtbevölkerungszahl der Siedlung nicht allzu groß gewesen sein dürfte - hier handelte es sich eher um ,villes vitrines', also um eine Art städtischer Schauprospekte, die vor allem dem Repräsentationsbedürfnis der lokalen Eliten dienten. ${ }^{23}$ Generell gilt, dass die Ausfüllung der Stadträume mit entsprechenden Ausstattungselementen wie etwa statuarischen Denkmälern nicht mit dem mediterranen Vorbild Schritt gehalten zu haben scheint, denn Basen für Kaiser- oder Ehrenstatuen sowie ,civic inscriptions' im Allgemeinen haben sich in den Städten der Tres Galliae nur in recht kleiner Zahl gefunden. ${ }^{24} \mathrm{Zu}$ vermuten steht zudem, dass die städtischen Lebensformen nicht unbedingt in vollem Umfang dem mediterranen Standard entsprachen - auch

22 Vgl. zum Folgenden auch Woolf 1998, 120, 135-141.

23 Ein Beispiel hierfür bietet das im Vergleich zu der relativ bescheidenen Ausdehnung des Stadtgebiets stark überdimensionierte Zentrum von Bagacum (Bavay) in Nordgallien, in dem insbesondere das großzügig ausgestaltete, im späteren 1. Jh. n. Chr. errichtete und in der zweiten Hälfte des 2. Jh.s nochmals grundlegend umgebaute Forum heraussticht; vgl. dazu Deru 2010, 35f. mit Abb. 23-25; Delmaire u.a. 2011, 97-138. Diese Anlage entsprach in ihren Ausmaßen in keiner Weise der Bedeutung des Ortes und scheint sich nach Ausweis der in Bavay gefundenen Inschriften auch kaum mit statuarischen Denkmälern gefüllt zu haben.

24 Gut demonstrieren lässt sich dies mit Blick auf die epigraphischen Hinterlassenschaften zweier bedeutender städtischer Zentren in Nord- bzw. Südgallien, zu denen in jüngster Zeit neue Inschriftenkorpora vorgelegt worden sind, nämlich Köln und Bordeaux; vgl. dazu Galsterer 2010 sowie Maurin/Navarro Caballero 2010. Aus der colonia Claudia Ara Agrippinensium, die immerhin eine römische Deduktionskolonie war, und aus deren unmittelbarer Umgebung sind ca. 750 Steininschriften bekannt. Der Großteil davon sind Weihe- und Grabinschriften. Auffälliger ist aber, dass es sich bei den - relativ wenigen Inschriften, die sich auf römische Kaiser beziehen, ausnahmslos um Bauinschriften oder Meilensteine handelt. Ähnliches lässt sich mit Blick auf die Inschriften für Senatoren und Ritter sowie für Angehörige der lokalen Elite beobachten: Auch hierbei dominieren Bau-, Weihe- und vor allem Grabinschriften. Lediglich zwei Ehreninschriften des 2. Jh.s waren augenscheinlich auf Statuenbasen angebracht und somit Teile von statuarischen Monumenten, die vermutlich auf einem der öffentlichen Plätze der Stadt standen. Aus praktisch jeder Kleinstadt in Hispanien oder Africa sind aber deutlich mehr solcher Denkmäler bekannt. Ein vergleichbares Bild ergibt sich für Burdigala, von wo sich etwa 400 römische Inschriften erhalten haben (viele davon aus der spätantiken Stadtmauer stammend; vgl. dazu u. Anm. 45). Unter diesen gibt es einige wenige Tituli, welche zu Ehrenmonumenten für Kaiser gehörten (der späteste davon für Gordianus III.); den gesamten Rest bilden jedoch ausschließlich Bau-, Weihe- und Grabinschriften. Auf diese eigentümliche Ausprägung des ,epigraphic habit ${ }^{\star}$ und der statuarischen Praxis in Gallien, welche dem öffentlichen Raum der Städte ein ganz anderes Gepräge gegeben haben muss als im Mittelmeerraum, haben bereits Wightman 1984 und Wightman 1985, 162-177 sowie Eck 1991 hingewiesen; vgl. ferner allgemein Woolf 1998, 77-105, bes. 81, 102. In der Spätantike war dieses Phänomen dann noch deutlicher ausgeprägt; dazu Witschel (im Druck). 
wenn der bauliche Rahmen hierfür zunächst durchaus vorhanden war. ${ }^{25}$ In diese Richtung deutet nicht zuletzt der starke Ausbau sekundärer Siedlungen (vici) auf dem Territorium der civitates, die sich oft um indigene Heiligtümer entwickelt hatten. ${ }^{26}$ Hieran zeigt sich einmal mehr die seit jeher gegebene Bedeutung des ländlichen Raumes für die Identität der gallischen Gemeinden - und dies bereits zu einer Zeit, als die städtischen Zentren noch expandierten.

All das mag erklären, warum in vielen gallischen Städten die Begeisterung für diese Art des Urbanismus offenbar nicht allzu lange anhielt. Die Phase des städtischen Ausbaus war in den meisten Orten zu Beginn oder spätestens um die Mitte des 2. Jh.s weitgehend abgeschlossen. Um den dadurch etablierten städtebaulichen Apparat aufrechtzuerhalten, waren erhebliche Investitionen von Seiten der lokalen Behörden bzw. der Angehörigen der munizipalen Oberschichten erforderlich. In einigen Fällen war man dazu aber augenscheinlich nur für eine bestimmte Zeit bereit, und so beobachten wir in nicht wenigen gallischen Städten meist in kleineren, aber durchaus auch in einigen größeren Zentren - das Phänomen, dass bereits am Ende des 2. Jh.s erste Gebäudekomplexe aufgelassen wurden oder verfielen, so dass das bebaute Stadtgebiet insgesamt schrittweise zu schrumpfen begann. ${ }^{27}$ Dieser Prozess verstärkte sich augenscheinlich im Laufe

25 Vgl. Witschel 1999, 309f.

$26 \mathrm{Zu}$ den gallischen vici vgl. die Beiträge in Maurin 1992a und Petit u.a. 1994.

27 So kam es in Bagacum (Bavay) in der Gallia Belgica, wie neuere Ausgrabungen nachweisen konnten, ab dem späteren 2. Jh. zu ersten Auflassungen besiedelter Zonen, ohne dass hierfür Zerstörungen durch Reichsfeinde verantwortlich gemacht werden könnten; vgl. Delmaire u.a. 2011, 94f. Leicht phasenverschoben können vergleichbare Entwicklungen auch im benachbarten Samarobriva (Amiens) beobachtet werden. Diese Stadt hatte im frühen 2. Jh. ihre größte Ausdehnung erreicht und konnte sich bis zum frühen 3. Jh. recht gut halten. Dann setzte jedoch die schrittweise Aufgabe einzelner Wohnquartiere ein, welche durch einen oder mehrere größere Brände um die Mitte des 3. Jh.s erheblich beschleunigt wurde, wobei jedoch erneut nicht sicher zu klären ist, ob hierfür (teilweise) Invasoren von außen verantwortlich waren. Als man sich in Amiens vermutlich um 320/30 - zum Bau einer Stadtmauer entschloss, umfasste diese nur noch einen Bruchteil der einstmals besiedelten Fläche (ca. 20 ha, was etwas mehr als 10\% der maximalen Ausdehnung des Stadtgebiets in der hohen Kaiserzeit entspricht); vgl. hierzu Bayard/Massy 1983, 201-246 sowie (mit leichten Korrekturen am Bild der älteren Forschung) Bayard 2007 und Pichon 2009, 29-50, bes. 45f. Ähnliche Prozesse lassen sich im aquitanischen Mediolanum (Saintes) ausmachen. Die Auflassung einzelner Gebäude und schließlich ganzer Stadtviertel begann dort eben-falls bereits recht frühzeitig, nämlich im späten 2. Jh., bis schließlich größere Partien der einstmals besiedelten Fläche mehr oder minder aufgegeben waren und teilweise gegen Ende des 3. Jh.s von Nekropolen überdeckt wurden. Das haben etwa die Ausgrabungen im Gebiet ,Ma Maison' im Zentrum der hochkaiserzeitlichen Stadt deutlich gezeigt; vgl. Maurin 1988, 25-38, 44-49; Maurin 1994, 42-45. Ein weiteres Beispiel für einen solchen urbanistischen Rhythmus stellt die Stadtentwicklung von Aginnum (Agen) dar, wo erste Auflassungen sogar schon im früheren 2. Jh. einsetzten, obwohl sich hier städtische Eliten und ihre Wohnsitze auch noch für das 4. Jh. nachweisen lassen; dazu Fages 1995, 93-151, bes. 110-112, sowie allgemein Witschel 1999, 322f. und Ferdière 2011, 36f. Schließlich ist auf die Situation in Tours zu verweisen: Caesarodunum, der Zentralort der civitas Turonum, hatte im Laufe des 2. Jh.s seine maximale Ausdehnung von ca. 100 ha erreicht, wobei das Stadtgebiet allerdings 
des 3. Jh.s, insbesondere in dessen zweiter Hälfte, als vielerorts Beschädigungen an Gebäuden etwa durch Schadensfeuer nicht mehr (oder zumindest für lange Zeit nicht) behoben wurden und dadurch der Verfall der städtischen Bausubstanz immer ausgeprägtere Züge annahm.

Nach wie vor nicht einfach zu klären ist, welche Rolle bei diesem Prozess die germanischen Invasionen der zweiten Hälfte des 3. Jh.s gespielt haben könnten, die zwar unzweifelhaft für eine erhebliche Erschütterung des Lebens in den gallischen Provinzen sorgten, deren Auswirkungen im Einzelnen aber nicht leicht zu beurteilen sind. ${ }^{28}$ Dies gilt sowohl für Beutezüge kleiner Germanengruppen, die

teilweise nur locker bebaut war. Auch hier setzten bereits ab dem späten 2. Jh. erste Auflassungsprozesse in der Peripherie des Stadtgebiets ein, die sich bis in das 4 . Jh. hinzogen, jedoch schrittweise abliefen, so dass hierfür keine punktu-ellen Anlässe gesucht werden müssen, zumal großflächigere Zerstörungsspuren offenbar zu fehlen scheinen; vgl. dazu Provost 1988, 76-105; Galinié 1997 und Galinié 2007, bes. 17, 326. In jüngster Zeit sind allerdings einige Zweifel an der Realität eines langgezogenen und schrittweisen Schrumpfungsprozesses in vielen gallischen Städten ab dem späten 2. Jh. aufgekommen; vgl. van Ossel 2011, 16. Andere Forscher halten hingegen an diesem Modell zumindest in Teilen fest, so Coquelet 2011, 238-243. Ähnliches gilt für Süd-gallien: Heijmans 2007, 155.

28 Vgl. zum Folgenden Witschel 1999 und Witschel 2011. Bezüglich der Frage, inwieweit und wie stark die einzelnen Gebiete Galliens von den germanischen Übergriffen des 3. Jh.s berührt wurden, sind sicherlich erhebliche regionale Unterschiede in Rechnung zu stellen. Besonders betroffen hiervon waren - angesichts der geographischen Lage naheliegend augenscheinlich Nordgallien und die Zonen entlang des Rheines; vgl. dazu die Beiträge in Schatzmann/Martin-Kilcher 2011. Bei einem genaueren Blick auf einzelne, gut ergrabene Orte zeigen sich allerdings komplexere Szenarien. Dies gilt etwa für den vicus von Bliesbruck auf dem Territorium der civitas Mediomatricorum, der im frühen 3. Jh. seine größte Ausdehnung erreicht hatte. Hier konnten mehrere Zerstörungsschichten des späteren 3. Jh.s, die von größeren Bränden herrührten, nachgewiesen werden. Diese erfolgten allerdings nach Ausweis der stratifizierten Münzen in den einzelnen Vierteln der Siedlung zu unterschiedlichen Zeitpunkten (um 260 sowie um 280/85). Die geschilderten Ereignisse hatten erhebliche Folgen für die Gestalt des Ortes, denn eines der Quartiere wurde gar nicht wieder aufgebaut, während die anderen zwar weiter bewohnt wurden, aber größere Veränderungen erfuhren (vgl. hierzu Petit 2011). Eine Verbindung dieser Phänomene mit den Germaneneinfällen der zweiten Hälfte des 3. Jh.s liegt ohne Zweifel nahe, ist aber nicht mit letzter Sicherheit zu beweisen (vgl. auch ebd., 196f.). Ein weiteres Beispiel stellt der längerfristige Transformationsprozess dar, durch den das Stadtbild sowie das Siedlungsgefüge der colonia Augusta Raurica (Augst) während der zweiten Hälfte des 3. Jh.s grundlegend verändert wurden. Nachdem bereits im mittleren 3. Jh. erste Auflassungen bzw. Umnutzungen von Gebäuden eingesetzt hatten, bildete die Errichtung einer vom Umfang her stark reduzierten Rückzugsbefestigung auf dem Kastelen-Hügel bald nach 276 den vorläufigen Abschluss dieses Prozesses, bevor sich im 4. Jh. der Siedlungsschwerpunkt nochmals in das um $300 \mathrm{n}$. Chr. direkt am Rhein errichtete castrum Rauracense (Kaiseraugst) und dessen Umgebung verlagerte; dazu Schatzmann 2011. Während dieser Vorgang zunächst schrittweise verlief, dürften in der Beschleunigungsphase um 270/80 auch äußere Einflüsse auf ihn eingewirkt haben, denn es haben sich im Stadtgebiet Spuren heftiger militärischer Auseinandersetzungen gefunden, welche kurz nach 273 stattgefunden haben müssen, ohne dass allerdings klar würde, wer hier gegen wen gekämpft hat. Vgl. ferner den zusammenfassenden Beitrag von Coquelet 2011 zur 
nachweislich bis nach Südwestgallien ausstrahlten, ${ }^{29}$ als auch für den großen Einfall von 275/76, bei dem angeblich alle gallischen Städte Schaden genommen haben sollen, was aber offensichtlich eine Übertreibung der literarischen Quellen ist. ${ }^{30}$ Die neuere archäologische Forschung ist jedenfalls - m.E. zu Recht - sehr viel vorsichtiger geworden, jegliche Zerstörungshorizonte (so die zahlreichen Brandbefunde) oder Auflassungsschichten, die sich (oft nur ungefähr) in das spätere 3. Jh. datieren lassen, automatisch und ausnahmslos den ,Barbaren' zuzuschreiben. ${ }^{31}$ Einzelne Siedlungen sind mit Sicherheit tatsächlich Opfer von plündernden Germanengruppen geworden, auch wenn dies in den Quellen nur selten explizit erwähnt wird; ${ }^{32}$ viele andere Städte werden aber von den germanischen

Entwicklung der nordgallischen Städte im späteren 3. Jh., die zu folgendem Fazit gelangt (ebd. 243): „Le bilan actuel des recherches archéologiques montre que peu des villes de Gaule Septentrionale ont subi des destructions violentes dans la seconde moitié du III $^{\mathrm{e}}$ siècle.“

29 Das zeigt etwa die Zusammensetzung des aus einem Altrheinarm geborgenen ,Beutehortes“ von Hagenbach, welcher größtenteils aus Objekten - insbesondere silbernen Votivblechen - besteht, die von einem Plünderungszug in den Südwesten der Provinz Aquitania stammen müssen; dazu Gorrochategui 2003 und Witschel 2011, 30.

30 Die wichtigsten Quellen für die große Invasion von 275/76 sind HA v. Pr. 13, 5-7; 15, 3; Eutr. 9, 17, 1; Jul. Caes. 314A-B; Zos. 1, 67. Danach seien 60 oder sogar 70 gallische Städte, mithin „ganz Gallien“, von den Barbaren überrannt und besetzt worden, was aber in dieser Allgemeinheit sicherlich stark übertrieben dargestellt ist. Zur Quellenkritik vgl. Wightman 1985, 198-201, 219f.; Whittaker 1995b; Christol 1997, 179-181; Deru 2010, 106f.; Witschel 2011, 44-46.

31 Vgl. hierzu die Bemerkungen von van Ossel 1992, bes. 42f., 61-82, 171-184; ferner Coquelet 2011, 236f. sowie insbesondere die methodisch wichtigen Beobachtungen von van Ossel 2011, der allerdings zu Recht darauf hinweist, dass man auf der anderen Seite die Auswirkungen der Invasionen auf die gallischen Städte auch nicht unterschätzen dürfe - und dies trotz aller Probleme, solche Zerstörungen archäologisch sauber nachzuweisen.

32 Einer der wenigen expliziten und detaillierten Belege für einen Überfall einer germanischen Gruppe auf eine Stadt im Hinterland Galliens ist Eus. Hist. FrGrH Nr. 101 Frg. 2, 5 (dazu Loriot/Nony 1997, 77 Nr. 37; Witschel 1999, 328): Hier wird eine nicht genauer datierbare Belagerung der Stadt Tours durch eine Gruppe von Germanen (die als „Kelten“ bezeichnet werden) beschrieben, welche eventuell zur Zeit des gallischen Sonderreiches erfolgte. Nach dem archäologischen Befund scheint dieses Ereignis aber keine größeren Schäden angerichtet zu haben; s.o. Anm. 27. Eine erst kürzlich gefundene Weiheinschrift aus dem vicus Ricciacum (Dalheim) im Gebiet der civitas Treverorum berichtet ferner von der Zerstörung der porticus eines Badegebäudes „durch die Gewalt der Barbaren“ (porticum balinei vi barbar[o]rum absum [ptam]), die bald darauf von den Einwohnern des Ortes restauriert wurde; s. dazu Krier 2011. Allerdings ist die Inschrift nicht genauer datiert (sie gehört augenscheinlich in das frühe oder mittlere 3. Jh.), und somit bleibt auch ihr historischer Kontext unbekannt. Der Erstherausgeber vermutet einen Zusammenhang mit einem angeblichen Einfall der Alamannen in die Gallia Belgica im Jahr 254 (Krier 2011, 333-337); dieser ist jedoch keineswegs sicher nachzuweisen; vgl. Witschel 2011, 42f. Andere Erwähnungen von germanischen Übergriffen sind in ihrer Historizität umstritten, so etwa die Schilderungen über die Aktionen des Alamannenkönigs Chrocus, der zur Regierungszeit der Kaiser Valerianus und Gallienus viele Gegenden in Gallien verwüstet haben soll, darunter auch Teile der Stadt Clermont (Greg. Tur. HF 1, 32; s. dazu auch u. Anm. 55). Diese Zerstörungen durch die Alamannen des Chrocus konnten aber bislang in 
Übergriffen nur marginal oder überhaupt nicht berührt worden sein, ${ }^{33}$ obwohl dies keineswegs ausschließt, dass sich auch an solchen Orten ein entsprechendes Bedrohungsgefühl entwickelt haben mag.

Das lässt dann auch einige Zweifel an dem Erklärungsmodell der älteren Forschung für den in dieser Zeit - d.h. ab dem späteren 3. Jh. - zu beobachtenden drastischen Wandel der Stadtbilder in weiten Teilen Galliens aufkommen. Dieses Modell lautete kurz (und überspitzt) dargestellt wie folgt: Die Zerstörungen der Germanen hätten in vielen Städten Ruinenlandschaften hinterlassen. Die Menschen hätten daher in ihrer Panik vor weiteren Attacken nichts anderes im Sinn gehabt, als so schnell wie möglich Befestigungen zu errichten, um sich gegen solche Übergriffe besser abzusichern. Das traf sich mit den Bedürfnissen der staatlichen Behörden, die das bis dahin weitgehend ungeschützte Gallien militärisch aufrüsten wollten und dazu den ,Masterplan' eines Netzes an Stadtbefestigungen an den strategisch wichtigen Verkehrsachsen entwickelten, der dann als kaiserlicher Auftrag in die gallischen Provinzen weitergegeben wurde. Daraufhin begann man vielerorts in aller Hast und unter Verwendung jedes Bausteines, dessen man habhaft werden konnte, mit der Errichtung von starken, aber im Umfang gegenüber der hochkaiserzeitlichen Bebauung deutlich reduzierten Stadtmauerringen. ${ }^{34}$ Der gesamte Prozess, der die gallischen Stadtbilder radikal und nachhaltig veränderte, war nach dieser Interpretation also im Wesentlichen exogen induziert, nämlich durch die Zerstörungen der Germanen bzw. die Furcht davor sowie durch den nachfolgenden kaiserlichen Befehl zur Errichtung von Stadtmauern.

Wie schon angedeutet, haben sich diesbezüglich in der neueren Forschung die Perspektiven nicht unerheblich verschoben. Leider fehlen uns allerdings zu die-

Clermont archäologisch nicht verifiziert werden; vgl. Provost/Mennessier-Jouannet 1994, 125. Dass um 255/60 eine solche Invasion von Alamannen unter ihrem Führer Chrocus nach Mittel- und Südgallien tatsächlich stattgefunden hat, wird zwar von manchen Forschern aufgrund des Zeugnisses von Gregor von Tours durchaus angenommen (so etwa von Demougeot 1962), bleibt aber m.E. sehr zweifelhaft; vgl. Witschel 1999, 35 Anm. 60.

33 Ein Beispiel für eine städtische Siedlung, die zwar im späten 3. Jh. einen einschneidenden Umwandlungsprozess in ihrem urbanistischen Gefüge erlebte (vor allem durch die Errichtung eines vom Umfang her reduzierten castrum gegen Ende des 3. Jh.s), bei der sich aber aufgrund der archäologischen Quellen, insbesondere aus den Gräberfeldern, ein hohes $\mathrm{Maß}$ an Kontinuität bei der örtlichen Bevölkerung und den ökonomischen Strukturen erkennen lässt, ist Turnacum (Tournai) in der Belgica II, wo zudem erhebliche Neubauaktivitäten des früheren 4. Jh.s in dem nunmehr intramuralen Bezirk beobachtet werden können; dazu Brulet 2011. Umfangreiche Zerstörungen, die auf feindliche Überfälle zurückzuführen wären, sind hingegen anscheinend nicht auszumachen, auch wenn es an einer Stelle nach 272 einen größeren Brand gab.

34 Zur Errichtung von Stadtmauern im spätantiken Gallien vgl. zusammenfassend Johnson 1973 und 1983; Maurin 1978, 332-343 und 1992b; Guilleux 2000, 243-246; Ferdière 2011, 137-139 sowie die neueren Interpretationen bei Garmy/Maurin 1996, bes. 188-193; Witschel 1999, 329-331; Loseby 2006, 75-78 und Heijmans 2007, 149-155 (zu Südgallien). Vgl. ferner zwei wichtige neue Beiträge: Dey 2010 und Bachrach 2010. Diese beiden Aufsätze sind leider zu spät zu meiner Kenntnis gelangt; auf sie kann daher nur an wenigen Stellen verwiesen werden. 
sem so wichtigen Vorgang ausführlichere schriftliche Quellen, die letztlich allein Klarheit über Motivation und Initiatoren bei der Errichtung von Stadtbefestigungen bringen könnten. ${ }^{35}$ Lediglich eine einzige gallische Stadtmauer, diejenige von Cularo (Grenoble), ist durch zwei gleichlautende Bauinschriften eindeutig als kaiserliche Stiftung des Diocletianus und Maximianus ausgewiesen. ${ }^{36}$ Es ist aber keineswegs gesagt, dass sich dieser Befund ohne weiteres auf alle anderen Mauern der Region übertragen lässt. Gegen ein einheitliches, von oben gesteuertes ,Programm ' bei der Errichtung der gallischen Stadtmauern sprechen aus meiner Sicht verschiedene Argumente. Zunächst ist auf den zeitlichen Rahmen dieses Phänomens zu verweisen: Obwohl die Datierung vieler Mauerringe nach wie vor unklar ist, deutet sich doch an, dass die Mauern in Gallien nicht alle zur selben Zeit erbaut wurden. Einige scheinen tatsächlich im späten 3. Jh. errichtet worden zu sein, andere jedoch erst im mittleren oder gar im späten 4 . Jh. ${ }^{37}$ Wieder andere

35 Vgl. auch Loseby 2006, 76. Die nach meinem Empfinden beste und abgewogenste Diskussion dieser Problematik findet sich bei Brassous 2011, 289-294.

36 CIL XII $2229=$ ILS $620=$ ILN V 2, 366. Diese Bauinschriften berichten davon, dass die beiden Herrscher muris Cularonensibus cum interioribus aedificiis providentia sua institutis adque perfectis portam Romanam Ioviam vocari iusserunt.

37 Ein Beispiel hierfür ist das spätantike castrum von Tours (Lugdunensis III), das in der nordöstlichen Ecke des hochkaiserzeitlichen Stadtgebiets errichtet wurde. Obwohl Tours eine der ganz wenigen gallischen Städte ist, von der wir sicher wissen, dass sie im 3. Jh. einer Belagerung durch feindliche Kräfte ausgesetzt war (s.o. Anm. 32), scheint man sich hier im späteren 3. Jh. zunächst mit einer eher provisorischen Befestigung begnügt zu haben, indem man das Amphitheater der Stadt mit einer dicken Wehrmauer versah und zusätzlich einen Graben vor dem Gebäude anlegte - auch dies war aber eine sorgfältig geplante und keineswegs improvisierte Maßnahme (vgl. Galinié 2007, 83-88, 238-246; eine ähnliche Entwicklung, die ebenfalls mit der Befestigung des Amphitheaters als Refugium für die städtische Bevölkerung um die Mitte des 3. Jh.s einherging, ist jüngst für Metz postuliert worden: Dreier 2011, 177f.). Erst im frühen 4. Jh. scheint man sich in Tours dazu entschlossen zu haben, eine regelmäßig angelegte Stadtmauer mit zahlreichen Türmen und mehreren Toren zu errichten, wobei erneut das Amphitheater als Ausgangspunkt diente. In die Mauer wurden, offenbar mit erheblicher Systematik, zahlreiche Spolien verbaut. Diese Baumaßnahme scheint sich über einen längeren Zeitraum erstreckt zu haben; sie kam erst gegen Mitte des 4. Jh.s, vielleicht sogar erst gegen 370/80, zum Abschluss; dazu Wood 1983, bes. 44f.; Galinié 2007, 247-255, 359-361. Eine weitere, archäologisch gut abgesicherte Datierung liegt mittlerweile für den umfangreichen spätantiken Mauerring von Reims in der Belgica II vor; vgl. Neiss/Sindonino 2004, 84-95. Auch dort hatte man lange Zeit einen direkten und kausalen Zusammenhang zwischen den Germaneneinfällen des späteren 3. Jh.s und der Errichtung der Mauern angenommen. Durch die Auswertung neuerer stratigraphischer Grabungen konnte aber nunmehr nachgewiesen werden, dass die Mauern erst in der Zeit zwischen 330 und 350, also in der spätkonstantinischen Epoche, errichtet worden sind, wobei dem eine Phase intensiver Planung und Vorbereitungen vorausgegangen sein muss. In Paris (Lugdunensis Senonia) wurde in der Spätantike eine zuvor periphere Zone befestigt, nämlich eine Insel in der Seine (die Île de la Cité). Grabungen haben für die Errichtung der Mauer einen dendrochronologisch ermittelten terminus post quem von 307/08 erbracht, und das Bauwerk muss vor der Mitte des 4. Jh.s fertig gestellt worden sein; dazu Busson 2001, 59; Mousseaux/Robin 2011, 60-63. Bei einem Blick auf die Datierung der spätantiken Stadtmauern in den beiden aquitanischen Provinzen scheinen sich ebenfalls unterschiedliche zeitliche 
Städte, etwa im Süden der Novempopulana, blieben zunächst gänzlich unbefestigt $^{38}$ und erhielten erst im frühen 5. Jh. einen Mauerring. ${ }^{39}$ Weiterhin ist zu be-

Horizonte abzuzeichnen: Einige Mauerringe wurden offenbar bereits im späteren 3. Jh. bzw. um 300 erbaut, so in Bordeaux, Saintes oder Poitiers (in keinem dieser Fälle ist die Datierung letztgültig gesichert, aber zumindest im Falle von Bordeaux gibt es mittlerweile eine Reihe von recht stichhaltigen Indizien für eine Ansetzung dieser Baumaßnahme um 280/90: Barraud 2009, 23). Anderenorts erfolgte der Mauerbau anscheinend nicht vor dem frühen oder mittleren 4. Jh. (Périgueux, Bourges) oder aber erst im späteren 4. Jh. (Clermont). In einigen weiteren Städten sind Mauern zwar durch literarische Quellen bezeugt, können aber nicht genauer datiert werden. Schließlich gibt es auch Orte, an denen ein spätantiker Mauerring bislang nicht mit Sicherheit nachgewiesen ist (so in Agen: Fages/Maurin 1991, 21; Fages 1995, 112); hierbei dürfte es sich jedoch teilweise um eine Forschungslücke handeln. Es bleibt nach wie vor ein Problem, dass an vielen Orten Galliens die Errichtung von Stadtmauern während der Spätantike nicht wirklich unabhängig - d.h. aufgrund archäologischer Befunde und Funde - datiert worden ist, sondern durch eine Verbindung mit vermeintlich gesicherten Daten der Ereignisgeschichte oder mit Hilfe eines Rekurses auf angeblich in bestimmten Regionen weitgehend einheitliche Programme zur Befestigung der Städte. So entstehen leicht Zirkelschlüsse, die dann nur mühsam korrigiert werden können. Vgl. auch Dey 2011, 827f.

38 Zumindest für einige Orte in der Novempopulana lassen sich urbanistische Entwicklungen ausmachen, die von denjenigen der weiter nördlich situierten Städte deutlich abwichen. So blieben die in der Ebene liegenden, in der Kaiserzeit ausgebauten Siedlungen von Auch (Maurin u.a. 2004, 18-24) und Éauze (ebd. 26-32) zu Beginn der Spätantike zunächst unbefestigt und relativ dicht besiedelt, wobei hier auch Hinweise (etwa in Form von Mosaikböden) auf die Existenz von reicher ausgestatteten domus vorliegen. Erst zu einem späteren Zeitpunkt, wohl im frühen 5. Jh. (s. die folgende Anm.), wurde zumindest in Auch ein benachbarter, jenseits des Gers befindlicher Hügel mit einem Mauerring umgeben, der nun nur noch ein Gebiet von ca. 6,5 ha umschloss. Eine ähnliche Situation lässt sich in Saint-Bertrand-de-Comminges beobachten (vgl. o. Anm. 10), während Dax zwar schon bald nach der Mitte des 4. Jh.s einen Mauerring erhielt, in den aber ein relativ großer Teil des kaiserzeitlichen Siedlungsgebiets inkorporiert wurde (vgl. u. Anm. 40). Wiederum anders war die Situation in der vermutlich erst zu Beginn der Spätantike eingerichteten civitas Consorannorum ganz im Südosten der Provinz: Die bedeutendste Siedlung in dieser Region scheint sich während der Kaiserzeit bei Saint-Girons in der Ebene befunden zu haben, bis dann - wohl ebenfalls zu Beginn des 5. Jh.s - in etwa 1,5 $\mathrm{km}$ Entfernung auf dem Hügel von Saint-Lizier ein spätantiker Mauerring errichtet wurde, der ein sehr kleines Gebiet von lediglich 2,6 ha umschloss; vgl. Dieulafait/Sablayrolles 1998; Maurin u.a. 2004, 86-93; Guyon 2006, 118f. Hier befanden sich offenbar die Einrichtungen des Bischofssitzes, aber über weitere Bauten innerhalb der Mauern ist nichts bekannt - das führt zu der Vermutung, dass dieser Platz (eine Art, ville fantôme') hauptsächlich einigen wenigen Repräsentanten der staatlichen (?), städtischen und kirchlichen Macht als Aufenthaltsort diente und darüber hinaus der benachbarten Bevölkerung in Krisenzeiten Schutz bot, jedoch - zumindest zunächst - kein bedeutenderes Siedlungszentrum war; vgl. auch Loseby 2006, 82.

39 Vgl. Souilhac 1998; Dieulafait/Sablayrolles 1998, 117-121; Esmonde Cleary u.a. 1998, 353f. und Esmonde Cleary 2004, 186f. Eine auch archäologisch abgesicherte zeitliche Einordnung in die Zeit um 400 liegt mittlerweile für die spätantiken Mauern von SaintBertrand-de-Comminges vor; vgl. dazu Jones u.a. 1998 sowie o. Anm. 10. Die meisten der - ziemlich kleinen - Mauerringe in der Novempopulana befanden sich in Höhenlagen, nicht selten außerhalb des hochkaiserzeitlichen Siedlungsgebiets der jeweiligen Stadt (vgl. die vorige Anm.). Als Auslöser für ihre Errichtung, die sich allerdings an einigen Orten 
achten, dass die Planung und Umsetzung der Baumaßnahmen an den einzelnen Orten ganz unterschiedlich erfolgte: Mancherorts wurde nur eine sehr kleine Fläche ummauert, so in Clermont, gewiss keine unwichtige Stadt inmitten einer großen civitas (Abb. 2). Anderenorts, so in Poitiers, wurde der Mauerring hingegen viel großzügiger dimensioniert. ${ }^{40}$ All das scheint mir dafür zu sprechen, dass wesentliche Entscheidungen über den Zeitpunkt der Mauererrichtung und die Art der Gestaltung des Mauerrings in erster Linie vor Ort, d.h. durch die munizipalen Institutionen, getroffen wurden. Letztere stimmten ihr Vorgehen sicherlich in der

nur sehr ungefähr datieren lässt, hat man erneut ein historisches Ereignis, nämlich die Barbareninvasionen des frühen 5. Jh.s, vermutet und sie daher einem zentral gesteuerten Programm von Befestigungsanlagen am Pyrenäenfuß zugeordnet (vgl. Maurin 1992b, 386), was jedoch m.E. nicht gesichert ist, zumal sich durchaus auch Unterschiede zwischen den einzelnen Mauern aufzeigen lassen.

40 In Augustonemetum (Clermont), dem in augusteischer Zeit begründeten Hauptort der ausgedehnten civitas Arvernorum, in dem in der hohen Kaiserzeit die bebaute Fläche eine Ausdehnung von mindestens ca. $90-100$ ha erreicht hatte, wurde bei der Errichtung der Stadtmauer im späteren 4. Jh. nur ein sehr kleiner Bezirk von deutlich weniger als 10 ha umschlossen (allerdings blieben auch einige suburbane Zonen besiedelt), obwohl die Stadt weiterhin von nicht zu unterschätzender Bedeutung war (s. etwa Amm. 15, 11, 13; Sidon. epist. 3, 1, 2 spricht hingegen von dem Arvernum municipiolum) und wenig später mit einem Kranz von christlichen Bauten versehen wurde (dazu u. Anm. 103); vgl. Prévot/ Barral i Altet 1989, 28-31; Provost/Mennessier-Jouannet 1994, 125f., 219-222; Rémy 1996, 36-38; Loseby 2006, 68-71. Limonum (Poitiers) hingegen, der Zentralort der ebenfalls großen civitas Pictavorum, wurde im späten 3. Jh. (?) mit einem - für gallische Verhältnisse - recht ausgedehnten Mauerring umgeben, der ein Gebiet von immerhin 4243 ha einfasste, was allerdings gegenüber der Ausdehnung des Siedlungsgebietes von Limonum in der hohen Kaiserzeit, die im mittleren 2. Jh. ein Maximum von ca. 180 ha erreicht hatte, dennoch eine ziemliche Reduktion bedeutete, zumal auch hier erhebliche Teile des monumentalen Apparates wie das Amphitheater außerhalb der Mauern verblieben; vgl. Hiernard 1987. Die intramurale Bebauung ist (wie üblich) eher schlecht bekannt; es scheint aber ab dem späteren 4. Jh. zur Auflassung einer Reihe von Gebäuden und sogar zur Anlage einer kleinen Nekropole innerhalb des Mauerrings gekommen zu sein, was in Gallien ganz ungewöhnlich war; vgl. dazu Le Masne de Chermont 1987, bes. 168f.; Maurin u.a. 1998, 72-80. Eine wiederum etwas andere Entwicklung ist für die Stadt Aquae (Dax) in der Provinz Novempopulana auszumachen: Hier kam es zwar im Laufe des 3. Jh.s zur Auflassung einiger wichtiger öffentlicher Gebäude, so des zentralen Tempels, aber die Bevölkerung scheint nicht wesentlich geschrumpft zu sein, denn als man im dritten Viertel des 4. Jh.s daranging, auch in Dax einen Mauerring zu errichten, umfasste dieser einen größeren Teil des hochkaiserzeitlichen Siedlungsgebiets, und im Inneren der Mauern lässt sich auch für das spätere 4. Jh. eine durchaus gehobene Bebauung unter Einschluss einiger reicherer Wohnhäuser ausmachen, während Teile des suburbium ebenfalls besiedelt blieben; vgl. Garmy/Maurin 1996, 82-125 (bes. ebd., 120 mit folgender Beobachtung: ,le style de la vie urbaine [...] ne paraît pas transformé") und Maurin u.a. 2004, 34-38. Zu den unterschiedlichen Ausdehnungen der spätantiken Stadtmauerringe in Gallien vgl. ferner die Übersicht bei Guilleux 2000, 32-35 mit Abb. 3. 


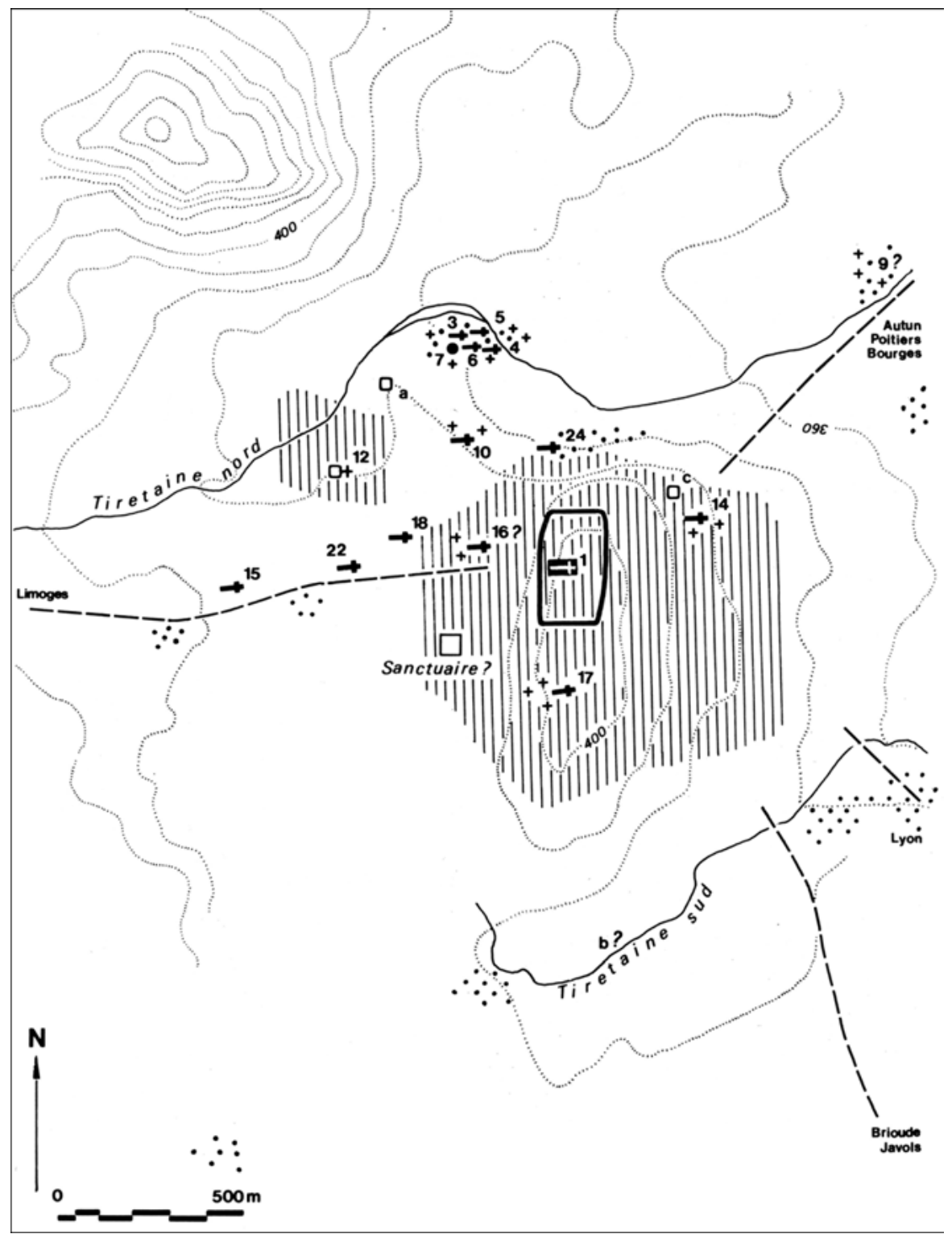

Abb. 2: Plan des spätantiken Stadtgebietes von Clermont.

Regel mit den provinzialen Behörden bzw. mit dem Kaiser ab - bei Bauprojekten von diesem Umfang war dies wegen der dafür benötigten Finanzmittel auch gesetzlich gefordert. Eine solche aufgrund der Kontrolle der städtischen Finanzen vorgeschriebene Genehmigungspflicht sollte jedoch nicht ohne weiteres als Indiz für ein von staatlicher Seite initiiertes und den Städten von oben aufgezwungenes 
Projekt zur flächendeckenden Einrichtung von Stadtbefestigungen verstanden werden. $^{41}$

Trotz der herausgestellten Unterschiede lässt sich allerdings auch eine ganze Reihe von Gemeinsamkeiten im gallischen Stadtmauerbau der Spätantike ausmachen. Zunächst sei nochmals darauf hingewiesen, dass der Umfang der Mauerringe im Vergleich zu der Ausdehnung, die das bebaute Stadtgebiet in der hohen Kaiserzeit erreicht hatte, fast immer mehr oder minder stark reduziert war. ${ }^{42}$ Das hatte zur Folge, dass in praktisch allen Städten größere Bezirke des in der frühen und hohen Kaiserzeit bebauten Stadtgebiets außerhalb der Mauern blieben - der

41 Schon seit dem 2. Jh. war vom kaiserlichen Gesetzgeber zunehmend eingefordert worden, dass die Städte Großbauprojekte, darunter gerade auch den Bau von Stadtmauern, beim Statthalter oder gar beim Herrscher selbst genehmigen ließen (so etwa Dig. 50, 10, 6); s. dazu die Zusammenstellung der einschlägigen Quellen bei Frere 1984, 66-68; ferner Witschel 1999, 130f. und 2008, 27 sowie Brassous 2011, 289f. Damit sollte der Gefahr begegnet werden, dass sich die Städte durch solche Aktionen finanziell ruinierten. Stärker durchsetzbar wurde dieser staatliche Kontrollanspruch dann offenbar im Gefolge der diokletianischen Provinzreformen, welche eine effektivere Aufsicht der Statthalter über das munizipale Bauwesen ermöglichten, was sich auch in der Formulierung der entsprechenden Inschriften manifestierte; dazu Lepelley 1999. All das bedeutet jedoch m.E. nicht, dass die Initiative und insbesondere die Detailplanung für größere städtische Baumaßnahmen während der Spätantike grundsätzlich immer von der Zentralregierung ausgegangen wären. Anders sieht dies Dey 2011, 826f., der die Initiative des Kaisers bzw. der Zentralregierung bei der Erbauung von Stadtmauern hervorhebt, die für ihn unbestreitbar ist, obwohl es hierfür nur wenige direkte Zeugnisse gibt. In Dey 2010 entwickelt er daher erneut das Modell eines von der kaiserlichen Regierung gesteuerten Programms zur Errichtung einer Serie von Stadtmauern in Gallien mit einem speziellen Design, das zur Verherrlichung des Herrschers im späten 3. Jh. gedient haben soll; seine diesbezüglichen Ausführungen sind aber nach meinem Dafürhalten wenig überzeugend. Auch Bachrach 2010, 41f. geht von einer zentral gesteuerten Initiative aus, die er - da er vor allem den militärischen Nutzen der Mauern betont sehen möchte - ohne jeden Beleg dem ,army high command“" zuschreibt.

42 Nur in einigen wenigen gallischen Städten, die bereits ausgedehnte Mauerringe aus der frühen Kaiserzeit besaßen, wurden diese in der Spätantike weiterhin genutzt. Dies trifft etwa auf Tolosa (Toulouse) zu, wo man die bestehenden Mauern lediglich im späten 3. Jh. (?) entlang der bislang unbewehrten Flussseite durch ein neues Befestigungswerk ergänzte; vgl. De Filippo 1993; Baccrabère/Badie 1998. Ein weiteres Beispiel hierfür bietet Augustodunum (Autun), der Zentralort der civitas der Häduer: Auch hier behielt man den in der augusteischen Gründungszeit errichteten Mauerring, der mit einer Länge von fast $6 \mathrm{~km}$ ein sehr großes Gebiet von ca. 200 ha umschloss und auf das Prestige der Gemeinde verwies, in der Spätantike zunächst bei; vgl. dazu Rebourg/Goudineau 2002, 48-59; Ferdière 2011, 59-65, 142. Das besiedelte Stadtgebiet hatte sich aber offenbar mittlerweile erheblich verkleinert (eventuell in einem rapiden Prozess ab dem späten 3. Jh.; s. van Ossel 2011, 16), auch wenn es weiterhin einige luxuriös ausgestattete domus beherbergte. Eine für Autun immer wieder postulierte reduzierte spätantike Befestigungsanlage im Süden der Stadt lässt sich jedoch nicht sicher nachweisen, so dass davon ausgegangen werden muss, dass man weiterhin den frühkaiserzeitlichen Mauerring nutzte, auch wenn dieser nur schwer in Gänze instand zu halten war. Das berichtet jedenfalls Amm. 16, 2, $1 \mathrm{zu}$ den Augustuduni civitatis antiquae muros spatiosi quidem ambitus, sed carie vetustatis invalidos. 


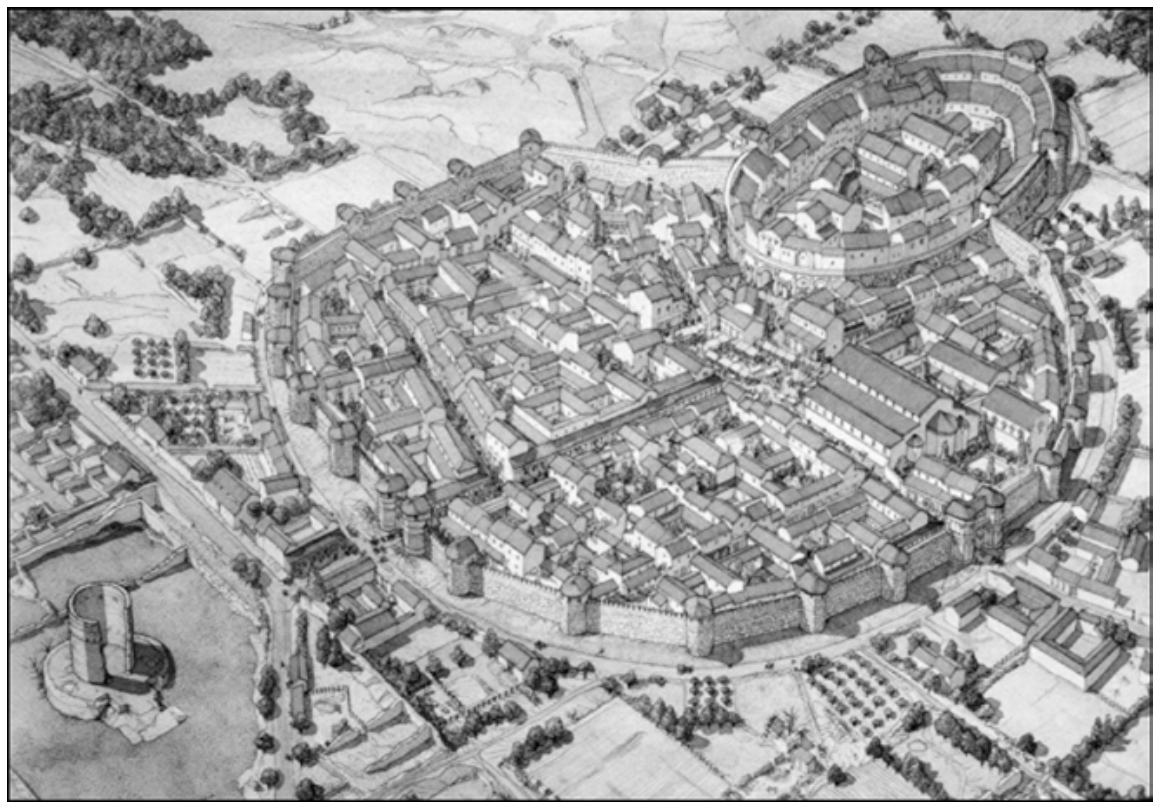

Abb. 3: Rekonstruktionszeichnung des spätantiken Stadtbildes von Périgueux.

Anteil konnte bis zu fünf Sechstel oder gar neun Zehntel betragen. Zahlreiche öffentliche Gebäude, die man Generationen zuvor mit hohem Aufwand errichtet hatte, befanden sich nun vor den Stadtmauern - und dies gilt nicht nur für die oft am Rande des Stadtgebiets liegenden Amphitheater. An vielen Orten hat man nämlich keineswegs versucht, das urbanistisch besonders ausgestaltete Zentrum der kaiserzeitlichen Stadt, also insbesondere den Forumsbezirk, in die Mauern zu integrieren (Abb. 3). ${ }^{43}$ Letztere wurden vielmehr nicht selten in einer Randlage

43 Anschaulich wird dies am Beispiel der beiden Städte Mediolanum (Saintes) und Vesunna (Périgueux) in der Provinz Aquitania II. In Saintes, wo auf die stürmische Ausbauphase des urbanen Zentrums im Laufe des 1. Jh.s n.Chr. (s.o. Anm. 20) bereits ab dem späteren 2. Jh. erste Auflassungserscheinungen gefolgt waren (s.o. Anm. 27), wurde dieser Prozess vermutlich im späten 3. Jh. durch die Errichtung eines vom Umfang her stark reduzierten Mauerrings (ca. 16 ha) abgeschlossen, der nur noch etwa ein Sechstel des einstmals besiedelten Gebiets umfasste, wobei der Forumsbereich augenscheinlich außen vor blieb; vgl. Maurin u.a. 1998, 56-59, bes. 57 Abb. In Périgueux war das städtische Zentrum, insbesondere das Forum und eine benachbarte Tempelanlage, nach Ausweis der epigraphischen Zeugnisse noch bis in das mittlere 2. Jh. ausgebaut worden; vgl. dazu Bost/Fabre 2001, Nr. 16-31 sowie allgemein Girardy-Caillat 1998 und zum Forum Doreau u.a. 1985. Umso drastischer war der Einschnitt, der im frühen 4. Jh. (?) durch die Errichtung eines sehr kleinen Mauerrings, welcher lediglich ein Terrain von ca. 5,5 ha einschloss, bewirkt wurde, denn dieser bezog zwar das Amphitheater ein, weil sich dieses für fortifikatorische Zwecke anbot, grenzte aber den gesamten übrigen, sehr großzügig dimensionierten urbanistischen Apparat der hohen Kaiserzeit aus, der dadurch dem Verfall anheimgegeben 
errichtet, wenn es die topographischen Gegebenheiten erforderlich machten. Dadurch wurde der städtische Raum völlig neu geordnet - bislang zentrale Zonen wurden zum suburbium, während bislang eher periphere Gebiete nun als intramuraler Bereich aufgewertet wurden. ${ }^{44}$

Die urbanistische Zäsur wurde fast überall noch dadurch verstärkt, dass für den Bau der Stadtmauern zahlreiche Bauglieder, Schmucksteine, Inschriftenblöcke oder auch Statuen als Spolien wiederverwendet wurden - und dies häufig an wenig sichtbaren Stellen im Fundament bzw. in der Sockelzone der Mauern, wo sie mit hohem technischem Aufwand verbaut wurden (Abb. 4). ${ }^{45}$ Das war zwar offensichtlich eine pragmatisch motivierte Vorgehensweise, da man auf diese Art Baumaterial sparte; aber es scheint zumeist nicht, wie die frühere Forschung gemutmaßt hat, eine aus reiner Not geborene Maßnahme gewesen zu sein, um die Trümmer der Germanenzerstörungen zu beseitigen und so rasch wie möglich Schutzmauern zu errichten. ${ }^{46}$ Wir haben schon gesehen, dass der Mauerbau vielerorts erst Jahrzehnte nach den turbulenten Ereignissen des mittleren und späteren 3. Jh.s erfolgte; und bei praktisch allen bekannten Mauern handelt es sich um sorgfältig geplante und ohne erkennbare Hast ausgeführte Bauprojekte. Sie waren zudem oftmals mit einem ästhetischen Anspruch gestaltet, wie gerade an dem aufgehenden Mauerwerk erkennbar ist, das in der Regel aus kleineren Bruchsteinen mit dazwischenliegenden Ziegelschichten bestand. ${ }^{47}$ Das entsprach der Funk-

oder auf der Suche nach wiederverwendbarem Material systematisch ausgeraubt wurde; vgl. Garmy/Maurin 1996, 128-154; Maurin u.a. 1998, 97-101; Mousseaux/Robin 2011, 28f. mit Abb. 23-24. Allerdings scheint das Forum nicht in allen aqui-tanischen Städten während der Spätantike aufgelassen worden zu sein. Ein Gegenbeispiel könnte die Situation in Rodez in der Aquitania I darstellen, wo sich die zentrale Platzan-lage nach der Errichtung des spätantiken Mauerrings intra muros befand und augenschein-lich, wenn auch mit erheblichen funktionalen Veränderungen, bis in das 5. Jh. fortbestand, bevor auch hier die Auflassung des Komplexes einsetzte; vgl. Catalo u.a. 1999.

44 Vgl. dazu u. Anm. 50 am Beispiel von Bordeaux.

45 Deutlich zeigt sich dies im Falle der Stadtmauer von Saintes (vgl. o. Anm. 43), denn bei ihrer Errichtung wurden in den Fundamenten zahlreiche ältere Architekturteile, die man aus ruinösen Gebäuden herbeigebracht hatte, als Baumaterial wiederverwendet, in einigen Fällen sogar schon zum zweiten Mal; vgl. Maurin 1994, 43f., 45-51. Ähnliches gilt für Bordeaux: Barraud 2009, 23; Maurin/Navarro Caballero 2010, 118-124 sowie ebd. 49 fig. 8. Vgl. ferner Mousseaux/Robin 2011, 80f.

46 Die massenhafte Verwendung von Spolien in unterschiedlichsten Kontexten war ein prägendes Element der spätantiken Stadtkultur. Es war reichsweit verbreitet und lässt sich daher auch in Gegenden beobachten, die wirtschaftlich prosperierten und keiner feindlichen Bedrohung ausgesetzt waren. Die intensive wissenschaftliche Beschäftigung der letzten Jahre mit diesem Phänomen hat deutlich gemacht, dass es zahlreiche verschiedene Spielarten im Umgang mit Altmaterial gab, die von einer rein pragmatisch motivierten Wiederverwendung von Bausteinen bis hin zu einer ideologisch oder ,museal' aufgeladenen Inszenierung tradierter Objekte reichte; vgl. dazu Brenk 1987; Kinney 1997; WardPerkins 1999; Witschel 2008, 61f.

47 Der Anspruch, die Außenseite der Mauern durch einen entsprechenden Dekor auch visuell eindrucksvoll zu gestalten, zeigt sich besonders gut bei dem um 280/300 n. Chr. Errichte- 
tion der Mauern, denn diese befriedigten nicht nur das nunmehr gestiegene Sicherheitsbedürfnis der Bevölkerung, sondern wurden auch zu einem allseits baren und dadurch sehr wirkmächtigen Symbol städtischen Prestiges. ${ }^{48}$

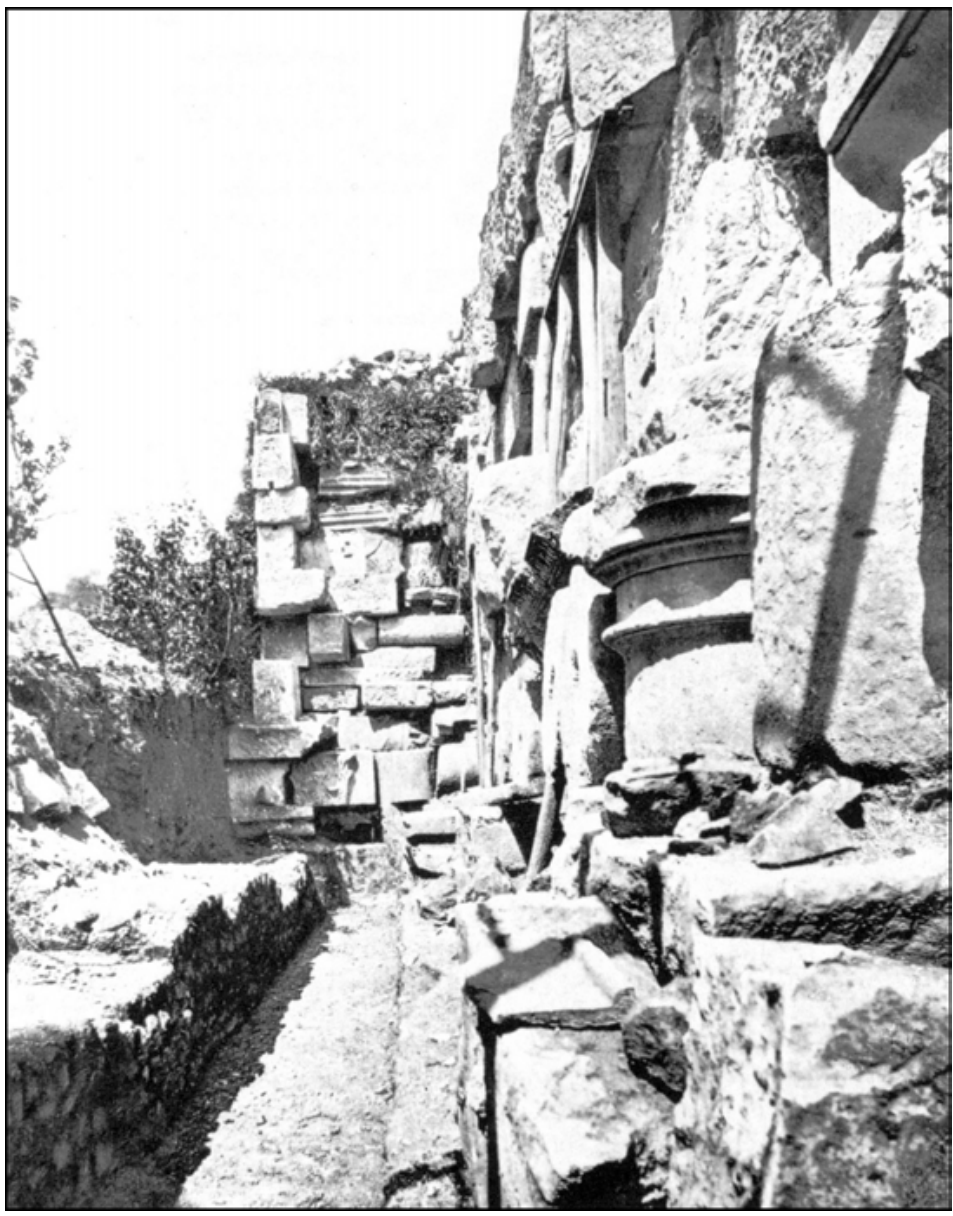

Abb. 4: Spolienverbauung in der spätantiken Stadtmauer von Saintes.

Dennoch bleibt festzuhalten, dass die massive Verwendung von Spolien für den Bau der Mauern, welche mit der Ausraubung zahlreicher kaiserzeitlicher Baukomplexe verbunden war, kaum anders interpretiert werden kann als ein Bruch mit der eigenen Vergangenheit und damit als eine Neuorientierung der städtischen

ten Befestigungsring von Le Mans (Lugdunensis III); dazu Guilleux 2000, bes. 191-222. Vgl. zu diesem Aspekt ferner zusammenfassend Dey 2010, 11-19.

48 So auch Loseby 2006, 76f.; Dey 2010, 5; Brassous 2011, 275, $292 \mathrm{f}$. 
Identität. ${ }^{49}$ Dies dürfte in denjenigen Orten, in denen sich - wie wir gesehen haben - schon seit Jahrzehnten Schrumpfungs- und Auflassungsprozesse vollzogen hatten, leichter gefallen sein, da hier der Mauerbau den Abschluss einer längerfristigen Entwicklung bei der Neuausrichtung des Stadtraumes bildete. Aber selbst dort ist der Einschnitt unverkennbar. Noch viel mehr gilt dies für andere Städte, die über weite Strecken des 3. Jh.s prosperiert hatten und wo somit die Errichtung eines reduzierten Mauerrings einen einschneidenden Eingriff in ein mehr oder minder intaktes Stadtgefüge darstellte. Ein gutes Beispiel für einen solchen Vorgang bietet die aquitanische Metropole Burdigala (Bordeaux) (Abb. 5): Hier wurde vermutlich im späten 3 . Jh. ein vom Umfang her deutlich reduziertes castrum errichtet, und zwar am Rande des hochkaiserzeitlichen Stadtgebiets im Bereich des Flusshafens, so dass etwa das Gebiet des Forums nunmehr in der extramuralen Zone lag. ${ }^{50}$ Im direkten Vorfeld der Mauern musste man, um ein Glacis zu schaffen, mehrere Gebäude - so eine Thermenanlage - systematisch abreißen; und dies geschah offenbar auch mit anderen nun nicht mehr benötigten Komplexen, deren Baumaterial man für den Mauerbau wiederverwendete. ${ }^{51} \mathrm{Be}-$

49 Simon T. Loseby spricht daher zu Recht von einem „renewal of urban landscapes through the creation of fortified cores" (s. seinen Beitrag in diesem Band, S. 229); Jean Guyon nennt dies ,une autre façon d'habiter la ville“ (s. seinen Beitrag in diesem Band, S. 202).

50 Das Stadtgebiet von Burdigala hatte während des 2. Jh.s eine Ausdehnung von ca. 150 ha erreicht, während der Mauerring des späten 3. Jh.s ein Gebiet von etwa 32 ha umschloss; vgl. dazu Garmy/Maurin 1996, 16-80; Barraud/Maurin 1998; Maurin/Navarro Caballero 2010, 46-48. Außen vor blieben praktisch alle bekannten öffentlichen Gebäude der hohen Kaiserzeit, so das Amphitheater am Rande des Stadtgebiets und wahrscheinlich auch der Forumsbezirk, der allerdings bislang noch nicht lokalisiert werden konnte. Nicht zu beweisen ist jedenfalls eine Identifizierung des Forums mit den bis in die Frühe Neuzeit erhaltenen Überresten der sog. ,Piliers de Tutelle'; oder aber mit den antiken Strukturen am Mont Judaïque, wo sich auch einige frühkaiserzeitliche Ehreninschriften für Mitglieder des Kaiserhauses gefunden haben. Beide Bezirke befanden sich ebenfalls außerhalb des spätantiken Mauerrings; vgl. Maurin/Navarro Caballero 2010, 38-41.

51 Garmy/Maurin 1996, 70f., 190f. In Reims, wo die spätantike Stadtmauer - unter Verwendung zahlreicher Spolien - im mittleren 4. Jh. (vgl. o. Anm. 37) im Zentrum des hochkaiserzeitlichen Siedlungsgebiets erbaut wurde, musste hierfür eine freie Zone von ca. $100 \mathrm{~m}$ Breite (für die Mauer selbst sowie das vorgelagerte Grabensystem und das Glacis) geschaffen werden, die offenbar zumindest an einigen Stellen in ein noch recht dicht besiedeltes Gebiet hineingetrieben wurde, wozu man um 320/30 den vorhandenen Baubestand systematisch abriss und niederlegte (vgl. Neiss/Sindonino 2004, 42, 75-81, 89). Auch in Reims scheint also die Planung der Stadtmauer eine recht plötzlich einsetzende Zäsur im Städteleben bewirkt zu haben, obwohl es schon seit dem späteren 3. Jh. zu einigen Auflassungen an der Peripherie des enorm ausgedehnten kaiserzeitlichen Siedlungsgebietes gekommen war, ohne dass dabei größere Zerstörungen nachzuweisen wären (ebd. 98, 119). In Le Mans musste bei der Errichtung der spätantiken Stadtmauer (vermutlich um 300) eine ca. $90 \mathrm{~m}$ breite Schneise in das Stadtgebiet geschlagen werden, um die Befestigungsanlage samt Glacis unterzubringen (Guilleux 2000, 120-123). Obwohl dabei der vorhandene Baubestand nach Möglichkeit geschont worden zu sein scheint, mussten doch einige Gebäude abgerissen werden, so eine Thermenanlage, die bis zum späten 3. Jh. in Benutzung war (ebd. 252-255). Auch in Tours wurde ein offenbar noch genutztes Thermengebäude bei der Errichtung der spätantiken Stadtmauer in der ersten 


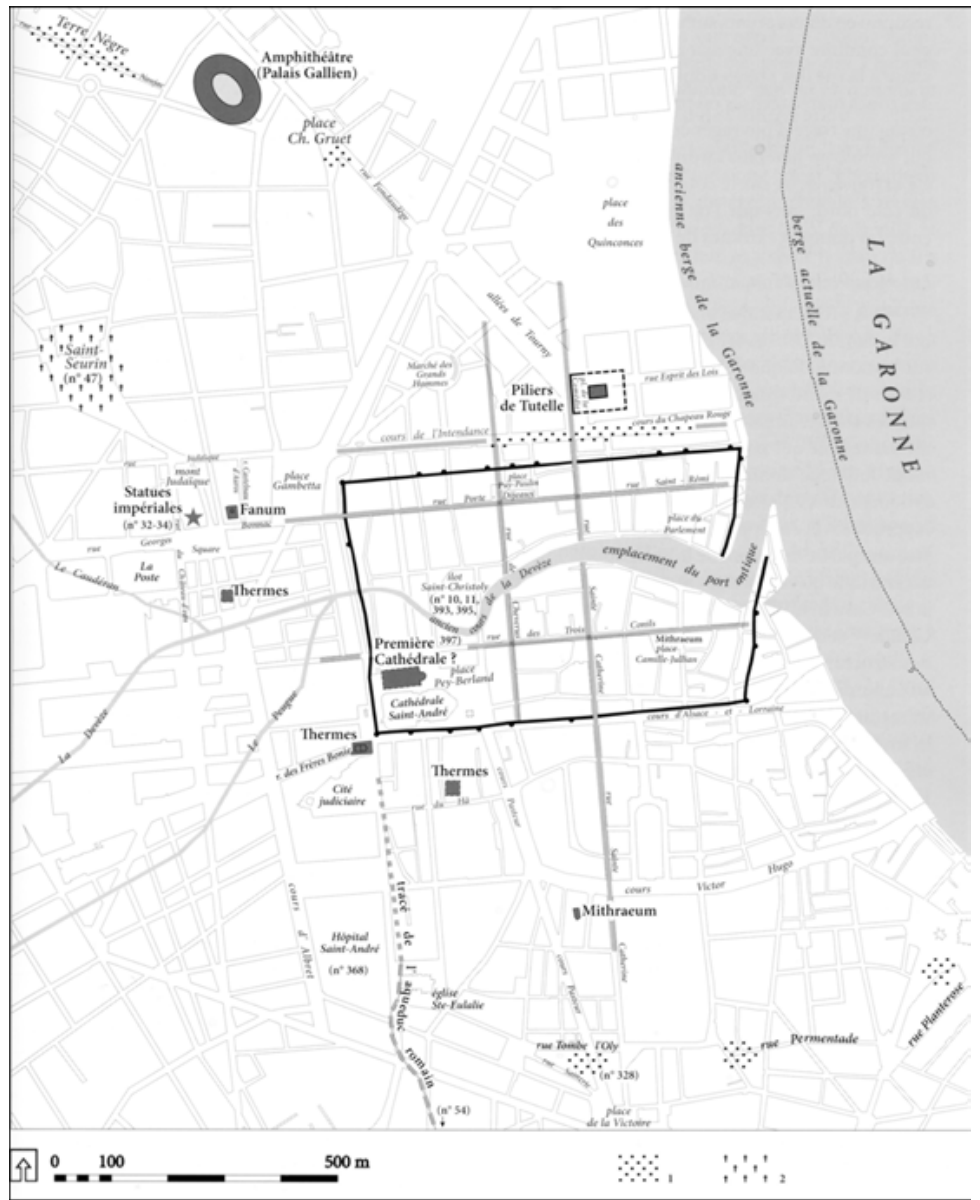

Abb. 5: Plan des Stadtgebietes von Bordeaux mit dem spätantiken Mauerring (castrum). 1: Heidnische Nekropole (bzw. Nekropole ohne klare Religionszugehörigkeit). 2: Nekropole mit christlichen Bestattungen.

sonders frappant ist, dass dabei auch ganze Nekropolen ihrer Grabsteine beraubt wurden $^{52}$ - einer von diesen ist exakt in das Jahr 261 datiert und hatte somit kaum

Hälfte des 4. Jh.s (s.o. Anm. 37) zunächst stillgelegt und dann teilweise abgetragen. Da es sich nun aber im Inneren des Mauerrings befand (und zwar in dessen Nordwestecke), wurde es nach einer jahrzehntelangen Unterbrechung gegen Mitte des 4. Jh.s wiederhergestellt und noch einmal in Betrieb genommen, bevor es im frühen 5. Jh. einer Wohnbebauung (für eine durchaus gehobene Gesellschaftsschicht) weichen musste; vgl. Galinié 2007, 61-74.

52 Vgl. Garmy/Maurin 1996, 67 mit Abb. 40; Maurin/Navarro Caballero 2010, 46 mit Anm. $154 \mathrm{f}$. 
eine Generation gestanden, als er in der Mauer verbaut wurde. ${ }^{53}$ Hiermit wurde also sogar in die familiäre memoria eingegriffen. Dies kann aber keineswegs allein durch einen plötzlichen sozialen Wandel oder eine völlige Neuformierung der städtischen Oberschicht erklärt werden - wir besitzen zwar nur wenige diesbezügliche Hinweise in den Quellen, aber diese können m.E. doch so interpretiert werden, dass durchaus ein gewisses Maß an Kontinuität bei der Zusammensetzung der Bevölkerung und auch der lokalen Eliten gegeben war. ${ }^{54}$ Das bedeutet wiederum, dass den angesprochenen Maßnahmen - gerade in Städten wie Bordeaux, wo sie anscheinend abrupt erfolgten - bewusste Entscheidungen zugrunde gelegen haben müssen; Entscheidungen, die meiner Ansicht nach vornehmlich durch die nach wie vor funktionstüchtigen städtischen Institutionen, also etwa aufgrund von Beratungen in der Curia, gefällt wurden. Zudem beobachten wir mancherorts in Bezug auf das urbanistische Erbe einen Selektionsprozess: Während einige Gebäude systematisch abgerissen wurden, geschah dies bei anderen nicht; denn diese ließ man stehen, so dass sie zwar langsam verfielen, als Ruinen aber noch lange sichtbar waren und entsprechend erinnert wurden - einige Male dienten sie in späterer Zeit sogar als Anknüpfungspunkte für eine christliche Traditionsbildung. ${ }^{55}$ Unglücklicherweise besitzen wir zu all diesen für die spätantike Stadtentwicklung in Gallien so entscheidenden Vorgängen keine Quellen, die uns über die Details der - möglicherweise kontroversen - Diskussionen in den Stadträten oder innerhalb der städtischen Bevölkerung informieren würden.

53 CIL XIII 633 = Maurin/Navarro Caballero 2010, Nr. 107; vgl. dazu den Kommentar von Sivan 1993, 37: „It appears that people were no longer interested in the sort of publicity which previously found an expression in inscriptions, but wished to be remembered for different reasons and actions."

54 Vgl. die Diskussion bei Witschel 1999, 310-312.

55 Vgl. hierzu etwa das Beispiel von Clermont, für das Gregor von Tours (HF 1, 32) die Geschichte von einem großen, am Rande der Stadt gelegenen Heiligtum überliefert, das auf indigene Wurzeln zurückging und in der keltischen Sprache Vasso Galate genannt wurde. Dieses sei von dem - vermutlich legendären - Alamannenkönig Chrocus im mittleren 3. Jh. in Brand gesetzt und völlig zerstört worden (s. dazu o. Anm. 32). Dennoch beschreibt Gregor im Anschluss daran ausführlich die architektonische Gestalt der Anlage, die also augenscheinlich zu seiner Zeit noch sichtbar war. Das lässt sich auch anderweitig bestätigen: Bei dem von Gregor beschriebenen delubrum handelte es sich um ein suburbanes keltisches Wasserheiligtum. Größere Reste des Tempels und des ausgedehnten Heiligtums waren noch in der Frühen Neuzeit zu sehen; vgl. dazu Prévot/Barral i Altet 1989, 30f.; Provost/Mennessier-Jouannet 1994, 143-151; Rémy 1996, 25-27. Zu der sich an diesen Ort knüpfenden christlichen Legendenbildung s.u. Anm. 103. Durch archäologische bzw. bauhistorische Befunde lässt sich das Fortbestehen eines erheblichen Teiles der kaiserzeitlichen Bausubstanz in den nunmehr extramuralen Zonen - in Form von nur teilweise abgetragenen Ruinen oder von weiterhin genutzten, aber in ihrer Funktion veränderten Gebäuden - beispielsweise für Paris aufzeigen; dazu Mousseaux/Robin 2011, $55-57$. 


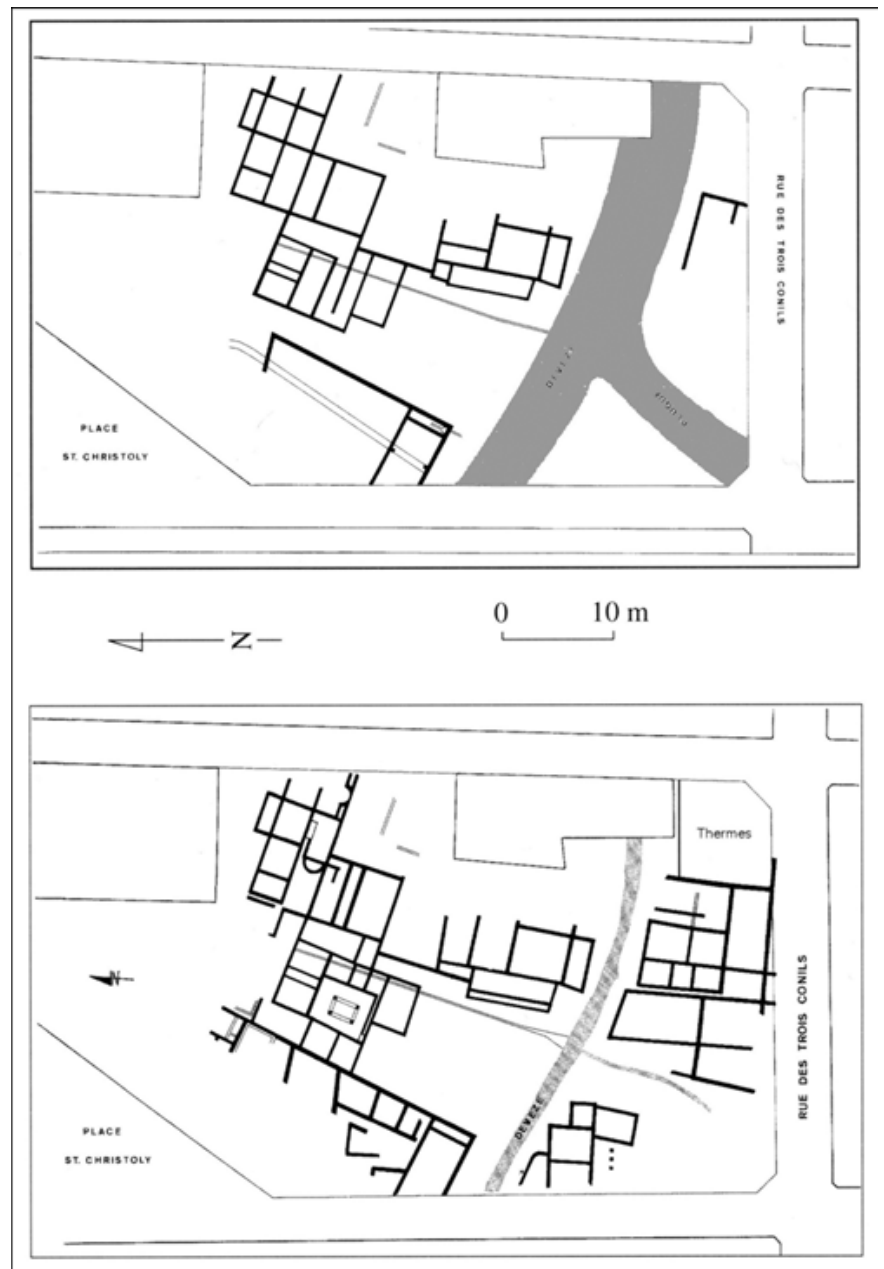

Abb. 6: Bebauung im Inneren des castrum von Bordeaux im Bezirk Saint-Christoly. Oben: Situation im früheren 3. Jh. (vor Errichtung der Stadtmauer). Unten: Situation im 4./5. Jh.

Wie schon gesehen, hat der Stadtmauerbau in der Zeit zwischen dem späten 3. und dem frühen 5. Jh. die räumliche Struktur vieler Städte in Gallien radikal neu definiert: Die Mauern, die eine gewaltige und sorgsam ausgeführte Baulichkeit darstellten, ${ }^{56}$ waren nun in ihrer physisch so unmittelbar erfahrbaren Präsenz das bestimmende und mancherorts zunächst sogar das einzige Symbol der urbanitas,

56 Die enormen Kosten sowie der erhebliche Aufwand an Arbeitskraft und Material, welcher mit dem Bau der Mauern verbunden war, werden gut herausgearbeitet von Bachrach 2010. Er sieht darin ein Zeichen der wirtschaftlichen Prosperität und demographischen Stärke in Gallien auch nach den Wirren des 3. Jh.s. 
das den städtischen Mittelpunkt von seinem ländlich geprägten Umland abhob. Sehr viel stärker als bei den Städten der hohen Kaiserzeit wurde hierdurch Inklusion bzw. Exklusion im urbanistischen Gefüge markiert. Allerdings wissen wir leider noch viel zu wenig über die Innenbebauung der meisten dieser spätantiken Anlagen. An einigen Orten - so erneut in Bordeaux - ist zu sehen, dass es im intramuralen Bereich zu einer Verdichtung der Besiedlung kam (Abb. 6, S. 175) $)^{57}$ Diese bestand in Bordeaux aus Wohnbebauung (darunter reicheren domus von Elitenangehörigen), Speicherbauten, einigen kleineren Thermenanlagen sowie Straßenzügen. Weitere öffentliche Gebäude sind hingegen nicht nachgewiesen. Für einige andere Städte sind Amtsgebäude, beispielsweise ein praetorium, zwar in den literarischen Quellen bezeugt, aber nicht im archäologischen Befund erhalten bzw. sicher zu identifizieren. ${ }^{58}$ Insgesamt ergibt sich der Eindruck einer deutlichen ,Verarmung' im städtebaulichen Kanon, da nun viele Arten von Gebäuden verzichtbar geworden waren, was den oben herausgestellten Eindruck bestätigt, jedoch nicht heißen soll, dass die verbliebenen Gebäude allesamt von primitiver Machart gewesen wären.

Gerade die Eliten der gallischen civitates haben bekanntlich ihren Reichtum nicht nur in den städtischen Zentren investiert, sondern auch in deren Umland, das in Gallien - wie gesehen - seit jeher eine erhebliche Bedeutung besaß. Die zumeist schon bestehenden Luxusvillen der Oberschicht insbesondere in Aquitanien wurden in der Spätantike großzügig ausgebaut und mit Mosaikschmuck sowie Statuensammlungen versehen. ${ }^{59}$ Hierdurch stellte die Oberschicht ihren verfeinerten Lebensstil und ihre stark in der klassischen Tradition verhaftete paideia demonstrativ zur Schau - was gleichzeitig zeigt, dass diese Werte im spätantiken Gallien keineswegs an Bedeutung verloren hatten. ${ }^{60}$ Ebenfalls abwegig ist die in der früheren Forschung oft vertretene Meinung, hierin habe sich eine Abwendung oder gar Flucht der Eliten aus der Stadt manifestiert. ${ }^{61}$ Das kann schon deshalb

57 Das haben vor allem die Ausgrabungen in dem innerhalb der spätantiken Stadtmauern von Bordeaux gelegenen Bezirk Saint-Christoly deutlich gemacht; vgl. dazu Saint-Christoly 1982, bes. 66 Abb. 59-60; Garmy/Maurin 1996, 72f.; Barraud/Maurin 1998, 42f. Eine ähnliche Verdichtung der Besiedlung intra muros lässt sich wohl für das spätantike Reims ausmachen: Neiss/Sindonino 2004, bes. 106.

58 So ist für das spätantike Tours ein solches praetorium (wohl das Amtsgebäude des Statthalters der Provinz Lugdunensis III) durch Sulp. Sev. dial. 3, 4, 2 bezeugt. Daneben befanden sich innerhalb des nur ca. 9 ha großen castrum von Tours im späteren 4. Jh. die Bischofskirche und die Bischofsresidenz (Galinié 2007, 287) sowie ein archäologisch nachweisbares Thermengebäude (s.o. Anm. 51) und einige Wohnhäuser der Elite. Trotz seiner administrativen und kirchlichen Bedeutung (dazu Pietri 1983, bes. 3-87, 339-350) muss das Stadtbild des spätantiken Tours somit eher bescheiden gewirkt haben; vgl. dazu auch Ferdière 2011, 142f.

59 Die spätantike Villenkultur in Aquitanien, die bis weit in das 5. Jh. hinein prosperierte, wird ausführlich behandelt von Balmelle 2001; zu den Statuensammlungen und dem Bildungshintergrund der Besitzer vgl. Stirling 2005.

60 Das lässt sich besonders gut an Ausonius und seinem Bekanntenkreis aufzeigen; vgl. hierzu Sivan 1993.

61 Dazu Witschel 2004/05, 256-258; Loseby 2006, 73. 
kaum richtig sein, weil bei Autoren wie Ausonius deutlich zu erkennen ist, dass die Oberschichtangehörigen weiterhin auf den urbanen Mittelpunkt als politisches, kulturelles und religiöses Zentrum angewiesen waren und daher immer auch eine Stadtresidenz besaßen, ${ }^{62}$ was es ihnen erlaubte, je nach Anlass zwischen Stadt und ländlichen Villen hin- und herzuwechseln - so wie es römische Oberschichtangehörige schon immer getan hatten. ${ }^{63}$ Zudem lassen sich im archäologischen Befund zahlreiche Querverbindungen zwischen Stadt und Land aufweisen: Die Mosaikböden der städtischen Häuser und der Villen wurden oftmals von denselben Werkstätten verlegt; und auch die in beiden Kontexten anzutreffenden sog. , aquitanischen' Prachtsarkophage des 5. und 6. Jh.s wurden in gemeinsamen Ateliers hergestellt, welche auch die entsprechende Bauplastik anfertigten ${ }^{64}$ Zwar deutet sich in diesen Befunden tatsächlich eine gewisse Bedeutungsverschiebung zwischen Stadt und Umland an; diese hat aber keine völlig neuen Strukturen geschaffen, und das in den Villen inszenierte Leben der Aristokraten war wiederum gerade durch seine so demonstrativ zur Schau gestellte urbanitas geprägt. ${ }^{65}$

Ein anderer Punkt verdient ebenfalls hervorgehoben zu werden: Gerade an den Orten, an denen die spätantiken Mauerringe sehr klein ausfielen, drängt sich die Frage nach der demographischen Entwicklung der städtischen Siedlungen auf.

62 Die domus des Ausonius in Bordeaux befand sich offenbar nicht innerhalb der Stadtmauern, sondern vor deren Toren nahe des pagus Novarus inmitten von Weinbergen. In der Nähe gab es eine dorfähnliche Ansiedlung (vicus) und eine vielbesuchte Kirche (ecclesia); s. Auson. ordo 82-90 (ed. Green 1991). Zur Lokalisierung dieser Örtlich-keiten vgl. Loyen 1960; Balmelle 1992, 358 und Maurin u.a. 1998, 27; skeptisch bleibt hingegen Green 1991, 662. Auch innerhalb der spätantiken Stadtmauern von Bordeaux gab es reicher ausgestattete Wohnhäuser, die Angehörigen der lokalen Elite gehört haben dürften; vgl. dazu Balmelle 1983.

63 Besonders deutlich wird dies von Auson. hered. 29-32 herausgestellt: Haec mihi nec procul urbe sita est, nec prorsus ad urbem, / ne patiar turbas utque bonis potiar; / et quotiens mutare locum fastidia cogunt, / transeo et alternis rure vel urbe fruor. Vgl. hierzu die guten Beobachtungen von Février 1981 sowie zu den einzelnen Villen des Ausonius Sivan 1993, 66-73; Balmelle 2001, 39f.

64 Zur Mosaikausstattung der spätantiken Elitenwohnsitze in Aquitanien vgl. Balmelle 1992, bes. 355-363, und Balmelle 1998, bes. 205f.; zu den Sarkophagen Briesenick 1962 sowie Balmelle 1993 und Balmelle 2001, 66-68.

65 Ein Beleg hierfür ist auch die - im gallischen Kontext allerdings exzeptionelle - Inschrift CIL XIII 128 = ILCV 391, ein langer, in Versen gefasster (christlicher) Grabtitulus wohl des frühen 5. Jh.s, der aus der Nähe der Großvilla von Valentine stammt, welche vermutlich im Territorium der civitas Convenarum gelegen war; vgl. dazu Sivan 1989; Premiers monuments chrétiens 1996, 207-209; Balmelle 2001, 424-426 Nr. 64. Der Verstorbene, ein Mann namens Nymfius, der vermutlich der Besitzer der Villa war, wird in dem Text unter anderem dafür gelobt, dass er als Spielegeber auftrat (wofür er mit Akklamationen im Theater bedacht wurde; s. Z. 11f.: excepere tuo quondam data munera sumptu / plaudentis populi gaudia per cuneos) und im politischen Bereich sowohl auf munizipaler wie auch auf provinzialer Ebene tätig gewesen war - obwohl sich nicht beweisen lässt, dass er diese Aufgaben in Lugdunum wahrnahm (vgl. Maurin u.a. 2004, 68), wird hier doch sicherlich kein ,Rückzug ins Private" des Landlebens evoziert, sondern vielmehr die nach wie vor bestehende enge Verbindung zwischen den städtischen Zentren und den umliegenden Territorien. 
Wenn das Innere des castrum wie in Tours (Abb. 7) oder Genf (Abb. 8) zudem durch einige öffentliche Gebäude und später Kirchen besetzt war, ${ }^{66}$ ist es ganz unklar, wo eigentlich der Großteil der städtischen Bevölkerung gewohnt hat, denn auch die bisweilen nachzuweisende Verdichtung der intramuralen Besiedlung ${ }^{67}$

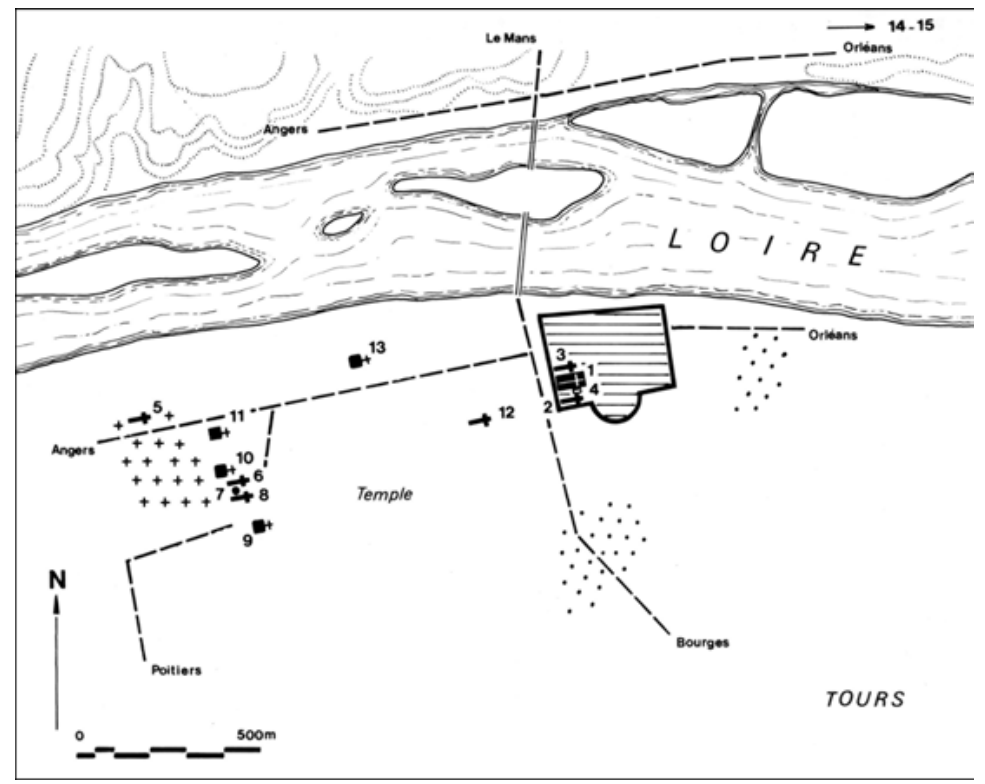

Abb. 7: Plan des spätantiken Stadtgebietes von Tours mit dem castrum.

konnte hier den Verlust an bebaubarer Fläche wohl kaum auffangen. Zwei Erklärungsmöglichkeiten bieten sich an: Zum einen ist für einige Orte durchaus davon auszugehen, dass die Bevölkerungszahl im Laufe der Zeit erheblich geschrumpft ist, ${ }^{68}$ die Städte also teilweise in der Spätantike nur noch eine Art Schaubühne für

$66 \mathrm{Zu}$ Tours vgl. o. Anm. 58; zu Genf s.u. Anm. 70. Ähnliches gilt etwa für Paris, wo die spätantike Befestigung auf der Île de la Cité eine Fläche von lediglich 9-10 ha umschloss, die zu einem erheblichen Teil von öffentlichen, im 4. Jh. neu errichteten Gebäuden belegt wurde; vgl. Busson 2001, 132-135, 144-149; Mousseaux/Robin 2011, 63-65, 86-90, 101-103. Hierzu zählten eine (vermutete) ,Palastanlage“ und ein großes basilikales Gebäude im Westteil der Insel, bis zu drei (kleinräumige) Badeanlagen sowie der sich ab dem späten 4. Jh. herausbildende christliche Komplex im südöstlichen Teil des castrum, zu dem zumindest eine Gemeindekirche, ein Baptisterium und eine Bischofsresidenz gehörten (dazu Picard u.a. 1992, 109-114; Premiers monuments chrétiens 1998, 151-158).

67 Vgl. o. Anm. $57 \mathrm{zu}$ der Situation in Bordeaux und Reims. Allerdings ist anzumerken, dass sich eine solche Verdichtung der intramuralen Besiedlung keineswegs für alle spätantiken Städte Galliens nachweisen lässt (vgl. etwa o. Anm. 40 zu Poitiers), zumal dieser Bereich vielerorts archäologisch eher schlecht erforscht ist.

68 Das ist etwa für Périgueux anzunehmen, wo sich nur sehr wenige Hinweise auf eine fortdauernde Besiedlung außerhalb des spätantiken Mauerrings gefunden haben; vgl. Garmy/ 


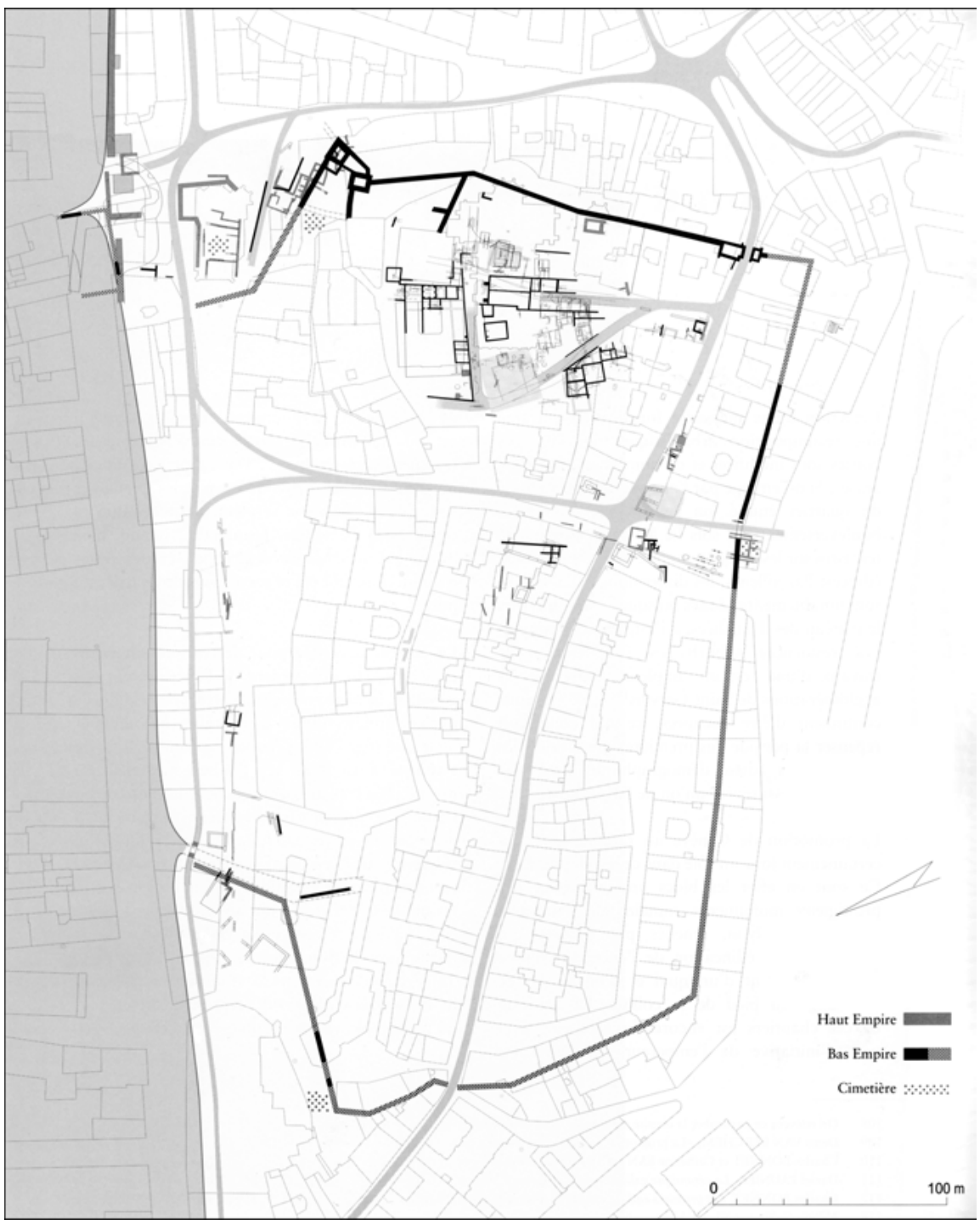

Abb. 8: $\quad$ Plan des Stadtgebietes von Genf mit der spätantiken Stadtmauer (spätes 3./ früheres 4. Jh.).

Maurin 1996, 152. Ähnliches hatte man für Tours angenommen (vgl. Galinié 1997, 68f.); inzwischen mehren sich aber die Hinweise darauf, dass einzelne Punkte außerhalb des spätantiken Mauerrings auch im 4. und 5. Jh. besiedelt blieben, wenn auch teilweise in sehr bescheidener bzw. temporärer Form, während sich gleichzeitig Flächen von ,schwarzer Erde‘ herausbildeten; vgl. dazu die einzelnen Hinweise in Galinié 2007. 
die zentralen administrativen und religiösen Funktionen der jeweiligen civitas waren, ohne dass dies mit einer entsprechend großen, vor Ort lebenden Bevölkerung korrespondiert hätte - womit sich eine Tendenz verstärkt hätte, die schon für manchen hochkaiserzeitlichen Stadtprospekt zu vermuten war. ${ }^{69}$ Als Alternative kommt in Betracht, dass die nunmehr außerhalb der Mauern liegenden und somit suburbanen Gebiete zumindest teilweise weiter bewohnt blieben. Das ist vielerorts bislang noch schwer nachweisbar, in einigen Städten aber zumindest ansatzweise zu belegen. ${ }^{70}$ Allerdings sah diese suburbane Bebauung nach allem, was wir darüber wissen, nun deutlich anders aus als zuvor: ${ }^{71}$ Neben einigen suburbanen Villen der städtischen Elite gab es hier ärmliche Behausungen, die sich nicht selten in den Ruinen früherer Gebäude eingenistet hatten, ferner landwirtschaftlich genutzte Flächen sowie größere Nekropolen, die nun näher an die Mauern

69 Vgl. o. Anm. 23.

70 Neue Erkenntnisse zu dieser Frage liegen aus Genf vor (vgl. Abb. 8, S. 179). Der vicus von Genava (im Gebiet der spätantiken Provinz Viennensis) war gegen Ende des 3. Jh.s zum Zentralort einer eigenen civitas erhoben worden (vgl. van Berchem 1982). Etwa zur gleichen Zeit wurde auf dem Stadthügel ein Mauerring erbaut, der eine im Vergleich zur kaiserzeitlichen Siedlungsausdehnung stark reduzierte Fläche umschloss. Innerhalb der Mauern wurden im Anschluss daran zahlreiche Terrassierungs- und Baumaßnahmen durchgeführt (vgl. hierzu Bonnet 2009), und um 380 wurde im östlichen Teil des ummauerten Bereichs innerhalb einer dicht besiedelten Zone eine erste Bischofskirche errichtet. Diese wurde gegen $400 \mathrm{zu}$ einer Doppel-Kathedralanlage erweitert und mit zahlreichen Annexgebäuden (so einem Baptisterium und einer Bischofsresidenz) versehen; vgl. dazu Bonnet 1993; Bonnet/Reynaud 2000; Bonnet/Privati 2000. Somit wurde ab dem 5. Jh. ein erheblicher Teil - mindestens ein Sechstel - des intramuralen Gebiets von dem ausgedehnten Kathedralbezirk eingenommen; und in dessen Nähe soll es auch noch weitere öffentliche Gebäude wie etwa ein praetorium sowie Wohnhäuser der Elitenangehörigen gegeben haben. Aus diesem Befund hatte man bislang auf einen starken Rückzug der Besiedlung auf die befestigte Oberstadt, welche als eine Art ,ville vitrine“ gedient habe, ab dem späten 3. Jh. geschlossen. Dies soll mit einer weitgehenden Entvölkerung der nunmehr im suburbanen Bereich gelegenen Zonen am Fuße des Hügels verbunden gewesen sein, die tatsächlich teilweise von Nekropolen überdeckt wurden. Neueste, im Rahmen des Museums unter der Kathedrale präsentierte Grabungsergebnisse können nun aber zeigen, dass spätestens im 6. Jh. der nördliche Abhang des Hügels zwischen Oberstadt und See nicht nur aus Freiflächen und Gärten bestand (wie noch in dem Stadtmodell von 1992 dargestellt; vgl. auch Bonnet 1993, 57 Abb.), sondern terrassiert und dicht bebaut war; und möglicherweise wurde auch dieser Bereich von der Stadtmauer umschlossen (vgl. hierzu schon Bonnet/Reynaud 2000, 247; Bonnet/Privati 2000, 384). Ein starker Bevölkerungsabfall muss also für das Genava der Spätantike nicht unbedingt postuliert werden; so auch Bonnet 2009, 123: „La baisse démographique n'est sans doute pas aussi sévère qu'on l'avait imaginée."

71 Vgl. zum Folgenden die Beispiele von Reims (Neiss/Sindonino 2004, 107-112) und Paris (Mousseaux/Robin 2011, 55-59, 69-71). In Paris ist die fortdauernde, wenn auch stark ausgedünnte Besiedlung des vormaligen kaiserzeitlichen Stadtzentrums am linken SeineUfer, das nach der Errichtung des spätantiken Stadtmauerrings auf der Île de la Cité im früheren 4. Jh. (vgl. o. Anm. 37) zur suburbanen Zone geworden war, sowohl durch Amm. 20, 4, 12 (in suburbanis; dazu Roblin 1951) als auch durch archäologische Befunde bezeugt. Ein kleiner spätantiker Besiedlungskern existierte ferner auf dem rechten SeineUfer um den dortigen Brückenkopf. 
heranrückten und dabei früher bebaute Zonen überdeckten. ${ }^{72}$ Im selben Bereich entstanden dann schließlich auch viele der extramuralen Märtyrer- und Begräbniskirchen (s.u.). ${ }^{73}$ Im Vergleich zu den planvoll ausgebauten urbanen Strukturen der hohen Kaiserzeit müssen diese suburbanen Bezirke in der Spätantike das eher ,unordentlich' wirkende Bild eines Nebeneinanders verschiedenster Funktionen und Bebauungsformen (unter Einschluss nicht mehr genutzter Ruinen) geboten haben - aber dies ist vermutlich eher die Perspektive des vergleichend vorgehenden modernen Betrachters als diejenige des spätantiken Stadtbewohners.

Dass es dennoch nicht zu einer radikalen Trennung zwischen dem intramuralen Kern der Städte und ihrer suburbanen Peripherie kam, war dem zweiten entscheidenden Phänomen der spätantiken Stadtentwicklung zu verdanken, nämlich der Christianisierung der Städte, die hier nur noch kurz angesprochen werden kann. ${ }^{74}$ Die Monumentalisierung kirchlicher Einrichtungen, durch die diese auch im Stadtbild präsent und wirkmächtig wurden, setzte in Gallien fast überall erst deutlich später ein als der Mauerbau, d.h. kaum jemals vor dem späteren 4. Jh.; und sie schrieb sich damit in ein gegenüber der Kaiserzeit bereits deutlich verändertes Stadtbild ein. Wie die neuere französische Forschung deutlich gemacht hat, ist davon auszugehen, dass die Bischofskirche (ecclesia) fast immer im intramuralen Bereich errichtet wurde. ${ }^{75}$ Dort konnte die Kirche allerdings in der Anfangszeit zumeist keine zentralen Positionen besetzen, sondern musste sich mit Randlagen beschränken, die ihr durch Grundstückskauf oder -schenkungen zufielen. ${ }^{76}$ Die ersten innerstädtischen Kirchengebäude waren zudem in der Regel noch recht klein, denn erst im Laufe des 5. und 6. Jh.s wurden sie erheblich erweitert.

Mehr Gestaltungsraum für die Etablierung einer christlichen Topographie gab es im suburbanen Bereich, wo gerade die oftmals erst in relativ später Zeit ,aufgefundenen` Märtyrergräber und die mit ihnen verbundenen Gedächtnisanlagen und Begräbnisstätten nach einer Monumentalisierung verlangten, die häufig ebenfalls

72 In Bordeaux ist erst kürzlich eine Nekropole entdeckt worden, die sich im frühen 4. Jh., d.h. wenige Jahre nach der Errichtung der spätantiken Stadtmauer, direkt nördlich von dieser am Mauerfuß herausgebildet hatte; dazu Barraud 2009, $25 \mathrm{f}$.

73 Vgl. zur Entwicklung der suburbia in den gallischen Städten während der Spätantike Witschel 2004/05, 241f.; Loseby 2006, 78f.

74 Zur Christianisierung der Stadtbilder in Gallien vgl. die einzelnen Beiträge in der Reihe TCG und in dem Sammelwerk Premiers monuments chrétiens 1995-98; ferner zusammenfassend Guyon u.a. 1992 und Guyon 2006.

75 Das ist ein zentrales Ergebnis der zahlreichen Studien zur christlichen Topographie der Städte Galliens, die im Rahmen der Reihe TCG erarbeitet worden sind; vgl. Guyon 2006, $108 \mathrm{f}$.

76 Vgl. dazu Loseby 1992, 149-155; Guyon u.a. 1992, 395f. und Witschel 2004/05, 262f.; s. ferner das Beispiel von Poitiers, wo der Vorgang einer schrittweisen Inbesitznahme eines bis dahin recht dicht besiedelten Viertels am Rande des (intra-muralen) Stadtgebiets durch die Kirche archäologisch besonders gut dokumentiert ist, auch wenn die Datierungen im Detail umstritten bleiben; dazu Le Masne de Chermont 1987; Premiers monuments chrétiens 1996, 290-301; Maurin u.a. 1998, 80-82; Hiernard u.a. 2004. 


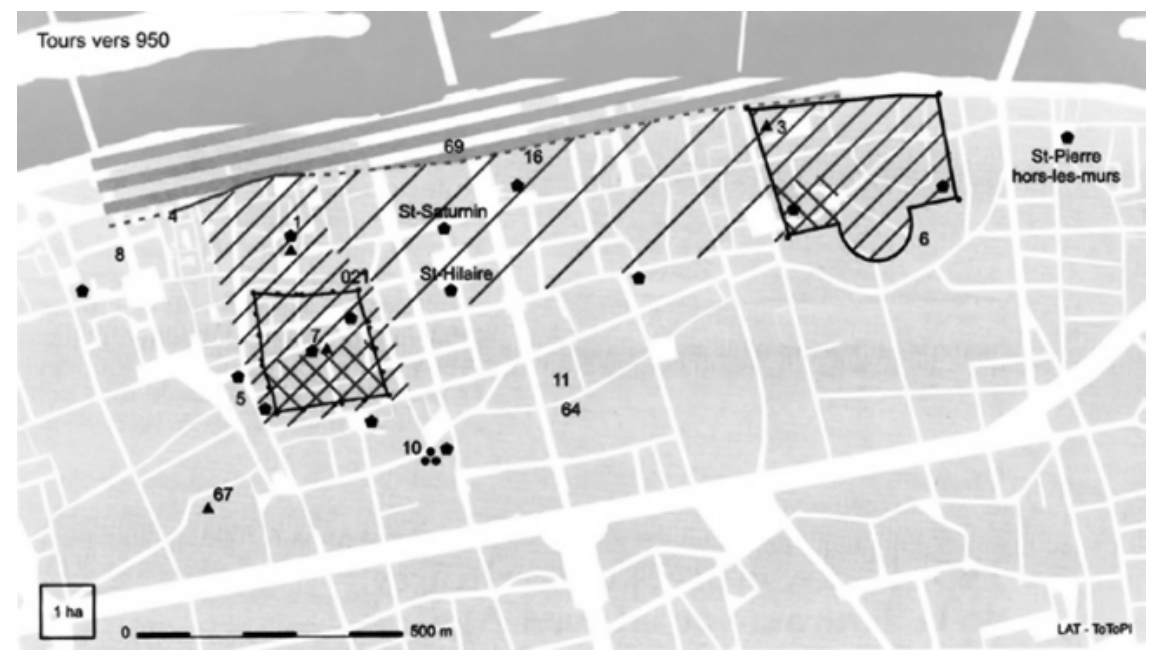

Abb. 9: Plan des Stadtgebietes von Tours im 10. Jh. mit ,zweipoliger` Besiedlungsstruktur.

im 5. oder 6. Jh. erfolgte. ${ }^{77}$ Diese vorstädtischen basilicae waren mit der Kernstadt durch eine Vielzahl von Ritualen verbunden, etwa Prozessionen zu wichtigen Anlässen, ${ }^{78}$ und sie wurden auf lange Sicht - allerdings kaum vor dem 6. Jh. - auch wieder zu Anlagerungspunkten für eine sich verdichtende Besiedlung, was dann im Früh- und Hochmittelalter die ,Zweipoligkeit‘ mancher französischen Stadt wie Limoges oder Tours zwischen civitas (Cité) und burgus (Bourg) bewirkte (Abb. 9). ${ }^{79}$

77 Ein Beispiel hierfür ist die Verehrungsstätte, die sich im Umkreis des Begräbnisplatzes des hl. Martialis in Limoges entwickelte; vgl. dazu Desbordes/Perrier 1990; Premiers monuments chrétiens 1996, 139-145. Das Grab des Martialis, der angeblich der erste Bischof von Limoges gewesen ist (s. Greg. Tur. HF 1, 30; glor. conf. 27-28), wurde wohl im Laufe des (früheren) 4. Jh.s angelegt, und zwar im Bereich eines Gräberfeldes, das sich im 3. Jh. innerhalb eines aufgelassenen Viertels der hochkaiserzeitlichen Stadt herausgebildet hatte und nunmehr in einiger Entfernung von dem offenbar befestigten spätantiken Siedlungskern lag. Spätestens um 500 scheint dann in diesem Bereich eine basilica über der crypta errichtet worden zu sein; und der Komplex erfuhr in karolingischer Zeit einen weiteren Ausbau.

78 Zur Bedeutung von christlichen, oftmals vom Bischof initiierten Prozessionen bei der Strukturierung des spätantiken Stadtraumes und -lebens vgl. die Beobachtungen von Jussen 1995, 694-698, 708-710 und Beaujard 1996, 142-145; ferner das Beispiel von Reims (s. Neiss/Sindonino 2004, 107 mit entsprechenden Belegen) sowie u. Anm. 104.

79 Zur Situation in Limoges, wo dieser Prozess spätestens im 10. Jh. zum Abschluss kam, s. Prévot/Barral i Altet 1989, 72; Perrier 1993, 116-119 sowie o. Anm. 77. Zur Entwicklung einer ähnlichen bipolaren Siedlungsstruktur in Tours ab dem späten 5. Jh., die durch die Errichtung einer eigenen Stadtmauer um das Viertel Saint-Martin im frühen 10. Jh. abgeschlossen wurde, vgl. Premiers monuments chrétiens 1996, 106-110; Galinié 1997, $71 \mathrm{f}$. 
Jedenfalls sorgten gerade diese Entwicklungen dafür, dass die reduzierten Kernstädte keine isolierten, sich durch ihre Mauern vom Umland abschottenden Entitäten wurden, sondern mit diesem durch eine Vielzahl lebensweltlicher und symbolisch aufgeladener Aktivitäten verbunden blieben. Gerade der Kranz von Märtyrerkirchen, der sich um manche Stadt (etwa in Clermont; s. Abb. 2, S. 167) bildete, stellte darüber hinaus auch einen Kristallisationspunkt für eine Neuausrichtung der städtischen Identität dar, die sich nun gerade an den dort verehrten Heiligen als Schutzpatronen und Trägern einer städtischen Tradition festmachte, worin man dann in der christlichen Legendenbildung auch die als Ruinen noch sichtbaren baulichen Reste der Vergangenheit einbeziehen konnte. ${ }^{80}$

\section{Die Widerspiegelung der urbanistischen Veränderungen in den literarischen Städtebeschreibungen der Spätantike}

Im Folgenden gilt es zu untersuchen, ob die soeben vornehmlich am archäologischen Befund herausgearbeiteten Veränderungen in der äußeren Erscheinungsform der Städte Galliens auch Spuren in den literarischen Quellen hinterlassen haben, was wiederum eventuell wertvolle Anhaltspunkte für den zu vermutenden Mentalitätswandel, der durch die Transformation der Stadtbilder ausgelöst worden sein oder diese sogar befördert haben könnte, zu geben vermag. Daher sollen nun einige ausgewählte Stadtbeschreibungen von gallischen Autoren des 4. bis 6 . Jh.s etwas genauer beleuchtet werden, wobei keinerlei Anspruch auf Vollständigkeit erhoben werden kann.

Beginnen möchte ich mit einer bekannten Passage aus dem Geschichtswerk des Gregor von Tours. Dieser beschreibt darin ausführlich die zu seiner Zeit recht bedeutende Siedlung von Divio (Dijon) und bemerkt dazu: ${ }^{81}$

und Galinié 2007, 18f., 290f., 364-367. Ähnliches ist in Reims auszumachen, wo sich ca. $900 \mathrm{~m}$ südlich des ummauerten Stadtgebiets um die dortigen, ab dem späteren 4. Jh. errichteten Begräbniskirchen ein neuer Besiedlungskern herausbildete, der im 7. Jh. als vicus sancti Remigii bezeugt ist und im 10. Jh. mit einer eigenen Mauer umgeben wurde; dazu Neiss/Sindonino 2004, 107, 109-111.

80 Vgl. zu beiden Aspekten u. Anm. 103.

81 Greg. Tur. HF 3, 19 (Übersetzung: Giesebrecht/Buchner): Erat enim tunc et beatus Gregorius apud urbem Lingonicam magnus Dei sacerdus, signis et virtutibus clarus. Sed quia huius pontificis meminimus, gratum arbitratus sum, ut situm loci Divionensis, in quo maxime erat assiduus, huic inseram lectione. Est autem castrum firmissimis muris in media planitiae et satis iocunda compositum, terras valde fertiles atque fecundas, [...]. A meridie habet Oscarum fluvium piscibus valde praedivitem, ab aquilone vero alius fluviolus venit, qui per portam ingrediens ac sub pontem decurrens, per aliam rursum portam egreditur, totum monitionis locum placida unda circumfluens, ante portam autem molinas mira velocitate divertit. Quattuor portae a quattuor plagis mundi sunt positae, totumque aedificium triginta tres torres exornant, murus vero illius de quadris lapidibus usque in viginti pedes desuper a minuto lapide aedificatum habetur, habens in altum pedes triginta, in lato pedes quindecim. Qui cur non civitas dicta sit, ignoro. Habet enim in circuitu praetiosus 
Es war nämlich damals der heilige Gregorius in der Stadt Langres der große Priester des Herrn, berühmt durch Zeichen und Wunder. Aber da ich diesen Bischof schon erwähnt habe, wird es, so denke ich, willkommen sein, wenn ich etwas über die Lage von Dijon einflechte, wo er sich am liebsten aufhielt. Es ist eine befestigte Siedlung (castrum) mit äußerst starken Mauern, mitten in einer reizenden Ebene gelegen; und dazu gehören auch sehr fruchtbare und gewinnbringende Äcker, [...]. Im Süden fließt die Ouche, die sehr fischreich ist; im Norden ein anderer kleiner Fluss, der durch eines der Tore hinein- und unter einer Brücke durchfließt, um durch ein anderes Tor die Stadt wieder zu verlassen, und mit sanften Wellen die gesamten Befestigungen umströmt, vor den Toren aber Mühlen mit bewundernswerter Schnelligkeit antreibt. Die vier Tore sind nach den vier Weltgegenden ausgerichtet, und das gesamte Befestigungswerk schmücken 33 Türme. Die Mauer selbst ist bis zu einer Höhe von 20 Fuß aus Quadersteinen gebaut, darüber aber aus kleinteiligem Bruchsteinmauerwerk; und sie hat insgesamt eine Höhe von $30 \mathrm{Fu}$ und eine Dicke von $15 \mathrm{Fu}$. Warum Dijon nicht als civitas [d.h. als Hauptort einer civitas] gilt, weiß ich nicht. Es gibt nämlich in der Umgebung auch wertvolle Quellen; und die Hügel gegen Westen hin sind voll von ertragreichen Weinreben, [...]. Die Alten erzählen nämlich, diese Siedlung sei von Kaiser Aurelian erbaut worden.

An dieser Schilderung sind mehrere Punkte bemerkenswert. Zunächst wird hier deutlich, dass die römische Auffassung von einer civitas und deren primär politisch-administrativer Funktion noch im späten 6. Jh. fortbestand. Divio war ursprünglich vermutlich ein vicus im Gebiet der civitas Lingonum, deren Hauptort Andematunum war, welches später Lingonica urbs (heute Langres) genannt wurde. ${ }^{82}$ Im späten 3. oder im frühen 4. Jh. wurde der Ort mit einer mächtigen, aus Spolien errichteten Mauer umgeben, die eine Fläche von nahezu 11 ha umschloss, was für ein gallisches castrum recht groß war und somit auf die Bedeutung verwies, die die Siedlung zu Beginn der Spätantike erreicht hatte. Seit der Mitte des 5. Jh.s war Divio zudem - wie von Gregor beschrieben - ein häufiger Aufenthaltsort der Bischöfe von Langres. ${ }^{83}$ Erst in späterer Zeit waren sie wieder ausschließlich in Langres zu finden. Mit Blick auf die städtische Infrastruktur und die zentralörtliche Bedeutung war also Dijon im späten 5. und im 6. Jh. dem alten civitas-Hauptort Langres mindestens ebenbürtig, wenn nicht sogar überlegen; und selbst der Bischof, mittlerweile die wichtigste Instanz der civitas, zog es in dieser

fontes; a parte autem occidentes montes sunt uberrimi viniisque repleti, [...]. Nam veteres ferunt ab Auriliano hoc imperatore fuisse aedificatum.

$82 \mathrm{Zu}$ der Siedlung von Divio, deren Ursprünge in der hohen Kaiserzeit weitgehend im Dunkeln liegen, vgl. Beaujard u.a. 1986, 55-63; zu Langres vgl. ebd. 51f. Zum spätantiken Dijon sowie zum Verhältnis zwischen diesem Ort und Langres vgl. ferner Picard 1984; Premiers monuments chrétiens 1998, 55f.; Loseby 2000, 85-87 (der zu Recht bemerkt, dass die Darstellung des Gregor von Tours keineswegs neutral angelegt ist, son-dern durchaus von eigenen bzw. familiären Interessen geleitet erscheint); Beaujard/Prévot 2004, 23.

83 So hielt sich im Jahr 485/86 Abrunculus Lingonicae civitatis episcopus im castrum Divionensis auf, wurde von den Burgundern der Konspiration mit den Franken verdächtigt und musste nach Clermont fliehen (s. Greg. Tur. HF 2, 23). 
Epoche zumeist vor, dort zu residieren. All das reichte aber für sich allein genommen noch nicht aus, um Divio in den Rang einer eigenständigen civitas zu erheben, auch wenn sich Gregor ob dieser Tatsache verwundert zeigte - hierzu hätte es eines offiziellen Aktes, etwa der förmlichen Verlegung des Verwaltungsmittelpunktes der civitas, bedurft, wie er anderenorts sehr wohl bezeugt ist, ${ }^{84}$ in diesem Fall aber augenscheinlich nicht erfolgte.

Für unseren Zusammenhang wichtiger ist aber die Beobachtung, wie viel Mühe Gregor darauf verwandte, die städtebaulichen Vorzüge von Divio herauszuarbeiten, um dadurch die Bedeutung des Ortes und seine Stellung innerhalb der umliegenden Region klar hervortreten zu lassen. Dieser Aspekt war also augenscheinlich auch im ausgehenden 6 . Jh. noch von erheblicher Bedeutung, wenn es darum ging, eine Hierarchie von Siedlungen zu definieren. Interessant ist nun, welche Elemente hierbei besonders betont wurden: Neben der Lage des Ortes und seinen wirtschaftlichen Funktionen war es vor allem der eindrucksvolle und von Gregor ausführlich beschriebene Mauerring mit seinen vier Toren und zahlreichen Türmen, welcher die Aufmerksamkeit des Betrachters erregte. Die Schilderung Gregors zum Aufbau dieser Befestigung lässt sich recht gut mit den erhaltenen spätantiken Stadtmauern in Gallien abgleichen und war somit sicherlich kein Phantasieprodukt. ${ }^{85}$ An dieser Stelle bestätigt sich der bereits zuvor (s.o. II.) gewonnene Eindruck, dass die städtischen Befestigungsanlagen im spätantiken Gallien zu einem der wichtigsten Abzeichen von urbanitas geworden waren, während andere Arten von Gebäuden (mit Ausnahme einer Brücke und der Mühlen) in der Beschreibung von Divio durch Gregor keine Berücksichtigung fanden.

Wenn wir nun von hier aus den Blick auf die Stadtbeschreibungen des 4. und 5. Jh.s lenken, so zeigt sich allerdings, dass eine solche Vorgehensweise keineswegs die alleinig dominierende war, denn viele Autoren bewiesen bei ihren literarischen Stadtansichten ein starkes Beharrungsvermögen, das an den Gattungstraditionen des Städtelobes orientiert war und auf den Wandel im äußeren Erscheinungsbild der Städte, der ja gerade im spätantiken Gallien nicht zu übersehen war, nur wenig Bezug nahm. So wurde oftmals weiterhin ein Kanon von Baulichkeiten vorgeführt, der seit jeher eine Stadt im Imperium Romanum ausgezeichnet hatte, dabei aber die zeitgenössische Realität zumindest teilweise ausgeblendet. Gut demonstrieren lässt sich dies an zwei Lobpreisungen der südgallischen Stadt Narbo (Narbonne): Ausonius geht in seinem Ordo urbium nobilium ausführlich auf die politische und wirtschaftliche Bedeutung des Ortes ein und hebt unter den dortigen Bauwerken vor allem das mächtige Capitolium hervor, das einstmals (quondam) den Ruhm von Narbo begründet habe. ${ }^{86}$ Während hier immerhin deutlich wird, dass der Blick von Ausonius dezidiert auf die städtebau-

84 Vgl. Beaujard/Prévot 2004, 33 sowie o. Anm. 8.

85 Vgl. Neiss/Sindonino 2004, 82f.

86 Auson. ordo 120-123: Quodque tibi Pario quondam de marmore templum / tantae molis erat, quantum non sperneret olim / Tarquinius Catulusque iterum, postremus et ille, aurea qui statuit Capitolini culmina, Caesar? Vgl. den Kommentar von Green 1991, 580f. 
liche Vergangenheit der Stadt gerichtet war, muss doch angemerkt werden, dass die Veränderungen, die auch das Stadtbild von Narbonne mittlerweile erfahren hatte, ${ }^{87}$ hierbei fast keine Berücksichtigung fanden. Noch klarer wird dies in einem Gedicht des Sidonius Apollinaris, der in den frühen 60er Jahren des 5. Jh.s ein Lob auf Narbo als die Heimatstadt des Adressaten, eines Mannes namens Consentius, anstimmte. ${ }^{88}$ Hier werden zwar im Rahmen einer langen Aufzählung von Bauwerken auch - und immerhin an erster Stelle - die mura angesprochen, aber es folgt eine lange und ganz konventionelle Liste weiterer Monumente und öffentlicher Anlagen wie portae, porticus, das Forum und das Theater sowie das Capitolium, Thermen, horrea usw. ${ }^{89}$ Ob es hierbei einen echten Bezug zu der urbanistischen Gestalt von Narbo im mittleren 5. Jh. gab, bleibt ganz unklar. Wahrscheinlich ist dies jedoch nicht, zumal Sidonius selbst etwas später im selben Gedicht auf semirutae arces und ruinae innerhalb der Stadt anspielt, ${ }^{90}$ die augenscheinlich eine Folge von Angriffen der Westgoten auf Narbonne waren auch an dieser Stelle ist aber davor zu warnen, eine solche Beschreibung zu wörtlich zu nehmen, denn die Schilderung des Verfalls und der Ruinen einer einstmals großen Stadt gehörten ebenso zum Arsenal literarischer Stadtdarstellungen in der Spätantike wie die panegyrische Überhöhung des Baubestandes. ${ }^{91}$ Die Reaktion des ,Normalbürgers' auf das spätantike Erscheinungsbild von Narbo ist aus solchen Passagen jedenfalls kaum zu rekonstruieren.

Auffällig ist in diesem Kontext noch ein anderes Phänomen, denn es gibt eine Gruppe von Gebäuden, welche weder bei Ausonius noch bei Sidonius Erwähnung fanden, ${ }^{92}$ obwohl sie mittlerweile die urbanistische Gestalt vieler gallischer Städte

87 Vgl. hierzu Witschel 1999, 315f. Auch in Narbo lässt sich für die Zeit ab dem späteren 2. Jh. ein schrittweiser Kontraktionsprozess ausmachen, durch den sich gerade die Randzonen des Stadtgebiets erheblich veränderten, bevor zu Beginn der Spätantike ein vom Umfang her stark reduzierter Mauerring errichtet wurde. Immerhin scheinen Teile der städtischen Infrastruktur noch bis in eine recht späte Zeit instand gehalten worden zu sein, wie die Inschrift CIL XII 4355 = ILS 5904 anzuzeigen scheint, die sich in das 4. oder 5. Jh. einordnen lässt und offenbar die Leistungen eines Mannes rühmte, der pontem portas aquiduct(us) quaru(m) r[erum] / usus longa incuria et vetustate co[rruptus e]/rat civitati restauravit ac reddi[dit]. Allerdings ist auch im Falle solcher Ehren- und Bauinschriften - von denen es aus dem spätantiken Gallien nur sehr wenige gibt - mit einem nicht zu unter-schätzenden $\mathrm{Ma}$ an rhetorischer Übertreibung zu rechnen.

88 Sidon. carm. 23; zu Consentius s. PLRE II Consentius 2.

89 Sidon. carm. 23, 37-47: Salve, Narbo potens salubritate, / urbe et rure simul bonus videri, / muris, civibus, ambitu, tabernis, / portis, porticibus, foro, theatro, / delubris, capitoliis, monetis, / thermis, arcubus, horreis, macellis, / pratis, fontibus, insulis, salinis, / stagnis, flumine, merce, ponte, ponto; / unus qui venere iure divos / Lenaeum, Cererem, Palem, Minervam spicis, palmite, pascuis, trapetis.

90 Sidon. carm. 23, 59-62: sed per semirutas superbus arces, / ostendens veteris decus duelli, / quassatos geris ictibus molares, / laudandis pretiosior ruinis.

91 Vgl. hierzu Witschel 1999, 33-38 sowie Loseby 2006, 72f.

92 Dies gilt im Übrigen selbst für die ausführliche Beschreibung von Divio bei Gregor von Tours (s.o. Anm. 81), denn hier werden ebenfalls keine Kirchenbauten erwähnt, obwohl es diese im Dijon des 6. Jh.s natürlich gab (und Gregor an anderen Stellen seines Werks sehr wohl auf sie verweist) - auch der Bischof von Tours stand an dieser Stelle also augen- 
dominierten, nämlich christliche Einrichtungen, insbesondere die intramurale Bischofs- und Gemeindekirche sowie die vorstädtischen Basiliken, die dem Märtyrerkult dienten und für Bestattungen genutzt wurden. ${ }^{93}$ Während man dies im Falle des Ausonius damit erklären könnte, dass zu seiner Zeit ein Kirchenbau im größeren Stil in Gallien gerade erst begonnen und viele Orte noch gar nicht erreicht hatte (vgl. o. II.), griffe eine solche Erklärung bei Sidonius mit Sicherheit zu kurz. Denn gerade in Bezug auf Narbonne verfügen wir über eine gute Evidenz, die zu zeigen vermag, dass das mittlere 5. Jh. eine Epoche intensiver Bauaktivitäten auf dem kirchlichen Sektor war. Diese wurden im Wesentlichen von dem örtlichen Bischof, Rusticus, vorangetrieben, der dabei von befreundeten Bischöfen und Angehörigen des Klerus, aber auch von Mitgliedern der provinzialen und lokalen Aristokratie unterstützt wurde und seine Aktivitäten sogar in mehreren, teils recht monumental gestalteten Inschriften festgehalten hat. ${ }^{94}$ All das muss Sidonius, dem späteren Bischof von Clermont, sehr wohl bekannt gewesen sein; dennoch hat er es nicht für wert erachtet, darauf in seinem Städtelob einzugehen.

Ähnliche Tendenzen beobachten wir mit Blick auf diejenigen Passagen im Werk des Ausonius, die sich mit seiner Heimatstadt Burdigala beschäftigen. Erneut sind wir hier mit einem eher ausschnitthaften und selektiven Bild der spätantiken Stadtlandschaft konfrontiert. Am eindrücklichsten ist das Lob der Stadt im letzten Abschnitt des Ordo urbium nobilium: ${ }^{95}$ Auch hier wird zunächst auf ein neuartiges und das spätantike Stadtbild dominierendes Element eingegangen, nämlich auf den quadratischen Mauerring mit seinen Türmen. Es folgen Hinweise auf die rechtwinklig angelegten Straßen und die weiträumigen Platzanlagen sowie auf den Flusshafen im Inneren der Mauern und schließlich - besonders ausführ-

scheinlich noch in der Tradition des klassisch-antiken Städtelobes, in dem kein Platz für christliche Kultbauten war.

93 Vgl. o. Anm. 74.

$94 \mathrm{Zu}$ den Kirchenbauaktivitäten des Rusticus von Narbonne, die sowohl Restaurierungen als auch Neubauten umfassten, s. bes. CIL XII 5336 und AE 1928, 85; dazu Marrou 1970.

95 Auson. ordo 128-168: Burdigala. Impia iamdudum condemno silentia, quod te, / o patria, insignem Baccho fluviisque virisque, / moribus ingeniisque hominum procerumque senatu, / non inter primas memorem, quasi conscius urbis / exiguae immeritas dubitem contingere laudes. [...] Quadrua murorum species, sic turribus altis / ardua ut aerias intrent fastigia nubes. / distinctas interne vias mirere, domorum / dispositum et latas nomen servare plateas, / tum respondentes directa in compita portas / per mediumque urbis fontani fluminis alveum; / quem pater Oceanus refluo cum impleverit aestu, / allabi totum spectabis classibus aequor. Quid memorem Pario contectum marmore fontem / Euripi fervere freto? Quanta umbra profundi! / Quantus in amne tumor! Quanto ruit agmine praeceps / marginis extenti bis sena per ostia cursu, / innumeros populi non umquam exhaustus ad usus! [...] Utque caput numeri Roma inclita, sic capite isto / Burdigala ancipiti confirmet vertice sedem. / Haec patria est, patrias sed Roma supervenit omnes. / Diligo Burdigalam, Romam colo. Civis in hac sum, / consul in ambabus: cunae hic, ibi sella curulis. Vgl. dazu Sivan 1993, 38-48; Barraud/Maurin 1998, 38-41; Maurin u.a. 1998, 26f.; Loseby 2006, 73-75. 
lich - auf eine berühmte Brunnenanlage. ${ }^{96}$ Keine Erwähnung finden hingegen weitere öffentliche Gebäude wie das Forum, Verwaltungsbauten oder Tempel, und auch kirchliche Bauten kommen nicht vor. Im ersteren Falle mag dies damit zu tun haben, dass diese Baulichkeiten tatsächlich im spätantiken Stadtbild von Bordeaux keine bedeutende Rolle mehr spielten, ${ }^{97}$ während andererseits Kirchen im späteren 4. Jh., als der Ordo entstand, in der Stadt noch nicht in größerer Zahl vorhanden waren. ${ }^{98}$ Insgesamt wird hier die Vorstellung eines wohl geordneten und großzügig dimensionierten Stadtprospekts innerhalb des Mauerrings evoziert. An weiteren Stellen seines Werks, insbesondere in den Briefen, vermittelt Ausonius allerdings ein deutlich anderes Bild von Bordeaux: Hier erscheint eine dicht bebaute Siedlung mit engen und verwinkelten Straßen, die von zahlreichen Menschen verstopft werden. ${ }^{99}$ Diese Schilderungen tauchen immer dann auf, wenn Ausonius darauf verweist, dass er den Unannehmlichkeiten des Stadtlebens entgehen und sich auf eines seiner zahlreichen Landgüter begeben wolle. Der scheinbare Widerspruch erklärt sich sicherlich zumindest teilweise dadurch, dass Ausonius in beiden Fällen bestimmten literarischen Vorgaben folgte. ${ }^{100}$ Die Darstellung von Burdigala im Ordo urbium nobilium gehört in den Bereich des panegyrischen Städtelobes, für das relativ genau festgelegt war, wie eine solche Schilderung auszusehen hatte. ${ }^{101}$ Das zeigt sich nicht zuletzt daran, dass sich ganz ähnliche Beschreibungen von Bordeaux auch in anderen Texten der Zeit finden. ${ }^{102}$ In den Briefen hingegen erkennen wir die typische Verachtung des lauten Städtelebens durch den Aristokraten, der das otium auf dem Lande vorzieht. $\mathrm{Zu}$ beachten ist aber eben auch, dass Bordeaux nach Ausweis des archäologischen Befundes im späteren 4. Jh. ein wesentlich komplexeres Bild bot, als es in den reichlich schematisierten Beschreibungen des Ausonius durchscheint.

Wenn wir von hier aus noch einmal zu Gregor von Tours zurückkehren und seine Schilderungen der Stadt Clermont betrachten, sehen wir uns mit einem zweiten wichtigen Element der spätantiken Stadtstruktur konfrontiert, das in den bislang behandelten Passagen keine Rolle spielte, nämlich mit der Bedeutung der

96 Diese konnte bislang nicht lokalisiert werden; vgl. Barraud/Maurin 1998, 40.

$97 \mathrm{Zu}$ den Veränderungen im Stadtbild von Bordeaux, die sich seit dem späteren 3. Jh. ergeben hatten, vgl. o. Anm. 50, 57 und 62 sowie Barraud/Maurin 1998, 41-53.

98 Vgl. die Aufstellung der Kirchenbauten von Burdigala bei Maurin u.a. 1998, 28-33, die demonstriert, dass die allermeisten dieser Gebäude nicht vor dem späten 4. Jh. und in der Mehrzahl sogar erst im 5. oder 6. Jh. errichtet worden sein dürften. Neue Grabungsergebnisse in der Südwestecke des spätantiken castrum können allerdings eventuell zeigen, dass hier eine erste größere Bischofskirche doch schon in der zweiten Hälfte des 4. Jh.s errichtet worden ist; s. Barraud 2009, 29-32; Maurin/Navarro Caballero 2010, 50.

99 So etwa Auson. epist. 4, 19-24 (ed. Green 1991): Nam populi coetus et compita sordida rixis / fastidientes cernimus / angustas fervere vias et congrege volgo / nomen plateas perdere. / Turbida congestis referitur vocibus echo: / Tene, feri, duc, da, cave!

100 Vgl. Guyon u.a. 1998.

101 Vgl. hierzu auch Beck 1969.

102 Eine vergleichbare Beschreibung des spätantiken Bordeaux findet sich etwa bei Paul. euch. 44-47. 
zahlreichen suburbanen Basiliken und Märtyrer-Verehrungsstätten als neuer Orientierungspunkte für die Bewohner der civitas. So berichtet Gregor davon, dass sich nahe bei der Stadt (iuxta hanc urbem) die Begräbnisorte und Erinnerungsstätten verschiedener Märtyrer befänden, wobei zumindest in einem Fall auch eine Verbindung zu der früheren Topographie der Stadt hergestellt wurde. Der Siedlungskern, der sich im Umkreis dieser Anlagen herausgebildet hatte, wurde „Dorf der Christen“ genannt. ${ }^{103} \mathrm{Zu}$ diesem vicus Christianorum führten aus Anlass hoher kirchlicher Feiertage, zur Feier der Märtyrer oder bei der Bestattung hochrangiger Persönlichkeiten regelmäßig Prozessionen, an denen eine größere Zahl von Menschen teilnahm, wie Gregor an einer anderen Stelle mit Bezug auf ein Ereignis im Jahr 576 berichtet: ${ }^{104}$

An dem heiligen Tage aber, an dem der Herr nach der Erlösung der Menschheit glorreich zum Himmel auffuhr, stürzte sich plötzlich, als der Bischof unter Chorgesang von der Hauptkirche zu der Begräbniskirche zog, die ganze Menge derer, die ihm folgten, auf die Synagoge der Juden [...]. Voll Freude über diese Botschaft [die Bekehrung der Juden] zog der Bischof, als er in der heiligen Pfingstnacht den Gottesdienst gehalten hatte [offenbar in der intramuralen Bischofskirche], zu der Taufkapelle vor den Mauern der Stadt, und dort verlangte die gesamte Menge der Juden auf den Knien von ihm die Taufe [...]. [Die Juden werden getauft:] Es brannten die Kerzen, es strahlten die Lampen, es glänzte die ganze Stadt von der schneeweißen Schar [...].

An dieser Stelle tritt die neue Gestalt der spätantiken gallischen Stadt mit ihrem stark verkleinerten intramuralen Kern und dem ihn umgebenden Kranz von Märtyrerkirchen im suburbium deutlich hervor, wobei beide Welten gerade durch Rituale wie die hier beschriebenen eng miteinander verbunden waren.

103 Greg. Tur. HF 1, 33: Iuxta hanc urbem Liminius Anatolianusque martyres requiescunt. Ibi Cassius ac Victorinus in dilectione Christi fraterno affectu sociati, per effusionem cruoris proprii caelorum regna pariter sunt adepti. Nam refert antiquitas Victorinum servum fuisse antedicti templi sacerdotis. Qui dum plerumque vicum, quem Christianorum vocant, ad persequendos Christianos adit, Cassium repperit Christianum. In diesem Bereich befanden sich zahlreiche Kirchen, die ab der Zeit um 400 errichtet worden waren; vgl. Prévot/Barral i Altet 1989, 33-35; Pietri 1997. Mit antedictum templum ist das bedeutende keltische Heiligtum gemeint, dessen Ruinen noch zur Zeit des Gregor zu sehen war (s.o. Anm. 55) und das hier als Referenzpunkt für eine christliche Märtyrererzählung diente.

104 Greg. Tur. HF 5, 11: Die autem beato, quo Dominus ad caelos post redemptum hominem gloriosus ascendit, cum sacerdos de ecclesiam ad basilicam psallendo procederet, inruit super sinagogae Iudaeorum multitudo tota sequentium [...] Gavisus autem nuntio pontifex, noctem sanctam pentecosten vigilias caelebratas, ad baptisterio forasmoraneum egressus est; ibique omnis multitudo coram eo prostrata baptismum flagitavit [...] Flagrabant caerei, lampades refulgebant, albecabat tota civitate de grege candido [...]. 


\section{Schluss}

Die soeben betrachteten literarischen Stadtbeschreibungen haben trotz aller immer wieder aufscheinender Traditions- und Gattungsgebundenheit, welche zur Ausblendung eines Teiles der zeitgenössischen Realität führte, auf einige wichtige Aspekte der Identitätsbildung in dem während der Spätantike umgestalten städtischen Raum in Gallien verwiesen. So erscheint in ihnen sehr klar die nunmehr dominante Rolle der zwischen dem späteren 3. und dem frühen 5. Jh. neu errichteten Stadtmauern. Ihre bauliche Gestalt wurde von den einzelnen Autoren häufig hervorgehoben und ausführlich beschrieben, da sie in der gewandelten Stadtlandschaft des spätantiken Gallien als ein besonders wirkmächtiges Symbol von urbanitas und städtischem Prestige galten. Ein weiteres, an zahlreichen Stellen thematisiertes und darum hervorstechendes Element der spätantiken Stadtstruktur in Gallien war die große Bedeutung der Märtyrer und Heiligen für die städtischen Gemeinschaften sowie die zentrale Rolle, die dabei ihre vor den Stadtmauern liegenden Gedenkstätten spielten. Letztere wurden im Laufe der Zeit zunehmend monumentalisiert, wodurch sie einen wichtigen Bezugspunkt für die Neuorientierung der städtischen Identität unter christlichen Vorzeichen bildeten.

Andere Faktoren, welche in dem Transformationsprozess der Städte in Gallien ebenfalls von hoher Relevanz gewesen sein müssen, werden in den uns zur Verfügung stehenden Quellen hingegen kaum oder gar nicht thematisiert, so dass wir nicht sicher beurteilen können, wie sich diese Vorgänge im Einzelnen abgespielt haben. Ein gutes Beispiel hierfür sind - wie schon angesprochen - die Entscheidungen, die auf städtischer Ebene der zumeist radikalen Umwandlung der Stadtbilder durch die Errichtung stark reduzierter Stadtmauerringe vorangegangen sein müssen. An diesem Punkt muss es m.E. intensive Aushandlungen unter den beteiligten Akteuren gegeben haben, da festzulegen war, wie genau der Mauerring im Einzelnen zu gestalten war und welche vorhandenen Bauten und Anlagen hierfür geopfert oder dem Verfall anheimgegeben werden sollten. Solche Verhandlungen und Entscheidungen dürften wiederum in nicht unerheblichem Maße auf die Neuformierung des Stadtgefühls im spätantiken Gallien zurückgewirkt haben - nur ist dies eben offenbar fast ohne greifbaren Reflex in den Quellen geblieben.

Die vielfach über einen längeren Zeitraum hinweg ablaufende, bisweilen aber auch abrupt erfolgende Umgestaltung des städtischen Raumes, die bewirkte, dass man an nicht wenigen Orten ziemlich radikal mit einer offensichtlich obsolet gewordenen urbanistischen Vergangenheit brach, was wiederum zu einer Neudefinition der städtischen Strukturen in dem nunmehr stark verengten intramuralen Bereich einerseits und in den - erheblichen Veränderungen unterworfenen - suburbanen Zonen andererseits führte, dürfte ebenfalls bedeutsame Auswirkungen auf die Mentalität der verbliebenen Stadtbewohner gehabt haben. Allerdings können wir nicht im Detail rekonstruieren, wie sie die angesprochenen Veränderungen jeweils erlebt und unmittelbar darauf reagiert haben. Fassbar ist für uns ledig- 
lich die längerfristige Transformation der gallischen Stadtbilder, die sich im chäologischen und städtebaulichen Befund so deutlich abzeichnet.

Zuletzt ist noch darauf hinzuweisen, dass eine solche Transformation der in der frühen Kaiserzeit etablierten städtebaulichen Strukturen und Leitbilder zumindest in Bezug auf ihre Radikalität und ihr frühzeitiges Einsetzen eine regionalspezifische gallische Besonderheit darstellte, da sie sich in dieser Form weder in den meisten anderen Regionen im Westteil des Imperium Romanum noch gar im Osten des Reiches finden lässt - jedenfalls nicht mit Blick auf das 3. und 4. Jh. ${ }^{105}$ Zwar wurden auch anderswo während der Spätantike zahlreiche neue Stadtmauern errichtet oder ältere Befestigungsanlagen ausgebessert, aber diese hatten zumeist einen erheblich größeren Umfang als die stark reduzierten gallischen Mauerringe, und so entwickelten sich sowohl die intramuralen Bezirke als auch die suburbanen Bereiche hier deutlich anders als in Gallien. Auf der anderen Seite hat der in Gallien so stark hervortretende Wandel der Stadtbilder trotz (oder gerade wegen) des damit verbundenen Bruches mit den Monumenten und urbanistischen Vorstellungen der Vergangenheit für die - in der großen Mehrzahl fortbestehenden - Städte Galliens und ihre Bewohner auch neuartige, in die Zukunft weisende Gestaltungsmöglichkeiten eröffnet - so etwa bei der Nutzung der nunmehr stark ausgeweiteten suburbanen Zonen für verschiedene Zwecke, insbesondere aber für kirchliche Bauten und Einrichtungen, welche wiederum auf lange Sicht Anlagerungspunkte für neue städtebauliche Entwicklungen bildeten. ${ }^{106}$

\section{Abkürzungen}

TCG: Topographie chrétienne des cités de la Gaule des origines au milieu du VIII siècle. CAG: Carte Archéologique de la Gaule.

\section{Literaturverzeichnis}

\section{Primärquellen}

Ammianus Marcellinus, Res gestae: Ammianus Marcellinus, Römische Geschichte. Lateinisch und deutsch und mit einem Kommentar versehen von Wolfgang Seyfarth, Berlin 1975-1978.

Ausonius, De herediolo: The Works of Ausonius. Edited with Introduction and Commentary by Roger P. H. Green, Oxford 1991, 19f.

Ausonius, Epistulae: The Works of Ausonius. Edited with Introduction and Commentary by Roger P. H. Green, Oxford 1991, 193-231.

Ausonius, Ordo urbium nobilium: The Works of Ausonius. Edited with Introduction and Commentary by Roger P. H. Green, Oxford 1991, 169-175.

105 Dazu Witschel 2008, 47-56.

106 Vgl. dazu o. Anm. 79. 
Codex Theodosianus: Theodosiani libri XVI cum constitutionibus Sirmondianis et leges novellae ad Theodosianum pertinentes, Bd. 1, ed. Paul Krüger und Theodor Mommsen, Berlin 1904.

Digesta: Corpus Iuris Civilis I: Institutiones, Digesta, ed. Paul Krüger und Theodor Mommsen, Berlin 1911.

Eusebius Historicus, Historiae (?): Die Fragmente der griechischen Historiker II A, hg. von Felix Jacoby, Berlin 1926, 480-482, Nr. 101.

Eutropius, Breviarium ab urbe condita: Eutropii Breviarium ab urbe condita, recogn. Carlo Santini, Stuttgart/Leipzig 1992.

Gregorius episcopus Turonensis, Historia Francorum: Gregor v. Tours, Historiarum libri decem - Zehn Bücher Geschichten. Auf Grund der Übersetzung W. Giesebrechts neu bearbeitet von Rudolf Buchner, Darmstadt ${ }^{9} 2000$.

Gregorius episcopus Turonensis, In gloria confessorum: Gregorii episcopi Turonensis miracula et opera minora, ed. Bruno Krusch (MGH SS rer. Merov. 1, 2), Hannover 1885, 294-370.

Historia Augusta, vita Probi: Histoire Auguste. Les Empereurs romains des $\mathrm{II}^{\mathrm{e}}$ et $\mathrm{III}^{\mathrm{e}}$ siècles. Édition bilingue latin-français, traduction du latin par André Chastagnol, Paris 1994, 1059-1101.

Iulianus, Caesares (Convivium): L'Empereur Julien, Euvres complètes II 2: Discours de Julien Empereur. Texte établi et traduit par Christian Lacombrade, Paris 1964, 1-71.

Paulinus Pellaeus, Eucharisticus: Ausonius. With an English translation by Hugh G. Evelyn White, vol. 2 (LCL), Cambridge (Mass.)/London 1985, 293-351.

Sidonius Apollinaris, Carmina: Sidoine Apollinaire, CEuvres, Bd. 1: Poèmes. Texte établi et traduit par André Loyen, Paris 1960.

Sidonius Apollinaris, Epistulae: Sidoine Apollinaire, Euvres, Bd. 2-3: Lettres. Texte établi et traduit par André Loyen, Paris 1970.

Sulpicius Severus, Dialogi: Sulpicii Severi libri qui supersunt, rec. et commentario critico instr. Karl Halm (CSEL 1), Wien 1866, 152-216.

Venantius Fortunatus, Carmina: Venanti Honori Clementiani Fortunati presbyteri Italici opera poetica, rec. Friedrich Leo (MGH Auct. ant. IV 1), Berlin 1881, 7-292.

Zosimus, Historia nova: Zosime, Histoire nouvelle I (livres I e II). Texte établi et traduit par François Paschoud, Paris 1971.

2. Inschriftencorpora

AE: Année Épigraphique.

CIL: Corpus Inscriptionum Latinarum.

ILCV: Ernst Diehl (Hg.), Inscriptiones Latinae christianae veteres I-IV, Berlin 1925-67.

ILN V: Bernard Rémy (Hg.), Inscriptions latines de Narbonnaise V 1-3: Vienne, Paris 2004.

ILS: Hermann Dessau, Inscriptiones Latinae selectae I-III 2, Berlin 1892-1916.

\section{Sekundärliteratur}

Aupert u. Monturet (1996): Pierre Aupert u. Raymond Monturet, Saint-Bertrand-deComminges - Lugdunum Convenarum. La cité des Convènes, Paris.

Baccrabère u. Badie (1998): Georges Baccrabère u. Alain Badie, „L'enceinte du BasEmpire à Toulouse“, in: Maurin u. Pailler 1998, 125-129. 
Bachrach (2010): Bernard S. Bachrach, „The Fortification of Gaul and the Economy of the Third and Fourth Centuries“, Journal of Late Antiquity 3, 38-64.

Balmelle (1983): Catherine Balmelle, „A propos d'une mosaïque tardive de Bordeaux“, in: Mosaïque. Recueil d'hommages à Henri Stern, Paris, 21-32.

Balmelle (1992): Catherine Balmelle, „L'habitat urbain dans le Sud-Ouest de la Gaule romain“, in: Maurin 1992a, 335-364.

Balmelle (1993): Catherine Balmelle, „Le répertoire végétal des mosaistes du Sud-Ouest de la Gaule et des sculpteurs des sarcophages dits d'Aquitaine“, Antiquité Tardive 1, 101-109.

Balmelle (1998): Catherine Balmelle, „Le décor en mosaïque des édifices urbains du SudOuest de la Gaule dans l'antiquité tardive“, in: Maurin u. Pailler 1998, 193-208.

Balmelle (2001): Catherine Balmelle, Les demeures aristocratiques d'Aquitaine. Société et culture de l'Antiquité tardive dans le Sud-Ouest de la Gaule, Bordeaux/Paris.

Barraud (2009): Dany Barraud, „Topographie chrétienne de Bordeaux dans l'antiquité tardive à la lumière des nouvelles découvertes archéologiques", in: Isabelle Cartron, Dany Barraud, Patrick Henriet u. Anne Michel (Hgg.), Autour de Saint-Seurin: lieu, mémoire, pouvoir. Des premiers temps chrétiens à la fin du moyen âge (Actes du Colloque Bordeaux 2006), Bordeaux, 23-33.

Barraud u. Maurin (1998): Dany Barraud u. Louis Maurin, „Bordeaux au Bas-Empire: de la ville païenne à la ville chrétienne“, in: Maurin u. Pailler 1998, 35-53.

Bayard u. Massy (1983): Didier Bayard u. Jean-Luc Massy, Amiens romain - Samarobriva Ambianorum, Amiens.

Bayard (2007): Didier Bayard, „Amiens 1983-2003, un bilan vingt ans après Amiens romain", in: Roger Hanoune (Hg.), Les villes romaines du Nord de la Gaule. Vingt ans de recherches nouvelles, Lille (Revue du Nord Hors série. Collection Art et Archéologie 10), 11-42.

Beaujard (1996): Brigitte Beaujard, „L'évêque dans la cité en Gaule aux V $\mathrm{V}^{\mathrm{e}}$ et VI siècles“, in: Claude Lepelley (Hg.), La fin de la cité antique et le début de la cité médiévale de la fin du III siècle à l'avènement de Charlemagne (Actes du Colloque Paris/Nanterre 1993), Bari, 127-145.

Beaujard u.a. (1986): Brigitte Beaujard, Nancy Gauthier u. Jean-Charles Picard, TCG VI: Province ecclésiastique de Lyon (Lugdunensis Prima), Paris.

Beaujard u. Prévot (2004): Brigitte Beaujard u. Françoise Prévot, „Introduction à l'étude

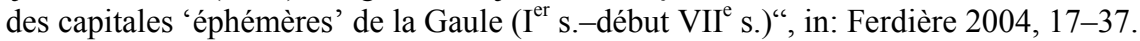

Beck (1969): Regula Beck, Die Tres Galliae und das Imperium im 4. Jh. Studien zum Ordo urbium nobilium des Decimus Magnus Ausonius, Zürich.

Bedon (1999): Robert Bedon, Les villes des trois Gaules de César à Neron dans leur contexte historique, territorial et politique, Paris.

Bonnet (1993): Charles Bonnet, Les fouilles de l'ancien groupe épiscopal de Genève (1976-1993), Genf.

Bonnet (2009): Charles Bonnet, Les fouilles de la cathédrale Saint-Pierre de Genève. Le centre urbain de la protohistoire jusqu'au début de la christianisation, Genf.

Bonnet u. Privati (2000): Charles Bonnet u. Béatrice Privati, „De la ville antique à la ville chrétienne. Les chantiers archéologiques de Genève", in: Romanité et cité chrétienne. Permanences et mutations, intégration et exclusion du $I^{e r}$ au VI $I^{e}$ siècle. Mélanges en l'honneur d'Y. Duval, Paris, 381-390. 
Bonnet u. Reynaud (2000): Charles Bonnet u. Jean-François Reynaud, „Genève et Lyon, capitales burgondes“, in: Gisela Ripoll u. Josep M. Gurt (Hgg.), Sedes regiae, ann. 400-800, Barcelona, 241-266.

Bost u. Fabre (1983): Jean-Pierre Bost u. Georges Fabre, „Quelques problèmes d'histoire dans deux cités de l'Aquitaine méridionale à l'époque gallo-romaine“, Aquitania 1, $25-36$.

Bost u. Fabre (2001): Jean-Pierre Bost u. Georges Fabre, Inscriptions latines d'Aquitaine: Pétrucores, Bordeaux.

Brassous (2011): Laurent Brassous, „Les enceintes urbaines tardives de la péninsule Ibérique“, in: Schatzmann u. Martin-Kilcher 2011, 275-299.

Brenk (1987): Beat Brenk, „Spolia from Constantine to Charlemagne: Aesthetics versus Ideology“, Dumbarton Oaks Papers 41, 103-109.

Briesenick (1962): Brigitte Briesenick, „Typologie und Chronologie der südwestgallischen Sarkophage“, Jahrbuch des Römisch-Germanischen Zentralmuseums Mainz 9, $76-182$.

Brulet (2011): Raymond Brulet, „Tournai: de la ville ouverte à las ville fermée“, in: Schatzmann u. Martin-Kilcher 2011, 221-234.

Busson (2001): Didier Busson, Paris ville antique, Paris.

Catalo u.a. (1999): Jean Catalo, Laurent Llech u. Jean-Luc Boudartchouk, „Le forum de Rodez (Aveyron) du IV ${ }^{\mathrm{e}}$ au VII $\mathrm{e}^{\mathrm{e}}$ siècle“", in: Bernadette Fizellier-Sauget (Hg.), L'Auvergne de Sidoine Apollinaire à Grégoire de Tours - histoire et archéologie, Clermont-Ferrand, 115-131.

Christol (1997): Michel Christol, L'Empire romain du III siècle. Histoire politique de 192 à 325 après J.-C., Paris.

Coquelet (2011): Catherine Coquelet, „Continuités et ruptures urbaines dans la seconde moitié du III $^{\mathrm{e}}$ siècle en Gaule Septentrionale“, in: Schatzmann u. Martin-Kilcher 2011, 235-246.

De Filippo (1993): Raphaël De Filippo, „Nouvelle définition de l'enceinte romaine de Toulouse“, Gallia 50, 181-204.

Delmaire u.a. (2011): Roland Delmaire, Jean-Claude Carmelez, Frédéric Loridant u. Christine Louvion-Deru, Le Nord, Bavay, Paris (CAG 59/2).

Demandt u. Engemann (2007): Alexander Demandt u. Josef Engemann (Hgg.), Imperator Caesar Flavius Constantinus - Konstantin der Große (Ausstellungskatalog Trier), Mainz.

Demougeot (1962): Émilienne Demougeot, „Les martyrs imputés à Chrocus et les invasions alamanniques en Gaule méridionale“, Annales du Midi 74, 5-28.

Deru (2010): Xavier Deru, Die Römer an Maas und Mosel, Mainz.

Desbordes u. Loustaud (1991): Jean-Michel Desbordes u. Jean-Pierre Loustaud, Limoges antique, Paris.

Desbordes u. Perrier (1990): Jean-Michel Desbordes u. Jean Perrier, Limoges - Crypte Saint-Martial, Paris.

Dey (2010): Hendrik W. Dey, „Art, Ceremony, and City Walls: The Aesthetics of Imperial Resurgence in the Late Roman West", Journal of Late Antiquity 3, 3-37.

Dey (2011): Hendrik W. Dey, „Urban Public Building during the 'Crisis' of the $3^{\text {rd }}$ c. A.D.“, Journal of Roman Archaeology 24, 822-830.

Dieulafait u. Sablayrolles (1998): Christine Dieulafait u. Robert Sablyarolles, „Le rempart de Saint-Lizier-en-Couserans: élément d'une défense pyrénéenne?“, in: Maurin u. Pailler 1998, 105-123. 
Doreau u.a. (1985): Jacques Doreau, Claudine Girardy u. Jean-François Pichonneau, „Contribution à l'étude du forum de Vésone (Périgueux, Dordogne)“, Aquitania 3, 91-104.

Dreier (2011): Christian Dreier, „Zwischen Kontinuität und Zäsur: Zwei aktuelle Befunde zur Entwicklung der Stadt Metz nach der Mitte des 3. Jahrhunderts“, in: Schatzmann u. Martin-Kilcher 2011, 167-179.

Duby (1980): Georges Duby (Hg.), Histoire de la France urbaine I: La ville antique des origines au $I X^{e}$ siècle, Paris.

Eck (1991): Werner Eck, „Die Struktur der Städte in den nordwestlichen Provinzen und ihr Beitrag zur Administration des Reiches“, in: Werner Eck u. Hartmut Galsterer (Hgg.), Die Stadt in Oberitalien und in den nordwestlichen Provinzen des römischen Reiches, Mainz, 73-84.

Esmonde Cleary (2004): Simon Esmonde Cleary, „The civitas-Capitals of Novempopulana“, in: Ferdière 2004, 183-189.

Esmonde Cleary u.a. (1998): Simon Esmonde Cleary, Michael J. Jones u. Jason Wood, „The Late Roman Defences at Saint-Bertrand-de-Comminges (Haute Garonne): Interim Report", Journal of Roman Archaeology 11, 343-354.

Fages (1995): Brieuc Fages, Le Lot-et-Garonne, Paris (CAG 47).

Fages u. Maurin (1991): Brieuc Fages u. Louis Maurin, Inscriptions latines d'Aquitaine: Nitiobroges, Agen.

Ferdière (2004): Alain Ferdière (Hg.), Capitales éphémères. Des capitales de cités perdent leur statut dans l'antiquité tardive (Actes du Colloque Tours 2003), Tours.

Ferdière (2011): Alain Ferdière, Gallia Lugdunensis. Eine römische Provinz im Herzen Frankreichs, Mainz.

Février (1980): Paul-Albert Février, „Vetera et nova: le poids du passé, les germes de l'avenir (III ${ }^{\mathrm{e}}-\mathrm{VI}^{\mathrm{e}}$ siècle) $)^{\text {“ }}$, in: Duby 1980, 393-493.

Février (1981): Paul-Albert Février, „Villes et campagnes des Gaules sous l'Empire“, Ktema 6, 359-372.

Frere (1984): Shepard S. Frere, „British Urban Defences in Earthwork“, Britannia 15, 63 74.

Galinié (1988): Henri Galinié, „Reflections on Early Medieval Tours“, in: Richard Hodges u. Brian Hobley (Hgg.), The Rebirth of Towns in the West, A.D. 700-1050, London, 57-62.

Galinié (1997): Henri Galinié, „Tours de Grégoire, Tours des archives du sol“, in: Gauthier u. Galinié 1997, 65-80.

Galinié (2007): Henri Galinié (Hg.), Tours antique et médiéval. Lieux de vie, temps de la ville. 40 ans d'archéologie urbaine, Tours.

Galsterer (2010): Brigitte Galsterer u. Hartmut Galsterer, Die römischen Steininschriften aus Köln, Mainz.

Garmy u. Maurin (1996): Pierre Garmy u. Louis Maurin (Hgg.), Enceintes romaines d'Aquitaine. Bordeaux, Dax, Périgueux, Bazas, Paris.

Gaudemet u. Basdevant (1989): Jean Gaudemet u. Brigitte Basdevant, Les canons des conciles mérovingiens (VI - VII siècles) I-II, Paris (SC 353/54).

Gauthier u. Galinié (1997): Nancy Gauthier u. Henri Galinié (Hgg.), Grégoire de Tours et l'espace gaulois (Actes du Congrès Tours 1994), Tours.

Girardy-Caillat (1998): Claudine Girardy-Caillat, Périgueux antique, Paris. 
Gorrochategui (2003): Joaquin Gorrochategui, „Las placas votivas de plata de origen aquitano halladas en Hagenbach (Renania-Palatinado, Alemania)“, Aquitania 19, 25 47.

Goudineau u. Rebourg (1991): Christian Goudineau u. Alain Rebourg (Hgg.), Les villes augustéennes de Gaule (Actes du Colloque Autun 1985), Autun.

Green (1991): Roger P. H. Green, The Works of Ausonius, Oxford.

Guilleux (2000): Joseph Guilleux, L'enceinte romaine du Mans, Saint-Jean-d'Angély.

Guyon (2000): Jean Guyon, „Toulouse. La première capitale du royaume wisigoth“, in: Gisela Ripoll u. Josep M. Gurt (Hgg.), Sedes regiae, ann. 400-800, Barcelona, 219240.

Guyon (2006): Jean Guyon, „La topographie chrétienne des villes de la Gaule“, in: JensUwe Krause u. Christian Witschel (Hgg.), Die Stadt in der Spätantike - Niedergang oder Wandel?, Stuttgart, 105-128.

Guyon u. Sablayrolles (1991): Jean Guyon u. Robert Sablayrolles, „From Lugdunum to Convenae: Recent Work on Saint-Bertrand-de-Comminges“, Journal of Roman Archaeology 4, 89-122.

Guyon u.a. (1992): Jean Guyon, Brigitte Boissavit-Camus u. Valérie Souilhac, „Topographie chrétienne des agglomérations“, in: Maurin 1992a, 391-404.

Guyon u.a. (1998): Jean Guyon, Brigitte Boissavit-Camus u. Valérie Souilhac, „Le paysage urbain de l'antiquité tardive ( $\mathrm{IV}^{\mathrm{e}}-\mathrm{VI}^{\mathrm{e}}$ siècles) d'après les textes et l'archéologie“, in: Maurin u. Pailler 1998, 9-18.

Harries (1978): Jill Harries, „Church and State in the Notitia Galliarum“, Journal of Roman Studies 68, 26-43.

Heijmans (2004): Marc Heijmans, Arles durant l'antiquité tardive. De la duplex Arelas à l'urbs Genesii, Rom/Paris.

Heijmans (2007): Marc Heijmans, „Les villes de l'antiquité tardive: enceintes et tissu urbain en Gaule méridionale“, in: M. Marcenaro (Hg.), Albenga città episcopale. Tempi e dinamiche della cristianizzazione tra Liguria di Ponente e Provenza I (Atti del convegno internazionale Albenga 2006), Genua/Albenga, 149-170.

Hiernard (1987): Jean Hiernard, „La topographie historique de Poitiers dans l'antiquité: bilan et perspectives", Bulletin de la Société des Antiquaires de l'Ouest et des Musées de Poitiers 5, ser.1, 163-188.

Hiernard u.a. (2004): Jean Hiernard u.a., Le baptistère Saint-Jean de Poitiers, Poitiers.

Johnson (1973): Stephen Johnson, „A Group of Late Roman City Walls in Gallia Belgica“, Britannia 4, 210-223.

Johnson (1983): Stephen Johnson, Late Roman Fortifications, London.

Jones u.a. (1998): Michael J. Jones, Simon Esmonde Cleary u. Jason Wood, „Les remparts de la ville haute de Saint-Bertrand-de Comminges 1993-1997: rapport préliminaire“, in: Maurin u. Pailler 1998, 65-71.

Jussen (1995): Bernhard Jussen, „Über ,Bischofsherrschaften“ und die Prozeduren politisch-sozialer Umordnung in Gallien zwischen ,Antike“ und ,Mittelalter"“, Historische Zeitschrift 260, 673-718.

Kaiserresidenz und Bischofssitz (1984): Trier: Kaiserresidenz und Bischofssitz. Die Stadt in spätantiker und frühchristlicher Zeit (Ausstellungskatalog Trier), Mainz.

Kinney (1997): Dale Kinney, „Spolia. Damnatio and renovatio memoriae“, Memoirs of the American Academy in Rome 42, 117-148.

Kolb (1984): Frank Kolb, Die Stadt im Altertum, München. 
Krause (2006): Jens-Uwe Krause, „Überlegungen zur Sozialgeschichte des Klerus im 5./6. Jh. n. Chr.“, in: Jens-Uwe Krause u. Christian Witschel (Hgg.), Die Stadt in der Spätantike - Niedergang oder Wandel?, Stuttgart, 413-439.

Krier (2011): Jean Krier, „Deae Fortunae ob salutem imperi. Nouvelles inscriptions de Dalheim (Luxembourg) et la vie religieuse d'un vicus du nord-est de la Gaule à la veille de la tourmente du III $^{\mathrm{e}}$ siècle“, Gallia 68, 313-340.

Le Masne de Chermont (1987): Nelly Le Masne de Chermont, „Les fouilles de l'ancien évêche de Poitiers“, Aquitania 5, 149-175.

Lepelley (1999): Claude Lepelley, „Témoignages épigraphiques sur le contrôle des finances municipales par les gouverneurs à partir du règne de Dioclétien“, in: Il capitolo delle entrate nelle finanze municipale in occidente ed in oriente (Actes de la $\mathrm{X}^{\mathrm{e}}$ Rencontre franco-italienne sur l'épigraphie du monde romain Rom 1996), Rom/Paris, 235-247.

Liebeschuetz (2001): J. H. Wolf G. Liebeschuetz, The Decline and Fall of the Roman City, Oxford.

Loriot u. Nony (1997): Xavier Loriot u. Daniel Nony, La crise de l'Empire romain (235285), Paris.

Loseby (1992): Simon T. Loseby, „Bishops and Cathedrals: Order and Diversity in the Fifth-Century Urban Landscape of Southern Gaul“, in: John F. Drinkwater u. Hugh Elton (Hgg.), Fifth-Century Gaul: A Crisis of Identity?, Cambridge, 144-155.

Loseby (1996): Simon T. Loseby, „Arles in Late Antiquity: Gallula Roma Arelas and urbs Genesii“", in: Neil Christie u. Simon T. Loseby (Hgg.), Towns in Transition. Urban Evolution in Late Antiquity and the Early Middle Ages, Aldershot, 45-70.

Loseby (1998): Simon T. Loseby, „Gregory's Cities: Urban Functions in Sixth-Century Gaul", in: Ian Wood (Hg.), Franks and Alamanni in the Merovingian period. An Ethnographic Perspective, Woodbridge, 239-284.

Loseby (2000): Simon T. Loseby, „Urban Failures in Late-Antique Gaul“, in: Terry R. Slater (Hg.), Towns in Decline, AD 100-1600, Aldershot, 72-95.

Loseby (2006): Simon T. Loseby, „Decline and Change in the Cities of Late Antique Gaul", in: Jens-Uwe Krause u. Christian Witschel (Hgg.), Die Stadt in der Spätantike - Niedergang oder Wandel?, Stuttgart, 67-104.

Loyen (1960): André Loyen, „Bourg-sur-Gironde et les villas d'Ausone“, Revue des Études Anciennes 62, 113-126.

Marrou (1970): Henri-Irénée Marrou, „Le dossier épigraphique de l'évêque Rusticus de Narbonne“, Rivista di Archeologia Cristiana 46, 331-349.

Maurin (1978): Louis Maurin, Saintes antique des origines à la fin du VI siècle ap. J.-C., Saintes.

Maurin (1988): Louis Maurin (Hg.), Les fouilles de ,Ma Maison'. Études sur Saintes antique, Bordeaux.

Maurin (1992a): Louis Maurin (Hg.), Villes et agglomérations urbaines antiques du SudOuest de la Gaule. Histoire et archéologie (Deuxième Colloque Aquitania), Bordeaux.

Maurin (1992b): Louis Maurin, „Remparts et cités dans les provinces du Sud-Ouest de la Gaule au Bas-Empire (dernier quart du $\mathrm{III}^{\mathrm{e}}$ siècle - début du $\mathrm{V}^{\mathrm{e}}$ siècle)“, in: Maurin 1992a, 365-389.

Maurin (1994): Louis Maurin, Inscriptions latines d'Aquitaine: Santons, Bordeaux.

Maurin u. Navarro Caballero (2010): Louis Maurin u. Milagros Navarro Caballero, Inscriptions latines d'Aquitaine: Bordeaux, Paris/Bordeaux. 
Maurin u. Pailler (1998): Louis Maurin u. Jean-Marie Pailler (Hgg.), La civilisation urbaine de l'antiquité tardive dans le Sud-Ouest de la Gaule (Troisième Colloque Aquitania; Aquitania 14, 1996), Bordeaux.

Maurin u. Thauré (1994): Louis Maurin u. Marianne Thauré, Saintes antique, Paris.

Maurin u.a. (1998): Louis Maurin u.a., TCG X: Province ecclésiastique de Bordeaux (Aquitania Secunda), Paris.

Maurin u.a. (2004): Louis Maurin u.a., TCG XIII: Province ecclésiastique de Éauze (Novempopulana), Paris.

Mitchell u. Wood (2002): Kathleen Mitchell u. Ian Wood (Hgg.), The World of Gregory of Tours, Leiden/Köln/New York.

Mousseaux u. Robin (2011): Rose-Marie Mousseaux u. Sylvie Robin (Hgg.), Et Lutèce devint Paris [...] Métamorphoses d'une cité au $I^{e}$ siècle (Ausstellungskatalog Paris), Paris.

Munier (1963): Charles Munier, Concilia Galliae a. 314-506., Turnhout (CCL 148).

Neiss u. Sindonino (2004): Robert Neiss u. Stéphane Sindonino (Hgg.), Civitas Remi. Reims et son enceinte au IVe siècle, Reims (Archéologie urbaine à Reims 6).

Pailler (2002): Jean-Marie Pailler (Hg.), Tolosa. Nouvelles recherches sur Toulouse et son territoire dans l'antiquité, Paris/Rom.

Perrier (1993): Jean Perrier, La Haute-Vienne, Paris (CAG 87).

Petit (2011): Jean-Paul Petit, „Le développement de l'agglomération secondaire de Bliesbruck (Moselle, F) au III ${ }^{\mathrm{e}}$ et au début du IV $^{\mathrm{e}}$ siècle“, in: Schatzmann u. MartinKilcher 2011, 181-200.

Petit u.a. (1994): Jean-Paul Petit, Michel Mangin u. Philippe Brunella (Hgg.), Les agglomérations secondaires. La Gaule Belgique, les Germanies et l'occident romain (Actes du Colloque Bliebruck-Rheinheim 1992), Paris.

Picard (1984): Jean-Charles Picard, „Langres et Dijon au haut Moyen-Âge: christianisation et réseau urbain en Bourgogne", in: Actes du $109^{e}$ Congrès National des Sociétés Savantes, Section d'archéologie et d'histoire de l'art I: La Bourgogne (Dijon 1984), Paris, 85-99.

Picard u.a. (1992): Jean-Charles Picard u.a., TCG VIII: Province ecclésiastique de Sens (Lugdunensis Senonia), Paris.

Pichon (2009): Blaise Pichon, Amiens, Paris (CAG 80/1).

Pietri (1983): Luce Pietri, La ville de Tours du IV au VI siècle. Naissance d'une cité chrétienne, Rom/Paris.

Pietri (1997): Charles Pietri, „L'espace chrétien dans la cité. Le vicus christianorum et l'espace chrétien de la cité arverne (Clermont)“, in: Charles Pietri, Christiana respublica. Élements d'une enquête sur le christianisme antique I, Rom/Paris, 413-445.

Premiers monuments chrétiens (1995): Les premiers monuments chrétiens de la France I: Sud-Est et Corse, Paris.

Premiers monuments chrétiens (1996): Les premiers monuments chrétiens de la France II: Sud-Ouest et Centre, Paris.

Premiers monuments chrétiens (1998): Les premiers monuments chrétiens de la France III: Ouest, Nord et Est, Paris.

Prévot u. Barral i Altet (1989): Françoise Prévot u. Xavier Barral i Altet, TCG VI: Province ecclésiastique de Bourges (Aquitania Prima), Paris.

Provost (1988): Michel Provost, L'Indre-et-Loire, Paris (CAG 37).

Provost u. Mennessier-Jouannet (1994): Michel Provost u. Christine Mennessier-Jouannet, Clermont-Ferrand, Paris (CAG 63/1). 
Pulchra imago (1991): Pulchra imago. Fragments d'archéologie chrétienne (Ausstellungskatalog Saint-Bertrand-de Comminges), Toulouse.

Rebourg u. Goudineau (2002): Alain Rebourg u. Christian Goudineau, Autun antique, Paris.

Rémy (1996): Bernard Rémy, Inscriptions latines d'Aquitaine: Arvernes, Bordeaux.

Roblin (1951): Michel Roblin, „Cités ou citadelles? Les enceintes romaines du BasEmpire d'après l'exemple de Paris“, Revue des Études Anciennes 53, 301-311.

Saint-Christoly (1982): Bordeaux Saint-Christoly. Sauvetage archéologique et histoire urbaine, Bordeaux.

Schatzmann (2011): Regula Schatzmann, „Augusta Raurica: Von der prosperierenden Stadt zur enceinte réduite - archäologische Quellen und ihre Deutung", in: Schatzmann u. Martin-Kilcher 2011, 65-94.

Schatzmann u. Martin-Kilcher (2011): Regula Schatzmann u. Stefanie Martin-Kilcher (Hgg.), L'Empire romain en mutation - répercussions sur les villes dans la deuxième moitié du III siècle, Montagnac.

Schmidt-Hofner (im Druck): Sebastian Schmidt-Hofner, „Der defensor civitatis und das Notabelnregiment vom 4.-6. Jh. n. Chr.“, in: Mischa Meier u. Steffen Patzold (Hgg.), Chlodwigs Welt. Organisation von Herrschaft um 500 (im Druck).

Sivan (1989): Hagith S. Sivan, „Town, Country and Province in Late Roman Gaul: the Example of CIL XIII 128“, Zeitschrift für Papyrologie und Epigraphik 79, 103-113.

Sivan (1993): Hagith S. Sivan, Ausonius of Bordeaux. Genesis of a Gallic aristocracy, London/New York.

Souilhac (1998): Valérie Souilhac, „Les fortifications urbaines en Novempopulanie“, in: Maurin u. Pailler 1998, 55-64.

Stirling (2005): Lea M. Stirling, The Learned Collector. Mythological Statuettes and Classical Taste in Late Antique Gaul, Ann Arbor.

van Berchem (1982): Denis van Berchem, „La promotion de Genève au rang de cité", in: ders., Les routes et l'histoire. Études sur les Helvètes et leurs voisins dans l'Empire romain, Genf, 253-263.

van Ossel (1992): Paul van Ossel, Etablissements ruraux de l'antiquité tardive dans le Nord de la Gaule, Paris.

van Ossel (2011): Paul van Ossel, ,Les cités de la Gaule pendant la seconde moitié du III ${ }^{\mathrm{e}}$ siècle. État de la recherche et des questions“, in Schatzmann u. Martin-Kilcher 2011, 9-21.

Ward-Perkins (1999): Bryan Ward-Perkins, „Re-Using the Architectural Legacy of the Past, entre idéologie et pragmatism“, in: Gian Pietro Brogiolo u. Bryan Ward-Perkins (Hgg.), The Idea and Ideal of the Town between Late Antiquity and the Early Middle Ages, Leiden, 225-244.

Whittaker (1995a): Charles R. Whittaker, „Do Theories of the Ancient City Matter?“, in: Tim J. Cornell u. Kathryn Lomas (Hgg.), Urban Society in Roman Italy, London, 926.

Whittaker (1995b): Charles R. Whittaker, „L'importance des invasions du Bas-Empire: peut-on faire confiance aux historiens?", Revue du Nord-Archéologie 77, 11-20.

Wightman (1984): Edith M. Wightman, „Imitation ou adaption? Une note sur les inscriptions dans le Nord de la Gaule romaine“, Revue du Nord - Archéologie 66, 69-72.

Wightman (1985): Edith M. Wightman, Gallia Belgica, London.

Witschel (1999): Christian Witschel, Krise - Rezession - Stagnation? Der Westen des römischen Reiches im 3. Jahrhundert n. Chr., Frankfurt a. M. 
Witschel (2004/05): Christian Witschel, „Trier und das spätantike Städtewesen im Westen des römischen Reiches“, Trierer Zeitschrift 67/68, 223-272.

Witschel (2008): Christian Witschel, „Sterbende Städte? Betrachtungen zum römischen Städtewesen in der Spätantike“, in: Angelika Lampen u. Armin Owzar (Hgg.), Schrumpfende Städte. Ein Phänomen zwischen Antike und Moderne, Köln/Weimar/Wien, 17-78.

Witschel (2011): Christian Witschel, „Die Provinz Germania superior im 3. Jahrhundert ereignisgeschichtlicher Rahmen, quellenkritische Bemerkungen und die Entwicklung des Städtewesens“, in: Schatzmann u. Martin Kilcher 2011, 23-64.

Witschel (im Druck): Christian Witschel, „Late Antique Statue Bases from Hispania, Gallia, and Raetia“, in: Roland R. R. Smith u. Bryan Ward-Perkins (Hgg.), The Last Statues of Antiquity (im Druck).

Wolff (1976): Hartmut Wolff, „Kriterien für latinische und römische Städte in Gallien und Germanien und die ,Verfassung der gallischen Stammesgemeinden", Bonner Jahrbücher 176, 45-121.

Wolff (1989): Hartmut Wolff, „Die regionale Gliederung Galliens im Rahmen der römischen Reichspolitik“, in: Gunther Gottlieb (Hg.), Raumordnung im römischen Reich. Zur regionalen Gliederung in den gallischen Provinzen, in Raetien, Noricum und Pannonien, München, 1-35.

Wood (1983): Jason Wood, „Le castrum de Tours: étude architecturale du rempart du BasEmpire“, in: Jason Wood u. Claire Mabire La Caille (Hgg.), Recherches sur Tours 2, Tours, $11-60$.

Woolf (1998): Greg Woolf, Becoming Roman. The Origins of Provincial Civilization in Gaul, Cambridge.

Zimmermann (1999/2000): Martin Zimmermann, „Was macht eine Siedlung zur Stadt?“, Jahrbuch des Heimat- und Altertumsvereins Heidenheim, 13-21.

\section{Abbildungsverzeichnis und -nachweise}

Abb. 1: Rekonstruktionszeichnung des Stadtgebietes von Limoges in der hohen Kaiserzeit, In: Jean-Pierre Loustaud, Limoges Antiques, Limoges 2000, 78 Fig. 6.

Abb. 2: Plan des spätantiken Stadtgebietes von Clermont-Ferrand, nach Prévot u. Barral i Altet (1989) Abb. auf S. 29.

Abb. 3: Rekonstruktionszeichnung des spätantiken Stadtbildes von Périgueux, in: Mosseaux u. Robin (2011) 29 fig. 24.

Abb. 4: Spolienverbauung in der spätantiken Stadtmauer von Saintes, in: Maurin (1994) 48 fig. 5.

Abb. 5: Plan des Stadtgebietes von Bordeaux mit dem spätantiken Mauerring (castrum), nach Maurin u. Navarro Caballero (2010) 37 Abb. 5.

Abb. 6: Bebauung im Inneren des castrum von Bordeaux im Bezirk Saint-Christoly, nach Barraud u. Maurin (1998) 44 fig. 4.

Abb. 7: Plan des spätantiken Stadtgebietes von Tours mit dem castrum, nach Luce Pietri u. Jacques Biarne, TCG V: Province ecclésiastique de Tours (Lugdunensis Tertia), Paris, Abb. auf S. 21.

Abb. 8: Plan des Stadtgebietes von Genf mit der spätantiken Stadtmauer (spätes 3./früheres 4. Jh.), nach Bonnet (2009) 124 fig. 70.

Abb. 9: Plan des Stadtgebietes von Tours im 10. Jh. mit ,zweipoliger' Besiedlungsstruktur, nach Galinié (2007) 383 fig. 56. 


\title{
Les chefs lieux de cités de Gaule méridionale aux $\mathrm{V}^{\mathrm{e}}$ et $\mathrm{VI}^{\mathrm{e}}$ siècles: un espace urbain en mutation
}

\author{
Jean Guyon
}

Deux raisons expliquent que j'aie choisi pour objet de ma communication la Gaule méridionale, soit le diocèse des Sept Provinces de l'administration romaine qui couvrait en gros tout le territoire au sud de la Loire.

La première, conjoncturelle, tient à la parution récente dans deux livraisons successives de la revue Gallia d'un dossier qui brosse un tableau de ce territoire pendant l'Antiquité tardive et le haut Moyen Âge dont j'ai assuré la coordination avec $\mathrm{M}$. Heijmans; mon propos pourra ainsi s'autoriser de cette synthèse récente à laquelle les meilleurs spécialistes nous ont fait l'amitié de collaborer. ${ }^{1}$ L'autre raison, plus fondamentale, est que la Gaule méridionale est entrée très précocement dans l'orbite de Rome: Narbonne a été fondée en 118 avant notre ère et la prouincia, on le sait par Pline, Historia naturalis 3, 4, n'a pas tardé à être tenue pour une autre Italie, Italia uerius quam provincia. Mais elle est également la région qui est restée le plus longtemps sous administration romaine: elle n'est passée aux mains de souverains dits Barbares qu'en 476, l'année de la disparition de l'Empire en Occident. Plus que la Gaule du Nord dont le faciès culturel a connu dès le début du $\mathrm{V}^{\mathrm{e}}$ siècle de profondes transformations du fait des migrations de ces mêmes "Barbares" et des destructions qu'elles ont entraînées, elle constitue un observatoire privilégié pour étudier les modalités du passage "d'un monde à l'autre", qui a été le fait des $\mathrm{V}^{\mathrm{e}}$ et $\mathrm{VI}^{\mathrm{e}}$ siècles, objets de notre colloque.

Cela est particulièrement vrai pour les villes et spécialement les chefs-lieux de cités auxquels je limiterai mon propos parce qu'ils sont exemplaires: ils constituaient autant de "vitrines" de la romanité dont le réseau structurait fermement l'espace gaulois. ${ }^{3}$ Pour faire bref cependant, je ne traiterai pas des transformations de ce réseau, mais le fait est de peu de conséquence car il ne s'agit nullement d'un trait propre à la période. Le Haut et le Bas-Empire avaient connu des transformations du même ordre que l'Antiquité tardive, avec la disparition de cités qui ont

1 Heijmans/Guyon 2006; Heijmans/Guyon 2007.

2 Guyon/Heijmans 2001.

3 Beaujard 2006. 
été autant de "capitales éphémères"4 et la promotion d'autres cités telles Die, Sisteron, Gap, Genève ou Grenoble. ${ }^{5}$

Le premier trait à relever à propos des villes de l'Antiquité tardive est qu'en règle générale, leur espace aggloméré est très réduit par rapport à celui de l'Antiquité classique. Cette situation procède pourtant d'une évolution bien antérieure dont les premiers signes, en règle générale, sont perceptibles dès ce qu'on a coutume d'appeler la "crise du III siècle". S'agissant de la Narbonnaise, on trouvera dans les actes d'un colloque tenu naguère à Aix une approche globale de ce phénomène; ${ }^{6}$ pour faire bref, je n'en retiendrai qu'un exemple: celui d'Aix-en-Provence où la déprise urbaine a été remarquable par sa précocité et sa massivité. Très tôt dans le $\mathrm{III}^{\mathrm{e}}$ siècle, des quartiers entiers semblent ici abandonnés, spécialement ceux qui comptaient des demeures aristocratiques. Le tissu urbain revêt dès lors une configuration "en peau de léopard", avec des secteurs à l'état de ruines en passe de devenir des terrains vagues, voire de retourner à l'état de campagne, et d'autres, plus rares, où l'habitat se maintient. ${ }^{7}$ Aux yeux de l'archéologue, l'antique Aquae Sextiae fondée en 123 avant notre ère paraît ainsi réduite à très peu de chose. Pourtant, elle a connu au siècle suivant une promotion qui a fait d'elle la capitale d'une province nouvellement créée, la Narbonnaise Seconde. Cela conduit à nuancer le jugement sévère qu'on est spontanément enclin à porter sur le devenir de son urbanisme à partir du $\mathrm{III}^{\mathrm{e}}$ siècle: cette évolution traduit en fait une "autre façon d'habiter la ville" qui n'a cessé de s'affirmer au cours de l'Antiquité tardive.

Le premier trait de ce nouveau rapport à la ville est qu'en règle générale, les demeures abandonnées des notables n'ont pas été reconstruites. Le cas d'Arles, sur ce point, n'est pas moins éclairant que celui d'Aix-en-Provence. Le quartier aristocratique de Trinquetaille, sur la rive droite du Rhône, n'a connu que de sporadiques et sommaires réoccupations et si, rive gauche, une domus a bien été reconstruite vers 400 au sud du rempart, cette nouvelle installation était plus simple d'allure et n'a eu qu'un temps. Il faut se tourner vers la ville même pour reconnaître d'autres établissements du tournant $\mathrm{du} \mathrm{V}^{\mathrm{e}}$ siècle qui ont connu un meilleur sort: une vaste domus, sans doute, au bord du Rhône, dont seule une partie des thermes a été reconnue; une autre, plus modeste, qui a pris place sur le cardo maximus désaffecté et est restée en usage jusqu'au XIII ${ }^{\mathrm{e}}$ siècle. ${ }^{8}$

Nulle mosaïque cependant dans ces domus, même plus fruste que celles des siècles précédents. Cela contraste avec l'autre Midi, le Midi Aquitain, dans lequel les pavements en mosaïque sont restés un élément obligé des demeures de notables et de leur décor. ${ }^{9}$ Le trait se vérifie en particulier à Bordeaux et à Saintes,

4 Ferdière 2004.

5 Beaujard 2006, 18-21.

6 Fiches 1996.

7 Nin 1996.

8 Heijmans 2004, 345-353.

9 Balmelle 2001. 
mais il vaut également à Clermont ou, en Novempopulanie, à Éauze et SaintBertrand-de-Comminges. La difficulté est que la datation de ces pavements n'est pas toujours bien assurée. Ils passent généralement pour être du $\mathrm{IV}^{\mathrm{e}}$ siècle, mais certains sont sûrement plus tardifs et beaucoup sont restés en usage plus ou moins longtemps pendant l'Antiquité tardive. Ils témoignent ainsi de la persistance d'un mode de vie aristocratique qui ne se reconnaît pas au même degré dans le reste du Midi.

De fait, le gros de l'habitat était constitué désormais par des demeures plus modestes dont les fouilles permettent de percevoir la configuration et l'évolution quand elles ont été suffisamment soigneuses. Ainsi à Toulouse pour ces maisons aux murs en galets et arases de briques qui ont subsisté à proximité du forum jusqu'à leur destruction par un incendie au début du $\mathrm{VI}^{\mathrm{e}}$ siècle. Ou encore, dans cette même ville, sur le site à l'angle des rues Sainte-Anne et Saint-Jacques où les recherches ont été plus éclairantes encore. ${ }^{10}$ Elle ont mis en évidence ici une évolution de la voirie héritée du Haut-Empire qui a connu un changement d'orientation dès le $\mathrm{V}^{\mathrm{e}}$ siècle avant d'être rétrécie au $\mathrm{VI}^{\mathrm{e}}$ siècle du fait de la construction sur ses rives d'habitations aux sols en cailloutis dont une, particulièrement vaste, est restée en usage jusqu'au milieu du siècle (fig. 1, p. 204).

Plutôt que de donner pour d'autres villes des exemples du même ordre, je préfère rester sur ce chantier qui donne à voir cet empiètement d'une maison sur une voie dont nous avons déjà rencontré une attestation à Arles avec l'installation d'une domus sur le cardo maximus. Mais en fait, les cas de ce type ne se comptent plus; ils témoignent de l'apparition d'un habitat généralement qualifié de "parasitaire", qui est un autre grand trait de l'urbanisme pendant l'Antiquité tardive. Un tel habitat n'était d'ailleurs pas cantonné aux rues, il concernait également les places, et jusqu'aux plus importantes. Arles fournit une bonne illustration de ce phénomène car le trait s'y est vérifié à peu près partout : sur une place au bord du Rhône; sur une autre place voisine du forum adiectum qui a été fouillée sous l'hôpital Van Gogh; sur le forum lui-même enfin, dont des colonnes ont été démontées tandis que des constructions, demeures ou boutiques, étaient installées sous ses portiques. ${ }^{11}$ Mais ce "parasitisme" a également affecté les monuments de spectacle.

Le fait est bien connu pour les amphithéâtres, en particulier pour les arènes d'Arles ou de Nîmes qui ont été le siège d'un habitat parasite dont elles n'ont été libérées qu'au début du XIX ${ }^{\mathrm{e}}$ siècle. Les dégagements, alors, ont été trop hâtifs pour permettre de reconnaitre la date d'apparition de cet habitat, mais il n'est pas douteux qu'elle relève de l'Antiquité tardive comme l'a confirmé pour Arles un sondage récent. ${ }^{12}$ Le phénomène se vérifie également pour les théâtres, ainsi qu'il ressort de fouilles récentes à Apt et à Aix-en-Provence. ${ }^{13}$ Dans cette dernière ville

10 Pailler 2001, 419-421.

11 Heijmans 2004, 365-371.

12 Heijmans 2004, 371.

13 De Michèle 2007; Nin 2008. 

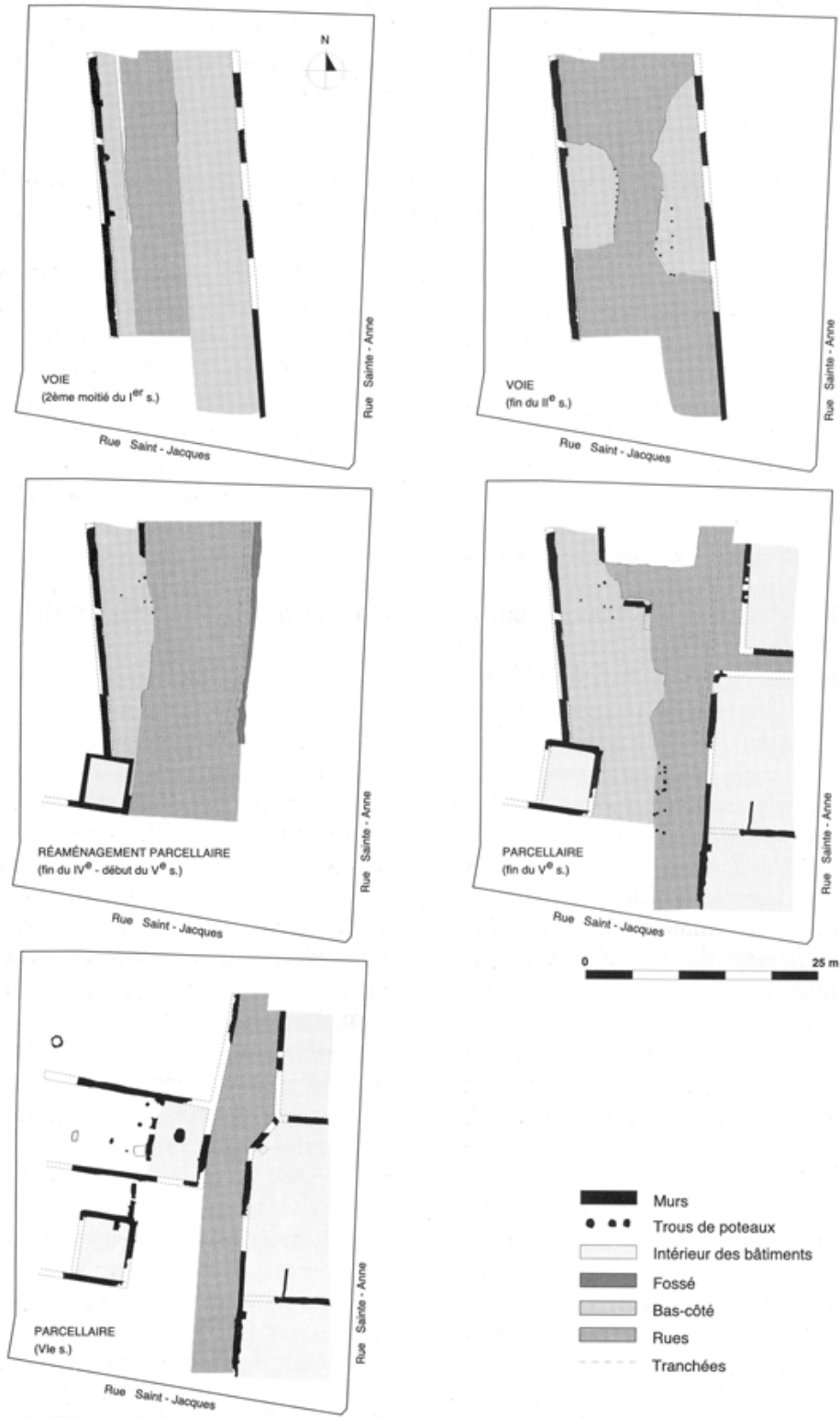

Fig. 1: Toulouse (Haute-Garonne): l'évolution de la voirie et de l'habitat du $\mathrm{I}^{\mathrm{er}}$ au $\mathrm{VI}^{\mathrm{e}}$ siècle de notre ère dans la fouille de l'îlot riverain des rues Saint-Jacques et Sainte-Anne, d'après Pailler 2001, 420, fig. 149. 
où elles ont eu une certaine étendue, elles donnent à voir à partir du $\mathrm{V}^{\mathrm{e}}$ siècle l'installation sur les gradins de la cavea de tout un quartier dont les maisons ont sans cesse été transformées pendant le haut Moyen Âge et au-delà (fig. 2). Quant au cirque d'Arles, ses alvéoles ont été systématiquement lotis alentour de 400 afin d'y aménager des habitations de deux pièces, l'une sous le couvert du monument et l'autre dans son prolongement, à l'extérieur. ${ }^{14}$

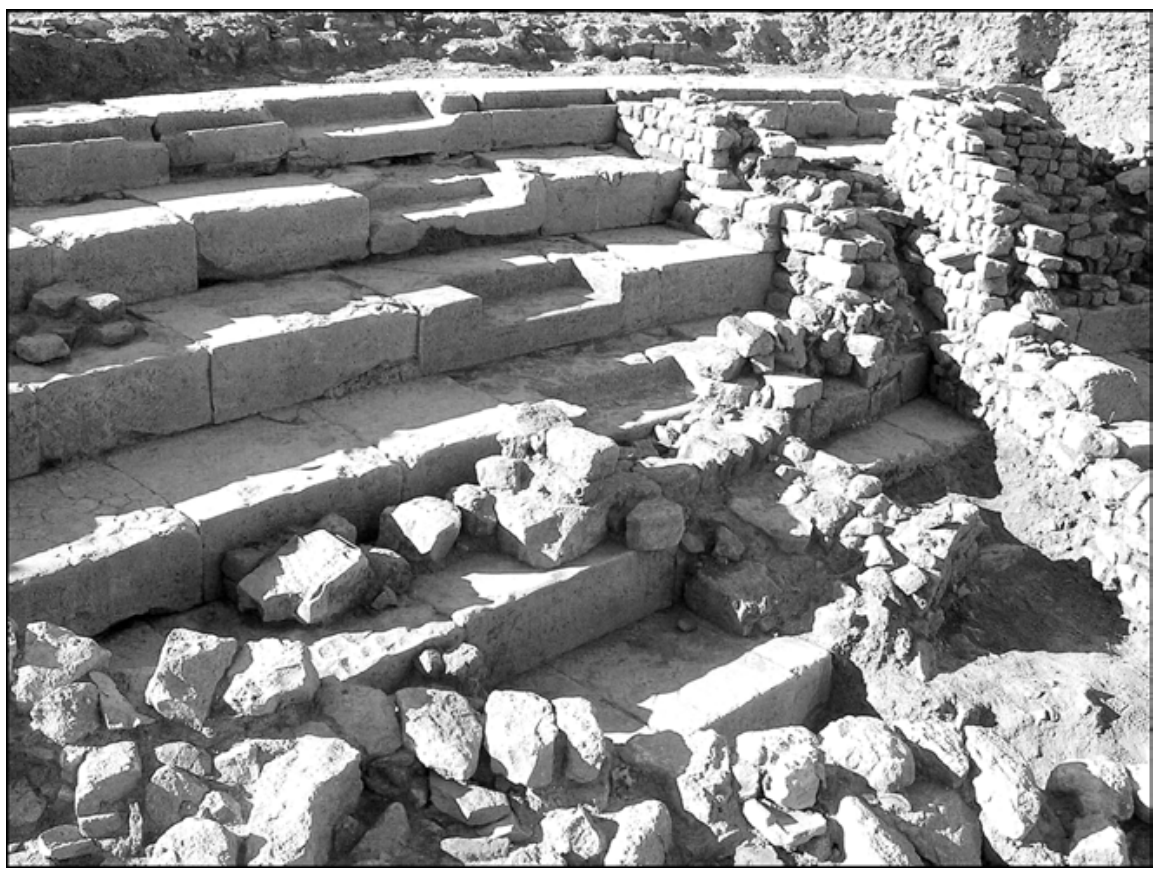

Fig. 2: Aix-en-Provence (Bouches-du-Rhône): habitat de l'Antiquité tardive installé sur la cauea du théâtre romain désaffecté (cliché Nuria Nin).

Cela ne signifie pas que tous ces édifices aient été dès lors désaffectés, les sermons de Césaire d'Arles, au VI siècle, le montrent assez. Mais ils avaient largement perdu leur raison d'être comme le prouve le fait qu'en bien des villes, ils ont été laissés à l'extérieur des "enceintes réduites" dont je dirai un mot dans un instant. Et le même constat vaut plus encore pour les thermes publics, car la thèse d'A. Bouet a bien montré qu'ils avaient en règle générale été désaffectés dès le III ${ }^{\mathrm{e}}$ siècle sans que l'on ait pourvu à les remplacer. ${ }^{15}$ Du coup, ils ont été eux aussi colonisés par un habitat, comme le confirme un sondage récent dans les thermes

14 Heijmans 2004, 360-365.

15 Bouet 2003 
du Nord de Cimiez qui doivent sans doute à cette réoccupation d'être encore partiellement conservés aujourd'hui en élévation. ${ }^{16}$

J'arrête là ces exemples d'installations parasites, non sans observer qu'il ne faudrait pas se méprendre sur le sens de ce mot et l'entendre en terme de "squatterisation". Les fouilles du cirque d'Arles, ainsi, ont livré nombre de monnaies, dont deux étaient en or. ${ }^{17}$ Et si les habitations construites au détriment de ses alvéoles sont assurément modestes, leur module est analogue à celui qui régit l'habitat protohistorique de la ville (fig. 3). On comprend que F. Benoit ait qualifié de "cases" des maisons assez semblables qu'il avait reconnues sur une portion de rempart arasée à Aix-en-Provence, ${ }^{18}$ il employait là le même terme que pour les unités d'habitation de l'oppidum d'Entremont tout proche dont il avait également été le découvreur.

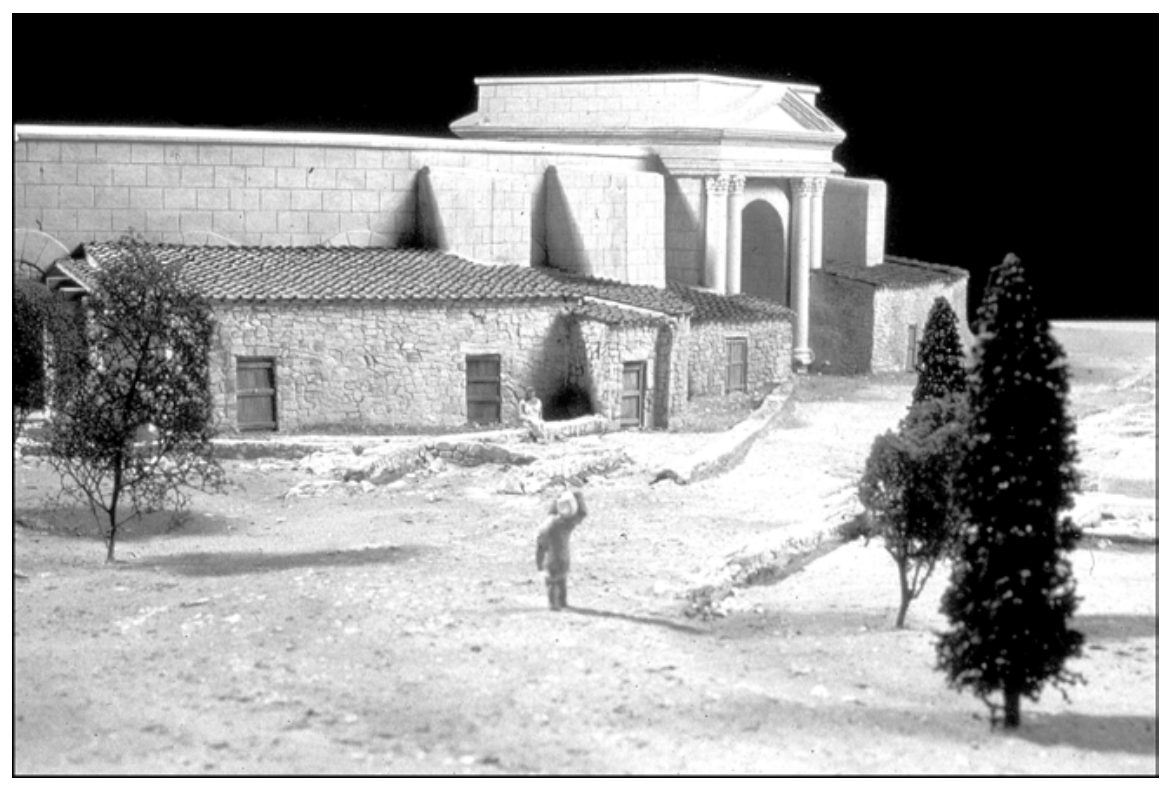

Fig. 3: Arles (Bouches-du-Rhône: habitat "parasitaire" installé au $\mathrm{V}^{\mathrm{e}}$ siècle dans les alvéoles du cirque antique (maquette du musée départemental de l'Arles antique; cliché Michel Lacanaud).

Ces rapprochements entre Antiquité tardive et protohistoire n'ont rien pour étonner: B. Ward-Perkins en a fourni bien d'autres en conclusion de l'essai brillant, mais parfois discutable, qu'il a consacré récemment à la "chute de Rome et la fin de la civilisation" - un titre en forme de clin d'œil aux thèses de Gibbon. ${ }^{19}$

16 Jannet-Vallat 2006, 870.

17 Heijmans 2004, 378.

18 Benoit 1954, 294-297.

19 Ward-Perkins 2005. 
$\mathrm{S}$ 'agissant des $\mathrm{V}^{\mathrm{e}}$ et $\mathrm{VI}^{\mathrm{e}}$ siècles, on pourrait en effet discuter, en tout cas nuancer la notion de déclin, mais quand les monuments publics, forum compris, qui étaient pour les Anciens les symboles mêmes de leur civilisation, ont ainsi été livrés à des particuliers ou, pis encore, tenus à l'écart de l'enceinte urbaine, comment douter de la radicalité de la mutation culturelle qui a été le fait de ces mêmes siècles?

Le trait apparait avec un relief particulier si l'on s'intéresse aux temples que j'ai pour l'instant négligés car ils n'ont pas connu de semblables réoccupations. La plupart ont été détruits, et parfois très précocement: le probable Capitole de Toulouse, ainsi, aurait été démantelé dès le tournant $d u \mathrm{~V}^{\mathrm{e}}$ siècle $^{20}$ et il en est peut-être allé de même pour le temple du culte provincial de Saint-Bertrand-deComminges sur le péribole duquel ont été installés des petits thermes, mais la fouille est trop ancienne pour que la chronologie de cette installation soit assurée. ${ }^{21} \mathrm{D}$ 'autres temples, pourtant, sont encore aujourd'hui conservés en élévation: la Maison Carrée de Nîmes, le temple d'Auguste et Livie à Vienne, le Tour de Vésone à Périgueux. Doivent-ils ce privilège au fait qu'ils ont été transformés en monuments publics, voire en églises? La chose est plausible, mais non certaine. Et leur éventuelle réaffectation comme lieux de culte chrétiens ne saurait en tout cas être rapportée à une date trop haute quand le seul cas avéré dans la région - la probable installation sur le podium du Capitole de Toulouse d'une église qui commémorait le martyre de Saturnin, le fondateur de l'Église locale - ne date que des dernières décennies du $\mathrm{VI}^{\mathrm{e}}$ siècle. ${ }^{22}$

Il est pourtant un élément de la parure monumentale de toute ville antique de quelque importance auquel les hommes de l'Antiquité tardive n'ont cessé de prêter à la fois attention et considération: l'enceinte. Cela au point de faire du rempart le symbole de la ville: à la fin du $\mathrm{VI}^{\mathrm{e}}$ siècle, Grégoire de Tours, Historia Francorum 3, 19, ne s'étonne-t-il pas que Dijon, pourtant dotée d'une belle et solide courtine, ne soit pas un chef-lieu, cur non ciuitas dicta sit, ignoro? Sa méprise s'explique parce qu'il vivait en un temps où, à la différence de celles de l'Antiquité classique, la plupart des villes étaient dotées d'un rempart.

Le trait est connu de longue date pour le Midi aquitain grâce aux travaux de P. Garmy et L. Maurin qui ont bien mis en évidence dans cette région l'existence de deux générations d'enceintes. ${ }^{23} \mathrm{La}$ première, hors de propos pour notre colloque, est le fait $\mathrm{d}$ "“enceintes réduites" du $\mathrm{IV}^{\mathrm{e}}$ siècle qui se rencontrent surtout dans les villes septentrionales de la région, telles Bordeaux où Saintes, où elles ont souvent laissé hors de leur périmètre, comme je l'ai déjà dit, nombre de monuments publics. La seconde génération est représentée plus au sud, en Novempopulanie. Elle compte des enceintes plus exiguës encore, aux courtines sensi-

20 Pailler 2001, 419.

21 Badie et al. 1994, 62-68.

22 Pailler 2001, 490-492.

23 Maurin 1992; Garmy/Maurin 1996. 
blement moins épaisses, qui sont le plus souvent situées sur des hauteurs dominant le site de piémont où était établie la ville de l'Antiquité classique.

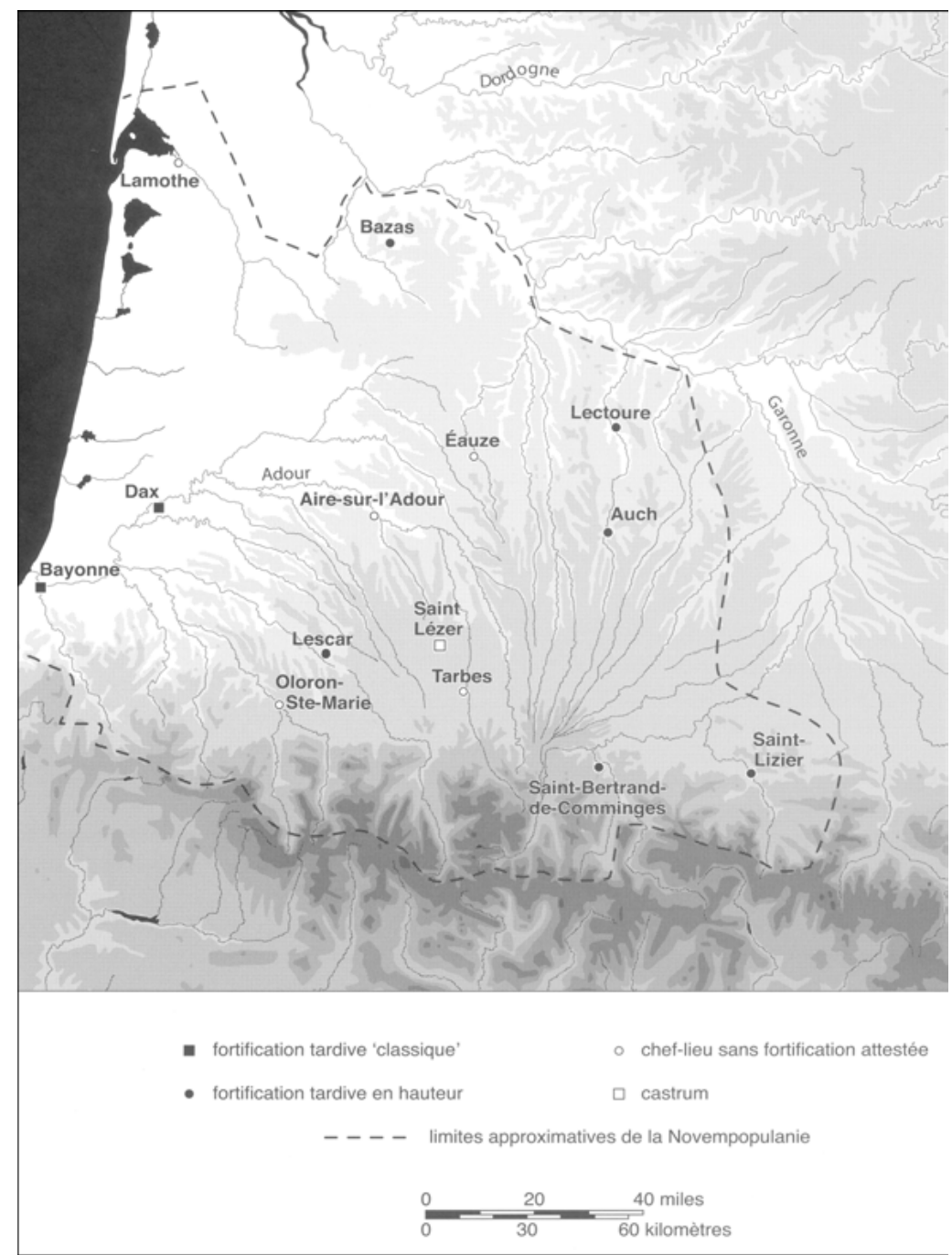

Fig. 4: Les villes fortifiées de Novempopulanie pendant l'Antiquité tardive, d'après Clary, Wood 2006, 222, fig. 257.

Elles font ainsi figure de citadelles qui pouvaient d'ailleurs avoir fière allure, comme le montrent les reconstitutions que S. Esmonde Cleary et J. Wood ont proposées pour celle de Saint-Bertrand-de-Comminges qu'ils ont pu dater par un sondage des environs de $400 .^{24}$ Cette datation vaut sans doute également pour la

24 Cleary/Wood 2006, 190-207. 
plupart des autres enceintes d'une province dont tous les chefs-lieux étaient sans doute remparés, même si la preuve manque encore quelquefois, en particulier pour la capitale, Éauze, dont il serait étonnant qu'elle n'ait pas reçu le même équipement que les villes qui lui étaient attachées. Seules, les enceintes de Dax et de Bayonne, qui s'apparentent aux "mastodontes de pierre" de la première génération, pourraient être un peu plus anciennes (fig. 4, p. 208).

Mais la nouveauté en fait d'enceintes provient de l'ancienne Narbonnaise augustéenne dont on pensait encore récemment qu'elle n'avait connu pendant l'Antiquité tardive que les remparts de ses villes coloniales des débuts de

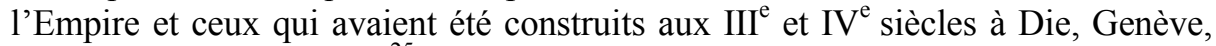
Grenoble et Carcassonne. ${ }^{25}$ La révision critique de cette thèse dont P.-A. Février s'était fait le meilleur défenseur à partir des années soixante du siècle dernier ${ }^{26} \mathrm{a}$ cependant permis à $\mathrm{M}$. Heijmans de porter sur la situation de cette région un regard plus nuancé.

En Narbonnaise Première ainsi, la portion de rempart découverte à Nîmes à proximité de l'amphithéâtre comme celle qui est visible à Narbonne auprès de la cathédrale ont toute chance d'appartenir à l'Antiquité tardive et Béziers aussi comptait sans doute un rempart dont le tracé est cependant malaisé à restituer. En Narbonnaise Seconde, il faut probablement recenser au moins Gap et Riez (où l'existence d'un rempart est connue par le Vita de l'évêque Maxime, $\S 8$ et 10), voire peut-être Antibes. En Viennoise enfin, où Avignon était sûrement remparée au témoignage de Grégoire de Tours, ${ }^{27}$ les deux villes majeures que sont Arles et Vienne ont probablement été dotées d'une enceinte réduite pendant l'Antiquité tardive. ${ }^{28}$ La preuve manque pour la seconde, mais on l'imagine mal s'être satisfaite du rempart démesuré dont elle avait été dotée au début de l'Empire. Dans la première où les traces d'un rempart prenant appui sur le théâtre et l'amphithéâtre ne sont pas douteuses (fig. 5, p. 210), rien ne dit qu'il faut les rapporter à la date tardive que P.-A. Février, qui les avait longtemps jugées indatables, ${ }^{29}$ tendait en fin de compte à leur assigner. ${ }^{30}$ La construction d'un tel ouvrage, manifestement destiné à la défense et non à l'ostentation, se comprendrait bien au $\mathrm{V}^{\mathrm{e}}$ siècle au cours duquel la ville a maintes fois été assiégée et cette datation pourrait valoir également pour les autres remparts de la région. ${ }^{31}$

Les murailles ne constituent pas cependant le seul élément nouveau apporté au décor urbain pendant l'Antiquité tardive. Une part au moins aussi importante revient aux édifices chrétiens qui constituaient, depuis les édits de Théodose à la

25 Où l'on a pourtant proposé récemment une date plus basse pour la courtine: Colin et al. 1995.

26 Février 1964, 43-48.

27 Greg. Tur. Franc. 2, 32; 5, 1.

28 Heijmans 2006a, 60-71.

29 Février 1964, 43-44.

30 Février 1983, 320-321: $\mathrm{X}^{\mathrm{e}}-\mathrm{XI}^{\mathrm{e}}$ siècle.

31 Heijmans 2004, 123-126. 


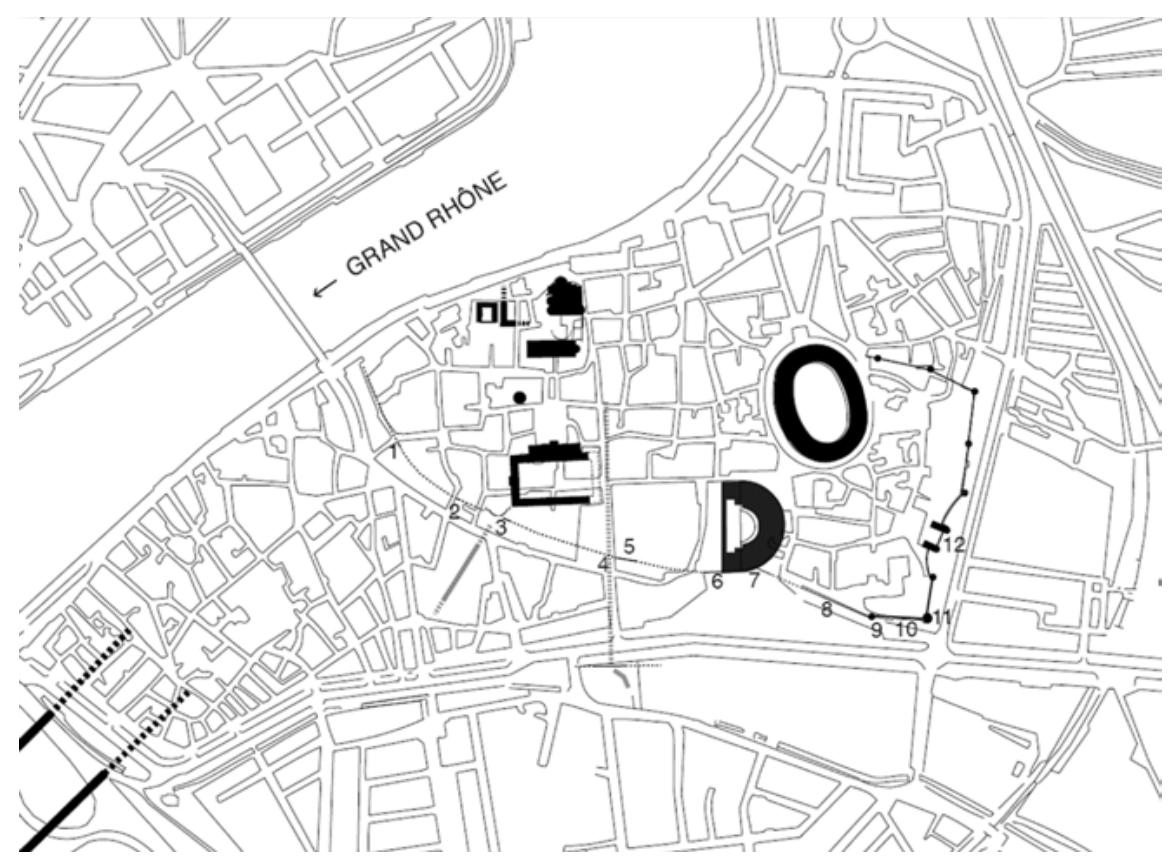

Fig. 5: Arles (Bouches-du-Rhône): le tracé de l'enceinte de l'Antiquité tardive (dessin Marc Heijmans).

fin du $I^{\mathrm{e}}$ siècle, des sortes de monuments publics. Ce qui explique que les membres de l'aristocratie convertie aient mis autant de soin à les doter de leurs évergésies que leurs ancêtres l'avaient fait aux siècles précédents pour les monuments publics de la cité classique, désormais sans objet. ${ }^{32}$ Et il s'agit en ce cas d'un phénomène propre à l'Antiquité tardive car la quasi-totalité des édifices de culte

chrétiens connus dans le Midi par les textes ou l'archéologie relève au plus tôt des dernières décennies du $\mathrm{IV}^{\mathrm{e}}$ siècle ou du tout début du siècle suivant.

Que cette émergence d'une topographie chrétienne ait été l'un des traits majeurs de la période n'implique pas qu'elle ait pris d'emblée le tour très affirmé qu'on dépeint généralement. J'en veux pour preuve les comptages auxquels je me suis livré dans le dossier, déjà signalé, de la revue Gallia. Avant 750, terme retenu pour mon enquête, et en excluant les groupes épiscopaux dont chacun était nécessairement pourvu, les chefs-lieux de cité du Midi n'auraient compté qu'entre 2, 14 et 3,51 édifices chrétiens selon que l'on retient ou non les monuments d'identification ou de chronologie incertaines. Ces chiffres, même faibles, devraient naturellement être revus à la baisse si le regard devait être arrêté, comme dans notre colloque, à la fin du VI ${ }^{\mathrm{e}}$ siècle. Et surtout ils ne rendent pas compte de

32 Duval/Pietri 1997. 
fortes disparités entre provinces, voire entre villes au sein d'une même province. En l'état de nos connaissances, qui sont certainement lacunaires, nombre de chefs-lieux de cités du Midi, dans les Alpes Maritimes ou en Novempopulanie notamment, n'ont connu dans l'Antiquité comme monument chrétien que leur groupe épiscopal. ${ }^{33}$

Cela a suffi cependant pour marquer d'une empreinte indélébile leur décor, et plus précisément leur décor proprement urbain. Car l'enquête de la Topographie chrétienne des cités de la Gaule, désormais presque achevée, ${ }^{34}$ a fait justice d'une tradition historiographique encore en vogue jusqu'aux années soixante du siècle dernier qui situait extra muros les premières cathédrales : dans le Midi, le cas ne se vérifierait (peut-être) qu'à Dax ou Béziers. Or si l'on songe qu'un groupe épis-
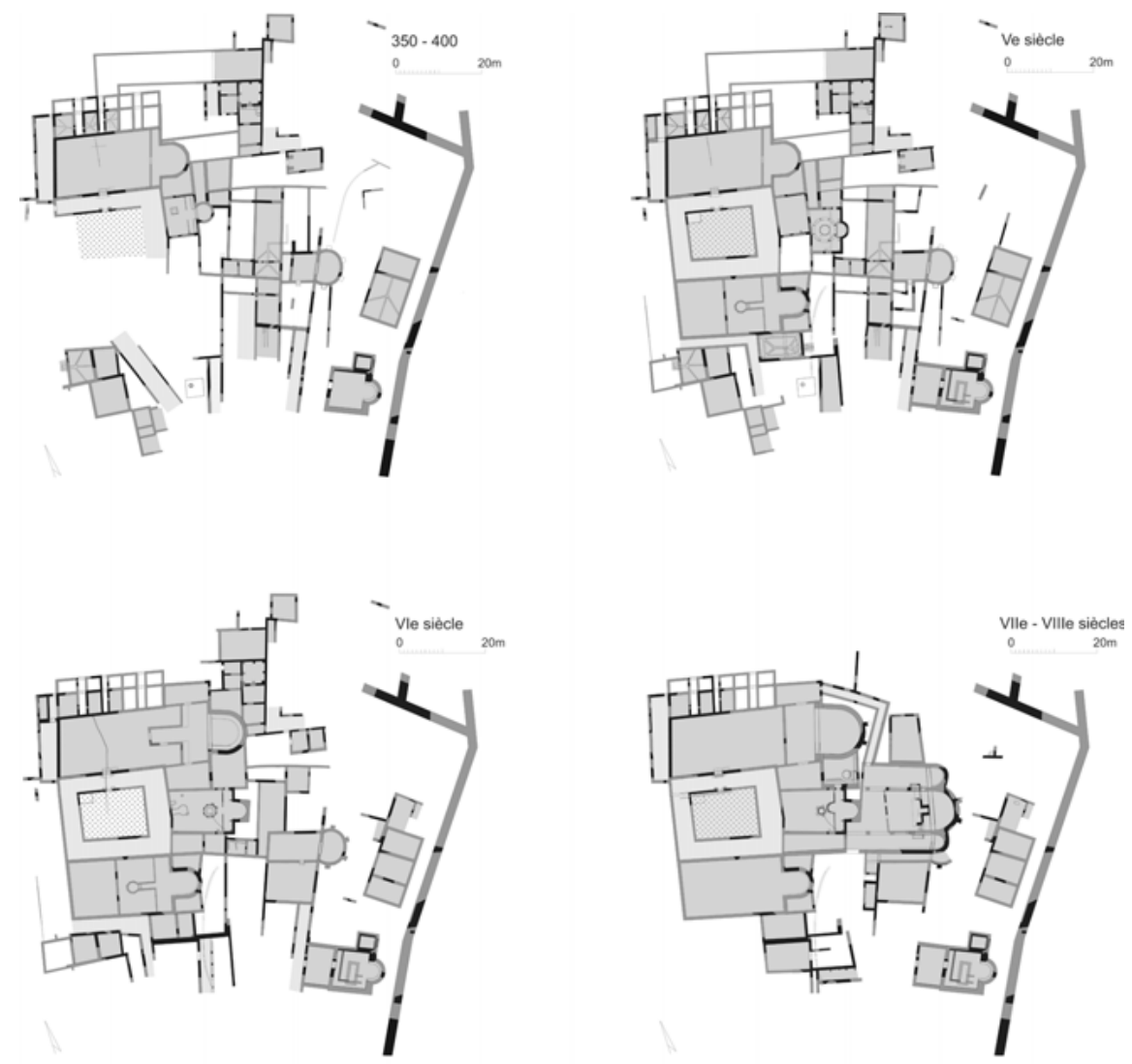

Fig. 6: Genève (Suisse): l'évolution du groupe épiscopal du $\mathrm{IV}^{\mathrm{e}}$ au $\mathrm{VIII}^{\mathrm{e}}$ siècle, selon Charles Bonnet (dessin Marion Berti).

33 Guyon 2006, 86-91.

34 TCCG 1986-?. 
copal rassemblait tous les éléments nécessaires à la vie d'une communauté chrétienne - une cathédrale, parfois double (voire triple comme à Genève), un baptistère, des locaux à usage liturgique ou de service, une résidence pour l'évêque (et éventuellement ses clercs) -, la place nécessaire intra muros pour un tel établissement pouvait être considérable.

C'est d'ailleurs ce que suggère l'examen des quelques groupes épiscopaux du Midi qui sont connus sur une certaine étendue. Celui de Genève (fig. 6, p. 211), dont les premiers éléments ont été établis dès la fin $\mathrm{du}_{\mathrm{IV}}^{\mathrm{e}}$ siècle, n'a pas tardé avec le temps à investir une bonne partie du quadrant nord-est de la ville qui était dévolue auparavant à une résidence aristocratique. ${ }^{35} \mathrm{~L}$ 'emprise sur la topographie urbaine est naturellement moindre à Marseille, dont l'ampleur est tout autre que celle de Genève, mais le groupe épiscopal n'est pas moins imposant dans cette ville, d'autant qu'aux éléments connus anciennement - la cathédrale et un baptistère qui est de loin le plus grand identifié à ce jour dans les Gaules -, il faut adjoindre désormais les restes de la probable domus épiscopale qui viennent d'être
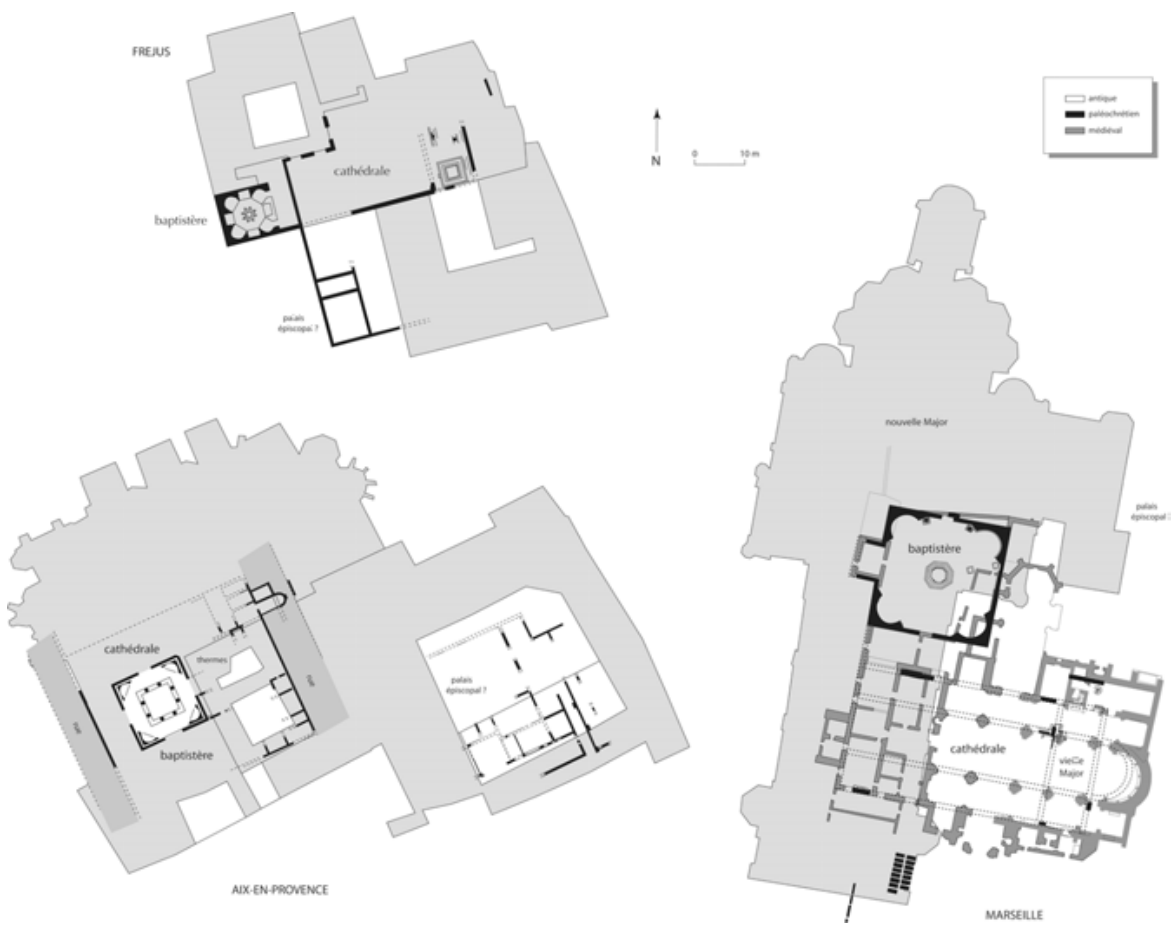

Fig. 7: Les groupes épiscopaux de Marseille (Bouches-du-Rhône), Aix-en-Provence (Bouches-du-Rhône) et Fréjus (Var) à même échelle (dessin Christian Hussy, Service régional de l'archéologie de Provence-Alpes-Côte d'Azur).

35 Bonnet 1993; Bonnet 2006; Bonnet/Peillex 2009; Bonnet/Peillex 2012. 
reconnus sur la rive nord du decumanus qui longeait le baptistère (Barra/Paone 2012). Une même disposition éclatée se reconnaît un siècle plus tard à Aix-enProvence où le groupe épiscopal est situé sur les deux rives d'un cardo secondaire, ses édifices de culte recouvrant à l'ouest un ensemble monumental qui peut être un forum secondaire tandis que son probable palais épiscopal, à l'est, réoccupe une insula d'habitation. ${ }^{36}$ À jus inversement, ${ }^{37}$ la demeure de l'évêque, plus ample que le palais épiscopal médiéval qui lui a succédé, était contiguë à la cathédrale (fig. 7, p. 212). Cette courte liste doit être augmentée désormais d'un établissement en cours de fouille à Arles sur le site de l'enclos Saint-Césaire qui occupe l'essentiel de l'espace disponible entre le decumanus maximus et l'angle sudest du rempart. M. Heijmans a découvert là un édifice d'une ampleur inusitée, surtout s'il date bien du $\mathrm{VI}^{\mathrm{e}}$ siècle - une datation donnée sous bénéfice d'inventaire comme il convient pour une enquête encore en cours. Sa largeur, seule reconnue, est en effet d'une cinquantaine de mètres et les aménagements liturgiques comme le décor sont à la mesure de ce monument d'exception. ${ }^{38}$

À cela il faut ajouter que les villes les plus importantes comptaient d'autres établissements que le groupe épiscopal. Des basiliques comme la basilica Constantia d'Arles - peut-

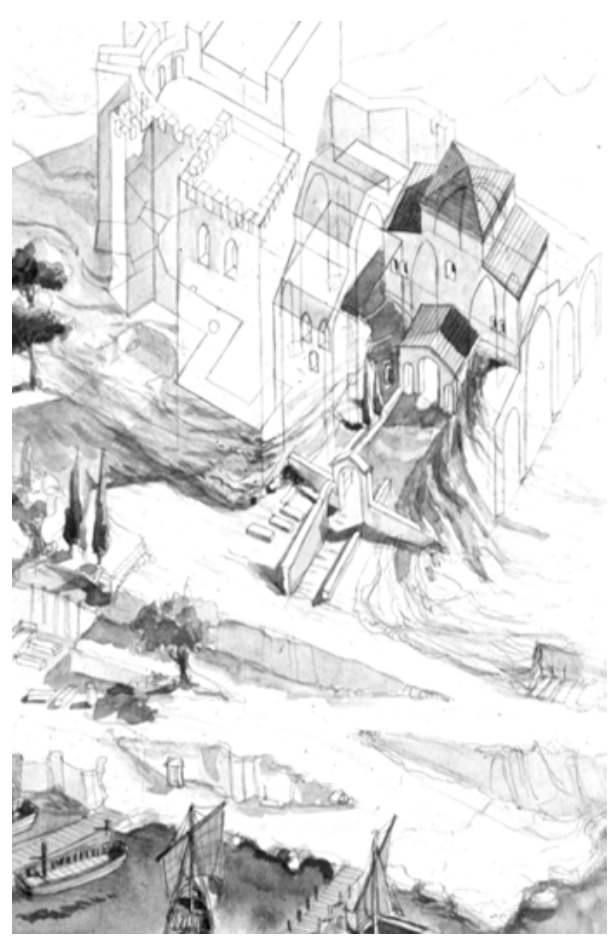

Fig. 8: Marseille (Bouches-du-Rhône): élévation restituée de la basilica sancti Victoris $\mathrm{du} \mathrm{V}^{\mathrm{e}}$ siècle; en traits fins, la silhouette de l'église abbatiale médiévale (dessin aquarellé de Jean-Marie Gassend). être un monument public réaffecté à un usage religieux ${ }^{39}$-, N.-D. de la Daurade à Toulouse, qui avait reçu au Moyen Âge ce nom à cause de son décor de saïques à fond d'or, ${ }^{40}$ ou encore la basilique du Plan, à Saint-Bertrand-deComminges, qui fait figure d'église de la ville basse au pied de la colline remparée où était la cathédrale. ${ }^{41}$ Sans parler des oratoires qui étaient le fait de particu-

36 Guild et al. 1995.

37 Février/Fixot 1995.

38 Heijmans $2006 b$.

39 Heijmans 2004, 193-194; 262-263.

40 Pailler 2001, 483-490.

41 Guyon/Paillet 1996. 
liers ou des monastères que nous font connaître les textes sans toujours préciser s'ils étaient intra ou extra muros. Cette incertitude est fâcheuse car l'impact de ces derniers établissements sur le tissu urbain revêt une importance qu'il importerait de pouvoir mesurer précisément : la clôture dont ils étaient pourvus contribuait à le nécroser, tandis que les œuvres d'assistance dont ils étaient prodigues contribuaient à lui rendre vie alentour.

Mais le suburbium n'a pas moins été touché par l'émergence d'une topographie chrétienne. Il le doit à la construction de basiliques funéraires pourvues de reliques et de sanctuaires élevés sur les tombes de quelques (rares) martyrs et surtout des évêques fondateurs des Églises locales. Le Midi est riche en édifices de ce type, dont certains n'ont rien à envier aux cathédrales pour leurs dimensions ou leur qualité. Songer ainsi pour les martyria à Saint-Just de Lyon et ses cryptoportiques ${ }^{42}$ ou à Saint-Victor de Marseille (fig. 8, p. 213) et son altière turris dressée face à la ville. ${ }^{43}$ Et pour les basiliques funéraires à Saint-Laurent de Grenoble,

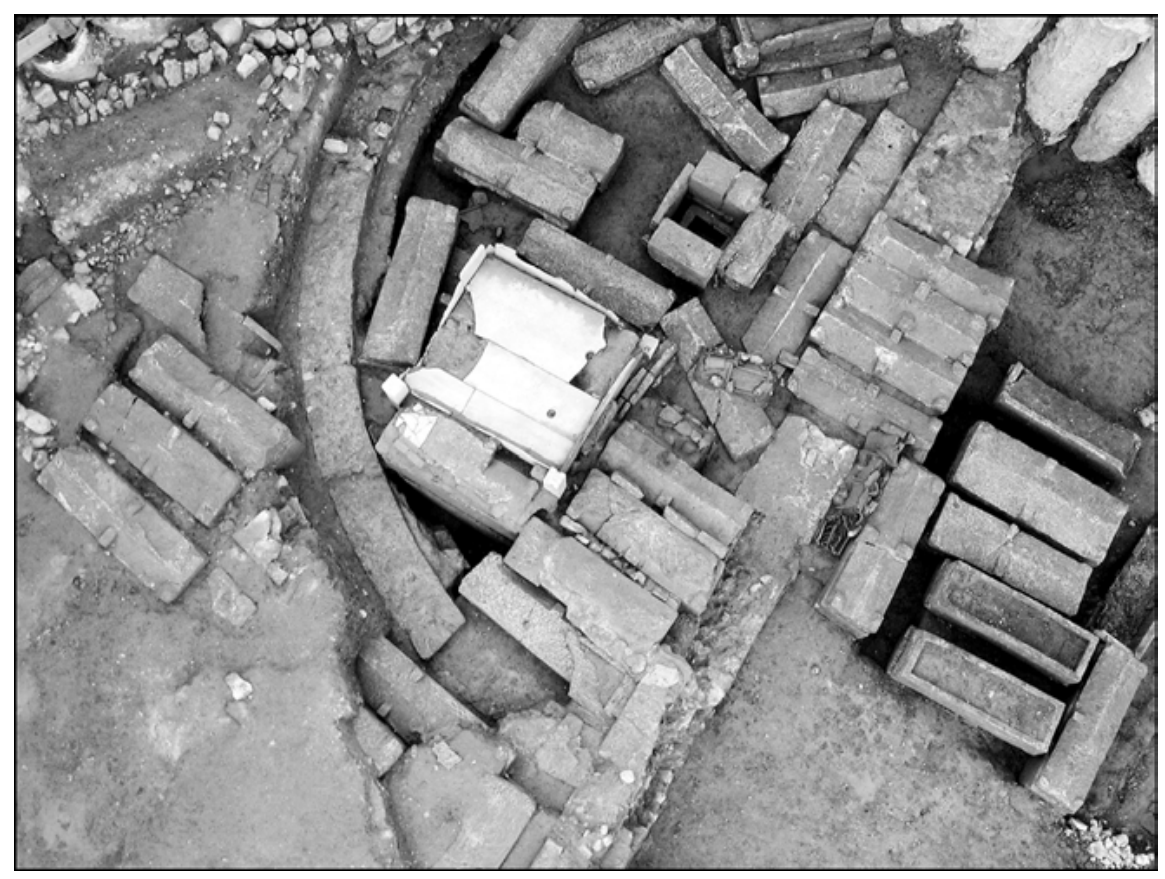

Fig. 9: Marseille (Bouches-du-Rhône): vue zénithale de la basilique funéraire de la rue Malaval; dans l'axe de l'abside, le reliquaire placé sous l'autel disparu; à proximité, la memoria renfermant deux tombes vénérées (cliché Manuel Moliner).

42 Reynaud 1998, 109-135.

43 Fixot/Pelletier 2004; Fixot/Pelletier 2009. 
d'une allure presque baroque, ${ }^{44}$ à la basilique du Clos-de-la-Lombarde à Narbonne, son transept et sa crypte, ${ }^{45}$ voire à celle de la rue Malaval à Marseille (fig. 9 , p. 214) qui fournit le premier exemple archéologique pour les Gaules d'une pratique bien attesté par les textes contemporains: la production de reliques par contact avec le reliquaire placé sous l'autel, mais aussi par le biais d'un circuit d'huile au sein de la memoria voisine qui abritait sous un habillage de marbre deux sarcophages renfermant des cercueils de plomb. ${ }^{46}$

Le plus important cependant n'est pas là, mais dans le fait que dans les villes les plus importantes, à cause d'une volonté pastorale très arrêtée des évêques, martyria et basiliques ont été établis tous azimuts alentour de la ville, comme autant de défenses spirituelles disposées en avant du rempart. Le trait apparaît avec clarté pour Marseille, par exemple, ${ }^{47}$ et plus encore à Clermont où les édifices hors les murs sont exceptionnellement nombreux. Et cela a partout conduit à un profond remodelage de la topographie du suburbium, du fait de la création alentour de ces sanctuaires de noyaux funéraires qui sont nés du désir des fidèles d'être inhumés ad sanctos et ont rapidement acquis une densité inconnue de l'Antiquité classique.

Et si ce n'était que les morts: les vivants aussi se pressaient auprès des reliques ou des restes des saints. Des familiers des disparus, toujours; des moines, parfois, dont étaient attendues les prières pour leurs défunts; des pèlerins souvent, en quête de miracles que nous fait connaître Grégoire de Tours dans l'In gloria martyrum et l'In gloria confessorum. Ainsi s'explique qu'à Clermont, un tel concours de population et la nécessité de pourvoir à ses besoins, matériels et spirituels, aient donné naissance à un "faubourg chrétien", uicus quem christianorum uocant comme le dit encore Grégoire, Historia Francorum 1, 33 (fig. 10, p. 216).

Le trait est à relever car il corrige, pour la fin $\mathrm{du} \mathrm{VI}^{\mathrm{e}}$ siècle, l'image d'une ville sans cesse en proie depuis le $\mathrm{III}^{\mathrm{e}}$ siècle à un dépérissement urbain sur laquelle j'ai ouvert cet exposé. Mais surtout il n'était pas propre à Clermont, car des villes comme Bourges ou Poitiers se prêteraient à des analyses du même ordre, et en ces cas comme en bien d'autres, il était gros d'avenir. Dans le Midi en effet, nombreux sont les monastères établis pendant l'Antiquité tardive auprès de tombes saintes qui ont donné naissance à époque romane à autant de "bourgs" autour desquels s'est structuré l'un des pôles de la renaissance des villes médiévales, dont l'autre pôle était constitué par la "cité" où était la cathédrale. ${ }^{48}$

Je pourrais m'arrêter là car avec ces considérations, il est donné de voir ce passage "d'un monde à l'autre" qui est l'un des objets d'étude de notre colloque. Je voudrais cependant ajouter un dernier mot sur d'autres éléments tirés de l'étude

44 Colardelle 2008.

45 Solier 1995.

46 Moliner 2006.

47 Guyon 2000.

48 Guyon 2006, 109-110. 


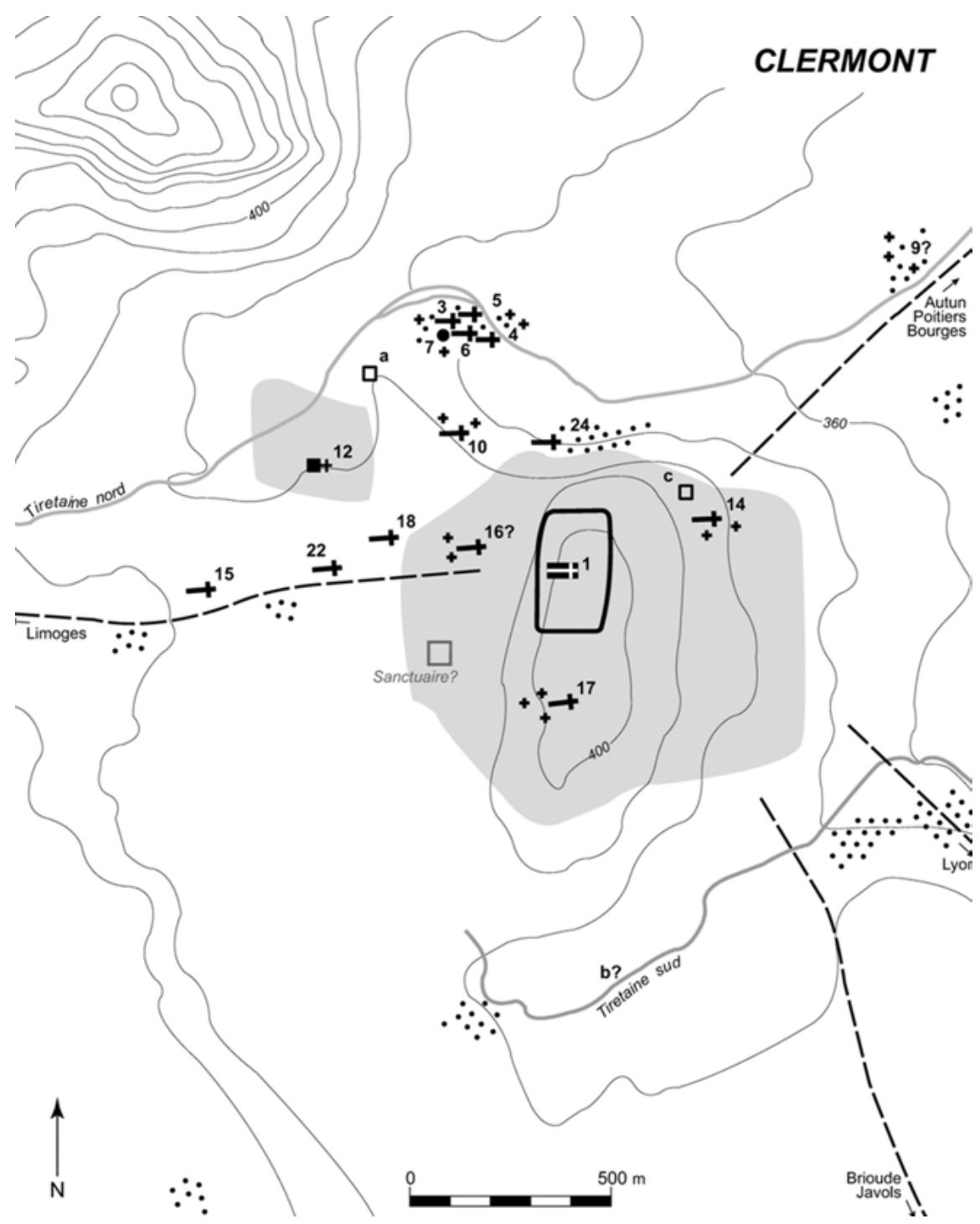

Fig. 10: Topographie chrétienne de Clermont (Puy-de-Dôme) pendant l'Antiquité tardive, d'après Guyon 2006, 108, fig. 52.

des premiers temps chrétiens qui ne sont pas sans intérêt pour d'autres aspects de nos débats.

Celui-ci, d'abord, qui nous conduira, par un paradoxe qui n'est qu'apparent, à faire un détour par le monde des campagnes qui n'avait pas tardé à être gagné lui aussi par la mission chrétienne. De ce fait, les évêques de l'Antiquité tardive y ont 
créé des paroisses auxquelles - le fait est patent dès le concile d'Agde, en 506 ils ont rapidement donné des attributions de "quasi-diocèse". ${ }^{49}$ Mais en cela, c'est bien le monde urbain qui demeurait la référence comme il l'avait été pendant 1'Antiquité classique. Et ce trait est resté prégnant pendant toute la période: à le négliger, on ne comprendrait pas qu'une fois passé l'étiage du haut Moyen Âge, le Midi ait connu à l'âge roman cette vive reprise urbaine que je signalais à l'instant.

Mais il y a plus: l'Église du chef-lieu n'a pas seulement donné ses structures au monde rural, elle lui a également transmis ses modèles d'édifices de culte. En est témoin la construction dans les campagnes d'établissements qu'on pourrait, par analogie avec les groupes épiscopaux, appeler des "groupes presbytéraux". L'exemple le plus achevé en est fourni par des bâtiments qui réunissent en un ensemble compact l'église et son baptistère (fig. 11). Ils se rencontrent sur le

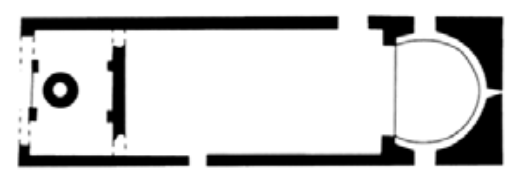

Saint-Hermentaire

(Draguignan, Var)

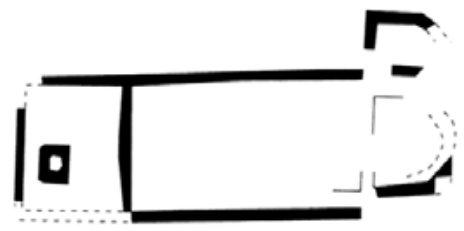

Notre-Dame-du-Brusc (Châteauneuf-de-Grasse, Alpes-Maritimes)

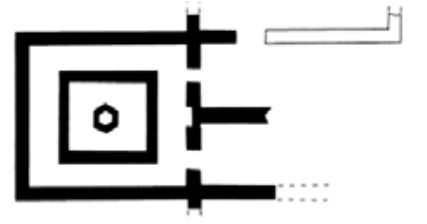

Église

(Saint-Maximin-la-Sainte-Baume, Var)

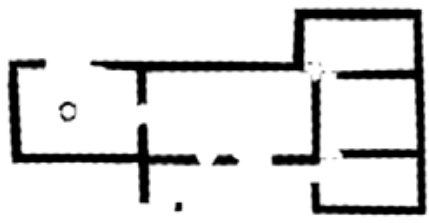

Roc de Pampelune (Argilliers, Hérault)

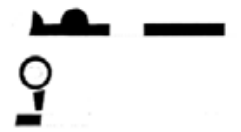

Église

(Oppedette, Alpes-de-Haute-Provence)

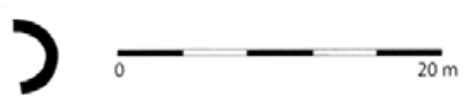

Saint-Jean (Roujan, Hérault)

Fig. 11: "Groupes presbytéraux" du Midi à même échelle (dessin Christian Hussy, Service régional de l'archéologie de Provence-Alpes-Côte d'Azur).

49 Guyon 2005, 252-253. 
littoral méditerranéen, de Capo Don en Ligurie jusqu'à Roujan ${ }^{50}$ et Argelliers dans l'Hérault ${ }^{51}$ en passant par la Provence qui n'a pas fourni moins de quatre édifices: Notre-Dame-du-Brusc à Châteauneuf-de-Grasse dans les AlpesMaritimes ${ }^{52}$ Saint-Maximin ${ }^{53}$ et Saint-Hermentaire, près de Draguignan, ${ }^{54}$ dans le Var; Oppedette dans les Alpes-de-Haute-Provence. ${ }^{55}$ Qu'on n'en ait (pour l'instant?) pas identifié d'autres ailleurs paraît témoigner d'une certaine régionalisation des pratiques architecturales dont les édifices chrétiens des villes offriraient d'autres attestations: songer ainsi aux "cathédrales doubles" de l'arc alpin ou aux baptistères provençaux qui donnent à voir de subtiles variations sur un plan qui tient en un octogone inscrit dans un carré. ${ }^{56}$ Mais à quoi bon insister quand j'ai déjà signalé dans l'architecture profane d'autres pratiques "régionales", pour les enceintes de villes, par exemple, ou l'habitat privé et son décor?

Cela pour dire - et c'est par là que je terminerai - que parler de "Gaule méridionale" pour l'Antiquité tardive, comme je l'ai fait ici, n'est qu'une commodité de langage. Il y avait en fait des Midi, et pas seulement le Midi méditerranéen et "l'autre Midi" - le Midi aquitain - qu'il m'est arrivé de distinguer chemin faisant. Car en Aquitaine, les hommes et les terroirs du Bordelais n'étaient pas ceux du piémont pyrénéen ou du Massif central. Et le contraste n'était pas moindre plus à l'est entre les contreforts alpins et le rivage méditerranéen de la Provence - cette Provence dont le nom affleure presque comme un nom propre à la fin $\mathrm{du} \mathrm{VI}^{\mathrm{e}}$ siècle sous la plume de Grégoire de Tours quand il distingue Masiliensis provintia et Arelatensis provintia,${ }^{57}$ des termes qu'on hésite à traduire par "province" ou "Provence" d'Arles et de Marseille. Ce qui montre combien la régionalisation du territoire était déjà, très largement, un fait acquis chez les meilleurs esprits du temps.

\section{Bibliographie}

Badie et al. (1994): Alain Badie, Robert Sablayrolles et Jean-Luc Schenck, SaintBertrand-de-Comminges. I. Le temple du forum et le monument à enceinte circulaire, Bordeaux.

Balmelle (2001): Catherine Balmelle, Les demeures aristocratiques d'Aquitaine. Société et culture de l'Antiquité tardive dans le Sud-Ouest de la Gaule, Paris/Bordeaux (Supplément à Aquitania 10).

Barra et Paone (2012): Catherine Barra et Françoise Paone, „Marseille: la demeure épiscopale durant l'Antiquité tardive et son déplacement au Moyen Âge, contributions de

50 Colin et al. 2007.

51 Schneider 2004, 186-187.

52 Février/Fixot 1995.

53 Guyon 1996.

54 Codou 1995.

55 Martin 2008.

56 Guyon 1989.

57 Greg. Tur. Franc. 10, 25, p. ex. 
l'archéologie (1995-2010)“, in: Sylvie Balcon-Berry, François Baratte, Jean-Pierre Caillet, Dany Sandron (eds.), Des domus ecclesiae aux palais épiscopaux (Actes du Colloque tenu à Autun du 26 au 28 novembre 2009) (Bibliothèque de l'Antiquité tardive publicé par l'association pour l'Antiquité tardive, 23), 99-114.

Beaujard (2006): Brigitte Beaujard, „Les cités de la Gaule méridionale du $\mathrm{III}^{\mathrm{e}}$ au VII ${ }^{\mathrm{e}}$ s.“, Gallia 63, 11-23.

Benoit (1954): Fernand Benoit, „Informations archéologiques“, Gallia 12, 294-299.

Bonnet (1993): Charles Bonnet, Les fouilles de l'ancien groupe épiscopal de Genève (1976-1993), Genève (Cahiers d'archéologie genevoise 1).

Bonnet (2006): Charles Bonnet, „Éléments de topographie chrétienne à Genève (Suisse)“, Gallia 63, 111-115.

Bonnet et Peillex (2009): Charles Bonnet, en collaboration avec Alain Peillex, Les fouilles de la cathédrale Saint-Pierre de Genève. Le centre urbain de la protohistoire jusqu'au début de la christianisation (Mémoires et document de la société d'Histoire et d'Archéologie de Genève 64), Gèneve.

Bonnet et Peillex (2012): Charles Bonnet, en collaboration avec Alain Peillex, Les fouilles de la cathédrale Saint-Pierre de Genève. Les édifices chrétiens du Groupe Épiscopal (Mémoires et document de la société d'Histoire et d'Archéologie de Genève, 65), Gèneve.

Bouet (2003): Alain Bouet, Les thermes privés et publics de Gaule Narbonnaise, Rom (Collection de l'École française de Rome, 320).

Cleary et Wood (2006): Simon Esmonde Cleary et Jason Wood, Saint-Bertrand-deComminges. III. Le rempart de l'Antiquité tardive de la ville haute, Bordeaux.

Codou (1995): Yann Codou, „Draguignan, église Saint-Hermentaire“, in: Noël Duval (ed.), Les premiers monuments chrétiens de la France. I. Sud-Est et Corse, Paris (Collection des Atlas archéologiques de la France), 151-154.

Colardelle (2008): Renée Colardelle, La ville et la mort. Saint-Laurent de Grenoble, 2000 ans de tradition funéraire, Turnhout (Bibliothèque de l'Antiquité tardive 11).

Colin et al. (1995): Marie-Geneviève Colin, Michel Passelac et Guy Rancoule, „Carcassonne, château comtal (nord-ouest de la cour d'honneur)“, Bilan scientifique de la région Languedoc-Roussillon 1995, 26-27.

Colin et al. (2007): Marie-Geneviève Colin, Laurent Schneider et Laurent Vidal, avec la participation de Martine Schwaller, ,Roujan-Medilianum (?) de l'Antiquité au Moyen Âge. De la fouille du quartier des sanctuaires à l'identification d'une nouvelle agglomération de la cité de Béziers", Revue archéologique de Narbonnaise 40, 117-193.

De Michèle (2007): Patrick De Michèle, „Le théâtre antique d'Apt (Vaucluse) aux $\mathrm{V}^{\mathrm{e}}$ et $\mathrm{VI}^{\mathrm{e}}$ siècles“, Antiquité tardive 15, 127-144.

Duval et Pietri (1997): Yvette Duval et Luce Pietri, „Évergétisme et épigraphie dans l'Occident chrétien (IV $-\mathrm{VI}^{\mathrm{e}}$ s.) “, in: Michel Christol, Olivier Masson (eds.), Actes $d u$ $X^{e}$ Congrès international d'épigraphie grecque et latine, Nîmes, 4-9 octobre 1992, Paris, 371-396.

Ferdière (2004): Alain Ferdière (ed.), Capitales éphémères. Des capitales de cités perdent leur statut pendant l'Antiquité tardive (Actes du colloque de Tours, 6-8 mars 2003), Tours (Supplément à la Revue Archéologique du Centre de la France 25).

Février (1964): Paul-Albert Février, Le développement urbain en Provence de l'époque romaine à la fin du XIV siècle (Archéologie et histoire urbaine), Paris (Bibliothèque des Écoles françaises d'Athènes et de Rome 202). 
Février (1983): Paul-Albert Février, „Aux origines de quelques villes médiévales du Midi de la Gaule“, Rivista di Studi Liguri 49, 316-355.

Février (1995): Paul Albert Février, „Fréjus, cathédrale, baptistère“ (avec un addendum de Fixot, Michel), in: Noël Duval (ed.), Les premiers monuments chrétiens de la France. 1. Sud-Est et Corse, Paris (Collection des Atlas archéologiques de la France), 155164.

Février et Fixot (1995): Paul-Albert Février et Michel Fixot, „Châteauneuf-de-Grasse, lieu-dit Notre-Dame-du-Brusc, église Notre-Dame-du-Brusc", in: Noël Duval (ed.), Les premiers monuments chrétiens de la France. 1. Sud-Est et Corse, Paris (Collection des Atlas archéologiques de la France), 100-102.

Fiches (1996): Jean-Luc Fiches (ed.), Le III siècle en Gaule Narbonnaise. Données générales sur la crise de l'Empire, Actes de la table ronde d'Aix-en-Provence, 15-16 septembre 1995, Antibes.

Fixot et Pelletier (2004): Michel Fixot et Jean-Pierre Pelletier (eds.), Saint-Victor de Marseille: de la basilique paléochrétienne à l'abbaye médiévale, Marseille.

Fixot et Pelletier (2009): Michel Fixot et Jean-Pierre Pelletier, Saint-Victor de Marseille, étude archéologique et monumentale, Turnhout (Bibliothèque de l'Antiquité tardive 12).

Garmy et Maurin (1996): Pierre Garmy et Louis Maurin (eds.), Enceintes romaines d'Aquitaine: Bordeaux, Dax, Périgueux, Bazas, Paris (Documents d'archéologie française 53).

Guild et al. (1995): Rollins Guild, Jean Guyon et Lucien Rivet, „Aix-en-Provence, groupe épiscopal Saint-Sauveur-Sainte-Marie“, in: Noël Duval (ed.), Les premiers monuments chrétiens de la France. 1. Sud-Est et Corse, Paris (Collection des Atlas archéologiques de la France), 109-117.

Guyon (1989): Jean Guyon, „Baptistères et groupes épiscopaux de Provence. Élaboration, diffusion et devenir d'un type architectural", in: Noël Duval (ed.), Actes $d u X I^{e}$ Congrès international d'archéologie chrétienne: Lyon, Vienne, Grenoble, Genève et Aoste (21-28 septembre 1986), Rome (Collection de l'École française de Rome 123), vol. 3, $1427-1449$.

Guyon (1996): Jean Guyon, „Les premiers monuments chrétiens de Saint-Maximin“, Bulletin de la Société nationale des antiquaires de France 1994, 285-295.

Guyon (2000): Jean Guyon, „La topographie chrétienne de Marseille pendant l'Antiquité tardive et le haut Moyen Âge“, in: Françoise Prévot (ed.), Romanité et cité chrétienne: permanences et mutations, intégration et exclusion du $I^{e r}$ au VI siècle, mélanges en l'honneur d'Y. Duval, Paris, 391-407.

Guyon (2005): Jean Guyon, „Conclusions“, in: Christine Delaplace (ed.), Aux origines de la paroisse rurale en Gaule méridionale ( $I V^{e}-I X^{e}$ siècles) (Actes du colloque international de Toulouse, 21-23 mars 2003), Paris, 251-255.

Guyon (2006): Jean Guyon, „Émergence et affirmation d'une topographie chrétienne dans les villes de Gaule méridionale“, Gallia 63, 85-110.

Guyon (2010): Jean Guyon, „La 'blanche robe' des premiers monuments chrétiens des Gaules ( $\mathrm{V}^{\mathrm{e}}-\mathrm{VI}^{\mathrm{e}}$ siècle“, in: Jorge Morín de Pablos, Jorge López Quiroga et Artemio Martínez Tejera (eds.), El tiempo de los „,barbaros“. Pervivencia y transformación en Galia e Hispania (ss. V-VI D. C., Halcalá de Henares, Madrid (Zona Arquelógica 11), 183-221. 
Guyon et Heijmans (2001): Jean Guyon et Marc Heijmans (eds.), D'un monde à l'autre Naissance d'une chrétienté en Provence ( $I V^{e}-V I^{e}$ siècle), Catalogue de l'exposition 15 septembre 2001 - 6 janvier 2002, Arles.

Guyon et Paillet (1996): Jean Guyon et Jean-Louis Paillet, „Saint-Bertrand-deComminges, basilique de la ville basse“, in: Noël Duval (Hg.), Les premiers monuments chrétiens de la France. II. Sud-Ouest et Centre, Paris (Collection des Atlas archéologiques de la France), 177-189.

Heijmans (2004): Marc Heijmans, Arles pendant l'Antiquité tardive: de la duplex Arelas à l'urbs Genesii. Rom (Collection de l'École française de Rome, 324).

Heijmans (2006a): Marc Heijmans, „La mise en défense de la Gaule méridionale aux IV $V I^{e}$ s. “, Gallia 63, 59-74.

Heijmans (2006b): Marc Heijmans, „L'église paléochrétienne de l'enclos Saint-Césaire à Arles (Bouches-du-Rhône)“, Gallia 63, 121-124).

Heijmans et Guyon (2006): Marc Heijmans et Jean Guyon (eds.), „Antiquité tardive, haut Moyen Âge et premiers temps chrétiens en Gaule méridionale. Première partie: réseau des cités, monde urbain et monde des morts“, Gallia 63, 1-170.

Heijmans et Guyon (2007): Marc Heijmans et Jean Guyon (eds.), „Antiquité tardive, haut Moyen Âge et premiers temps chrétiens en Gaule méridionale. Seconde partie: monde rural, échanges et consommation“, Gallia 64, 1-189.

Jannet-Vallat (2006): Monique Jannet-Vallat, „Le baptistère de Cimiez dans son environnement - Nouvelles approches“, in: Mario Marcenaro (ed.), Albenga città episcopale, tempi e dinamiche della cristianizzazione tra Liguria di Ponente e Provenza, Convegno internazionale e tavola rotonda, Albenga, 21-23 settembre 2006, Genova/Albenga, 862-890.

Martin (2008): Lucas Martin, „Une église à piscine baptismale du haut Moyen Âge à Oppedette (Alpes-de-haute-Provence)“, in: Jacques Élie Brochier, Armelle Guilcher et Mireille Pagni (eds.), Archéologies de Provence et d'ailleurs, Mélanges offerts à Gaëtan Congès et Gérard Sauzade, Aix-en-Provence (Supplément au Bulletin archéologique de Provence 5), 723-733.

Maurin (1992): Louis Maurin, „Remparts et cités dans les trois provinces du Sud-Ouest de la Gaule au Bas-Empire (dernier quart du $\mathrm{III}^{\mathrm{e}}$ siècle - début $\mathrm{V}^{\mathrm{e}}$ siècle)“, in: Villes et agglomérations urbaines antiques du Sud-Ouest de la Gaule. Histoire et archéologie. Actes du $2^{e}$ Colloque Aquitania, Bordeaux, 13-15 septembre 1990, Bordeaux (Supplément à Aquitania 6), 365-389.

Moliner (2006): Manuel Moliner, „La basilique funéraire de la rue Malaval à Marseille“, Gallia 63, 131-136.

Nin (1996): Nuria Nin, „Modalités du délaissement de l'agglomération d'Aix-enProvence“, in: Jean-Luc Fiches (ed.), Le III siècle en Gaule Narbonnaise. Données générales sur la crise de l'Empire, Actes de la table ronde d'Aix-en-Provence, 15-16 septembre 1995, Antibes, 135-154.

Nin (2008): Nuria Nin, „La réoccupation des monuments antiques: l'exemple du théâtre d'Aix-en-Provence (Bouches-du-Rhône)“, in: Jacques Élie Brochier, Armelle Guilcher et Mireille Pagni (eds.), Archéologies de Provence et d'ailleurs, Mélanges offerts à Gaëtan Congès et Gérard Sauzade, Aix-en-Provence (Supplément au Bulletin archéologique de Provence 5), 627-674.

Pailler (2001): Jean-Marie Pailler (ed.), Tolosa. Nouvelles recherches sur Toulouse et son territoire dans l'Antiquité, Rom (Collection de l'École française de Rome 281). 
Reynaud (1998): Jean-François Reynaud, Lugdunum christianum - Lyon du IV au VIII s.: topographie, nécropoles et édifices religieux, Paris (Documents d'archéologie française 69).

Schneider (2004): Laurent Schneider, „Entre Antiquité et haut Moyen Âge: traditions et renouveau de l'habitat de hauteur dans la Gaule du Sud-Est", in: Michel Fixot (ed.), Paul-Albert Février, de l'Antiquité au Moyen Âge, Actes du colloque de Fréjus (2001), 173-200.

Solier (1995): Yves Solier, „La basilique funéraire du Clos-de-la-Lombarde“, in: Noël Duval (ed.), Les premiers monuments chrétiens de la France. 1. Sud-Est et Corse, Paris (Collection des Atlas archéologiques de la France), 32-38.

TCCG (1986-?): Nancy Gauthier et Jean-Charles Picard (eds.), puis Nancy Gauthier, Brigitte Beaujard et Françoise Prévot (eds.), Topographie chrétienne des cités de la Gaule des origines au milieu du VIII siècle. Paris (15 volumes parus qui couvrent l'ensemble des Gaules; le manuscrit du seizième (addenda et corrigenda) est en voie d'achèvement).

Ward-Perkins (2005): Bryan Ward-Perkins, The Fall of Rome and the End of Civilization, Oxford.

\section{Légendes des illustrations}

Fig. 1: Toulouse (Haute-Garonne): l'évolution de la voirie et de l'habitat du $\mathrm{I}^{\mathrm{er}}$ au $\mathrm{VI}^{\mathrm{e}}$ siècle de notre ère dans la fouille de l'îlot riverain des rues Saint-Jacques et Sainte-Anne, d'après Pailler 2001, 420, fig. 149.

Fig. 2: Aix-en-Provence (Bouches-du-Rhône): habitat de l'Antiquité tardive installé sur la cauea du théâtre romain désaffecté (cliché Nuria Nin).

Fig. 3: Arles (Bouches-du-Rhône: habitat "parasitaire" installé au $\mathrm{V}^{\mathrm{e}}$ siècle dans les alvéoles du cirque antique (maquette du musée départemental de l'Arles antique; cliché Michel Lacanaud).

Fig. 4: Les villes fortifiées de Novempopulanie pendant l'Antiquité tardive, d'après Clary, Wood 2006, 222, fig. 257.

Fig. 5: Arles (Bouches-du-Rhône): le tracé de l'enceinte de l'Antiquité tardive (dessin Marc Heijmans).

Fig. 6: Genève (Suisse): l'évolution du groupe épiscopal du $\mathrm{IV}^{\mathrm{e}}$ au VIII ${ }^{\mathrm{e}}$ siècle, selon Charles Bonnet (dessin Marion Berti).

Fig. 7: Les groupes épiscopaux de Marseille (Bouches-du-Rhône), Aix-en-Provence (Bouches-du-Rhône) et Fréjus (Var) à même échelle (dessin Christian Hussy, Service régional de l'archéologie de Provence-Alpes-Côte d'Azur).

Fig. 8: Marseille (Bouches-du-Rhône): élévation restituée de la basilica sancti Victoris $\mathrm{du} \mathrm{V}^{\mathrm{e}}$ siècle; en traits fins, la silhouette de l'église abbatiale médiévale (dessin aquarellé de Jean-Marie Gassend).

Fig. 9: Marseille (Bouches-du-Rhône): vue zénithale de l'abside de la basilique funéraire de la rue Malaval; au centre, le reliquaire placé sous l'autel disparu; à proximité, la memoria renfermant deux tombes vénérées (cliché Manuel Moliner).

Fig. 10: Topographie chrétienne de Clermont (Puy-de-Dôme) pendant l'Antiquité tardive, d'après Guyon 2006, 108, fig. 52.

Fig. 11: "Groupes presbytéraux" du Midi à même échelle (dessin Christian Hussy, Service régional de l'archéologie de Provence-Alpes-Côte d'Azur). 


\title{
Lost cities
}

The end of the civitas-system in Frankish Gaul

\author{
Simon T. Loseby
}

When the Merovingian kings Guntram and Childebert II met at Andelot late in November 587, they were looking to draw a line under the internecine struggles that had bedevilled the regnum Francorum since Charibert's untimely death some twenty years before, and to achieve a settlement both in the present, and for the future. In doing so, they and the proceres and sacerdotes who formed their negotiating teams dealt primarily in two currencies of power: civitates and leudes. The majority of the clauses of the treaty that emerged from this summit, as quoted verbatim shortly afterwards by Gregory of Tours, were concerned with the attribution either of cities - sometimes subdivided into fractions - or of warrior aristocrats. ${ }^{1}$ With regard to the latter, the recurrent political instability of the last two decades had encouraged magnates to switch allegiances between rulers, and those rulers to be only too keen to receive them. The two kings agreed to restrain this burgeoning 'transfer market' by binding aristocrats to the oaths of loyalty to one kingdom or another that they had originally taken after the death of Lothar I, and by agreeing that they themselves would no longer tap up, receive, or offer refuge to any of the other's leudes. As far as the allocation of cities was concerned, meanwhile, the fundamental element of the pact was Guntram's waiving of his prior claim, as the only surviving son of Lothar I, to the entire kingdom in favour of Childebert's right, and that of his heirs, to his father Sigibert's share of it, albeit alongside a number of interesting but essentially minor adjustments which cannot concern us here. A similar but subsidiary compromise saw Guntram accept that after his death the five cities which his brother Chilperic had formerly bestowed upon his Visigothic wife Galswinth as her morgengabe should be inherited by Galswinth's sister and Childebert's mother Brunhild, who was herself party to the negotiations at Andelot. ${ }^{2}$ The twofold emphases of the agreement upon the fixing of aristocratic and civic loyalties were encapsulated immediately

1 Greg. Tur. Franc. 9, 11 (meeting), 9, 20 (text of treaty).

2 Among discussions of the Treaty of Andelot from various perspectives, see Drabek 1970; Ewig 1976a, 146-147; Jussen 2000, chs. 4-6, 11; Kershaw 2011, 125-128. 
before Andelot in the kings' mutual condemnation to death of Guntram Boso, the magnate who had hitherto been especially adept at exploiting the divisions within the ruling house, and upon the more festive occasion of the signing of the treaty by Childebert's acceptance back into their host kingdom of two prominent magnates, Dynamius and Lupus, and Guntram's handing over to Brunhild of Cahors, one of the five cities due to her, as if on account. ${ }^{3}$ By the following year, however, the 'pure and simple faith and charity' the signatories had mutually promised to maintain was again mired in the murky and treacherous waters of Merovingian politics. ${ }^{4}$ The kings were once more at odds, accusing each other of contravening either the letter of the treaty, by failing to return aristocrats or make over shares of cities as they had promised, or, more problematically, its spirit, as Guntram reserved the right to make provision - in the form of 'two or three cities somewhere' - for a third Merovingian, the infant Lothar II, conspicuous only by his absence from the arrangements agreed upon at Andelot. ${ }^{5}$

The fragmented nature of Merovingian rulership made treaties between kings a recurrent feature of the allocation of power within the Frankish polity from 511 onwards, but in general their contents have to be inferred from unreliable narrators and anecdotal data. Although the pactio concluded at Andelot seems likely to be broadly representative of such concordats, the exceptional nature of its survival makes it difficult to be sure to what extent its preoccupations were shaped by the specific contours of contemporary Merovingian politics as portrayed by Gregory of Tours, in whose Histories the fortunes of individual cities and magnates episodically ebb and flow, held in a shifting and intermittently volatile relationship with rulers whose power-struggles more often assume the character of a game of Risk than one of Diplomacy. Royal concern to curb the political manœuvrings of the leudes, in exchange for guarantees over their rights to property and freedom of movement across kingdoms, may have been a by-product of the constantlyshifting allegiances encouraged by the febrile intergenerational politics of the preceding twenty years, the consequences of which were still far from being fully played out at the time of Andelot. The meticulous attribution of rights to individual cities, on the other hand, is likely to have been a routine aspect of all such negotiations of royal power, because throughout the sixth century the various Frankish kingdoms were regarded as the sum of their civitates. These cityterritories formed units of resource that could be apportioned individually, as in the case of Galswinth's aforementioned morgengabe, or combined and recombined into regna without any necessary regard for their geographical integrity, as is particularly apparent in the controversial redistribution of Charibert's cities between his three surviving brothers after 567, arguably the fons et origo of the

3 Greg. Tur. Franc. 9, 8-11.

4 Greg. Tur. Franc. 9, 20: placuit atque convenit, ut [...] fidem et caritatem puram et simplicem sibi debeant conservare.

5 Greg. Tur. Franc. 9, 20: aut duas aut tres in parte aliqua civitatis. Cf. Franc. 10, 28. 
troubles that ensued. ${ }^{6}$ In exploring elsewhere in what ways and why cities had become the organising principles of the Merovingian polity, I located this development towards the end of a distinctive, and broadly late antique, phase of GalloRoman urbanism which would have begun as early as the later second century, and extended down at least as far as the end of the sixth, concluding that by this time the role of the civitates in structuring rural territories and royal power was 'beginning to come under some strain, particularly in the secular sphere'. ultimate intention here is to flesh out that airy assertion by identifying the symptoms of such strain, and striving to elucidate their causes and effects. The emphasis will therefore be upon the changes taking place in Frankish cities up to and within the seventh century from an institutional and administrative rather than a topographical or economic perspective, though those aspects of contemporary urbanism will also be touched upon in what follows. First, this final stage in the history of the ancient civitas-system in Gaul will be set in the context of its prior phases; in so doing, I will take the opportunity provided by the framework of this collection of papers to qualify somewhat the integrity of the extended late antique phase identified in my earlier paper. Next, in order to identify what changed around 600, the various ways in which the significance of the civitates within the Frankish polity was manifested in the time of Gregory of Tours will be summarised. Finally, it will be shown how the early seventh century does indeed mark a decisive shift in emphasis away from the hybrid city- and magnate-based politics that determined the content of the Treaty of Andelot to a political culture that had finally ceased to be structured and perceived through the civitas system, at least in the secular sphere.

For heuristic purposes, and with all due acknowledgement of the extent of local and regional variation, four phases in the history of the Gallic civitates might be proposed, as defined principally by structural shifts in the relationship between local (or civic) and central (whether imperial or royal) authorities, but which can also be associated in most cases with significant changes in urban form. The initial phase of expansion need detain us only briefly. It begins in the Augustan era, and consists in the rolling-out across Gaul of a network of cities and dependent territories, Rome's preferred ideological and functional solution to the perennial problem of exercising power over distance, which involved the devolution of a significant measure of autonomy down to municipal elites, exercised through the institutional framework of the city-council, in exchange for their maintenance of order and supervision of resource extraction at the local level. In competing for civic power and pre-eminence in a context secured by Roman arms and defined by imperial values, the newly-constituted curiales of the Three Gauls enthusiastically sought to catch up with their Narbonensian neighbours in becoming Roman. Gradually, through the first century AD and on into the second, they invested lavishly in the monuments and amenities of their cities as vehicles for the asser-

6 Ewig 1976a, 138-139; its incoherent consequences are mapped in James 1988, 172.

7 Loseby 2006, with quotation at 96-97; cf. Loseby 1998a, 264-265. 
tion and legitimation of their social standing, creating their own versions of canonical classical urban landscapes according to their means. ${ }^{8}$ Despite the weight of the historiographical tendency to judge the subsequent evolution of GalloRoman urbanism in the light of these developments and find it wanting, this phase should not be regarded as normative. It was, however, doubly and decisively formative - administratively in that it established an urban network of over a hundred cities, and topographically in that it created the basic parameters of the urban environments that future generations of city-dwellers would go on inhabiting for centuries to come. In both respects, the subsequent modification of the massive and inescapable urban legacy of this period would take place only slowly and, for the most part, incrementally, however enthusiastic its architects.

The second phase of Gallo-Roman urbanism, which might be broadly characterised as one of retrenchment, would prove rather more complex and far more protracted. Its initial indicators are material rather than institutional. From around the middle of the second century $\mathrm{AD}$ onwards, archaeological evidence from Gallic cities begins to indicate a slowdown in both public and private urban building projects, the first signs of failures to maintain existing monuments, and the start of a slow retreat in the extent of urban settlement, all phenomena which increase over time and can be seen to proliferate through the troubled third century, in this regard, as in others, a period of beschleunigter Wandel. ${ }^{9}$ This slow retreat of classical urbanism was then consolidated (but certainly not instigated) by the systematisation of the recent reforms of the administrative machinery of the Roman state under Diocletian and Constantine, which had the overall effect of drawing the exercise and representation of power away from devolved civic institutions towards an imperial bureaucracy that was significantly enhanced in scale and authority. ${ }^{10}$ This centralisation was by now culturally feasible, and no doubt administratively desirable, but it meant that the curiales saw their responsibilities increased even as they forfeited much of their influence and status, not to mention a large slice of their budget; in compounding the growing reluctance or inability of local elites to sustain established levels of amenity through their spending, it further undermined already-weakening traditions of urban munificence. ${ }^{11}$ The consequences for cities of these empire-wide trends were intensified more specifically in Gaul by the new and regular presence of an imperial court on the Rhine frontier that offered a readily-accessible focus for elite ambition. As standing in the imperial hierarchy came to be a decisive determinant of the fortunes of cities as well as individuals, a handful of favoured centres such as Trier, and to a lesser extent Arles, benefitted from centrally-administered patronage, but the moribund

8 Woolf 1998, esp. ch. 5. For a sense of the chronology of monumentalisation, see Bedon et al. 1988.

9 For the third century in general, Witschel 1999. Among sundry examples, see Amiens (Bayard and Massy 1983, esp. 214-220), Tours (Galinié et al 2007, 325-326), or various cities in Narbonensis, notably Arles: Fiches (ed.) 1996, Heijmans 2004, ch. 2.

10 Jones 1964, ch. 19; Ward-Perkins 1998; Kelly 2004.

11 Loseby 2009, 142-148. 
state of fourth-century provincial capitals in Gaul such as Tours or Aix-enProvence offers a salutary warning against the assumption that such largesse routinely cascaded very much further down the administrative hierarchy. ${ }^{12}$

This phase of retrenchment starts to be visible in urban landscapes, therefore, from the later second century onwards, and in the social power of civic officeholders from the late third. The disavowal of the urban values of the early imperial period, whether on grounds of a decline in the social capital associated with them, their cost, their cultural redundancy, or more probably a combination thereof, helped to make most late antique Gallic cities less expansive, and their wealthier residents less visible. However, the gradual playing-out of these developments was intercut and greatly complicated by the simultaneous reconfiguration of urban landscapes and leadership in response to contemporary social priorities, even if, crucially, almost all existing cities were maintained. This third phase, which has its roots in the decades either side of 300 but only really takes off in the fifth century, is therefore one of renewal, and it runs in parallel with the inexorable and increasingly severe effects of retrenchment. It can be characterised by three main features, each of which is familiar, and need not be given more than summary consideration here. The first, but least susceptible of these to easy synthesis, is fortification. Between the late third and the fifth centuries, most cities in Gaul either had their existing defences upgraded or, more often, acquired walls de novo which typically enclosed only part - and sometimes a mere fraction - of the urban areas of earlier periods. ${ }^{13}$ In an increasingly insecure Gaul, this was obviously a practical measure, for which subsequent generations would have lasting cause to be grateful, and it gave cities an enduring (if not quite exclusive) significance as defensive strongholds for centuries to come. Equally, city-walls now assumed an enhanced symbolic resonance in the conception of urban identity, to the extent that by the end of the sixth century they had completely eclipsed any other category of secular public building in the mind, for example, of Gregory of Tours. $^{14}$

The second element in late antique urban renewal is, of course, Christianisation, a process at once more organic in nature and incremental in impact than fortification, but arguably more consistent in its overall impact upon Gallic cities. The projection of the administrative organisation of the church directly on to that of the existing network of civitates established a new and distinctly urban potentate in the person of the bishop, who would go on to reinvigorate the link between cities and their territories through his exclusive liturgical responsibilities, and to inspire new urban patronage networks and outpourings of monumental and chari-

12 Trier: Witschel 2004/5; Arles: Heijmans 2004, Loseby 1996, 49-52; Tours: Galinié et al 2007, 355-361; Aix: Guyon et al 1998, 291-298.

13 Here much has changed since the syntheses of Butler 1959 and Johnson 1983 (in particular in regard to issues of chronology); in the absence of a recent overview of comparable scope, see especially Maurin 1992; Heijmans 2006; Dey 2010.

14 Loseby 1998a. 
table munificence. ${ }^{15}$ From the fourth century onwards, but with far greater intensity from the fifth, every city in Gaul generated a new Christian landscape alongside the old, typically combining a cathedral complex at its heart (within the walls, wherever they existed) with the growing array of funerary basilicas that were variously clustered within and scattered across its suburban, extra-mural cemeteries; these enshrined the tombs of those locally venerated as saints, whose cults, zealously sponsored by bishops, provided new contexts for urban selflegitimation and monumental patronage, and for the formation of distinctive identities proper to individual communities. ${ }^{16}$ Churches thus took their place alongside walls in the new rhetoric of urbanism, and Christian writers deftly rationalised the practical and conceptual restructuring of urban space around the two into a coherent whole at once topographically realistic and conceptually symbolic, in which the bishop at the heart of the city, the saints in the suburbs round about, and the walls in between, worked in concert for the protection of their communities from dangers both visible and invisible. ${ }^{17}$ In practice, even so, the impact of Christianisation on the conception and experience of urban space ran counter to that of fortification by offsetting its centripetal implications and drawing the sanctified suburbs into the orbit of collective civic practice through regular liturgical observance, breaking down the distinction between urban and suburban, and drawing them together in radically new ways. ${ }^{18}$

Finally, as implied in the previous paragraph, this phase of renewal assumed an institutional as well as a topographical and cultural dimension. In Gaul, as elsewhere, the decline in the status of the city-councils as organs of government encouraged the gradual (and, in its early stages, largely invisible) reconstitution of civic leadership around local figures of standing within the imperially-sponsored hierarchies of state and church that now offered real access to social power. ${ }^{19}$ These shadowy and self-selecting bodies would prove enduringly resistant to formal or consistent definition, in part by their very nature, but it becomes clear that they generally included the bishop, the new urban patron par excellence, alongside local senators, officials, and other major landowners. In the western empire, this shift in urban power was only at an inchoate stage when it was distorted by the impact of the 'fall of Rome'. But even as that grander narrative was getting under way, Gallo-Roman urbanism was already set upon two contradictory and, in large measure, endogenous trajectories, each of which were gathering momentum in the fifth century. On the one hand, the long-established markers of urban retrenchment become increasingly visible archaeologically in the prolifera-

15 Scheibelreiter 1983; Beaujard 1996; Gauthier 2000.

16 Brown 1981; Beaujard 2000.

17 E.g. Alc. Avit. hom. 24; Greg. Tur. glor. conf. 78; vit. patr. 4, 2; 17, 4; Franc. 3, 29; Loseby 1998a, 252-256, Gauthier 1999, 207-209.

18 Hen 1995, ch. 4, for urban sanctoral cycles with Pietri 1983, ch. 6 for the specific example of Tours.

19 For various recent interpretations of the general chronology and character of these changes, see Liebeschuetz 2001, 104-136, Cecconi 2006 and Laniado 2002. 
tion of a familiar litany of late antique urban phenomena: the dereliction or re-use of public buildings and spaces, the partial degradation of the urban infrastructure, the contraction or disaggregation of areas under occupation, the increased resort to recycled or inferior building-materials, the proliferation of smaller and more utilitarian residential units, and so on. ${ }^{20}$ On the other, the new drivers of an urbanism centred around security and salvation were simultaneously contributing to the renewal of urban landscapes through the creation of fortified cores, substantial and lavishly-embellished cathedral complexes, and a sanctified suburban sprawl, as dormant traditions of urban monumental patronage were channelled in new directions, demolishing some of the fabric and much of the logic of the monumental urban legacy of earlier periods along the way. ${ }^{21}$

These contrasting currents were neither instigated nor significantly interrupted by the ensuing disintegration of the western empire and the eventual fragmentation of political authority in Gaul among various barbarian rulers, but cities were central to the transition, for various reasons. ${ }^{22}$ Their fortifications lent them considerable strategic importance in periods of conflict, while their bishops often emerged as pivotal figures in the management of political change, both by virtue of the considerable pastoral and legal responsibilities already vested in them, and in default of other local authorities similarly accredited to represent the interests of their communities; the siege of Clermont in the early 470 s can suffice to illustrate both themes. ${ }^{23}$ For their part, the new barbarian masters were desperately keen to appropriate existing ideologies of power and representation as far as possible, which meant that they favoured urban settings for display and selflegitimation, and in some cases embarked upon monumental building programmes in time-honoured fashion. ${ }^{24}$ It is in the attitudes of the upper echelons of the Gallo-Roman aristocracy that the more revolutionary adjustment can instead be found. In practice, the disappearance of imperial office-holding scarcely levelled out the elaborate hierarchy of ranks 'through which one was accustomed to tell the high from the low' quite as efficiently as Sidonius wistfully alleged (Gregory of Tours knew that even if you contrived to give away all your property besides, you could still keep your status intact). ${ }^{25}$ Even so, in the absence of sus-

20 The scale and timing of these changes varies from city to city, e.g. from Tours (Galinié $e t$ al 2007, 355-361) to Arles (Heijmans 2004, ch. 6), but all cities with significant archaeological data from this period show symptoms of some or all of them by the fifth century.

21 Loseby 2006, 78-83; Guyon 2006. It is this combination of retrenchment and renewal that goes some way to explaining the very different views of fifth-century Metz propounded by Halsall 1996 and Bachrach 2002.

22 Halsall 2007, chs. 7-9; see also the papers by Michael Kulikowski and Christian Witschel in this volume.

23 Harries 1994, 222-238.

24 This is clearest in Visigothic Toulouse (Guyon 2000), but there are signs of it in the Frankish and Burgundian kingdoms besides: McCormick 1989; Dierkens/Périn 2000, 270-277; Bonnet/Reynaud 2000.

25 Sidon. epist. 8, 2, 2: per quas solebat ultimo a quoque summus quisque discerni; Greg. Tur. glor. conf. 108 (of Paulinus of Nola). 
tainable alternative sources of political authority and social legitimation outside the courts of barbarian rulers, it certainly had the effect of renewing the interest of the regional senatorial aristocracy in the pursuit of whatever power was still worth having at the level of the civitas. ${ }^{26}$ This obliged them to insinuate themselves back into the second-tier milieu of the municipaliter natus whom Sidonius had previously affected to disdain - and indeed, as bishop of Limoges, Ruricius would testily suggest that his dignity transcended that of his city - but it certainly did not entail any substantive return to the urban political culture of earlier centuries, which was already internally fractured beyond repair. ${ }^{27}$ In general, instead, the renewed participation of the senatorial class in local politics accelerated the gravitating of civic leadership away from legally-constituted city-councils towards the more informal collectives of socially-superior individuals who, as we have seen, were assuming similar pre-eminence over urban communities in areas that remained firmly within the empire. More specifically, competition for civic power in post-imperial Gaul came inevitably to revolve around the office of bishop, in which much local authority had been vested before imperial collapse, and which now offered the only post-imperial source of public prestige and legitimation that remained if not outside, then at least at one remove from the uncertain sphere of barbarian political control. ${ }^{28}$ In this fast-changing context, it is no coincidence either that the job specification for episcopal appointments was adjusted to favour nobilitas over charisma, or that a spurt of major church-building projects were carried out in cities amid all the political confusion of the later fifth century, in some centres perhaps temporarily adjusting the ongoing tension between urban retrenchment and renewal in favour of the latter. ${ }^{29}$ But this adaptability of the Gallic aristocracy in the short-term also had far-reaching consequences, for it was the continuity of the episcopal office and the expectations associated with it that would, above all, sustain urban political communities through the ensuing centuries as their elites continued to compete for the post and to engage in urban munificence in support of their claims. ${ }^{3}$

If we fast-forward through the working-out of the various political upheavals of the decades either side of 500 and leave to one side the variations peculiar to particular kingdoms and regions, then on emerging in the period of fully-fledged Frankish domination of much of Roman Gaul from the late 530s onwards, we find ourselves confronted by a network of cities that owes something to each of the phases of expansion, retrenchment, and renewal outlined above, and by a broadly homogeneous framework of relations between civic and central authority across much of Francia. By now, the upper tiers of late Roman secular admi-

26 Van Dam 1985, chs. 6-8; Mathisen 1993.

27 Sidon. epist. 1, 11, 5; Ruric. epist. 2, 33. For the fracturing, see especially Lepelley 1983.

28 Heinzelmann 1976; Heinzelmann 1988, with Jussen 1995; Jussen 2001.

29 For church-building, see, in anticipation of its thematic syntheses, the remarkable Topographie chrétienne series (Gauthier et al. 1986-2007).

30 For a well-documented example of such competition and the promotion of the saints' cults associated with it at Clermont, see Wood 1983 and 2002. 
nistration, the diocese and the province, had almost entirely disappeared, while such larger units as did exist, such as Provence, Septimania, and Burgundy, were of more recent political origin. ${ }^{31}$ Within the organisation of the church, the Roman provincial structure was perpetuated in the jurisdiction of the metropolitan bishops, but it had been lost from the secular sphere, where it exercised no particular influence over recurrent divisions of territory between rulers; the resulting dislocation between metropolitan and royal authority was one of the factors that would intermittently complicate relations between bishops and kings. ${ }^{32}$ In striking contrast, however, the network of cities and their dependent territories that had originated in the formative phase of Gallo-Roman urbanism proved remarkably resilient across more than four-fifths of Francia. ${ }^{33}$ If we compare the Gallic cities listed in the Notitia Galliarum of c. 400 with those centres documented as having bishops in the later sixth century, then over a hundred survive as the centres of territorial units, with by far the greatest disruptions to the network occurring in the far north-east, where social dislocation was most pronounced, in the Breton peninsula outside direct Frankish control, and, subsequently, among the small fortress-cities of Novempopulana. Across the heartlands of Gaul, however, only four of the 117 cities listed in the Notitia appear to have lost their status outright. ${ }^{34}$ Their persistence represents more than simple inertia, since the network did continue to evolve, but in small-scale and incremental fashion, sometimes through transfers of civitas-capital within a territory, or sometimes through the subdivision of existing city-territories to create additional sees; such developments had been characteristic of the Gallic urban network since its inception, and as such tend to confirm its continued responsiveness to local or political imperatives rather than its subjection to any fundamental post-imperial upheavals. ${ }^{35}$ This core stability of the civitas-network is no doubt mainly attributable to its perpetuation within the administrative organisation of the Church. But given that the same institution had proved insufficient to sustain the provincial structure outside its own framework, it seems likely that the reconfiguration of social power at the local level and the recognition by the rulers of the successor-states of the continued (or reconstituted) utility of civic administrative organisation were also significant factors in the widespread survival of the civitates as functioning units through the transition from Roman to barbarian rule.

If the Gallic civitates had therefore remained largely as they were as territorial units, their internal operation as political communities seems by the mid-sixth

31 Rouche 1997.

32 E.g. Conc. Gall. 2, 212-217, Greg. Tur. Franc. 7, 17, re Sigibert's uncanonical creation of a see at Châteaudun and its eventual suppression.

33 Loseby 2000; Beaujard/Prévot 2004.

34 Contrast Italy, where the rate of attrition was far higher, though so was the density of the urban network in the first place: Schmiedt 1974, La Rocca 1994.

35 Kaiser 1990 for the new sixth-century sees. 
century to have completed its evolution along post-curial lines. ${ }^{36} \mathrm{~A}$ handful of isolated or residual references apart, the ongoing activities of city-councils, or of individuals calling themselves curiales are visible thereafter only in the formulae that survive from several cities in the Loire valley, and in the occasional charter, in each case in connection with the registration of title to land in the municipal archives, a significant but essentially notarial responsibility. ${ }^{37}$ The absence of city-councils and curiales from works as rich in city-based anecdote as those of Gregory of Tours is perhaps not altogether as decisive as it might seem at first sight, given his manifest determination to portray bishops like himself as the acknowledged leaders of urban communities, but the recurrent appearances in his writings of a bewildering variety of persons - whether maiores (natu), seniores, honorati, priores, viri magnifici, or mere cives - who appear to exercise influence over urban communities on an informal rather than corporate basis, appears unlikely simply to reflect Gregory's particular historiographical purposes, since it is entirely consistent with contemporary trends in imperial territories. ${ }^{38}$ Quite who these politically-active people were, or precisely what distinctions might have existed between these various categories of persons is, as in the eastern empire, never wholly transparent, and it would be risky in any case to assume that the intriguing variations in the terminology with which Gregory refers to them necessarily reflect subtle gradations of social standing rather than the circumstances, actual or literary, of the situation being described, or the bishop's giddy pursuit of lexical variety. ${ }^{39}$ Generally speaking, even so, they appear to comprise the major local landowners, be they scions of the senatorial class, the wealthier members of the municipal aristocracy, or, in some cases, local Franks, who variously feature alongside the bishop and the leading members of his clergy in Gregory's urban narratives, and can sometimes be seen deliberating the interests of their city. ${ }^{40} \mathrm{~A}$ great deal more visible in such settings, however, is the activity of one particular public official, the count, who, as the king's representative in the city, was himself more often than not selected from among that self-same local landed elite.

The prominence in Gregory's writings of the comes civitatis as the regular mediator of the relationship between kings and their cities epitomises the continuing operation across much of Gaul of the city-territory as a framework for secular

36 For post-curial government, see the references above, and the synthesis in Wickham 2005, 596-602.

37 Classen 1977; Rio 2009, 177-182; Loseby 2006, 90-91.

38 E.g. Greg. Tur. Franc. 2, 23; 4, 43; 5, 48; 6, 11; 8, 21; 8, 31; 10, 16; GC 58, 60.

39 The lurking inconsistencies are most obvious in Gregory's usage of civis: see Durliat 1997, Heinzelmann 1988, 60-62, and, more compehensively (but with questionable attempts to establish clear categories), Weidemann 1982, ii, 307-319.

40 Franks: e.g. Greg. Tur. Franc. 8, 31. For both lay and clerical seniores, see e.g. Franc. 5, 48, where Leudast sits in judgement cum senioribus vel laicis vel clericis, though Gregory more often prefers to distinguish between clergy and the seniores, as e.g. in Franc. 10, 16, where a marriage-feast in the Holy Cross nunnery at Poitiers had occurred coram pontifice, clero vel senioribus. Passio Praejecti, 13 offers one later seventh-century indication of the existence of recognised senior clergy in Clermont. 
administration, even as it illustrates the obsolescence of the curial mechanisms through which similar obligations to ruling authorities had previously been organised. The stages through which a post that seemingly had its origins in the twilight years of the western empire in the appointment of directly-accountable officials to strategic centres became a widely-adopted feature of the management of relations between central and local power are obscure (and, unusually for this period, lacking in direct eastern Mediterranean parallels). ${ }^{41}$ But by the late sixth century such officials are visible in some two dozen cities scattered across Gaul, and since it is generally difficult to spot other local office-holders exercising equivalent responsibilities, they presumably existed in many more. ${ }^{42}$ In their earliest manifestations, the holders of this title seem to have operated alongside the old structures of civic government (as was the case, for example, in Visigothic Gaul around $500^{43}$ ), but by Gregory's day such formerly curial tasks as the maintenance of local order, the administration of justice, and the raising of taxes appear to have been absorbed into the competence of the count and his subordinates. Beyond all that, the count was also required to ensure the mobilisation of local levies for the performance of military service. Whatever the specific origins or precise extent of this obligation, it can only be post-imperial. As such, it appears indicative of a conscious attempt among the Frankish rulers to rule through the civitas-system in adapting it to current needs as well as in long-established ways. $^{44}$ The inhabitants of the Gallic civitates had long paid together and prayed together; now they fought alongside each other besides, and often, such was the patchwork effect created by the sixth-century royal partitions of the Merovingian kingdom, against the inhabitants of neighbouring cities, on behalf of rival kings, or, sometimes, on their own initiative. ${ }^{45}$

The Frankish world depicted by Gregory of Tours is thus very much a world of cities, not merely as the venues for much of the action which he describes (though this, needless to say, is a distortion that tells us more about the bishop's field of vision than the whereabouts of the majority of the population), but, more tellingly, as the units through which power was regularly exercised and identity routinely ascribed. ${ }^{46}$ Kingdoms were accumulations of civitates, control of which could always potentially be determined on a city-by-city basis, whether by negotiation, as at Andelot, or by force, which could have unfortunate consequences for

41 Claude 1964.

42 Weidemann 1982, i, 63-86, with Murray 1986 for the identification of the grafio as the north-eastern equivalent of the count. For one exception to this pattern, see the Austrasian partes of Provence, where the earlier Ostrogothic administrative structure was retained, and such tasks came under the competence of an official variously titled rector, praefectus, or patricius: Buchner 1933, 15-29.

43 Dumézil 2008.

44 Weidemann 1982, i, 238-246; Bachrach 1972, esp. 65-73; Halsall 2003, 46-48.

45 Greg. Tur. Franc. 7, 2, for reciprocal raids by local levies on neighbouring cities, taking advantage of a political vacuum to demonstrate a collective civitas-identity independent of royal command.

46 Breukelaar 1994, 198-200; Loseby 1998a. 
the inhabitants of those centres, such as Tours, which lay on the fault-lines between rival regna. The city-communities themselves had their identities repeatedly reinforced in moments of collective spiritual, military, or political action, whether in responding to their bishop's promotion of the cult of their own special patron, to a call to arms from their count, or to the unwelcome imposition of new taxes. Such situations could inspire resistance as well as obedience, and are often the moments when the new-style civic leaders - the maiores and their ilk emerge momentarily from obscurity to figure alongside the bishops in Gregory's urban narratives. It might be pushing the point a little too far to infer that 'in times of civil war, it was the loyalty of the cities which counted', though not because civic identity was unimportant, but because no city seems either greatly inclined or seriously capable of mounting any sustained opposition to royal authority. ${ }^{47}$ But it was certainly at this level that loyalty was consistently demanded, through the oaths that rightful or prospective rulers compelled civic leaders to swear in moments of political crisis or uncertainty. ${ }^{48}$

The late sixth century might therefore be said to represent the maturation of the phase of urban renewal across much of Gaul, if only in terms of the apparent pervasiveness of the city as a hub of social and political action, and a routine interface between central and local authority. Cities had to some extent regained the administrative pre-eminence and the role as a focus for personal loyalties that they had been assigned in the early imperial period, albeit this time faute de mieux, as a consequence of a prolonged period of political fragmentation that had precluded the perpetuation of existing administrative units more extensive than the civitas or retarded the emergence of new ones. In every other respect bar their locations, nevertheless, the later sixth-century civitates had only residual features in common with their Augustan antecedents, whether in their operation as political communities, or in their built environments. The duoviri who counted in these cities were no longer magistrates at the head of a formally-constituted curial ordo, but the bishop and count, both of whom were in effect royal appointees, for all that their overlapping jurisdictions often found them at loggerheads. ${ }^{49}$ Urban landscapes will still have featured many of the monuments of earlier centuries, but these were generally in varying stages of decay, as they were put to new purposes, stripped out for building materials, or simply left to the ravages of time. ${ }^{50}$ We are sometimes allowed a glimpse of the continuous relationship that must have existed between this inescapably monumental legacy and the present inhabitants, as for example when something miraculous occurs to heal those engaged

47 Brown 2002, 11. For resistance and its limits, see the temporising of the "bishop and the citizens' of Poitiers in Greg. Tur. Franc. 7, 12-13; 7, 24. Contemporary urban communities in Visigothic Spain appear more independently-minded: Collins 1980.

48 Frye 1995.

49 See Lauranson-Rosaz/Jeannin 2001 for a specific example of their joint assumption of a formerly curial function, that of replacing lost acta, James 1983 for one of the main sources of tension between them.

50 Effros 2001. 
in the work of reclamation or repair, but in general our sources only have eyes for city-walls, now more sporadically maintained and repaired, or for urban churches or monasteries, which continue steadily to accumulate. ${ }^{51}$ The archaeological evidence confirms by its largely impoverished character that this 'renewed' urbanism is otherwise very different from the old, and indeed so pared down in scale and conception in some centres that it can reasonably be questioned whether a city such as late sixth-century Tours, as busy and dynamic as Gregory makes it sound, really deserves to be considered urban at all if one takes into consideration its lack of demographic or economic weight. ${ }^{52}$ But then these were not criteria that would have been understood by Gregory or his contemporaries, for whom cities were routinely the places from which power was exercised by bishops or counts, and through which territories were controlled and resources extracted by their rulers.

During the early seventh century, however, this changed quite quickly, as the relationship between centralised authority and city-based power-structures entered a final phase that saw the abandonment of the civitates as the organising principles of secular administration. The coincidence between this notional turning-point and the moment at which we cease to see Francia from Gregory of Tours' city-centric perspective may seem too close for comfort, and it is also the case that the uneven distribution of the different categories of Merovingian source material compounds the problem of comparison between the sixth and seventh centuries more generally, but, even so, the indications of change are cumulatively clear, and can in many ways be seen to represent the logical development of trends already perceptible in the works of the bishop of Tours. Perhaps the clearest example of this is provided by the disavowal by the Merovingian kings of any further attempts to overhaul the land-tax. ${ }^{53}$ Here defeat was effectively sounded by Lothar II, with his promise in 614 to repudiate any new census upon request, thereby resigning himself to the impossibility of meaningful fiscal reform even though, as sole ruler, he was arguably in a better position to bring it about than predecessors such as his father, whose characteristically ambitious but ultimately unsuccessful efforts to impose new taxes upon some of his cities had allegedly resulted in a mass exodus of their inhabitants to other kingdoms. ${ }^{54}$ But in truth this concession may represent little more than an acknowledgment of the increasingly incidental and anachronistic character of such exactions in a polity which was no longer maintaining a professional army or extensive salaried bureaucracy that needed to be supported through taxation. The land-tax was clearly proving difficult to collect, in part, it would appear, for logistical reasons deriving from the uneven post-imperial survival or inconsistent upkeep of the machinery of

51 Miracles linked with spoliation or repair: e.g. Honoratus, Vita Hilarii 20; Passio Praejecti 11. For the erratic maintenance of walls through the early Middle Ages, see Bourgeois 2006, 119-123.

52 Galinié 1997.

53 Kaiser 1979; Goffart 1982.

54 Cap. Merow. 9, c. 8; for Chilperic's tax-drive, Greg. Tur. Franc. 5, 28; 5, 34, in his hyperbolic register. 
assessment from one city-territory to the next, but more fundamentally because of resistance to its very legitimacy from both Franks, who regarded such payments as beneath their dignity, and churchmen, who were wont to portray them as symptomatic of royal greed. ${ }^{55}$ As claims to Frankish identity intensified and ecclesiastical institutions accumulated ever more estates, so the extent of the notionally tax-liable land concentrated in the hands of those who either saw themselves as exempt from payment, or were, at best, reluctant to co-operate increased. The kings themselves were, moreover, implicated in this gradual disintegration of the Roman fiscal legacy through their concession of immunities from fiscal and other obligations to favoured individuals, churches, and indeed whole cities, as Gregory was at pains to emphasise in the particularly privileged case of Martin's Tours. ${ }^{56}$ These two trends came together when Lothar II agreed that exemptions from any public charge should apply not merely to specific parcels of land, but to all the properties of those churches and clerics entitled to them. ${ }^{57}$ In Gregory's day the efforts of contemporary rulers to take tax were already appearing more akin in their centrally-directed and precisely-targeted nature to military campaigns than to routine, locally-administered exactions, and all for what were apparently limited returns. ${ }^{58}$ Their early seventh-century successors came to realise, we might assume, that such battles were no longer worth fighting; the income to be gained was scarcely worth the resentment generated. Taxation would linger on in residual form for some time to come in certain areas, but the available data suggests that it was increasingly left to the landowners themselves to collect it from their own estates and forward some proportion of it on if required; the collective, city-based framework for taxation in place since the Augustan era, and still in intermittent and fragmentary operation in the late sixth century had finally disintegrated. ${ }^{59}$

Meanwhile, the proliferation of immunities did not disappear with taxation. By the time that examples of such grants begin to survive in number, from the mid-seventh century onwards, if only in favour of ecclesiastical recipients, it was rather their emphasis that had changed. Kings were still looking to use immunities as convenient mechanisms for bestowing favour upon those institutions or individuals whose spiritual and political services, past or prospective, deserved recognition - indeed, they seem increasingly to have become routine instruments of policy - but the focus of such gifts had shifted from the fiscal to the judicial sphere. ${ }^{60}$ Any reference to immunity from fixed taxation in such documents dis-

55 Logistics: e.g. Greg. Tur. Franc. 9, 30; 10, 7. Frankish resistance: e.g. Franc. 3, 36; 7, 15. For perceptions of the morality of taxation in general, Lot 1928, 83-107, though not all bishops were necessarily as hostile as Gregory to taxation in principle, as the efforts of Maroveus of Poiters in Hist. 9, 30 merely to secure a more up-to-date assessment show.

56 Greg. Tur. Franc. 9, 30; Kaiser 1979, 9-10.

57 Cap. Merow. 8, c. 11; Goffart 1982, 17-19.

58 Devroey 2003, 242, for the simile, Lot $1928,85-86$, for the returns.

59 Wickham 2005, 110-115. For a wholly different view, see Durliat 1990, 95-187, asserting the generalised survival of the tax-system.

60 Amid a vast bibliography, see Murray 1994, Fouracre 1995, and Rosenwein 1999, ch. 4. 
appeared, to be superseded by an emphasis on the exclusion of the count and his subordinates from the exercise of jurisdiction within privileged lands, conceding the provision and profits of justice to the recipient instead. The social capital that accrued to rulers through such arrangements may have been every bit as valuable to them as the actual capital that they were giving away, but these developments meant that the role of the comes civitatis came to be doubly circumscribed, firstly by the creeping privatisation of royal prerogatives, and secondly by the hollowing out of his jurisdiction through the proliferation of the immunities granted to leading landowners, superseding a territorial framework of social organisation with one structured around lordship. More speculatively, the shortage in seventhcentury sources of further references to city-levies of the type which can be seen in Gregory of Tours' narrative to have been regularly called out to march upon neighbouring civitates might be thought to imply that the innovation that had seen military obligations organised on the basis of the city-territory had also been abandoned, perhaps in favour of more selective troop-mobilisations, and certainly in conjunction with the superimposition of the broader conceptions of kingdomwide identity discussed below, so further dissolving the link between the comes and the civitas. ${ }^{61}$ The count of the city had always been a relatively minor official, but in the sixth century the utility of the civitas as a unit of secular administration had made it necessary, if not quite to invent him, then to expand his role as the linchpin of the relationship between royal and central power, in succession to the obsolete curial-system. But in the course of the seventh century both the integrity and administrative content of his jurisdiction was substantially eroded, allowing the title ultimately to float free of territorial definition, and severing any necessary connection between secular office-holding and the civitas-network. ${ }^{62}$ Nor would the pagi that emerge ever more ubiquitously from the later seventh century onwards as dominant spatial conceptions in succession to the civitates equate neatly in future with the comitatus that came to define the personal competence of the counts. $^{63}$

While the retreat of the secular administrative mechanisms that had made the civitas an operational framework of collective action combined with the rise of immunities to dissolve the integrity of city-territories from within, their significance as defining units of personal and collective identity was at the same time coming under pressure from without, as the Reichsteil of the sixth century, conceived around a king and his sedes, mutated rapidly into the Teilreiche of the seventh, the tria regna of Austrasia, Neustria and Burgundy that could exist with or without a king, and, as such, became established as the standard frames of

61 The only seventh-century examples of such levies known to me appear in Fredegar 4, 73 and 4,87 , vastly outnumbered by references to armies described by more extensive territorial frames of reference. The general sketchiness of our understanding of Merovingian military obligations is effectively brought out by the summary of divergent scholarly opinions provided in Goffart 2008, 178 n. 39.

62 Claude 1964, 59-79.

63 Innes 2000, 118-121. 
reference for the representation of political authority. ${ }^{64}$ This transformation is well-known, but it is worth dwelling for a moment on the speed with which it took place, if only to counter the convenient but misleadingly teleological tendency to describe the later sixth-century kingdoms in the same terms, notwithstanding the very limited presence of such conceptions in the works of Gregory of Tours and the volatile and unpredictable nature of the contemporary political situation, the effect of which can be to obscure the significance of the changes that took place around $600 .{ }^{65}$ Within the space of two generations after the death of Childebert II, the Merovingians and their magnates arrived, by a mixture of accident and design, at a mutually-acceptable distribution of power - and, crucially, of access thereto - that transcended the level of the civitas, and depended upon the maintenance of stable, and, for the most part, territorially-coherent regna, the consolidation of which was cemented by a lengthy period of internal peace. While he was relying on Gregory of Tours, the chronicler known as Fredegar retained something of his framing of political action, but in picking up where the bishop's narrative left off (or so he imagined), he routinely identified Frankish kings, magnates, armies, and territories alike in terms of the tria regna, reverting to a citybased frame of reference only when defining the temporary subkingdom of Charibert II in Aquitaine, where power was still divided and continued to be conceived on the basis of the civitates. ${ }^{66}$ His practice can serve to epitomise the decisive affirmation of regional political identities in later Merovingian sources more generally, culminating in the succinct summary of the origin of Lothar II's sole rule offered, with the benefit of hindsight, by the author of the Liber Historiae Francorum: "the Burgundians and the Austrasians made peace with the rest of the Franks [his word for Neustrians], and raised up King Lothar to the kingship over all three kingdoms'. ${ }^{67}$

The phrasing from an early eighth-century perspective of this précis of the events of 613 might well have perplexed Gregory of Tours, but the potential for

64 Cardot 1987, 123-138. Ewig 1976b remains the classic account of the seventh-century Teilreiche, although the assumption of an ongoing conflict of interest between kings and aristocracy that underpins it has been superseded, as for example in Fouracre 2005.

65 Gregory uses Burgundy seven times to refer to the Frankish kingdom or its people (Franc. 2,$33 ; 4,16 ; 4,42 ; 5,13 ; 8,30 ;$ glor. mart 83; Mart. 1, 36), Austrasia three times (Franc. 5, 14; 5, 18; Mart. 4, 29 [as Austria]), Neustria not at all. Gregory's Francia is not a synonym for Neustria (as in some later sources), but for Austrasia (Franc. 4, 14; 4, 16; GC 40; and perhaps Mart. 1, 26); its more generic use in the text of Andelot in Franc. 9, 20 is not Gregory's own.

66 Fredegar 3, 29; 3, 55; 3, 80, for examples of his retention of Gregory's usage both in describing divisions of the kingdom and for military action, and 3, 82f. for his sustained adherence to Gregory's spatial terminology. Fredegar 4, 57 for Charibert's subkingdom, comprising five cities (which he calls pagi), and an otherwise undefined area between them and the Pyrenees in what was formerly Novempopulana; cf. Fredegar, Cont. 46. For the perpetuation of the idea of the tria regna and the affirmation of their independent political identity under Childeric II in the 670s, see Vita Balthidis 5, Passio Leudegarii 7.

67 Lib. hist. Franc. 40; Ewig 1976c. 
such political integration was already present in his day, when neither the fragmented structure nor the geographical scale of the Merovingian polity precluded regular connections between the royal courts and the cities on the periphery of their realms, as is evident, for example, in the late sixth-century history of Marseille and the routine implication of its leading magnates, Bishop Theodore and the patricius Dynamius, in the political intrigues of the $580 \mathrm{~s}^{68}$ What was changing was the frame of reference in which such aristocratic manœuvring took place, which now became politically but not geographically circumscribed, as elites pursued power and legitimation within their respective regna rather than exploiting differences between kings to flit between them, as they had in the runup to Andelot. Indeed, some of the most prominent seventh-century magnates, such as Desiderius of Cahors and his peers, grew up within this framework through their formation at the royal court; after distinguished administrative careers, they might eventually return to their home civitates as bishops, but they never forgot the shared, kingdom-wide identity that tied them to their fellowalumni. ${ }^{69}$ The outcome was a species of consensus politics built around the regular participation of the aristocracy in the business of the court, where their rivalries were played out before their peers under the ultimate authority of the king, as outlined in the narrative sources and epitomised in surviving placita, with their extensive witness-lists and formulaic assertions of collective royal and aristocratic judgement: proinde nos taliter una cum nostris proceribus constetit decrevisse. ${ }^{70}$ This centralisation of political practice around the courts coincided, as we have seen, with the delegation of royal rights at the local level directly to lay or ecclesiastical landholders, whose interests might be scattered through a number of civitates. The relationship between local and central authority - or between the pagus and the palace, as the formularies had it - was by now mediated predominantly through personal rather than territorial relationships. The seventh-century polity came to be integrated not by the cities and their associated remnants of the ancient administrative infrastructure, but by the aristocracy itself. It had come, finally, to be based upon their land- and office-holding, and not upon a city-based bureaucratic framework that had outlived its usefulness.

At much the same time, and in a further symptom of their diminished significance, the cities finally lost any privileged connection with the representation as well as the exercise of secular power, as Frankish kings began to base themselves primarily upon their rural estates. The late sixth-century Merovingians had retained some sense of the symbolic resonance of urban settings - seemingly strongest, as usual, in the aspirational Chilperic, with his persistent designs upon

68 Loseby 1998b, 225-227.

69 Desiderius, epist. 1, 11. Some of the distinguished witnesses in 654 to ChLA XIII, 558 in favour of St-Denis seem similarly to be early-career courtiers, but would end up on opposite sides in the faction-fighting of the mid-670s.

70 Fouracre 1986, Fouracre 1998. Marculf 1, 37 gives the formula regularly reproduced in extant placita. 
Paris and his plans for urban public entertainments ${ }^{71}$ - but, again from the pivotal reign of Lothar II, they decisively shifted the focus of their activities to rural palaces round about. ${ }^{72}$ Clichy was certainly not far from Paris, as Fredegar helpfully points out, but in terms of political culture it was a world away from the conventional urban framing of dynastic power that contemporary Visigothic and Lombard rulers were simultaneously making considerable efforts to reaffirm. ${ }^{73}$ Dagobert I consolidated his father's preference for Clichy, and while he and subsequent rulers would still occasionally grace urban stages, in particular for their occasional forays into Burgundy, the disassociation between cities and royal residence would become sufficiently complete within Francia for Charlemagne to opt to dignify Aachen, with its tempting baths, rather than establishing himself in one of the existing civitas-capitals. ${ }^{74}$ In shifting the emphasis of their activities to the countryside, the Frankish kings were probably adopting the existing practice of secular magnates, who appear predominantly to have been rurally-based, again in conspicuous contrast to their urban Italian counterparts. ${ }^{75}$ Precise evidence for their whereabouts is nevertheless somewhat vague by comparison, not least because the dispersed nature of their holdings probably encouraged itineration; surviving wills show how their extensive property portfolios continued to include town-houses and other urban holdings alongside rural estates. ${ }^{76}$ In the absence of much evidence for elite investment in elaborate rural residences, meanwhile, the clearest indication of a shift in the focus of their investment and self-legitimation from the cities out into the countryside again occurs in the seventh century with the explosion of monastic foundations on rural estates, as the aristocracy embraced a vehicle for displaying their piety that did not require them to yield up control over the lands that were the basis of their family power. ${ }^{77}$

This ruralisation of royal and aristocratic power may have diminished the preeminence of the civitates, but it could scarcely spell the end of the cities as centres for the local exercise of power and patronage, since one powerful component of the magnate community, the episcopate, remained resolutely urban. The bishops were, moreover, the foremost beneficiaries of the royal delegation of local powers and, with the eclipse of the count, assumed ever-greater responsibility for the administration of their cities, including the upkeep of the city-walls and the provi-

71 Greg. Tur. Franc. 4, 22; 5, 1; 5, 17; 6, 27.

72 Barbier 1990, esp. 261-269.

73 Fredegar 4, 53; Velázquez/Ripoll 2000; Brogiolo 2000.

74 Burgundy: e.g. Fredegar 4, 58; 4, 90; Passio Leudegarii 9; Fredegar, Cont. 48. Aachen: Nelson 2001; Wickham 2009, 78-80.

75 Wickham 2005, 605-608, though in pursuit of the clear contrast with Italy, this risks pinning the Frankish aristocracy down beyond what the fragmentary evidence permits, and more decisively than is necessary.

76 E.g. Bertram, Test. 24, 25, 30, 36, 71. Alongside the evidence for urban elite residences assembled in Claude 1997, 331-333, see e.g. Pardessus 2. no. 406 for inlustri viri acknowledged as resident in Reims in 686.

77 Residences: Samson 1987. Proliferation of monasteries: Atsma 1976, 168. 
sion of public services. ${ }^{78}$ The overarching extent of their prerogatives, and the zeal with which they might be exercised, is most obvious in the corpus of material associated with Bishop Desiderius of Cahors, but it is incidentally reflected in seventh-century Frankish hagiography in general, which confirms by its allusions to the deadly rivalries swirling around episcopal office that it had lost nothing of its attraction. ${ }^{79}$ With power went danger, as bishops continued to be obliged simultaneously to negotiate the pitfalls of central and local politics; it was only when the centripetal pull upon aristocratic competition exerted by the royal courts temporarily weakened in the early eighth century that episcopal office could sometimes emerge within the interstices of centralised authority as an effective basis for the exercise of a measure of local autonomy. ${ }^{80}$ In the interim, nevertheless, the spiritual jurisdiction of the bishop over his civitas had been coming under pressures similar to those which had undermined the count, especially once any existing weakening of his properly territorial prerogatives in the face of proprietary interests (potentially including those of his fellow-bishops) began to be exacerbated by the seventh-century proliferation of aristocratic monastic foundations, since these were frequently backed by concessions of immunity granted by rulers supportive of the desire of their founders to free their religious investments from episcopal control. ${ }^{81}$ This Klosterpolitik certainly extended the permeation of personal lordship based on landholding further into the spiritual sphere, although the resulting 'deterritorialisation' of episcopal authority would prove neither so thorough nor so decisive as that which vitiated the jurisdiction of the counts. ${ }^{82}$ But it did mean that while the bishop remained a city-based focus of considerable social power, the coherence of the civitas as a community of worship under his direction was partially undermined by the growing numbers of churches and monasteries, both urban and rural, that aspired to some measure of independence from his authority; this was a trend that the Carolingians would strive, not altogether successfully, to reverse. ${ }^{83}$

In concluding, it would be as well variously to qualify the significance of those changes that we have seen to cluster around the early seventh century. First, many - perhaps most - of the ancient civitas-capitals retained a pre-eminent role as the centres around which local society revolved, just as the royal courts did for the operation of the regna as a whole. Despite a levelling-down of the settlement hierarchy that meant they were facing increased competition for this preeminence from other categories of central place, the cities would retain a range of

78 Durliat 1996, effectively countering the argument of Prinz 1974 that bishops had usurped these rights.

79 Durliat 1979. For rivalries, see e.g. Passio Leudegarii 2, Passio Praejecti 12-14.

80 Fouracre 1990 for the interaction of royal and local politics, with Fouracre 2003 on the sometimes fatal consequences for bishops; for episcopal independence, Kaiser 1981.

81 Ewig 1976d.

82 For the process of 'deterritorialisation' over the longer-term see Lauwers and Ripart 2007, though they see it as having a significant impact from an earlier date than is argued here.

83 Mazel 2009. 
functions that more specialised rural monasteries, emergent emporia, and royal palaces, let alone aristocratic estate-centres, would prove unable to match. ${ }^{84}$ They too were beginning to benefit from the economic upturn of the later Merovingian period, not least by virtue of their nodal locations in transport- and communications-networks, which facilitated the roles as regular market-centres and providers of specialist services to their hinterlands that still generally differentiated them archaeologically from other categories of settlement. ${ }^{85}$ Even in the absence of a permanently resident aristocracy, the cities remained privileged theatres of public action, as shown by the charter evidence that begins to emerge in the eighth century for the role of centres such as Mainz in structuring regional social and economic networks. ${ }^{86}$ It was in the cities, above all, that the politics of land were formally played out, in the purchases, sales, exchanges, and bequests documented in charters and given due witness by local elites, who no doubt periodically stayed in their town-houses for precisely such purposes. It was also in the cities that competition between these elites for local status was still intensely pursued in rivalries over episcopal office or in familiar and by now substantially Christianised patterns of patronage. The spread of monasticism to the countryside in no way precluded parallel investment by elites in urban churches and monasteries, driven by the same pursuit of present legitimation and future salvation, and exemplified by foundations such as the communities for women implanted by Eligius and Ebroin within, respectively, the walls of Paris and Soissons, or by the substantial legacies to existing urban religious institutions that feature prominently in seventh-century wills. ${ }^{87}$ The accumulation by the end of the Merovingian period of dozens of such establishments in cities from which suitably comprehensive documentation survives - such as Metz, Le Mans, Clermont, or Auxerre should not be rather dismissively regarded as evidence for the 'clericalisation' of the city to the exclusion of other, supposedly more properly urban functions, but rather as manifestations of the continued importance of cities as stages for competitive aristocratic munificence. To judge from later seventh-century urbancentred texts such as the Passio Leudegarii or Passio Praejecti, such competition had changed little in either its dynamics or its intensity since the days of Gregory of Tours, and, in Clermont at least, it was still being pursued by scions of the same elite families, whose posthumous translations might draw in a crowd like an

84 Verhulst 2000. For model studies of changing regional settlement hierarchies in the Midi over the longer-term, see Schneider 2007, Schneider 2008.

85 For the textual evidence, see Claude 1985, esp. 45-56 for markets. For urban archaeological indications of later Merovingian economic revival, see Henning 2007, with Lebecq 1996, Lebecq 2000 for rather different perspectives on both the chronology of these developments and the place of the monasteries within them.

86 Innes 2000, 95-101.

87 Eligius: Jonas, Vita Columbani 2, 10, Vita Eligii 1, 17; Ebroin: Pardessus 2, no. 355 (he also had a house in the city). ChLA 14, 594 is one such will, favouring a mixture of urban and rural churches in and around Paris. 
assembled army, or, more suggestively, that one might expect to see on a marketday. 88

Secondly, the impact upon the built environment of cities of the changes taking place in the early seventh century was negligible by comparison with the material transformations that had accompanied each of the three preceding phases of Gallo-Roman urbanism. Since the civitates no longer carried any distinct monumental identity as organs of secular administration, their loss of importance within the operation of the Merovingian polity did not in itself have any fundamental topographical consequences. Instead, long since liberated from the conventions and formal layouts of classical urbanism, but still bound by the possibilities and problems presented by its massive monumental legacy, urban landscapes continued slowly to evolve around the structuring elements of their walls and churches. In this regard, the tension between the breaking down of the distinction between urban and suburban encouraged by the spread of extra-mural religious establishments, and its constant perpetuation by the city-walls was tending to resolve itself in favour of the former. The specific outcomes in each case were determined primarily by local topographical circumstances but, in general, the field of action for urban communities grew more extensive - particularly when substantial monastic communities developed upon their fringes - even as occupation within that expanded space became more discontinuous and incoherent, and parts of it were given over to cultivation. These loose and polyfocal urban landscapes were very different from their Roman predecessors, but owed their origins to the working out of trends that had been set in train in late Antiquity, not to developments within the Merovingian period; they would be modified only by developments that lie beyond the scope of this paper, such as renewed imperatives to fortification and the emergence of distinct urban lordships.

Finally, the eclipse of the civitas as an operational framework of administration in the early seventh century derived in part from its essential fragility. The cities offered a ready-made framework for the extraction of resources to which the rulers of post-imperial Gaul had defaulted in the absence of viable alternative solutions to the perennial problem of exercising power over distance, and which they used as the basis of their kingdoms through the sixth century, seeking to sustain it through the agency of the comes civitatis, and even to expand it into the novel sphere of military service. But this reliance on an essentially bureaucratic framework of government was a sticking-plaster solution that came to prove increasingly obsolete and anachronistic because it lacked the requisite machinery and the social legitimacy to operate effectively. By achieving one of the aims of their immediate predecessors at Andelot, the binding of leading aristocrats more securely into their regna, the rulers of the early seventh-century Merovingian polity were able to move to a system of rule based firmly on personal relations

88 Wood 1983; Vita Boniti 40, re the occasion of the translation of the saint's remains: tanta erat populi cum clericis multitudo, ut exercitum coadunatum aut nundinas crederes celebrari. 
and the politics of land that could finally leave the mediation of their power through the civitates behind.

\section{Bibliography}

\section{Primary sources}

Avitus Viennensis, Homiliae: Alcimi Ecdicii Aviti Viennensis episcopi opera quae supersunt, rec. Rudolf Peiper (MGH Auct. ant. 6, 2), Berlin 1883, 103-157.

Bertram of Le Mans, Testamentum: Margarete Weidemann, Das Testament des Bischofs Berthramn von Le Mans vom 27. März 616. Untersuchungen zu Besitz und Geschichte einer fränkischen Familie im 6. und 7. Jahrhundert, Mainz 1986.

Capitularia Merowingica: MGH Capit. 1, denuo ed. Alfred Boretius (MGH Legum sectio 2, 1), Hanover 1883, 1-23.

Chartae Latinae Antiquiores XIII, publ. by Hartmut Atsma and Jean Vezin, Dietikon/Zurich 1981.

Chartae Latinae Antiquiores XIV, publ. by Hartmut Atsma and Jean Vezin, Dietikon/Zurich 1982.

Concilia Galliae A.511-A.695, cura et studio Charles de Clercq (CCSL 148A), Turnhout 1963.

Desiderius of Cahors, Epistulae: Epistolae Merowingici et Karolini aevi, vol. 1, ed. Ernst Dümmler, Hanover 1892 (MGH Epp. 3), 191-214 (ed. Wilhelm Arndt).

Fredegar, Chronicarum quae dicuntur Fredegarii Scholastici Libri IV cum continuationibus: Fredegarii et aliorum Chronica. Vitae sanctorum, ed. Bruno Krusch (MGH SS rer. Merov. 2), Hanover 1888, 1-214.

Gregorius Turonensis, De virtutibus sancti Martini episcopi: Gregorii episcopi Turonensis miracula et opera minora, ed. Bruno Krusch (MGH SS rer. Merov. 1, 2), Hanover $1885,124-210$.

Gregorius Turonensis, Liber in gloria Confessorum: Gregorii episcopi Turonensis miracula et opera minora, ed. Bruno Krusch (MGH SS rer. Merov. 1, 2), Hanover 1885, 294-370.

Gregorius Turonensis, Liber in gloria Martyrum: Gregorii episcopi Turonensis miracula et opera minora, ed. Bruno Krusch (MGH SS rer. Merov. 1, 2), Hanover 1885, 34-111.

Gregorius Turonensis, Libri Historiarum decem (=Historia Francorum): Gregorii episcopi Turonensis libri historiarum X, ed. Bruno Krusch and Wilhelm Levison (MGH SS rer. Merov. 1, 1), Hannover ${ }^{2} 1951$.

Gregorius Turonensis, Vita Patrum: Gregorii episcopi Turonensis miracula et opera minora, ed. Bruno Krusch (MGH SS rer. Merov. 1, 2), Hanover 1885, 211-294.

Honoratus Massiliensis, Vita Sancti Hilarii episcopi Arelatensis: Vitae sanctorum Honorati et Hilarii episcoporum Arelatensium, rec. Samuel Cavallin, Lund 1952.

Jonas, Vita Columbani abbatis discipulorumque eius: Passiones vitaeque sanctorum aevi Merovingici, vol. 2, ed. Bruno Krusch (MGH SS rer. Merov. 4), Hanover 1902, 1152.

Liber Historiae Francorum: Fredegarii et aliorum Chronica. Vitae sanctorum, ed. Bruno Krusch (MGH Scriptores rer. Merov. 2), Hanover 1888, 215-328. 
Marculf, Formularum libri duo: Formulae Merowingici et Karolini aevi, ed. Karl Zeumer, (MGH Legum sectio 5), Hanover 1886, 32-112.

Pardessus, Jean-Marie (ed.), Diplomata, chartae, epistolae, leges aliaque instrumenta ad res Gallo-Francicas spectantia, 2 vol., Paris 1843-1849.

Passio Leudegarii episcopi et martyris Augustodunensis I: Passiones vitaeque sanctorum aevi Merovingici, vol. 3, ed. Bruno Krusch and Wilhelm Levison (MGH SS rer. Merov. 5), Hanover 1910, 249-362.

Passio Praejecti episcopi et martyris Arverni: Passiones vitaeque sanctorum aevi Merovingici, vol. 3, ed. Bruno Krusch and Wilhelm Levison (MGH SS rer. Merov. 5), Hanover 1910, 212-227.

Ruricius of Limoges, Epistulae: Gai Sollii Apollinaris Sidonii epistulae et carmina. Accedunt Fausti aliorumque epistulae ad Ruricium aliosque, Ruricii epistulae, rec. Christian Lütjohann (MGH Auct. ant. 8), Berlin 1887, 299-350.

Sidonius Apollinaris, Epistulae: Gai Sollii Apollinaris Sidonii epistulae et carmina. Accedunt Fausti aliorumque epistulae ad Ruricium aliosque, Ruricii epistulae, rec. Christian Lütjohann (MGH Auct. ant. 8), Berlin 1887, 1-172.

Vita Boniti episcopi Arverni: Passiones vitaeque sanctorum aevi Merovingici, vol. 4, ed. Bruno Krusch and Wilhelm Levison (MGH SS rer. Merov. 6), Hanover 1913, 110 139.

Vita Eligii episcopi Noviomagensis: Passiones vitaeque sanctorum aevi Merovingici, vol. 2, ed. Bruno Krusch (MGH SS rer. Merov. 4), Hanover 1902, 634-741.

Vita sanctae Balthildis: Fredegarii et aliorum Chronica. Vitae sanctorum, ed. Bruno Krusch (MGH SS rer. Merov. 2), Hanover 1888, 475-508.

\section{Secondary sources}

Atsma (1976): Hartmut Atsma, „Les monastères urbains du nord de la Gaule“, Revue d'Histoire de l'Eglise de France 62, 163-187.

Bachrach (1972): Bernard S. Bachrach, Merovingian military organisation 481-751, Minneapolis.

Bachrach (2002): Bernard S. Bachrach, Fifth-century Metz: late Roman Christian urbs or ghost town?", Antiquité Tardive 10, 363-381.

Barbier (1990): Josiane Barbier, „Le système palatial franc: genèse et fonctionnement dans le nord-ouest du regnum“, Bibliothèque de l'École des Chartes 148, 245-299.

Bayard \& Massy (1983): Didier Bayard and Jean Luc Massy, Amiens Romain: Samarobriva Ambianorum, Amiens.

Beaujard (1996): Brigitte Beaujard, „L'évêque dans la cité en Gaule aux Ve et VIe siècles", in: C.Lepelley (Hg.), La fin de la cité antique et le début de la cité médiévale de la fin du IIIe siècle à l'avènement de Charlemagne, Bari, 127-146.

Beaujard (2000): Brigitte Beaujard, Le culte des saints en Gaule. Les premiers temps. D'Hilaire de Poitiers à la fin du VIe siècle, Paris.

Beaujard \& Prévot (2004): Brigitte Beaujard and Françoise Prévot, „Introduction à l'étude des capitales "éphémères" de la Gaule (Ier s. - début VIIe s.)", in: A.Ferdière (Hg.), Capitales éphémères. Des capitales de cités perdent leur statut dans l'antiquité tardive (Revue Archéologique du Centre de la France, supp. 25), Tours, 17-37.

Bedon et al. (1988): Pierre Bedon, Raymond Chevallier and Robert Pinon, Architecture et urbanisme en Gaule romaine, 2 Bde., Paris. 
Bonnet \& Reynaud (2000): Charles Bonnet and Jean-François Reynaud, „Genève et Lyon, capitales burgondes“, in: G.Ripoll and J.-M.Gurt (Hgg.), Sedes regiae (ann. 400800), Barcelona, 241-266.

Bourgeois (2006): Luc Bourgeios, „Les résidences des élites et les fortifications du haut Moyen Âge en France et en Belgique dans leur cadre européen: aperçu historiographique“, Cahiers de Civilisation Médiévale 49, 113-142.

Breukelaar (1994): Adriaan H. P. Breukelaar, Historiography and episcopal authority in sixth-century Gaul: the Histories of Gregory of Tours interpreted in their historical context, Göttingen.

Brogiolo (2000): Gian Pietro Brogiolo, „Capitali e residenze regie nell'Italia Longobarda“, in: G.Ripoll and J.-M.Gurt (Hgg.), Sedes regiae (ann. 400-800), Barcelona, 135-162.

Brown (1981): Peter R.L. Brown, The cult of the saints. Its rise and function in Latin Christianity, Chicago.

Brown (2002): Peter R.L. Brown, „Gregory of Tours: introduction“, in: K.Mitchell and I.N.Wood (Hgg.), The world of Gregory of Tours, Leiden, 1-28.

Buchner (1933): Rudolf Buchner, Die Provence in merowingischer Zeit: Verfassung Wirtschaft - Kultur, Stuttgart.

Butler (1959): Ronald M. Butler, „Late Roman town-walls in Gaul“, Archaeological Journal 116, 25-60.

Cardot (1987): Fabienne Cardot, L'espace et le pouvoir. Étude sur l'Austrasie mérovingienne, Paris.

Cecconi (2006): Giovanni A. Cecconi, „Crisi e trasformazioni del governo municipale in Occidente fra IV e VI secolo“, in: J.-U.Krause and C.Witschel (Hgg.), Die Stadt in der Spätantike - Niedergang oder Wandel?, Stuttgart, 285-318.

Classen (1977): Peter Classen, „Fortleben und Wandel spätrömischen Urkundenwesens im frühen Mittelalter“, in: id. (Hg.), Recht und Scrift im Mittelalter, Sigmaringen, 13-54.

Claude (1964): Dietrich Claude, „Untersuchungen zum frühfränkischen Comitat“, Zeitschrift der Savigny-Stiftung für Rechtsgeschichte, Germanistische Abteilung 81, 1-79.

Claude (1985): Dietrich Claude, „Aspekte des Binnenhandels im Merowingerreich auf Grund der Schriftquellen“, in: K.Düwel et al (Hgg.), Untersuchungen zu Handel und Verkehr der vor- und frühgeschichtlichen Zeit in Mittel- und Nordeuropa, iii, Der Handel des frühen Mittelalters, Göttingen, 9-97.

Claude (1997): Dietrich Claude, „Haus und Hof im Merowingerreich nach den erzählenden und urkundlichen Quellen“, in: H.Beck and H.Steuer (Hgg.), Haus und Hof in urund frühgeschichtlicher Zeit, Göttingen, 321-334.

Collins (1980): Roger Collins, „Mérida and Toledo: 550-585“, in: E.James (Hg.), Visigothic Spain: new approaches, Oxford, 189-219.

Devroey (2003): Jean-Pierre Devroey, Économie rurale et société dans l'Europe franque (VIe-IXe siècles), I: Fondements matériels, échanges et lien social, Paris.

Dey (2010): Hendrik W. Dey, „Art, ceremony, and city-walls: the aesthetics of imperial resurgence in the third-century west", Journal of Late Antiquity 3, 3-37.

Dierkens \& Périn (2000): Alain Dierkens and Patrick Périn,,Les sedes regiae mérovingiennes entre Seine et Rhin“, in: G.Ripoll and J.-M.Gurt (Hgg.), Sedes regiae (ann. 400-800), Barcelona, 267-304.

Drabek (1970): Anna M. Drabek, „Der Merowingervertrag von Andelot aus dem Jahr 587““, in: Mitteilungen des Instituts für Österreichische Geschichtsforschung 78, 3441. 
Dumézil (2008): Bruno Dumézil, „Le comte et l'administration de la cité dans le Bréviare d'Alaric", in: M.Rouche and B.Dumézil, Le Bréviare d'Alaric. Aux origines du Code civil (Paris), 73-90.

Durliat (1979): Jean Durliat, „Les attributions civiles des évêques mérovingiens: l'exemple de Didier, évêque de Cahors (630-655)“, Annales du Midi 91, 237-254.

Durliat (1990): Jean Durliat, Les finances publiques de Diocletian aux Carolingiens (284889), Sigmaringen.

Durliat (1996): Jean Durliat, „Évêque et administration municipale au VIIe siècle“, in: C.Lepelley (ed.), La fin de la cité antique et le début de la cité médiévale de la fin du IIIe siècle à l'avènement de Charlemagne, Bari, 273-286.

Durliat (1997): Jean Durliat, „Episcopus, civis et populus dans les Historiarum Libri de Grégoire“", in: N.Gauthier and H.Galinié (Hgg.), Grégoire de Tours et l'espace gaulois, Tours, 185-193.

Effros (2001): Bonnie Effros, „Monuments and memory: repossessing ancient remains in early medieval Gaul", in: M.de Jong and F.Theuws, Topographies of power in the early middle ages (Transformation of the Roman World, 6), Leiden, 93-118.

Ewig (1976a): Eugen Ewig, „Die fränkischen Teilungen und Teilreiche (511-613)“, in: E.Ewig, Spätantikes und fränkisches Gallien, 1, München, 114-171.

Ewig (1976b): Eugen Ewig, „Die fränkischen Teilungen im 7. Jahrhundert (613-714)“, in: E.Ewig, Spätantikes und fränkisches Gallien, 1, 172-230.

Ewig (1976c): Eugen Ewig, ,Volkstum und Volksbewusstsein in Frankenreich des 7. Jahrhunderts“, in: E. Ewig, Spätantikes und fränkisches Gallien, 1, 231-273.

Ewig (1976d): Eugen Ewig, „Das Privileg des Bischofs Berthefrid von Amiens für Corbie von 664 und die Klosterpolitik der Königin Balthild“, in: E.Ewig, Spätantikes und fränkisches Gallien, 2, 538-583.

Fiches (Hg.) (1996): Jean-Luc Fiches, Le IIIe siècle en Gaule Narbonnaise. Données régionales sur la crise de l'empire, Sophia Antipolis.

Fouracre (1986): Paul Fouracre, ,'Placita' and the settlement of disputes in later Merovingian Francia“, in: W.Davies and P.Fouracre (Hgg.), The settlement of disputes in early medieval Europe, Cambridge, 7-22.

Fouracre (1990): Paul Fouracre, „Merovingian history and Merovingian hagiography“, Past and Present 127, 3-38.

Fouracre (1995): Paul Fouracre, „Eternal light and earthly needs: practical aspects of the development of Frankish immunities“, in: P.Fouracre and W.Davies (Hgg.), Property and power in the early Middle Ages, Cambridge, 53-81.

Fouracre (1998): Paul Fouracre, ,The nature of Frankish political institutions in the seventh century", in: Ian N.Wood (Hg.), Franks and Alamanni in the Merovingian period. An ethnographic perspective, Woodbridge, 285-301.

Fouracre (2003): Paul Fouracre, „Why were so many bishops killed in Merovingian Francia?“, in: N.Fryde and D.Reitz (Hgg.), Bischofsmord im Mittelalter, Göttingen, 13-35.

Fouracre (2005): Paul Fouracre, „Francia in the seventh century“, in: P.Fouracre (Hg.), The New Cambridge Medieval History, I, c.500 - c.700, Cambridge, 371-396.

Frye (1995): David Frye, „Transformation and tradition in the Merovingian civitas“, Nottingham Medieval Studies 39, 1-11.

Galinié (1997): Henri Galinié, „Tours de Grégoire, Tours des archives du sol“, in: N.Gauthier and H.Galinié (Hgg.), Grégoire de Tours et l'espace gaulois, Tours, 6580 . 
Galinié (ed.) (2007): Henri Galinié, „Tours antique et médiéval, lieux de vie, temps de la ville, 40 ans d'archéologie urbaine, Tours.

Gauthier (1999): Nancy Gauthier, „La topographie chrétienne entre idéologie et pragmatisme", in: G.P.Brogiolo and B.Ward-Perkins, The idea and ideal of the town between late antiquity and the early middle ages (Transformation of the Roman World, 4), Leiden, 195-209.

Gauthier (2000): Nancy Gauthier, „Le réseau de pouvoirs de l'évêque dans la Gaule du haut Moyen-Âge“, in: G.P.Brogiolo, N.Gauthier and N.Christie, Towns and their territories between late Antiquity and the early Middle Ages (Transformation of the Roman World, 9), Leiden, 173-208.

Gauthier et al. (1986-2007): Nancy Gauthier, Jean-Charles Picard, Brigitte Beaujard and Françoise Prévot: Topographie chrétienne des cités de la Gaule des origines au milieu $d u$ VIIIe siècle, 15 vols., Paris.

Goffart (1982): Walter Goffart, „Old and new in Merovingian taxation“, Past and Present $96,3-21$.

Goffart (2008): Walter Goffart, „Frankish military duty and the fate of Roman taxation', Early Medieval Europe 16, 166-190.

Guyon (2000): Jean Guyon, „Toulouse, la première capitale du royaume wisigoth“, in: G.Ripoll and J.-M.Gurt (Hgg.), Sedes regiae (ann. 400-800), Barcelona, 219-240.

Guyon (2006): Jean Guyon, „La topographie chrétienne des villes de la Gaule“, in: J.U.Krause and Christian Witschel (Hgg.), Die Stadt in der Spätantike - Niedergang oder Wandel?, Stuttgart, 105-128.

Guyon et al. (1998): Jean Guyon, Nuria Nin, Lucien Rivet and Sylvie Saulnier, Atlas topographique des villes de Gaule méridionale, 1, Aix-en-Provence, Montpellier.

Halsall (1996): Guy Halsall, „Towns, societies and ideas: the not-so-strange case of late Roman and early Merovingian Metz", in: N.Christie and S.T.Loseby (Hgg.), Towns in transition: urban evolution in late antiquity and the early middle ages, Aldershot, $235-261$.

Halsall (2003): Guy Halsall, Warfare and society in the barbarian west, 450-900, London.

Halsall (2007): Guy Halsall, Barbarian migrations and the Roman West, 376-568, Cambridge.

Harries (1994): Jill Harries, Sidonius Apollinaris and the fall of Rome, Oxford.

Heijmans, M. (2004): Arles durant l'Antiquité tardive. De la Duplex Arelas à l'Urbs Genesii, (Collection de l'Ecole française de Rome, 324), Rome.

Heijmans (2006): Marc Heijmans, „La mise en défense de la Gaule méridionale aux IVeVIe s.“, Gallia 63, 59-74.

Heinzelmann (1976): Martin Heinzelmann, Bischofsherrschaft in Gallien, München.

Heinzelmann (1988): Martin Heinzelmann, „Bischof und Herrschaft vom spätantiken Gallien bis zu den karolingischen Hausmeiern. Die institutionellen Grundlagen“, in: F.Prinz (Hg.), Herrschaft und Kirche, Stuttgart, 23-82.

Hen (1995): Yitzhak Hen, Culture and religion in Merovingian Gaul, AD 481-751, Leiden.

Henning (2007): Joachim Henning, „Early European towns: the development of the economy in the Frankish realm between dynamism and deceleration, AD 500-1100“, in: J. Henning (Hg.), Post-Roman towns, trade and settlement in Europe and Byzantium, I: the heirs of the Roman West, Berlin/New York, 3-40.

Innes (2000): Matthew Innes, State and society in the early Middle Ages. The middle Rhine valley, 400-1000, Cambridge. 
James (1983): Edward James, „Beati pacifici: bishops and the law in sixth-century Gaul“, in: J.Bossy (Hg.), Disputes and settlements. Law and human relations in the west, Cambridge, 25-46.

James (1988): Edward James, The Franks, Oxford.

Johnson (1983): Stephen Johnson, Late Roman fortifications, London.

Jones (1964): Arnold H. M. Jones, The later Roman empire, 284-602. A social, economic, and administrative survey, 3 Bde., Oxford.

Jussen (1995): Bernhard Jussen, Über Bischofsherrschaften und die Prozeduren politischsozialer Umordnung in Gallien zwischen Antike und Mittelater", Historische Zeitschrift 260, 673-718.

Jussen (2000): Bernhard Jussen, Spiritual kinship as social practice. Godparenthood and adoption in the early middle ages (tr. P.Selwyn), Newark, DE.

Jussen (2001): Bernhard Jussen, „Liturgy and legitimation, or how the Gallo-Romans ended the Roman empire“, in: B. Jussen (Hg.), Ordering medieval society. Perspectives on intellectual and practical modes of shaping social relations, Philadelphia, $147-199$.

Kaiser (1979): Reinhold Kaiser, „Steuer und Zoll in der Merowingerzeit“, Francia 7, 1-18.

Kaiser (1981): Reinhold Kaiser, Bischofsherrschaft zwischen Königtum und Fürstenmacht. Studien zur bischöflichen Stadtherrschaft im westfränkisch-französischen Reich im frühen und hohen Mittelalter, Bonn.

Kaiser (1990): Reinhold Kaiser, „Bistumsgründungen im Merowingerreich im 6. Jahrhundert", in: R.Schieffer (Hg.), Beiträge zur Geschichte des Regnum Francorum, Sigmaringen, 9-39.

Kelly (2004): Christopher Kelly, Ruling the later Roman empire, Cambridge, MA.

Kershaw (2011): Paul J.E. Kershaw, Peaceful kings: peace, power, and the early medieval political imagination, Oxford.

La Rocca (1994): Cristina La Rocca, „Castrum vel potius civitas. Modelli di declino urbano in Italia settentrionale durante l'alto medioevo“, in: R.Francovich and G.Noyé (eds.), La storia dell'alto medioevo italiano (VI-X secolo) alla luce dell'archeologia, Florenz, 545-54.

Laniado (2002): Avshalom Laniado, Recherches sur les notables municipaux dans l'empire protobyzantin, Paris.

Lauranson-Rosaz \& Jeannin (2001): Christian Lauranson-Rosaz and Alexandre Jeannin, „La résolution des litiges en justice durant le haut Moyen Âge: l'exemple de l'appenis à travers les formules, notamment celles d'Auvergne et d'Angers“, in: Le règlement des conflits au Moyen Âge, Paris, 21-33.

Lauwers \& Ripart (2007): Michel Lauwers and Laurent Ripart, „Représentation et gestion de l'espace dans l'occident médiéval (Ve - XIIIe siècle)“, in: J.-P.Genet (ed.), Rome et l'état moderne européen, Rome, 115-171.

Lebecq (1996): Stéphane Lebecq, „Le devenir économique de la cité dans la Gaule des Ve-IXe siècles“, in: C.Lepelley, (Hg.), La fin de la cité antique et le début de la cité médiévale de la fin du IIIe siècle à l'avènement de Charlemagne, Bari, 287-309.

Lebecq (2000): Stéphane Lebecq, „The role of the monasteries in the systems of production and exchange of the Frankish world between the seventh and the beginning of the ninth centuries“, in: I.L.Hansen and C.Wickham (Hgg.), The long eighth century. Production, distribution and demand (Transformation of the Roman World, 11), Leiden, 121-148 
Lepelley (1983): Claude Lepelley, „Quot curiales, tot tyranni. L'image du décurion oppresseur au Bas-Empire“, in: E.Frézouls (Hg.), Crise et redressement dans les provinces européennes de l'Empire, Strasbourg, 143-156.

Liebeschuetz, J. H. Wolf G. (2001): The decline and fall of the Roman city, Oxford.

Loseby (1996): Simon T. Loseby, „Arles in late Antiquity: Gallula Roma Arelas and urbs Genesii"“, in: N.Christie and S.T.Loseby (Hgg.), Towns in transition: urban evolution in late antiquity and the early middle ages, Aldershot, 45-70.

Loseby (1998a): Simon T. Loseby, „Gregory's cities: urban functions in sixth-century Gaul“, in: I.N.Wood (Hg.), Franks and Alamanni in the Merovingian period. An ethnographic perspective, Woodbridge, 239-270.

Loseby (1998b): Simon T. Loseby, „Marseille and the Pirenne thesis, I: Gregory of Tours, the Merovingian kings, and 'un grand port'“, in: R.Hodges and W.Bowden (Hgg.), The sixth century: production, distribution and demand, Leiden, 203-229.

Loseby (2000): Simon T. Loseby, „Urban failures in late antique Gaul“, in: T.R.Slater (Hg.), Towns in decline, AD 100-1600, 72-95.

Loseby (2006): Simon T. Loseby, „Decline and change in the cities of late antique Gaul', in: J.-U.Krause and Christian Witschel (Hgg.), Die Stadt in der Spätantike - Niedergang oder Wandel?, Stuttgart, 67-104.

Loseby (2009): Simon T. Loseby, „Mediterranean cities“, in: P.Rousseau (Hg.), A companion to late Antiquity, Oxford, 139-155.

Lot (1928): Ferdinand Lot, L'impôt foncier et la capitation personelle sous le bas-empire et à l'époque franque, Paris.

Mathisen (1993): Ralph W. Mathisen, Roman aristocrats in barbarian Gaul. Strategies for survival in an age of transition, Austin, TX.

Maurin (1992): Louis Maurin, „Remparts et cités dans les trois provinces du Sud-Ouest de la Gaule au Bas-Empire (dernier quart du IIIe siècle-début du Ve siècle)“, in: Villes et agglomérations urbaines antiques du sud-ouest de la Gaule: histoire et archéologie, Bordeaux (Aquitania, Supplement 6), 365-389.

Mazel (2009): Florian Mazel, „Cités, villes et campagnes dans l'ancienne Gaule de la fin du VIIIe siècle au milieu du XIe siècle", in: Città e campagna nei secoli altomedievali (Settimane di studio del centro italiano di studi sull'alto medioevo, 56), 337-390.

McCormick (1989): Michael McCormick, „Clovis at Tours, Byzantine public ritual and the origins of medieval ruler symbolism“, in: E.K.Chrysos and A.Schwarcz (Hgg.), Das Reich und die Barbaren, Köln/Wien, 155-180.

Murray (1986): Alexander C. Murray, „The position of the grafio in the constitutional history of Merovingian Gaul“, Speculum 64, 787-805.

Murray (1994): Alexander C. Murray, „Immunity, nobility, and the Edict of Paris“, Speculum 69, 18-39.

Nelson (2001): Janet L. Nelson, „Aachen as a place of power“, in: M.de Jong and F.Theuws, Topographies of power in the early middle ages, Leiden (Transformation of the Roman World 6), 217-241.

Pietri (1983): Luce Pietri, La ville de Tours du IVe au VIe siècle: naissance d'une cité chrétienne (Collection de l'École Française de Rome, 69), Rome.

Prinz (1974): Friedrich Prinz, „Die bischöfliche Stadtherrschaft im Frankenreich von 5 bis 7 Jahrhundert", Historische Zeitschrift 217, 1-35.

Rio (2009): Alice Rio, Legal practice and the written word in the early middle ages. Frankish formulae, c.500-1000, Cambridge. 
Rosenwein (1999): Barbara H. Rosenwein, Negotiating space. Power, restraint, and privileges of immunity in early medieval Europe, Manchester.

Rouche (1997): Michel Rouche, „Entre civitas et sedes regni: Grégoire de Tours et les espaces politiques de son temps", in: N.Gauthier and H.Galinié (Hgg.), Grégoire de Tours et l'espace gaulois, Tours, 179-184.

Samson (1987): Ross Samson, „The Merovingian nobleman's home: castle or villa?“, Journal of Medieval History 13, 287-315.

Scheibelreiter (1983): Georg Scheibelreiter, Der Bischof in merowingischer Zeit, Wien/Köln/Graz.

Schmiedt (1974): Giulio Schmiedt, „Città scomparse e città di nuova formazione in Italia in relazione al sistema di comunicazione“, in: Topografia urbana e vita cittadina nell'alto medioevo in occidente (Settimane di studio del centro italiano di studi sull'alto medioevo, 21), Spoleto, 503-608.

Schneider (2007): Laurent Schneider, „Structures du peuplement et formes de l'habitat dans les campagnes du sud-est de la France de l'Antiquité au Moyen Âge (IVe-VIIIe s.)“, Gallia 64, 11-56.

Schneider (2008): Laurent Schneider, „Aux marges méditerranéennes de la Gaule mérovingienne. Les cadres politiques et ecclésiastiques de l'ancienne Narbonnaise $I^{\mathrm{re}}$ entre Antiquité et Moyen Âge (Ve-IXe siècles)“, in: F.Mazel (Hg.), L'espace du diocèse. Genèse d'un territoire dans l'occident médiéval (Ve-XIIIe siècle), Rennes, 69-95.

Van Dam (1985): Raymond Van Dam, Leadership and community in late antique Gaul, Berkeley/Los Angeles/London.

Velázquez \& Ripoll (2000): Isabel Velázquez and Gisela Ripoll, „Toletum, la construcción de una urbs regia“, in: G.Ripoll and J.-M.Gurt (Hgg.), Sedes regiae (ann. 400-800), Barcelona, 521-578.

Verhulst (2000): Adriaan Verhulst, „Roman cities, emporia and new towns (sixth-ninth centuries)', in: I.L.Hansen and C.Wickham (Hgg.), The long eighth century: production, distribution and demand, Leiden, 105-120.

Ward-Perkins (1998): Bryan Ward-Perkins, „The cities“, in: A.Cameron and P.Garnsey (Hgg.), The Cambridge Ancient History, XIII: The late empire, A.D. 337-425, Cambridge, 371-410.

Weidemann (1982): Margarete Weidemann, Kulturgeschichte der Merowingerzeit nach den Werken Gregors von Tours, 2 vols., Mainz.

Wickham (2005): Chris Wickham, Framing the early middle ages. Europe and the Mediterranean, 400-800, Oxford.

Wickham (2009): Chris Wickham, „Bounding the city: concepts of urban-rural difference in the west in the early middle ages“, in: Città e campagna nei secoli altomedievali (Settimane di studio del centro italiano di studi sull'alto medioevo 56), 60-81.

Witschel (1999): Christian Witschel, Krise - Rezession - Stagnation? Der Westen des römischen Reiches im 3. Jahrhundert n. Chr., Frankfurt.

Witschel (2004/5): Christian Witschel, „Trier und das spätantike Städtewesen im Westen des römischen Reiches“, Trierer Zeitschrift 67/68, 223-272.

Wood (1983): Ian N. Wood, „The ecclesiastical politics of Merovingian Clermont“, in: P.Wormald, D.Bullough and R.Collins (Hgg.), Ideal and reality in Frankish and Anglo-Saxon society: studies presented to J.M.Wallace-Hadrill, Oxford, 34-55.

Wood, Ian N. (2002): „Constructing cults in early medieval France: local saints and churches in Burgundy and the Auvergne, 400-1000", in: A.Thacker and R.Sharpe (Hgg.), Local saints and local churches in the early medieval west, Oxford, 155-187. 
Woolf, G. (1998): Becoming Roman: the origins of provincial civilization in Gaul, Cambridge. 
IV.

ZWISCHEN AUßENSEITER UND RÖMISCHEM BÜRGER:

ZUR MODELLIERUNG VON RANDGRUPPEN

IM SPÄTANTIKEN GALLIEN 



\title{
Salvian and the Bacaudae
}

\author{
David Lambert
}

\section{The Bacaudae}

In 289 the Gallic orator Mamertinus, in a panegyric to Diocletian's junior colleague Maximian, described how, when Maximian first arrived in Gaul, he had had to fight farmers who took on the garb of soldiers, ploughmen who became foot-soldiers and shepherds who fought as cavalrymen. ${ }^{1}$ Mamertinus, writing in the elevated language of panegyric, does not use a vulgar term like 'Bacaudae', which first appears in fourth-century historical sources. ${ }^{2}$ After their appearance under Maximian we hear nothing of Bacaudae for more than a hundred years. Then, in the fifth century, they suddenly appear again.

Unlike the references to third-century Bacaudae, which all relate to a single incident, those from the fifth century are spread over several decades and widely separated locations, from the Alps in the first decade of the century to Spain in the $450 \mathrm{~s}^{3}$ As well as sources which mention Bacaudae by name, ${ }^{4}$ we have a number which do not use the word but have been identified by modern historians as referring to them. ${ }^{5}$ All the references to the Bacaudae have one characteristic, however: they are extremely brief. The only generalizations that can be drawn from them with certainty are that those they call Bacaudae were to be found in rural

1 Pan. Lat. X (II), 4, 3

2 Aur. Vict. Caes. 39, 17-20; Eutr. 9, 20, 3; Jerome, Chron. 2303. These, dating from the mid to late fourth century, are not, of course, primary sources in their own right. They all depend on the lost historical work known as the Kaisergeschichte, which itself probably dates from the mid 350s, and certainly no earlier than c. 337 (Burgess 1995).

3 Alps: Zos. Historia nova 6, 2, 5. Spain: Hyd. Chron. 117 [125], 120 [128], 133-134 [125126], 150 [158] (ed. Burgess).

4 Salvian, gub. 5, 21-26; Chron. Gall. a. 452, 117, 119, 133 and the works cited in n. 3 above.

5 Zos. 6, 5, 2-3; Rut. Nam. 1, 213-216; Anon. Querolus 30 (ed. Jacquemard-Le Saos, p. 19); Merob. Paneg. 2, 8-22, 148-186; Constant. Vita Germani 28, 40; Sidon. carm. 7, 246-248. The Zosimus, Rutilius Namatianus, and Querolus passages relate to Armorica in the first two decades of the fifth century; those from Merobaudes, Sidonius, and the Vita Germani to the 430 s and 440 s. 
areas and were engaged in some form of illegal violence. ${ }^{6}$ Those sources which refer to the background of the Bacaudae portray them as rustics: peasants or even slaves (such the Gallic Chronicle of 452, which uses the word servitia). ${ }^{7}$ Others are less specific: they merely depict individuals or groups engaged in violence and use the word 'Bacaudae' to refer to them, without defining it. ${ }^{8}$ Their rural character is unambiguous: no ancient source ever associates any element of the urban population with the Bacaudae. ${ }^{9}$ The aims behind their rebellion are not even hinted at in most of the sources, and some of those which have been held to be most indicative of them by modern historians (such as Rutilius Namatianus) may not refer to the Bacaudae at all. However, those sources which say something about their aims (notably Salvian and the Chronicle of 452) imply that they were hostile to the existing social order. ${ }^{10}$

For the most of the twentieth century, the view that the Bacaudae were peasants rebelling against the social system was accepted more or less without challenge. ${ }^{11}$ The best representation of this point of view in Anglophone scholarship can be found in the writings of E. A. Thompson. ${ }^{12}$ Thompson argued that the revolt of the Bacaudae was a direct response to the oppression and exploitation of peasants by landowners, and that the Bacaudae had a positive programme to overthrow and replace the established social system. ${ }^{13}$ Thompson's interpretation of the Bacaudae as a phenomenon of class conflict is faithful to their portrayal in many of the sources, but Thompson extended his claims far beyond what these sources actually attest. ${ }^{14}$ This is true of his claims about the geographical spread of the Bacaudae, ${ }^{15}$ about the utopian nature of their social aims, ${ }^{16}$ and that Bacau-

6 Sánchez León 1996a provides a full collection of the sources for the Bacaudae, together with extensive discussion of each text; for his discussion of the general problems relating to the sources, see pp. 19-22.

7 Chron. Gall. a. 452, 117.

8 This is the case with Hydatius' references to Bacaudae in mid fifth-century Spain, and Zosimus' reference to Bacaudae plundering Gothic federate troops in the Alps in 407 or 408 (n. 3 above).

9 For a discussion of the vocabulary used by ancient writers to describe the Bacaudae, see Sánchez León 1996b, 43-44. Cf. also Wickham 2005, 530.

10 Noted by Wickham 2005, 530-532.

11 The Bacaudae were, predictably, a major focus of publication by ancient historians in the Soviet bloc: references to a number of such publications can be found in SzádeczkyKardoss 1968. For similar perspectives in western scholarship, see e.g. Dockès 1980.

12 Chiefly Thompson 1952 and 1956 with reference to Gaul, and Thompson 1977 (repr. Thompson 1982, 161-187), with reference to Spain (though numerous other writings by Thompson touch on the Bacaudae).

13 Most forcefully at Thompson 1952, 18-20.

14 For critiques of Thompson's viewpoint see Okamura 1988, 288-293; Drinkwater 1984, 369-370; and of Marxist portrayals of the Bacaudae in general, Sánchez Léon 1996b, 7071.

15 See e.g. Thompson 1952, 17: 'Bearing in mind how scanty are our authorities for fifthcentury history and how reluctant they are to record the struggles of the oppressed classes, 
dic-type revolts took place as early as the second century. ${ }^{17}$

A wholly different interpretation of the Bacaudae was put forward in 1985 by Raymond Van Dam, who argued that they did not seek to rebel against either the local upper classes or the Roman state, but were the followers of local leaders who found themselves exercising power in times of disruption, insecurity, and the withdrawal of official government structures. ${ }^{18}$ Van Dam explained the implications of class-conflict in some of the primary sources as being purely rhetorical: an attempt by the imperial authorities to discredit these local leaders by portraying them as nothing but rebellious peasants or bandits. ${ }^{19}$ As for the reason why such discrediting should be necessary, Van Dam argued that in order to exercise power credibly at even a local level, leaders were obliged to adopt 'the vocabulary of imperial authority, ${ }^{20}$ thus inadvertently appearing to the imperial authorities as usurping emperors who had to be crushed, even though they themselves had no such intention. ${ }^{21}$

Van Dam's central idea, that the Bacaudae should best be interpreted not as a social revolutionary movement, but as a phenomenon produced by the weakening control of the centre over the periphery, has been accepted and built upon in subsequent research (primarily that of John Drinkwater). In the form in which Van Dam presented it, it was weakened by being attached to some untenable ideas, such as his claim that it was possible for those who exercised power at a local level to drift into becoming a rebel or usurper without intending it, a claim which is wholly at odds with the actual evidence relating to usurpation in late antiquity. ${ }^{22}$ Van Dam's claim that the depiction of the Bacaudae as rebels from the lower classes was merely an expression of propaganda against perceived usurpers also relies excessively on texts such as the panegyric of Mamertinus and does not take account of the fact that many of the authors who are most vocal about the Bacaudae - Salvian, the author of the Chronicle of 452, Constantius, Hydatius -

we need have little doubt that Spain and Gaul swarmed with peasants in open revolt as Western Imperial history drew towards its close.'

16 Thompson 1952, 18-19. Thompson's view is based on a literal interpretation of Rutilius Namatianus' De reditu suo 1, 215-216 and the Querolus. In both cases Thompson's interpretation can be challenged, and in the case of Rutilius' poem, the text of the relevant passage is questionable (on this see Bartholomew 1982; Lütkenhaus 1998, 104-107).

17 Thompson 1952, 12-15. Thompson argued that the revolts of Maternus and Bulla Felix in the second and third centuries (described respectively by Herodian 1, 10, 1-7, and Cass. Dio 76, 10) were essentially of the same kind as that of the Bacaudae. More recently, Thomas Grünwald has shown that the emphasis on social conflict in their accounts, emphasized by Thompson, is almost entirely a moralizing literary construction by Dio and Herodian themselves (Grünwald 2004, 110-136 and 162-164).

18 Van Dam 1985, 9-56.

19 Van Dam 1985, 7, 25-27, 46.

20 Van Dam 1985, 23.

21 See especially Van Dam 1985, 23-24; similarly 20, 27, 29-30, 36, 46.

22 On this point Van Dam is comprehensively refuted by Drinkwater 1989, 198-199. Cf. also Wickham 2005, 531. 
are provincial writers with no known links to court circles, whose work is difficult to interpret as an expression of imperial propaganda, or even a second-hand reflection of it. ${ }^{23}$

However, purged of these more dubious elements, Van Dam's observation that the Bacaudae are associated with the loss of effective power by the imperial government in peripheral areas, and the consequent devolution of power to local figures, reflects the wider historical context in fifth-century Gaul and Spain, and has an obvious plausibility. It has been developed by John Drinkwater, ${ }^{24}$ who has argued that in both the third and the fifth centuries the disruption caused by barbarian invasions and civil war affected parts of Gaul to such an extent that the structure of Roman administration was effectively destroyed, and the established upper class would have been largely removed with it, through withdrawal or dispossession, leading figures lower down the social order (at 'the highest feasible level' as Drinkwater puts it) to gain de facto local power. ${ }^{25}$ In some cases, such as Armorica in the early fifth century, this situation may have lasted for many years, leading to the situation becoming institutionalized. The reimposition of imperial control, involving the suppression of independent local leaders and the restoration of such burdens as taxation, would itself have provoked opposition. In other words, the Bacaudae drew both on popular support and the leadership of locally powerful figures, but their conflict with the Roman state was essentially reactive and defensive: neither an active rebellion against the Roman social system, as claimed by Thompson, nor a confused situation in which merely exercising local power made people look like rebels, as argued by Van Dam, but an attempt by the inhabitants of areas which had become autonomous to resist the reimposition of imperial rule and its burdens. The 1996 monograph on the Bacaudae by Juan Carlos Sánchez Léon, largely accepts the framework laid down by Drinkwater, though continuing to argue in favour of the idea that the Bacaudae wished actively to reject certain elements of Roman society (notably Roman law). ${ }^{26}$

One element that should be stressed about this picture of the context in which the Bacaudae appear is that it remains compatible with a strong element of social conflict. One of the most important features of the Roman administrative and taxsystem was that local elites were heavily implicated in it, and were themselves major beneficiaries from it. The removal of Roman power-structures from an area was therefore harmful to the interests of the local landowning elite, from whom it removed both a substantial source of income and the legal system which protected their property and their status as members of legally-privileged social groups such

23 Van Dam still has some advocates on this point: see e.g. Halsall 2007, 218, 244.

24 The key ideas are expressed at Drinkwater 1984, 367-368; Drinkwater 1989, 200; Drinkwater 1992, 215-217.

25 Drinkwater 1989, 200.

26 Sánchez Léon 1996b, 73-74, 78-80. 
as curiales (members of city councils) or honorati (former officials). ${ }^{27}$ Their interests were served by the rapid restoration of existing social and administrative structures; those whose interests were damaged by such a restoration, to the extent that they were prepared to resist it by force, would precisely be those who were among the losers in the existing social system. While this group need not have been confined to peasants, it is likely to have consisted of social groups well below the existing elite.

The clearest exposition of this feature of late-Roman society, and its relation to the Bacaudae is presented by Chris Wickham. ${ }^{28}$ Wickham agrees with Drinkwater and other recent researchers in placing the Bacaudae in the context of weakening control by the state, but argues that the true significance of this was that it facilitated revolt by peasants who would otherwise have been able to evade burdens such as taxation only by more passive means, such as flight or by seeking the protection of patrons. ${ }^{29}$ Wickham's is also the only account which points out the extent to which Salvian, the only ancient author who professes to diagnose the reasons for revolt by the Bacaudae, attributes it directly to the oppressiveness of the Roman tax-system. ${ }^{30}$ While it cannot necessarily be extended to the situation of the early fifth century, let alone to the Bacaudae of the $280 \mathrm{~s}$, this model seems to me to the one which most clearly fits the situation in the $430 \mathrm{~s}$ and $440 \mathrm{~s}$, the period when Salvian was writing.

\section{Salvian}

The longest single ancient account of the Bacaudae is to be found in De gubernatione dei, the tract on the fate of the Roman empire written in the early to mid 440 s by the Gallic priest Salvian. ${ }^{31}$ This fact is testimony in itself to the sparseness of the sources, since Salvian's discussion fills little more than a page of text in a modern printed edition. ${ }^{32}$ Furthermore, Salvian mentions the Bacaudae in the course of an argument focussed on other issues, and in which accurately describing their identity was not a priority.

27 Cf. Wickham 2005, 168: 'The aristocracies of the empire, both central and local, were too imbricated with the state, from which they derived all their essential distinguishing marks, not to be altered totally when the state changed.'

28 Wickham 2005, 527-533.

29 Wickham 2005, 529, 532.

30 Wickham 2005, 532; cf. also 62-64.

31 I cite De gubernatione dei from the Sources Chrétiennes edition, edited by G. Lagarrigue (Paris 1975).

32 Salvian's specific discussion of the Bacaudae occurs at Salvian, gub. 5, 21-26, but it forms part of a wider discussion $(5,17-45)$ of the social consequences of Roman taxation, and can only be understood in this context. 
The central argument of De gubernatione dei is that the barbarian invasions were a punishment inflicted by God on the Roman people for their sins. ${ }^{33}$ This claim rests on a number of presuppositions. One is the idea that Christian society had declined from a previous state, in which Christians had striven sincerely to obey all God's commandments, into the corrupt and sinful society of Salvian's own time. Salvian makes remarks about this idealized past which show that he placed it in the early Christian period. ${ }^{34} \mathrm{He}$ presents no historical account of how Christian society had changed from one state to another, but merely juxtaposes the present and the past. Salvian also juxtaposes an idealized Roman past with the present, in a manner parallel to that of his treatment of the Christian past. ${ }^{35}$ As with the church, he uses conventional images of the moral superiority of the early Romans in order to provide a contrast with the corruption he portrays in present day society; once again, he juxtaposes the present state of Roman society with what had existed in the past, without giving any account of how and when it had changed from one state to another. ${ }^{36}$

Finally, Salvian's argumentation in the later books of De gubernatione dei rests on a contrast between the corruption of the Romans and the superior morality of the barbarians, especially the Goths and the Vandals. At the time when Salvian wrote, these were the only two barbarian peoples in the West which had adopted Christianity, and they were also the ones which had been most successful in conquering territory from the Romans. Salvian repeatedly uses the barbarians as an ideal to be held against the Romans: they carry out the demands of Christianity in the way that the Romans no longer do. ${ }^{37} \mathrm{I}$ have argued elsewhere that Salvian's portrayal of the barbarians is determined by his belief that the growth of their power at Roman expense was only explicable by their role as God's instruments, and that God's favour proved their worthiness. ${ }^{38} \mathrm{He}$ is, however, very much alive to the more traditional use of the comparison of barbarians and Romans as a piece of provocative rhetoric.

In order to demonstrate that the barbarian invasions were a punishment for the Romans' sins, Salvian devotes most of De gubernatione dei to an exposition of these sins. After an introductory section focussed mainly on the issue of divine punishment in the Bible (De gub. 1-2), Salvian builds up his argument in an episodic fashion, denouncing a particular sin, portraying it as ubiquitous in the Ro-

33 Stated directly at e.g. Salvian, gub. 4, 54 .

34 E.g. Salvian, gub. 3, 22.

35 See Salvian, gub. 1, 10-12; 6, 50-52, 98-99; 7, 2, as well as the passage in Book 5 under discussion.

36 For discussions of Salvian's treatment of Roman history, see Badewien 1980, 117-121; Inglebert 1996, 660-661; Lambert 1999, 125-126.

37 Salvian's portrayal of the barbarians is the subject of a large, but now mostly obsolete literature. The best treatment of the general character of his portrayal is Maas 1992; for a discussion going into more detail about his argumentation, see Lambert 2000. References to older literature can be found in these articles and in Badewien 1980, 127-138.

38 Lambert 2000, 110-113. 
man world, and then moving on to the next one. Hence Book 3 focuses on various everyday (but, Salvian would say, no less serious) sins such as lying and stealing, Book 4 on swearing oaths and various forms of impiety, Book 5 on social injustice, Book 6 on the games and the theatre. As the work progresses, Salvian devotes a steadily greater amount of attention to the contrast between Romans and barbarians, an issue which is left in the background in the early books, but becomes absolutely central from Book 5 onwards, until in Books 7 and 8, his argument is based entirely on direct comparisons between the morality of the Romans and that of the Goths and Vandals. Salvian's attacks on social oppression and injustice therefore have the same function in the overall structure of De gubernatione dei as his denunciations of swearing oaths $(4,71-77)$ or going to the theatre $(6,10-38)$ : they illustrate the extent of Roman sinfulness. Book 5 is the only book of De gubernatione dei which focuses on social injustice, though there are brief discussions of the issue in other books. ${ }^{39}$

\section{Salvian's immediate historical context}

Salvian was writing in the early 440s, in the aftermath of the fall of Carthage to the Vandals, and the defeat by the Goths of the Roman general Litorius, the last datable events mentioned in De gubernatione dei, which both occurred in 439 (De gub. 6, 68-9; 7, 39-45; 7, 94). His work is therefore roughly contemporary with the Bacaudic revolt (or revolts) in Armorica in the 430s and 440s mentioned in the anonymous Gallic Chronicle of 452 and in the life of Germanus of Auxerre by Constantius of Lyon. ${ }^{40}$ The chronological framework has to be taken from the Chronicle, which states that in the twelfth regnal year of Valentinian III (equivalent to A.D. 435) 'Gallia ulterior' seceded from unity with the Roman empire under a leader named Tibatto, and that beginning from that territory, almost all the slaves (servitia) of Gaul conspired in a Bacaudic revolt. ${ }^{41}$ Two years later it states that the revolt of the Bacaudae (commotio Bacaudarum) had been suppressed, Tibatto captured and the other leaders taken prisoner or killed, and that subsequently, with Gaul now pacified (there had also been wars with the Goths and Burgundians), Aetius had returned to Italy. ${ }^{42}$ Later it states, without mentioning the Bacaudae, that the lands of Gallia ulterior had been given by Aetius to the Alans, to divide with the inhabitants, but that when there was resistance

39 Salvian, gub. 3, 50-55; 4, 29-31; 7, 91-93.

40 Chron. Gall. a. 452, 117, 119, 133; Constant. Vita Germani 28, 40.

41 Chron. Gall. a. 452, 117: Gallia ulterior Tibattonem principem rebellionis secuta a Romana societate discessit, a quo tracto initio omnia paene Galliarum servitia in Bacaudam conspiravere. The author uses the noun Bacauda to denote the whole revolt rather than an individual rebel.

42 Chron. Gall. a. 452, 119, 123. 
against them they had expelled the landowners and taken possession by force. ${ }^{43}$ Finally, in about 448, it states that Eudoxius, a doctor, described as having 'wicked but able talents' had fled to the Huns after taking part in a Bacaudic rebellion. ${ }^{44}$

These details are filled out to some extent by the life of Bishop Germanus of Auxerre, written by Constantius of Lyon in the 470s. This refers to a revolt in Armorica, which caused Aetius to turn the region over to be ravaged by the Alans, only for Germanus to intervene and dissuade the Alan king from acting. ${ }^{45}$ Germanus subsequently travels to Italy to persuade Aetius or the emperor to spare Armorica (a journey which is associated by Constantius with an attempt by Germanus to gain a remission of taxes). ${ }^{46}$ Constantius declares that he would have succeeded, except that at the last moment, the 'fickle and undisciplined people' renewed their previous rebellion as a result of 'the perfidy of Tibatto'. ${ }^{47}$ The Vita Germani provides no explicit dates in its narrative at all, but from internal evidence the latter events are usually dated to about 448, so are contemporary with the revolt mentioned by the Chronicle which involved the doctor, Eudoxius. A further source which is much less circumstantial in its reference to events, but is contemporary, is Merobaudes' second panegyric to Aetius, delivered in 446, which refers in general terms to a revolt in Armorica which had now been suppressed. $^{48}$

It will be evident that the precise chronology of these events is uncertain, and there are a number of possible inconsistencies in the accounts of different sources. ${ }^{49}$ These are issues which are still disputed, and it is not my intention to try to resolve them here. ${ }^{50}$ The evidence is substantial enough, however, to show that Salvian was writing in a period during which there were repeated revolts in Armorica or Gallia ulterior which the sources attribute to the Bacaudae. Salvian does not give any information about the events of these revolts or the individuals involved, confining himself to making generalizations about the motives of the Bacaudae, but the events must form the background to his text: in writing about the Bacaudae, Salvian is not describing a timeless phenomenon, though his treatment tends to suggest this, but an urgent contemporary event.

43 Ibid., 127.

44 Ibid., 133.

45 V. Germ. 28

46 V. Germ. 19, 24.

47 V. Germ. 40: nisi Tibattonis perfidia mobilem et indisciplinatum populum ad rebellionem pristinam reuocasset.

48 Merobaudes, Panegyricus Aetii 2, 8-15. There is also a very brief reference by Sidonius Apollinaris to a revolt in Armorica: Carmina 7, 246-248.

49 For an attempted reconstruction, see Wood 2000, 533-534.

50 See, especially on chronology, Mathisen 1981; Thompson 1984, 62-65; Barrett 2009. 
By far the greater part of Salvian's social criticism in Book 5 of De gubernatione $d e i$ is directed at the Roman tax-system and its consequences $(5,17-45) .{ }^{51}$ Salvian's account of the Bacaudae $(5,19-26)$, forms part of this attack, as does his account of rural patronage and the plight of the coloni $(5,38-45)$. These issues are often discussed in isolation, but it cannot be emphasized too strongly that both are presented by Salvian as consequences of the operation of the tax-system. ${ }^{52}$

Salvian begins by claiming that the tax-system is exploited by those who turn public taxation into their own private gain $(5,17,25)$. He names those responsible for collecting taxes: at provincial level, governors and their staff (iudices and iudicibus obsequentes - 5, 17), at city level curiales, and especially the principales, the group of senior members of the curia who were responsible for organizing the collection of taxes in each city $(5,18$; cf. also 5,33$)$. They force the poor and weak to bear the taxes of the rich $(5,28-29)$. Salvian subsequently adds two more specific claims: that the rich impose additional exactions (munera and indictiones) on the poor in order to pay the expenses of envoys (nuntii, epistolarii) from the imperial government $(5,30-31)$, and that they prevent the poor from benefitting from remissions of unpaid tax $(5,34-35) .{ }^{53}$ Salvian insists again that all the injustices he has described are characteristic of the Romans but alien to the barbarians, as can be proved, he argues, by the fact that ordinary Romans prefer to live under barbarian rule $(5,36-37)$. Finally, Salvian goes on to claim that those small landowners who are unwilling to abandon their land and possessions have no protection against the depredations of the tax-collectors except to put themselves under the 'protection' of a powerful landowner, thus losing both their property and their free status $(5,38-45)$.

Salvian's specific claims about the abuses of the tax-system are embedded within lengthy passages of rhetorical development on the themes of the cruelty of those who benefit from the system, variously characterised as tyrants $(5,18)$, bandits $(5,18 ; 5,25-26)$, wild beasts $(5,18 ; 5,25)$, and murderers $(5.24,26)$, and of the weakness and vulnerability of their victims, characterised as widows and orphans $(5,18,21)$, sancti - in Salvian's usage this encompasses anyone who has devoted their life to religion $(5,18)$, and the poor $(5,21 ; 5,28-36 ; 38-39,42) .^{54}$ By utilising such rhetoric to the utmost, Salvian is able to convey a powerful image of Roman society as bitterly and cruelly divided, in which the strong prey

51 The end of Book $5(5,52-61)$ attacks priests who behave like secular potentes. The beginning of the book $(5,1-14)$ is a discussion of Gothic and Vandal Arianism, and is not directly relevant to what follows.

52 On Salvian and taxation, see Badewien 1980, 106-108; Lepelley 1983; Drinkwater 1992, 212-214; Wickham 2005, 8-9, 62-64, 86, 527-529, 532.

53 The general claim that the poor bear the taxes of the rich, and the more specific allegation that the rich ensure that only they and not the poor benefit from remission of taxes had been made briefly by Salvian in the preceding book $(4,30-31)$.

54 On what Salvian meant when he referred to pauperes, see Grey 2006. 
mercilessly on the weak: the opposite of the situation that should exist in this nominally Christian society. ${ }^{55}$ In structural terms, this deepens Salvian's general indictment of the sinfulness of Roman society, and emphasizes its contrast with the united society of the barbarians.

The hyperbole of Salvian's language is obvious. However, the references to actual officials and their roles in tax-collection which are embedded in his tirade appear to be factually accurate. ${ }^{56}$ Within the curial order, he notes the central role of the principales, who are named directly at 5,18 , and are almost certainly alluded to in a subsequent passage $(5,33)$ in which Salvian imagines an ordinary member of the curia complaining about the pauci potentes who take all the decisions. ${ }^{57}$ The principales were a group of the wealthiest and most senior members of the curia, who had overall supervision of its activities, and especially of the organization of tax-collecting. ${ }^{58}$ Salvian's claims about them reflect their power over the curia as a whole, and is reflected in the legal sources. ${ }^{59}$

Salvian also refers to the exactores $(5,28,43)$, who were the officials responsible for pursuing tax arrears, ${ }^{60}$ but came to gain greater responsibility for the administration of the whole process of tax-collection. ${ }^{61}$ Some evidence demonstrably shows exactores being drawn from the curiales, ${ }^{62}$ though the role may also have been taken by officials or ex-officials from the offices of provincial

55 On Salvian's paternalistic conception of social relations see Lambert 1999, 121-126.

56 The fundamental account of the assessment and collection of taxes in the later Roman empire remains Jones 1964, 448-469, 727-731. See also Delmaire 1989; Laniado 2002, 103-129; and for a discussion specific to Salvian's evidence, Lepelley 1983, 148-154. On the social consequences of Roman taxation, see Wickham 2005, 57-72, 527-529.

57 On the principales, see Jones 1964, 730-731 ("a kind of executive committee of the council, which tended to usurp its functions"), 757, 774; Lepelley 1983, 144 ("Ils jouaient un rôle essentiel dans l'établissement de l'assiette de l'impôt dans la cité, donc dans la repartition du fardeau fiscal entre les contribuables"); Laniado 2002, 201-211.

58 The supervisory role of the principales in tax-collection is stated by $C T h 8,15,5,3$, probably of 365 (officiales atque municipes, qui exactiones quascumque susceperint [...] insuper principales, a quibus distributionum omnium forma procedit). Other significant laws defining the role and privileges of principales include CTh 7, 6, 1 (365); 9, 35, 2 (376), 6 (399); 12, 1, 171 (412).

59 CTh 11, 16, 4 (328) refers to one of the issues about which Salvian complains, principales corruptly allotting the burden of munera to their own benefit. Other abuses by principales appear in CTh 12, 1, 79 (375); 12, 3, 2 (423); 13, 11, 10 (399) - this list is not exhaustive.

60 Major items of legislation regarding the duties (and abuses) of exactores are CTh 10, 17, 3 (392); 11, 1, 3 (336); 11, 1, 14 (372/374); 11, 7, 4 (327); 11, 7, 16 (401); 11, 7, 20 (412); 11, 26, 2 (400); 12, 6, 20 (386), 22 (386).

61 On exactores see Lepelley 1983, 144: "Si sa fonction spécifique était d'exiger le paiement des arrières d'impôt, il acquit rapidement une compétence plus large et devint le responsable municipal des affaires fiscales"; Delmaire 1989, 63: "tous les textes qui parlent avec précision de l'activité des exactores montrent qu'ils interviennent après la levée et après le collecteur, pour réclamer (exigere) les arriérés et les impayés."

62 As in the municipal album of Timgad, where two senior decurions are listed as exactores (Lepelley 1983, 144); also CTh 12, 6, 22 (386), which refers specifically to exactores being drawn from the curia. 
governors. ${ }^{63}$ The exactor's task of pursuing arrears in taxation self-evidently gave him particular scope for illicitly extracting wealth. ${ }^{64}$ The fact that the job was seen as a desirable one is attested by the fact that emperors had to legislate to limit the time it could be held, ${ }^{65}$ and (repeatedly) to prohibit imperial officials such as agentes in rebus and the staff of palatine ministries from undertaking it. ${ }^{66}$ While Salvian therefore directs some general rhetorical fire at the curia as a whole, his more specific claims identify the specific individuals who held the greatest power in the system and had the greatest capacity to manipulate it. ${ }^{67}$

The last set of officials singled out by Salvian for condemnation are the $i u$ dices, or provincial governors $(5,17,24-25) .{ }^{68}$ Governors had a general supervisory role in the collection of taxes and it must be this which Salvian primarily has in mind, given the context in which he refers to them. It is worth noting his complaint about the oppressive behaviour not merely of iudices but of iudicibus obsequentes $(5,17)$, in light of the suggestion by Delmaire that the staffs of governors' offices were directly involved in the exaction of tax arrears. ${ }^{69}$ However, the role of governors as judges is probably not absent from his mind, given the near ubiquity of complaints of judicial corruption in late-antique literature. ${ }^{70}$

Salvian's rhetoric in passages such as his attack on taxation and the role of curiales in tax-collecation has often been dismissed as hyperbole, and this is evidently true to an extent. ${ }^{71}$ But it should be noted that the terms in which he refers to abuses in the tax system are common not merely to much literature of the time, but to many of the laws themselves. ${ }^{72}$ Even language that appears merely to be rhetorical may have a more specific meaning: for example, when Salvian talks about 'those who make public taxation into private gain and fiscal debts into private profits' $(5,17,25)$, his language appears unspecific. ${ }^{73}$ However, it closely parallels the language of a law which condemns a particular abuse: the practice of tax-collectors or exactores lending poorer tax payers money to pay their taxes; a

63 Argued by Delmaire 1989, 63-64.

64 One of the powers specifically granted to exactores was to sell the land of fiscal debtors:

CTh 11, 7, 4 (327).

65 CTh 12, 6, 22 (386); Lepelley 1983, 151.

66 E.g. CTh 8, 8, 6 (395); 11, 7, 16 (401), 17 (408); 12, 10, 1 (373).

67 Lepelley 1983, 151-152, 154.

68 On governors in general, see Jones 1964, 374-401.

69 Delmaire 1989, 63-64.

70 On corrupt governors see Jones 1964, 399-401, 479. For a survey of the kinds of accusations of judicial malpractice and corruption made in the period, see Harries 1999, 153-171.

71 See e.g. Badewien 1980, 103, condemning Salvian's 'indiscriminate' attack on curiales.

72 In addition to the examples above, see CTh 8, 11: an entire title of the Theodosian Code relating to the levying of illicit charges for the expenses of envoys and messengers (Salvian, gub. 5, 30-31).

73 [...] quibus exactio publica peculiaris est praeda, qui fiscali debiti titulos faciunt quaestus esse privatos $(5,17)$; qui exactionis publicae nomen in quaestus proprii emolumenta verterunt et indictiones tributarias praedas suas esse fecerunt $(5,25)$. 
public debt then literally became a private debt, on which the lender could exact interest, and which was not cancelled out even if there was a remission of taxes. ${ }^{74}$

What should be emphasized in Salvian's attack, as regards the Bacaudae, is his insistence throughout that it is the oppressiveness and violence associated with the tax-system which have driven them to revolt, not, for example, the general treatment of tenants by landowners. It was the interaction between taxation and private power which drove people to revolt or to flee. ${ }^{75}$

\section{Salvian's account of the Bacaudae}

Salvian's attack on the fiscal system contains not merely an account of its evils, however, but of how its victims responded to it, a theme which he introduces at an early stage in the discussion:

5, 21: Inter haec uastantur pauperes, uiduae gemunt, orphani proculcantur, in tantum ut multi eorum et non obscuris natalibus editi et liberaliter instituti ad hostes fugiant, ne persecutionis publicae adflictione moriantur, quaerentes scilicet apud barbaros Romanam humanitatem, quia apud Romanos barbaram inhumanitatem ferre non possunt.

Among all this the poor are laid waste, widows groan, orphans are trampled down, to such an extent that many of them, including those who are not of obscure birth and have had a liberal education, flee to the enemy, so that they should not die through the affliction of public persecution. They seek Roman humanity among the barbarians because they cannot bear barbaric inhumanity among the Romans.

The first response to fiscal oppression, therefore, is simple flight to territory outside the control of the Romans (the most obvious candidate for such territory in Salvian's southern Gallic milieu being the Visigothic kingdom in Aquitaine). This point is reiterated by Salvian throughout his attack (the most notable passages being 5, 21-24 and 5, 36-37) and is used as one of the key items in his depiction of the sickness in Roman society. But after a brief discussion of the willingness of escaping Romans to put up with such cultural differences among the barbarians as different standards of personal hygiene $(5,21)$, Salvian introduces a new element:

5, 22: Itaque passim uel ad Gothos uel ad Bacaudas uel ad alios ubique dominantes barbaros migrant, et commigrasse non paenitet; malunt enim sub specie captiuitatis

74 CTh 11, 28, 10 (415): Indulgentiam [...] nonnulli visi sunt in suum compendium rapinamque convertere, ut fierent privata debita, quae fuerant publica. The indulgentia was a remission of outstanding taxes.

75 Cf. Wickham 2005, 64: "One does not have to believe Salvian as an accurate reporter to be struck by the fact that, for him, as for other writers, taxation defined and framed rural oppression. Contrast medieval societies, where such oppression was overwhelmingly seen as the work of unjust lords, not state officials, until well into the fourteenth century." 
uiuere liberi quam sub specie libertatis esse captiui. Itaque nomen ciuium Romanorum, aliquando non solum magno aestimatum sed magno emptum, nunc ultro repudiatur ac fugitur, nec uile tantum sed etiam abominabile paene habetur. 5, 23: Et quod esse maius testimonium Romanae iniquitatis potest quam quod plerique, et honesti et nobiles et quibus Romanus status summo et splendori esse debuit et honori, ad hoc tamen Romanae iniquitatis crudelitate compulsi sunt ut nolint esse Romani?

5, 22: So on all sides they migrate to the Goths, or the Bacaudae, or the other everywhere-dominant barbarians, and do not regret migrating; for they prefer to live free under the appearance of captivity than to be captives under the appearance of liberty. Thus the name of Roman citizen, once not only greatly valued but dearly bought, is now willingly repudiated and abandoned, and is considered not only worthless but even loathsome. 5, 23: And what greater testimony of Roman iniquity could there be than that very many people, both honourable and noble, and for whom Roman status should be the highest splendour and honour, are forced by the cruelty of Roman iniquity that they should be unwilling to be Roman?

The Bacaudae are therefore introduced as merely one facet of the wider phenomenon of flight to territories outside Roman control. Salvian introduces them in a way that seems to imply that they were an actual barbarian gens, like the Goths. ${ }^{76}$ This has been interpreted as a sign of carelessness or confusion. ${ }^{77}$ However, I believe it is a deliberate rhetorical choice by Salvian. By making the Bacaudae and the Goths comparable entities, it stresses that migrating to them brings the same benefits, but also the same loss: of citizenship and status as a Roman. The issue of Romans being driven out of their own state is one of the key items of Salvian's indictment, and the parallel drawn here helps to establish that. Salvian enlarges on this point in the next stage of his argument:

5, 23: Et hinc est quod etiam hi qui ad barbaros non confugiunt, barbari tamen esse coguntur: scilicet ut est pars magna Hispanorum et non minima Gallorum, omnes denique quos per uniuersum Romanum orbem fecit Romana iniquituas iam non esse Romanos. 5, 24: De Bacaudis nunc mihi sermo est, qui per malos iudices et cruentos spoliati, afflicti, necati, postquam ius Romanae libertatis amiserant, etiam honorem Romani nominis perdiderunt. Et imputatur his infelicitas sua, imputamus his nomen calamitatis suae, imputamus nomen quod ipsi fecimus. Vocamus rebelles, uocamus perditos, quos esse compulimus criminosos.

5, 23: And so it happens that even those who do not flee to the barbarians are forced to be barbarians: as it is with a great part of the Spanish and not the smallest part of the Gauls: all those indeed through the whole Roman world whom Roman iniquity

76 Of the three medieval manuscripts of De gubernatione dei (there are a number of latemedieval apographs which have no significance for establishing the text) two have Bacaudas in this sentence, and the third has Abagaudas, an obvious scribal error for Bacaudas or Bagaudas. There is no reason to believe that Salvian originally wrote the name of another barbarian gens here.

77 Drinkwater 1992, 209. 
has caused not to be Roman. 5, 24: It's about the Bacaudae that I am speaking now, who were despoiled, broken and murdered by bad and cruel judges, and after they had lost the right of Roman liberty, lost even the honour of the Roman name. And their own misery is blamed on them, we blame them for the name of their calamity, we blame them for the name which we ourselves made. We call them rebels, we call them depraved, those whom we compelled to be criminal.

Here Salvian defines the Bacaudae more closely: they are people who have not fled to the barbarians, but in some sense have been forced to become barbarians themselves. (What Salvian means by this will be discussed below.) Finally Salvian enlarges on the provocations that drove the Bacaudae to revolt:

5, 25: Quibus enim aliis rebus Bacaudae facti sunt nisi iniquitatibus nostris, nisi improbitatibus iudicum, nisi eorum proscriptionibus et rapinis qui exactionis publicae nomen in quaestus proprii emolumenta uerterunt et indictiones tributarias praedas suas esse fecerunt [...]. 5, 26: Ac sic actum est ut latrociniis iudicum strangulati homines et necati inciperent esse quasi barbari, quia non permittebantur esse Romani. Adquieverunt enim esse quod non erant, quia non permittebantur esse quod fuerant; coactique sunt uitam saltim defendere, quia se iam libertatem uidebant penitus perdidisse.

5, 25: For by what other things were the Bacaudae made except by our iniquities, except by the corrupt acts of governors, except by the proscriptions and rapine of those who have turned the name of public taxation into the spoils of private profit, and have made fiscal tax-assessments into their own booty [...]. 5, 26: And thus it has been brought about that the people strangled and killed through the robberies of the governors began to be like barbarians, because they were not being permitted to be Romans. They tolerated being what they were not, because they were not permitted to be what they had been; they were forced at length to defend their life, because they saw that they had already completely lost their liberty.

Salvian goes on to state that all the lower classes (he uses the quasi-legal term humiliores) would wish to become Bacaudae, and do not do so only because they are too weak $(5,26)$. With this, he ends his direct discussion of the Bacaudae. As noted above, he continues with his denunciation of the tax-system $(5,29-35)$, before ending his argument with a climactic restatement of his claim that the taxsystem has driven most Roman citizens to prefer to live under barbarian rule (5, 37-38), concluding with the political point that the Romans should not be surprised that they cannot conquer the Goths, if ordinary Roman people prefer to live under Gothic rule $(5,37)$.

Salvian then goes on to deal with coloni and rural patrocinium $(5,38-45)$. It is impossible to discuss this passage in detail within the scope of the present article, but two points should be made: first that Salvian also attributes the phenomenon of rural patrocinium to the tax-system (people seek the protection of powerful patrons in an attempt to escape from the demands of the tax-collectors); secondly, that the passage continues to develop the theme that people are being stripped of 
their status as Roman citizens: those who leave and become Bacaudae are turned into quasi barbari; those who stay and become coloni are turned into quasi slaves $(5,45)^{78}$

Salvian's discussion of the Bacaudae focuses rhetorically on one point, which he emphasizes again and again: the scandal that Roman citizens have been forced out of the Roman state and turned into aliens. ${ }^{79}$ Nonetheless, certain factual claims come through in his argument: one of the most interesting is that while he repeatedly stresses the poverty of those who flee, he makes reference to those who were well-born and educated $(5,21)$, and were et honesti et nobiles $(5,23)$. The latter phrase cannot possibly refer to people of a social position lower than the curial class; Salvian is often guilty of hyperbole as a writer, but it is unlikely that he would have invented a point like this outright. He clearly knew or believed that those who fled from Roman-controlled territory included not merely peasant smallholders, but larger-scale, even curial, property owners who were unable to defend their own possessions against more powerful and predatory figures. ${ }^{80}$

This should not be overemphasized as a key to the composition of the Bacaudae: ${ }^{81}$ Salvian's language does not necessarily imply that such people were typical of those fleeing to the barbarians and the Bacaudae, and he might have given the phenomenon undue emphasis in order to strike a stronger chord with his (presumably well-born and educated) audience. It should be contrasted with the language of the Chronicle of 452, which refers to Tibatto's supporters as servitia. This is almost certainly a contemptuous reference to the lower classes in general, rather than specifically to slaves, but shows what the chronicler considered to be the social composition of the Bacaudae. ${ }^{82}$ But it can be taken as evidence that flight from Roman-controlled territory included members of the existing propertied classes who had been impoverished or expropriated.

When Salvian refers in general terms to escaping to the barbarians or the Bacaudae, in a Gallic context, he must be referring to the Gothic kingdom in Aquitaine (he refers explicitly to the Goths in the passage: 5, 22), and to the areas of north-western Gaul with which the Bacaudae are associated in other sources. Throughout his account, Salvian portrays joining the Bacaudae and fleeing to barbarian territory as being parallel responses to oppression. While he begins by referring to the Bacaudae as if they were a barbarian gens $(5,22)$, he then writes of them as those who have not fled to barbarian territory, but are forced to be barbarians, and that they form "a great part of the Spanish and not the smallest

78 On Salvian's description of the plight of coloni, see Krause 1987; Grey 2006; Goffart 2009.

79 See especially Salvian's language in the passages quoted above from Salvian, gub. 5, 22 24.

80 For legislation discussing this kind of downward social mobility, see Nov. Maj. 7, 1 (458).

81 Cf. the remarks of Van Dam 1985, 43; Drinkwater 1992, 212-214.

82 Note that Salvian's rhetorical stress on citizenship would be impossible if the Bacaudae had been regarded as consisting, or largely consisting, of slaves. 
part of the Gauls" $(5,23)$. They have therefore not moved to what was recognized as barbarian territory, but had still become non-Romans, and by migrating to the places where they lived one could escape from the factors which made life intolerable under Roman rule. This implies that people were migrating to relatively well-defined areas, comparable to the territories occupied by the barbarians (though of course, not given the same kind of official recognition). These would presumably be the areas which were outside the control of the imperial regime as a consequence of the revolt(s) in Armorica described in the Chronicle of 452 and the Vita Germani.

\section{Salvian's use of the Bacaudae}

Salvian's purpose was not, of course, to pass on information about the Bacaudae, but to use the Bacaudae as support for his arguments about Roman sin and divine justice. The way he presents the Bacaudae is shaped by his own presuppositions, and by what he believed would influence his audience.

The most striking thing in these passages is the overwhelming stress on the issue of Roman identity. The first thing that this enables Salvian to do is to embark on an exercise in sustained irony by describing the process by which Romans escape oppression by Romans through taking refuge with barbarians $(5,21-$ $23,28,37)$. At a literary level, this plays on the traditional classical image of the barbarian in order to highlight the inversion of values that actually exists among the Romans. ${ }^{83}$ This is most obvious in the wordplay of the passage in which he considers the phenomenon of Romans fleeing to barbarian territory, and draws an antithesis between apud barbaros Romanam humanitatem and apud Romanos barbaram inhumanitatem $(5,21)$. Salvian is here indulging in a very traditional classical style of contrasting barbarians and Romans as a form of social criticism, even evoking the clichéd, image of the barbarians' foul-smelling clothes. ${ }^{84}$

However, the negative characteristics of the barbarians are morally neutral, unlike those of the principales, exactores, iudices and other Roman potentes. In their way of life the traditional differences between Romans and barbarians remain, but their moral qualities have been reversed. Hence Salvian's antithesis between humanitas and inhumanitas. It is this which traditional ideology held to be the essential distinction between Romans and barbarians, yet in real life they have become transposed. The moral order has been turned upside down.

It is in relation to the Bacaudae, however, that Salvian's stress on identity becomes most interesting. As we have seen, the heart of his argument about the Bacaudae is that Romans have been forced no longer to be Romans. They have been deprived of their identity, and, as Bacaudae, turned into something like a gens, equivalent to a barbarian group such as the Goths $(5,22)$. But what is most

83 Lambert 1999, 126.

84 Corporum atque induuiarum barbaricarum foetore dissentiant $(5,21)$. 
notable in Salvian's language is the intense significance he attaches to Roman identity as a particular status, with rights attaching to it, something that has slightly different connotations than the moral criticism implied by his antithesis of humanitas and inhumanitas.

This is the significance of another political term employed by Salvian in this passage, libertas. He defines life under the barbarians as libertas in the guise of captivity, while life under the Romans is slavery in the guise of freedom $(5,22)$. The Bacaudae seceded because they had already lost the ius Romanae libertatis, the right of Roman freedom $(5,24)$. In another inversion of the moral order, the freedom which ought to be synonymous with Roman status is lost by those who remain Roman: under the oppression of the potentes they are reduced to a state indistinguishable from slavery or captivity by the enemy $(5,26)$; those who are too weak to join the Bacaudae are reduced as coloni to a condition close to literal slavery $(5,38-45)$. The free - Romans in the Roman empire - are reduced to slavery; the only way in which they can achieve freedom is voluntarily to live under barbarian rule, or else to join the Bacaudae and endure being deemed rebels and quasi barbari $(5,24,26)$.

The emotional weight with which Salvian invests these traditional Roman political concepts is considerable. He emphasizes the fact that those who flee Roman territory or become Bacaudae lose the honour of the Roman name, honorem Romani nominis $(5,24)$, the name of Roman citizens, nomen ciuium Romanorum $(5,22)$. It is this which he chooses to highlight rather than any more practical losses that people experienced through such emigration. A particularly noticeable element of Salvian's rhetoric is his stress on citizenship. It is unusual to find citizen status being given such rhetorical emphasis at this period. The precise function and social role of Roman citizenship in the fifth century is an issue which remains in some obscurity. Since the Constitutio Antoniniana of 212, almost all free inhabitants of the empire had been Roman citizens. ${ }^{85}$ Many studies of Roman citizenship simply stop at this point, on the basis that the status was no longer significant. ${ }^{86}$ The traditional view of the situation after 212 is that citizen status as such became insignificant by comparison with other legally defined status-groups within Roman society. ${ }^{87}$ In fact, closer scrutiny of late-Roman law and society suggests that even if gaining or losing Roman citizenship no longer had the vital importance that it had under the Republic or early empire, it was by no means without practical significance even in Salvian's day. ${ }^{88}$

It is clear that for Salvian the moral implication of being a Roman citizen are much more important that any practical issues relating to citizenship. References

85 Sherwin-White 1973, 386-394.

86 Cf. Garnsey 2004, 140: "For some modern observers, it was all over for Roman citizenship after Caracalla's edict."

87 See e.g. Liebeschuetz 1998, especially 136-138.

88 See especially Garnsey 2004; Mathisen 2006; on more specialised issues Demougeot 1981; Mathisen 2009; and on religious and cultural factors, Inglebert 2002. 
to citizenship in the political rhetoric of the fourth and fifth centuries use it primarily as a sign of Roman identity in contrast to the barbarians. ${ }^{89}$ For Salvian it is useful precisely because it crystallized the boundary between Romans and barbarians, and thereby emphasized the scandal that the nature of the boundary was being reversed. Furthermore, the status of citizen implied that each individual, however humble, had a certain stature and dignity within society; it is in this sense that it is tied directly to the concept of libertas. ${ }^{90}$ It is this aspect of the idea of citizenship which has the greatest emotional force for Salvian, because of the way in which it is affronted by the powerful, who strip their fellow-citizens of this stature and treat them as little more than prey. ${ }^{91}$

There is a final nuance to Salvian's references to Roman citizenship. His reference to citizenship as something that was once greatly valued and dearly bought $(5,22)$ shows that he is looking backwards in this passage to earlier periods of Roman history in which citizen status was something desirable in itself. Though it is not directly expressed, behind Salvian's language in this passage is an idealised vision of the Roman past, in which all citizens were free, and Romans did not prey on each other as they do in the society from which the Bacaudae are driven out. Salvian's language when writing about the Bacaudae, the terms in which he conceptualised and wrote about what they had lost, therefore reflect his implicit view of Roman history as a story of a decline from a just and virtuous past. This is expressed elsewhere in De gubernatione dei, but never with the emotional force that it has here. ${ }^{92}$ The knowledge of Roman history shown by Salvian in his works is limited, and is confined almost entirely to standard exempla from the Roman republic which were commonplace in literary education. ${ }^{93}$ In this, he is typical of late-antique Latin writers in general, both Christian and secular. ${ }^{94}$ But Salvian shows here, in the use he makes of this idealized and apparently insubstantial image of the past, how powerful it could still be as a source of moral and social criticism.

89 On this see Lepelley 1992, 943, 945-946; Inglebert 2002, 251-252.

90 'Libertas primarily denotes the status of a 'liber', i.e. a person who is not a slave, and comprises both the negation of the limitations imposed by slavery and the assertion of the advantages deriving from freedom" (Wirszubski 1950,1).

91 Salvian is not entirely alone in pursuing this theme, which can be found even in laws: see especially Nov. Val. 1, 3, 2 (450). Another important instance is Augustine, Ep. 10*, on the seizure of poor people in Africa by slave traders (note especially Ep. 10*, 5: pro libertate Romana [...] quis resistit?); see Lepelley 1992, 946.

92 Salvian, gub. 1, 10-12; 6, 50-52, 98-99; 7, 2.

93 For discussions of Salvian's use of Roman history, see Badewien 1980, 117-121; Inglebert 1996, 660-663, 668-669.

94 On this tendency in secular literature, see Nixon 1990. 


\section{Conclusion}

All Salvian's arguments and statements about the Bacaudae, flight to the barbarians, and the horrors of the late Roman tax system, are made in order to support his claims about the corruption and cruelty of the Roman ruling class, and furthermore to support the contrast which he wants to make between barbarians and Romans, between those who love one another and those who prey upon and persecute one another. Salvian's ideal is not an egalitarian society, but one in which the possessors of wealth and power care for those they have power over in a paternal fashion. ${ }^{95}$ The rhetoric of poverty is an extremely powerful one for a Christian writer, and it is one which Salvian uses to the full here, though in the process it becomes clear that for him the poor include marginal and downwardly-mobile members of the propertied class. His stress on the loss of Roman identity serves his overall rhetorical purpose by giving the strongest possible impression of a society which is morally disordered and divided against itself. But Salvian's argument also conveys profound nostalgia for an imagined past in which Roman status was something to be coveted and to be a citizen was to be free and secure. However little practical significance citizen status had in the day-to-day life of fifth-century Gaul, the concept of Roman citizenship was one that for Salvian at least, retained immense emotional and rhetorical power.

As for the Bacaudae, while it is always prudent to remember that Salvian is using them for his own rhetorical ends, and that his account cannot be taken as a straightforward account of reality, ${ }^{96}$ close examination of his claims makes clear that he at least believed that they were responding not to the general oppression of the poor and landless by the propertied, but to the very specific nexus between state power and private self-interest represented by the Roman tax-system, a nexus from which escape had become possible through the political fragmentation of Gaul and the weakening of the effective power of the Roman government which went with it.

\section{Bibliography}

\section{Primary sources}

Anonymus, Querolus - Aulularia: Querolus (Aulularia). Le Grincheux (comédie de la petite marmite). Texte établi et trad. par Cathérine Jacquemard-Le Saos (Collection des universités de France. Série latine 319), Paris 1994.

Aurelius Victor, Liber de Caesaribus: Sexti Aurelii Victoris liber de Ceasaribus, rec. Franz Pichlmayr, iterum collegit et adiecit Roland Gründel, Lipsiae 1970.

Cassius Dio, Historia Romana: Dio's Roman history: in nine volumes, ed. and with an English transl. by Earnest Cary (LCL), London 1968-1970.

95 See, in general terms, Lambert 1999; Grey 2006.

96 Cf. Wickham 2005, 8-9, 64. 
Chronica Gallica a. 452: Chronica minora saeculi IV, V, VI, VII, rec. Theodor Mommsen (MGH Auct. ant. 9), Berlin 1892, 615-666.

Constantius, De vita Germani: Constance de Lyon, Vie de Saint Germain d'Auxerre. Introduction, traduction, texte critique et notes par René Borius (SC 112), Paris 1965.

Eutropius, Breviarium ab urbe condita: Eutropii Breviarium ab urbe condita, recogn. Carolus Santini, Leipzig 1979.

Herodian, Ab excessu divi Marci libri octo: Herodian. With an English translation by Charles R. Whittaker, 2 vol., London 1969-1970.

Hydatius, Chronicon: The ,Chronicle of Hydatius' and the ,Consularia Constantinopolitana': two contemporary accounts of the final years of the Roman Empire. Edited with an English Translation by Richard W. Burgess, Oxford 1993.

Jerome (Hieronymus), Chronicon: Eusebius, Werke, Bd. 7, 1: Die Chronik des Hieronymus. Hieronymi Chronicon, hg. u. berarb. von Rudolf Helm (GCS 47), Berlin ${ }^{2} 1956$.

Flavius Merobaudes, Panegyricus II: Fl. Merobaudis reliquiae, Blossii Aemilii Dracontii carmina, Eugenii Toletani episcopi carmina et epistulae, ed. Friedrich Vollmer (MGH Auct. ant. 14), Berlin 1905, 11-18.

Novellae Maioriani: Theodosiani libri XVI cum constitutionibus Sirmondianis et leges novellae ad Theodosianum pertinentes, edd. Theodor Mommsen, Paul M. Meyer u. Paul Krüger, vol. 2, Berlin 1905, 155-178.

Novellae Valentiniani: Theodosiani libri XVI cum constitutionibus Sirmondianis et leges novellae ad Theodosianum pertinentes, edd. Theodor Mommsen, Paul M. Meyer u. Paul Krüger, vol. 2, Berlin 1905, 69-154.

XII Panegyirici Latini, recogn. brevique adnotatione critica instr. Roger A. B. Mynors, Oxford 1964.

Rutilius Namatianus, De reditu suo: Rutilius Namatianus, Sur son retour, texte établi et trad. par Étienne Wolff, Paris 2007.

Salvian, De gubernatione dei: Salvien de Marseille, Euvres, t. 2 : Du gouvernement de Dieu. Introduction, texte critique, traduction et notes par Georges Lagarrigue (SC 220), Paris 1975.

Sidonius Apollinaris, Carmina: Sidoine Apollinaire, Euvres, t. 1: Poèmes. Texte établi et traduit par André Loyen, Paris ${ }^{3} 2008$.

Zosimos, Historia nova: Zosimus, New History. A Translation with Commentary by Ronald T. Ridley (Byzantina Australiensia 2), Canberra 1984.

\section{Secondary sources}

Badewien (1980): Jan Badewien, Geschichtstheologie und Sozialkritik im Werk Salvians von Marseille, Göttingen.

Barrett (2009): Anthony A. Barrett, „Saint Germanus and the British Missions“, in: Britannia 40, 197-217.

Burgess (1995): Richard W. Burgess, „On the Date of the Kaisergeschichte“, Classical Philology 90, 111-128.

Delmaire (1989): Roland Delmaire, „Cités et fiscalité au Bas-Empire: A propos du rôle des curiales dans la levée des impôts", in: C. Lepelley (Hg.), La fin de la cité antique et le début de la cité médiévale de la fin du III siècle à l'avènement de Charlemagne, Bari, 59-70.

Demougeot (1981): Emilienne Demougeot, „Restrictions à l'expansion du droit de cité dans la seconde moitié du IV siècle“, in: Ktema 6, 381-393. 
Dockès (1980) : Pierre Dockès, „Révoltes Bagaudes et ensauvagement“, in: P. Dockès and J.-M. Servet, Sauvages et ensauvagés, Lyon, 143-261.

Drinkwater (1984): John F. Drinkwater, „Peasants and Bagaudae in Roman Gaul“, in: Échos du monde classique/Classical Views 28, 349-371.

Drinkwater (1989): John F. Drinkwater, „Patronage in Roman Gaul and the Problem of the Bacaudae“, in: A. Wallace-Hadrill (Hg.), Patronage in Ancient Society, London, 189-203.

Drinkwater (1992): John F. Drinkwater, „The Bacaudae of fifth-century Gaul“, in J. Drinkwater and H. Elton (Hgg.), Fifth-Century Gaul: A Crisis of Identity?, Cambridge, 208-217.

Garnsey (2004): Peter Garnsey, „Roman Citizenship and Roman Law in the Later Empire", in: S. Swain and M. Edwards (Hgg.), Approaching Late Antiquity: The Transformation from Early to Later Empire, Oxford, 133-155.

Goffart (2009): Walter Goffart, „Salvian of Marseille and the 'Colonate' Problem”, in: L'Antiquité Tardive 17, 269-288.

Grey (2006): Cam Grey, ,Salvian, the ideal Christian community and the fate of the poor in fifth-century Gaul", in: M. Atkins and R. Osborne (Hgg.), Poverty in the Roman World, Cambridge, 162-182.

Grünwald (2004): Thomas Grünwald, Bandits in the Roman Empire: Myth and Reality, trans. J. Drinkwater, London.

Halsall (2007): Guy Halsall, Barbarian Migrations and the Roman West, 376-568, Cambridge.

Harries (1999): Jill Harries, Law and Empire in Late Antiquity, Cambridge.

Inglebert (1996) : Hervé Inglebert, Les Romains chrétiens face à l'histoire de Rome. Histoire, christianisme et romanités en Occident dans l'Antiquité tardive (III $I^{e} V^{e}$ siècles), Paris.

Inglebert (2002): Hervé Inglebert, „Citoyenneté romaine, romanités et identités romaines sous l'Empire", in: H. Inglebert (Hg.), Idéologies et valeurs civiques dans le monde romain. Hommage à Claude Lepelley, Paris, 241-260.

Jones (1964): Arnold H. M. Jones, The Later Roman Empire, 284-602. A Social, Economic, and Administrative Survey, Oxford.

Krause (1987): Jens-Uwe Krause, Spätantike Patronatsformen im Westen des Römischen Reiches, Munich.

Lambert (1999): David Lambert, „The Uses of Decay: History in Salvian's De Gubernatione Dei“" in: Augustinian Studies 30, 115-130.

Lambert (2000): David Lambert, „The Barbarians in Salvian's De Gubernatione Dei“, in: G. Greatrex and S. Mitchell (Hgg.), Ethnicity and Culture in Late Antiquity, London, $103-115$.

Laniado (2002): Avshalom Laniado, Recherches sur les notables municipaux dans l'Empire protobyzantin, Paris.

Lassandro (1981-82): Domenico Lassandro, „Le rivolte bagaudiche nelle fonti tardoromane e medievali: aspetti e problemi (con appendice di testi)“, in: Invigilata Lucernis 3/4, 57-110.

Lepelley (1983): Claude Lepelley, „Quot curiales, tot tyranni. L'image du décurion oppresseur au Bas-Empire“, in: E. Frézouls (Hg.), Crise et redressement dans les provinces européennes de l'Empire (milieu du III siècle - milieu du IV ${ }^{e}$ siècle ap. J.-C.), Strasbourg, 143-156. 
Lepelley (1992): Claude Lepelley, 'Ciuis, ciuitas', in C. Mayer (Hg.) Augustinus-Lexikon, vol. 1, fasc. 5/6, Basel, cols. 942-957.

Liebeschuetz (1998): Wolf Liebeschuetz, „Citizen Status and Law in the Roman Empire and the Visigothic Kingdom“, in: W. Pohl and H. Reimitz (Hgg.), Strategies of Distinction. The Construction of Ethnic Communities, 300-800, Leiden, 131-152.

Lütkenhaus (1998): Werner Lütkenhaus, Constantius III.: Studien zu seiner Tätigkeit und Stellung im Westreich 411-421, Bonn.

Maas (1992): Michael Maas, „Ethnicity, orthodoxy and community in Salvian of Marseille“, in: J. Drinkwater and H. Elton (Hgg.), Fifth-Century Gaul: A Crisis of Identity?, Cambridge, 275-284.

Mathisen, Ralph W. (1981), „The Last Year of Saint Germanus of Auxerre“, Analecta Bollandiana 99, 151-159.

Mathisen (2006): Ralph W. Mathisen, „Peregrini, Barbari, and Cives Romani: Concepts of Citizenship and the Legal Identity of Barbarians in the Later Roman Empire", American Historical Review 111, 1011-1039.

Mathisen (2009): Ralph W. Mathisen, „Provinciales, Gentiles, and Marriages between Romans and Barbarians in the Late Roman Empire“, Journal of Roman Studies 99, $140-155$.

Nixon (1990): C. E. V. Nixon, „The Use of the Past by the Gallic Panegyrists“, G. Clarke (Hg.), Reading the Past in Late Antiquity, Potts Point NSW, 1-36.

Okamura (1988): Lawrence Okamura, „Social Disturbances in Late Roman Gaul: Deserters, Rebels, and Bagaudae“, in: T. Yuge and M. Doi (Hgg.), Forms of Control and Subordination in Antiquity, Leiden, 288-302.

Sánchez León (1996a): Juan Carlos Sánchez León, Les sources de l'histoire des Bagaudes. Traduction et Commentaire, Paris.

Sánchez León (1996b): Juan Carlos Sánchez León, Los Bagaudas: rebeldes, demonios, mártires. Revueltas campesinas en Galia e Hispania durante el Bajo Imperio, Jaén.

Sherwin-White (1973): Adrian Nicholas Sherwin-White, The Roman Citizenship, 2nd ed., Oxford.

Szádeczky-Kardoss (1968): Samu Szádeczky-Kardoss, „Bagaudae“, in: Paulys Realencyclopädie, Supplementum XI, Stuttgart, cols. 346-354.

Thompson (1952): Edward A. Thompson, „Peasant Revolts in Late Roman Gaul and Spain", Past and Present 2, 11-23.

Thompson (1956): Edward A. Thompson, „The Settlement of the Barbarians in Southern Gaul“, Journal of Roman Studies 46, 67-75.

Thompson (1977): Edward A. Thompson, „The End of Roman Spain. Part II“, Nottingham Mediaeval Studies 21, 3-31.

Thompson (1982): Edward A. Thompson, Romans and Barbarians: The Decline of the Western Empire, Madison, Wisconsin.

Thompson (1984): Edward A. Thompson, St Germanus of Auxerre and the End of Roman Britain, Woodbridge.

Van Dam (1985): Raymond Van Dam, Leadership and Community in Late Antique Gaul, Berkeley.

Wickham (2005): Chris Wickham, Framing the Early Middle Ages, Oxford.

Wirszubski (1950): Chaim Wirszubski, Libertas as a Political Idea at Rome during the Late Republic and Early Principate, Cambridge.

Wood (2000): Ian Wood, „The Barbarian Invasions and First Settlements“, A. Cameron and P. Garnsey (eds.), The Cambridge Ancient History, vol. 13, Cambridge, 516-537. 


\title{
Unrömische Römer und römische Barbaren
}

\author{
Die Fluidität vermeintlich präziser Leitbegriffe der Forschung \\ zum spätantiken Gallien
}

Philipp von Rummel

\begin{abstract}
Veränderungsprozesse im Westen des spätrömischen Reiches und das politische Ende des weströmischen Kaisertums werden nach einer Phase, in der vor allem die Diversität und Komplexität des Phänomens im Zentrum des Interesses standen, in letzter Zeit wieder verstärkt mit einwandernden Barbaren in Verbindung gebracht. ${ }^{1}$ Die Diskussion um den barbarischen Einfluss auf das Ende des Römischen Reiches hat hierdurch wieder deutlich an Fahrt gewonnen. ${ }^{2}$ Auch wenn die Annahme einer germanischen Eroberung Galliens in der Spätantike mittlerweile durch differenziertere Erklärungsmodelle ersetzt wurde, ${ }^{3}$ gilt die barbarischrömische Dichotomie weithin als Interpretationsrahmen der sichtbaren Veränderungsprozesse. Dies gilt im Besonderen auch für die Archäologie, die zu dieser Frage nur dann beitragen kann, wenn sie im archäologischen Fundmaterial Barbarisches von Römischem unterscheiden kann. Statt die seit den Anfängen der Forschung angenommenen Distinktionskriterien zu bestätigen und zu schärfen, haben die letzten Jahrzehnte jedoch vor allem gezeigt, wie schwierig sich der Erkenntnisprozess tatsächlich gestaltet. Der vorliegende Aufsatz plädiert im Rahmen dieser Debatten für eine Aufgabe des Primats des dichotomen, römisch-barbarischen Erklärungsmodells zugunsten flexiblerer und differenzierterer Modelle.
\end{abstract}

\section{Ausgangssituation}

Im frühen 5. Jh. verringert sich der Einfluss der kaiserlichen Administration auf die gallischen Gebiete mit zunehmender Schnelligkeit, während das Gewicht unterschiedlicher militärischer Anführer und ihrer Gruppen steigt. Um 500 hat sich die politische Struktur Galliens grundlegend gewandelt. Statt des überregio-

1 Tedesco 2006. - Vgl. Heather 2005; Ward-Perkins 2005; Heather 2011.

2 Vgl. zur Übersicht etwa Heather 2009; Delogu 2010; Wickham 2010; Pohl 2010. - Zur Betonung des barbarischen Einflusses vgl. Valenti 2009; Giostra 2011.

3 Werner 1996. 
nalen Römischen Reiches ist Gallien nun in den Königreichen der Westgoten, Burgunder und Franken organisiert. ${ }^{4}$ In dieser Umbruchsperiode sind die Eliten der gallischen Provinzen gezwungen, sich neu zu orientieren und zu organisieren. ${ }^{5} \mathrm{Zu}$ den alten Werten und Größen, die mit den neuen Gegebenheiten im Konflikt standen, gehörten die traditionellen Ordnungskategorien des Römischen und des Barbarischen, genau wie die Autorität des römischen Denk- und Legitimationsrahmens als Ganzes. ${ }^{6}$ Altes stie $\beta$ auf Neues, ,Römer' und ,Barbaren' mischten sich und neue Reglements mussten für die unterschiedlichsten Bereiche des Lebens gefunden werden.

Um die intensive Debatte um die Rolle der barbarischen Gruppen auf Reichsboden mit weiteren Informationen zu bereichern, ist es für Historiker wie Archäologen nötig, ihre analytischen Kategorien gut definieren und möglichst trennen zu können. Bei den archäologischen Quellen sind hier zwei unterschiedliche Gruppen zu unterscheiden: erstens direkte Spuren, also Funde und Befunde, die unmittelbar mit ,Barbaren' verbunden werden, etwa Fibeln, Schnallen, Waffen oder Architekturformen, denen ethnische Attribute zugewiesen werden. Davon zu trennen sind zweitens die indirekten Spuren, die als Folge der barbarischen Anwesenheit anzusehen sind, aber nichts spezifisch Barbarisches darstellen. Hier wären etwa wirtschaftliche Veränderungen, bestimmte urbanistische Entwicklungsprozesse und nicht zuletzt Spuren von Kämpfen und Zerstörung anzuführen. Voraussetzung für das Erkennen des ersten Falls, also der direkten Spuren, ist, dass die Barbaren andere Zeichen hinterlassen haben als der Rest der Bevölkerung. Obwohl dies häufig a priori angenommen wird, ist es dennoch nicht sicher. Es handelt sich daher um einen Vorgang, bei dem das zu findende Objekt erst nach erfolgreicher Suche bestimmt werden kann. Eine Fibel etwa ist nicht per se römisch oder unrömisch, sondern erst dann, wenn dies über ein extrem komplexes Verfahren der Diskussion von Überlieferungsfiltern wahrscheinlich gemacht werden kann. In diesem Feld ist die Debatte über die Möglichkeiten und Grenzen der ethnischen Interpretation archäologischer Funde angesiedelt, die sich in den letzten Jahren zu einer der interessantesten theoretischen Debatten der ur- und frühgeschichtlichen Archäologie entwickelt hat. ${ }^{7}$ Die Debatte selbst ist jedoch alt und geht auf die Anfänge der Gräberfeldarchäologie zurück. Damals wie heute kommt Gallien, und hier vor allem dem nordgallischen Raum, wegen des Reichtums an Grabfunden eine entscheidende Rolle in der Diskussion zu.

Wie in weiten Teilen des Römischen Reiches wird die in der frühen Kaiserzeit vorherrschende Praxis der Brandbestattung seit dem 3. Jh. auch in Gallien allmählich durch die Körperbestattung abgelöst. Im 4. Jh. finden sich im nördlichen Gallien auf den Nekropolen ähnlich wie in der Alamannia und an der Donau

4 Wood 1994; Geary 1994.

5 Drinkwater/Elton 1992; Jussen 1998.

6 Jussen 1995.

7 Brather 2004; Bierbrauer 2004; Pohl/Mehofer 2010; von Rummel 2010; Giostra 2011; Halsall 2011.

8 Fehr 2010, 21-677. 
nun im Unterschied zu den mediterranen Regionen des Reichs zunehmend Gräber, in denen Männer mit Waffen und militärischer Ausrüstung und Frauen mit Fibeln, Haarnadeln und Schmuck beigesetzt wurden. ${ }^{9}$ Diese Gräber unterscheiden sich von der Mehrheit der Gräber, die keine oder nur wenige Beigaben, zumindest keine Waffen oder Fibeln, besitzen und traditionell mit dem ,romanischen Kulturmodell' und somit im Kontrast zu den Germanen mit der ,einheimischen' Bevölkerung in Verbindung gebracht werden. ${ }^{10}$ Besonders die Beisetzung mit Hiebwaffen gilt in der Tradition der deutschsprachigen Forschung als Kennzeichen germanischer Bestattungen. Hintergrund dieser alten Interpretation, die schon um die Mitte des 19. Jh.s aufkommt, ist wohl, dass der militärisch geprägte Habitus dieser Gräber dem Bild der wilden Germanenvölker entsprach, die das vorrangig zivile Römische Reich heimsuchten. Die Fibeln der Frauengräber galten als germanisch, weil sie nicht zur althergebrachten römischen Kleidung im Zentrum des Reiches gehörten. ${ }^{11}$

Während die Gräber in der älteren Forschung zuerst als Zeugnisse der Eroberung Galliens angesehen wurden, später dann als Gräber von angesiedelten Laeten, gelten sie heute weithin als Hinterlassenschaften von germanischen Föderaten, deren schrittweise Ansiedlung im 4. und 5. Jh. zu einer ,Barbarisierung Nordgalliens führte und die ethnischen und sozialen Strukturen dieser Provinzen nachhaltig veränderte. ${ }^{12}$ Gemeinsam ist diesen Erklärungsmodellen, dass sie die Gräber als Zeugnisse von Fremden ansehen, die, ob auf friedliche oder kriegerische Weise, von anderswo nach Gallien kamen und dort bedeutenden Einfluss auf den Strukturwandel der Provinz nahmen. Als Erkennungsmerkmale der Invasoren gelten neben spezifischen Kleidungsmerkmalen Bestattungsrituale und Architekturformen, vor allem die Holzarchitektur im Gegensatz zum römischen Steinbau. Das dichotome römisch-barbarische Modell erweist sich in Hinsicht auf die Bestattungsrituale jedoch als zunehmend ineffektiv. Es zeigt sich vielmehr, dass die als ,barbarisch' angesprochenen beigabenführenden Gräberfelder, die vor allem innerhalb der römischen Grenzen und nicht außerhalb liegen, mit der allgemeinen Militarisierung der gallorömischen Gesellschaft und mit der breiten Übernahme von ,barbarischen' Kulturelementen einer Grenzkultur, in der römische und andersartige Elemente bereits untrennbar miteinander verschmolzen waren, besser erklärt werden können. ${ }^{13}$ Auf ähnliche Weise gilt es, auch für die als Ausdruck von persönlichen Identitäten so wichtige äußere Erscheinung differenziertere Aussagemöglichkeiten zuzulassen als schlicht die Entscheidung zwischen ,römisch" und ,barbarisch'.

9 Böhme 1996, 92; Fehr 2010, 725-783.

10 Bierbrauer 1996.

11 Fehr 2010; von Rummel 2007.

12 Böhme 1996, 101.

13 Fehr 2010, bes. 705-724; Theuws/Alkemade 2000; Whittaker 1994, bes. 271. 


\section{Das barbarische Äußere}

Die Frage, ob es eine Kleidung gegeben hat, an der Barbaren als solche erkannt werden konnten, kann mit einem klaren Ja beantwortet werden. Es gab Elemente und Kombinationen in der äußeren Erscheinung, die als unrömisch galten. Die Klarheit dieser Antwort hängt jedoch stark davon ab, was man als barbarisch und was als römisch bezeichnet. Die Unsicherheit in dieser Frage ist erstaunlich groß, nicht nur heute, sondern auch in den Quellen des 4. und 5. Jh.s Natürlich war jedem Einwohner einer größeren Stadt des Reichs, allen voran den Römern (also den Einwohnern Roms), klar, wer ein Barbar war und wer nicht. Hunderte von Monumenten machten diese für das römische Selbstverständnis so wichtige und auch selbstverständliche Aussage auch noch in der Spätantike jedem mehr als deutlich: Der Römer war der triumphierende Sieger, zivilisiert, gebildet und gutaussehend, während der wilde Barbar hierzu den notwendigen, zuweilen auch positiven Kontrast bildete. Diese Perspektive zieht sich auch in der Spätantike konstant durch Bilddarstellungen wie Texte und unterstreicht die Bedeutung der frühen Kaiserzeit für spätantike Identitätskonstruktionen. ${ }^{14}$

Die so dargestellten extremen Kontraste zwischen Römischem und Barbarischem entsprachen jedoch nicht der alltäglichen Realität im Römischen Reich. Die Übergänge vom Römischen zum Nichtrömischen waren erstens graduell und zweitens stark von der Perspektive des Betrachters abhängig. Natürlich gibt es aber dennoch gute Beispiele, die das Gegenteil betonen. Zum Beispiel Sidonius Apollinaris, der in einem Brief an seinen Freund Catullinus klagt, er könne nicht dichten, da er unter langhaarigen Scharen sitze und germanische Worte aushalten und zudem loben müsse, was der vollgefressene Burgunder singt, der mit ranziger Butter sein Haar beschmiert. Sein Freund sei schließlich nicht wie ein alter Großvater bis zum Abend von einer Menge von Riesen belästigt, so viele und so große, dass auch die Küche des Alcinous sie nicht ernähren könnte. ${ }^{15}$ Hier meint man fast wieder eine der alten Barbarendarstellungen vor sich zu sehen, nicht ohne einen gewissen humoristischen Zug, wenn wir uns den gebildeten Aristokraten vorstellen, der jugendliche, ständig hungrige Krieger in seinem Haus hat, die sich nach dem neuesten Chic Fett in die Haare schmieren, nach Knoblauch stinken, dem Dichter mit dem Grölen seltsamer Lieder auf die Nerven gehen und dafür auch noch gelobt werden wollen. Dass hier Extreme aufeinanderprallen, ist nicht zu leugnen. Hier wird mehr als deutlich, was sog. Außenseiter dem Elitendiskurs

14 Dauge 1981; Heather 1999; von Rummel 2013.

15 Sidon. carm. 12, 1-19: Quid me, etsi valeam, parare carmen / Fescenninicolae iubes Diones / inter crinigeras situm catervas / et Germanica verba sustinentem, / laudantem tetrico subinde vultu / quod Burgundio cantat esculentus / infudens acido comam butyro? / vis dicam tibi, quid poema frangat? / ex hoc barbaricis abacta plectris / spernit senipedem stilum Thalia, / ex quo septipedes videt patronos. / felices oculos tuos et aures / felicemque libet vocare nasum / cui non allia sordidaeque cepe / ructant mane novo decem apparatus, / quem non ut vetulum patris parentem / nutricisque virum die nec orto / tot tantique petunt simul Gigantes, / quot vix Alcinoi culina ferret. 
entgegenhalten konnten. Das Schwert eines Burgunders war im Ernstfall letztendlich mächtiger als die Paideia des aristokratischen Traditionalisten, der selbst nicht in der Lage war, ,römisch' und ,barbarisch' wirklich fein zu trennen. ${ }^{16}$

Diese vermeintlich klare römisch-germanische Dichotomie darf jedoch nicht darüber hinwegtäuschen, dass kulturelle Identitätskonstruktionen auf unterschiedlichen Ebenen vielfältig und damit hochkomplex sind und dass wir daher zu voreilig dazu tendieren, den Römerbegriff genau wie den noch viel schwammigeren des Germanischen als fest gefügtes Fundament zu verwenden, auf dem der Bau des Interpretationsgebäudes ausgeführt werden kann. ${ }^{17}$ Wer weiß, wie sich das Dienstpersonal von Sidonius mit den jungen Burgundern verstanden hat oder ob Sidonius sich mit den Anführern dieser Truppe nicht auch vernünftig unterhalten konnte. Wie wäre es gewesen, wenn statt einer burgundischen einige Jahrzehnte zuvor eine römische Truppe einquartiert worden wäre? Es ist zumindest unwahrscheinlich, dass jene Soldaten gemeinsam mit Sidonius Vergil rezitiert hätten.

Es ist in diesem Sinn dann also richtig, den barbarischen Habitus in ein bipolares System einzuordnen und ihn mit dem Römischen zu kontrastieren, wenn ideale Römer auf typische Barbaren treffen. Für die Frage, wie ,fremd' dieser in den Schriftquellen erfassbare barbarische Habitus im Reich tatsächlich war und wie stark seine Beziehungen zu den Herkunftsgebieten der unterschiedlichen Barbarengruppen waren, ist diese Bipolarität jedoch nicht hilfreich. Es muss vielmehr unterstrichen werden, dass das gesamte Phänomen des Barbarischen in der Spätantike nicht grundsätzlich und ausschließlich als Gegenkonzept zum Römischen verstanden werden darf, sondern auch die zweite Seite der gleichen Medaille sein kann. Dies heißt nicht, die Differenz zwischen Barbaren und Römern auf ein Minimum reduzieren zu wollen. Es bedeutet lediglich, dass nicht alles, was in den Quellen als barbarisch beschrieben wird, in einer Art clash of civilizations als Fremdkörper von außen in das Reich eingedrungen ist. Reichsinternes, also ,römisches Barbarisches', konnte gewaltigen Einfluss auf die Entwicklung des Reichs haben, und dies ist durchaus formulierbar, ohne historische Vorgänge weichzuspülen oder zu verharmlosen. Es geht also nicht darum, zu postulieren, Römer und Barbaren seien nicht unterscheidbar gewesen, sondern viel eher um die Frage, wer sich hier von wem abgegrenzt hat, und letztendlich um die Semantik der Schlüsselbegriffe.

16 Harries 1996, 44. - Zur Selbstinszenierung des Sidonius vgl. Näf 1995, 132-165; Mratschek 2008, bes. 367-377. Zur Situation der Eliten: Brown 2000, bes. 333-335. Zur senatorischen Aristokratie: Salzman 2002; Schlinkert 1996; Näf 1995.

17 Vgl. beispielsweise Amory 1994; Goetz 2002; Jarnut 2004; Fehr 2010, 21-173; von Rummel 2013. 


\section{Sigismer und Childerich}

Wenden wir den Blick für ein Fallbeispiel nach Lyon. Von dort berichtet um 469 n. Chr. Sidonius Apollinaris seinem Freund Domnicius brieflich von dem Besuch des wahrscheinlich fränkischen Prinzen Sigismer am burgundischen Königshof: ${ }^{18}$

Wenn Du den jungen, nach Stammesart gekleideten Prinzen Sigismer gesehen hättest, wie er als Bräutigam den Palast seines Schwiegervaters besuchte! Ein festlich geschmücktes Pferd ging ihm voraus, andere Pferde, beladen mit funkelnden Edelsteinen, gingen ihm voran und folgten ihm. Aber der schönste Anblick dieser Prozession war der Prinz selbst, der zu Fuß mitten unter seinen Läufern und Dienern einherschritt, gekleidet in flammendes Rot, gelbglänzendes Gold und milchweiße Seide, während sein gepflegtes Haar, seine rötlichen Wangen und seine weiße Haut den Farben dieser reichen Kleidung entsprachen.

Was aber die Adeligen und das Gefolge betrifft, die ihn begleiteten, so gewährten sie sogar in Friedenszeiten einen furchterregenden Anblick. Ihre Füße waren bis zum Knöchel in Schuhe aus Fell eingeschnürt, die Unterschenkel und Waden waren nicht bedeckt. Darüber schloß sich eine enganliegende, bunte Bekleidung an, hochgerafft, die kaum bis den nackten Kniekehlen herunterreichte; die Ärmel bedeckten den oberen Teil des Armes. Ihre grünen Mäntel trugen dunkle Borten. Ihre Schwerter hingen in Wehrgehängen von der Schulter herab und drückten gegen die Taille, die von einem edelsteinverzierten Ledergürtel umgeben war. Diese Ausrüstung schmückte und schützte sie zugleich. Lanzen mit Widerhaken und Wurfäxte lagen in ihren rechten Händen; ihre linken Hüften waren durch Schilde geschützt, deren Glanz - silberweiß an den Rändern, goldgelb an den Schildbuckeln in der Mitte - sowohl den Reichtum als auch die Leidenschaft ihrer Träger verriet. [...]. ${ }^{19}$

18 Zur Datierung vgl. Amherdt 2001, 421. - Zur ethnischen Ansprache s. von Rummel 2007, 174 mit Anm. 431-434.

19 Sidon. epist. 4, 20, 1-3: Tu, cui frequenter arma et armatos inspicere iucundum est, quam voluptatem, putamus, mente conceperas, si Sigismerem regium iuvenem ritu atque cultu gentilicio ornatum, utpote sponsum seu petitorem, praetorium soceri expetere vidisses! Illum equus quidem phaleris comptus, immo equi radiantibus gemmis onusti antecedebant vel etiam subsequantur, cum tamen magis hoc ibi decorum conspiciebatur, quod cursoribus suis sive pedisequis pedes et ipse medius incessit, flammeus cocco rutilus auro lacteus serico, tum cultui tanto coma rubore cute concolor. regulorum autem sociorumque comitantum forma et in pace terribilis; quorum pedes primi perone saetoso talos adusque vinciebantur; genua crura suraeque sine tegmine; praeter hoc vestis alta stricta versicolor vix appropinquans poplitibus exertis; manicae sola brachiorum principia velantes; viridantia saga limbis marginata puniceis; penduli ex umero gladii balteis supercurrentibus strinxerant clausa bullatis latera rhenonibus. eo quo comebantur ornatu muniebantur; lanceis uncatis securibusque missilibus dextrae refertae clipeis laevam partem adumbrantibus, quorum lux in orbibus nivea, fulva in umbonibus ita censum prodebat ut studium. cuncta prorsus huiusmodi, ut in actione thalamorum non appareret minor Martis pompa quam Veneris. Sed quid haec pluribus? Spectaculo tali sola praesentia tua defuit. Nam cum viderem quae tibi pulchra sunt non te videre, ipsam eo tempore desiderii tui inpatientiam desideravi. - Übersetzung: Kaufmann 1995. 
Es handelt sich bei dieser Passage um eine der genauesten Beschreibungen spätantiker Kleidung überhaupt. ${ }^{20}$ Da Sidonius explizit feststellt, der Prinz sei ritu atque cultu gentilicio ornatus aufgetreten, scheint er betonen zu wollen, und die meisten neuzeitlichen Betrachter sind dieser Sichtweise gefolgt, dass Sigismer eben nicht römisch ausgesehen habe und dass der äußerliche Unterschied zwischen Barbaren und Römern ein klarer gewesen sei. ${ }^{21}$ So einfach ist es jedoch nicht. Die von Sidonius beschriebene Kleidung des Prinzen, gekleidet in flammendes Rot, gelbglänzendes Gold und milchweiße Seide, ist per se keineswegs unrömisch. Hohe römische Offiziere trugen rote Mäntel, goldene Fibeln und Gürtel sowie nicht selten weiße Tuniken. Auch die Waffen ${ }^{22}$ und Gewänder der Begleiter Sigismers stehen in keinem Gegensatz zu ,römischen' Accessoires. Der in einem anderen Brief von Sidonius angesprochene Gallorömer Germanicus trug genau wie die Begleiter Sigismers enganliegende Hosen (vestis adstricta) und Stiefel (tensus coturnus). ${ }^{23}$ Schon Quicherat vermutete, dass es sich bei den coturni um eine ähnliche Art militärischer Stiefel handelte, ${ }^{24}$ die im Codex Theodosianus unter dem Namen tzancae in Rom verboten wurden. ${ }^{25}$ Die teilweise auch jugendlich konnotierte Kombination von engen Hosen, Stiefeln, Tunika und Mantel war über ethnische Grenzen hinweg beliebt, hatte aber vor allem deutliche militärische Elemente. Der militärische Aspekt wiederum stellt die Kleidung in das römisch-barbarische Spannungsfeld. ${ }^{26}$ Wolf Liebeschuetz hat in einer kritischen Betrachtung der wichtigen Schriftquellen zum habitus barbarus zu Recht bemerkt, Sidonius habe mit dem Hinweis auf Sigismer ritu atque cultu gentilicio ornatus unterstreichen wollen, dass der Prinz eben nicht so ausgesehen habe wie junge römische Aristokraten. ${ }^{27}$ Hier ist ihm insofern zuzustimmen, als junge römische Aristokraten den alten zivilen Idealen verpflichtet waren. ${ }^{28}$ Repräsentierten sie sich und ihren Stand regelkonform, war ein Auftreten wie dasjenige Sigismers nicht möglich. Regelverstöße sich nicht standesgemäß gebender Jünglinge der Oberschicht gab es freilich auch. ${ }^{29}$ Die Tatsache, dass sie als solche bemerkt und beschrieben wurden, unterstützt die These, dass die Frage nach römisch und nichtrömisch auf einer anderen Ebene angesiedelt ist als die Unterscheidung innerhalb versus außerhalb des Römischen Reiches. Im Falle Sigismers

20 Ausführlicher zu dieser Quelle von Rummel 2007, 172-181.

21 Vgl. etwa Harries 1996, 35f.

22 Zu den Waffen vgl. von Rummel 2007, 174-179.

23 Sidon. epist. 4, 13, 1.

24 Quicherat 1877, 69f.

25 CTh. 14, 10, 2-3 (ed. Mommsen u.a., 788).

26 von Rummel 2010.

27 Liebeschuetz 2013, 18-20.

28 Vgl. Brown 2000, bes. 334. - Zum senatorischen Standesbewusstsein vgl. Näf 1995.

29 Z.B. Ambr. de Hel. 13, 46: Apage igitur hinc adulescentes lubricos, ad convivia proeliatorum venimus. inter arma prandendum est. stipatores hic sunt bellici, qui ministrant succincti auro et Babylonicis lumbos suffulti balteis, aureis torquibus nitent colla, aureis bullis zonam tegunt, aureis thecis cultros includunt suos, quibus dimicent cum epulis dividendis. 
und seiner Begleiter wird die Ausstattung durch den Kontext ,barbarisch ${ }^{6}$. Leider überlässt es der Autor gleichwohl der Phantasie und der Erfahrung der Leser, sich den Prinzen vorzustellen und das, was an seiner Erscheinung ,gentil' ist.

Ein archäologischer Glücksfall kann zumindest einige der von Sidonius nicht erwähnten, uns aber interessierenden Details klären. Es handelt sich um das 1653 entdeckte Grab des fränkischen Königs Childerich, der 481/2, also ungefähr zwölf Jahre nach der von Sidonius geschilderten Begebenheit, starb und in Tournai bestattet wurde. ${ }^{30} \mathrm{Zu}$ den Grabfunden gehören Gegenstände der persönlichen Ausstattung Childerichs, darunter der berühmte Siegelring mit dem Namen und Titel, eine goldene Zwiebelknopffibel, ein goldener Kolbenarmring, eine goldene Schilddornschnalle mit ovalem Beschlag, eine cloisonnéverzierte Spathagurtschnalle, ein cloisonnéverziertes Schuhschnallenpaar, Reste weiterer Schnallen, ein Taschenbügel und an Waffen eine Goldgriffspatha, ein Sax, eine Lanzenspitze, eine Franziska und ein Schildbuckel. Dieter Quast identifizierte jüngst eine Bergkristallkugel aus dem Grab als Teil eines Zepters. ${ }^{31}$ Die goldene Zwiebelknopffibel schloss an der Schulter einen Mantel, und auch sonst kommt uns diese Ausstattung recht bekannt vor. Fast hören wir Sidonius den Prinzen Sigismer beschreiben: Die Spatha und der Sax mit den zugehörigen edelsteinverzierten Gurten schmückten und schützten ihn zugleich, eine Lanze und eine Wurfaxt lagen in seiner Hand, seine linke Hüfte war durch einen Schild geschützt, vielleicht silberweiß an den Rändern, goldgelb an den Schildbuckeln in der Mitte. Dank des Childerichgrabes können wir uns etwas konkreter vorstellen, wie Sigismer und seine Begleiter ritu atque cultu gentilicio ornatus ausgesehen haben mögen. Weitere Gräber wie etwa das von Pouan geben uns ein ganz ähnliches Bild dieser Ausstattung, in diesem Fall mit Spatha, Sax, Halsring, Armring, beide aus Gold, Siegelring und Teile unterschiedlicher Gürtel und Riemen. ${ }^{32}$

Bei der Betrachtung dieser Funde beginnt nun jedoch das vermeintliche Problem. Denn die Kleidungsbestandteile und die Waffen aus Tournai oder Pouan sind ebenso wenig unrömisch wie die von Sidonius beschriebene Kleidung. Sie unterscheidet sich kaum von der Ausstattung eines römischen Offiziers dieser Epoche. Auf dem Diptychon von Monza etwa sehen wir einen römischen Offizier mit Mantel mit Fibel, Gürtel, Schwert, Lanze und Schild. Die Ansprache des Offiziers als Stilicho hat in der Forschung dazu geführt, dass mit Stilicho (und vor allem mit Claudius Claudianus) auch die Ausrüstung des Offiziers auf dem Diptychon als barbarisch angesprochen wurde. Dem ist jedoch zu widersprechen. Es handelt sich hier, wie an anderer Stelle ausführlich dargelegt, um die Amtstracht der spätrömischen militia, der Armee also und der militärischen Administration, an der jedes einzelne Detail als ,römisch` zu bezeichnen ist, weil eben ein römischer

30 Zum Einstieg in die reichhaltige Literatur zum Childerichgrab vgl. Chiflet 1665; Périn/Kazanski 1996; Müller-Wille 1998; Halsall 2001; Halsall 2010.

31 Quast 2010.

32 Kazanski 1982; Kazanski 1996. 
Offizier dargestellt ist und kein fremder Krieger. ${ }^{33}$ Unabhängig davon, ob auf dem Diptychon von Monza tatsächlich Stilicho dargestellt ist oder nicht, hat Stilicho mit großer Wahrscheinlichkeit eine derartige Ausrüstung getragen. Dennoch, und wiederum völlig unabhängig davon, war es seinen Feinden möglich,

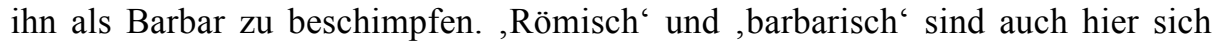
nicht zwangsläufig gegenseitig ausschließende Gegensatzpaare. Sigismer, Childerich oder der Offizier auf dem Diptychon trugen eine Ausstattung, die einerseits vollkommen römisch war, weil sie von Römern getragen wurde, aus einem anderen Blickwinkel heraus aber eben auch nicht, weil sie nicht dem entsprach, was auch schon Jahrhunderte vorher als charakteristisch römisch gegolten hatte.

Die Schnittmenge zwischen der ,römischen' und der ,barbarischen' Betrachtungsweise ist der militärische Aspekt, der in dieser Zeit auch in anderen Bereichen immer schwerer von dem Barbarischen zu trennen ist. Literarische Quellen vermitteln zwar durchaus den Eindruck, dass es eine derartige Schnittmenge nicht gegeben habe und römisch und barbarisch durchaus klar und deutlich voneinander zu trennen sind. ${ }^{34}$ Diese Schriften werden jedoch allzu häufig als objektive Aussagen angesehen, auf denen man eine weitergehende Interpretation, etwa archäologischer Quellen, aufbauen könne. Dies ist jedoch mit Gefahren verbunden. Wir sollten in Betracht ziehen, dass die meisten literarischen Quellen, die über fremde Kleidung berichten, aus der Perspektive eines traditionsbewussten und gebildeten Personenkreises berichten, der der wachsenden Bedeutung militärischer Machthaber kritisch gegenüberstand. Manche Schriftsteller, Claudius Claudianus wäre hier etwa zu nennen, versuchten, die wachsende Differenz zwischen senatorischem Adel und militärischen Machthabern literarisch zu überbrücken. ${ }^{35}$ Der Konflikt zwischen den Mitgliedern der traditionsbewussten senatorischen Elite und aufstrebenden Persönlichkeiten aus Armee und Reichsadministration, die besonders seit Valentinian I. bis in höchste Führungsämter und somit senatorische Kreise aufgestiegen waren, ${ }^{36}$ ist dennoch ein Charakteristikum dieser Zeit. Aus der senatorischen Position heraus versuchte man, die alten Privilegien mit einem einflussreichen Mittel zu verteidigen: Schriftlichkeit und klassische Bildung. ${ }^{37}$ Hierin eingeschlossen war die Möglichkeit, bei Bedarf auf ein großes Spektrum alter Barbarentopoi zurückgreifen zu können. Dies heißt jedoch nicht, das muss an dieser Stelle betont werden, dass es keine Unterschiede zwischen Barbaren und Römern gegeben habe. Ganz im Gegenteil war es im jeweiligen Kontext und für die beteiligten Personen durchaus klar, ob jemand etwa Franke war oder eben nicht. ${ }^{38}$ Als heuristisches Mittel der modernen Forschung dienen die Begriffe jedoch nur, wenn sie klar abzugrenzen sind. Die Schwierigkeit liegt demnach nicht in der Frage nach der Existenz von Unterschieden, sondern im Erkennen

33 von Rummel 2007, 206-213.

34 Vgl. Liebeschuetz 2013, passim.

35 von Rummel 2007, 376-400; von Rummel 2010, 71-74.

36 Salzman 2002, 19-68; Schlinkert 1996; Näf 1995.

37 Vgl. Brown 2000; Brown 1995; Näf 1995.

38 Wenn die Identifikation zuweilen auch scheitert: Pohl 1998. 
dieser Unterschiede. Das Problem zeigt sich in besonderer Schärfe bei weiten Teilen des Phänomens, das als habitus barbarus zusammengefasst werden kann: Der habitus barbarus ist nicht vornehmlich das Relikt von Migrationsströmen in das Reich, sondern Produkt weitaus komplexerer Veränderungsprozesse im Reich selbst.

Im nördlichen Gallien war zu dem Zeitpunkt, zu dem man in Rom noch versuchte, mit Gesetzen gegen den wachsenden Einfluss des Militärs vorzugehen, schon eine andere Situation eingetreten. In der ersten Hälfte des 5. Jh.s ließen sich hier lokale militärische Eliten durch ein Kleidungsverbot nicht mehr in Schach halten. Ein Prozess der Ausbildung einer regionalen Ordnung hatte begonnen, der beim Tod Childerichs schon weit fortgeschritten war. Childerich zeigt sich daher zumindest in dem, was an persönlicher Ausstattung aus seinem Grab bekannt ist, auch nicht, wie es Stéphane Lebecq formuliert hat, als Person mit zwei Gesichtern, einem römischen und einem barbarischen ${ }^{39}$ sondern mit einem einzigen, relativ homogenen Gesicht als regionaler militärischer Herrscher einer nur noch lose in den administrativen Strukturen des Reichs verankerten römischen Provinz. Selbst die auf dem Siegelring zu erkennende Langhaarfrisur, die für die Merowinger so charakteristisch wurde, entspricht einer Militärmode, die etwa bei den kaiserlichen Leibgarden des 4. und 5. Jh.s auch in den Zentren des Reichs verbreitet war. ${ }^{40}$ Ist die Frisur nun jedoch von der Peripherie ins Zentrum gelangt oder vom Zentrum in die Peripherie? Die meisten Interpretationen betonen den ersten Fall, also die Übernahme ,unrömischer' Elemente bei den kaiserlichen Leibgarden. Helmut Roth sprach die in der kaiserlichen Repräsentationskunst des 4. bis 6. Jh.s dargestellten Leibwachen mit längeren Haaren mit Verweis auf den Childerichring gar als barbarische Vasallenkönige an. Die langen Haare seien gemeinsam mit Halsringen und Lanzen kognitive Signale für den römischen Betrachter, fremdes Königtum zu erkennen. ${ }^{41}$ Es spricht jedoch vieles dafür, dass hier genau die gegensätzliche Einflussrichtung gewirkt hat. Im Rahmen spätantik-kaiserlicher Repräsentation waren die genannten Merkmale m.E. nicht primär Zeichen von Fremdheit, sondern sie symbolisierten die den Kaiser begleitenden Eliteeinheiten des römischen Heeres. ${ }^{42}$ Als solche hatten sie eine große Strahlkraft nach außen und wurden bis hinter die Grenzen des Reiches nachgeahmt. Childerichs Grab zeigt zudem, dass der König in der Ausstattung eines Feldherrn und Kommandanten der Belgica Secunda bestattet wurde, dessen Bezugsrahmen stark römisch geprägt war. ${ }^{43}$ Nicht imitatio imperii wurde hier praktiziert. Childerich und sein Grab waren vielmehr pars imperii in beständiger Wechselwirkung mit dem Zentrum. Das dichotomische, zwischen ,römischen` und ,barbarischen' Ein-

39 Lebecq 2002.

40 von Rummel 2007, bes. 215-225, 265-268.

41 Roth 2002, 134.

42 von Rummel 2007, bes. 213-231.

43 von Rummel 2007, 368-375. - Das von Quast 2010 mit großer Wahrscheinlichkeit identifizierte Zepter unterstreicht diesen Aspekt. 
flüssen pendelnde und Childerich zwei Gesichter verleihende Modell hat hier nur sehr begrenzten heuristischen Wert.

Gallien, und vor allem dessen Norden, ist durch die Vielzahl von beigabenführenden Gräbern dennoch eine besondere Landschaft im Westen des Römischen Reiches. Aber selbst hier weist die Mehrzahl der Friedhöfe traditionelle provinziale Bestattungsrituale auf. Gräber mit den typischen früher als germanisch angesprochenen Beigaben sind für das 4. und 5. Jh. niemals in großer Zahl belegt. Das Phänomen scheint eher auf kleine Gruppen beschränkt gewesen zu sein. Die Tatsache, dass viele der Grabfunde, auch etwa die berühmten Tutulusfibeln, ihren Ursprung eher in der Provinz als außerhalb des Reiches haben, macht es wie die Ausstattung der Männer mit römischen Waffen oder die nicht seltene Nähe der Friedhöfe zu Militärstützpunkten wahrscheinlich, dass es sich auch abseits der allerhöchsten Ebene von Childerich oder Sigismer bei den so Bestatteten um Mitglieder jener neuen Provinzelite handelt, die das größer werdende Machtvakuum in der Provinz schlossen. Wie Guy Halsall, Frans Theuws oder Hubert Fehr überzeugend gezeigt haben, ist es auch jene Provinzelite, die die großzügig ausgestattete Bestattung der verstorbenen Angehörigen, wie bewusst auch immer, als Teil der sozialen Kompetition praktiziert hat. ${ }^{44}$ Bei den Waffenfunden in den als ,germanisch` angesehenen Gräbern handelt es ganz überwiegend um römische Produkte und die Vergesellschaftung der Funde spricht dafür, dass jene ,Germanen“ Angehörige des römischen Heeres waren. Bezeichnend ist etwa, dass die römische Zwiebelknopffibel, die einen wichtigen Bestandteil der römischen Militärkleidung darstellt, zwar innerhalb der Provinz in den Gräbern gefunden wird, außerhalb davon, hier also rechts des Rheins, dagegen jedoch kaum. ${ }^{45}$ Die für die Männergräber der gallischen Provinzen so bezeichnende Franziska, die Wurfaxt der Franken, ist kein Objekt, das von Germanen im Rahmen einer Landnahme nach Gallien gebracht wurde, sondern ist eine Waffe der gallischen Provinzialen, mit denen etwa die gallischen Truppen während der von Ammianus anschaulich geschilderten persischen Belagerung von Amida/Diyabarkır 359 n. Chr. kämpfen. ${ }^{46}$ Auch die Waffenbeigabe im spätrömischen Gallien lässt sich nicht direkt aus dem rechtsrheinischen Raum herleiten. Sie scheint vielmehr eine Neuschaffung in der Provinz zu sein, in der neue Strategien der sozialen Stabilisierung entwickelt wurden. ${ }^{47}$

44 Halsall 2000; Theuws/Alkemade 2000; Halsall 2001; von Rummel 2007, 381-386; Halsall 2010; Fehr 2010, 705-774.

45 Vgl. Halsall 2000; Fehr 2010, bes. 759-762.

46 Amm. 19, 6, 7: Galli [...] securibus gladiisque succinti.

47 Fehr 2010, 725-783. 


\section{Unrömische Römer}

Diese Sichtweise unterscheidet sich in einem kleinen, aber bedeutsamen Punkt von der gängigen Forschungsmeinung. Allgemein wird davon ausgegangen, dass sich nicht nur in Gallien, sondern auch in anderen Provinzen des Westens zwei ethnisch definierte Kulturmodelle gegenübergestanden haben: einerseits das einheimische romanische und andererseits das zugewanderte germanische. ${ }^{48}$ Die hier vorgetragene Interpretation schlägt eine Entwicklung vor, die nicht vornehmlich von der Zuwanderung eines fremden Elements geprägt ist. Das Phänomen, das sich in Gallien oder in der Alamannia in den reich ausgestatteten Gräbern äußert, ist in seinen Grundelementen auch in anderen Regionen zu beobachten und war keineswegs ein germanisches Phänomen. Wie in Gallien entstehen etwa auch in Nordafrika auf dem Boden der ehemaligen Provinzen neue Gruppen, ohne Einwanderung von Fremden, sondern als Zusammenschluss der lokalen Bevölkerung. $\mathrm{Zu}$ nennen wären hier etwa Gemeinschaften wie diejenige des berühmten Masuna, rex gentium Maurorum et Romanorum, oder die Frexen des Antalas. ${ }^{49}$ Bezeichnenderweise sind diese neuen ethnischen Prozesse in Afrika jedoch erst etwa fünfzig bis hundert Jahre später als in Nordgallien zu beobachten, jene Zeitspanne, um die in Afrika die römische Autorität länger Bestand hatte als in Gallien. Dann war es aber auch hier so weit, dass das überregionale Modell des Römischen Reiches nicht mehr die beste aller Alternativen war. Während eine immer kleiner werdende Gruppe von Menschen wie Sidonius die Tradition Roms aufrechtzuerhalten suchte, veränderte sich die Umwelt immer schneller, wurden die Menschen trotz großer Kontinuitäten immer unrömischer.

Das seit dem 4. Jh. zu beobachtende Phänomen, dass ein bestimmter Teil der Gesellschaft mit umfangreichen Beigaben bestattet wird, und die in den Gräbern sichtbar werdende Ausstattung selbst liefern Hinweise zur Rekonstruktion dieser Vorgänge. Texte, Bilder und Grabfunde geben, so heterogen sie naturgemäß sind, gemeinsam Auskunft über eine in weiten Teilen des römischen Westens gleichartige Bevölkerungsgruppe: eine neue, militärisch basierte Elite von Aufsteigern mit den von ihnen geführten Gruppen, die von den traditionellen senatorischen Eliten bekämpft wurde, die verständlicherweise ihren alten Einfluss verteidigten. Aus dem Umfeld Letzterer stammen jene Texte und Bilder, die über die ,Fremden ' Auskunft geben. Ihnen gemeinsam ist eine latente Feindseligkeit, die tief in den Fundus alter Bilder greift, um die Konkurrenz zu diskreditieren. Aus dem Kreise der Aufsteiger stammen die Prunkgräber mit Waffen und Fibeln, in denen uns die von Archäologen als ,barbarisch' bezeichnete Kleidung entgegentritt. Die Gräber spiegeln nach dem Archäologen Georg Kossack ein Phänomen wider, das sich zu unterschiedlichen Zeiten und in verschiedenen Regionen immer wieder zeigt und daher einen gewissen konstanten Charakter zu haben scheint. Prunkvolle Bestattungen tauchen in sozialen bzw. gesellschaftlichen Konfliktsituationen

48 Bierbrauer 1996.

49 Modéran 2003; von Rummel 2011. 
und häufig in Kontaktzonen ungleichartiger Kultursysteme immer wieder als Repräsentationsmittel bedrängter Eliten auf.

Die traditionell mit hoher symbolischer Bedeutung aufgeladene Kleidung erlaubt es, einen der wichtigsten die Spätantike charakterisierenden Konflikte in Bilder zu fassen: die Ablösung der traditionell zivilen, städtischen und senatorischen Eliten durch homines novi, deren Macht meist militärischer Art war. Ihre Kleidung war ,unrömisch“ in dem Sinn, dass sie nicht der Repräsentationskultur der traditionellen senatorischen Elite entsprach, die den habitus Romanus für sich beanspruchte. Der habitus barbarus war die äußere Erscheinung ihrer Gegner, die, wenn man es freundlich ausdrücken will, den Elitenkonflikt schließlich erfolgreicher überstand als ihr römisch-ziviler Gegenpart. Die politische und wirtschaftliche Macht lag zunehmend in ihrer Hand, während die zivilen Eliten sich an die neue Situation anpassten und kontinuierlich zugunsten des militärischen und religiösen Bereichs verschwanden.

\section{Literaturverzeichnis}

\section{Primärliteratur}

Ambrosius, De helia et ieiunio: Sancti Ambrosii opera, pars 2, rec. Carolus Schenkl, (CSEL 32, 2), Wien 1897, 409-465.

Ammianus Marcellinus, Res gestae: Ammianus Marcellinus, Römische Geschichte. Lateinisch und deutsch und mit einem Kommentar versehen von Wolfgang Seyfarth, Darmstadt 1983-1986.

Codex Theodosianus: Theodosiani libri XVI cum constitutionibus Sirmondianis et leges novellae ad Theodosianum pertinentes, edd. Theodor Mommsen, Paul M. Meyer u. Paul Krüger, Bd. 1, Berlin 1904.

Sidonius Apollinaris, Epistulae: Sidonius, Poems and Letters, with an English translation by William B. Anderson (LCL), Cambridge Mass. 1963-1965.

Sidonius Apollinaris, Carmina: Sidonius, Poems and Letters, with an English translation by William B. Anderson (LCL), Cambridge Mass. 1963-1965.

\section{Sekundärliteratur}

Amherdt (2001): David Amherdt, Sidoine Apollinaire. Le quatrième livre de la correspondance. Introduction et commentaire, Bern/Berlin/Frankfurt a. M. (Sapheneia. Beiträge zur Klassischen Philologie 6).

Amory (1994): Patrick Amory, „Ethnographic rhetoric, aristocratic attitudes and political allegiance in post-roman Gaul“, Klio 76, 438-453.

Bierbrauer (1996): Volker Bierbrauer, „Romanen im fränkischen Siedelgebiet“, in: Die Franken - Wegbereiter Europas (Ausstellungskatalog Mannheim/Paris/Berlin, 199697), Mainz, 110-120.

50 Kossack 1974. 
Bierbrauer (2004): Volker Bierbrauer, „Zur ethnischen Interpretation in der frühgeschichtlichen Archäologie“, in: Walter Pohl (Hg.), Die Suche nach den Ursprüngen, Wien (Forschungen zur Geschichte des Mittelalters 8), 45-84.

Böhme (1996): Horst Wolfgang Böhme, „Söldner und Siedler im spätantiken Nordgallien“, in: Die Franken - Wegbereiter Europas (Ausstellungskatalog Mannheim/Paris/ Berlin, 1996-97), Mainz, 91-101.

Brather (2004): Sebastian Brather, Ethnische Interpretationen in der frühgeschichtlichen Archäologie. Geschichte, Grundlagen und Alternativen, Berlin/New York (Ergänzungsband zum Reallexikon der germanischen Altertumskunde 42).

Brown (1995): Peter Brown, Macht und Rhetorik in der Spätantike. Der Weg zu einem christlichen Imperium, München.

Brown (2000): Peter Brown, „The Study of Elites in Late Antiquity“, Arethusa 33/3, 321346.

Chiflet (1665): Jean-Jaques Chiflet, Anastasis Childerici I. Francorum regis, sive thesaurus sepulchralis Tornaci Nerviorum effossus et Commenatrio illustratus, Antwerpen.

Dauge (1981): Yves Albert Dauge, Le barbare: recherches sur la conception romaine de la barbarie et de la civilisation, Brüssel.

Delogu (2010): Paolo Delogu, „Introduzione. Il V secolo come problema della storiografia“, in: Paolo Delogu u. Stefano Gasparri (Hgg.), Le trasformazioni del V secolo. L'Italia, $i$ barbari e l'occidente romano (Atti del Seminario di Poggibonsi, 18-20 ottobre 2007), Turnhout, 7-13.

Drinkwater u. Elton (1992): John F. Drinkwater u. Hugh Elton (Hgg.), Fifth-Century Gaul: A Crisis of Identity?, Cambridge.

Fehr (2010): Hubert Fehr, Germanen und Romanen im Merowingerreich. Frühgeschichtliche Archäologie zwischen Wissenschaft und Zeitgeschehen, Berlin/New York (Ergänzungsband zum Reallexikon der germanischen Altertumskunde 68).

Geary (1994): Patrick Geary, Die Merowinger. Europa vor Karl dem Großen, München.

Giostra (2011): Catarina Giostra, „Goths and Lombards in Italy: the potential of archaeology with respect to ethnocultural identification“, Post Classical Archaeologies 1, 736.

Goetz (2002): Hans-Werner Goetz, „Zur Wandlung des Frankennames im Frühmittelalter", in: Walter Pohl u. Max Diesenberger (Hgg.), Integration und Herrschaft. Ethnische Identitäten und soziale Organisation im Frühmittelalter, Wien (Forschungen zur Geschichte des Mittelalters 3), 133-150.

Halsall (2000): Guy Halsall, „Archaeology and the Late Roman Frontier in Northern Gaul: the so-called Föderatengräber reconsidered“, in: Walter Pohl u. Helmut Reimitz (Hgg.), Grenze und Differenz im frühen Mittelalter, Wien (Forschungen zur Geschichte des Mittelalters 1), 167-180.

Halsall (2001): Guy Halsall, „Childeric's grave, Clovis’ succession, and the origins of the Merovingian kingdom“, in: Ralph W. Mathisen u. Danuta Shanzer (Hgg.), Society and Culture in Late Roman Gaul. Revisiting the Sources, Aldershot, 116-133.

Halsall (2010): Guy Halsall, „Commentary three: Once more unto Saint-Brice“, in: Guy Halsall, Cemeteries and Society in Merovingian Gaul. Selected Studies in History and Archaeology, 1992-2009, Leiden/Boston, 188-197.

Halsall (2011): Guy Halsall, „Ethnicity and early medieval cemeteries“, Arqueologia y Territorio Medieval 18, 15-27.

Harries (1994): Jill Harries, Sidonius Apollinaris and the Fall of Rome AD 407-485, Oxford. 
Harries (1996): Jill Harries, „Sidonius Apollinaris and the Frontiers of Romanitas“, in: Ralph W. Mathisen u. Hagith S. Sivan (Hgg.), Shifting Frontiers in Late Antiquity, Aldershot, 31-44.

Heather (1999): Peter Heather, „The Barbarian in Late Antiquity: Image, Reality and Transformation“, in: Richard Miles (Hg.), Constructing Identities in Late Antiquity, London, 234-258.

Heather (2005): Peter Heather, The Fall of Rome: A New History, London.

Heather (2009): Peter Heather, Empires and Barbarians: Migration, Development and the Birth of Europe, London.

Heather (2011): Peter Heather, Invasion der Barbaren. Die Entstehung Europas im ersten Jahrtausend nach Christus, Stuttgart.

Jarnut (2004): Jörg Jarnut, „Germanisch. Plädoyer für die Abschaffung eines obsoleten Zentralbegriffes der Frühmittelalterforschung“, in: Walter Pohl (Hg.), Die Suche nach den Ursprüngen, Wien (Forschungen zur Geschichte des Mittelalters 8), 107-113.

Jussen (1995): Bernhard Jussen, „Über ,Bischofsherrschaften“ und die Prozeduren politisch-sozialer Umordnung in Gallien zwischen ,Antike" und ,Mittelalter" ", Historische Zeitschrift 260, 673-718.

Jussen (1998): Bernhard Jussen, „Liturgie und Legitimation, oder: Wie die Gallo-Romanen das römische Reich beendeten", in: Reinhard Blänkner u. Bernhard Jussen (Hgg.), Institutionen und Ereignis. Über historische Praktiken und Vorstellungen gesellschaftlichen Ordnens, Göttingen (Veröffentlichungen des Max-Planck-Instituts für Geschichte 138), 75-136.

Kaufmann (1995): Frank-Michael Kaufmann, Studien zu Sidonius Apollinaris, Frankfurt a. M. u.a. (Europäische Hochschulschriften, Reihe 3, 681).

Kazanski (1982): Michel Kazanski, „Deux riches tombes de l'époque des grandes invasions au nord de la Gaule (Airan et Pouan)“, Archéologie Medievale 12, 17-33.

Kazanski (1996): Michel Kazanski, „Les tombes „princières“ de l'horizon Untersiebenbrunn, le problème de l'identification ethnique“, in: L'identité des populations archéologiques (Actes des $\mathrm{XVI}^{\mathrm{e}}$ Rencontres Internationales d'Archéologie et d'Histoire d'Antibes), Sophia Antipolis, 109-126.

Kossack (1974): Georg Kossack, „Prunkgräber. Bemerkungen zu Eigenschaften und Aussagewert“, in: Georg Kossack u. Günther Ulbert (Hgg.), Studien zur vor- und frühgeschichtlichen Archäologie. Festschrift für Joachim Werner I, München, 3-33.

Lebecq (2002): Stéphane Lebecq, „,The two faces of King Childeric. History, archaeology, historiography“", in: Walter Pohl u. Max Diesenberger (Hgg.), Integration und Herrschaft. Ethnische Identitäten und soziale Organisation im Frühmittelalter, Wien (Forschungen zur Geschichte des Mittelalters 3), 119-132.

Liebeschuetz (2013): Wolfgang Liebeschuetz, „Habitus barbarus. Did barbarians look different from Romans?“, in: Pierfrancesco Porena u. Yann Rivière (Hgg.), Expropriations et confiscations dans l'empire tardif et les royaumes barbares. Une approche régionale, Rome (École Française de Rome), 13-28.

Modéran (2003): Yves Modéran, Les Maures et l'Afrique romaine (IV -VII siècle), Rom.

Mratschek (2008): Sigrid Mratschek, „Identitätsstiftung aus der Vergangenheit: Zum Diskurs über die trajanische Bildungskultur im Kreis des Sidonius Apollinaris“, in: Therese Fuhrer (Hg.), Die christlich-philosophischen Diskurse der Spätantike: Texte, Personen, Institutionen, Stuttgart, 363-380. 
Müller-Wille (1998): Michael Müller-Wille, Zwei religiöse Welten: Bestattungen der fränkischen Könige Childerich und Chlodwig (Abhandlungen der Geistes- und Sozialwissenschaftlichen Klasse, Akademie der Wissenschaften und der Literatur Mainz, 1998/1), Mainz.

Näf (1995): Beat Näf, Senatorisches Standesbewusstsein in spätrömischer Zeit, Freiburg i.Ue (Paradosis 40).

Périn u. Kazanski (1996): Patrick Périn u. Michel Kazanski, „Das Grab Childerichs I.“, in: Die Franken - Wegbereiter Europas (Ausstellungskatalog Mannheim, Paris, Berlin 1996-97), Mainz, 173-182.

Pohl (1998): Walter Pohl, „Telling the Difference: Signs of Ethnic Identity“, in: Walter Pohl u. Helmut Reimitz (Hgg.), Strategies of Distinction. The Construction of Ethnic Communities, 300-800, Leiden/Köln, 17-69.

Pohl (2010): Walter Pohl, „Il V secolo e le trasformazioni del mondo romano“, in: Paolo Delogu u. Stefano Gasparri (Hgg.), Le trasformazioni del V secolo. L'Italia, i barbari e l'occidente romano (Atti del Seminario di Poggibonsi, 18-20 ottobre 2007), Turnhout, 741-760.

Pohl u. Mehofer (2010): Walter Pohl u. Matthias Mehofer (Hgg.), Archaeology of Identity - Archäologie der Identität, Wien (Forschungen zur Geschichte des Mittelalters 17).

Poulter (2007): Andrew Poulter, „Invisible Goths within and beyond the Roman Empire“, in: John F. Drinkwater u. Benet Salway (Hg.), J. H. Wolf G. Liebeschuetz Reflected, London (Bulletin of the Institute of Classical Studies, Supplement 91).

Quast (2010): Dieter Quast, „Ein spätantikes Szepter aus dem Childerichgrab“, Archäologisches Korrespondenzblatt 40, 285-296.

Quicherat (1877): Jules E. J. Quicherat, Histoire du costume en France depuis les temps les plus reculés jusqu'à la fin du XVIII siècle, Paris.

Quirós Castillo (2011): Juan Antonio Quirós Castillo, „Trends and thoughts on the archaeology of Germanic cemeteries“, Arqueologia y Territorio Medieval 18, 9-14.

Roth (2002): H. Roth, „Childerichs Ring - Fremde Könige mit den Augen von Byzanz aus gesehen?", Acta Praehistorica et Archaeologica 34, 129-134.

Salzman (2002): Michele R. Salzman, The Making of a Christian Aristocracy: Social and Religious Change in the Western Roman Empire, Cambridge/Mass.

Schlinkert (1996): Dirk Schlinkert, Ordo senatorius und nobilitas. Die Konstitution des Senatsadels in der Spätantike, Stuttgart (Hermes Einzelschriften 72).

Tedesco (2006): Paolo Tedesco, ,Il ritorno dei barbari. Studi recenti sulla crisi dell'impero romano", Studi Romani 54, 116-135.

Theuws u. Alkemade (2000): Frans Theuws u. Monica Alkemade, „A Kind of Mirror for Men. Sword Depositions in Late Antique Northern Gaul“, in: Frans Theuws u. Janet Nelson (Hgg.), Rituals of Power. From Late Antiquity to the Early Middle Ages, Leiden/Köln/New York (Transformation of the Roman World 8), 401-476.

Valenti (2009): Marco Valenti, „Ma i ,barbari' sono veramente arrivati in Italia?“, in: Giuliano Volpe u. Pasquale Favia (Hg.), V Congresso Nazionale di Archeologia Medievale (Foggia/Manfredonia, 30 settembre - 3 ottobre 2009), Firenze, 25-30.

von Rummel (2007): Philipp von Rummel, Habitus barbarus. Kleidung und Repräsentation spätantiker Eliten im 4. und 5. Jahrhundert, Berlin/New York (Ergänzungsband zum Reallexikon der germanischen Altertumskunde 55). 
von Rummel (2010): Philipp von Rummel, „Gotisch, barbarisch oder römisch? Methodologische Überlegungen zur ethnischen Interpretation von Kleidung“, in: Walter Pohl u. Matthias Mehofer (Hgg.), Archaeology of Identity - Archäologie der Identität, Wien (Forschungen zur Geschichte des Mittelalters 17), 51-77.

von Rummel (2011): Philipp von Rummel, „The Frexes: Late Roman Barbarians in the Shadow of the Vandal Kingdom“, in: Florin Curta (Hg.), Neglected Barbarians, Turnhout (Studies in the Early Middle Ages 32), 571-603.

von Rummel (2013): Philipp von Rummel, „The Fading Power of Images. Romanbarbarian binary schemata and the problem of interpreting ,Romaness' in a changing world“, in: Walter Pohl u. Gerda Heydemann (Hgg.), Christian and Barbarian Identities in the Early Medieval West, Turnhout (Cultural Encounters in Late Antiquity and the Middle Ages 14).

Ward-Perkins (2005): Bryan Ward-Perkins, The Fall of Rome and the End of Civilization, Oxford.

Werner (1996): Karl Ferdinand Werner, „La ,conquête franque' de la Gaule. Itinéraires historiographiques d'une erreur", Bibliothèque de l'École des Chartes 154, 7-45.

Whittaker (1994): Charles R. Whittaker, The Frontiers of the Roman Empire: A Social and Economic History, Baltimore.

Wickham (2010): Chris Wickham, „Le trasformazioni del V secolo“, in: Paolo Delogu u. Stefano Gasparri (Hgg.), Le trasformazioni del $V$ secolo. L'Italia, $i$ barbari e l'occidente romano (Atti del Seminario di Poggibonsi, 18-20 ottobre 2007), Turnhout, 731-740.

Wood (1994): Ian Wood, The Merovingian Kingdoms, 450-751, London. 

V.

VERFAHREN UND KULTURELLE METHODEN

KOLLEKTIVER IDENTITÄTSSTIFTUNG

IN DEN BARBARISCHEN REGNA 



\title{
So-called Fictitious Trial in the Merovingian Placita
}

\author{
Alexander Callander Murray
}

Nineteen examples of the judicial decisions of the Frankish royal tribunal have come down to us from the Merovingian period. This pool of charters, dating from mid and late seventh century, is made up of sixteen originals and three genuine copies; it can be supplemented with three or four specimens from the Marculf formulary, plus, from the same source, a similar number of examples of auxiliary orders of the king that help explain how the royal tribunal worked. ${ }^{1}$ The charters and formulae as a whole provide us with an invaluable body of evidence for the court practice of the late Merovingian kings and the character of Frankish procedure in general. To distinguish these charters from other enactments of the royal will, namely the broad mass of diplomas comprising royal grants of property and privileges of various sorts, scholars have dubbed the decisions of the royal court placita, a term now apparently unavoidable, if misleading, since it was never used in the Merovingian period to record the findings of the king's court. ${ }^{2}$ The legal substance of the placitum (dispositio, as we now define it) is the royal command in the present tense, but the king does not sign his name, as in other diplomas. The placitum typically bears simply the signature of the referendary and the royal seal.

On the basis of their contents, the nineteen surviving placita can be divided into two broad categories: thirteen placita dealing with various stages of dispute process and six placita recording royal confirmations of private law conveyances - sales and donations brought by the parties before the royal tribunal. ${ }^{3}$ For almost

1 The charters are in the new edition of the MGH Diplomata, edited by Theo Kölzer, vol. 1 [items henceforth abbreviated DM]. The edition also contains two other placita, DM 103 and 118, classed respectively as spurious and interpolated. Neither is of value for the theme of this paper. The formulae are in the MGH edition of Karl Zeumer: Marculf I 25, 37, 38 [henceforth abbreviated FMarc]. Auxiliary commands of the king are FMarc I 26, 27, 28, 29. The Supplement to Marculf (no. 2) also contains a formula that could be classed as a placitum, or, since it is addressed to a count, as an auxiliary executive order. It is Carolingian but almost certainly a copy of a Merovingian model.

2 There is no arenga in the surviving genuine examples, though FMarc I 25 suggests that is not a definitive trait.

3 Disputes: DM 79 (copy), 88, 93, 94, 95, 126, 135, 137, 141, 149, 156, 157, 167. The earliest is dated 642, but this is a copy; the earliest original is 657/78. Add to this group FMarc 
a hundred and forty years, however, our understanding of the nature of the placita and the processes they embody has been complicated by a misapprehension about the procedures underlying both the conveyances and the disputes. ${ }^{4}$ There is a widespread conviction that the same procedure lies behind both disputatious suits and the confirmations of consensual conveyances. As a consequence, it is commonly said that the parties to the confirmations - namely the seller or donor on one hand, and the buyer or beneficiary on the other - resort to a fictitious trial before the court in which they play out the roles of defendant and plaintiff as in a real contested action. Conversely, it seems to follow, that if a confirmation can take the form of a suit, then a suit can disguise a legal process that actually confirms a conveyance, where plaintiff and defendant are really consensual participants in transactions that have already been completed - from one to three of the ostensible disputes have been identified as not really disputes at all, but disguised confirmations carried out in the form of a trial. ${ }^{5}$

One or both of these interpretations - that the conveyance placita on one hand and select dispute placita on the other record fictitious trials (Scheinprozesse in German) - have now become entrenched fixtures in the literature of the placita and have insinuated their way into political evaluations of late Merovingian politics. The new MGH edition of the diplomas, for instance, has incorporated the concept of fictitious procedure directly into summaries of the relevant placita, identifying all six charter confirmations and two of the dispute charters as containing Scheinprozesse, though no placitum ever so characterizes itself; a seller in one of them is even said to be 'condemned' to hand over property to the buyer, though the language of judicial condemnation is never actually used. ${ }^{6}$ The MGH is in line with the classification of the leading authority on the diplomatics of the placita, who regards the confirmations and two of the disputes as based on fictitious trials, though with incidental reservations on his part that make one marvel at the inertia of received opinion. ${ }^{7}$ Even scholars sceptical of reclassing dispute

I $25,37,38$; the four auxiliary commands in $\mathrm{n} .1$ also concern disputes. Conveyance confirmations: DM 136, 143, 153, 155, 158 (copy), 187 (copy). The earliest is dated 692. FMarc Supp. 2, is in the form of a conveyance confirmation.

4 The impression of Brown 2001, 83, that the concept of fictitious disputes in Merovingian law derives from Ian Wood and Paul Fouracre (in Davies and Fouracre 1986) is doubly wrong. Barbara Rosenwein's perception in Rosenwein 1999, 91 that Scheinprozesse were first identified and analysed by Bergmann 1976 is only marginally better.

5 DM 156, 157. Gerberding 1987, 103-104 has also argued that DM 149 is fictitious, but he has not been widely followed. Cf. n. 55, 57 .

6 Summary of DM 155 . The summary to DM 136 erroneously suggests conflicting claims between the parties. The ChLA characterization of the conveyance confirmations waivers equally between seeing them as confirming or awarding 'definitivement' the property claims brought before the court.

7 Bergmann 1976, 1-186; reservations: p. 98, esp.: "Vom rechtshistorischen Standpunkt aus erscheint der Begriff des Scheinprozesses nicht unbedingt treffend, da weder Kläger noch Beklagte, Klage oder sonst irgend etwas, was einen Prozeß charakterisieren, vorhanden 
processes as disguised confirmations have nevertheless embraced the conveyance confirmations as lawsuits, 'fake disputes' as one historian calls them, displaying plaintiffs, defendants, and royal judgments. ${ }^{8}$ These characterizations are usually presented as if sound, undisputed facts of charter study.

Criticisms challenging the aptness of fictitious trial as a category for interpreting the placita have for a long time been few and far between. The Romanist Ernst Rabel in 1905 rejected in passing the concept for Frankish law as he did in exhaustive detail for archaic Roman procedure, seeing the conveyances for what they are, not mock trials. Rabel's seminal work, which appeared in the Zeitschrift der Savigny-Stiftung was located, it seems, in the wrong Abteilung to make an impact on the study of Frankish law, for, as far as I can tell, early medievalists have passed it by. ${ }^{9}$ In 1934, again in passing, the Romanist Henri Levy-Bruhl, who is credited incidentally as being the founder of legal anthropology in France, in a study of archaic Roman procedure rejected the fictitious, dispute character of one of the Frankish conveyances that had incidentally come to his attention. ${ }^{10}$ In 1950, Cesare Manaresi turned the issue on its head: in a study of Italian placita from the ninth to the eleventh century, he claimed that a procedure there (generally called an ostensio chartae in the literature), which seems analogous to the Frankish conveyance procedure, was not a fictitious trial because it was always part of a real dispute processes. ${ }^{11}$ In more recent times, the pace of criticism has quickened somewhat but generally in passing and without systematic examination of the evidence. ${ }^{12}$ From a Germanist perspective, Jurgen Weitzel repudiated the

sind. Die Rechtsgrundlage eines solchen Verfahrens ist ursprünglich eine andere." But cf. the conventional discussion beginning p. 93, and the contradictions quoted below n. 18 Perhaps the desire to extend the concept of Scheinprozess from confirmations to disputes, and thus to invent a tool for recreating them as political documents, generates a reluctance to just let the idea go. See below pp. 312-316.

8 Classen 1956, 70 limited Scheinprozeß to the conveyance confirmations. Hübner 1891, no. 4-9 lists only the confirmations as Scheinprozess. 'Fake disputes': Fouracre 1986, 26. Rosenwein 1999, 91f. goes Fouracre one better and calls so-called Scheinprozess placita 'showcase' trials. This only slightly dramatizes the way scholars have treated them. For the context of this idea, see below, n 55 .

9 Rabel 1905, 347-348.

10 Lévy-Bruhl 1934, 96-135; the placitum is DM 153, p. 135 - a contentious placitum, as it turns out (see Appendix I). He cites a source collection for the singular text he examines.

11 Manaresi 1950-1951, esp. 179, 208-210, where he included brief reference to the Merovingian evidence. The characterization of Italian procedure as an ostensio chartae derives from a formula in the so-called Cartularium Langobardorum, 600, no. 17. Manaresi's views have not been acknowledged for the Frankish context, as far as I can tell. The context of charters displaying the ostensio cartae formula are complicated and not reducible to a simple type (see n. 14).

12 The main detailed anlyses are Brunner 1873 (as in n. 17), Bergmann 1976 (as n. 7), and Kano 2007, 329-353, who came to my attention during the final revisions of this paper. 
value of the concept of Scheinprozesse for Frankish law, apparently to little avail, in 1985 and returned to the subject in 2006. ${ }^{13}$ In 1994, Mauricio Lupoi, surveying assemblies as the locus of general confirmations of legal relations, rejected the concept of 'fictitious trial' for the Frankish conveyances, linking them to the Italian ostensio chartae procedure, which he saw (in complete contrast to Maneresi) as non disputatious. ${ }^{14}$ Olivier Guillot in 1995 , while claiming to be agnostic on whether the Frankish conveyances are fictitious or not, offered an alternative to what he classified as the 'classic interpretation,' considering them as possibly real disputes, much in the fashion of Manaresi, in which a defeated party was forced to acknowledge his cession of property. ${ }^{15}$ In 2005 , in reviewing the new edition of the Merovingian diplomas, I devoted a few paragraphs to disputing the allegedly fictitious character of the placita marked out there as Scheinprozesse, seeing them simply as conveyances. I would like to thank the organizers of the present conference for the opportunity to expand and clarify those remarks.

'Legal fiction' is an important subject in European and comparative law whose literature stretches across various languages outfitted with assorted conceptual and terminological conventions. ${ }^{16}$ If the placita fitted comfortably into this complicated framework, the theoretical dimensions of the concept might be worth exploring. But since they do not, my remarks will mainly be concerned with exploring the context in which the concept of fictitious procedure entered the study of Frankish law and in asking in what sense the procedures in the relevant placita could have been considered fictitious to begin with. For reasons of both priority and time I am going to concentrate on the conveyance confirmations, but

All write from the general perspective of the validity of the concept of fictitious trial. Kano has important observations modifying the views of his predecessors.

13 Weitzel 1985, vol. 2, 839f., 844-847; 2006, 307-311.

14 Lupoi 2000, 215-222, esp. 219, 221. The original Italian edition was published in 1994. Lupoi deals with unilateral and bilateral appearances before assemblies of varying types. His rejection of lis ficta does not stop him from dealing with bilateral appearances as if between plaintiff and defendant. His treatment of the Italian ostensio cartae is rather narrow. What the literature calls ostensio cartae seems to have been used widely in Italy in various contexts, including that of dispute, conveyance and contract. Compare Bougard 1995, 319-329, who notes in passing 'les vrais "Scheinprozesse" de l'époque mérovingienne', and Wickham 1997, esp. 185-191. Wickham's conclusion about the context of the Italian ostensio cartae (p. 191) seems, at this point, about right: "The placitum [meaning the hearing that produced the final document] was an important legal occasion; it had many legal functions. It heard disputes; it ratified contracts; it made private agreements public. But we cannot always tell which is which."

15 Guillot 1995, 711f. The argument appears in n. 195 bis. Manaresi is not cited.

16 The two most relevant surveys to my theme are French: Dekkers 1935 and DumontKisliakoff 1970. Neither is interested in, or apparently aware of, the Merovingian placita. For a sense of how far and how pointlessly the concept can be stretched, see the classic of Henry Sumner Maine 1861, ch. II. 
will conclude with some comments about the isolated disputes that have sometimes been classed as fictitious.

I.

In 1873 fictitious procedure as a category for understanding the early Frankish conveyance confirmations was established by Heinrich Brunner, who was also the first to argue that a placitum apparently about a dispute could also conceal a matter previously settled among the litigants. ${ }^{17}$ He saw the purpose of the conveyance placita as the acquisition of an unchallengeable royal charter, which, he claimed, was obtained by a fictitious lawsuit staged between the parties before the royal tribunal. His principal argument was that the form of procedure in the conveyances was a lawsuit about property, and he proceeded to compare one of the conveyance confirmations with a regular dispute to demonstrate his contention. It is hard to see initially why he did so with such satisfaction. In the summary of the two procedures I am about to give, you should note that the Merovingian texts provide no terms for plaintiff and defendant, or, to use the terms suitable for the conveyance procedure, petitioner and respondent. The role of the parties has to be inferred from the content of their claims and the response of the court, and from the term the confirmations clearly do use for respondent. ${ }^{18}$ This singular term, used in five of the six conveyance confirmations, is auctor, warrantor, a term derived from the Roman law of sale and conveyance. ${ }^{19}$

17 Brunner 1873 (Repr. 1931). Brunner was anticipated by Bethmann-Hollweg 1868, 493, for the Franks and see at n. 25; and, on Italian matters, by Ficker 1868, vol. 1, 37-45 (note the pointed comment as to Ficker's priority by Manaresi 1950, 179). For the common source, see von Jhering $1852-1865$; 2nd ed. 1869 , vol. 3, 503-542 at $\mathrm{n}$. 28 . The trail is clear in the cases of Brunner and Bethmann-Hollweg, but no less sure for Ficker, despite no acknowledgment.

18 The comment by Bergmann 1976, 93: "Die [...] Parteien treten fiktiv als Kläger und Beklagte auf und werden in der Urkunde als solche formulargemäß bezeichnet", is assuredly mistaken. The first part of the statement is an interpretation unsupported by the language of the charter form. Cf. n. 7 above.

19 The auctor is the previous owner, obligated to warrant the title of the property and, in classical law, subject to penalities if the purchaser was later evicted by a rightful owner. See Berger 1953, s.v., for the basic definition. Auctor is a rare occurrence in the standard Roman law handbooks, but the term is all over later legislation. In Frankish law the physical presence of the auctor seems to have have been essential to the suit: FAnd 47, 53; FMarc I 36 - the generally sure-footed translations of Alice Rio 2008 stumble a bit here. FMarc I 36 is the most illuminating because it refers to the need for royal permission to take over the defence of auctores who had died without heirs. Thirty-year prescription did away with the need for an auctor in a defence (e.g. see DM 126). I leave aside the role of auctores in the third-hand procedure of Lex Salica. 
The disputes comprise a complicated group of five separate procedures: 1) Direct judgments in which the dispute is recorded from the appearance of the parties before the court to the command of the king in favour of one them. 2) Interlocutory judgments in which the court, having heard the pleadings as in a direct judgment, calls for one of the parties to produce proof of its contention at a future hearing. 3) Judgments after proof has been provided as demanded by an interlocutory judgment. 4) Judgments after one party defaults, that is fails to appear at a hearing appointed by an interlocutory judgment. And 5) Confirmations of a previous judicial finding. ${ }^{20}$ Despite the various streams into which the dispute procedure could be channelled, there is a fairly uniform pattern to the way the pleadings were carried out. The plaintiff and defendant appeared before the royal tribunal and the plaintiff laid a charge against the defendant, usually for wrongfully retaining property that by right belonged to the plaintiff. The verb commonly used for laying a charge is interpello, but occasionally suggero is used, a more dispassionate term that means 'to bring forward information' or to petition. The information as it is reported, however, is clearly a charge of wrongful detention of the plaintiff's property. The placitum then immediately reports the rejection of the claim by the defendant. Sometimes we are told of a plaintiff's rejoinder to the rebuttal of the defense. Documents are commonly produced by the parties and examined by the court. The court then proceeds to an interlocutory judgment, awaiting further proof, or a direct judgment expressed through a royal command. The command is given on the basis of the testimony of the count of the palace that the placitum's account of the proceedings is accurate and that these were carried out properly.

The procedure for the confirmation of conveyances is far less diverse than for disputes. The petitioner appears before the tribunal opposite the respondent and lays the information about the previous transaction between the parties before the court. $^{21}$ The verb used for filing the petition is always suggero. The petitioner produces the documents relevant to the transaction, the bill-of-sale or donation charter, to be read before the court. The respondent then steps forward and is asked by the court to confirm the veracity of the petitioner's claim, to verify the authenticity of the documents presented to the court, and to stand as warrantor of

20 1) DM 88, 93, 94, 95, 149, 156, 167; 2) DM 135; 3) DM 126; 4) DM 79, 137, 141; 5) DM 157.

21 'Opposite': the occasional word adversus is probably the only term shared between disputes and confirmations that could conceivably indicate dispute. It is found in six or seven placita (the text of DM 88 is uncertain), in about equal proportions between confirmations and disputes. It is not an essential element in the formulae. In the confirmations it is attached to the participle veniens, describing the petitioner's appearance before the court in company with the warrantor (DM 136, 153, 187). In the disputes it is attached to the main verb indicating a petition or a charge being brought before the court (DM 95, 141, 156). The preposition is not of course limited to hostile contexts. It seems to refer to the two parties, standing opposite one another before the court, one laying his petition before the tribunal with respect to the other. 
the transaction now and in the future. The placitum then ends with the royal command asserting the petitioner's full title to property as established by the original documents of conveyance and enjoining the transferor to stand as warrantor in the future. ${ }^{22}$ This last detail, by the way, shows that the property was not deemed to have been removed irrevocably as a source of a future claim by another party just because the document was issued in the name of the king. The placitum confirmed the right of the petitioner merely on the basis of the reported transaction; just as importantly it established a clear warrantor, should it become the subject of a third party suit at a later date. ${ }^{23}$

The common assertion that the procedure of conveyance confirmations and the trial of disputes are the same is demonstrably false. ${ }^{24}$ The dispute and conveyance placita obviously share some terminology - I am about to return to this subject - and forms, but the procedures are distinct and it is difficult to detect elements of the confirmations that could be construed as fictional, never mind the process as a whole. The petitioner never lays a charge or claims that the respondent was unlawfully withholding property. The respondent never challenges the petitioner's claim but willing supports it. The conveyance is presented in the past tense as lawfully concluded. The respondent in fact appears not as defendant but generally as warrantor of the property and its previous alienation. The royal command does not create the petitioner's title but confirms the original conveyance. In other words, the conveyance placita contain independent procedures that need to be dealt with in their own terms, not as adjuncts of lawsuits.

If there are no obvious fictional elements in the conveyance confirmation, it is worth asking how the concept of Scheinproze $\beta$ came to enter the study of early Frankish law. Brunner was a great scholar. Why did he so confidently claim to have detected fictional disputes in the conveyances? The answer I believe is to be found in the state of Romanist scholarship at the time he first proposed his theory of Scheinprozesse. Brunner acknowledged that he was not the first to classify the conveyance confirmations as fictitious suits. Bethmann-Hollweg a few years earlier, noting the resemblance of the conveyance processes to the celebrated Roman conveyance of in iure cessio, had already declared the Frankish procedure to be a fictitious vindicatio, or action for the recovery of property, designed to equip the new owner with an unchallengeable royal charter. ${ }^{25}$ Bethmann-Hollweg borrowed the term vindicatio from Roman procedure and from in iure cessio

22 The exception is DM 153, on which see Appendix 2.

23 Cf. Kano 2003, 44 and 2007, 335f., 338 who sees confirmation of the warranty as the principal aim of 'procès fictif'. Cf. Weitzel 2006, 308.

24 "Das Verfahren eines solchen Scheinprozesses entspricht formal dem eines echten Prozess" (Bergmann 1976, 93). Only slightly less categorical ("in allen wesentlichen Zügen"): Brunner/von Schwerin 1928, vol. 2, 683; which also declares that the "plaintiff's claim is disputed zum Schein".

25 Bethmann-Hollweg 1868, 493. 
itself, though there is an echo of it in the Merovingian texts. It is hard to escape the impression that the Roman in iure cessio was seen as some kind of pattern for the interpretation of the Frankish institution. Brunner too called the procedure of the conveyance placita a Scheinvindikation, and though he initially confined in iure cessio to his footnotes, he clearly viewed it as a critical analogy to procedures in German law. Later he referred to the confirmations of the placita as being carried out through a fictitious lawsuit 'in the mode of the Roman in iure cessio'. ${ }^{26}$ Unlike recent commentators, Brunner's contemporaries too noted the resemblance between the Roman and Frankish institutions. ${ }^{27}$ There is a reason for the deserved prominence of in iure cessio in these accounts other than simply a Romanist background among the legal fraternity. According to the dominant Romanist doctrine of the day, as developed by Rudolf von Jhering, in iure cessio was a prime exhibit, in some ways the parade piece, of those archaic Roman procedures he dubbed Scheingeschäfte, or fictional transactions. ${ }^{28}$ These included the common Roman conveyance of mancipatio, whose language imprinted itself on the new world of written instruments during the imperial period and continues to surface in Merovingian and early medieval texts. At the time Bethmann-Hollweg and Brunner wrote, in iure cessio was regarded with assurance as a fictitious process based on a truncated action, or vindication, for the restoration of property. ${ }^{29}$

The resemblances between in iure cessio and Frankish confirmations of conveyance before the royal tribunal are striking. Gaius provides a brief description of the archaic Roman law procedure. The parties to the conveyance appear before the magistrate, namely the praetor in Rome or the governor in the provinces once again there are no plaintiff and defendant. Appearance before a magistrate is the meaning of in iure, corresponding in traditional Roman litigation to the first stage preceding the magistrate's assignment of a judge to try the case. In iure cessio means a cession of property made before a magistrate, not as the result of a lawsuit. To return to Gaius - the transferee, the person receiving the conveyance, claims the property before the court using an ancient phrase common to both litigation and private law transactions. ${ }^{30}$ Then the magistrate asks the transferor whether he wishes to make a counter claim. The transferor replies in the negative

26 "[...] nach Art der römischen in iure cessio": Brunner 1889, 275. Brunner included the Anglo-Norman institution of fine and the later English common recovery as 'Germanic analogies' to in iure cessio because of their fictional elements (ibid. 286).

27 For example Richard Schröder 1889, 271 who follows his colleague, even apparently independently using the phrase as quoted in previous note.

28 Rudolf von Jhering 1852-1865; I have used the 2nd ed. 1869, vol. 3, 503-42. There is a French translation of the third edition of vol. 3 by O. de Meuenaere 1887. It employs the term actes apparents for Scheingeschäfte. The Italian equivalent is processi apparenti used in the discussion of ostensio cartae.

29 The legis actio sacramento is generally claimed as a model.

30 Hunc ego hominem ex iure Quiritum meum esse aio: Gai. Inst. II 24 for in iure cessio; I 119 for mancipatio; IV 16 for sacramentum in rem (litigation). The slave (homo) is just an example of property. 
or remains silent. The magistrate then 'assigns' the property to the transferee's. ${ }^{31}$ The word used to express the transferee assertion of ownership over the property is vindicare, a verb that just means to claim, but in the specialized substantive form vindicationes was applied by Gaius to a class of lawsuits for the return of property. 32

I do not want to belabour the resemblances between the Frankish and Roman institutions, in part because the juridical implications of both procedures would take us down a twisted track of conjecture that for the purposes of the present subject would be a distraction. But some of the formal correspondences are worth noting. The parties in both cases appear before the court in a fashion with parallels in lawsuits. The claim of the petitioner is quickly resolved without any actual disputation at all (in the archaic Roman case the claim never enters the dispute stage before the judge). The claim is initiated by the transferee in the conveyance; Buckland has noted that the benefitting party making the declaration is a characteristic feature of Roman formal transactions. ${ }^{33}$ Acquiescence to the claim by the respondent settles the matter in the eyes of the court.

There appear to be verbal echoes between the procedures as well. Evindicare, a Merovingian variant of the Roman vindicare, is used in the royal command of the placita to express the transferee's acquisition of title to the property. ${ }^{34}$ In the

31 Gai. Inst. II 24. The verb is addico; the range of meanings in the literature (adjuge, award, confirm) tends to follow dogmatic interpretations of the procedure's meaning.

32 Gai. Inst. IV 5: Appellantur autem in rem quidem actiones uindicationes, in personam uero actiones $[\ldots]$ condictiones.

33 Buckland 1939, vol. 1, 16-26.

34 The usual phrase in disputes over property and in confirmations of conveyances is along the lines of DM 141: ipso locello [=accus.] [...] habiat evindicatum, meaning 'let him have the place in full title' or 'let him have acquired full title to the place'. That there is still a technical sense to (e)vindicare is shown by omission of the phrase in the one dispute regarding debt (DM 137). The 'e' presumably strengthens the simple vindicare to produce 'to vindicate thoroughly'. Vindicare in Lex Salica need have no connection with a lawsuit: LS $67=$ 'claim', in the sense of 'have a right to', with tenere as a near synonym; similarly LS $100 \S 1$. It appears also ca. 600 in Ravenna donations with the same meaning (with near synonyms, habere, tenere, possidere, defendere): portionem [...] iure dominioque, more quo voluerit, im perpetuo vindicent (Tjäder, nos. 20, 31-33; 31, I, 10; 37, 55f.; cf. Tjäder, vol. 1, 461). It means to acquire ownership in the highest sense: conparatorem [...] ingredi, habere, tenere, possidere, vindere, donare, [commutare a] c suo iuri in perpetuo vendicare permisit (no. 36, a sale). Levy 1951, 210-219 outlines the range of meanings in late sources. The idea of lawsuit, however, was never essential for the concept, no matter its usual classical law connotations. By 694 a newly coined synonym vel elidiatum was added to the Merovingian evindicatum clause in dispute formulae; the same appeared in the confirmations soon after, appearing by 702 (missing, and likely omitted in the copy DM 158 a. 710). It is generally, though not universally, believed that this is the verb elitigare (on the doubts, see Vielliard 1927, 50 n. 3). It can be used outside of dispute contexts simply to express the full legal right to something. For example in formula no. 48 of the Cartae Senonicae, it is applied to the full right to fruits in a vineyard used as a security 
procedure of in iure cessio, after the petitioner makes his claim, the magistrate asks the transferor if he wishes to respond. ${ }^{35}$ This is the interrogatio of in iure procedure, originally, at least, carried out in litigation by the plaintiff, and exceptionally as in in iure cessio by the magistrate; it was designed to elicited answers binding on the other party. ${ }^{36}$ Interrogatio appears in all six of the Merovingian placita following the declaration of the petitioner and it seems plain that the answers elicited are supposed to bind the respondent to the truth of the petitioner's claim of ownership.

Two questions immediately arise from the comparison I have just presented.

(1) The first question is awkward but unavoidable. Do the resemblances just outlined constitute grounds for supposing that Frankish conveyance confirmations are based on the in iure cessio procedure? In posing this question one should suppose that the details of in iure cessio as provided by Gaius would have in time been adapted to a legal world shorn of much of the archaism of classical, and earlier, law and would have become dominated by written instruments. The juridical meaning of the two institutions can be distinguished on various points based on fixed dogmatic constructs, but just as easily can be brought into almost complete harmony, especially if one recognizes distinct stages in a singular institutional development. ${ }^{38}$ Connections in language and form between the two are recognizable.

The lesson of in iure cessio for Frankish law, however, may not lie in arguing that the Frankish procedure is a continuation of its Roman counterpart. The main difficulty in seeing the Roman and Frankish institutions as linked is the chronological gap in the historical record between the two. In iure cessio remained a living institution well into the classical period, which is why Gaius and others could write about it. But so far as we can tell, it did not in practice survive the legal changes of the fourth century, at least insofar as the view encompassed by

(cautio). It is not uncommon in the formulae in the phrase elidiato ordine, meaning to have 'with full rights' or 'with protection of the law', regarding donation, usufruct, and possession (FSalBig 10, FSalMerk 21, 33, 34). The earliest appearance I can find of the phrase is in DM 157 a. 709.

35 Praetor interrogat eum qui cedit an contra uindicet (Gai. Inst. II 24).

36 Berger 1952, s.v. Cognitio rolled up the various ancient distinctions into a much more flexible process, driven by the judge.

37 The formula in five instances is interrogatum ei fuit where ei is the warrantor. An infinitive constructon is used once, in the confirmation DM 153, which also shows the question is posed by the tribunal. Interrogatio appears twice in the disputes in contexts that are similar: once to examine and disqualify a second ex parte defendant (DM 141), and once to question the mayor's son Drogo and disqualify his claim that his wife had a right to the property in dispute (DM 149).

38 Levy-Bruhl 1934, 135, calls DM 153 (on which, see Appendix I) "le meilleur example d'in jure cessio concrète" that we have, but this is intended, I believe, as a comparative not an historical analysis. He viewed both as simply confirmations. 
late imperial sources is concerned. The last reference to it as a functioning institution is in a constitution of Diocletian from 293. Nevertheless, it continues to be referenced in legal literature until the sixth century, though not in a form that readily suggests a legal source for contemporary institutions. ${ }^{39}$ It is hardly coincidental that its role in publicly attesting transactions suffered demise in the sources just as the practice of registration before the municipal councils and other officials provided a ready forum for recording transactions of various description. The role of municipal councils in providing a model for the procedure of the Frankish royal tribunal is accepted in the literature, though the details have not been fully explored. ${ }^{40}$ The undoubted resemblances between the court confirmations of the Frankish kings and curial registration, however, creates its own conundrum, because those elements where the placita and gesta procedure overlap tend to correspond to elements of in iure cessio, namely: the forum of a public body, the petition by the beneficiary, and the presence of the alienator as warrantor of the transaction. Moreover in the gesta procedure, a court interrogatio could also occur but at the request of the petitioner; this is analogous if not quite identical to that of in iure cessio and the placita. ${ }^{41}$ In iure cessio still remains the closest parallel to the placita confirmation conveyances. The various resemblances and chronological difficulties suggest two ways of resolving the relation of the placita and Roman procedure. The first possibility is that there is a direct relationship between in iure cessio because it survived into the Frankish period as a prerogative of courts presided over by supreme magistrates in the regions of Gaul. It seems clear that it was never abolished and since it was a prerogative of office it may never have been relinquished. The second possibility is that a procedure basically reproducing the elements of in iure cessio was reconstituted by the Me-

$39 C J 8,53,11$, which omits the passage mentioning in iure cessio. It is supplied by the Consultatio veteris iurisconsulti VI 10. In iure cessio also appears in the Fragmenta Vaticana in writings attributed to Paul 47-51, 75, 5. Boethius treated it while commenting on Gaius (Boeth., in top. Cic., p. 322, 15-25).

40 Classen 1956, 70. Bergmann 1976, 101, provides a useful schematic, optimistic comparison (apparently based on B. Hirschfeld's dissertation of 1904) but avoids the variations of gesta form.

41 In Tjäder, no. 29 (a. 504), a fragment showing the registration of a sale in Ravenna, the purchaser requests the curia to question the vendor, who is present. In no. 31 (a. 540), agents of the curia leave the tribunal to seek out and question the vendor who is not present at the hearing. A similar procedure is followed in the famous donation to Pierius (nos. 1011, a. 489). No. 32 (a. 540) is a letter by the vendors vouching to the curia for a sale to the purchaser; its intention may be in part to serve in lieu of the vendors' appearance. The Frankish sources that deal with conveyances provide no evidence of the dual appearance of petitioner and warrantor. Instead the party applying (prosecutor) to the curia to open the records appears with a mandate: FAnd 1 (mandate from the beneficiary; applicant is donor and mandatarius); FMarc II 37, 38 (mandate from a donor or testator); FTur 2, 3 (mandate from a donor). In the Marculf and Tours documents there is no sign of the beneficiary. 
rovingian kings out of traditional Roman elements that had already been folded into registration as this occurred before the local curia.

(2) The second question is, do the few points of contact between in iure cessio and a lawsuit, a vindicatio rei, justify the former being classed as a fictional procedure? Its secure position among Jhering's Scheingeschäfte warranted Bethmann-Hollweg's and Brunner's characterization of the corresponding Frankish institution. But within a little more than a generation criticism began that slowly turned Romanist opinion against Jhering's interpretation. ${ }^{42}$ This criticism is now reflected in various ways in the handbooks where in iure cessio is no longer regarded as a fictitious trial but as just 'a conveyance which had to be performed in court', or as a derived or hybrid, though still independent, mode long since separated from its putative links to vindicationes in the sense of litigation. ${ }^{43}$ Where its alleged fictitious or collusive character is still invoked, this is part of an explanation for its origin, not its character in historically attested times. ${ }^{44}$ Arguments in favour of the fictitious roots of in iure cessio in fact belong to the heady realm of conjectural history.

There are lessons for us in the now out-dated Romanist infatuation with fictitious trial as a key to understanding the bringing of conveyances before a public body. Fictitious procedure as a concept entered the study of Merovingian law from Roman-law studies but we have failed to notice its eventual rejection and the implication of this for our understanding of procedure before the royal tribunal. Bereft of the supposition that we have to be witnessing a fictitious trial, the resemblances between the conveyance confirmations and a lawsuit or trial in Frankish law seem to be rather minor: they share the opening formula describing the sitting of the king's court, the petitioner's appearance and request, and the employment of the royal command to implement the court's decision. In between, the real procedural meat of the hearing, they steer different courses. The confirmations of conveyances are not trials in any sense. The most that can be said is that they are potential trials. Whether the process before the tribunal will remain on the confirmation track of the petitioner's request depends on the respondent's answer to the interrogatio of the court. All our examples of course show the respondents affirming the petitioners' claims, but at least on a formal level, the procedure seems open to a negative response diverting the hearing along one of the tracks revealed in the dispute placita.

The sharing of parallel forms and expressions does not make one procedure real and the other fictitious or collusive. Nor need it mean that one is derived from

42 M. Wlassak 1904 and 1907 and Ernst Rabel 1906 and 1907 were the tipping point. Dumont-Kisliakoff 1970, 11-15, provides a survey of later works. See also Levy-Bruhl in n. 10 .

43 The quotation comes from Fritz Schultz 1951, 338; see also Wlassak, Rabel, and LevyBruhl as in previous note. Mitteis 1908, 278 ("hybrid"), Kaser 1966, 36 ("nachgeformt") following Rabel.

44 Nicholas 1962, 64. 
the other. If we look at Frankish procedure more broadly, there is certainly no reason to follow the Romanist penchant for speculating on some original pre or proto-historical legal collusion that might, according a particular modern theoretical framework, have first given rise to the court's involvement in conveyances.

By the time we see the Merovingian royal tribunal taking under its mandate the confirmations of private law transactions, there was a long tradition of using the forum of public institutions as means of publicizing, validating and strengthening legal transactions. To this point I have commented on the connections between the Roman-law approach to public attestation and the language and forms of the placita. I have mentioned in iure cessio, the closest parallel to the placita, and the procedure before the municipal curia, still attested in Frankish sources. However, there is another side to the Merovingian legal experience which, though much shallower in the depth of its historical record, also has a general bearing on the Gallic habituation to the court, including the royal court, as a forum for private transactions.

Frankish law and contemporary practice was no stranger to non-dispute court processes, including conveyances. ${ }^{45}$ Lex Salica and Lex Ribvaria alone provide half a dozen examples of transactions before local courts and that of the king, including a form of testamentary conveyance, and sales in mallo that thereby claim the right to a notarized bill-of-sale. ${ }^{46}$ The formularies provide not only evidence of appearances before the curia involving registration in the public records but also transactions before regional courts, and, slightly more ambiguously, 'before the king': the last included a form of testamentary conveyance. ${ }^{47}$ In all we are talking about a dozen forms of transaction that in the course of the sixth and seventh centuries could take place before public fora.

It seems reasonable to suppose, then, that by the time the placita record appears, the concept of court validation of private law transactions was a legal notion of considerable antiquity, enhanced by the ability of courts at various levels to issue written confirmation of the acts that took place before them. The Gallic habituation to the use of courts as a forum for private transactions was long standing by the time the conveyance placita are attested in the late seventh century, and there is no reason why the royal tribunal would resort to the collusion of a

45 Lupoi's general point (as in n. 14) about the role of assemblies is surely correct.

46 LS 44 (disbursement of reipi); LS 100 (disbursement of achasius); LS 60 (unilatereal repudiation of kinship ties); LRib 57 (manumission); LS 46, LRib 50 (testamentary conveyances); LRib 62 (sales in mallo) and cf. LS 47, which mentions in passing that transactions like sales, exchanges, and payments, had to take place publice - in LS $46 \S 4$, C redaction, publice $=$ in mallo; in LS $25 \S 3$ it means 'openly'.

47 FAnd $1 \mathrm{a}, \mathrm{b}, \mathrm{c}$ (ratification of a mandate and registration of donation). FAnd 32 (confirmation of property holding when title deeds destroyed); its opening formula describing the sitting of the joint episcopal and comital court echoes the placita. FMarc I 12 (mutual donation), FMarc I 13 (testamentary conveyance). FMarc I 21 (creation of a mandate) 
fictional trial and the drama of mock litigation to carry out the rather mundane confirmation of simple sales and donations.

To say 'by the time the placita record appears' avoids rather pointedly the question of when bi-lateral conveyance confirmations, involving petitioner and conveyancer/warrantor, became a commission of the officials making up the royal tribunal. The placitum form as whole in fact appears pretty much at the same time as does the charter record and is thus conditioned by the rather lopsided pattern of document preservation that characterizes Merovingian evidence. ${ }^{48}$ There is no reason to suppose that it, any more than conventional diplomas, was a new form in the seventh century. ${ }^{49}$ The conveyance placita appear in the 690 s. In concluding on the difficult problem of placita origins, I will limit myself to reservations about the current view that so-called fictitious trials were intrinsically late arrivals to the royal court. First, this view needs testing against our dependence on the central role of the Saint-Denis archive in creating the chronological profile of the Merovingian diploma, on the circumstances of the archive's survival during the medieval period, and its employment in forgery. (The earliest original diplomas survive largely because their text sides were glued down on backing and their reverse sides, giving the appearance of great age, were used for spurious charters). Second, the perspective that the appearance of conveyance placita in the late seventh century is a sign of the declining power of the monarchy seems rather overdrawn at the expense of recognizing the placitum's merits as facilitating a relatively speedy, bureaucratic response to the desire for legal stability and a more extensive intervention of the monarch's authority into the private law transactions of its subjects. The principal argument for a late appearance of the bi-lateral conveyances (that is the so-called fictious trials) as a mark of declining royal power is based on the survival pattern of unilateral confirmation diplomas: the latter are among the earliest surviving diplomas but leave no traces among later specimens. ${ }^{50}$ This pattern is to be accounted for, so it is argued, by the monarchy losing

48 Legislation for the sixth and early seventh century, diplomas (including placita) for the seventh. There is no intrinsic reason for this pattern. Legislation was continued in the seventh century and diplomas were issued in the sixth. Another pattern among the diplomas is that original and genuine ones are vitually all Neustrian. See Murray 2005, 251-261 on the significance, or lack therof, of this pattern.

49 "Das neue, nicht-römische Instrument der Placita ist ein Resultat des [...] Funktionswandels der Urkunde nach dem Verfall der letzten Reste spätantiker-römischer Aktenführung" (Kölzer 2004, 46) begs a number of questions. Cf. Murray (as in note 48) on the alleged importance of the political altercations of the late sixth century. There are further reservations by Goffart (Ganz/Goffart 1990, 919f.).

50 Early, original unilateral confirmations: DM 22 before a. 628 (testamentary donation); and see Debus 1967, 19. DM 28 a. 625 (donation); and see Debus 1967, 11. DM 32 a. 629 (inheritance and purchases), one of the only two uncoverted papyrus originals from SaintDenis, this one bearing Dagobert's signature. DM 75 a. 639/50 (various deeded properties); Kölzer 2001, 191, argues it is not clear when the document reached the Saint-Denis 
control of the confirmation process and the replacement by the 690s of unilateral confirmations with bi-lateral conveyance placita that reflected better the aristocratic interests controlling the court. ${ }^{51}$ However, unilateral confirmations mainly survive because an early sequence of them was converted by Saint-Denis forgers. ${ }^{52}$ The idea that unilateral confirmations ceased in the late seventh century just because specimens do not survive in the corpus of late diplomas also seems flawed. ${ }^{53}$ The formulary of Marculf shows that wholesale confirmations of property including sales, donations, and exchanges continued to be issued by the monarchy to laypersons and ecclesiastical corporations in response to unilateral petitions. ${ }^{54}$ Unilateral and bilateral confirmations, by diploma and placitum respectively, existed side by side. The placita are more a testament to the routinization of government than a special indicator of the dwindling political power of the monarchy.

To summarize my remarks thus far. The concept of fictitious procedure in the study of Frankish law is a distraction. Scheinproze $\beta$ was introduced to the study of Frankish law as an offshoot of Romanist concerns about the peculiarities of early, by which I mean archaic, Roman procedure. The unexpressed implication in the early literature of the placita is that such archaic modes might be applicable to early Frankish procedure. No one has noticed that in the meantime Romanists have rightly moved on, and thus abandoned the conceptual constraints of the idea of Scheingeschäfte. The concept of fictitious trial has nothing to contribute to our

archive, though before 1061/65 when it was used in a forgery. A very early copy example is an interpolated Le Mans charter, DM 25. For the sake of simplicity, I give MGH dates.

51 Bergmann 1976, 96ff., 100.

52 As a result of being pasted down on backing, they are in miserable shape, trimmed, lacunose and barely readable. Their attraction was that they were papyrus, a mark of age. As for the apparently unconverted DM 32, Kölzer 2001, 87, argues that it was a late addition, after the eleventh century, to the Saint-Denis archive, a circumstance that would account for its relatively intact survival. Brühl 1998, 44 attributes its survival before the forger's hand to a clear autograph of Dagobert. In any case, on the borders, there are still remnants of glue (Kölzer 2001, 88).

53 As already argued by Kano 2007, 348-350. He uses a slightly differenct body of texts than I do. See next note. I reserve judgment on the deperdita that he cites. The general point is surely correct.

54 FMarc I 31 (for a layman): de omni corpore facultatas suae, tam quod regio munere [...] quam quod per vindicionis, cessionis, donationis, commutationesque titulum ad praesens iustae et rationabiliter est conquestum et ad presens possidere videtur. FMarc I 35 (for a monastery): omnes facultates [...] quicquid aut regia conlationem aut privatorum munere vel antecessores abbatis [...] est legaliter atquestum aut comparatum. Kano 2001, 348 cites FMarc I 12, a mutual donation between spouses of usufruct, which I take not to be unilateral and limited in effect; FMarc I 13, a form of testamentary donation in which the king is a party to the act - there is a cession of property by festuca; and two rather difficult diploma deperdita (nos. 250 and 388, Kölzer 2001, vol. 2). 
analysis of the procedure of the Merovingian royal tribunal. It operated in a world conceptually connected to the recent Roman past and obviously contemporary Frankish procedure. None of this background, which readily accepted the use of public fora to register conveyances and other types of judicial business, suggests any predisposition to employ fictions to accomplish fairly straightforward legal ends. Nor does this background suggest that the procedure of the conveyance placita was necessarily a new creation nor a sign of waning Merovingian power. Other sources can tell us about that. We divert our attention from the real significance of the placita and related documents by clinging to outmoded concepts of legal history.

II.

The implications of this diversion are prominent not only in the tendency to read the conveyances as markers of declining royal power but also in efforts to cast select dispute placita in turn as Scheinprozesse. ${ }^{55}$ The judicial claims in these cases all involve, and always indirectly, the mayor of the palace, Grimoald. A leading assumption here is that kings were mere ciphers; the interest of mayors could not have been seen to be jeapordized in court cases before the tribunal, and therefore such trials, touching on what are perceived to be mayoral interests, must simply be confirmations and fictitious in some way. A counter assumption for those detecting continuing power of Merovingian kings is to see the same cases as indicators of the still contained power of the mayors. The power of the late mayors, however, is hardly a good starting point in reading late disputes. Jettisoning the concept of fictitious procedure, can help check the introduction of invented, tendentious circumstances into the record. ${ }^{56}$

There are two principal candidates for fictitious trial among the disputes, one first suggested by Brunner and one by Bergmann. ${ }^{57}$ The two placita have consi-

55 The conveyance placita, however, have not been exempt from the attempt to read into them specific political significances. Rosenwein 1999, 91-96, developing the term 'fictive disputes' into 'showcase trials', interprets them as political instruments, ritual enactments of enmity and rapproachment, by which Neustrian factions and the Pippinids announced their powers or made a show of capitulation. DM 136, the earliest of the conveyances (a. 692/3), is interpreted as a marker of division and reconciliation within a Chambliois faction whose doings are further traced in the famous dispute placitum DM 149 (here interpreted as Scheinprozess) between the abbot of Tussonval and Drogo, son of the mayor of the palace. The defeat of the latter is seen as a concession staged by the mayor Pippin to conciliate the Chambliois faction.

56 Kölzer 2004 provides a valuable, and pointed overview of the problems of conceptualizing royal and mayoral power in the late seventh and early eight centuries. I do not endorse all his conclusions.

57 Gerberding 1987, 103-104 suggested DM 149 (cf. previous note 55, which draws on this notion) mainly because the loser was Drogo, the mayor's son. Wood's rebuttal, defending 
derable intrinsic interest and, with more time, would be worth exploring. On the question of their fictitious character, however, whatever traction this idea has had stems largely from the perception that fictitious trials formed an element in the placita to begin with (on which I have said more than enough) and its counterpart that real trials virtually disappeared before the late Merovingians. ${ }^{58}$ One can readily show, however, that both placita do not have fictitious elements and fit comfortably into the pattern of conventional dispute process.

Brunner regarded DM 157 to be a Scheinklage, despite all appearances to the contrary that it simply concluded a suit. The subject of the placitum is SaintDenis's claim as plaintiff to a mill held by the fisc, whose own claim was defended by its representatives, agents of Grimoald, Mayor of the Palace. The fisc and its representatives were the defendants, not Grimoald personally. The monastery's claim was settled by an inquest ordered by the mayor, and on the basis of the mayoral judgment proceeding from the inquest, the placitum confirms St-Denis' right. ${ }^{59}$ Like so many placita DM 157 is a confirmation, but of a judicial decision ending a suit not of a conveyance.

Interpretation of this placitum is complicated by the sequence of events outlined in its narratio which presents the reader with voice problems that are not easily resolved. Basically there are two ways to read the sequence preceding the confirmation of the royal court. $^{60}$ (1) The judicial process began before the mayoral court and subsequently was brought before the royal tribunal for confir-

the powers of the later Merovingians (Wood 1994, 263), is also political. He accepts it as a genuine dispute because he can detect two later opponents of the Pippinids in the "witness list' (by which he means members of the tribunal). The tribunal has about twenty names, supplemented by 'cunctis nostris fidelibus'. Both seem to regard the procedural elements as irrelevant to their arguments and are oblivious to the idea that there were times when rulers were subject to the processes they represented themselves as defending.

58 Cf. the characterization of the placita of the 'last Merovingians', apparently those after 700, by Heidrich 1967, 108f. All placita of the period are confirmations, she claims, with the single exception of DM 167. The implications here are quite misleading and depend on classing DM 157 as a confirmation, which is technically true, but it confirms a judgment and comes at the end of a dispute, and dismissing DM 156 as a dispute only in appearance. A better view of the late placita would find that four are conveyances and three are disputes. The big picture of the placita is not quite as skewed by the later record as Heidrich implies. Of the six placita originals and good copies before the 690s when the conveyances appear, all are judgments; but of the five originals, four are converted Saint-Denis papyrus specimens of which three reflect a dossier of some kind, since they are connected with a certain Ermelinus. Of the six placita of the 690s (all originals), two are conveyances. Of the thirteen placita from the 690s to 726 (originals and good copies), six are confirmations and seven are disputes. The tilt towards conveyance confirmations is real but it is subtle. Among Saint-Denis originals, the period after 700 produces two conveyances and three disputes.

59 Formally the judgment of the mayor is decisive; procedurally the verdict is supplied by the inquest.

60 Murray 2005, 269f. and see Appendix 2. 
mation. This is the view of Brunner and Bergmann. (2) The process began with a petition before the king. It was then taken up by the mayor for further investigation. The royal court then confirmed the mayoral judgment. Whether St-Denis' claim began in the palace or not, however, is incidental to the question whether the final procedure before the tribunal contains fictional elements or not.

Brunner's argument is that the procedure before the tribunal approximates that of the conveyance confirmations, which he had already defined as Scheinprozesse. ${ }^{61}$ It takes the form of a lawsuit though it is intended to acquire a confirmation. He laid stress particularly on the lack of the phrase malo ordine in the charge laid by St-Denis, implying that while the form of procedure resembled a lawsuit, the subject of the appearance was no longer really a claim about the illegal withholding of property, and therefore was at the same time both disputatious and fictitious. In rejoinder it can be pointed out that the confirmation conveyances are what they are: they are not lawsuits, they are not fictitious and have no bearing on DM 157. The procedure before the tribunal about the mill is likewise what it appears to be: the confirmation of a judgement ending a suit. There is no attempt to disguise the substance of the proceedings. The first part of the placitum provides the history behind the monastery's claim; there is no new charge of withholding property. Whether malo ordine had ever been part of the original charge is a moot point. There would have been no significance in its omission if it were not. Not all property disputes have it, nor should we suppose that it was essential to a charge. Moreover its inclusion in a claim against the royal fisc, which is what the mayor's representatives served, might have seemed impertinent. The dispute outlined in DM 157 was not about personal property and illegal acts but an administrative disagreement among the great servants of the king, the fisc and the monastery of Saint-Denis, on how public resources ultimately derived from the crown had been allocated. DM 157 is merely a record of the tribunal's confirmation of the happy outcome for Saint-Denis. There are no fictional elements in it.

Administrative friction also forms the context of the other dispute placitum, DM 156, cited as a Scheinprozess. Again it is a quarrel between the fisc, that is the agents of the mayor, and Saint-Denis and was concluded in Saint-Denis' favour the day before DM $157 .^{62}$ (In a short period of time, therefore, Saint-Denis won two victories, but of course given the nature of the record we never hear about its losses.) The candidacy of DM 156 as a Scheinprozess is recent and the argument owes much to its association with DM 157 and the argument made

61 This seems to be the reason for Bergmann's assertion (p. 176) that the mayor's auditor (the equivalent of the king's count of the palace) was physically present at the confirmation before the royal court: he would act in the role of the respondent as in the conveyance confirmations. But the auditor Rigofredus' attestation is only in the mayoral judgment; he is not said to be physically present to respond to the court. There is no interrogatio.

62 A translation is provided in Appendix III. 
about the latter. ${ }^{63}$ In DM 156 representatives of Saint-Denis appeared before the royal tribunal and claimed that its right to tolls collected from merchants at the fair of Saint-Denis was being infringed by agents of the count of Paris and Grimoald, mayor of the palace. Saint-Denis supported its claim with a sheaf of documents from previous kings. Grimoald's representatives objected that the share they themselves collected was customary. Saint-Denis responded that an earlier count had introduced this custom by force. An examination of various persons and the diplomas of earlier kings was conducted. As it upheld Saint-Denis' claim to the tolls in their entirety, its finding was accepted by the mayor and the rest of the court. Bergmann, whose argument is the most circumstantial, claims there was a previous mayoral judgment favorable to St-Denis issued before the St-Denis' appearance in court as in DM 157 about the mill; DM 156 is thus like DM 157 a Scheinprozess. ${ }^{64}$ In fact only mayoral agreement to the consensus of the court is mentioned - no mayoral hearing, no mayoral judgment. The dispute took place before the royal tribunal and the language of dispute, claim, and counterclaim is unmistakable. The lengthy account of the issues and the different claims of the sides read easily enough as genuine litigation. Again, there are no signs of fictional elements in what is a direct judgment of the tribunal.

There has been a tendency to view the late placita involving Pippinids as political indicators of their strength. The concept of fictitious trial allows them to be savvy political manipulators; its rejection shows them still not to be in the saddle but blocked by their enemies. The possibility that the cases have nothing much to do with either of these scenarios is largely unacknowledged. The routinization of procedure is ignored. The systematic, and bureaucratic, character of court procedure is disregarded. The structures of Frankish government are thoroughly personalized and reduced to a political show.

I do not want to suggest that the placita are of no value in arguments about the political conditions of the last phase of Merovingian history. I do argue however that the concept of fictional trial does not add to that discourse and is an unnecessary distraction. Moreover, I want to suggest that the placita, even those

63 Bergmann 1976, 173-175, imports Brunner's argument re malo ordine and the supposition of a previous mayoral hearing. Kölzer 2001, 389; 2004, 55 accepts a previous hearing. The confirmation of Pippin DK 6 = ChLA 15: 602, which refers to a previous judgment, (illo iudicio evindicato domno Hiltberto rege et avunculo nostro Grimoaldo maiorum domo) proves only the obvious: the existance of DM 156, not a separate, previous judgment by Grimoald. Grimoald's agreement with the court finding is found in DM 156. Further argument here seems pointless: there is no previous mayoral hearing in the text or in DK 6. Inventing a Pippinid deperditum here seems slightly perverse: Heidrich 1966, 270, no. 25. Though Heidrich eschews the term Scheinprozess, her earlier interpretation of the suit in DM 156 suggested it was a dispute in name only.

64 There is an amazing circularity to the accrual of Scheinprozesse: the conveyance confirmations are claimed to be fictitious; DM 157, like the conveyances, is a confirmation and so must be fictitious like them; DM 156 (though quite superficially) resembles 157 and therefore it must be a fictitious trial too. 
involving mayor's servants, and mayor's sons, are testimony to administrative and legal processes, first and foremost. We all know that these exist within particular political environments, but we also know that outside of modern, true authoritarian contexts they can operate according to rules that do not simply reflect the will of rulers or even elites. It would be worthwhile if there were some appreciation of the common regularities of law and administration before headlong, unchecked fixations on power heedlessly distort evidence that has important things to tell us about the functioning of early Medieval society. ${ }^{65}$

\section{Appendix I}

\section{Explaining DM 153}

The placita, as scholarship has so designated them, readily break down according to content into two groups: disputes, namely a heterogeneous group of judgments and phases in the judgment process; and conveyance confirmations, which have been discussed in the previous pages as a fairly uniform legal category. The placitum form, however, was likely very flexible and may have encompassed a variety of circumstances that have not come down to us. ${ }^{66}$ There is no reason to assume placita only encompassed judgments about disputes and simple conveyance confirmations. Some slightly anomalous features of one of the latter needs discussion, for it is possible that the placitum in question comes at the end of an extrajudicial disputatious process, even though it is presented, quite unfictitiously, as a conveyance. By any reading, it contains an immediate cession of rights of a kind that is not found in the other conveyance placita.

DM 153, dated 702, records the conveyance to Saint-Germain-des-Prés of a monastery by Adalgudis and her deceased husband Gammo, as confirmed by a representative of Adalgudis called Aigatheus, who, the language of the placitum suggests, may be a party to the transaction before the tribunal. Only Aigatheus is present before the court. ${ }^{67}$ Aigatheus confirms the documents made by Adalgudis and her husband in favour of Saint-Germain. Then Aigetheus "both on behalf of himself and Adalgudis by festuca also said to the assembly on behalf of himself and Adalgudis that in all respects he was quit" of the small monastery that was

65 Cf. remarks by Weitzel 2006, 311.

66 Murray 2005, 271. This owes much to Classen's observation 1955-1956, 69-70 about the resemblance of the form to minutes, well-known in Roman and ecclesiastical sources.

67 Bergmann's not very exact summary 1976, 171f. ignores Aigatheus and treats Adalgudis as if she acts before the court in person and was the sole donor. Woman had standing before the tribunal. The use of a representative must mean that she was not there at all, that she was present but preferred not to stand before the court, or that the representative acted not only on her behalf but also on his own. 
the subject of the donation. ${ }^{68}$ The conclusion of the court's decision confirming the documents also adds, uncharacteristically, the wish that "dispute regarding this matter be set to rest in the future". ${ }^{69}$ Aigatheus, on behalf of Adalgudis or himself, never offers, or is asked, to stand as warrantor of the donation. DM 153 thus stands out from the other conveyances for three reasons: immediate cession of an interest in the property by festuca; no mention of the opposite party standing as warrantor; the wish that in the future dispute may be set at rest. These features are the basis of a recent argument that DM 153 concludes a real dispute. ${ }^{70}$

It is true that DM 153 is the closest we can come among the conveyance confirmations to language that indicates a dispute, but there is no mention of a previous judgment in it and the form still hews pretty closely to standard conveyance confirmations. If it did come at the end of some disagreement between the parties, that dispute seems likely to have been extrajudicial, the subject of negotiations, mediation, or arbitration (to use terms of increasing formality that still fall short of litigation).

It is possible to speculate on some of the circumstances behind the placitum because DM 153 is unique in another way. There is a cartulary copy, dated 697, of what purports to be the terms of a donation agreement - the original one, we must presume, behind DM 153 - between Saint-Germain and the couple Gammo and Adaltrudis, made five years before the lacitum. $^{71}$ To go by the copy, Gammo and Adaltrudis made a donation of the monastery to Saint-Germain but, typical of the period, reserved usufruct over the place for the rest of their own lives and that

68 Qui et ipsi [=ipse] Aigatheus in praesenti per sua festuca tam pro se quam et pro ipsa Adalgude se in omnebus de ipso monasthyriolo Lemauso una cum adiecencias [...] dixit esse exitum. In praesenti = openly, before those present, before the court; it can sometimes mean, 'on the spot', 'immediately'. The subject of dixit could of course be Adelgudis, but while this shifts the focus of the procedure a little, I do not think it clarifies anything.

69 Et sit inter ipsis ex hac re in postmodo subita causacio. A future wish of no dissension hardly constitutes grounds for assuming that a dispute has just taken place, but the phrase is used in dispute placita (see Appendix II for an example) and only in this one conveyance confirmation. The phrase may be suggestive but is hardly conclusive of anything.

70 Kano 2007, 340-342; DM 153 is thus not a Scheinprozess, but a real trial, according to categories of traditional scholarship. Kano, recognizing the obscurities of the context, never presses his interpretion home. He acknowledges that the dispute could have been extrajudicial. I hope some of my comments help resolve the distinctive features of the placitum.

71 The modern edition is Poupardin, no. $10=$ Pardessus, no. 442. Brühl 1998, 115 and n. 51, supports its essential genuineness because of the existence of DM 153, but detects "deutliche Zeichen später Überarbeitung". The incompatibilities listed are minor (they go back to Mabillon) and of the readily detectable kind. There is more wrong with this charter, some of which I think could be established with close reading. The usufruct and the two daughters still emerge from the text, sometimes awkwardly, despite intrusions. I take the familial usufruct as genuine because it fits the cession of rights by festuca of DM 153 . 
of two daughters, one an abbess of the monastery and another called Maria. ${ }^{72}$ The donation, so it seems, was widely publicised when it was originally made. ${ }^{73}$ None of these details are alluded to in DM 153. Nevertheless, the existence of usufructuary rights seems to me obviously connected with the cession of residual interest in the property by means of a festuca recorded by the placitum. By the time of Aigatheus' appearance before the tribunal, Gammo had obviously died, and we are left to guess the fate of the daughters. DM 153 may simply be a confirmation of the original donation, occasioned possibly by the deaths of one or more of the principals and Adalgudis' decision to finally be quit of her interest in the monastery (which would not occasion the subject of warranty because the donation had been widely publicized). Thus, the confirmation is secondary; the main purpose behind the appearance before the tribunal is the cession of usufructuary rights. ${ }^{74}$

If there is more to it than that, then, I would suggest the following scenario. Aigatheus, whom the placitum treats as an agent of Adalgudis and as an interested party on his own, is a relation, possibly a husband or even son of the said Maria, with an interest in the fate of the property. He has been persuaded to drop his interest (through negotiations, to follow the simplest course, that for all we know involved due consideration for his good will). He appears before the court as representative of Adalgudis, the only way in fact by which he could have standing, to confirm the donation in her name and to cede her and his own remaining interest in the property. ${ }^{75}$ The question of being a warrantor is never addressed to him because Aigetheus was never an owner of the property and, after his cession of interest, will never be one. His warranty is immaterial. By this reading of the placitum the focus of the procedure is really Saint-Germain and Aigatheus, whose standing before the court depends on his role as agent of Adalgudis, but whose cession of interest in the property Saint-Germain is eager to have acknowledged.

By either reading, or some combination thereof, nothing is fictitious. There is no mock trial, no real trial, no distortion of confirmation procedure. The tribunal is exploited, but openly and legally to acknowledge the cession of proprietary interest in the monastery by Adalgudis, and Aigatheus. DM 153 is still a conveyance confirmation (Adalgudis' and Gammo's original donation), and also a little more than that: the cession of residual rights in the property.

72 The term usufruct is not used, though that is how we would understand the arrangement. The couple and their daughters retain the right res tenere vel dominare for as long as they live.

73 The donation supposedly received considerable public, even royal acknowlegment: Epistola huius donationis [...] Bituricas in civitate in conventu nobilium, in praesentia regis domini nostri Childeberti relectas, et Parisius civitate in monasterio Sancti Vicentii [...] super altare Sanctae Crucis posita.

74 See Kano 2007, 341, whose comments are made within the self-imposed burden of defining 'fictitious trial'.

75 For intervenors without standing, see DM 141, where the son of the defendant is questioned and fined after his intervention. The penalties are pledged in court by festuca. 


\section{Appendix II}

The Sequence of Hearings in DM 157

In the text I noted that ambiguities in the use of voice in DM 157 make it difficult to be clear about the sequence of appearances before the king and the mayoral court. The usual view is to read the appearance of Saint-Denis before the king as the one and only presentation of the case before the royal court. The background to the dispute, which concerned a mill, is consequently all part of a narration provided by Saint-Denis, including notice of the monastery's disputation with the mayor's officials and then the settlement of the dispute by the mayor's judgment (parts 1-2, in translation below). The mayoral judgment is then confirmed by the royal tribunal. The hearing referred to in the opening formula is in this scenario the same as the one that issues the final decision concluding the placitum. In the text I noted another way of reading the placitum in which the opening formula refers to a first appearance before the king. The case is thereafter taken up by the mayor who issues a decision in favour of Saint-Denis, which then comes back before the royal court to receive confirmation. There are thus in this scenario two appearances before the king. I would like to explore this reading a little more fully and consider the features of the placitum that seem to point in that direction. I have appended a translation, marked by arabic numerals noting what I take to be the main components of the placitum and the main phases of the dispute process.

1. Petition to the king. It may seem to some natural to read the opening formula as a description of the beginning of the same hearing that gives a decision. But that practice is true only of placita that contain direct judgments and conveyance confirmations, in both of which a judicial determination follows directly on the appearance of the parties; there is no break in the proceedings, and so judgment follows on the appearance of the parties before the tribunal. This pattern is demonstrably not true for the range of procedures dependent on interlocutory judgments that involved at least two hearings. In these cases, the opening formula of the placitum refers to the first hearing when plaintiff and defendant appear together. The placitum itself is dated to the final hearing when, at least in the case of defaults, only one party was present. ${ }^{76}$ The opening formula of DM 157, therefore, need not refer to the day the confirmation is given. The placitum, with its

76 DM 79, 141 (defaults after interlocutory judgments); DM 126 (proof after interlocutory judgment). DM 126 has an ante dies superscript in the opening formula noting the dislocation between charge and judgment. The charge was laid in Compiègne and the judgment issued at Luzarches. In DM 157 appearance and royal confirmation both took place at Montmacq, an inconclusive detail, because the place in dispute is only a short distance away and the total length of time for completion of the trial process need not have taken very long. In DM 141, despite possibly multiple hearings, the place of the initial hearing and judgment were the same, Valenciennes. 
background to the suit and its course up until judgment, was written at the time of the confirmation but ranged back to the initiation of the complaint.

There are also positive reasons to doubt that the hearing in the opening formula of DM 157 is in fact a meeting of the tribunal at all. The king alone is mentioned in the formula, a pattern parallelled in one other placitum, DM 137, which raises similar problems to that of DM $157 .^{77}$ Only the agents of Saint-Denis are said to appear (the fisc's initial response appears in the narrative of the monastery). There is no mention of a counter party, equivalent of a defendant in direct judgments and a respondent in conveyance confirmations. The plea looks to be completely unilateral. The procedure portrayed reads easily as a petition brought before the king not a lawsuit before the dedicated tribunal. The common view that DM 157 resembles a conveyance confirmation also seems quite unwarranted. There is no respondent, no following interrogatio, no affirmation of the petitioner's claim, indeed no sign of another party at all.

The outcome of the petition is that Grimoald, in conjunction, typically enough, with other officials, agrees to investigate the monastery's complaint, which would fall under the jurisdiction of the fisc anyway. The monks, it seems, were able to make a prima facie case as to their version of the mill's relationship to Saint-Denis, a factor that is reflected in the mayoral prescription of proof in a form that privileges Saint-Denis' claim (below 2). One can imagine that SaintDenis, frustrated in its attempts to gain satisfaction before local fiscal officials, has decided to approach the king and the palace directly. Having gained the attention of the mayor and palace officials, the case was speedily subject to mayoral inquiry.

2. Transfer to the court of the mayor. Grimoald decided to subject the issue to a form of inquest, requiring an oath from locals from both the mayoral and monastic collection centres who were to swear as to their knowledge of previous practices involving Saint-Denis.

3. Report on the mayoral hearing. The findings of the inquest and the decision of the mayoral court are found in the report of the proceedings made by Rigofridus, the mayor's auditor (a mayoral parallel to the royal count of the palace); the report is obviously the basis for the confirmation of the royal tribunal.

77 The form is Bergmann's B class of introductions 1976, 61, 64 common only to DM 137 and 157. The case for the suit beginning before the king is a little more difficult to make for DM 137. It seems to start with a unilateral petition to the king, but since the placitum records a default process, the unilateral character of the introductory formula can be accounted for by the non-appearance of the defendant. The problem in DM 137 is whether the case started in an episcopal court and was only completed before the tribunal or whether a royal order, in response to a petition by the plaintiff, required the episcopal court to resolve the dispute by trial if possible. FMarc I 27 provides a possible model. The stages from petition, to failed resolution in the episcopal court, back to the royal court for final proof and default seemed to be marked by the relative adverb unde, but a conclusive argument is not yet possible. 
The decision of the mayoral judgment, as reported in the placitum, confirmed the priority of the Saint-Denis claim. It should be noted that, though judgment is given by the mayor, it is based on what amounts to a verdict issued by a local panel. The judgment of the mayor, for all his power, follows the finding of the inquest. The officials of the fisc, that is to say the defendants, we are told, accepted the verdict and the mayoral judgment, conceding to Saint-Denis its right to the mill.

4. Decision of the tribunal and royal command. The submission of the mayoral judgment really marks the substance of the procedure that took place on 14 December 709. There is no indication if Rigofredus is on hand to confirm the mayoral judgment in person or not. The document, with signatures and a seal, should have been sufficient. The mayor may or may not have been present as a member of the tribunal. Attestation by Rigofrid of Grimoald's judgment, the decision of the king's court to confirm that judgment, and, critically at least from a procedural point of view, the royal count of the palace's attestation that all of these steps were carried out properly in turn becomes the foundation for the point of the placitum, the royal command, validated by the referendary or his substitute.

When examined closely, DM 157 resembles neither a direct judgment nor a conveyance procedure. It has minor resemblances to interlocutory judgments. It really stands apart for what it is: the sole example of the confirmation of a previous judgment. It is obviously not fictitious in any of its elements. DM 157 attests to what is essentially an administrative dispute. Whatever politics there are behind it (and there surely were some) are wrapped in the regularities of petitions, hearings, inquests, and judgments. The royal confirmation may attest to the high value of documents issued by the king, as is usually supposed, but it may also be tied to the fact that the royal court is where the process began and where it was assumed to end. Nothing important for the mayor or the monarchy really hinged on a decision about a mill. Saint-Denis seems to have had a good case. The monks won. Neither king nor mayor, we may suppose, lost any sleep over the decision.

Translation. The Latin text may be consulted in the DM 157 or ChLA 587 versions.

[1. Petition to the king] Agents of the basilica of our special patron lord Dionysius, wherein the precious man himself rests in the body and the venerable abbot Dalfinus presides as its head, brought [a petition] to our attention at our palace at Montmacq that agents of the illustrious mayor of the palace were withholding the mill in the place called Cadolaicus in the district of Uernus, which mill for a long time their predecessors always possessed [as an adjunct] to the basilica's villa of Latiniacus and [the agents of the mayor] were saying that it was dependent on his villa of Uernus. The agents of Saint Dionysius next said ${ }^{78}$ that for a period of many years that mill was never dependent on Uernus but on the villa of Latinia-

78 Dicebant postia, and cf. postia dicebant in DM 156, concluding the complaint. 
cus belonging to the basilica; Ebroinus, mayor of the palace, in his own day, when he was in possession of the villa, caused it to be so dependant and quite legitimately renders were made to them or the house of the holy Dionysius.

[2. Transfer to the court of the mayor] Now $^{79}$ after that, Grimoald, the mayor of our palace, along with our fideles ordered this claim to be brought before him so that he might investigate it with more care, and he has done so. Thus it was prescribed by Grimoald that six men of good faith from Uernus and six from Latiniacus should swear together in his oratory on the mantle of Saint Martin that for a long time the mill has always been dependant on Latiniacus, the curtis of the monastery of Saint Dionysius, and quite legitimately dues were paid there.

[3. Report on the mayoral hearing in 2] Now, ${ }^{80}$ in so far as the illustrious Rigofridus, auditor of Grimoald, has attested that those men fulfilled in all respects the decision of Grimoald just as he prescribed it and those agents [of the fisc] accepted the oath, as prescribed, and the judgment, confirmed by the hand of Rigofridus and sealed with the ring of Grimoald, [acknowledging] that Dalfinus and his monastery of Saint Dionysius should possess and control the mill with secure title:

[4. Decision of the tribunal and royal command, based on 3] Whereas we have so decided along with out leading men, insofar as the illustrious Bero, count of our palace, substituting for the likewise illustrious count of our palace Gimbercthus, has verified that the said Rigofredus has provided his attestation, that this case was so done and decided before Grimoald, mayor of the palace, we order, now that the judgment of Grimoald, mayor of our palace, has been examined, just as he proclaimed it, that the aforesaid agents [of Saint-Denis] have gained title and acquired for all time possession of that mill on behalf of Dalfinus and the monastery of Saint Dionysius, without any further claim by Grimoald and against his agents, heirs, successors and anyone else; and may dispute about this matter be laid to rest in the future.

Dagobertus, substituting for Angilbaldus, has validated.

Given on 14 December in the sixteenth year of our reign at Montmacq under good auspices.

79 Sed at the beginning of a sentence does not mean 'but' in Merovingian legal Latin. It generally marks a long pause, that can be rendered in English by a paragraph break, with or without the adverbs 'then' in the sense of next, or 'now' as a means of emphasis marking a slight change of focus or subject. The sed passage comes at the point where the defendant should respond, rebutting the charges, in a conventional dispute.

80 See previous note. 


\section{Appendix III}

\section{DM 156, A Judgment in Favour of Saint-Denis Regarding Tolls Translation of the text of DM 156.}

I have marked out the stages of the pleadings and the judicial decision in italics. The alleged previous mayoral judgment is supposed to be found in [5]. The Latin text can be consulted in the DM 156 or ChLA 586 versions.

[1. S-D's case] When in our presence and that of our leading men, in our palace at Montmacq, representatives of the venerable abbot Dalfinus of the basilica of our special patron, Saint Dionysius, wherein the precious lord rests in the body, came into our presence and made allegations about the representatives of the illustrious mayor of our palace Grimoald, saying that over a long period of time the late Chlodouius our grandfather and afterward our uncle Childericus and our lord and father Theudericus, and also our brother Chlodocharius, as stated by their directives, granted to the church of Saint Dionysius in its entirety that toll that [was collected] from all the merchants, Saxons and those of other nations, attending the market on the feast of lord Dionysius; there was also the condition that neither afterwards or then would the fisc exact or collect on its own behalf either there at the market or within the pagus of Paris or in the city tolls from the merchants, but the toll was bestowed and granted in its entirety on the said basilica of lord Dionysius. Whereupon they presented to the court such directives of the said princes to be read out. When they were read and examined it was found that the grant had been so made by those princes in its entirety to that house of God. Next they said that agents of Grimoald, mayor of our palace, and also the count of that pagus of Paris took half of that toll from them and removed it from the possession of the basilica.

[2. Case of the fisc] The agents of Grimoald, the mayor of our palace, alleged that for a long time the custom existed whereby the house of Saint Dionysius received half and the count received the other half on behalf of our fisc.

[3. S-D's rebuttal] The agents of Saint Dionysius asserted in reply that the late Gairinus count of Paris imposed this custom there by force and at times took away half of the toll from them, but those agents informed the palace of this and always renewed their directives in their entirety.

[4. Examination] Again an examination was conducted of many persons and also of the directives which the aforesaid princes originally and subsequently granted and confirmed without diminution.

[5. Judgment] Thus, with the agreement of Grimoald, mayor of our palace, our other many fideles also resolved and decided that the agents of Grimoald on behalf of our fisc should invest that toll once again on the agents of Saint Dionysius by means of a gage - which they have done.

[6. Royal command] Now whereas this matter was so treated, concluded, examined and determined, as the illustrious count of our palace Rigofredus has attest- 
ed it was, we command, now that the previous directives to the monastery have been examined, that the monastery of Saint Dionysius, wherein the precious lord rests in the body, and abbot Dalfinus and his successors have gained and acquired title for all time to that toll in its entirety from the feast of Saint Dionysius, both that which arises on the lands of the basilica and after that in Paris.

[Added guarantee] In earlier times the market was moved on accout of a catastrophe from the site of Saint Dionysius and was established in the city of Paris between the basilicas of Saint Martin and Saint Laurence and for that reason they received directives from the aforesaid princes that the aforesaid basilica of Saint Dionysius should get the toll in its entirety there or whereever it set up to to conduct business and commerce on the occasion of the feast. In view of these circumstances, should it happen that on account of some catastrophe or interruption the fair should be moved somewhere else, let that aforesaid toll, because of our devotion to that holy place, in present and future times, remain granted and bestowed upon that house of God to offset the cost of lighting [the basilica] of Saint Dioysius in respect for that holy place.

And on the part of our fisc and that of the agents of Saint Dionysius, may all dispute and contention be laid to rest.

Actulius has by command validated.

Given on the December 13 in the sixteenth year of our reign, at Montmacq, under good auspices.

\section{Bibliography}

\section{Primary sources}

Boethius, commentarii in Ciceronis topica: M. Tullii Ciceronis opera quae supersunt omnia ac deperditorum fragmenta, Bd. 5, 1: Scholiastae, ed. Johann K. von Orelli and Johann G. Baiter, Zürich 1833, 269-395.

Cartae Senonicae: Formulae Merowingici et Karolini aevi, ed. Karl Zeumer (MGH Legum sectio 5), Hanover 1886, 185-211.

Cartularium Langobardorum: Leges Langobardorum, ed. Friedrich Bluhme and Alfred Boretius (MGH LL 4), Hanover 1868, 595-602.

Chartae Latinae Antiquiores: Facsimile-Edition of the Latin Charters Prior to the Ninth Century, XIII, publ. by Hartmut Atsma and Jean Vezin, Dietikon/Zurich 1981.

Chartae Latinae Antiquiores: Facsimile-Edition of the Latin Charters Prior to the Ninth Century, XIV, publ. by Hartmut Atsma and Jean Vezin, Dietikon/Zurich 1982.

Codex Iustinianus, recogn. et retr. Paul Krüger, Berlin 1915.

Consultatio veteris cuiusdam iurisconsulti: Fontes iuris antejustiniani, in usum scholarum ed. Salvatore Riccobono et al., vol. 2, Florence 1968 ( $2^{\text {nd }}$ ed.), 591-613 (ed. Johannes Baviera).

Diplomata regum Francorum e stirpe Merovingica - Die Urkunden der Merowinger, nach Vorarbeiten von Carlrichard Brühl (†) hg. von Theo Kölzer unter Mitwirkung von Martina Hartmann und Andrea Stieldorf, 2 vol., Hanover 2001. 
Diplomata Karolinorum - Die Urkunden der Karolinger, vol. 1, unter Mitwirkung von Alfons Dopsch, Johann Lechner, Michael Tangl bearbeitet von Engelbert Mühlbacher, Hanover 1906.

Formulae Andecavenses:

Formulae Merowingici et Karolini aevi, ed. Karl Zeumer (MGH Legum sectio 5), Hanover 1886, 1-25.

The Formularies of Angers and Marculf: Two Merovingian Legal Handbooks, translated with introduction and notes by Alice Rio (Translated Texts for Historians 46), Liverpool 2008, 47-101.

Formulae Salicae Bignonianae: Formulae Merowingici et Karolini aevi, ed. Karl Zeumer (MGH Legum sectio 5), Hanover 1886, 227-238.

Formulae Salicae Merkelianae: Formulae Merowingici et Karolini aevi, ed. Karl Zeumer (MGH Legum sectio 5), Hanover 1886, 239-264.

Formulae Turonenses: Formulae Merowingici et Karolini aevi, ed. Karl Zeumer (MGH Legum sectio 5), Hanover 1886, 128-165.

Fragmenta qui dicuntur Vaticana: Fontes iuris antejustiniani, in usum scholarum ed. Salvatore Riccobono et al., vol. 2, Florence 1968 ( $^{\text {nd }}$ ed.), 461-540 (ed. Johannes Baviera).

Gaius, institutiones: Gai institutionum commentarii quattuor, in: Fontes iuris antejustiniani, in usum scholarum ed. Salvatore Riccobono et al., vol. 2, Florence 1968 ( $2^{\text {nd }}$ ed.), 3-192 (ed. Johannes Baviera).

Lex Ribvaria, ed. Franz Beyerle and Rudolf Buchner (MGH LL nat. Germ. 3, 2), Hanover 1954.

Lex Salica: Pactus Legis Salicae, ed. Karl A. Eckhardt (MGH LL nat. Germ. 4, 1), Hanover 1962.

Marculf, Formularum libri duo:

Formulae Merowingici et Karolini aevi, ed. Karl Zeumer (MGH Legum sectio 5), Hanover 1886, 32-112.

The Formularies of Angers and Marculf: Two Merovingian Legal Handbooks, translated with introduction and notes by Alice Rio (Translated Texts for Historians 46), Liverpool 2008, 124-244.

Pardessus, Jean-Marie (ed.), Diplomata, chartae, epistolae, leges aliaque instrumenta ad res Gallo-Francicas spectantia, 2 vol., Paris 1843-1849.

Poupardin, René (ed.), Recueil des chartes de l'abbaye de Saint-Germain-des-Prés des origines au début du XIIIe siècle, Paris 1909.

Tjäder, Jan-Olof (ed.), Die nichtliterarischen lateinischen Papyri Italiens aus der Zeit 445-700, (Acta Instituti Romani Regni Sueciae, series in $4^{\circ}$, vol. 19), 2 Bde., Uppsala 1955/Stockholm 1982.

\section{Secondary sources}

Berger (1953): Adolf Berger, Encyclopedic Dictionary of Roman Law, Philadelphia (Transactions of the American Philosophical Society N.S. 43/2).

Bergmann (1976): Walter Bergmann, „Untersuchungen zu den Gerichtsurkunden der Merowingerzeit“, Archiv für Diplomatik 22, 1-186.

Bethmann-Hollweg (1968): Moritz A. von Bethmann-Hollweg, Der Civilprozess des gemeinen Rechts in geschichtlicher Entwicklung, 4 vol., Bonn. 
Bougard (1995): François Bougard, „La Justice dans le royaume d'Italie“, Bibliothèque des écoles d'Athenes et de Rome 289, Rome.

Brown (2001): Warren Brown, Unjust Seizure: Conflict, Interest, and Authority in an Early Medieval Society, Ithaca.

Brühl (1998): Carlrichard Brühl, Studien zu den merowingischen Königsurkunden, ed. Theo Kölzer, Köln/Weimar/Wien.

Brunner (1873): Heinrich Brunner, „Das Gerichtszeugnis und die fränkische Königsurkunde“", Festgabe für A.W. Heffter, Berlin, 1873 (Repr. 1931 in his Abhandlungen zur Rechtsgeschichte: Gesammelte Aufsätze, Weimar, vol.1, 441-448).

Brunner (1889): Heinrich Brunner, Zur Rechtsgeschichte der römischen und Germanischen Urkunden, Berlin.

Brunner \& Schwerin (1906-1928): Heinrich Brunner and Claus von Schwerin, Deutsche Rechtsgeschichte, 2. Auflage, Leipzig/München.

Buckland (1939): W. W. Buckland, „Ritual Acts and Words in Roman Law“, Festschrift Paul Koschaker, Weimar, vol. 1., 16-26.

Classen (1955-1956): Peter Classen, „Kaiserreskript und Königsurkunde: Diplomatische Studien zum römisch-germanischen Kontinuitätsproblem“, Archiv für Diplomatik $1,1-87 ; 2,1-115$.

Debus (1967): Karl H. Debus, „Studien zu merowingischen Urkunden und Briefen: Untersuchungen und Texte I", Archiv für Diplomatik 13, 1-109.

Dekkers (1935): Renée Dekkers, La Fiction juridique: Étude de droit romain et de droit comparée, Paris.

Dumont-Kisliakoff (1970): Nadia Dumont-Kisliakoff, La Simulation en droit romain, Paris.

Ficker (1868-1874): Julius Ficker, Forschungen zur Reichs- und Rechtsgeschichte Italiens, vol. 1, Innsbruck (rpt. Aalen 1961).

Fouracre (1986): Paul Fouracre, "Placita and the Settlement of Disputes in Later Merovingian Francia”, in: Wendy Davies and Paul Fouracre (eds.), Settlement of Disputes in Early Medieval Europe, Cambridge.

Ganz \& Goffart (1990): David Ganz and Walter Goffart, "Charters Earlier than 800 from French Collections", Speculum 65/4, 906-932.

Gerberding (1987): Richard Gerberding, The Rise of the Carolingians and the Liber Historiae Francorum, Oxford.

Guillot (1995): Olivier Guillot, „La Justice dans le royaume Franc“, in: La Giustizia nell'alto Medioevo (secoli $V$-VIII), Spoleto (Settimane di studio del Centro Italiano di studi sull'alto medioevo 42), vol. 2, 653-735.

Heidrich (1965-1966): Ingrid Heidrich, „Titular und Urkunden der arnulfingischen Hausmeier", Archiv für Diplomatik 11/12, 71-279.

Hübner (1891): Rudolf Hübner, „Gerichtsurkunden der fränkischen Zeit“, ZSS GA 12 appendix I, 1-118.

Jhering (1852-1865; 2. Auflage 1865-1869), Rudolf von Jhering, Der Geist des römischen Rechts, 4 vols, Leipzig (French translation of 3rd ed., by O. de Meuenaere 1886-1888, Paris).

Kano (2003): Osamu Kano, „La disparition des actes de judgement: une conséquence de la reconstruction de l'éspace de communication des diplômes par les Carolingiens?", SITES. Journal of Studies for the Integrated Text Science 1/1, 31-50.

Kano (2007): Osamu Kano, „Procès fictif, droit romain et valeur de l'acte royal à l'époque Mérovingienne“, Bibliothèque de l'École des chartes 165, 329-353. 
Kaser (1966): Max Kaser, Römisches Privatrecht, 5th ed., Munich/Berlin.

Kölzer (2004): Theo Kölzer, „Die letzen Merowingerkönige: rois fainéants?“, in: Matthias Becher and Jörg Jarnut (eds.), Der Dynastiewechsel von 751: Vorgeschichte, Legitimationsstrategien und Erinnerung, Münster.

Levy (1951): Ernst Levy, West Roman Vulgar Law: The Law of Property, Philadelphia.

Lévy-Bruhl (1934): Henri Lévy-Bruhl, Quelques problèmes du très ancien droit Romain, Paris.

Lupoi (2000): Maurizio Lupoi, The Origins of the European Legal Order, trans. Adrian Belton, Cambridge (translation of Alle radici del mondo giuridico europeo, 1994).

Maine (1861): Henry S. Maine, Ancient Law, London.

Manaresi (1950-1951): Cesare Manaresi, "Della non esistenza di processi apparenti nel territorio del regno", Rivista di Storia del diritto italiano 23, 179-217; 24, 7-45.

Mitteis (1908): Ludwig Mitteis, Römisches Privatrecht, Leipzig.

Murray (2005): Alexander C. Murray, „The New MGH Edition of the Charters of the Merovingian Kings“, Journal of Medieval Latin 15, 246-278.

Nichols, Barry (1962), An Introduction to Roman Law, Oxford.

Rabel (1906-1907): Ernst Rabel, „Nachgeformte Rechtsgeschäfte: Mit Beitragen zu den Lehren von der Injurezession und vom Pfandrecht“", ZSS RA 27, 290-335; 28, 311379.

Rosenwein (1999): Barbara Rosenwein, Negotiating Space: Power, Restraint, and Privileges of Immunity in Early Medieval Europe, Ithaca.

Schröder (1889): Richard Schröder, Lehrbuch der deutschen Rechtsgeschichte, Leipzig.

Schulz (1951): Fritz Schulz, Classical Roman Law, Oxford.

Vielliard (1927): Jeanne Vielliard, Le Latin des diplôme royaux et chartes privées de l'époque mérovingienne, Paris.

Weitzel (1985): Jürgen Weitzel, Dinggenossenschaft und Recht, 2 vol., Cologne/Vienna (Quellen und Forschungen zur höchsten Gerichtsbarkeit im alten Reich 15 1/2).

Weitzel (2006): Jürgen Weitzel, „Diplomatik und Rechtsgeschichte“, Archiv für Diplomatik 52, 297-311.

Wickham (1997): Chris Wickham, ,Justice in the Kingdom of Italy in the Eleventh Century“, in: La giustizia nell'alto medioevo: secoli IX-XI, Spoleto, 179-255 (Settimane di studio del Centro italiano di studio sull'alto Medioevo).

Wlassak (1904-1907): M. W. Wlassak, „Der Gerichtsmagistrat im gesetzlichen Spruchverfahren: Römischrechtliche Studien, mit Beiträgen zur Lehre von der Einlassung und vom gerichtlichen Anerkenntnis“, ZSS RA 25 (1904), 81-188; 28 (1907), 1-114.

Wood (1994): Ian Wood, The Merovingian Kingdoms, London/New York. 



\section{VI.}

HEIDNISCHE MODELLE UND CHRISTLICHE KULTUR:

FUNKTIONSFELDER VON TRADITIONSBEZUG

IN DER SPÄTANTIKEN LITERATUR 



\title{
Picture and Poetry
}

\section{Conceptions of the Hereafter and of Court Scenes in the Works of Ausonius of Bordeaux and Paulinus of Nola}

\author{
Meinolf Vielberg
}

Paulinus of Nola was a disciple of Ausonius who, like his teacher, came from Bordeaux. Upon separating, Ausonius served as a tutor to the later Roman Emperor Gratian in Trier, while his disciple was appointed Bishop of Nola. Their correspondence not only evidences a physical geographical distance but also testifies to a parting of intellectual ways. How did this come about? What were the reasons for their discord, and could the latter have been a symptom of the social crisis, and a seed of the structural change, befalling $5^{\text {th }}$-century Gaul? Answers to these and related questions may be obtained by comparing the conceptions of the hereafter which Paulinus (I) and Ausonius (II), in their respective literary works, developed with reference to conceptions of the hereafter and of Judgement Day in contemporary paintings. After all, the matters of this world and of the other do not belong to separate realms but mutually depend on one another, so much so that those who disagree on the hereafter are not likely to compromise with each other in this world.

I.

Wishing to depict Paulinus in a mural beside the monastic bishop of Tours, Sulpicius Severus had asked his friend and fellow disciple for a portrait he could use for the illustration of the baptistery at Primuliacum. In a letter from the summer of 404, Paulinus consents to this request. He does so with some hesitation - and on condition that his poetic tituli be used to present the deceased monastic bishop as the epitome of a felicitous life, while he himself was to serve as a cautionary example. ${ }^{1}$ Christian representations of the deceased, albeit restricted to the sepul-

1 Paul. Nol. epist. 32,3: adstat perfectae Martinus regula vitae, Paulinus veniam quo mereare docet (Walsh 1967, 136, translates: "Martin is here so that you see a model of 
chral sphere, had existed since the end of the third century, but not until Damasus of Rome's massive promotion did the cult of martyrs come to be 'reflected in pictures of the deceased that claimed intercessories and intermediaries such as Peter and Paul or local saints to lead them before the face of Christ'. ${ }^{2}$ Thus, Sulpicius Severus's portrayal of the monastic bishop of Tours along with Paulinus in an above-ground church and Paulinus's poetical illustration of this double portrait with explanatory verses are novelties in ancient art and literature. Above all, however, their joint work embodies their common endeavour to set the monastic bishop up as a Christian model which, as an expression of a cultural pattern of late antiquity, was to remain in force throughout the Middle Ages and into the modern era. In so doing, Severus and Paulinus were acting in accordance with Church doctrine. This becomes clear from the reconstruction of a court scene which, originally depicted in the apsidal mosaic of the church founded by Paulinus in Fundi ${ }^{3}$ and symbolising the Holy Trinity, is given literary form in the same letter. In it, the Day of Judgement is hinted at in the separation of the undeserving goats (to the left of the judge) from the deserving sheep (to his right). ${ }^{4}$

II.

The combination of painting and poetry can also be found in Ausonius, the common teacher of Severus and Paulinus, who, in a letter to Proculus Gregorius, calls to the recipient's mind a mural which the latter had seen in the triclinium of Zoilos at Trier. ${ }^{5}$ The painting, he writes, which was familiar to the praefectus

perfect life, whereas Paulinus schools you in how to merit forgiveness"). As for the events and questions here referred to, see Vielberg 2006.

2 See Zimmermann 2007, 162.

3 See Lehmann 2004, plate 79, figure 98.

4 Paul. Nol. epist. 32, 17: Et quia praecelsa quasi iudex rupe superstat, / bis geminae pecudis discors agnis genus haedi / circumstant solium; laevos avertitur haedos / pastor et emeritos dextra complectitur agnos. Below the Judgement Day scene, there is an altar with the bones of apostles and martyrs, similar to the one below the picture of Clarus in Primuliacum (epist. 32, 6), on which the attributes of Christ's martyrdom such as the cross, the body and blood, are regrouped, lines 3-4: cuncta salutiferi coeunt martyria Christi, / crux corpus sanguis martyris, ipse deus. See Matthew 25, 31-34.

5 Auson. Cupid. cruc. praef.: En umquam vidisti tabulam pictam in pariete [...]? vidisti utique et meministi. Treveris quippe in triclinio Zoili fucata est pictura haec [...] (quoted from Green 1999). For a comprehensive presentation of the state of research, see Liebermann/Schmidt 1989 and the useful research report in Ezquerra 1991; for the subsequent period, see Gruber 2006; the commented edition by Franzoi 2002 is useful; recently published: Dräger 2002, Schmitzer 2006, Gindhart 2006. This article is in the most of its parts similar to and in some identical with the paper "Cupido cruciatus: Jenseitsvorstellungen des antiken Epos im Spiegel von Aus. XIX“, in: W. Ameling (ed.), Topographie des Jenseits, Studien zur Geschichte des Todes in Kaiserzeit und Spätantike, Stuttgart 2011 (AwK 21), 143-159. 
praetorio Galliarum of the year 383 and the consul of the year $384,{ }^{6}$ showed some motivic correspondences with Virgil and had inspired himself to write a poetical ekphrasis. And although he admits that the little epic that had originated from it was not a masterpiece, he promises that Gregorius will appreciate it as a work of Ausonius's pen.

The subject matter of the mural - and, hence, of the epyllion - is the punishment imposed on Cupid in the underworld by women who have unhappily fallen in love. The poem consists of three or more scenes that might bear relation to one or several of the murals on dining room walls in the house of Zoilos. ${ }^{8}$ The first scene depicts the mulieres amatrices gathered in the groves of myrtle in the underworld (Auson. Cupid. cruc., 1-44); the heroines, introduced in a catalogue of women, can be recognised by the instruments with which they committed suicide (ibid., 3-4 et sua quaeque, / ut quondam occiderant, leti argumenta gerebant. $[\ldots]$ each one of them bearing tokens of the death she died of old, $\left.[\ldots]^{9}\right)$. This introductory scene is followed by the arrival of the unsuspecting Cupid and his capture (ibid., 45-55). A third scene then portrays the eponymous incident of the poem (ibid., 56-98), Cupido cruciatur: The women tie the love god to a myrtle tree known from the myth in which Proserpina, the queen of Hades, ties Adonis to it and tortures him out of jealousy. The goddess wanted him to forget Venus (ibid., 57-58 cruciaverat illic - spreta olim memorem Veneris Proserpina Adonin - Thereon had Proserpine, once slighted, tormented Adonis, mindful of his Venus). It is now the place of Cupid's suffering. With both hands tied behind his back, and his feet shackled, he hangs on the myrtle tree, incapable of escaping the women torturing him with their lethal instruments. They torture him both physically, with ropes, swords and torches, and psychologically, by threatening to throw him down the cliffs and by simulating that they are drowning him in the sea. Even the goddess of love has unhappily fallen in love and expresses her solidarity with the heroines. Venus rails at her son and hits him with a wreath of ros-

$6 \quad$ See Jones et al. 1971, s.v. Proculus Gregorius 9.

7 Auson. Cupid. cruc. praef.: hanc ego imaginem specie et argumento miratus sum. denique mirandi stuporem transtuli ad ineptiam poetandi. mihi praeter lemma nihil placet, sed commendo tibi errorem meum; naevos nostros et cicatrices amamus, nec soli nostro vitio peccasse contenti affectamus ut amentur. verum quid ego huic eclogae studiose patrocinor? certus sum, quodcumque meum scieris, amabis; quod magis spero quam ut laudes.

8 Most researchers assume the existence of a mural in Trier. See, for instance, Steiner 1927, 68; Fauth 1974, 39; Liebermann/Schmidt 1989, 297; Schmitzer 2006, 168; Jasinski 1935, 297 , note 35 , believes that the hall was part of the imperial palace at Trier; Green 1991, 526, and Schmitzer 2006, 169, assume that there were four scenes, to which corresponded several paintings in the triclinium of Zoilos; Kröner 1979, 15, believes that the mural summarised several episodes which Ausonius transformed into a single event that then developed into three separate scenes; Dräger 2002, 125, distinguishes five or six scenes; these might have corresponded to an existing mural, supposedly a fresco in the "continuous style', whose technique comprised the depiction of light effects.

9 This and all further translations of Ausonius are by White in Ausonius 1919. 
es. It is only when the red roses begin to turn deep red from Cupid's blood that the women realise they have imposed a punishment on Cupid too severe for his offences (ibid., 88-96):

\author{
nec satis in verbis: roseo Venus aurea serto \\ maerentem pulsat puerum et graviora paventem. \\ olli purpureum mulcato corpore rorem \\ sutilis expressit crebro rosa verbere, quae iam \\ tincta prius traxit rutilum magis ignea fucum. \\ inde truces cecidere minae vindictaque maior \\ crimine visa suo, Venerem factura nocentem. \\ ipsae intercedunt heroides et sua quaeque \\ funera crudeli malunt ascribere fato.
}

But words were not enough: with her rosy wreath golden Venus scourged the boy who wept and feared yet harsher punishment. From his torn body the entwined roses drew forth a ruddy dew with many a stroke and, though already dyed before, took on a hue more fiery red. Thereat the fierce threats died away, and the punishment seemed too great for the offence, as like to leave the guilt on Venus' side. The heroines themselves intervene, each one preferring to blame Fate's cruelty for her death.

The pains inflicted on Cupid in the underworld are, in the women's opinion, disproportionate to the pains caused by him in this world. Thus, the mulieres amatrices decide to champion for her victim and absolve the love god of his guilt, putting their hard lot down to cruel fate. Only in the final scene is the 'riddle' solved (ibid., 99-103): it is the 'ivory gate', i.e. the gate of delusive dreams, by which the love god makes his exit from Hades (ibid., 103 portaque evadit eburna - [...] and passes forth by the gate of ivory).

The commentators of Cupido cruciatus were wont to base themselves on the accompanying letter in which Ausonius emphasises the epyllion's intermedial relations with ancient art and literature. Even though no traces of Zoilos's domus were found in Trier, these commentators could refer to several murals in Pompeii houses in which literary and other art forms were used to depict Venus punishing the fettered Cupid. ${ }^{10}$ According to Pausanias, the $\Lambda \varepsilon \dot{\sigma} \chi \eta$ of the Cnidians housed a portrait of a scene in Hades in which a number of heroines with their symbols were portrayed; the names of four of the deceased can be found in Ausonius. ${ }^{11}$

10 See Hodske 2007, 152, and plate 18; Fauth 1974, 47, and Gindhart 2006, 230, note 34.

11 Paus. 10, 29, 3-8 (Hitzig III, 2, 594-595). The Cnidians' consultation hall in Delphi was illustrated with works of Polygnotus. One of the murals showed a scene in Hades with more than 40 souls of the dead, which seems to have been modelled after Homer's Nekyia. There is mention of other models, too (Paus. 10, 28, 1): "The other part of the picture, the one on the left, shows Odysseus, who has descended into what is called Hades to inquire of the soul of Teiresias about his safe return home. The objects depicted are as follow. There is water like a river, clearly intended for Acheron, with reeds growing in it; the forms of the fishes appear so dim that you will take them to be shadows rather than fish." 
Five of the heroines identified by him are depicted in a cycle of paintings discovered in the vicinity of a villa at Tor Marancio in Rome. ${ }^{12}$ Among the numerous analogies with mystery cults that have been pointed out, the parallel drawn by Ausonius between Cupid and Adonis is particularly interesting. ${ }^{13}$ If we base our judgement on Ausonius's ekphrasis, the painting(s) contained only a few unimportant references to the ancient religion. The arrival of Cupid, for instance, is probably more to do with the literary motif of his 'idling' (cf. Moschos 1) than with his function as psychopomp. ${ }^{14}$

As a poet, Ausonius might have found references to painting and mystery cults less important than literary models. As a matter of fact, the poem abounds with intertextual references to Virgil, Ovid, Statius and Valerius Flaccus that are organically connected with one another and twisted into a tightly-woven network. ${ }^{15}$ None of this literary erudition is displayed for its own sake. Even when Ausonius, in the accompanying letter, warns the reader that he considers the epyllion an error and only finds its subject matter, the lemma, to his liking, but not its execution, he does not do so to present a virtuoso sample of antiquarian escapism nor to play a literary game in the fashion of Hellenistic technopaignia. Such interpretations would be as much beside the point as those which, in view of similar reservations, deny Ausonius's serious poetic intention and argue that he is availing himself of the subtle self-irony which had been used in poetic texts and paratexts ever since the classical period and which was required, according to the rules of its rhetoric, if a proem was to dampen readers' expectations. ${ }^{16}$

For although it is true that Ausonius's points of reference are the poetry and painting of antiquity, he transcends his presumed, identified or reconstructed artistic models in a twofold manner. The epyllion is not a patchwork hastily seamed together. On the contrary, its literary pre-texts are organically interwoven with one another. The aesthetic intent of the self-contained artistic draft is clearly

(Translation by Jones from Pausanias 1935). The persons depicted are Charon, Elpenor, Odysseus kneeling over a pit, and ten of the fifteen women mentioned in the Odyssey, including his mother Anticleia: Iphimedeia, Ariadne, Phaedra, Chloris, Procris, Klymene as well as Megara, Heracles' wife, Tyro, Eriphyle with a necklace (Paus. 10, 29, 3-9).

12 See Helbig 1963, I, 353ff. (quoted after reference in Fauth 1974, 47).

13 Fauth 1974, 50-55; on the basis of lines 56-63, in particular 56, on Eros-Cupido as a kind of successor to Adonis in his capacity as Venus' lover, “[...] as far as his suffering in Hades in concerned. Persephone, the queen of shadows, tortured the young man entrusted to her care at an early age, because he had spurned her love, just as Eros is now tortured by Venus-Aphrodite for the pains of love caused by him (among which, the pain for the loss of Adonis)". However, the analogy which Fauth points at is incomplete, inasmuch as the goddesses, albeit both suffering from pain of love, act in different situations and out of different motives.

14 See Green 1991, 527.

15 See Lucifora 1978; id. 1979; Polymerakis 1996; there is partial similarity of motifs with Modestinus, AL Sh. B. 267, see Lebek 1985, who, instead of an interdependence of the texts, assumes a common cultural background.

16 See Vielberg 1995. 
discernible: it would not have been capable of an execution in the medium of painting but only in that of poetry. ${ }^{17}$ A painting (or a cycle of paintings) and its location in space and time would have a priori ruled out the presentation of Ausonius's particular aesthetic intent. Even without knowledge of the artistic reference object in the triclinium of Zoilos, we can therefore assume that we are dealing with a creative transgression of the artistic tradition.

In order to develop the different dimensions of this thesis, we will now investigate the 'topography of the hereafter' in Ausonius's Cupido cruciatus. In this, special attention will be given to the question of the development of the epic plot under the particular conditions of the depicted topography of the underworld. By 'topography', we understand all the phenomena capable of being ascertained topographically. These include (1) the spatial order of the hereafter: its different zones and borders; (2) the objects described: fields and woods, lakes and rivers, the shores and their flora, the boys and kings transformed into flowers, the heroines and their attributes; (3) the specific situation in the hereafter as a condition for the possibility of the epic plot; (4) the epic plot considered as dependent on these conditions and in its development from action and reaction to a series of interactions.

III.

(1) The spatial order of the 'hereafter': its 'zones' and 'borders'

Already in his accompanying letter, Ausonius had made it clear that the 'fields of mourning', the lugentes campi, as field of action are an allusion to a passage in Virgil's Katabasis (Auson. Cupid. cruc. praef. quarum partem in lugentibus campis Maro noster enumerat - Some of these our own Virgil recounts in his description of the Fields of Mourning; Aen. 6, 440-441 monstrantur [...] lugentes campi $-[\ldots]$ are shown the Mourning Fields ${ }^{18}$ ). The reference is renewed and emphasised when Ausonius, at the beginning of his epyllion, avails himself of the Virgilian juncture errantes silva in magna $-[\ldots]$ and wandering in a great wood, $[\ldots]$ (Auson. Cupid. cruc. 5; see Verg. Aen. 6, 451; Stat. Theb. 4, 741-742). By this, the reader is reminded of the Dido episode and of Aeneas' famous reunion with the Queen of Carthage. Forsaken by Aeneas, Dido had killed herself and, upon meeting the hero in Hades, in silence turns her back on him. ${ }^{19}$ In spite of the omissions, a reader familiar with Virgil will exactly recognise the location in the outer precincts of Hades as the abode of those died from violence. What is more, he will even be capable of locating, in the Aeneid's underworld landscape, both the zones that have been omitted and the standpoint of the narrator whom is he

17 See Lessing 1766, in particular XV und XVI.

18 This and all further translations of Virgil are by Fairclough in Virgil 1999.

19 See Vogt 2008, 31-40 and research literature in note 11. 
obliged to follow. This is so because Virgil, in his literary approach to Homer's Nekyia and in his description of the outer precincts of Hades on both banks of the Acheron, with Tartarus, Elysium and the Grove of Lethe, ${ }^{20}$ had created an underworld richly structured in terms of topography and which continued to serve as a literary model throughout the High Empire and late antiquity, well into the Middle Ages and even down to Dante's days. ${ }^{21}$

An educated Roman learned the Latin language and grammar from the Aeneid. Just like church father Augustin, he would have wept because of Dido's suicide. $^{22}$ One can thus take it for granted that the reader of Ausonius was familiar with the division of Hades into divers sections and with the sequence which they are given in the book VI of the Aeneid. Considering the tremendous amount of allusions and echo effects, this reader will have felt obliged to follow the epyllion's authorial narrator in incorporating the group of the unhappily loving heroines into the Virgilian landscape of Hades. But how may such a knowledgeable reader have imagined the 'hereafter'? If we take it for granted that the ideas which readers of late antiquity formed in their minds were influenced not only by painters of triclinium frescoes but also by artists such as the illustrators of the Vatican Virgil, then this illuminated manuscript from the beginning of the $5^{\text {th }}$-century might be of some avail in reconstructing these ideas. The Codex Vaticanus Palatinus latinus

20 Norden 1957, 14; see Vielberg 2010, 169-170. Representations of the hereafter were very popular; in Oriental literature, for instance, a journey to the underworld is depicted on Tablet X of the Epic of Gilgamesh; see Maul 2006, particularly the preliminary summary of the Tablet's content and lines 169-323. For representations of the hereafter and journeys thither in ancient literature in general, see Rohde 1876; Dieterich 1913; Kroll 1932. For testimonies from ancient literature and philosophy see Pfannenmüller 1953.

21 Among the post-Virgilian epic poets, Statius, Lucan and Silius Italicus need to be mentioned. The major passages are: Stat. Theb. 4, 473ff., where the blind prophet Teiresias conjures up the Phoebian Manto who has a vision of the underworld (Theb. 4, 519-578). For Statius, taking into account Seneca's Oedipus (582ff.), see Vessey 1973, 250-255; for the reception of Statius in general, see Vannucci 1989. In Lucan's Bellum Civile, Sextus Pompeius, the son of Pompeius Magnus, tries to anticipate the future by asking the Thessalian witches to open the gates of Elysium for him (Lucan. 6, 419-434a; 588-603). One of the witches advises him to cast a necromantic spell onto a corpse in the fields of Thessaly. The spirit of the dead, when conjured up (Lucan. 6, 720ff.), begins to speak (Lucan. 6, 777ff.) and predicts the advent of civil wars. In Silius Italicus, the Sibyl inspires Scipio with a vision of Hades (Sil. 13, 523ff.), whereupon Scipio betakes himself to the underworld. In a 'vision of heroes', he there encounters a number of historical and literary figures such as, for instance, heroes from the Second Punic War and the early history of Rome, Alexander the Great, Croesus, but also a number of Homer's heroes and Homer himself. This vision is followed by two catalogues of women, which include heroines from the time of the Kingdom and the early days of the Republic (Sil. 13, 806-830: Lavinia, Hersilia, Euandria, Tanaquil, Lucretia, Verginia, Cloelia) and the discouraging fate of women from Roman history (Sil. 13, 831-850: Tullia, Tarpeia and an anonymous vestal virgin). See Vessey 1973, 249-250; Reitz 1982 and Juhnke 1972, particularly 215-297.

22 Aug. conf. 1, 13, 20-21: [...] plorare Didonem mortuam, quia se occidit ab amore [...]. See also Gantar 2008. 
1631 offers the example of an illustration incorporated into the text. ${ }^{23}$ "The dense sequence of images consists of 50 miniatures which follow one another at intervals of about 45 verses and of which 41 are illustrations of scenes from the Aene$i d$. All of these miniatures are characterised by a detailed colouring and a richness of figures motivated in the scenes. Due to the compact frame, the reader's attention is drawn to landscapes (some of which foreshortened) and a rich architectural background." Some of the miniatures illustrating the Katabasis provide a clearer insight into the regions and borders of Virgil's underworld, which Ausonius discernibly imitates or silently presupposes. Miniature folio 48 verso shows how Aeneas observes the Sibyl, who accompanies him, soothing Cerberus with a soporific cake (Wright 1993, 50). When the hound of Hades has fallen asleep, Aeneas and his companion betake themselves past the dog into the outer precincts of Hades where they find Ausonius's mulieres amatrices. In the first precinct, they encounter the prematurely dead, the ówoor (Verg. Aen. 6, 426-429), who, in the lower register to the right side of the cave, are represented by two new-born children (Vatic. lat. pal. folio 48v; Wright 1993, 50). As the lifetime allotted to them by fate has not been completed, they have to wait between Acheron and the inner precincts of Hades on the opposite bank of the river. According to the system drawn up by Eduard Norden $\left(4^{\text {th }}\right.$ ed. 1957, 13-14), this is also the location of the second group of $\beta 1 \alpha 10 \theta \alpha$ óv $\alpha$ ot. There are altogether four groups of those who died

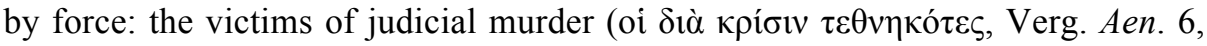

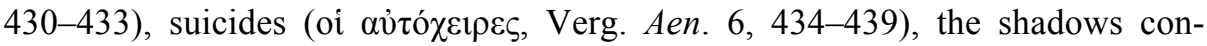

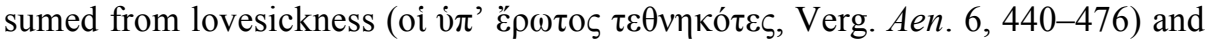

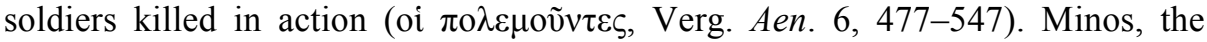
judge of the dead, sits enthroned above the cave. To his left, there is an apparatus for casting lots. Shadows of those who were unjustly condemned to death in this

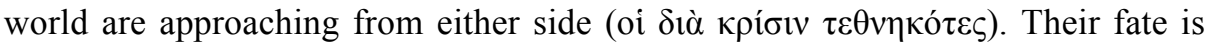
newly pondered by Minos. The tiny figures, presented as disembodied shadows, have been painted with special subtlety. Just like the majority of Ausonius's $m u$ -

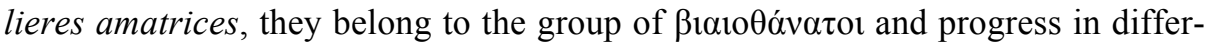
ent positions. Aeneas and the Sibyl now encounter Deiphobus (Vatic. lat. pal. folio 49r. Wright 1993, 53), who was horribly mutilated in the capture of Troy (Verg. Aen. 6, 494-497). Deiphobus belongs to the $\pi \circ \lambda \varepsilon \mu о \tilde{v} v \tau \varepsilon \varsigma$, the last group of $\beta 1 \alpha 10 \theta \alpha$ va $\tau 0$ in the outer precincts of Hades. Tartarus is visible in the right half of the picture. The boiling river Phlegethon surrounds its triple wall, while its huge gate is guarded by the sleepless fury Tisiphone (Verg. Aen. 6, 548-558). The Sibyl explains to Aeneas that Tartarus is the abode of the unrepentant wicked (oi

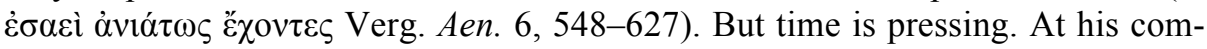
panion's behest, Aeneas therefore moves on until he reaches the gates of Elysium. Folio 52 recto shows how the Trojan, under the Sibyl's guidance, plants the golden bough onto the threshold of the palace (Wright 1993, 55). By so doing, he is granted access to the Elysium where Orpheus is playing the lyre and the souls of

23 See Wright 1993 for this and the next quotation. 
the dead heroes are doing sports. While the outer precincts of Hades were veiled in darkness, the Elysian Fields are depicted in bright colours, brightness being a prerequisite for the 'vision of heroes' (Aen. 6, 640-641 largior hic campos aether et lumine vestit / purpureo, solemque suum, sua sidera norunt - Here an ampler ether clothes the meads with roseate light, and they know their own sun, and stars of their own). Folio 53 verso, in turn, combines several different scenes (Wright 1993, 56). It shows how Aeneas, under the guidance of Musaeus, finds Anchises (Aen. 6, 677-678), how the son unsuccessfully tries to embrace his father three times (ibid., 700-702) and how the souls of the dead, wishing to forget, drink from Lethe (ibid., 713-715). Following Anchises' prophecy of the destinies of Rome and his descendants, i.e. of the Aeneads until Augustus, Aeneas makes his departure from the chthonic realm through the same gate as Cupid in Ausonius (Cupid. cruc. 103 evolat [sc. Cupido] ad superos portaque evadit eburna - [...] flits forth to the gods above, and passes forth by the gate of ivory). The ivory gate is portrayed in folio 57 recto (Wright 1993, 59). Anchises takes leave of his son and of the Sibyl, before the two make their exit from Hades - through the gate of ivory, not through the gate of horn (Verg. Aen. 6, 893-898):

\section{Sunt geminae Somni portae, quarum altera fertur cornea, qua veris facilis datur exitus umbris, altera candenti perfecta nitens elephanto, sed falsa ad caelum mittunt insomnia Manes. his ibi tum natum Anchises unaque Sibyllam prosequitur dictis portaque emittit eburna.}

Two gates of Sleep there are, whereof the one, they say, is horn and offers a ready exit to true shades, the other shining with sheen of polished ivory, but delusive dreams issue upward through it from the world below. Thither Anchises, discoursing thus, escorts his son and with him the Sibyl, and sends them forth through the ivory gate [...].

One of the great issues of Virgil studies is associated with these famous lines and one, at that, which already in the days of Ausonius was discussed in great detail by grammarians of late antiquity such as Servius ${ }^{24}$ and Neo-Platonists such

24 Serv. Aen. 6, 893 (Thilo-Hagen II, 122-123): sunt geminae somni portae pro somniorum. est autem in hoc loco Homerum secutus, hoc tantum differt, quod ille per utramque portam somnia exire dicit, hic umbras veras per corneam, per quas umbras somnia indicat vera. Et poetice apertus est sensus: vult autem intellegi falsa esse omnia quae dixit. In Servius, this 'poetic' interpretation is followed by a 'physiological' one, according to which the gate of horn symbolises the cornea; the gate of ivory, on the other hand, the mouth (on account of the colour of teeth). Servius goes on to expound that what comes out of the mouth might be wrong, whereas that which is perceived by the eyes is beyond any doubt true. For Servius, a third explanation of the meaning of the passage in Virgil results from the fact that, in paintings, Sleep is portrayed with horns. For the discussion in antiquity, see Steiner 1952; Norden 1957, 47-48; Glei 1991, 168, note 244; for the thesis of a denial or restraint, see particularly Christmann 1976; Tarrant 1982; with an interpretation based on the 
as Macrobius. ${ }^{25}$ At the same time, this issue is a question relating to Homer, for the gate of ivory, as the symbol of an insignificant and inauspicious dream, was

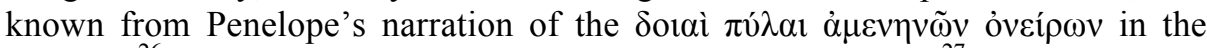
Odyssee. $^{26}$ Ausonius takes up this motif in another passage, too. ${ }^{27}$

\title{
(2) Objects in the hereafter
}

Before we join Cupid and Aeneas in passing through the gate of ivory and on their way out of the inhospitable climes of the hereafter, it seems advisable to look more closely at the objects that can be found there, for it is only from their arrangement that the 'topography of the hereafter' is revealed. The introductory lines of Ausonius's epyllion provide a succinct presentation of the most important of these objects. They are followed in the first, rather static scene by the comprehensive catalogue of mulieres amatrices (Auson. Cupid. cruc. 1-12):

\author{
Aeris in campis, memorat quos Musa Maronis, \\ myrteus amentes ubi lucus opacat amantes \\ orgia ducebant heroides et sua quaeque, \\ ut quondam occiderant, leti argumenta gerebant, \\ errantes silva in magna et sub luce maligna \\ inter harundineasque comas gravidumque papaver \\ et tacitos sine labe lacus, sine murmure rivos; \\ quorum per ripas nebuloso lumine marcent \\ fleti, olim regum et puerorum nomina, flores \\ mirator Narcissus et Oebalides Hyacinthus \\ et Crocus auricomans, et murice pictus Adonis \\ et tragico scriptus gemitu Salaminius Aeas.
}

In the aerial fields, told of in Virgil's verse, where groves of myrtle o'ershade lovers lorn, the heroines were holding frantic rites, each one of them bearing tokens of the death she died of old, and wandering in a great wood, lit by scanty light, 'mid tufted reeds, and full-blown poppies, and still meres without a ripple, and unbabbling streams, along whose banks flowers of woe hung drooping in the murky light, bearing the names of kings and boys of old: here was admiring Narcissus, Hyacinthus, son of Oebalus, golden-headed Crocus, Adonis purple-stained, and Aeas of Salamis inscribed with the word of woe.

Aeneid's mythical and historical levels of narrative (which approximate each other in the Katabasis, without commingling), Pollmann 1993; Möllendorff 2000.

25 Macr. Somn. 1, 3, 6ff.

26 Hom. Od. 19, 562ff.: "Two gates there are for unsubstantial dreams, one made of horn and one of ivory. The dreams that pass through the carved ivory delude and bring us tales that turn to naught; those that come forth through polished horn accomplish real things, whenever seen" (Translation by George Herbert Palmer from Homer 2003, 247).

27 Auson. ephem. 8, 24f.: et geminas numero portas: quae fornice eburno / semper fallaces glomerat super aera formas, / altera quae veros emittit cornea visus. See also Schetter 1961, 377, and Davis 1994, 166-168. 
While the Muse of Maro recalls the proem of the Aeneid (Verg. Aen. 1, 8), "aerial fields", "groves of myrtle" and "scanty light" are clearly allusions to the Katabasis intended to locate the events in the Virgilian underworld. Only the leti argumenta, the tokens of the death, have no parallel in Virgil; orgia, the technical term for the secret forms of worship there conducted by the heroines, alludes to ancient mystery cults; in conjunction with ducere, orgia is attested in Virgil, even though their syntactic combination is missing in Aen. 6, 517-518. ${ }^{28}$ Papaver with its epithet gravidum is reminiscent of opium poppies and their soporific effect, but also of sleep as the brother of death (Auson. Cupid. cruc. 6). The 'flowers of woe' bring Ovid to mind - the names of young men and kings are associated with famous metamorphoses. Narcissus is stooping over a bank of the river Styx, just as of old he was bending over a pool and gazed enamoured at his own reflection (Auson. Cupid. cruc. 10; Ov. met. 3, 39-510). Hyacinthus had accidentally been struck dead by a discus thrown by Apollo. The god transformed the beautiful young man, whom he had loved, into the eponymous flower (Auson. Cupid. cruc. 10; Ov. met. 10, 162-219). Finally, Adonis, whom Venus had fallen in love with, when Cupid's arrow struck her heart, was mortally wounded by a boar and turned into an anemone when Venus sprinkled his blood with sweet-smelling nectar (Auson. Cupid. cruc. 11; Ov. met. 11, 7, 15).

The first scene, somewhat static in character, is followed by the long catalogue of mulieres amatrices, which starts with a quote from Virgil (Cupid. cruc. 5 errantes silva in magna - [...] and wandering in a great wood, [...]; Verg. Aen. 6, 451) and also ends in a Virgilian tone (Cupid. cruc. 40 errat et ipsa - She also wanders here, $[\ldots])$. There is mention of a number of women who already figure as suicides and unfortunate lovers in Homer ${ }^{29}$ and Virgil. ${ }^{30}$ Further women are taken from other literary sources such as Ovid's Metamorphoses and his Heroides. $^{31}$ The heroines succumb to pain and grief. The skilful arrangement of

28 See Green 1991, 528 for v. 3 and Franzoi 2002, 50; it is clear that orgia bears relation to the mystery cults, see Burkert 1991, in particular 38-39; 89-90.

29 Hom. Od. 11, 235ff.: Tyro (v. 235), Antiope (v. 260), Alkmene (v. 266), Megara (v. 269), Epikaste (v. 271), Chloris (v. 281), Leda (v. 298), Iphimedeia (v. 305), Phaidra (v. 321), Prokris (v. 321), Ariadne (v. 321), Maira (v. 326), Clymene (v. 326), Eriphyle (v. 326). If we include Anticleia (v. 152ff.), the catalogue of women comprises 15 heroines.

30 Verg. Aen. 6, 445ff. Phaedra (v. 445), Procris (v. 445), Eriphyle (v. 445), Euadne (v. 447), Pasiphae (v. 447), Laodamia (v. 447), Caeneus (v. 448), Dido (v. 450). If we include Myrrha (v. 73), Ausonius's catalogue comprises, just like Homer's, 15 heroines: Semele (v. 16), Caenis (v. 20), Procris (v. 21), Hero (v. 23), Sappho (v. 24), Eriphyle (v. 26), Pasiphae (v. 30), Ariadne (v. 31), Phaedra (v. 32), Laodamia (v. 36), Thisbe (v. 37), Canace (v. 37), Dido (v. 37), Luna (v. 42).

31 Although there is no catalogue of women in Ovid, all of the heroines listed by Ausonius can be found in his works, too. See, for instance, in Metamorphoses: Semele (3, 253-315); Caenis (12, 171-209); Procris (7, 796-862); Pasiphae (9, 735-740); Thisbe (4, 55-166); Luna/Diana (3, 131-252); Myrrha (10,300-502). Some of the heroines only appear in Heroides: Hero (letter to Leander, epist. 19); Ariadne (to Theseus, epist. 10); Phaedra (to Hippolytos, epist. 4); Laodamia (to Protesilaus, epist. 13); Canace (to Macareus, epist. 11); 
the catalogue can be seen, amongst other things, from the fact that it begins with Semele, the mother of Dionysus (Ov. met. 3, 253-312), and ends with the goddess Luna. There are several alternating principles of arrangement. One of them is the method of suicide used (by sword, rope or by jumping from a cliff); another, the genealogy (with Pasiphae, Ariadne and Phaedra, for instance, three women from the Minoan-Athenian legend follow one another). The catalogue is skilfully designed, and yet remains open because it is mentioned that there were another hundred dead (Cupid. cruc. 43 centum aliae - A hundred more besides, [...]) there. We shall see that the author mentions at least one more heroine and thus maintains the unity of his poetic draft also in this respect.

(3) Optical and acoustic phenomena in the hereafter as a condition of the possibility for the epic plot

The catalogue begins with Semele brandishing the flame of a simulated bolt of lightning (Cupid. cruc. 18: ventilat ignavum simulati fulguris ignem - [...] and brandishes the harmless fire of an imagined thunderbolt). Halfway through, there is mention of an oil-lamp as Hero's attribute (ibid., 22-23: fert fumida testae / lumina $-[\ldots]$ carries her smoking earthen lamp [...]). The moon goddess Luna, who as Endymion's unhappy lover concludes the catalogue, is bearing a torch (ibid., 42: cum face et astrigero diademate Luna bicornis - [...] twy-horned Luna with her torch and starry diadem). These indirect references to the darkness that prevails in the outer precincts of Hades are supplemented by indirect indications to shadows (ibid., 2: opacat), adverse lighting conditions (ibid., 5: sub luce maligna) and poor visibility (ibid., 8: nebuloso lumine). The finding does not come as a surprise: already Virgil had emphasised that the Trojan hero had difficulty recognising the shadow-obscured Dido, "even as, in the early month one sees or fancies he has seen the moon rise amid the clouds" (Aen. 6, 452-454: adgnovitque per umbras / obscuram, qualem primo qui surgere mense / aut videt aut vidisse putat per nubila lunam. - [...] and knew her, a dim form amid the shadows - even as, in the early month, one sees of fancies he has seen the moon rise amid the clouds [...]), and some lines further down, one reads of the "abysmal night" (ibid., 462: noctemque profundam) and the "shady grove" (ibid., 473: in nemus umbriferum). But while the optical conditions in the hereafter are presented in a way such as to fulfil the expectations harboured by experts of the ancient epic, the presentation of the acoustic conditions leaves a lot to be desired. From the Katabasis, we know of the 'triple-throated baying' of Cerberus, the hound of Hades (ibid., 417), and of the woeful crying of the weeping infants' spirits (ibid., 426-427). Styx, by whose nine-fold floods the suicides are confined (ibid., 439), is described as a roaring stream (ibid., 327: rauca fluenta). Ausonius, in contrast, underlines that the rivers of Hades flow silently (Cupid. cruc. 7: sine murmure),

Sappho (to Phaon, epist. 15). Schmitzer 2006, 171, points out the existence of catalogues of women in the Culex and in the Alcestis Barcinonensis. 
and in the second half of the line, the lakes of the underworld are portrayed as taciturn (ibid.: tacitos sine labe lacus). How can this be accounted for? What purpose did Ausonius have in mind by presenting the optical and acoustic conditions in this way?

(4) The development of the epic plot: from action and reaction to interaction

In order to elucidate the features particular to the presentation of the hereafter against the background of the further development of the plot, we will now consider the synaesthesia as the sensual phenomenon eponymous to the special form of metaphor on which the epic plot - i.e. Cupid's recognition, capture, torture and

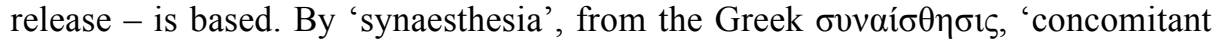
sensation', we primarily understand a sensation in one part of the body by stimulus in another, e.g. the regular occurrence of colour sensations when listening to sounds (and vice versa). Alexander of Aphrodisias explained the phenomenon of a sensory stimulus that produces two distinct sensations, one adequate, the other inadequate, in his commentary on Aristotle, De sensu 438b8ff., emphasising that for a synaesthesia to occur it was necessary that a sensory stimulus was processed, not by the recipient sense organ (i.e. where it arises), but centrally along with the stimuli of other senses. ${ }^{32}$ Secondary (and, hence, inadequate) sensations of an optical nature are called 'photisms'; secondary listening experiences occurring concomitant to optical perceptions, 'phonisms'. 33 Synaesthesiae can be encountered in all sensory organs: tactile sensations, for instance, are often accompanied by olfactory ones. However, synaesthesia is also a form of metaphoric expression, frequently encountered as a poetic device in Romanticism (Brentano), French Symbolism (Rimbaud, Mallarmé) and German Neo-Romanticism (Rilke, Hofmannsthal). ${ }^{34}$ Ausonius avails himself of it in the portrayal of Cupid's appearance and his experiences by synthesising the acoustic and optical features particular to the 'topography' of the hereafter, darkness and silence, with one another (Cupid. cruc. 45-55):

quas inter medias furvae caliginis umbram dispulit inconsultus Amor stridentibus alis. agnovere omnes puerum memorique recursu communem sensere reum quamquam humida circum

32 Alex. Aphr. in Sens. 36, 12 (ed. P. Wendland, Berlin MCMI, Commentaria in Aristotelem

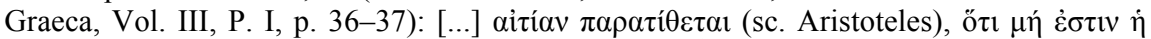

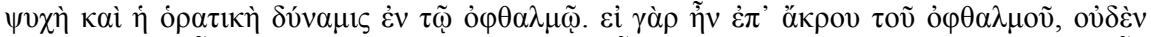

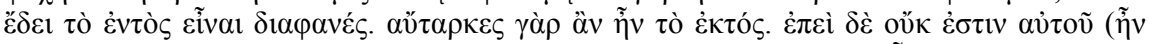

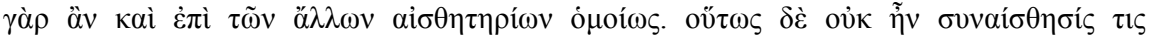

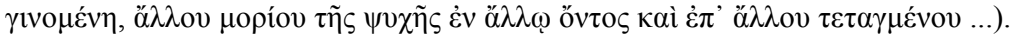

33 For German Classicism and its precursors, for Winckelmann, Herder and Goethe, see Wellek 1936, 90-98.

34 See Braak 1974, 32. 
nubila et auratis fulgentia cingula bullis

et pharetram et rutilae fuscarent lampados ignem.

agnoscunt tamen et vanum vibrare vigorem

occipiunt hostemque unum loca non sua nactum,

cum pigros ageret densa sub nocte volatus,

facta nube premunt; trepidantem et cassa parantem

suffugia in coetum mediae traxere catervae.

Into the midst of these Love rashly broke scattering the darkness of that murky gloom with rustling wings. All recognized the boy, and as their thoughts leapt back, they knew him for the one transgressor against them all, though the damp clouds obscured the sheen of his golden-studded belt, his quiver, and the flame of his glowing torch. Yet they recognize him, and essay to wield their phantom strength against him, and upon their one foe, now lighted on a realm not his own where he could ply his wings but feebly under the clogging weight of night, gathering in a throng they press: him trembling and vainly seeking to escape, they dragged into the midst of the crowding band.

Cupid, we read in this passage, finds himself among the heroines (Cupid. cruc. 45: quas inter medias) and dispels the shadows of black darkness with a whirr of his wings (ibid., 45-46: furvae caliginis umbram / dispulit inconsultus Amor stridentibus alis). But while it is clear that the darkness that prevails in Hades cannot be driven away by the love god's pinions, their loud whirr has the heroines prick up their ears and recognise their winged enemy, especially if one considers the punctuated, if not absolute silence of the hereafter. The synaesthesia that provides the basis for the complex metaphor consists in the abrupt transition from the optical to the acoustic-haptic sphere. The sense of seeing is replaced by the sense of hearing. By taking up the predicate agnovere (ibid., 47) in the initial agnoscunt (ibid., 51), Ausonius makes it clear to the reader that a cognitive process of primarily optical nature (and described with expressions for light and darkness) is continued by being transferred to the sphere of touch and then superseded by the acoustic sphere: although the shining gems on his belt, his quiver and the fire of his flaming torch are obscured by damp mist, the love god is recognised by the heroines (ibid., 48-51: quamquam humida circum / nubila et auratis fulgentia cingula bullis / et pharetram et rutilae fuscarent lampados ignem. / agnoscunt tamen). Another synaesthesia, again paradoxical in character, is the metaphorical combination of the sense of touch (in the images of density and thronging) with the sense of seeing (in the images of 'night' and of a 'cloud' of shadows). When Cupid, in the thick (sc. instead of dark) night makes a feeble attempt to retreat (ibid., 53: cum pigros ageret densa sub nocte volatus), the shadows of the dead women accumulate into a cloud to overwhelm him (ibid., 54: facta nube premunt). Unlike the preceding synaesthesiae, which were accidental and only served to prepare the reader, this double synaesthesia is both paradoxical and necessary for the epic plot to begin (and for it to be explained). The shadows in 
the hereafter are disembodied. Despite his three attempts to do so, Aeneas is incapable of embracing his dead father (Verg. Aen. 6, 700-702: ter conatus ibi collo dare bracchia circum; / ter frustra comprensa manus effugit imago, / par levibus ventis volucrique simillima somno - Thrice there he strove to throw his arms about his neck; thrice the form, vainly clasped, fled from his hands, even as light winds, and most like a winged dream), just as Odysseus cannot embrace his mother (who had died while he waged war against Troy), when he encounters her

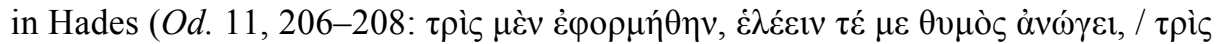

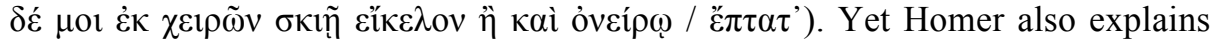
why this is so. The respective passage, quoted here in George Herbert Palmer's translation, ${ }^{35}$ is relevant for understanding Ausonius in general. The speaker is Odysseus' mother, Anticlea (Od. 11, 198-222):

"[...] Even so I also died and met my doom: not that at home the sure-eyed huntress attacked and slew me with her gentle arrows; nor did a sickness come, which oftentimes by sad decay steals from the limbs the life; but longing for you - your wise ways, glorious Odysseus, and your tenderness, - took joyous life away."

As she thus spoke, I yearned, though my mind hesitated, to clasp the spirit of my mother, even though dead. Three times the impulse came; my heart urged me to clasp her. Three times out of my arms like a shadow or a dream she flitted, and the sharp pain about my heart grew only more; and speaking in winged words, I said:

"My mother, why not stay for me who long to clasp you, so that in the very house of Hades, throwing our arms round one another, we two may take the our fill of piercing grief? Or is it a phantom high Persephone has sent, to make me weep and sorrow more?"

So I spoke, and straight my honored mother answered: "Ah, my own child, beyond men ill-fated! In no manner is Persephone, daughter of Zeus, beguiling you, but this is the way with mortals when they die [italics mine, M.V.]: the sinews then no longer hold the flesh and bones together; for these the strong force of the blazing fire destroys, when once the life leaves the white bones, and like a dream the spirit flies away."

If we compare Homer and Virgil and, instead of interpreting the ways in which they present the hereafter allegorically, stick to the wording, it can be ruled out right from the start that the love god is overwhelmed by the heroines' disembodied shadows, just as Ovid's Eurydice does not cling to Orpheus but as a shadow is pulled back into Hades. ${ }^{36}$ Here, however, the disembodied shadows accumulate into a 'cloud' and overwhelm the love god, after they have 'condensed' in the synaesthesia of haptic and visual sense, as Ausonius confides to in a tongue-in-

35 Homer 2003, 135f.

36 Ov. met. 10, 57; see also Vielberg 2008, 332, with literature 331, note 35 . Of course, there is a tradition according to which the souls of the dead have a body, and there would be no underworld punishments such as those imposed on Tantalus, Sisyphus and Tityos, who has his liver torn out by two vultures, if these heroes were bodiless. The epic tradition relevant for Ausonius, however, assumes that the umbrae are disembodied; see Burkert 1977, 301. 
cheek manner. This interdependency is inherent in the very formulation. The hemistich facta nube premunt is a quote from Book XII of the Aeneid, where Virgil describes how the Rutulians, observing an omen sent to them by Juturna, are persuaded to break the peace treaty which they have just concluded with the Trojans (Verg. Aen. 12, 244-258):

\author{
his aliud maius Iuturna adiungit et alto \\ dat signum caelo, quo non praesentius ullum \\ turbavit mentes Italas monstrosque fefellit. \\ namque volans rubra fulvus Iovis ales in aethra \\ litoreas agitabat avis turbamque sonantem \\ agminis aligeri, subito cum lapsus ad undas \\ cycnum excellentem pedibus rapit improbus uncis. \\ arrexere animos Itali, cunctaeque volucres \\ convertunt clamore fugam (mirabile visu), \\ aetheraque obscurant pennis hostemque per auras \\ facta nube premunt, donec vi victus et ipso \\ pondere defecit praedamque ex unguibus ales \\ proiecit fluvio penitusque in nubila fugit. \\ Tum vero augurium Rutuli clamore salutant \\ expediuntque manus $[\ldots]$.
}

To these Juturna adds another and mightier impulse, and in high heaven shows as sign, than which none was more potent to confound Italian minds and cheat them with its miracle. For, flying through the ruddy sky, Jove's golden bird was chasing the fowls of the shore and the clamorous rout of their winged troop, when, swooping suddenly to the water, shameless, he snatches up in his crooked talons a stately swan. All alert become the Italians, when lo! one and all, wondrous to behold, the birds wheel clamorously their flight, and, darkening the sky with wings, in serried cloud drive their foe through the air, till, overborne by the onset and the sheer weight, the bird gave way, dropped the booty from his talons into the stream, and sped far within the clouds. Then in truth the Rutulians hail the omen with a cheer and spread out their hands.

The Rutulians observe a flock of birds defending itself against an eagle. The swans are flocking so densely that they form a 'cloud' (Auson. Cupid. cruc. 54: facta nube) and, having joined forces, overwhelm (premunt) the raptor that then drops its prey. The quote has been carefully chosen by Ausonius. ${ }^{37}$ The birds'

37 Lucifora 1979, 268, points to the parallel but fails to interpret it. Also Gindhart 2006, 227, note 25 , only records an allusion. Another possible explanation for this, mentioned here for the sake of completeness, is opened up by recourse to early Greek philosophy. Anaximenes postulates that air is the first source (archē) of all things, arguing that everything originated from, and will some day resolve itself into, air: "Just as our soul, being air, holds us together and controls us, so do breath and air surround the whole cosmos" (13 B2 DielsKranz). Simpl. Phys. 24, 26 reports that, according to Anaximenes, all things owed their existence to a certain compression and rarefaction of air (13 A5 Diels-Kranz). Taken to- 
ability to fly corresponds to the skills for which the love god is known (and to those of the hovering souls in Hades). Virgil illustrates how potential victims unite against a superior aggressor and prevail over him as supposed 'underdogs'. Now, seeing that Cupid, in Virgil's Eclogues, is depicted as the superior aggressor (Verg. ecl. 10, 69), the tertium comparationis which we can transfer to the action of the epyllion is the overwhelming of the aggressor by a majority of supposedly inferior victims.

Thus the victims turn into perpetrators. They set Cupid in their midst (Auson. Cupid. cruc. 55: in coetum mediae traxere catervae) and tie him to a myrtle tree known from the martyrdom of Adonis (ibid., 56: eligitur maesto myrtus notissima luco), where he is bound fast. The metaphors and 'synaesthesiae' used in the subsequent court and punishment scene are derived from the attacks to which the tortured god is exposed. They are based on the sense of touch. Mostly tactile stimuli - blows, strokes, pinpricks - are transferred to other sense organs. Haptic sensations intermingle with other senses, as the women use their lethal instruments as torture devices with which they tantalise the defenceless god. They torture Cupid with ropes and swords, the classical suicide devices. ${ }^{38}$ There is explicit mention of Myrrha, the daughter of Cinyras, who was changed into a myrtle tree (Ov. met. 10, 298ff.). With her, Cinyras begets Adonis, who was tortured after being tied to the same myrtle tree. Myrrha takes part in the events in a very peculiar manner. She cuts a slit into her bark - or, according to Ausonius, into her womb - which is full with shining tears wept for her son Adonis and then lets these tears of resin drop on the love god (Auson. Cupid. cruc. 72-74: rescindit adultum / Myrrha uterum lacrimis lucentibus inque paventem / gemmea fletiferi iaculatur sucina trunci - Myrrha, with glistening tears, rends open her ripe womb and hurls at the trembling boy the drops of sparkling amber which trickle from her stem). Through the optical phenomenon of luminescence (lucentes; gemmeus), the tactile process of dripping (lacrimae; sucinum) is enhanced with a second dimension, to which may be added a third, for the secreted resin particles, before they turn into amber, also affect the sense of smelling. Cupid is taunted by other women, too, who put their torches to his genitals and torment him until he bleeds. A pin is used to squeeze "tender blood" from under his skin (a synaesthetic condensation of "blood from under his tender skin"), from which the rose is said to have originated (ibid., 77: eliciat tenerum, de quo rosa nata, cruorem). Eventually, Venus makes her appearance, reviles Cupid for the sufferings which he had caused her and beats him with a wreath of roses. When the roses (which are red anyhow) begin to turn "deep red" from Cupid's blood (another synaesthesia gained at the tortured god's expense), it is suddenly brought home to the women, who had followed the talion principle without putting Cupid on trial (ibid., 62-63), that the punishment imposed on Cupid in the hereafter is inade-

gether, these two axioms could be used to explain that the souls of the dead heroines 'materialise' and thus become capable of 'overwhelming' Cupid.

38 See Habermehl 2006, 259-260 (with further literature) on Petron. 94, 8. 
quate in relation to the offences he had committed in this world. Having changed their minds, they release the love god, who then makes his escape from the underworld.

\section{IV.}

It has become apparent that Ausonius, in his portrayal of Cupid in the underworld, makes considerable use of ancient poetry and painting. But although he obeys the rules of an imitation-oriented ancient poetics, thus meeting the expectations of his audience, he would not have been able to comply with the rules of tradition in each and every aspect, even if he had wanted to. The reason why Ausonius's deviance from tradition is worth mentioning is that there is a system behind it. The fact that he sends Cupid on a journey to Hades testifies to a vivid imagination. The god's overwhelming by women in love fits well into this picture. It lends a fanciful and illusionary effect to the epyllion that the rules of logic are repeatedly violated by disregard for the ancient epic standards and if this violation is superficially healed, and hence emphasised, by the systematic use of metaphorical and synaesthetic junctures. The unity of a poetic draft, which is based on the simultaneous violation and restoration of the poem's internal logic, corresponds to the final resolution of the enigmatic contradictions - a resolution to which the Virgilian motto Aeris in campis (Auson. Cupid. cruc. $1 \sim$ Verg. Aen. 6,887 ) has paved the way, if we take into consideration that aer, for Ausonius, is the location of dreams. ${ }^{39}$ The crucial point is that the events that take place in the hereafter eventually turn out to have been Cupid's nightmare. In a dream, however, fanciful and illusionary elements as well as the spontaneous suspension of the laws of logic are absolutely appropriate. If the whole point of Cupido cruciatus is that the attack on Cupid proves to have been a nightmare, then what we are looking at in the first place is a literary play with ancient poetry and the ideas associated with, and set forth by, it. Ausonius provides proof of his poetic virtuosity and, in so doing, implicitly complies with the ancient (yet then still current) cultural pattern of dealing with death and afterlife which Pliny the Younger, in exemplary manner, had developed in epist. 3,7 with regard to the life and works of Silius Italicus. In view of the brevity of human life, endurance beyond death is here sought, in accordance with the traditional cultural patterns, in the achievement of immortal fame in posterity: ${ }^{40}$

sed tanto magis hoc, quidquid est temporis futilis et caduci, si non datur factis (nam horum materia in aliena manu), certe studiis proferamus, et quatenus nobis denegatur diu vivere, relinquaтus aliquid, quo nos vixisse testemur.

39 Auson. ephem. 8, 25, according to Green 1991, ad loc., who also points to M. Cap. 2, 151.

40 Plin. epist. 3, 7, 14-15. 
All the more reason then why we should prolong all our passing moments, uncertain though they are, not perhaps by action, since here the opportunity no longer rests with us, but at any rate by literary work. Since we are denied a long life, let us leave something to bear witness that at least we have lived. ${ }^{41}$

Ausonius complies with this cultural pattern, which primarily had been embraced and propagated by the Augustan poets, ${ }^{42}$ in his other works, too. In Parentalia, for instance, he is seeking to provide for his family's memoria; in Commemoratio professorum Burdigalensium, for the fama of his predecessors, to whom he is connected by his literary fame, the love of his country and the quest for education. ${ }^{43}$ But there is something else that separates him from Paulinus. For the attention to detail and the poetic sophistication, which Ausonius seems to have mustered in the portrayal of the torture scene, make it impossible to take his airs of 'affected modesty' seriously and to speak of a merely playful approach to ancient mythology and to the claim made by the mystery religions of late antiquity. By initially qualifying the epyllion as an error and by duplicating the dream motif, Ausonius, it is true, dissociates himself from the content of his work. In view of the conspicuous manner in which he does so, however, one feels inclined to ask whether there is an intention behind this. The question is whether Ausonius's portrayal of the god tortured at the myrtle tree implies, if only as a calculated side-effect, a hidden allusion to, and dissociation from, Christian doctrine. For despite the fact that we can only account for the poem's internal contradictions if we take into consideration the historical situation at the time of its writing and the poet's intentions - a poet, besides, who, in the medium of the picture, was probably interested in more than educational matters alone ${ }^{44}$ and who had neither occasion nor obligation to expound his intentions with utmost clarity -, it cannot be refuted that his view of the hereafter, developed on the basis of ancient mythology, does not conform to the poetic description of the presentation of Judgement Day given by Paulinus of Nola. Rather, what becomes apparent here is that $5^{\text {th }}$ century Gaul saw a fundamental disagreement between a universally recognised poet and rhetorician who had been admitted to the imperial court, on the one hand, and one of his best disciples, on the other. It is a disagreement that became the origin of strong tendencies of transformation and that triggered a long-lasting process of restructuring. For under the supposedly uniform surface of a comprehensive political and cultural nexus, changes occurred independently of external

41 Translation by Radice from Pliny 1969, Cambridge, 187.

42 See, for instance, Hor. carm. 3, 30, 6-7: non omnis moriar multaque pars mei / vitabit Libitinam; Ov. met. 15, 875-79: parte tamen meliore mei super alta perennis / astra ferar, nomenque erit indelebile nostrum, / quaque patet domitis Romana potentia terris, / ore legar populi, perque omnia saecula fama, / siquid habent veri vatum praesagia, vivam.

43 Auson. prof. praef.: vos etiam, quos nulla mihi cognatio iunxit, / sed fama et carae religio patriae / et studium in libris et sedula cura docendi, / commemorabo viros morte obita celebres.

44 See Schmitzer 2006, 171. 
challenges which - particularly on a regional and local scale, but also, beyond the borders of South Gaul, in Spain, Italy and other parts of the Roman Empire - led to a redefinition of the group affiliations and cultural patterns on the basis of which collective identities are shaped.

\section{Bibliography}

\section{Primary Sources}

Alexander of Aphrodisias, in librum de sensu commentarium: Commentaria in Aristotelem Graeca, Vol. III, ed. Paul Wendland, Berlin 1901.

Ausonius, opera:

Ausonius. With an English translation by Hugh G. Evelyn White, vol. 1 (LCL), Cambridge (Mass.) 1919.

Ausone, Euvres en vers et en prose. Traduction nouvelle de Max Jasinski, 2 vol., Paris $1934 / 35$.

Decimi Magni Ausonii Opera recogn. brevique annotatione critica instr. Roger P. H. Green, Oxford 1999.

The Works of Ausonius. Edited with Introduction and Commentary by Roger P. H. Green, Oxford 1991.

Decimo Magno Ausonio, Cupido messo in croce. Introduzione, testo, traduzione e commento a cura di Alessandro Franzoi (Studi latini 47), Napoli 2002.

Homer, Odyssea: Homer, The Odyssey. Introduction and notes by Robert Squillace, translated by George Herbert Palmer, New York 2003.

Paulinus of Nola, Epistulae: Letters of St. Paulinus of Nola, translated and annotated by Peter G. Walsh, vol. 2: letters 23-51, Westminster 1967.

Pausanias, Graeciae descriptio: Pausanias, Description of Greece. Books VIII.22-X, with an English translation by William H. S. Jones, Cambridge (Mass.) 1935.

Pliny, Epistulae:

C. Plini Caecili Secundi epistularum libri decem, rec. Roger A. B. Mynors, Oxford 1963.

Pliny, Letters and Panegyricus. With an English Translation by Betty Radice, vol 1 (LCL), Cambridge (Mass.) 1969.

Servius, Aeneidos librorum VI-XII commentarii: Servii Grammatici qui feruntur in Vergilii carmina commentarii, rec. Georg C. Thilo and Hermann Hagen, vol. 2, Leipzig 1884.

Virgil, Opera:

P. Vergili Maronis Opera, rec. Roger A. B. Mynors, Oxford 1986.

Virgil, Eclogues. Georgics. Aeneid I-VI. With an English translation by H. Rushton Fairclough. Revised by George P. Goold (LCL), Cambridge (Mass.) 1999.

Virgil, Aeneid VII-XII, The Minor Poems. With an English translation by H. Rushton Fairclough (LCL), Cambridge (Mass.) 1986. 


\section{Secondary Sources}

Braak (1974): Ivo Braak, Poetik in Stichworten. Literaturwissenschaftliche Grundbegriffe. Eine Einführung, Kiel.

Burkert (1977): Walter Burkert, Griechische Religion der archaischen und klassischen Epoche, Stuttgart.

Burkert (1991): Walter Burkert, Antike Mysterien, München.

Christmann (1976): Eckhard Christmann, „Der Tod des Aeneas und die Pforten des Schlafs", in: Herwig Görgemanns and Ernst August Schmidt (eds.), Studien zum antiken Epos, Meisenhain a. Glan (Beiträge zur klassischen Philologie 72), 251-279.

Davis (1994): N. Gregson Davis, „Cupid at the Ivory Gates. Ausonius as a Reader of Vergil's Aeneid“, Classical Quarterly 30, 162-170.

Dieterich (1913): Albrecht Dieterich, Nekyia. Beiträge zur Erklärung der neuentdeckten Petrusapokalypse, Berlin.

Dräger (2002): Paul Dräger, „Ein verschollenes Trierer Wandgemälde der Spätantike (Ausonius, Cupido Cruciatur)“, TZ 65, 121-139.

Ezquerra (1991): Antonio A. Ezquerra, „Überblick über die neuesten Untersuchungen zu Ausonius“, in: Manfred Joachim Lossau (ed.), Ausonius, Darmstadt (WdF 652), 446462.

Fauth (1974): Wolfgang Fauth, „Cupido cruciatur“, Grazer Beiträge 2, 39-60.

Gantar (2008): Kajetan Gantar, „Beobachtungen zu Vergils Schullektüre in Augustins Confessiones. Von den Prügeln der Lehrer zu den Tränen um Didos Schicksal“, in: Stefan Freund and Meinolf Vielberg (eds.), Vergil und das antike Epos, Festschrift $H$. J. Tschiedel, Stuttgart (AwK 20), 425-435.

Gindhart (2006): Marion Gindhardt, „Evolat ad superos portaque evadit eburna. Intertextuelle Strategien und Vergilparodie im Cupido cruciatus des Ausonius", RhM 149, 214-236.

Glei (1991): Reinhold F. Glei, Der Vater der Dinge. Interpretationen zur politischen, literarischen und kulturellen Dimension des Krieges bei Vergil, Trier.

Gruber (2006): Joachim Gruber, „16 Jahre Ausonius-Forschung 1989-2004 - ein Überblick“, Gymnasium 113, 359-382.

Habermehl (2006): Peter Habermehl, Petronius. Satyrica 79-141. Ein philologischliterarischer Kommentar, Vol. 1: Sat. 79-110, Berlin/New York (Texte und Kommentare 27/1).

Helbig (1963): Wolfgang Helbig, Führer durch die öffentlichen Sammlungen der klassischen Altertümer in Rom, 4. völlig neu bearb. Auflage, Tübingen.

Hodske (2001): Jürgen Hodske, Mythologische Bildthemen in den Häusern Pompejis. Die Bedeutung der zentralen Mythenbilder für die Bewohner Pompejis, Stendal (Stendaler Winckelmann-Forschungen 6).

Jones et al. (1971): Arnold Hugh Martin Jones, John Robert Martindale and John Morris, The Prosopography of the Later Roman Empire, vol. I, AD 260-395, Cambridge.

Juhnke (1972): Herbert Juhnke, Homerisches in römischer Epik flavischer Zeit, München (Zetemata 53).

Kroll (1932): Josef Kroll, Gott und Hölle. Der Mythos von Descensuskampfe, Leipzig/Berlin.

Kröner (1979): Hans-Otto Kröner, „Ausonius und Trier“, Trierer Beiträge 6, 10-18.

Lebek, Wolfgang Dieter (1985), „Modestinus AL I 1, 267 Shackleton Bailey (=273 Riese)“, ZPE 58, 37-45. 
Lehmann (2004): Tomas Lehmann, Paulinus Nolanus und die Basilica Nova in Cimitile/Nola. Untersuchungen zu einem zentralen Denkmal der spätantik-frühchristlichen Architektur, Wiesbaden.

Lessing (1766): Gotthold E. Lessing, Laokoon oder über die Grenzen der Mahlerey und Poesie, Berlin.

Liebermann \& Schmidt (1989): Wolf-Lüder Liebermann and Peter Lebrecht Schmidt, „Ausonius“, in: Reinhart Herzog and Peter Lebrecht Schmidt (eds.), Restauration und Erneuerung, Die lateinische Literatur von 284 bis 374 n. Chr., München (HLL 5), 268-308.

Lucifora (1978): Rosa Maria Lucifora, „Il cupido cruciatus di Ausonio rivisitato”, AAPel $54,305-318$.

Lucifora (1979): Rosa Maria Lucifora, „I loci similes del Cupido cruciatus”, AAPel 55, 261-271.

Maul (2006): Stefan M. Maul, Das Gilgamesch-Epos, München.

Möllendorff (2000): Peter von Möllendorff, „Aeneas und Odysseus. Die ,Tore des Schlafs“ in Aen. 6, 893-899“, Jürgen Paul Schwindt (ed.), Zwischen Tradition und Innovation, Poetische Verfahren im Spannungsfeld Klassischer und Neuerer Literatur und Literaturwissenschaft, München, 43-66.

Norden (1957): Eduard Norden, P. Vergilius Maro Aeneis Buch VI, Darmstadt.

Pfannenmüller (1953): Gustav Pfannenmüller, Tod, Jenseits und Unsterblichkeit in der Religion, Literatur und Philosophie der Griechen und Römer, München.

Pollmann (1993): Karla Pollmann, „Etymologie, Allegorese und epische Struktur. Zu den Toren der Träume bei Homer und Vergil“", Philologus 137, 232-251.

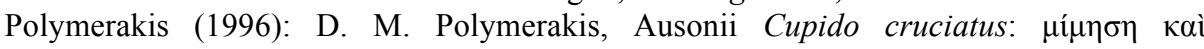

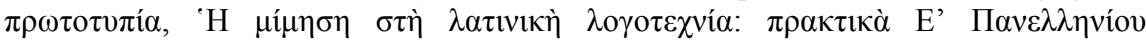

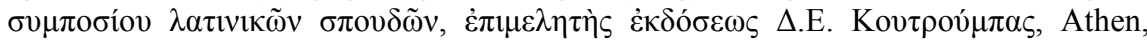
$345-363$.

Reitz (1982): Christiane Reitz, Die Nekyia in den Punica des Silius Italicus, Frankfurt a. M.

Rohde (1876): Erwin Rohde, Psyche. Seelencult und Unsterblichkeitsglaube der Griechen, Leipzig.

Schetter (1961): Willy Schetter, „Das Gedicht des Ausonius über die Träume (eph. 8, p. 14/15 P.)“, RhM 104, 366-378.

Schmitzer (2006): Ulrich Schmitzer, „Amor in der Unterwelt. Zu Ausonius' Gedicht $\mathrm{Cu}$ pido Cruciatus", in: Ulrich Schmitzer (ed.), Suus cuique mos. Beiträge zur paganen Kultur des lateinischen Westens im 4. Jahrhundert n. Chr., Göttingen, 167-184.

Steiner (1927): Paul Steiner, „Römische Wandmalerei in Trier“, TZ 2, 54-68.

Steiner (1952): Hans Rudolf Steiner, Der Traum in der Aeneis, Bern (Noctes Romanae 5), $88-96$.

Tarrant (1982): Richard J. Tarrant, „Aeneas and the Gates of Sleep“, CPh 77, 51-55.

Vannucci (1989): Laura Vannucci, „Ausonio fra Virgilio e Stazio. A proposito dei modelli poetici del Cupido cruciatus", Atene e Roma 34, 39-54.

Vessey (1973): David Vessey, Statius and the Thebaid, Cambridge.

Vielberg (1995): Meinolf Vielberg, „Horaz, Carmen 1, 1“, Hermes 123, 193-210.

Vielberg (2006): Meinolf Vielberg, Der Mönchsbischof von Tours im ,Martinellus'. Zur Form des hagiographischen Dossiers und seines spätantiken Leitbilds, Berlin/New York. 
Vielberg (2010): Meinolf Vielberg, „Omnia mutantur, nihil interit? Virgil's Katabasis and the Ideas of the Hereafter in Ovid's Metamorphoses“, in: Tobias Nicklas, Joseph Verheyden, Erik M.M. Eynikel and Florentino García Martínez (eds.), Other Worlds and Their Relation to This World. Early Jewish and Ancient Christian Traditions, Leiden, 169-187.

Vogt (2008): Ernst Vogt, „Didos Schweigen. Ein homerisches Motiv bei Vergil“, in: Stefan Freund and Meinolf Vielberg (eds.), Vergil und das antike Epos, Festschrift $H$. J. Tschiedel, Stuttgart (AwK 20), 31-40.

Wellek (1936): Albert Wellek, „Das Doppelempfinden im 18. Jahrhundert“, Deutsche Vierteljahresschrift für Literaturwissenschaft 14, 75-102.

Wright (1993): David H. Wright, The Vatican Vergil. A Masterpiece of Late Antique Art. Berkeley.

Zimmermann (2007): Norbert Zimmermann, „Verstorbene im Bild. Zur Intention römischer Katakombenmalerei“, Jahrbuch für Antike und Christentum 50, 154-179. 



\title{
Mito e politica nei Panegyrici di Sidonio Apollinare
}

\author{
Antonella Bruzzone
}

Nella tarda età imperiale, nell'ecumene grecoromana pur ormai definitivamente cristiana, il ricorso alla mitologia tradizionale rimane costante, tenace, e si presta a funzioni diversificate, non solo in ambito letterario: il mito è galleria di exempla e di immagini per la retorica epidittica e di argomenti utili alla dialettica della probatio, elemento essenziale di identità collettiva, storica e culturale, specie in contrapposizione alle civiltà ,altre" (i barbari: ma in alcuni casi il mito serve ad assimilarli nel mondo romano), ${ }^{1}$ mezzo per rappresentare sia la realtà sia l'utopia politica, strumento di propaganda, travestimento autobiografico, fattore di rinnovamento del linguaggio filosofico, morale, religioso.

Mentre nella prosa l'impiego del mito è quasi sempre connesso con una intenzione ideologica, in poesia esso è più pesantemente condizionato, nella frequenza, nella tipologia e nello spirito, dalla tradizione letteraria e in fondo da una certa convenzionalità topica.

La raffinata cultura e il ricercato gusto letterario di Sidonio Apollinare si esibiscono in una cospicua insistenza di richiami al mito.

É escluso naturalmente che Sidonio, cristiano ormai di terza generazione, con un curriculum biografico e culturale che appare a tratti quasi come il sintetico paradigma di un'epoca (di aristocrazia senatoria, imbevuto della lezione dei classici, assurto poi alle alte gerarchie della Chiesa, in prima fila come vescovo nella difesa culturale e militare per la sopravvivenza dei valori tradizionali nel nuovo regno romano-barbarico), attribuisse al mito e all'apparato divino pagano un rilievo religioso, la salvaguardia di riti, culti o credenze pagani: la questione è stata lungamente dibattuta e dunque ne possiamo qui senz'altro prescindere. ${ }^{2}$

È nella densa strutturazione del suo progetto culturale e politico che occorre indagare per accertare la valenza e il ruolo che i temi mitologici assumono di volta in volta nel suo tessuto espositivo.

1 Non si esitava, ad esempio, a sfruttare il racconto mitico per opportunità politica, allo scopo di ricostruire artificiosamente una comune genealogia e di scoprire quindi affinità fra il popolo romano e quello barbaro visigotico: approfondimenti in Gualandri 1999, 60 ss.; Gualandri 2006, 129.

2 La bibliografia in merito è autorevole ed esaustiva: per tutti Bonjour 1982, 5; Gualandri 1989a, 27 ss. (e Gualandri 1989b); Gualandri 1999, 49 ss. (cfr. Markus 1990, ad es. cap. 1; cap. 7; cap. 8); Gualandri 2006, 125 ss. Cfr. anche Stika 2002. 
Alla loro base si coglie soprattutto un aspetto erudito: in questo senso le notazioni mitologiche non si differenziano complessivamente da quelle di natura geografica, storica o letteraria, mostrano compiacimento descrittivo, e rientrano in una più generale ostentazione di dottrina. ${ }^{3}$

Tuttavia non è adeguato ritenere che il fenomeno si riduca tutto a categorie quali „ornamento“, „consuetudine letteraria“, „retorica“.

Infatti nei Panegyrici in versi in particolare (il panegirico è un genus di straordinaria complessità, innervato da molteplici istanze, letterarie politiche religiose ideologiche $)^{4}$ si rintracciano ampi spazi in cui il ricorso al mito, thesaurus di ,memoria culturale', può acquistare una connotazione pragmatica, non solo esornativa; l'uso del mito può essere non un semplice orpello formale ma una componente sostanziale.

In questi casi il mito e l'exemplum mitico si caricano di una sorprendente pregnanza per esprimere visioni ideologiche e politiche: l'interazione fra momento mitologico e momento contingente, più o meno esplicita o magari solo attivata mediante un elegante gioco di allusioni e di associazioni di idee, suggerisce una lettura orientata delle vicende contemporanee. Ovvero, sovrapponendosi in trasparenza all'episodio narrato, lo schema del racconto mitico ne rivela, per analogia, implicazioni non altrimenti percepibili, insinua interpretazioni angolate e spesso parziali della realtà. Ne deriva che, senza palesemente alterare i dati di fatto, dalla assidua interferenza fra i due piani, quello attuale e quello mitico, il poeta può ricavare preziosi spunti di propaganda.

Vorrei addurre un esempio, a mio parere emblematico, per illustrare uno di questi risvolti, per verificare come il mito rappresenti per Sidonio Apollinare anche un modo di guardare la realtà attraverso il filtro di una letteratura recepita sì come occasione di sfoggio erudito, ma nondimeno profondamente rivissuta: un esempio in cui il mito è vettore ideologico e il suo utilizzo produce significati politici.

Mi accingo qui ad esaminare alcuni passi dei suoi tre Panegyrici (il panegirico per Avito [carm. 7], recitato nel 456; il panegirico per Maioriano [carm. 5], recitato nel 458; il panegirico per Antemio [carm. 2], recitato nel 468$)^{5}$ che più

3 Importanti indicazioni di metodo (anche in un orizzonte più ampio e sull'uso del mito in Claudiano e in altri autori tardoantichi) in Consolino 1974; Moroni 1982; Gualandri 1989a, 27 ss.; Gualandri 1989b; Gualandri 1992, partic. 24-29; 37-38; 42-44; Gualandri 1993; Gualandri 1999; Fo 2002. Cfr. anche Santelia 1999.

4 Non meno del panegirico in prosa, il panegirico in esametri, pur con i suoi moduli convenzionali a volte addirittura sclerotizzati e con la reiterazione di tematiche consacrate da una prassi secolare, rimane comunque una forma letteraria ben radicata nella realtà politico-sociale del tempo. Cfr. la vasta ricognizione recentemente condotta da Schindler 2009.

5 Come è noto l'ordine di trasmissione dei Panegyrici sidoniani è inverso rispetto a quello cronologico e in quasi tutte le edizioni moderne si conserva questa successione. Per i motivi di maggior rilievo sotto il profilo storico relativi a questi panegirici si vedano Stevens 1933, 30 ss.; 46 ss.; 97 ss.; Loyen 1942; Günther 1982; Harries 1994; Kaufmann 1995. 
direttamente testimoniano le vicende dell'Italia alle prese con l'invasione dei Vandali a partire dal 455, anno del sacco di Roma perpetrato da Geiserico; a quello sconvolgente avvenimento seguirono reiterate scorrerie dalle coste africane sul territorio italico. ${ }^{6}$

Tutti e tre gli imperatori oggetto dei panegirici furono coinvolti dall'urgenza di far fronte all'aggressione vandalica: Avito, proclamato imperatore all'indomani dell'assalto di Roma. ${ }^{7}$ Maioriano, la cui priorità politica fu proprio la guerra contro Geiserico. ${ }^{8}$ Antemio, inviato in aiuto dall'imperatore d'Oriente Leone I con una consistente forza navale. ${ }^{9}$

Il panegirico per Flavio Eparchio Avito (= carm. 7; Avito era il suocero di Sidonio), il primo, in ordine cronologico, dei tre panegirici composti da Sidonio, viene recitato il $1^{\circ}$ gennaio 456 a Roma, dove Avito assume il consolato. ${ }^{10}$ Nella critica vacanza del trono imperiale dopo l'uccisione di Valentiniano III e di Petronio Massimo, Avito, di illustre famiglia senatoria dell'Arvernia, era stato eletto dai Galloromani con l'appoggio dei Visigoti, sui quali regnava allora Teoderico II. ${ }^{11}$ Sidonio naturalmente doveva promuovere nella nobiltà romana il consenso intorno al nuovo imperatore e console (che prima di allora non aveva ricoperto alcuna magistratura né aveva avuto alcun rapporto con la corte, ed era salito al trono in modo inusuale), ${ }^{12}$ ed evidenziare i vantaggi della sua elezione che la pars Orientis non aveva avallata. I tragici momenti dell'anno precedente, allorché i Vandali si erano impadroniti di Roma e l'avevano depredata, non potevano peraltro essere trascurati: ma fino a oltre la metà del carme non sono dichiaratamente sottolineati in tutta la loro gravità. Il panegirico si apre invece sull'immagine sublimata di un concilio divino, presieduto da Giove, ritratto nella sua superiore

6 Harries 1994, 77; Courtois 1955, 194 ss.; Stein 1959, 365 ss.; Frankovich Onesti 2002, 6061.

7 Stein 1959, 367; Courcelle 1964, 166-168; Harries 1994, 54 ss.; Mathisen 1981, 240-244.

8 Le sue imprese furono tutte finalizzate alla guerra contro Geiserico: a tale scopo l'imperatore aveva allestito una flotta e reclutato un considerevole esercito terrestre, con ampi arruolamenti di mercenari unni, rugi e ostrogoti, per trasferire le operazioni in Africa. Courtois 1955, 199 ss.; Stein 1959, 374 ss.; Courcelle 1964, 168 ss.; Harries 1994, 87-88. Una recente messa a punto in Oppedisano 2009, 543 ss.; 557-558. La spedizione di Maioriano si risolse in una catastrofe e nell'autunno del 460, dopo aver sottoscritto un deludente accordo di pace, Maioriano tornò in Gallia.

9 Tale operazione si concluse con un fallimento: Courtois 1955, 201 ss.; cfr. Stein 1959, 389 ss.; Demougeot 1969, II/2, 591-594. Vd. anche Harries 1994, 245-246 e Watson 1998, 185.

10 Stevens 1933, 30 ss.; Loyen 1942, 35-58; Harries 1994, 54 ss.; Mathisen 1981, 232-247; Kaufmann 1995, 81-105 (sui panegirici come espressione di „Romglaube und Lokalpatriotismus").

11 Su Avito cfr. ancora Martindale 1980, 196 ss.; Mathisen 1998a. Per l'alleanza fra Teoderico II e l'aristocrazia gallica nonché sui rapporti di Avito con la corte visigotica di Tolosa cfr. Courcelle 1964, 166 ss.; Harries 1994, 68-75; Gualandri 2000, 107 ss.; Brocca 2004. Sui Visigoti di quest'epoca cfr. anche Heather 1991, 84 ss.

12 Watson 1998, 184-185; Consolino 2000, 190; ma la nobilitas romana sempre gli negò l'appoggio: cfr. Brocca 2004, 290 ss. 
potenza e serenità: a lui una Roma affranta denuncia le difficoltà che affliggono l'impero, e da lui implora l'ausilio di un novello Traiano (vv. 45-118). ${ }^{13}$ Giove le risponde (vv. 123-598) con un lungo discorso (che si estende per il resto del carme: 475 versi) in cui pronuncia di fatto il panegirico di Avito, lodandone l'educazione, la carriera militare e diplomatica, e ripercorrendo via via gli ultimi eventi fino alla sua proclamazione in Gallia. ${ }^{14}$

Mi sono occupata in un precedente lavoro della rielaborazione del topos del concilium deorum nella poesia panegiristica tardoantica e delle sue potenzialità celebrative e propagandistiche: ${ }^{15}$ qui basti ricordare che, attraverso la mediazione di Claudiano, ${ }^{16}$ lo schema rievoca la scena del primo libro dell'Eneide, in cui Venere, angosciata per le sorti del figlio, si reca presso Giove e ne ottiene la garanzia dell'eterna gloria destinata alla stirpe di Enea. ${ }^{17}$

Nessun dubbio in merito all'effetto, politicamente rassicurante, comportato da questa ambientazione epica, che se non altro consente di ricondurre la vicenda ad un quadro di ottimistica aspettativa; ${ }^{18}$ ed inoltre, più nel dettaglio, anche in Sidonio sarà Giove a sancire che, in generale, il fatum di Roma è vincere (vv. 136-138 te mirum est vinci; incipies cum vincere, mirum / non erit; utque tibi pateat quo surgere tandem / fessa modo possis, paucis, cognosce, docebo), e, per quel che concerne il frangente particolare della guerra contro Geiserico, a vincere è destinato Avito, da Giove stesso raccomandato: v. 588 hic tibi restituet Libyen per vincula quarta. Non è arduo rendersi conto del risalto encomiastico e della finalità propagandistica congiunti con l'idea di una investitura addirittura divina di Avito, la cui ascesa al potere, come si è detto, il poeta aspirava a legittimare. ${ }^{19} \mathrm{Ma}$ su questo torneremo più oltre.

Per quanto riguarda il saccheggio vandalico di Roma Giove si esprime in questi termini:

13 Analisi approfondita del passo in Gualandri 1999, 58 ss.; Brocca 2004, 280. Sulle implicazioni ideologiche di questa categorica richiesta di „un altro Traiano“ cfr. Watson 1998, 193; Brocca 2004, 281 ss.

14 Recenti studi letterari d'insieme sul carme 7 (con ulteriori abbondanti indicazioni bibliografiche): Condorelli 2008, 20 ss.; Schindler 2009, 182 ss.

15 Bruzzone 2004 (con bibliografia). Sulle varie tipologie delle personificazioni nei Panegyrici di Sidonio Apollinare e sul loro valore ideologico vd. Bonjour 1982; cfr. anche Stika 2003, 71 ss.

16 Claud. Gild. 17 ss.: Bonjour 1982, 10; Fo 1982, 206 ss.; Gualandri 1999, 59-60.

17 Gualandri 1999, 58 ss.; Brocca 2004, 279 ss.; Gualandri 2006, 127 ss.

18 Moroni 1982, 231 ss.; Gualandri 1998, 113 ss.; Gualandri 1999, 60 e n. 64; Consolino 2000, 191 e n. 52; Gualandri 2006, 127 ss. Qualche spunto anche in Stika 2002, partic. 3639.

19 Courcelle 1964, 167; Harries 1994, 77; Watson 1998, 184 ss.; Brocca 2004, passim e 290 ss.; Schindler 2009, 214-215. 
Sidon. carm. 7, 441-451:

Interea incautam furtivis Vandalus armis te capit, infidoque tibi Burgundio ductu extorquet trepidas mactandi principis iras. Heu facinus! in bella iterum quartosque labores perfida Elisseae crudescunt classica Byrsae. 445 Nutristis quod, fata, malum? conscenderat arces Evandri Massyla phalanx montesque Quirini Marmarici pressere pedes rursusque revexit quae captiva dedit quondam stipendia Barce. Exilium patrum, plebis mala, principe caeso captivum imperium ad Geticas rumor tulit aures. ${ }^{20}$

Cependant le Vandale, profitant de la surprise, par une attaque brusquée, s'empare de toi, ô Rome, et un Burgonde, par ses perfides excitations, éveille en toi un tel accès de fureur que tu immoles ton souverain. Lamentable forfait! A nouveau les perfides trompettes de Byrsa la Phénicienne annoncent, de leurs cruels accents, les épreuves d'une quatrième guerre. O destins, quel malheur nourrissiez-vous? Les bataillons massyles montaient à l'assaut de la citadelle d'Evandre, les fantassins marmariques foulaient la colline de Quirinus et Barcé ramenait chez elle la rançon que sa captivité lui avait autrefois coûtée. La nouvelle parvint aux oreilles des Goths de l'exil du Sénat, des malheurs du peuple, du meurtre de l'Empereur, de la captivité de l'Empire. ${ }^{21}$

„Di nuovo, i perfidi squilli di tromba della Byrsa elissea inasprendosi incitano alle prove di una quarta guerra. O destino, quale male hai nutrito?"

C'è da chiedersi per quale ragione Giove dietro la furia degli accadimenti („La falange Massila aveva invaso le rocche di Evandro [cioè il Palatino], e i fanti marmarici calpestarono i colli di Quirino $[\ldots]^{\text {") }}$ ) chiami espressamente in causa la responsabilità dei fata.

La risposta va cercata negli espedienti più sofisticati della poesia che Sidonio Apollinare intimamente conosce e sistematicamente pratica.

Secondo un procedimento caratteristico della poesia ,,preziosa“ tardoantica, $^{22}$ è un dato esterno al testo, ma elemento di memoria letteraria, a integrarne e a ,governarne“ per così dire la ricezione: il significato più profondo può essere decifrato solo presupponendo una correlazione con un contesto parallelo della tradizione culturale, sul quale misurare in un certo senso l'esperienza coeva. ${ }^{23}$

20 Il testo dei Panegyrici di Sidonio Apollinare (= carm. 2, 5 e 7) è citato secondo l'edizione di Loyen 2008.

21 Le traduzioni di Sidonio Apollinare sono di Loyen 2008.

22 L'espressione è mutuata dal classico Loyen 1943; vd. anche Kaster 1988, passim, spec. 95; e ad es. Gualandri 1979; Gualandri 1989c, 527; Roberts 1989; Gualandri 1992, partic. 2429; 37-38; 42-44. Sulla cultura di Sidonio cfr. anche Horváth 2000; Colton 2000.

23 Vd. Bruzzone 2003-2005, 377 ss. e la bibliografia ivi citata nell'Appendice, 383-384. 
Il brano è impostato su una dinamica allusiva che si riporta ancora all'Eneide virgiliana, così come abbiamo rilevato per l'ambientazione del panegirico, costruita sul fondamento del concilium deorum del primo libro del poema virgiliano. Un indizio di allusività quasi impercettibile, disposto lì con apparente noncuranza (conformemente a una delle tecniche di implicazione proprie a Sidonio), ${ }^{24}$ è in verità decisivo: l'aggettivo Elisseus, ${ }^{25}$ che attiva un aggancio estremamente puntuale a uno dei più celebrati passi dell'Eneide e suscita immediatamente una precisa atmosfera. Siamo alla fine del quarto libro e Didone (anzi Elissa ${ }^{26}$ come lei stessa si chiama al verso 610) prorompe nelle sue violente e disperate à $\rho \alpha$ í invocando un fato terribile di inimicizia fra Roma e Cartagine:

Verg. Aen. 4, 607 ss.:

Sol, qui terrarum flammis opera omnia lustras, tuque harum interpres curarum et conscia Iuno, nocturnisque Hecate triviis ululata per urbes et Dirae ultrices et di morientis Elissae, accipite haec meritumque malis advertite numen, et nostras audite preces. Si tangere portus infandum caput ac terris adnare necesse est, et sic fata Iovis poscunt, hic terminus haeret: at bello audacis populi vexatus et armis, finibus extorris, complexu avulsus Iuli auxilium imploret videatque indigna suorum funera; nec, cum se sub leges pacis iniquae tradiderit, regno aut optata luce fruatur, sed cadat ante diem mediaque inhumatus harena.

Haec precor, hanc vocem extremam cum sanguine fundo.

Tum vos, o Tyrii, stirpem et genus omne futurum exercete odiis, cinerique haec mittite nostro munera. Nullus amor populis nec foedera sunto. Exoriare aliquis nostris ex ossibus ultor, qui face Dardanios ferroque sequare colonos, nunc, olim, quocumque dabunt se tempore vires. Litora litoribus contraria, fluctibus undas imprecor, arma armis: pugnent ipsique nepotesque. ${ }^{27}$

O sole, che illumini con le fiamme tutte le opere della terra, e tu, Giunone, autrice e complice dei miei affanni, Ecate invocata per la città nei notturni trivii ululando,

24 Gualandri 1979, passim, spec. 85; Fo 2002, 170.

25 Termine fra l'altro molto raro e connotato: sul suo impiego mi sono già soffermata in Bruzzone 2003-2005, 378-379.

26 Sulle valenze ideologiche e sulle sfumature affettive connesse con questo nome alternativo di Didone nell'Eneide cfr. Sala 1985, 48 ss.; Maggiulli 1985, 202-203.

27 Il testo dell'Eneide è citato secondo l'edizione di Conte 2009. 
e Dire vendicatrici, e dei della morente Elissa,

accogliete quello che dico, punite con giusto nume i malvagi,

e ascoltate le mie preghiere. Se l'infame deve raggiungere

il porto e approdare alla terra e questo richiedono

i fati di Giove, e il termine resta immutabile:

ma travagliato dalle armi e dalla guerra d'un popolo audace,

bandito dalle terre, strappato all'abbraccio di Iulo,

implori aiuto, e veda le immeritate morti

dei suoi, e quando si sia piegato alle leggi d'una pace

iniqua, non goda del regno e del dolce lume;

ma cada prima dell'ora, insepolto tra la sabbia.

Di questo vi prego, col sangue effondo quest'ultima voce.

E voi, o Tirii, tormentate con odio la sua stirpe

e tutta la razza futura, offrite un tal dono

alle nostre ceneri. Non vi sia amore né patto tra i popoli.

E sorgi, vendicatore, dalle mie ossa,

e perseguita col ferro e col fuoco i coloni dardanii, ora, in seguito, o quando se ne presenteranno le forze.

Lidi opposti ai lidi, onde ai flutti

auguro, armi alle armi; combattano essi e i nipoti. ${ }^{28}$

Questa interpretazione sidoniana degli scontri fra Romani e Vandali/Africani come conseguenza del fato connesso alla maledizione di Didone ${ }^{29}$ non è isolata. Già Flavio Merobaude pochi anni prima, in un passaggio del suo panegirico poetico per Aezio del 446 d.C. (= paneg.), aveva adombrato, appunto tramite l'ascendente virgiliano abilmente richiamato nel suo testo con lo stesso aggettivo Elissaeus e con l'aggettivo fatalis applicato alle armi del Vandalo (nonché con la menzione delle Tyriae arces), che Geiserico, impossessandosi di Cartagine, nel 439, e facendone un regno nemico di Roma, era venuto a rilanciare la condanna di quel destino: si era così comprovato esecutore - quasi un secondo Annibale proprio di quella maledizione di Elissa/Didone:

Merob. paneg. 24 ss.:

Insessor Libyes quamvis fatalibus armis ausus Elissaei solium rescindere regni milibus Arctois Tyrias conpleverat arces.

Nunc hostem exutus pactis proprioribus arsit

Romanam vincire fidem Latiosque parentes

adnumerare sibi sociamque intexere prolem. ${ }^{30}$

28 Le traduzioni dell'Eneide sono di Canali 1978.

29 Cfr. già Gualandri 1999, n. 64.

30 Il testo di Merobaude è citato secondo l'edizione di Vollmer 1905 (il passo in questione è alla p. 12). 
L'occupatore della Libia (scil. Geiserico) pur con armi fatali (cioè volute dal Fato) osando alienare (scil. da Roma) il trono del regno di Didone aveva riempito le rocche tirie con innumeri orde calate dalle plaghe settentrionali. Ora invece, deposto il ruolo di nemico, arde dal desiderio di vincolare la parola romana con patti più personali e di ascriversi parenti latini.

Tale brano di Merobaude, che ho approfondito in altra sede, ${ }^{31}$ si configura esattamente come l'intermediario fra Virgilio e Sidonio. Direi senz'altro che Sidonio ad esso si sia ispirato: evidentemente il mito didoniano forniva utili spunti di propaganda alla poesia politica del $\mathrm{V}$ secolo in materia di rapporti romano-barbarici.

Merobaude aveva proiettato la realtà contemporanea (l'espugnazione di Cartagine compiuta da Geiserico nel 439 e il successivo trattato con cui Roma nel 442 ratificava le conquiste del re Vandalo) ${ }^{32}$ sullo sfondo di quell'antica maledizione allo scopo, propagandistico, di prospettare la perdita di Cartagine non tanto come uno smacco per Roma (e Aezio) quanto come il cedimento dell'Africa stessa alla inesorabilità di un destino perverso, che la provincia era costretta a patire contro la sua propria volontà.

Così in Sidonio, in modo ancora più articolato: i Vandali hanno provocato una quarta guerra punica (quartos [...] labores: tornerò in seguito su questo aspetto), di nuovo i Romani si apprestano ad affrontare prove tremende (crudescunt) ${ }^{33}$ come in passato. ${ }^{34}$ Tutto questo avviene non per una intrinseca debolezza di Roma, per una qualche sua colpa, ma perché i barbari sono sospinti da un fatum spietato e inevitabile (nutristis quod, fata, malum?), il fato preteso dal rancore di Didone (non casuale credo anche la scelta del toponimo Byrsa come ulteriore allusione alla regina fenicia: ${ }^{35}$ Byrsa è il nome dell'acropoli di Cartagine, impiegato una sola volta nell'Eneide, nell'ambito del racconto di Venere ad Enea circa la fondazione della città proprio ad opera di Didone [Aen. 1, 367]: mercatique solum, facti de nomine Byrsam, / taurino quantum possent circumdare tergo), che li forza a non rispettare i patti (nec foedera sunto in Virgilio; perfida [...] classica in Sidonio: al concetto di perfidia si ricorre spesso in relazione al nemico in guer-

31 Bruzzone 2003-2005 (cfr. anche Bruzzone 1999, 110 ss.).

32 Bruzzone 1999, 110 ss. (comm. ai vv. 24-29: con bibliografia su tali avvenimenti storici; si aggiungano Courcelle 1964, 164 ss.; Francovich Onesti 2002, 37 ss.).

33 Sui valori traslati dell'incoativo crudesco cfr. ThlL s.v., col. 1232, 11. 51 ss. Cfr. anche Savaro 1609, 105 n. 441 che pensa ad un simplex pro composito: „Perfida Elisseae crudescunt classica Byrsae] id est, Africana bella recrudescunt. perfida, quia semper Romae aemula Carthago fuit et inimica. Syllius. 1. 13 [...]".

34 Ma di nuovo i Romani saranno in grado di superarle. Il motivo è topico nei panegirici: nella realtà storica attuale si compiono imprese belliche uguali o addirittura superiori a quelle realizzate nel glorioso passato (cfr. Luiselli 1992, 416 ss. sul significato culturale). Sopra, nei versi 127-135, a Roma umile e triste Giove aveva rivolto parole di conforto rievocatrici del superamento di altri antichi momenti di crisi: quelli dovuti a Porsenna, a Brenno, ad Annibale.

35 Cfr. Savaro 1609, 105 n. 441: „Elysseae Byrsae] id est Carthaginis ab Elissa conditae“. ThlL s.v., col. 2266, 11.14 ss.; Byrsa anche in Sidon. carm. 2, 351 (vd. infra); 5, 600; $23,256$. 
ra; per i Punici era proverbiale, e in generale la slealtà è topicamente imputata ai barbari). ${ }^{36}$

Una analoga giustificazione ideologica delle sconfitte inferte da Geiserico ai Romani - 1'ineluttabilità del destino scatenato da Didone attenua ovviamente la percezione che i Romani hanno della gravissima crisi e diminuisce l'umiliazione - viene riproposta nel panegirico per Maioriano (carm. 5) del 458 (recitato per l'adventus a Lione del nuovo imperatore). ${ }^{37}$

Anche in questo panegirico la cornice narrativa prevede un concilium di epica fattura: un „concilio delle province“ presieduto da Roma, introdotta come fiera bellatrix. ${ }^{38}$ Fra la moltitudine delle terre convenute per renderle omaggio, in lacrime, prende la parola Africa, personificata, tutta lacera (il modello di questa rappresentazione si rivela ancora il Claudiano del De bello Gildonico). ${ }^{39}$ Lamenta le sue miserevoli condizioni, si appella alla necessità che la costringe, al di sopra della sua volontà, ad assoggettarsi a un perpetuo stato conflittuale, insistendo sul carattere di indefettibile irriducibilità del destino: è obbligata dai fata a questo nuovo scontro (vv. 88-89 quid merui? fatis cogor tibi bella movere, / cum volo, cum nolo) - naturalmente, addebitando al fato la responsabilità dei contrasti, Africa, ovvero gli Afroromani ${ }^{40}$ (sottoposti dai conquistatori a confische dei beni, esilii e aspre persecuzioni), mirava a esercitare una pressione su Maioriano af-

36 Cfr. ThlL s.v. perfidus, col. 1390, 11. 44 ss.; s.v. perfidia, col. 1385, 11. 44 ss.; e ad es. Del Chicca 1991, 111-112; Luiselli 1992, 386-387.

37 Per la cronologia del carme Loyen 1942, 59 n. 1. In generale Stevens 1933, 46 ss.; Loyen 1942, 59-84. Il panegirico per Maioriano, a differenza degli altri due, venne composto non per celebrare l'ascesa al consolato dell'imperatore (avvenuta nel 457) ma per l'appunto in occasione del suo arrivo a Lione l'anno successivo. Sugli eventi principali connessi con l'impero di Maioriano e sulla sua politica cfr. ancora Courcelle 1964, 168 ss.; Harries 1994, 82 ss.; Watson 1998, 183; inoltre Martindale 1980, 703; Mathisen 1998b. Le parole premonitrici con cui Giove nel panegirico per Avito rinfrancava Roma supplice annunciando l'azione risolutiva del nuovo imperatore (carm. 7, 588: vd. supra) erano dunque rimaste inadempiute; d'altra parte le intenzioni belliche di Avito contro i Vandali, che persistevano nel minacciare le coste italiche con scorribande piratesche, erano state soffocate dalla politica pacifista dell'imperatore d'Oriente Marciano: e così Avito aveva potuto esperire solo negoziazioni diplomatiche destinate a rivelarsi fallimentari (Mathisen 1981, 240244). Per la complessa situazione storica che si produsse in Gallia dopo Avito con l'ascesa di Maioriano vd. Mathisen 1979, 597-627 (in questo panegirico per Maioriano sembra anche trapelare la personale amarezza dell'autore per il nuovo clima politico: cfr. Rousseau 2000, 251-257); Harries 1998, 54 ss. Cfr. anche la discussione di Santelia 2005 (partic. 204 ss.) e la bibliografia ivi citata.

38 Un recente studio letterario d'insieme: Condorelli 2008, 48 ss. (con rimandi bibliografici). Ancora una personificazione di Roma, ma assai differente rispetto a quella del panegirico per Avito: vd. Bonjour 1982, 16-17 sulla funzione non solo decorativa ma anche politica di queste prosopopee. Su questo passo anche Luiselli 1992, 419.

39 Cfr. già Sirmondus 1652, 117; Geisler in Luetjohann 1887, 390; Brolli 2004, 299. Analisi del concilio claudianeo in Fo 1982, 200 ss.; Moroni 1982, 230 ss.; Bruzzone 2004, 133 134. Per Sidon. carm. 5, 53-55 cfr. Claud. Gild. 134 ss.; per Sidon. carm. 5, 56 ss. cfr. Claud. Gild. 161 ss.

40 Courcelle 1976, 50. 
finché affrettasse lo sbarco, ${ }^{41}$ predisponendosi nel contempo una scusante nell'evenienza che alle sue richieste di aiuto Roma, ovvero l'imperatore romano, rimproverasse le passate ostilità:

Sidon. carm. 5, 53 ss.:

\section{[...] Subito flens Africa nigras}

procubuit lacerata genas et cernua frontem

iam male fecundas in vertice fregit aristas

ac sic orsa loqui: „Venio pars tertia mundi,

infelix felice uno [cioè Geiserico]. Famula satus olim

hic praedo et dominis extinctis barbara dudum

sceptra tenet tellure mea penitusque fugata

nobilitate furens quod non est non amat hospes.

60

$O$ Latii sopite vigor, tua moenia ridet

insidiis cessisse suis. Non concutis hastam?

non pro me vel capta doles? tua nempe putantur

surgere fata malis et celsior esse ruina.

Soudain l'Afrique en pleurs se jeta aux pieds de la déesse, ses joues noires déchirées. Courbant le front, elle brisa les épis aujourd'hui bien légers de sa couronne et parla en ces termes: „Me voici, moi, la troisième partie du monde, malheureuse à cause du bonheur d'un seul. Ce fils d'une esclave, ce pillard, ayant fait disparaître mes chefs, tient depuis longtemps mon sol sous son sceptre barbare; bien que fédéré, il a chassé entièrement la noblesse, déchaîné contre elle, car il n'aime pas ce qu'il n'est pas luimême. $\mathrm{O}$ force assoupie du Latium! il rit d'avoir vu tes murs céder devant ses ruses. Et tu ne brandis pas ta lance? Toi qui as connu aussi la captivité, tu ne compatis pas à ma peine? On pense avec raison que le malheur grandit ta destinée et que tu sors plus altière de tes ruines.

Sidon. carm. 5, 85 ss.:

Me quoque (da veniam quod bellum gessimus olim)

post Trebiam Cannasque domas, Romanaque tecta

Hannibal ante meus quam nostra Scipio vidit.

Quid merui? fatis cogor tibi bella movere,

cum volo, cum nolo. Trepidus te territat hostis,

sed tutus claudente freto, velut hispidus alta

sus prope tesqua iacet claususque cacuminat albis

os nigrum telis gravidum; [...]

41 La risoluzione dei problemi con Geiserico in Africa avrebbe prodotto forse una situazione vantaggiosa anche per la Gallia, alla quale l'imperatore avrebbe finalmente potuto dedicare il suo impegno (Heather 1991, 94; Brolli 2004, 298-299): interessata risulta pertanto la scelta di Sidonio di riservare proprio all'organizzazione dell'impresa bellica antivandalica un posto centrale nell'economia narrativa del panegirico per Maioriano. 
Moi aussi (pardonne-moi de t'avoir autrefois fait la guerre) après la Trébie et Cannes, tu me soumis et pourtant mon Hannibal avait vu les maisons romaines avant que Scipion eût vu les nôtres. Quelle est ma faute? Ce sont les destins qui me contraignent à engager la guerre contre toi, que je le veuille ou non. L'ennemi qui t'alarme est luimême inquiet, mais il s'abrite derrière le rempart des flots. Tel un sanglier velu qui se cache près des hauts lieux sauvages; retranché, il aiguise les blanches défenses qui chargent son groin noir.

Conclude rivolgendo a Roma la preghiera di concederle un uomo capace non solo di liberarla dal popolo invasore, ma anche di liberarla da quel fatum funesto, onde Cartagine non debba più combattere contro l'Italia:

Sidon. carm. 5, 347-349:

Atque ideo hunc dominum saltem post saecula tanta

ultorem mihi redde, precor, ne dimicet ultra

Carthago Italiam contra.

Et c'est pourquoi, je t'en prie, donne-moi comme autrefois, après tant de siècles, un maître; donne-moi Majorien qui me vengera, pour que Carthage cesse de lutter contre l'Italie.

Nettissima anche in questa supplica finale la presenza di Didone, la Didone colma di astio di Aen. 4, 624 ss.: ${ }^{42}$

[...] Nullus amor populis nec foedera sunto.

Exoriare aliquis nostris ex ossibus ultor,

qui face Dardanios ferroque sequare colonos,

nunc, olim, quocumque dabunt se tempore vires.

Litora litoribus contraria, fluctibus undas

imprecor, arma armis: pugnent ipsique nepotesque.

Non vi sia amore né patto tra i popoli.

E sorgi, vendicatore, dalle mie ossa,

e perseguita col ferro e col fuoco i coloni dardanii, ora, in seguito, o quando se ne presenteranno le forze.

Lidi opposti ai lidi, onde ai flutti

auguro, armi alle armi; combattano essi e i nipoti,

ma con uno slittamento di piani se non un rovesciamento. L'ultor sollecitato da Didone (Aen. 4, 625) perché perseguitasse col ferro e col fuoco la progenie di Enea si trasforma in un vendicatore che deve però infrangere definitivamente il sortilegio che schiacciava Roma e Cartagine in una perenne belligeranza; la ma-

42 Le riprese da Virgilio sono state rimarcate fra gli altri da Courcelle 1976, 49-51; Courcelle 1984, 23 ss.; Veremans 1991, 497 ss. 
ledizione scagliata da Didone con l'impiego del verbo imprecor $($ Aen. 4, 629) si risolve in una preghiera positiva (precor) ${ }^{43}$ indirizzata con devozione ad una entità più alta $\left(\right.$ Roma ,divinizzata $^{\text {( }): ~ e ~ R o m a ~ r i s p o n d e ~ c o n ~ u n ~ t o n o ~ c o n f o r m e, ~ p r o-~}$ mettendo l'imperatore Maioriano come vindice (v. $351 \mathrm{ss}$.): his haec Roma refert: „Longas succinge querelas, / o devota mihi; vindex tibi nomine divum / Maiorianus erit $[\ldots]$ “..

Proprio alla fine della perorazione di Africa, nelle sue ultime tre parole si evidenzia un ulteriore referente letterario, ad arricchire e completare la cifra ideologica del testo. La sequenza del v. 349 Carthago Italiam contra indubbiamente riecheggia il proemio del poema virgiliano. ${ }^{44}$

Verg. Aen. 1, 12-14:

Urbs antiqua fuit (Tyrii tenuere coloni)

Karthago, Italiam contra Tiberinaque longe

ostia, dives opum studiisque asperrima belli.

Città antica fu, la tennero coloni tirii,

Cartagine, lontano di fronte all'Italia e alla foce

del Tevere, ricca di mezzi, fortissima di ardore guerriero.

Il preciso rinvio all'ostilità originaria fra Roma e Cartagine è operato con il primo segmento dell'esametro virgiliano (il v. 13) in cui è nominata per la prima volta la città fondata dai Tyrii: con esso l'inizio del v. 349 del panegirico di Sidonio combacia alla perfezione. Ma quella che nel proemio dell'Eneide voleva essere, alla lettera, una materiale notazione geografica, contra, qui palesa il suo metaforico valore oppositivo (sulla scorta del v. 628 del quarto libro dell'Eneide, dove l'uso dell'aggettivo contraria [scil. litora] da parte di Didone furente denota il medesimo sviluppo semantico: litora litoribus contraria, fluctibus undas / imprecor, arma armis: pugnent ipsique nepotesque); e in verità già quel geografico contra di Aen. 1, 13 appare piegarsi verso il fatale contrasto fra le due città egemoni prefigurato nei versi successivi.

43 Sul differente uso di precor e imprecor vd. Caper gramm. VII 99, 19 ed. Keil: precor prospera, inprecor taetra (ma rileverei anche che Didone in Aen. 4, 621 si era avvalsa del verbo precor a riguardo del destino che lei augurava ad Enea infelicissimo; al v. 629 Didone impiega invece il verbo imprecor); Beck 1883, 78, 38: precari rogare est, imprecari male dicere, deprecari excusare et purgare est (Agroec. gramm. VII 115, 3-4 ed. Keil: precari autem est rogare, inprecari maledicere, deprecari excusare et expurgare; Isid. diff. 1, 321; 437; Beda gramm. VII 284, 24-25 ed. Keil: precari est rogare, deprecari excusare vel purgare); Aug. epist. 149, 13 PL 33, coll. 635-636: precari [...] esse precando bona optare, imprecari mala [...] Di norma precor è rivolto ad esseri superiori, e naturalmente è frequente con le divinità: ThlL s.v. precor, col. 1153, 11. 21 ss.; col. 1154, 11. 35 ss.; cfr. anche s.v. imprecor, col. 675 , 11. 42 ss. e s.v. deprecor, col. $598,11.50$ ss.

44 Savaro 1609, 58 n. 349: „,ne dimicet [...] contra] hemistichium, Verg. 1. Aen. Carthago Italiam contra"; Geisler in Luetjohann 1887, 393; Courcelle 1976, 50; Courcelle 1984, 23; Veremans 1991, 498. 
Ancora più marcato il ricordo del proemio dell'Eneide nei versi 101-104 del panegirico per Maioriano:

Sidon. carm. 5, 98 ss.:

\section{[...] Quid proelia differs?}

quid mare formidas, pro cuius saepe triumphis

et caelum pugnare solet? quid quod tibi princeps

100

est nunc eximius, quem praescia saecula clamant

venturum excidio Libyae, qui tertius ex me

accipiet nomen? Debent hoc fata labori,

Maioriane, tuo. Quem cur conscendere classem

ac portus intrare meos urbemque subire,

si iubeas, cupiam, paucis ex ordine fabor.

Pourquoi remettre les combats? Pourquoi redoutes-tu la mer, toi que si souvent le ciel même aide à triompher? Bien plus, ne possèdes-tu pas à présent un empereur éminent dont les siècles prophétiques proclament qu'il viendra pour la destruction de la Libye et qui, le troisième, recevra de moi son nom? Voilà, Majorien, la récompense que le destin doit à tes travaux. Pourquoi je désire le voir s'embarquer sur la flotte, entrer dans mes ports, pénétrer dans ma Ville, je vais, si tu permets, le dire brièvement, dans l'ordre des événements.

L'avvio del verso 102 coincide ad verbum con quello dell'esametro virgiliano (Aen. 1, 22) in cui si ascrive a Giunone la consapevolezza, per lei nefanda, che dal sangue troiano sarebbe sorta un giorno una stirpe che avrebbe prodotto la rovina della prediletta città di Cartagine: ${ }^{45}$ così filavano le Parche:

Verg. Aen. 1, 19-22:

Progeniem sed enim Troiano a sanguine duci

audierat Tyrias olim quae verteret arces;

hinc populum late regem belloque superbum

venturum excidio Libyae: sic volvere Parcas.

Tuttavia sapeva che sarebbe discesa da sangue troiano una stirpe che un giorno abbatterebbe le rocche tirie; di qui un popolo largamente sovrano e superbo in guerra verrebbe a rovina della Libia: così filavano le Parche.

Nel brano sidoniano, Africa adduce questo presagio per incoraggiare Maioriano: è lui il pronosticato distruttore di Cartagine, la sua vittoria è reclamata da una fatale

45 Savaro 1609, 42 n. 102: „Venturum excidio Libyae] haec ex sortibus Vergilianis. I. Aeneid.“; Geisler in Luetjohann 1887, 391; Courcelle 1976, 50; Courcelle 1984, 24-25; Veremans 1991, 498. 
necessitas storica (vv. 101-102 praescia saecula clamant / venturum excidio Libyae).

Non solo. Africa si dice anche convinta che Maioriano, terzo, sarà insignito dell'appellativo di Africanus (vv. 102-103 qui tertius ex me / accipiet nomen): questa volta l'extratestuale sponda analogica è fornita da un precedente propriamente storico. Maioriano sarà il terzo „Africano“, terzo dopo gli Scipioni (rispettivamente il vincitore a Zama e il distruttore di Cartagine): ${ }^{46}$ la guerra contro Geiserico deve essere valutata come una nuova guerra punica a pieno titolo.

La guerra contro Geiserico e i suoi Vandali, originatasi dal fatum maligno reclamato da Didone, viene così riassorbita in una predeterminata galleria delle glorie di Roma: ricondotta nella sfera di pertinenza del fatum vittorioso su Cartagine, anticipato nel proemio dell'Eneide, e nella scia delle guerre puniche (vale forse la pena notare che Geiserico, il nemico di Maioriano, acquista in Sidonio tratti affini a quelli che la tradizione letteraria aveva assegnato ad Annibale, il nemico di Scipione). ${ }^{47}$

Come abbiamo potuto constatare, sia nel panegirico per Avito sia in quello per Maioriano l'aggancio all'Eneide si estrinseca tanto sul versante mitico, le ảpaí di Didone, quanto sul versante storico, le guerre puniche.

Ora nel panegirico per Avito vorrei mettere l'accento sulla finezza con cui questi due piani, il mitico e lo storico, non solo si correlano nel rapporto di causaeffetto, ma addirittura si sovrappongono in un'unica parola. Mi riferisco a carm. 7, 444-445:

\section{Heu facinus! in bella iterum quartosque labores perfida Elisseae crudescunt classica Byrsae.}

Lamentable forfait! A nouveau les perfides trompettes de Byrsa la Phénicienne annoncent, de leurs cruels accents, les épreuves d'une quatrième guerre.

Per significare che gli scontri con Geiserico si profilano come una nuova, quarta guerra dopo quelle antiche tre guerre puniche nate dalle maledizioni della regina

46 Lo notavano già ad es. Savaro 1609, 42 n. 102; Sirmondus 1652, 117; cfr. Kaufmann 1995, 98. Un analogo gioco di parole sul futuro soprannome Africanus, terzo dopo gli Scipioni (carm. 5, 102 ss.) e l'epiteto ultor (attribuito qui, carm. 5, 348, a Maioriano, un imperatore romano) ricorrevano in Silio Italico a proposito di Scipione nella profezia in cui Proteo ne prediceva alle Nereidi il trionfo a Zama $(7,487-491)$ : dunque già Silio Italico aveva operato una attualizzazione del mito con dislocazione di referente (l'ultor preconizzato da Proteo alle Nereidi come vincitore della battaglia di Zama si identificava con Scipione; cfr. anche Sil. 16, 593): Brolli 2004, 301. Vd. anche infra nel testo per ulteriori spunti analogici.

47 Un Annibale degradato, però: l'argomento meriterebbe di essere approfondito. Cfr. Watson 1998, 193; Brolli 2004, 302-303. Claudiano da parte sua aveva disegnato Alarico (nel contesto del racconto delle sue campagne in Italia nel 402, presentate come „reenactment" della più grande crisi della storia repubblicana romana) con le stesse fattezze di Annibale: cfr. Dewar 1994. 
cartaginese contro la discendenza dell'eroe troiano, Sidonio adotta il termine labores $^{48}$ (cfr. anche carm. 5, 103-104: debent hoc fata labori, Maioriane, tuo), il quale non può non richiamare al lettore dotto i celebri labores di Enea, menzionati proprio all'inizio del poema:

Verg. Aen. 1, 8 ss.:

Musa, mihi causas memora, quo numine laeso quidve dolens regina deum tot volvere casus insignem pietate virum, tot adire labores

impulerit. Tantaene animis caelestibus irae?

O Musa, dimmi le cause, per le quali offese al suo nume, di cosa dolendosi, la regina degli dei costrinse un uomo insigne per pietà a trascorrere tante sventure, ad imbattersi in tanti travagli? Tali nell'animo dei celesti le ire?

Se il contingente odio fra Vandali e Romani trovava un prototipo nella tradizione mitica relativa a Didone, la carica evocativa di labores, il termine più connotativo delle sofferenze e delle fatiche di Enea, progenitore dei Romani, spingeva verso la sezione del testo virgiliano in cui figurava la profezia sulla discendenza troiana che avrebbe un giorno raso al suolo la rocca di Cartagine (Byrsa precisamente nel testo sidoniano: vedi supra per le valenze ideologiche associate; forse non privo di importanza l'abbinamento dell'aggettivo derivato Byrsicus e di Elisseus anche in Sidon. epist. 7, 17 v. 17 spernis Elisseae Byrsica tecta domus).

Verg. Aen. 1, 19-22:

Progeniem sed enim Troiano a sanguine duci audierat Tyrias olim quae verteret arces; hinc populum late regem belloque superbum venturum excidio Libyae: sic volvere Parcas.

Tuttavia sapeva che sarebbe discesa da sangue troiano una stirpe che un giorno abbatterebbe le rocche tirie; di qui un popolo largamente sovrano e superbo in guerra verrebbe a rovina della Libia: così filavano le Parche.

E se si riflette che gli Arverni rivendicavano fermamente la discendenza da Troia (rammentata da Sidonio anche all'inizio di questo panegirico [carm. 7, 139] nella

48 Cfr. già Savaro 1609, 105 n. 440 („Quartosque labores] fuere enim tria Punica bella, quibus annumerat hoc quartum, quia scilicet Genzericus e Carthagine Romam venit, et cepit. Prosper. Procopius Euagrius, Iornandes“). 
circostanza in cui Giove tesse l'elogio dell'Arvernia), ${ }^{49}$ se ne deduce l'efficacia amplificata del messaggio propagandistico che l'autore intendeva veicolare in favore del galloromano Avito di fronte alla nobilitas romana: Avito poteva bene impersonare il discendente troiano predestinato ad annientare Cartagine (si legga già Sil. 1, 14-15 reseravit Dardanus arces / ductor Agenoreas [...]; e 4, 472-473 - profezia formulata al giovane Scipione - tum celso e curru Mavors: „Carthaginis arces / exscindes ", inquit, ,, Tyriosque ad foedera coges [...]").

E ancora: il trionfo di Avito, preannunciato solennemente da Giove stesso alla fine del componimento (vi ho fatto sopra un accenno), costituiva un monito di vittoria che porgeva l'occasione per rilanciare l'idea dell'imperium sine fine per i Romani (nel rispetto della solenne promessa di Giove a Venere in Aen. 1, 257 ss.) in ideale continuum con i successi ottenuti nelle guerre puniche (quarta infatti vengono detti i vincula con cui Avito tornerà a legare l'Africa a Roma):

Sidon. carm. 7, 588:

Hic tibi restituet Libyen per vincula quarta. ${ }^{50}$

Il te rendra la Libye, pour la quatrième fois dans les fers.

Riepilogando il nostro percorso: Sidonio parla di avvenimenti dell'attualità ammantandoli di frammenti della tradizione letteraria, individuando corrispondenze fra passato (mitico o storico) ${ }^{51}$ e presente.

Due Leitmotive paralleli e complementari, entrambi ricavati dall'Eneide, vengono assunti a riferimento esemplare nel resoconto delle vicende romanovandaliche che interessarono l'Italia dei suoi tempi e rifunzionalizzati in tema di rapporti romano-barbarici:

1) il fatum di inestinguibile inimicizia fra Roma e Cartagine, invocato da Didone nel quarto libro dell'Eneide;

2) il fatum per il quale la progenies troiana avrebbe distrutto la rivale Cartagine, fatum custodito nel proemio dell'Eneide.

È facile comprendere di quali risonanze emotive e significati politici questi referenti archetipici fossero portatori: lo schermo letterario virgiliano permette a Sidonio di narrare il presente nel segno di una consequenzialità con la storia/mito

49 Cfr. carm. 7, 139 ss. est mihi, quae Latio se sanguine tollit alumnam, / tellus [...]. Per tutta l'importante questione storico-culturale vd. Luiselli 1978, passim (partic. 90 ss.); Luiselli 1992, 477 e 642; Luiselli 1999, 11; Gualandri 2000, nn. 55 ss. e contesto (con ulteriore bibliografia).

50 Cfr. già Savaro 1609, 112 n. 583: „Hic tibi restituet Libiă (ma nel testo Libyen) per vincula quarta] i. Africam Imperio Romano reformabit, quae ei a Genserico subtracta est s. hoc Carm. 2 et 5 per vincula quarta, ut s. quartosque labores, id est, ut dixi, quatuor bella $\mathrm{Pu}-$ nica, ita hic per vincula quarta, triumphum quartum praesagiens.“ Courcelle 1964, 167.

51 Per questa sostanziale intercambiabilità fra il mito e la storia della Roma repubblicana già nei panegirici di Claudiano vd. Gualandri 1998, 124 ss. 
di Enea, al cospetto di un pubblico colto, perfettamente in grado di percepire qualsiasi allusione, anche la più sottile, all'Eneide. Nell'Eneide, precisamente nell'anatema di imperitura ostilità fra Roma e Cartagine gettato da Didone, Sidonio reperiva una giustificazione capace di mascherare le reali motivazioni politiche della drammatica situazione in cui Roma versava, ma nell'Eneide medesima egli reperiva anche l'impulso ad una reazione, la solida certezza che dal sangue troiano si sarebbe generata un giorno una stirpe che avrebbe prodotto la rovina della Libia.

Da tutto questo conseguiva un motivo propagandistico supplementare. Le proiezioni eneadiche si erano pienamente realizzate: l'ultor cartaginese auspicato da Didone si era incarnato in Annibale, ma a sua volta la progenies Troiano a sanguine preconizzata come annientatrice delle arces Tyriae si era incarnata negli Scipioni. Ebbene, considerare il presente storico, cioè le guerre romanovandaliche, come un riflesso diretto di quel passato lungo una linea ininterrotta evidentemente equivaleva a rintracciare in quella gloriosa vetustas la garanzia di nuovi trionfi romani.

Del resto è risaputo come assai spesso alla trattazione panegiristica dei conflitti romano-barbarici sia contestuale la rievocazione di fulgidi momenti e figure della trascorsa storia di Roma, appunto perché dalla somiglianza tra eventi coevi ed eventi remoti nasceva il sentimento della continuità, nei successi e negli insuccessi, tra l'eroico passato e il travagliato presente. ${ }^{52}$ L'aggancio alle guerre puniche svolge un ruolo di tutto rilievo in Claudiano, ad esempio, a proposito della guerra contro Gildone in cui si era consumato uno dei passaggi più delicati della leadership stiliconiana, soprattutto nel De consulatu Stilichonis, e con enfasi minore anche nel De bello Gildonico. ${ }^{53}$

Un'ultima risultanza.

Nel terzo panegirico (il panegirico per il nobile orientale Antemio, del 468 [il carm. 2]: un panegirico consolare), ${ }^{54}$ l'Italia personificata in visita al Tevere ${ }^{55}$ deplora la minaccia vandalica come un capovolgimento del fatum (quel fatum secondo il quale all'inverso avrebbe dovuto essere Roma ad invadere e ad abbattere Cartagine): ${ }^{56}$

52 Luiselli 1992, 416 ss.; Watson 1998, 192 ss.

53 Perrelli 2000, 176 ss.; Brolli 2004, 302 e nn. 16 e 17. Il tema punico è abbondantemente sfruttato anche nel De bello Getico e nel panegirico composto per il sesto consolato di Onorio, dove il paragone di Alarico con Annibale è ricorrente: Dewar 1994; Perrelli 2000, 178 e n. 9 (vd. anche supra n. 47).

54 Loyen 1942, 85-95; Courcelle 1964, 174; Harries 1994, 141 ss. (partic. 148-150); Watson 1998, 183 ss. Su Antemio cfr. anche Mathisen 1998c. Recenti studi letterari d'insieme (entrambi con ricca biliografia): Condorelli 2008, 70 ss.; Schindler 2009, 198 ss.

55 Consolino 2000, 191-192 sull'estensione ipertrofica dell'apparato mitologico in questo panegirico; Condorelli 2008, 77-78; Watson 1998, 186 ss. Vd. anche Gualandri 1994, 313 (personificazioni tributarie di forme ben presenti e diffuse nelle arti figurative).

56 Gualandri 1999, n. 64. 
Sidon. carm. 2, 348 ss.:

\author{
[...] Hinc Vandalus hostis \\ urget et in nostrum numerosa classe quotannis \\ militat excidium, conversoque ordine fati \\ torrida Caucaseos infert mihi Byrsa furores.
}

C'est pourquoi l'ennemi vandale nous presse et sur sa flotte innombrable, chaque année, combat pour notre ruine; l'ordre du destin est renversé: c'est la brûlante Byrsa qui lance contre moi les fureurs caucasiennes.

Per un avvenimento tanto inconcepibile quanto destabilizzante, che esige provvedimenti drastici (peraltro la pars Occidentis aveva dovuto chiedere la collaborazione di Costantinopoli: ed era stato l'imperatore d'Oriente, Leone I, a nominare Antemio), ${ }^{57}$ il poeta cerca soccorso ancora una volta nelle dinamiche fatali.

I Cartaginesi (torrida [...] Byrsa: vd. quanto detto sopra sul nome Byrsa, allusivo alla fondazione di Cartagine da parte di Didone)/Vandali hanno rovesciato l'ordo fati, la norma immutabile, empiamente contrapponendosi con il loro fu$\operatorname{ror}^{58}$ caucasico (a parere di Sidonio i Vandali sono originari del Caucaso: ${ }^{59} \mathrm{ma}$ non si può non scorgere nell'aggettivo un riferimento alla durezza, selvaticità, inospitalità che questa catena montuosa aveva sempre per antonomasia simboleggiato; ${ }^{60}$ e forse un richiamo anche ad Aen. 4, 365 ss., dove nelle parole di Didone adirata con Enea spicca l'antitesi Dardanus / Caucasus, cioè fra chi discende da Dardano e chi è nato nel Caucaso) ${ }^{61}$ al fatum di vittoria dei Romani (è il fatum del proemio dell'Eneide di cui in questi versi si stigmatizza il ribaltamento).

Se si pensa poi che già nell'Eneide il furor, nella maggioranza dei casi (anche il furor di Didone), ostacola il destino, la pietas, la missione di Enea, ${ }^{62}$ forse il fatum di cui qui Sidonio biasima il rovesciamento è anche quello più complessivo che affidava a Roma il compito di regere imperio populos (Verg. Aen. 6, 851), di riunificare il mondo sotto le sue leggi (è questo il più autentico disegno divino,

57 Sui risvolti politici Watson 1998, 185 ss.; 191-192; cfr. anche Harries 1994, 245-246.

58 Il furor barbarico è un topos di sempre, appartiene al repertorio tradizionale delle caratteristiche convenzionalmente associate dai Romani alla natura barbarica: Luiselli 1992, 386 ss.; altra bibliografia in Bruzzone 1999, 90 (comm. al v. 1). Il tema del rapporto di Sidonio con i barbari è già stato molto esplorato: cito solo a titolo di esempio Loyen 1943, 51 ss.; 87; Pricoco 1965, 131; Gualandri 1979, 25 e 27; Luiselli 1992, passim (vd. 927 s.v. ,Sidonio Apollinare, suo misobarbarismo'); Gualandri 2000; Fo 2002. Sulla rappresentazione delle popolazioni germaniche cfr. anche Kaufmann 1995, 106-170 (nelle pp. 160-170 considerazioni generali).

59 Savaro 1609, 25 nn. 351 e 352; Sirmondus 1652, 112; Loyen 2008, 174 n. 47.

60 Ad es. Fo 1984, 713; Giardina 1996; Bruzzone 1999, 92.

61 Sidonio altrove (carm. 5, 529-532), in tutto altro contesto, richiama questo luogo virgiliano (e la valutazione della ripresa risulta assai problematica): cfr. Courcelle 1976, 50-51; Courcelle 1984, 334-336; Veremans 1991, 500; Brolli 2004, 308 n. 34; Condorelli 2008, 58.

62 Farron 1985, 622b. 
comunicato dal padre degli dèi ad Enea per bocca di Mercurio in Aen. 4, 230-231 [...] genus alto a sanguine Teucri / proderet ac totum sub leges mitteret orbem), anche al di là delle contingenze che la vedevano intaccata nel suo prestigio dai barbari e parzialmente subordinata a Costantinopoli. ${ }^{63}$

Poche considerazioni per concludere.

Credo che da questa pur breve e circoscritta esemplificazione possano trarsi indicative e suggestive conferme alle direttrici generali circa le funzioni del ricorso al mito nei Panegyrici di Sidonio Apollinare:

a) in un contesto di grandioso scontro di civiltà, quella grecoromana e quella ,altra', cioè barbarica, il mito costituiva un possente elemento di coesione, politica, culturale, spirituale, una forza identitaria da contrapporre alla minaccia che da più direzioni premeva sull'enorme limes e da un certo periodo in poi insidiava l'unità imperiale entro i suoi stessi confini; nel caso di Sidonio Apollinare si imponeva, difficilissimo, il problema della convivenza;

b) in una società caratterizzata da una epocale crisi dei valori morali e civili, in un formidabile sbandamento e disgregamento delle coscienze, il mito continuava ad offrire ancora saldi punti di riferimento universalmente riconosciuti;

c) di fronte alle drammatiche e imprevedibili prospettive politiche il mito accanto alla storia evenemenziale del passato era ancora in grado di produrre parametri di autorevole paradigmaticità, con feconde potenzialità propagandistiche.

\section{Bibliografia}

\section{Letteratura primaria}

Agroecius, Ars de orthographia: Grammatici Latini 7: Scriptores de orthographia, rec. Heinrich Keil, Hildesheim 1961 (Leipzig 1880), 113-125.

Augustinus, Epistulae: Sancti Aurelii Augustini Hipponensis episcopi opera omnia, post Lovanensium theologorum recensionem opera et studio monachorum ordininis sancti Benedicti e congregatione s. Mauri, accurante Jacques-Paul Migne, t. 2 (PL 33), Paris 1865 .

Beda, De arte metrica et de orthographia: Grammatici Latini 7: Scriptores de orthographia, rec. Heinrich Keil, Hildesheim 1961 (Leipzig 1880), 217-294.

63 Watson 1998, 185 ss. (Sidonio cerca comunque di convincere l'Audience romana della Romanitas di Antemio - analogamente a quanto nel panegirico per Avito aveva tentato di fare per i Visigoti che avevano sostenuto Avito nell'elezione ad imperatore -: spunti in Watson 1998, 191-192). Si tratta della solita compiaciuta visione della superiorità romana sui barbari propria degli intellettuali romani: il dualismo Romani-barbari è sperequativo, e la situazione di ,normalità', di ordine è quella che si ristabilisce quando a prevalere è la parte romana (cfr. Luiselli 1992, 386 ss. e passim). 
Caper, De orthographia: Grammatici Latini 7: Scriptores de orthographia, rec. Heinrich Keil, Hildesheim 1961 (Leipzig 1880), 92-112.

Flavius Merobaudes, Panegyricus II: Fl. Merobaudis reliquiae, Blossii Aemilii Dracontii carmina, Eugenii Toletani episcopi carmina et epistulae, ed. Friedrich Vollmer (MGH Auct. ant. 14), Berlin 1905, 11-18.

Publius Vergilius Maro, Aeneis, rec. Gian Biagio Conte, Berlin 2009.

Publius Vergilius Maro, Aeneis: Virgilio, Eneide, a. c. d. Ettore Paratore, trad. di Luca Canali, Milano 1978-1983.

Sidonius Apollinaris, Carmina: Sidoine Apollinaire, Euvres, t. 1: Poèmes. Texte établi et traduit par André Loyen, Paris ${ }^{3} 2008$.

\section{Letteratura secondaria}

Bonjour (1982): Madeleine Bonjour, „Personnification, Allégorie et Prosopopée dans les Panégyriques de Sidoine Apollinaire“, Vichiana n.s. XI, 5-17.

Brocca (2004): Nicoletta Brocca, „Memoria poetica e attualità politica nel panegirico per Avito di Sidonio Apollinare", in: Lucio Cristante e Andrea Tessier (edd.), Incontri triestini di filologia classica III, 2003-2004, Trieste, 279-295.

Brolli (2004): Tiziana Brolli, „Silio in Sidonio: Maggioriano e il passaggio delle Alpi“, in: Lucio Cristante e Andrea Tessier (edd.), Incontri triestini di filologia classica III, 2003-2004, Trieste, 297-314.

Bruzzone (1999): Antonella Bruzzone, Flavio Merobaude - Panegirico in versi. Introduzione e commento, Roma.

Bruzzone (2004): Antonella Bruzzone, „Il concilium deorum nella poesia panegiristica latina da Claudiano a Sidonio Apollinare“, in: Anna Maria Taragna (ed.), La poesia tardoantica e medievale, Atti del II Convegno internazionale di studi, Perugia 15-16 novembre 2001, Centro internazionale di studi sulla poesia greca e latina in età tardoantica e medievale. Quaderni 2, 2002, Alessandria, 129-141.

Bruzzone (2003-2005): Antonella Bruzzone, „Archetipi culturali nei panegirici di età romanobarbarica“, Romanobarbarica 18, 371-384.

Colton (2000): Robert E. Colton, Some Literary Influences on Sidonius Apollinaris, Amsterdam.

Condorelli (2008): Silvia Condorelli, Il poeta doctus nel V secolo $d$. C. Aspetti della poetica di Sidonio Apollinare, Napoli.

Consolino (1974): Franca Ela Consolino, „Codice retorico e manierismo stilistico nella poetica di Sidonio Apollinare", Annali della Scuola Normale Superiore di Pisa, s. III, vol. IV, 2, 423-460.

Consolino (2000): Franca Ela Consolino, „Poesia e propaganda da Valentiniano III ai regni romanobarbarici (secc. V-VI)“, in: Franca Ela Consolino (ed.), Letteratura e Propaganda nell'Occidente latino da Augusto ai regni romanobarbarici (Atti del Convegno Internazionale, Arcavacata di Rende, 25-26 maggio 1998), Roma, 181-227.

Courcelle (1964): Pierre Courcelle, Histoire littéraire des grandes invasions germaniques, Troisième édition, augmentée et illustrée, Paris.

Courcelle (1976): Pierre Courcelle, „Les lecteurs de l'Énéide devant les grandes invasions germaniques", Romanobarbarica 1, 25-56.

Courcelle (1984): Pierre Courcelle, Lecteurs païens et lecteurs chrétiens de l'Énéide. 1. Le témoignages littéraires, Paris.

Courtois (1955): Christian Courtois, Les Vandales et l'Afrique, Paris. 
Del Chicca (1991): Fanny Del Chicca, „Panegiristi e barbari: tra convenzionalità e originalità di notazioni“, Romanobarbarica 11, 109-128.

Demougeot (1969): Émilienne Demougeot, La formation de l'Europe et les invasions barbares, Paris.

Dewar (1994): Michael Dewar, „Hannibal and Alaric in the later poems of Claudian“, Mnemosyne XLVII, 349-372.

Farron (1985): Steven Farron, „Furie/furor“, in: Enciclopedia virgiliana, vol. II, Roma, $620-622$.

Fo (1982): Alessandro Fo, Studi sulla tecnica poetica di Claudiano, Catania.

Fo (1984): Alessandro Fo, „Caucaso“, in: Enciclopedia virgiliana, vol. I, Roma, 713.

Fo (2002): Alessandro Fo, „Arginare la decadenza da 'minore'. Sidonio Apollinare“, in: Silvia Ronchey (ed.), La decadenza (Un seminario, 15 aprile 1999), Palermo, 154-190.

Francovich Onesti (2002): Nicoletta Francovich Onesti, I Vandali. Lingua e storia, Roma.

Giardina (1996): Andrea Giardina, „Roma e il Caucaso“, in: Il Caucaso: cerniera fra culture dal Mediterraneo alla Persia (secoli IV-XI) (Settimane di studio del Centro Italiano di Studi sull'Alto Medioevo XLII, 20-26 aprile 1995), Spoleto, t.1, 85-141.

Gualandri (1979): Isabella Gualandri, Furtiva lectio. Studi su Sidonio Apollinare, Milano.

Gualandri (1989a): Isabella Gualandri, „Il classicismo claudianeo: aspetti e problemi“, in: Antonio Garzya (ed.), Metodologie della ricerca sulla Tarda Antichità (Atti del Primo Convegno dell'Associazione di Studi Tardoantichi), Napoli, 25-48.

Gualandri (1989b): Isabella Gualandri, ,Alla corte imperiale di Milano nel IV secolo d.C.: riflessi politici del classicismo claudianeo“, Archivio Storico Lombardo CXV, 9-35.

Gualandri (1989c): Isabella Gualandri, „Persistenze e resistenze locali: un problema aperto“, in: Guglielmo Cavallo, Paolo Fedeli e Andrea Giardina (edd.), Lo spazio letterario di Roma antica, II: La circolazione del testo, Roma, 509-529.

Gualandri (1992): Isabella Gualandri, „L'eredità tardo-antica“, in: Guglielmo Cavallo, Claudio Leonardi e Enrico Menestò (edd.), Lo spazio letterario del Medioevo. 1. Il Medioevo latino, I: La produzione del testo, t. 1, Roma, 15-44.

Gualandri (1993): Isabella Gualandri, „Elegi acuti: il distico elegiaco in Sidonio Apollinare", in: Giuseppe Catanzaro e Francesco Santucci (edd.), La poesia cristiana latina in distici elegiaci (Atti del Convegno Internazionale, Assisi, 20-22 marzo 1992), Assisi, 191-216.

Gualandri (1994): Isabella Gualandri, „Aspetti dell'ekphrasis in età tardo-antica“, in: Testo e immagine nell'alto medioevo (Settimane di studio del Centro Italiano di Studi sull'Alto Medioevo, XLI, 15-21 aprile 1993), Spoleto, t. 1, 301-341.

Gualandri (1998): Isabella Gualandri, „La poesia di Claudiano tra mito e storia“, in: Cultura latina pagana fra terzo e quinto secolo dopo Cristo (Atti del Convegno, Mantova, 9-11 ottobre 1995), Firenze, 113-143.

Gualandri (1999): Isabella Gualandri, „Gli dei duri a morire: temi mitologici nella poesia latina del quinto secolo“, in: Giancarlo Mazzoli e Fabio Gasti (edd.), Prospettive sul Tardoantico (Atti del Convegno di Pavia 27-28 novembre 1997), Como, 49-68.

Gualandri (2000): Isabella Gualandri, „Figure di barbari in Sidonio Apollinare“, in: Giuliana Lanata (ed.), Il tardoantico alle soglie del duemila. Diritto, religione società (Atti del Quinto Convegno Nazionale dell'Associazione di Studi Tardoantichi), Pisa, $105-130$.

Gualandri (2006): Isabella Gualandri, „Il mito fra paganesino e cristianesimo“, in: Gemma Sena Chiesa (ed.), Il mito oltre il mito. Archeologia, arte, storie di eroi e dei, Milano, $113-130$. 
Günther (1982): Rigobert Günther, „Apollinaris Sidonius. Eine Untersuchung seiner drei Kaiserpanegyriken“, in: Gerhard Wirth (ed.), Romanitas-Christianitas. Untersuchungen zur Geschichte und Literatur der römischen Kaiserzeit, Johannes Straub zum 70. Geburtstag am 18. Oktober 1982 gewidmet unter Mitwirkung von Karl-Heinz Schwarte und Johannes Heinrichs, Berlin/New York, 654-660.

Harries (1994): Jill Harries, Sidonius Apollinaris and the Fall of Rome ad 407-485, Oxford.

Heather (1991): Peter J. Heather, „The Emergence of the Visigothic Kingdom“, in: John F. Drinkwater e Hugh Elton (edd.), Fifth-century Gaul. A Crisis of Identity?, Cambridge, 84-94.

Horváth (2000): Ágnes Horváth, „The Education of Sidonius Apollinaris in the Light of his Citations“, Acta Classica Universitatis Scientiarum Debreceniensis XXXVI, 151162.

Kaster (1988): Robert A. Kaster, Guardians of Language. The Grammarian and Society in Late Antiquity, Berkeley/Los Angeles/Londra.

Kaufmann (1995): Frank-Michael Kaufmann, Studien zu Sidonius Apollinaris, Frankfurt a.M.

Loyen (1942): André Loyen, Recherches historiques sur les panégyriques de Sidoine Apollinaire, Paris.

Loyen (1943): André Loyen, Sidoine Apollinaire et l'esprit précieux en Gaule aux dernier jours de l'Empire, Paris.

Loyen (1968): André Loyen, „Études sur Sidoine Apollinaire“, Revue des Études Latines $46,83-90$.

Luetjohann (1887): Gai Sollii Apollinaris Sidonii epistulae et carmina, recensuit et emendavit Christianus Luetjohann, Berlino (Monumenta Germaniae Historica, Auctores Antiquissimi VIII).

Luiselli (1978): Bruno Luiselli, „Il mito dell'origine troiana dei Galli, dei Franchi e degli Scandinavi“, Romanobarbarica 3, 89-121.

Luiselli (1992): Bruno Luiselli, Storia culturale dei rapporti tra mondo romano e mondo germanico, Roma.

Luiselli (1999): Bruno Luiselli, „I Celti dell’ultima Irlanda pagana e della prima Irlanda cristiana di fronte a Roma e all'Europa“, in: Marcello Rotili (ed.), Memoria del passato, urgenza del futuro. Il mondo romano fra V e VII secolo (Atti delle VI giornate di studio sull'età romanobarbarica, Benevento 18-20 giugno 1998), Napoli, 7-16.

Maggiulli (1985): Gigliola Maggiulli, „Elissa“, in: Enciclopedia virgiliana, vol. II, Roma, 202-203.

Markus (1990): Robert A. Markus, The End of Ancient Christianity, Cambridge (traduzione italiana Roma 1996).

Martindale (1980): John R. Martindale, The Prosopography of the Later Roman Empire. Vol. II, A.D. 395-527, Cambridge.

Mathisen (1979): Ralph W. Mathisen, „Resistence and Reconciliation: Majorian and the Gallic Aristocracy after the Fall of Avitus“, Francia 7, 597-627.

Mathisen (1981): Ralph W. Mathisen, „Avitus, Italy and the East in A.D. 455-456“, Byzantion LI, 232-247 (ristampato in Mathisen, Ralph W., Studies in the History, Literature and Society of Late Antiquity, Amsterdam 1991, 168-173).

Mathisen (1993): Ralph W. Mathisen, Roman Aristocrats in barbarian Gaul. Strategies for Survival in an Age of Transition, Austin. 
Mathisen (1998a): Ralph W. Mathisen, „Avitus (9/10 July 455, 17-18 October 456)“, in: De Imperatoribus Romanis. An Online Encyclopedia of Roman Emperors. www.roman-emperors.org/avitus.htm (18.3.1998).

Mathisen (1998b): Ralph W. Mathisen, „Julius Valerius Maiorianus (18 February/28 December 457, 2-7 August 461)“, in: De Imperatoribus Romanis. An Online Encyclopedia of Roman Emperors. www.roman-emperors.org/major.htm (7.2.1998).

Mathisen (1998c): Ralph W. Mathisen, „Anthemius (12 April 467, 11 July 472 A.D.)“, in: De Imperatoribus Romanis. An Online Encyclopedia of Roman Emperors. www.roman-emperors.org/anthemiu.htm (2.2.1998).

Moroni (1982): Brunella Moroni, „Tradizione letteraria e propaganda: osservazioni sulla poesia politica di Claudiano“, Scripta Philologa III, 213-239.

Oppedisano (2009): Fabrizio Oppedisano, „Il generale contro l'imperatore. La politica di Maioriano e il dissidio con Ricimero", Athenaeum 97, 543-561.

Perrelli (2000): Raffaele Perrelli, „La praefatio al terzo libro del De consulatu Stilichonis“, in: Franca Ela Consolino (ed.), Letteratura e Propaganda nell'Occidente latino da Augusto ai regni romanobarbarici (Atti del Convegno Internazionale, Arcavacata di Rende, 25-26 maggio 1998), Roma, 173-179.

Pricoco (1965): Salvatore Prococo, „Studi su Sidonio Apollinare“, Nuovo Didaskaleion $15,69-150$.

Roberts (1989): Michael Roberts, The Jeweled Style. Poetry and Poetics in Late Antiquity, Ithaca/London.

Rousseau (2000): Philip Rousseau, „Sidonius and Majorian: the Censure in Carmen V“, Historia 49, 251-257.

Sala (1985): Mariella Sala, „Didone“, in: Enciclopedia virgiliana, vol. II, Roma, 48-63.

Santelia (1999): Stefania Santelia, „Sidonio Apollinare e gli dèi pagani (a proposito di Carm. 9, 168-180)“, Invigilata Lucernis 21, 341-355.

Santelia (2005): Stefania Santelia, „Maioriano-Ercole e Sidonio supplex famulus (Sidon. carm. 13)“, Annali della Facoltà di Lettere e Filosofia dell'Università di Bari 48, $189-208$.

Savaro (1609): Iohannes Savaro (ed.), Caii Sollii Apollinaris Sidonii Arvernorum episcopi opera, Io. Savaro Claromontensis, Regis Christianiss. Consiliarius, Praeses et praefectus Arverniae, multo quam ante castigatius recognovit, et librum commentarium adiecit. II. Editio multis partibus auctior et emendatior; accesserunt indices locupletissimi, Paris.

Schindler (2009): Claudia Schindler, Per carmina laudes. Untersuchungen zur spätantiken Verspanegyrik von Claudian bis Coripp, Berlin/New York.

Sirmondus (1652): Iacobus Sirmondus (ed.), C. Sol. Apollin. Sidonii Arvernorum episcopi opera, Iac. Sirmondi Societ. Iesu Presb. cura et studio recognita, Notisque illustrata. Editio secunda, ad eiusdem Autographum praelo iampridem paratum diligenter exacta, Paris.

Stein (1959): Ernst Stein, Histoire du Bas Empire, tome premier: De l'État Romain à l'État Byzantin (284-476). Édition française par Jean-Remy Palanque, Paris/Bruges (ed. originale Wien 1928).

Stevens (1933): Courtenay E. Stevens, Sidonius Apollinaris and his Age, Oxford.

Stika (2002): Jerzy Stika, „Die Poetik des Mythos bei Sidonius Apollinaris“, Classica Cracoviensia 7, 33-43.

Stika (2003): Jerzy Stika, „Epische Ästhetic von Sidonius Apollinaris: kaiserliche Panegyrica“, Classica Cracoviensia 8, 55-90. 
Veremans (1991): Jozef Veremans, „La présence de Virgile dans l'oeuvre de Sidoine Apollinaire, évêque de Clermond-Ferrand", in: Marc Van Uytfanghe e Roland Demeulenaere (edd.), Aevum inter utrumque, Mélanges offerts à Gabriel Sanders, professeur émérite à l'Université de Gand, Steenbrugis (Instrumenta patristica XXIII), 491-502.

Watson (1998): Lynette Watson, „Representing the Past, redefining the Future: Sidonius Apollinaris' Panegyrics of Avitus and Anthemius“, in: Mary Whitby (ed.), The Propaganda of Power. The Role of Panegyric in Late Antiquity, Leiden/Boston/Köln, 177-198. 


\title{
Un remodelage identitaire
}

\section{Enquête sur les concepts de vitae exordium et d'innocentia dans la Passion des martyrs d'Agaune d'Eucher de Lyon}

\author{
Philippe Bruggisser
}

La passion de saint Maurice et de la légion thébaine ${ }^{1}$ est transmise dans deux versions dont le contenu diffère. Alors que l'une est anonyme, l'autre a été composée par Eucher de Lyon à une date que l'on tient généralement pour proche de 430 .

La dernière édition critique de la Passion d'Eucher a été procurée par Bruno Krusch dans les Monumenta Germaniae Historica en 1896. Le témoin le plus ancien du texte est un manuscrit précarolingien, le Paris. Lat. 9550, de la fin du $\mathrm{VI}^{\mathrm{e}}$ siècle. ${ }^{2}$

L'œuvre composée par Eucher comprend la Passion à proprement parler qui, sur le plan de la narratologie, se termine avec Sabaoth au $\S 11$ de l'édition Krusch, suivie d'un épisode consacré au vétéran Victor (\$12), avant de se prolonger par des compléments: martyrs connus par leur nom et martyrs inconnus (§13), passion d'Ours et Victor à Soleure $(\S 14)$, mort de Maximien (\$15), découverte des corps des martyrs par l'évêque Théodore et construction d'une basilique (§16), punition et conversion d'un ouvrier païen surpris le dimanche sur le chantier de la basilique $(\S 17)$, guérison d'une mère infirme $(\S 18)$, déclaration finale, selon laquelle la liste des miracles pourrait être considérablement allongée $(§ 19)$.

Or, ces compléments figurent, sous une forme et dans un ordre semblables, dans la plupart des manuscrits de la Passion anonyme. De surcroît, la majeure partie des manuscrits de la Passion anonyme sont infiltrés par des interpolations qui proviennent de la Passion euchérienne.

Je suis chargé, avec le Dr. Werner Steinmann et Bruno Sudan, d'un projet parrainé par le Fonds national suisse de la recherche scientifique, projet qui don-

\footnotetext{
* Les traductions des passages cités dans cette contribution sont personnelles.

1 Pour la problématique, le lecteur peut se reporter à Wermelinger et al. 2005.

2 Pour une étude approfondie et récente de ce manuscrit, voir Holtz 2008. Sur le jumeau que Krusch a supposé à tort à ce manuscrit et qu'il plaçait également à l'abbaye de SaintOyend, voir Bruggisser 2008b.
} 
nera le jour à une édition de ce texte sur nouveaux frais, accompagnée d'une traduction et d'annotations.

La Passion écrite par Eucher relate la tradition selon laquelle Maurice et ses compagnons chrétiens de la légion thébaine, stationnée à Agaune - aujourd'hui Saint-Maurice en Valais (Suisse) -, offrirent leur vie en proclamant leur foi et en refusant de s'en prendre à une population chrétienne que l'empereur païen Maximien leur ordonnait de combattre.

Bouillonnant de colère, Maximien ensanglante les rangs des Thébains par deux décimations successives ( $\$ 6$ et $\S 7)$, dans l'espoir de faire céder le restant de la légion sous l'effet de la peur. La mesure n'entame pas la détermination des survivants.

Le morceau de bravoure de l'oeuvre est constitué par le discours dans lequel les soldats thébains, conscients de la menace de mort et emmenés par le primicier Maurice, l'instructeur Exupère et le sénateur des soldats Candide, expliquent leurs motivations profondes et justifient leur refus devant le souverain persécuteur:

his itaque primoribus suis adque auctoribus animati, Maximiano insania adhuc aestuanti mandata mittunt sicut pia, ita et fortia, quae feruntur fuisse in hunc modum: Milites sumus, imperator, tui, sed tamen servi, quod libere confitemur, Dei. tibi militiam debemus, illi innocentiam; a te stipendium laboris accepimus, ab illo vitae exordium sumpsimus. sequi imperatorem in hoc nequaquam possumus, ut auctorem negemus Deum, utique auctorem nostrum, Deum auctorem, velis nolis, tuum. si non in tam funesta conpellimur, ut hunc offendamus, tibi, ut fecimus hactenus, adhuc parebimus; si aliter, illi parebimus potius quam tibi. offerimus nostras in quemlibet hostem manus, quas sanguine innocentium cruentare nefas ducimus.

Aussi est-ce sur les encouragements de leurs supérieurs et garants qu'ils font parvenir à Maximien, bouillonnant encore de folie, un message empreint de courage et, dans la même mesure, de sens du devoir, ${ }^{3}$ dont on rapporte qu'il le fut dans cette teneur: C'est de toi, empereur, que nous sommes les soldats, mais cependant c'est de Dieu que nous sommes les serviteurs, ce que nous proclamons librement. A toi nous devons le service des armes, à lui un comportement d'innocence; de toi nous avons reçu le salaire de l'effort, de lui nous avons acquis l'origine de la vie. Suivre l'empereur, nous ne le pouvons aucunement au point de nier Dieu créateur, en tous les cas notre créateur, Dieu, que tu le veuilles ou non, ton créateur. Si nous ne sommes pas contraints à des actes si funestes que nous l'offensions, nous continuerons de t'obéir, comme nous l'avons fait jusqu'à aujourd'hui; s'il en est autrement, c'est à lui que nous obéirons

3 C'est dans le discours des soldats qu'Eucher concentre presque exclusivement l'utilisation de pius (2 occurrences: mandata [...] pia [...] et fortia; pios et cives), qui n'apparaît qu'une seule fois ailleurs dans l'œuvre (§11 corporibus piorum); quant à pietas, le substantif n'est présent qu'ici. On trouve leurs antonymes une fois dans le discours (impios atque inimicos) et trois fois hors du discours: $\S 2$ impietate, $\S 10$ impium ferrum et $\S 15$ impiam vitam. Pius signifie ,qui reconnaît et remplit ses devoirs (envers les dieux, la patrie, les parents)“ et j'ai restitué, dans la traduction, cette notion de sens du devoir, car elle annonce et sous-tend toute l'argumentation des soldats, dont la pietas, sur le plan divin, est naturellement transférée à Dieu. 
plutôt qu'à toi. Nous prêtons, contre quelque ennemi que ce soit, nos mains que nous jugeons sacrilège de souiller du sang des innocents.

dexterae istae pugnare adversum impios adque inimicos sciunt, laniare pios et cives nesciunt. meminimus nos pro civibus potius quam adversus cives arma sumpsisse. pugnavimus semper pro iustitia, pro pietate, pro innocentium salute. haec fuerunt hactenus nobis pretia periculorum. pugnavimus pro fide; quam quo pacto conservabimus tibi, si hanc Deo nostro non exhibemus? iuravimus primum in sacramenta divina, iuravimus deinde in sacramenta regia; nihil nobis de secundis credas necesse est, si prima perrumpimus. christianos ad poenam per nos requiri iubes. iam tibi ex hoc alii requirendi non sunt, habes hic nos confitentes: „Deum patrem auctorem omnium et filium eius Iesum Christum deum credimus. “

Ces mains savent combattre contre les impies et les ennemis, elles ne savent pas déchirer les justes et les citoyens. Nous n'oublions pas que nous avons pris les armes pour les citoyens plutôt que contre les citoyens. Nous avons combattu sans relâche pour la justice, pour la piété, pour le salut des innocents. Telles furent pour nous jusqu'ici les récompenses puisées dans les périls. Nous avons combattu au nom de la loyauté; par quel moyen te la conserverons-nous, si nous ne la prouvons pas à l'égard de notre Dieu? Nous avons d'abord pris des engagements ${ }^{4}$ envers Dieu, nous avons ensuite pris des engagements envers notre souverain. Il est nécessaire que tu aies la conviction que les seconds ne comptent pour rien à nos yeux si nous brisons les premiers. Tu ordonnes que par nous des chrétiens soient recherchés pour subir le châtiment. Désormais tu n'as plus à en rechercher d'autres, pour une raison, c'est que tu nous as ici, nous qui proclamons: „Nous croyons en Dieu le père créateur de toutes choses et en son fils Jésus-Christ, dieu. “5

vidimus laborum periculorumque nostrorum socios, nobis quoque sanguine aspersis, trucidari ferro, et tamen sanctissimorum conmilitonum mortes et fratrum funera non flevimus, non doluimus, sed potius laudavimus et gaudio prosecuti sumus, quia digni habiti essent pati pro domino Deo eorum. et nunc non nos vel haec ultima (var. 1. -mae Krusch) vitae necessitas ${ }^{6}$ in rebellionem coegit, non nos adversum te, imperator,

4 Sacramenta divina [...] sacramenta regia: sacramentum présente ici le double caractère, si difficile à traduire, de „sacrement“ reçu par le baptisé et de „serment“ prêté par le soldat. Aussi ai-je opté pour le terme „engagement“ censé recouvrir les deux champs lexicaux du substantif latin.

5 On pourrait éventuellement comprendre, si l'on ponctuait après omnium: „,nous qui proclamons que Dieu le père est le créateur de toutes choses, et nous croyons en son fils Jésus Christ, dieu."

6 J'ai démontré (Bruggisser 2004) que l'expression ultima necessitas, comme euphémisme de la mort, est une création de Sénèque (brev. 1, 3; epist. 17, 9 et 70,5) et que Tacite, dans l'ensemble de son œuvre, ne présente qu'une seule et unique occurrence de cette expression, réservée précisément à la mort du philosophe (ann. 15, 61, 4). Comme je l'ai fait valoir (Bruggisser 2006b), Eucher a emprunté cette formulation au philosophe, en y glissant, entre l'adjectif ultima et le substantif necessitas, un complément vitae, qui peut s'expliquer par interférence avec la tournure periculum vitae (pour periculum vitae au sens de ,danger de mort", voir p. ex. Caes. civ. 2, 6, 1; 2, 7, 1 ad extremum periculum vitae; Cic. Brut. 313; Cluent. 11; fin. 2, 79; Curt. 4, 6, 6; Liv. 40, 11, 10). 
armavit ipsa saltim, quae fortissima est in periculis, desperatio. tenemus, ecce! arma et non resistimus, quia mori quam occidere satis malumus et innocentes interire quam noxii vivere praeoptamus. si quid in nos ultra statueris, si quid adhuc iusseris, si quid admoveris, ignes, tormenta, ferrum subire parati sumus. christianos nos fatemur, persequi christianos non possumus. ${ }^{7}$

Nous avons vu que les compagnons de nos peines et périls ${ }^{8}$ ont été massacrés par le fer, au moment où nous aussi avons été aspergés de leur sang, et cependant nous n'avons pas pleuré la mort de nos très vénérables compagnons d'armes et le trépas de nos frères, nous n'avons pas éprouvé de douleur, mais, bien plus, nous nous sommes répandus en éloges et nous avons formé un cortège funèbre avec joie, parce qu'ils avaient été jugés dignes de subir le martyre pour leur Seigneur Dieu. Et maintenant même cet ultime enjeu de la vie ne nous a pas acculés à la rébellion; contre toi, empereur, le désespoir qui, au milieu des dangers, est hardi à l'extrême, ne nous a pas armés un tant soit peu. Nous tenons, les voici, les armes et nous n'opposons pas de résistance, parce que nous aimons bien mieux mourir que de tuer et que nous préférons périr en innocents plutôt que vivre en coupables. Si tu prends en plus quelque décision contre nous, si tu émets encore quelque ordre, si tu passes à l'acte, nous sommes prêts à subir feux, tortures, fer. Nous déclarons que nous sommes chrétiens, nous ne pouvons poursuivre des chrétiens. ${ }^{9}$

Je souhaite me concentrer dans cette analyse sur la profession d'allégeance des soldats envers Dieu et envers l'empereur. J'aimerais examiner plus particulièrement les notions de vitae exordium et d'innocentia. Au préalable, je voudrais m'arrêter sur la tournure par laquelle Eucher introduit les déclarations des soldats.

\section{In hunc modum: le ton de l'historiographe}

Eucher a soin de préciser qu'il rapporte le discours des soldats in hunc modum. Cette locution est la formule récurrente par laquelle les historiens romains introduisent les discours dans leur œuvre:

7 Le discours des soldats thébains permet à l'auteur de multiplier les fines touches littéraires. J'ai examiné, dans deux études récentes, quelques-uns des ces aspects: Bruggisser 2006b et 2008a.

8 Pour laborum periculorumque, expression consacrée du langage militaire, voir Bell. Alex. 69, 1; Cic. fin. 5, 67; Liv. 38, 23, 11; 39, 27, 4; Flor. 1 praef. 2; Iust. 12, 4, 10. L'utilisation au génitif pluriel tire parti de l'homéotéleute (pour le même effet, voir Cic. Arch. 28; Liv. 21, 43, 8; 25, 31, 7; Vell. 2, 122, 2; Tac. Germ. 18, 3; Amm. 15, 8, 13). La traduction „peines et périls“ tente de compenser cet effet sonore par la similitude du début des mots.

9 Eucher. pass. Acaun. 9 (Krusch 1896). Je reprends ici, avec des modifications, la traduction que j'ai donnée dans Bruggisser 2010, 105-107. 
Sall. hist. 1, 76 (Maurenbrecher): in hunc modum disseruit

Liv. 34, 13, 10: in hunc modum maxime adhortatus pronuntiat se nocte ad castra hostium ducturum (après un discours)

Liv. 37, 45, 11: respondere Africanum placuit. is in hunc modum locutus fertur Liv. 38, 17, 1: pro contione milites in hunc maxime modum adlocutus est consul Liv. 38, 47, 1: Manlium in hunc maxime modum respondisse accepi

Tac. Agr. 29, 4: in hunc modum locutus fertur

Tac. ann. 1, 58, 1: verba eius in hunc modum fuere

Tac. ann. 2, 71, 1: Caesar [...] adsistentes amicos in hunc modum adloquitur

Tac. ann. 3, 50, 1: contra M. Lepidus in hunc modum exorsus est

Tac. ann. 3, 52, 3: sed Tiberius [...] postremo litteras ad senatum composuit, quarum sententia in hunc modum fuit

Tac. ann. 3, 65, 3: Graecis verbis in hunc modum eloqui

Tac. ann. 4, 34, 2: in hunc modum exorsus est

Tac. ann. 12, 10, 1: [...] legati Parthorum [...] senatum ingrediuntur mandataque in hunc modum incipiunt

Tac. ann. 12, 19, 1: simul legatos litterasque ad Caesarem in hunc modum mittit

Tac. ann. 12, 36, 3: in hunc modum locutus est

Tac. ann. 14, 42, 2: in hunc modum disseruit

Tac. hist. 1, 15, 1: igitur Galba, apprehensa Pisonis manu, in hunc modum locutus fertur

Tac. hist. 1, 29, 2: Piso pro gradibus domus vocatos in hunc modum adlocutus est

Tac. hist. 2, 96, 2: in hunc modum etiam Vitellius apud milites disseruit

Tac. hist. 4, 57, 3: vocata contione in hunc modum disseruit

Tac. hist. 4, 64, 1: in hunc modum protulit

Tac. hist. 4, 65, 1: in hunc modum respondent

Il convient de peser soigneusement le sens de l'expression. Elle exclut une restitution littérale des propos du ou des locuteur(s), mais confère une nuance d'approximation au discours inséré dans le tissu littéraire de l'œuvre historiographique. L'historien antique possède la liberté de retoucher, de remanier, voire d'inventer le discours de ses personnages ${ }^{10}$ - un privilège qui ferait scandale si un historien contemporain s'avisait d'y recourir.

Eucher adopte ainsi le ton de l'historien. In hunc modum fonctionne comme un signal dans le rapport de l'auteur à son public. Par ces mots, l'auteur suscite l'attente du lecteur. Le public sait qu'il s'agit d'un discours non pas mot à mot, mais remodelé, et attend par conséquent de l'auteur qu'il fasse la démonstration de son talent. Eucher y trouve ainsi l'occasion de déployer toute l'envergure et l'originalité de sa culture et de sa pensée.

10 Voir p. ex., à date récente, Ratti 2009, 102 (pour Salluste); 142-143 (pour Tite-Live); 188189 et 214 (pour Tacite). 


\section{Vitae exordium: l'orientation du penseur}

Cicéron introduit l'expression vitae exordium dans un passage de sa traduction du Timée $^{11}$ de Platon, qui traite de l'Ame du Monde:

animum igitur cum ille procreator mundi deus ex sua mente et voluntate genuisset, tum denique omne quod erat concretum atque corporeum substernebat animo interiusque faciebat atque ita medio medium accomodans copulabat. sic animus a medio profectus extremitatem caeli a suprema regione rotundo ambitu circumiecit seseque ipse versans divinum sempiternae sapientisque vitae induxit exordium. ${ }^{12}$

Alors que le dieu créateur du Monde avait donc façonné l'Âme conformément à sa pensée et à sa volonté, il soumettait enfin tout ce qui était concret et corporel à l'Âme, le disposait au dedans et unissait ainsi en les ajustant le centre au centre. Ainsi l'Âme, partie du centre, enveloppa d'un mouvement circulaire l'extrémité du ciel à partir de la région la plus élevée et, tournant sur elle-même, généra le principe divin d'une vie éternelle et sage.

L'Arpinate traduit - ou transpose - les considérations du fondateur de l'Académie sur le même thème:

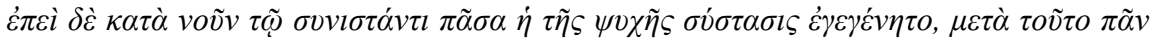

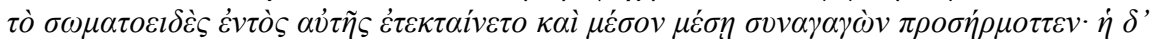

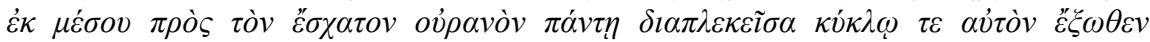

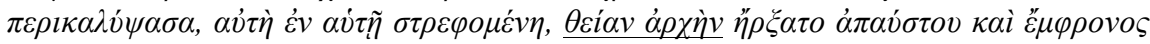

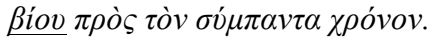

quand toute l'ordonnance de l'Âme eut été réalisée selon la volonté de l'ordonnateur, après cela il construisit à l'intérieur d'elle tout ce qui est corporel et il les ajusta en les liant centre à centre; celle-ci, tissée en tous sens du milieu jusqu'à l'extrémité du ciel et l'enveloppant en cercle de l'extérieur, en tournant d'elle-même sur elle-même, commença d'un commencement divin une vie perpétuelle et raisonnable pour toute la durée des temps. ${ }^{13}$

Les mots de Cicéron divinum [...] vitae [...] exordium restituent ceux de Platon

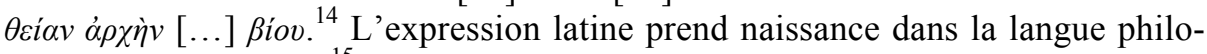
sophique de Cicéron ${ }^{15}$ (ni Sénèque ni $\mathrm{C}(\mathrm{h})$ alcidius ne l'emploieront), pour

11 Sur cette traduction par Cicéron du dialogue de Platon, voir Prost 2003.

12 Cic. Tim. 26 (ed. Bayer/Bayer 2006).

13 Plat. Tim. 36, d-e (ed. Albert Rivaud, CUF, 1925).

14 Widmann 1968, 218-219.

15 Elle apparaît une autre fois chez Cicéron en fin. 5, 18: ut illa prudentia [...] in earum trium rerum aliqua versetur, a qua totius vitae ducat exordium 'de sorte que la sagesse [...] s'enferme dans l'un ou l'autre de ces trois principes, pour en faire dériver la trame du tissu de toute la vie' (comprendre: in earum trium rerum aliqua $[\ldots]$ a qua re prudentia $[. .$. 
s'éclipser jusqu'à la période tardive, où elle apparaîtra presque exclusivement au pluriel, ${ }^{16}$ en prose ${ }^{17}$ et en poésie, quasiment toujours en fin de vers, ${ }^{18}$ mais avec un sens différent, celui de ,premiers temps de la vie“.

Dans le contexte cicéronien, vitae exordium résulte d'un acte de création, derrière lequel se tient un créateur $\left(\right.$ procreator $\left.^{19}\right)$ qui est dieu (deus) unique. ${ }^{20}$

Le contexte euchérien n'est pas sans analogie avec le contexte cicéronien:

milites sumus, imperator, tui, sed tamen servi, quod libere confitemur, Dei. tibi militiam debemus, illi innocentiam; a te stipendium laboris accepimus, ab illo vitae exordium sumpsimus. sequi imperatorem in hoc nequaquam possumus, ut auctorem negemus Deum, utique auctorem nostrum, Deum auctorem, velis nolis, tuum.

C'est de toi, empereur, que nous sommes les soldats, mais cependant c'est de Dieu que nous sommes les serviteurs, ce que nous proclamons librement. A toi nous devons le service des armes, à lui un comportement d'innocence; de toi nous avons reçu le salaire de l'effort, de lui nous avons acquis l'origine de la vie. Suivre l'empereur, nous ne le pouvons aucunement au point de nier Dieu créateur, en tous les cas notre créateur, Dieu, que tu le veuilles ou non, ton créateur.

Les Thébains professent que Dieu est leur créateur, tout comme il est celui de l'empereur. Ils mettent en évidence la primauté de la vie surnaturelle, présentée comme la source de la vie véritable. A leurs yeux, le créateur non seulement donne la vie mais encore guide la vie: c'est la raison pour laquelle les soldats doivent s'abstenir de nuire (innocentiam). Vitae exordium se comprend au sens causal de création et temporel de point de départ. Le créateur est un absolu: c'est par lui et avec lui que commence et se développe la vie véritable.

La référence inconditionnelle au créateur, dans la bouche des soldats, correspond à la pensée d'Eucher, pour qui le devoir prioritaire de l'homme est de con-

ducat 'dans quelqu'une de ces trois choses [...] de laquelle chose [...] la sagesse tire la trame de toute la vie').

16 On la trouve toutefois au singulier dans Hier. in psalm. 138, 16 (CCSL 72): et est sensus: omne tempus aetatis, cui iam ab exordio vitae istius sunt curricula deputata, certo fine decurrit: nec una dies aut plus aut minus est quam tu conditor esse voluisti.

17 Iulian. in Iob 3, 15 (CCSL 88): quomodo mihi non fuisset utile in amaritudine posito ad ipsa vitae exordia non venisse? Après Eucher: Ennod. epist. 7, 13 (CSEL 6): cui inter vitae exordia ludus est lectionis assiduitas et deliciae sudor alienus.

18 Iuuenc. 2, 190 (CSEL 24): quis poterit coeptae revocare exordia vitae?; Prud. apoth. 169 exuit antiquae corrupta exordia vitae; Hil. hymn. 2, 33-34 (CSEL 65): renata sum - o vitae laetae exordia!; Prosp. carm. de ingrat. 481-482 (Huegelmeyer): dum cuique ad verae capienda exordia vitae / naturam affectum fidei conferre docetis. Après Eucher: Arator act. 1, 244-245 (CCSL 130): claudus erat, cui prima dies exordia vitae / membrorum cum strage dedit.

19 Le composé est une création de Cicéron: cf. ThlL, s. u.

20 Bayer/Bayer 2006, 116: ,die Gottheit, die das All erschaffen wird, ist als personaler Gott gedacht. Diese Vorstellung ist monotheistisch.“ 
naître son auctor divin et de lui rendre un culte, comme l'écrivain en fait la recommandation à Valérien, un proche à qui il dédie le traité Sur le mépris du monde:

primum instituti atque in lucem editi hominis officium est, mi Valeriane carissime, proprium cognoscere auctorem cognitumque suscipere vitamque, id est divinum donum, in divinum officium cultumque conferre [...].

avant tout, le devoir de l'homme, créé et venu au jour, mon très cher Valérien, est d'apprendre à connaître son propre créateur et, une fois connu, de l'accueillir et de consacrer sa vie, c'est-à-dire un don divin, au service et au culte de Dieu [...]. ${ }^{21}$

Eucher se montre explicite sur ce point; l'être humain est créé par et pour Dieu:

sana quippe opinione agimur, ut eductos nos sicut ab ipso ita ipsi arbitremur. unde ille plene magnificeque perspicit creatoris nostri in effingendo homine sententiam, quisquis ita intelligit quod nos et ipse et sibi fecit.

nous sommes guidés par une pensée judicieuse de considérer que nous avons été mis au monde aussi bien par lui que pour lui. C'est pourquoi il pénètre pleinement et brillamment l'intention de notre créateur en façonnant l'homme, celui qui comprend que c'est lui qui nous a faits, et pour lui. ${ }^{22}$

\section{Innocentia: la conscience du soldat chrétien}

Les explications que donnent les soldats thébains s'intègrent dans un réseau de dons et de dettes: la différenciation s'opère entre ce qu'ils ont reçu de l'instance supérieure dont ils relèvent et ce qu'ils lui doivent. De Dieu, ils ont reçu l'origine de la vie, de l'empereur le salaire de leur peine; de l'empereur, la vie matérielle, de Dieu la vie surnaturelle. Voilà pour ce qui leur a été donné ! La contrepartie est ce qu'ils doivent: à l'empereur ils sont redevables de la militia, à Dieu de l'innocentia. En faveur de l'un comme de l'autre ils déploient un service: service armé pour le premier, service moral pour le second.

21 Eucher. cont. mundi, p. 56, 36-40 (Pricoco 1990).

22 Eucher. cont. mundi, p. 58, 42-47 (Pricoco 1990). 


\section{Dieu}

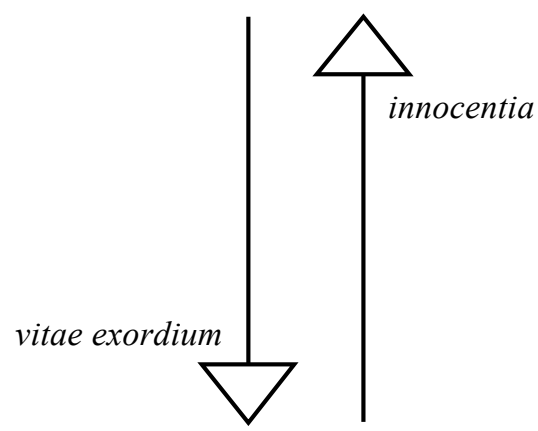

Soldat

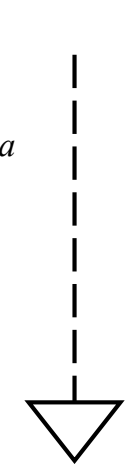

Don
Dette

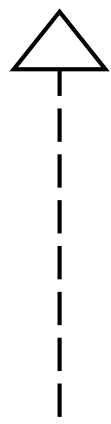

stipendium

laboris
Empereur

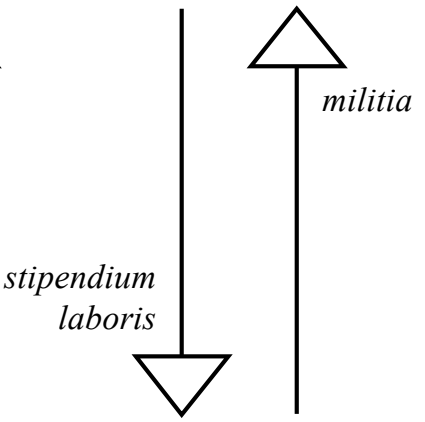

Soldat

C'est dans cette imbrication de dons et de devoirs, sous deux formes, la première avec le créateur, la seconde avec le souverain, que le concept d'innocentia correspond pleinement à son impact. L'innocentia n'est pas un état de grâce inné, mais une orientation de vie qui dicte les actes qui la composent. Cicéron déjà en a dessiné les contours:

nam est innocentia adfectio talis animi quae noceat nemini.

car l'innocence est une disposition de l'âme qui incite à ne nuire à personne. ${ }^{23}$

L'innocentia est la vertu du prince par excellence, telle que l'incarne Trajan aux yeux de son panégyriste Pline le Jeune:

ecquid ergo discimus experimento, fidissimam esse custodiam principis innocentiam ipsius?

n'apprenons-nous pas ainsi par expérience, que la garde la plus fidèle d'un prince est sa propre innocence? ${ }^{24}$

C'est dans des mots proches de ceux de Pline qu'Eucher comprend cette exigence de la conscience, tout en la dirigeant dans un sens chrétien:

proinde iam nunc omnia dicta factaque tua ad deum vel propter deum dirige. obtine ut tibi comes semper sit illa et tibi custos erit-tam fida est! - innocentia.

23 Cic. Tusc. 3, 16. Dans l'esprit d'Augustin, l'innocentia requiert le dépassement de toute inimitié: in ps. 7, 8 (BA 57A): illa est vera innocentia quae nec inimico nocet "la véritable innocence est celle qui refuse de nuire même à son ennemi."

24 Plin. paneg. 49, 3. 
par conséquent, oriente désormais toutes tes paroles et actions vers Dieu et pour Dieu! Assure-toi d'avoir toujours pour compagne l'innocence et elle sera pour toi une protectrice - tant elle est fidèle! ${ }^{25}$

L'innocentia, dans la doctrine d'Eucher, est clairement définissable à travers des normes:

atque idcirco non sero Dominus legem innocentiae in decem verba collegit cuius iam insita in pectoribus humanis origo praecesserat. nec tarde eam saxeis tabulis rursus inscripsit quam iam antea paginis cordis insculpserat; etenim ante hanc Mosi legem habebat natura legem suam, per quam et Deum mundi vitaeque auctorem agnoscere et per hoc diligere in promptu erat et iustitiam erga proximum dilectionemque servare.

et c'est à dessein que le Seigneur ne tarda pas à résumer en dix paroles la loi de l'innocence, dont l'origine, déjà implantée dans la poitrine des hommes, avait été antérieure; et sans délai, il l'inscrivit encore sur des tables de pierre, elle qu'il avait auparavant déjà gravée sur les pages du cœur; le fait est que, avant cette loi de Moïse, la nature contenait sa propre loi, par laquelle il était aisé de reconnaître Dieu comme auteur du monde et de la vie et, à ce titre, de l'aimer, et d'observer la justice et l'amour envers son prochain. ${ }^{26}$

Par l'intervention de Dieu, la loi naturelle et spontanée de l'innocence est devenue loi divine et révélée. La loi de l'innocence est donc explicitée à l'homme, elle est énoncée dans le Décalogue, dans les dix commandements donnés par Yahvé à Moïse sur le Sinaï. L'innocentia implique ainsi pour l'homme tourné vers Dieu une série de valeurs qu'il est appelé à respecter et qu'il est tenu de pratiquer dans sa vie. On reconnaît dans cette réflexion des Instructiones la pensée d'Eucher telle qu'elle se manifeste à travers le discours des soldats: 1'homme, singulièrement le chrétien, est relié à son créateur (auctor) par une obédience qui relève de l'innocence (innocentia).

Dans la mesure où exordium vitae, don de Dieu à l'homme, a pour répondant l'innocentia, hommage que l'être créé rend à son créateur dans la réalisation de sa vie, on se rend compte que la notion d'exordium vitae est à la fois cause produisant la vie et cause influant sur la vie.

S'ils sont les soldats de l'empereur, les Thébains sont les serviteurs de Dieu, les servi Dei, dans toute l'extension biblique et théologique de l'expression. Dans le langage spirituel, servus (ou $\delta o \tilde{v} \lambda o \varsigma$ ) renvoie à la relation de dépendance et de service qui unit l'homme à Dieu, le maître absolu dont l'homme se sent la propriété. $^{27}$

25 Eucher. cont. mundi, p. 112, 802-805 (Pricoco 1990).

26 Eucher. instr. 1, 295-302 (Mandolfo 2004).

27 Weiser ${ }^{2}$ 1992, part. 847. Pour servus Dei présentant, dans la Bible, la construction de nom et de complément du nom, cf. 1 Esr 5, 11: nos sumus servi Dei caeli et terrae; Sap 10, 16: intravit in animam servi Domini Dei; Tt 1, 1: Paulus servus Dei; Apc 7, 3: quoadusque si- 
Ce statut d'esclave, qui, certes, procède d'un libre choix (quod libere confitemur), cet esclavage consenti traduit une dépendance plus étroite que le statut de soldat aux ordres de l'empereur. L'obéissance à Dieu, qui s'impose au premier plan, est infrangible et précède l'obéissance à l'empereur, qui intervient au second plan. La hiérarchie de la subordination définit la priorité des devoirs: l'innocentia l'emporte sur la militia. Une dépendance supérieure entraîne, justifie une allégeance plus forte.

Parce qu'elle est due à Dieu, le soldat chrétien privilégie l'innocentia à tout prix, comme les Thébains le répètent à Maximien. L'innocentia a une implication immédiate, elle interdit de s'en prendre aux innocentes: nostras [...] manus, quas sanguine innocentium cruentare nefas ducimus. Le devoir des soldats thébains consiste, au contraire, à combattre pour le salut des innocents (pro innocentium salute), et, se refusant à trahir cette mission, les combattants sont prêts à mourir en innocents (innocentes interire) plutôt que de vivre en coupables (noxii vivere). On saisira l'importance de ce concept dans le manifeste des soldats en considérant que, dans la Passion des martyrs d'Agaune due à Eucher, les termes d'innocentia et d'innocens se concentrent exclusivement dans leur discours, qui couvre à lui seul la moitié des occurrences de ces deux vocables dans l'ensemble de l'œuvre euchérienne. ${ }^{28}$ On notera encore que substantif et adjectif sont absents du lexique de la Passion des martyrs d'Agaune dans la version anonyme. ${ }^{29}$

L'innocentia pose aux soldats un interdit, celui de porter atteinte, en tant que chrétiens, à d'autres chrétiens:

christianos nos fatemur, persequi christianos non possumus.

nous déclarons que nous sommes chrétiens, nous ne pouvons poursuivre des chrétiens.

Cette volonté de ne pas nuire, ce refus de porter préjudice démontre que l'innocentia se comprend non comme une valeur acquise mais comme une valeur

gnemus servos Dei nostri in frontibus eorum; Apc 15, 3: et cantant canticum Mosi servi Dei.

28 Dans l'ensemble de l'œuvre d'Eucher, innocens compte 5 occurrences: 3 dans le discours des soldats inclus dans la Passion, 1 dans une citation biblique figurant dans les Formulae: 690 manus opus; in psalmo: „et lavi inter innocentes manus meas" la main est l'oeuvre; dans le psaume: „et j'ai lavé mes mains dans l'innocence“ [Ps 25, 6; 73 (72), 13], et 1 en même temps qu'innocentia: instr. 1, 387-391: „quid respondendum Iuadeis obicientibus testimonium illud: ,maledictus omnis qui pendet in ligno?' maledictum esse hominem qui in ligno pendeat, sed noxium non innocentem. neque enim innocentiae potest esse maledictum poena peccati“ „,que faut-il répondre aux Juifs qui objectent ce témoignage: ,Maudit quiconque est pendu à un arbre!' [Deut 21,23]? qu'est maudit l'homme qui est pendu à un arbre, mais le coupable, non l'innocent; en effet, le châtiment d'une faute ne saurait être une malédiction pour l'innocence." Quant à innocentia, le substantif compte 4 occurrences, toutes citées dans cet article, dont l'une dans le discours des soldats.

29 L'édition critique de ce texte a été procurée par Chevalley 1990. 
à acquérir ou à démontrer par le comportement de celui qui s'en réclame ou y aspire. L'innocentia n'est pas un état passif, mais une attitude active, une orientation de vie. Le chrétien parle et agit selon Dieu, une conduite qui lui garantit de pratiquer l'innocentia.

Le discours illustre l'axiologie énoncée dans la partie antérieure de l'œuvre. Les soldats thébains concrétisent ce qu'Eucher dit précédemment d'eux en les décrivant comme ,nobles en courage, mais encore plus nobles par la foi. ${ }^{\text {‘30 }}$

\section{Métamorphose}

\section{a) vitae exordium}

Nous avons vu que la formulation vitae exordium chez Eucher remonte à Cicéron et que le contexte dans lequel Eucher l'utilise n'est pas dépourvu de liens avec le contexte dans lequel Cicéron l'utilise. Eucher puise-t-il directement à sa source cicéronienne? Il n'est pas possible de le prouver, pas plus qu'il n'est possible de prouver le contraire. En tout état de cause, il est légitime de formuler deux remarques:

1. Eucher dispose d'une formation d'aristocrate lettré ${ }^{31}$ et sa culture lui vaut les éloges insistants de ses contemporains et de ses successeurs; ${ }^{32}$ or, Cicéron figure en bonne place dans l'horizon intellectuel d'un Romain cultivé.

2. On a de bonnes raisons de supposer qu'Eucher a puisé dans les Tusculanes ${ }^{33}$ et dans le traité Sur les devoirs ${ }^{34}$ de Cicéron; est-il interdit d'imaginer, par analogie, qu'il ait accédé à un autre écrit philosophique de l'Arpinate qu'est la traduction du Timée? ${ }^{35}$ Eucher a envoyé un traité de Caper sur l'orthographe et sur la propriété et la différence des expressions à Agroecius $^{36}$ afin qu'il le corrige; ce dernier le retourne à Eucher avec une lettre qui célèbre en son correspondant un maître de la langue: ${ }^{37}$

30 Eucher. pass. Acaun. 3 (Krusch 1896): virtute nobiles, sed nobiliores fide. Sur cette caractérisation, voir Bruggisser 2006a.

31 Courcelle 1968, 399; 407-409.

32 Sur les éloges que les Anciens prodiguent à Eucher pour son talent littéraire, voir Bruggisser 2006b, 406-408.

33 Cic. Tusc. 3, $1 \sim$ Eucher. cont. mundi, p. 56, 36-72 (Pricoco 1990; texte partiellement cité plus haut dans le présent article); sur ce rapprochement, cf. Pricoco 1990, 28; 128-130.

34 Cic. off. 3, $2 \sim$ Eucher. laud. er. 31-32 (Pricoco 1965, 66-67), rapprochement esquissé par Courcelle 1968, 398.

35 Sur la culture philosophique d'Eucher, voir Pricoco 1990, 27-28.

36 Sur ce grammairien, que l'on a cherché à identifier avec l'évêque de Sens, voir Goetz 1894; Schanz et al. 1920, §1100, 206-207; PLRE 2, 1980, „Agroecius (3)“, 39 (rectifier le renvoi au volume de Keil [VII, et non pas VI]); Kaster 1988, n ${ }^{\circ}$ 181, 381-382.

37 Agroec. gramm. VII, 113, 1-114, 6 Keil, acccompagnée d'une traduction personnelle. J'ai fait état de cette lettre dans Bruggisser 2006b, 418-419. 
DOMINO EVCHERIO EPISCOPO AGROECIVS. libellum Capri de orthographia misisti mihi. haec quoque res proposito ${ }^{38}$ tuo et moribus tuis congrua est, ut, qui nos in huius vitae actibus corrigere vis, etiam in scribendi studiis emendares. nihil ergo quod in nobis est alienum a castigatione tua credis: omnia nostra, et quae dictu parua ${ }^{39}$ sunt, sollicita indage rimaris, a vivendo ad scribendum, ab animo ad manum, a corde ad articulum ${ }^{40}$ pervenis. hoc est vere summum dei sacerdotem <esse $>$, commissos sibi homines, ut ipsi dicitis, et secundum spiritum imbuere et secundum litteram perdocere. huic ergo Capri libello, qui est de orthographia et de proprietate ac differentia sermonum, quaedam adicienda subieci, non quod vir tantae peritiae aliquid praetermiserit, tam multis praesertim litterarum operibus celebratus et in commentando etiam Cicerone praecipuus, sed quia nos difficilia putamus quae ille ut facilia neglexit. ego autem credidi haec ambigua aliquantis videri, quia mihi obscura frequenter fuissent. ad te igitur hoc opusculum mittitur, in quo laborabis plurimum, cui necesse est emendare ipsum qui aliquid emendare praesumpsit. donabit divina pietas ut, qui scriptum a te observare volumus, etiam praescriptum tuum servare possimus. vale memor nostri, decus et praesidium meum.

AGROECIUS AU SEIGNEUR EVEQUE EUCHERIUS. Tu m'as fait parvenir le précis de Caper sur l'orthographe. Cette initiative aussi est conforme à ta vocation et à tes mœurs: en homme qui entends nous corriger dans les actions de cette vie, tu nous amendes jusque dans nos efforts pour écrire. Tu juges donc que rien de ce qui se trouve en nous ne se soustrait à un épurement de ta part: tout ce que nous faisons, même ce qui relève du détail, tu le scrutes en une enquête fouillée, tu passes de la vie à l'écriture, de l'esprit à la main, du cœur au doigt. Vraiment le propre d'un éminent prêtre de Dieu est à la fois d'imprégner selon l'esprit et d'instruire selon la lettre, comme vous le dites vous-même, les hommes confiés à ses soins. Donc, à ce précis de Caper, qui porte sur l'orthographe et sur la propriété et la différence des expressions, j'ai joint certains compléments, non qu'ait commis quelque oubli un homme d'une compétence si élevée, cité dans des ouvrages si nombreux, surtout de littérature, et remarquable en commentant même Cicéron, mais parce que nous jugeons difficile ce qu'il a écarté comme facile. Quant à moi, j'ai pensé que ces points paraîtraient douteux à d'aucuns, parce qu'ils avaient été souvent obscurs pour moi. C'est donc vers toi que prend son chemin ce précis, auquel tu voueras le plus grand labeur, pour lequel il est nécessaire de corriger celui qui s'est risqué à corriger quelque chose. La bonté divine nous accordera, à nous qui voulons nous en tenir à ce qui est écrit par toi, de

38 Sur les sens que peut revêtir propositum dans la langue des chrétiens, cf. Blaise ${ }^{2} 1962$, s.u. Pour propositum désignant le principe intérieur de la vocation religieuse, on mentionnera encore Sulp. Sev. Mart. 10, 2 (ed. J. Fontaine, SC 133, 1967): atque ita, plenus auctoritatis et gratiae, inplebat episcopi dignitatem, ut non tamen propositum monachi virtutemque desereret „c'est ainsi qu'il remplissait les fonctions épiscopales, plein d'autorité et de prestige, sans déserter pour autant sa profession ni ses vertus monastiques“, avec le comm. ad $l$. de J. Fontaine (SC 134, 1968, 664-665).

39 Pour cette iunctura volontiers associée à res, voir Liv. 5, 47, 8; 9, 30, 5; 34, 1, 1; Curt. 4, 2, 10; Flor. 1, 22, 47; pour d'autres emplois, voir Liv. 30, 34, 1; Plin. nat. 2, 24 ou encore nat. 7, 7: parvum dictu.

40 Sur le sens du vocable dans notre passage (,membra, praecipue minora ${ }^{6}$, speciatim digi$\left.t i^{\circ}\right)$, cf. ThlL articulus, 693, 57-59. 
pouvoir observer encore ce qui est prescrit par toi. Porte-toi bien, en te souvenant de nous, toi mon honneur et ma protection!

Il me paraît improbable qu'Eucher s'impose autour de lui comme une autorité en matière de rectitude de la langue latine, autrement dit de Latinitas, sans avoir lu étroitement Cicéron. Qui plus est, Caper, le grammairien qu'Eucher est censé corriger, passe pour un brillant commentateur de Cicéron.

Ce qui est sûr, c'est qu'Eucher, qu'il se rapporte directement à sa source ou non, véhicule une dénomination d'ascendance cicéronienne et, derrière elle, un concept d'ascendance platonicienne, et qu'il les réinvestit dans une perspective chrétienne.

Dans l'un et l'autre cas, la vie prend son origine dans l'ordre divin. Mais les analogies ne sauraient cacher les différences. D'un cas à l'autre, on passe du créateur dans sa relation à l'univers (avec Cicéron, et, en amont, Platon) au créateur dans sa relation à l'homme (avec Eucher), d'une vision généralisée à une vision humanisée. Le paradigme cosmologique, dans lequel Dieu est pensé en fonction du monde, cède à un paradigme anthropologique, dans lequel Dieu est pensé en fonction de l'homme et pour l'homme.

Du Dieu du cosmos au Dieu des chrétiens, on voit comment s'opère, chez Eucher, la métamorphose intellectuelle et spirituelle du Romain lettré au penseur chrétien. Eucher enfouit une racine antique dans un terreau nouveau. Ou, comme dans la composition d'une mosaïque, une pièce ancienne s'incorpore dans une œuvre d'art nouvelle, qui redessine le visage du créateur. Un fondement de la culture antique trouve son second souffle dans une régénérescence chrétienne.

C'est ainsi que le triple relais: grec - romain - chrétien, est assuré par notre auteur, et notre exemple jette un éclairage particulièrement suggestif sur la métamorphose que subit la culture antique dans le monde chrétien.

\section{b) innocentia}

L'innocentia appartient au vieux fonds romain des vertus républicaines. ${ }^{41}$ Elle est la vertu de Caton l'Ancien, ${ }^{42}$ elle sera celle de Caton d'Utique. ${ }^{43}$

Elle imprègne l'activité du bon gouverneur. Par ses rapines qui ont dévasté la province, Verrès, gouverneur de Sicile, est aux antipodes de l'innocentia ${ }^{44}$ et c'est en raison de son innocentia que les Siciliens choisissent Cicéron pour défendre leurs intérêts. ${ }^{45}$ Dans les conseils que Quintus Cicéron prodigue à son frère candidat en 64 pour le consulat de 63 et qu'il rassemble dans le Commentariolum petitionis, l'auteur fait valoir à quel point Cicéron apparaît comme innocens face à ses

41 Hellegouarc'h ${ }^{2} 1972,283$.

42 Liv. 39, 40, 10: rigidae innocentiae.

43 Sall. Cat. 54, 6: cum innocente abstinentia certabat.

44 Cic. Verr. II 3 (frum.) 21; cf. aussi 217.

45 Cic. Verr. I 34. 
concurrents Antoine et Catilina. ${ }^{46}$ Lorsqu'à son tour Quintus Cicéron sera proconsul d'Asie, Cicéron lui fera des remontrances, en le prévenant que son caractère emporté risque de jeter de l'ombre sur une innocentia qui fait indiscutablement partie de ses mérites. ${ }^{47}$ Un bon général qui respecte l'innocentia s'abstient de vendre les grades dans l'armée, de détourner l'argent public alloué aux besoins de la guerre, de piller les alliés. ${ }^{48}$

L'innocentia auréole le lointain passé de Rome, avant que, sous l'effet de la décadence, elle ne soit prise pour de la malveillance. ${ }^{49}$ Elle est le fondement sur lequel se construisent les valeurs de la romanité, selon une gradation que décrit Scipion Emilien:

ex innocentia nascitur dignitas, ex dignitate honor, ex honore imperium, ex imperio libertas.

de l'innocence naît la dignité, de la dignité l'honneur, de l'honneur le pouvoir, du pouvoir la liberté. ${ }^{50}$

Dans l'antiquité profane, l'innocentia renvoie le détenteur d'un pouvoir à ses responsabilités. Elle esquisse déjà la dimension active, influant sur la vie, qu'elle revêtira chez Eucher.

Mais Eucher imprime au concept d'antique tradition une inflexion nouvelle. L'auteur associe explicitement l'innocentia aux dix commandements que Dieu a confiés à l'homme. L'innocentia subit un changement de constellation: elle passe des normes que l'homme, face à sa conscience, se dicte à lui-même aux normes que Dieu dicte à l'homme pour diriger sa vie.

\section{c) Identité et rupture}

Expliquer Eucher par Eucher offre, à n'en pas douter, la clé d'interprétation la plus sûre: exordium vitae et innocentia sur les lèvres des Thébains se comprennent à partir et à la lumière des écrits d'Eucher. Le discours des soldats est en réalité le discours d'Eucher. La formule d'approximation in hunc modum qui introduit leurs propos revêt toute sa pertinence: ce ne sont pas les paroles des combattants qui sont rapportées en tant que telles, mais sous leurs idées, sous leurs mots filtrent la pensée et la langue de l'auteur. Le profit d'une telle approche est de mettre en relation la Passion avec le reste de l'œuvre et de percevoir Eucher en sa qualité de penseur et d'écrivain.

46 Q. Cic. pet. 8; cf. aussi 13. Sur cet aspect, voir Bruggisser 1984, 118-119.

47 Cic. ad Q. fr. 1, 2, 7.

48 Cic. Manil. 36-38.

49 Sall. Cat. 12, 1.

50 Scip. min. or. frg. 32 Malcovati (ap. Isid. orig. 2, 21, 4). 
Au demeurant, Eucher puise verbe et esprit dans le patrimoine classique, qu'il vivifie par une réactivation chrétienne. Les notions de vitae exordium et d'innocentia démontrent avec une particulière acuité comment les apports d'une culture nouvelle se superposent sur les strates d'une culture ancienne.

Le souvenir antique franchit ainsi la barrière du temps et échappe à la destruction: il a gagné une nouvelle fonction, il s'est ouvert à une nouvelle vie. L'héritage classique est transféré en un processus qui allie identité et rupture, continuité et renouvellement, tradition et innovation.

Nous voyons à travers ce réinvestissement combien l'aristocratie chrétienne reste attachée aux trésors de la littérature profane et qu'une façon de sauver, - au sens fort de garder sauve, de garder vivante - la culture antique et de la perpétuer est de la remodeler en une symbiose avec le christianisme.

A travers cette métamorphose - à laquelle nos collègues et amis de l'Université d'Augsbourg nous ont si aimablement et profitablement invités à réfléchir ${ }^{51}$ - à travers cette métamorphose qui est à la fois transmission, transition et transformation, la Gaule chrétienne à l'époque tardive, ici celle du $\mathrm{V}^{\mathrm{e}} \mathrm{s}$., apporte sa contribution à la préservation et à l'enrichissement de la culture européenne.

\section{Bibliographie}

\section{Sources primaires}

Agroecius grammaticus, Ars de orthographia: Gramatici latini 7: Scriptores de orthographia, rec. Heinrich Keil, Leipzig 1880 (rééd. Hildesheim 1961), 113-125.

Arator Subdiaconus, De actibus apostolorum: Aratoris Subdiaconi Historia Apostolica cum summariis adiunctis, cura et studio Arpád P. Orbán (CCSL 130), Turnhout 2006.

Eucherius Lugdunensis, De contemptu mundi: Eucherio di Lione, Il Rifiuto del Mondo/De contemptu mundi, a cura di Salvatore Pricoco, Firenze 1990.

Eucherius Lugdunensis, De laude eremi: Eucherii de laude eremi, rec., apparatu critico et indicibus instruxit Salvator Pricoco, Catania 1965.

Eucherius Lugdunensis, Instructiones: Eucherii Lugdunensis opera, pars 1: Formulae spiritalis intellegentiae. Instructionum libri duo, cura et studio Carmelo Mandolfo (CCSL 66), Turnhout 2004, 77-216.

Eucherius Lugdunensis, Passio Acaunensium martyrum: Passiones vitaeque Sanctorum aevi Merovingici et antiquiorum aliquot, ed. Bruno Krusch (MGH SS rer. Merov. 3), Hannover 1896, 20-41 (32-41).

Gaius Vettius Aquilinus Iuvencus, Libri Evangeliorum IV: Gai Vetti Aquilini Iuvenci Evangeliorum libri quattuor, rec. Johann Huemer (CSEL 24), Wien 1891.

Hilarius Pictaviensis, Tractatus mysteriorum: S. Hilarii Episcopi Pictaviensis opera, pars 4, rec. Alfred L. Feder (CSEL 65), Wien 1916, 1-38.

51 Sur le rayonnement du culte de saint Maurice, voir l'ouvrage fondamental de Müller 2006. 
Iulianus Aeclanensis, Expositio libri Iob: Iuliani Aeclanensis Expositio libri Iob. Tractatus prophetarum Osee, Iohel et Amos, ed. Lucas de Coninck (CCSL 88), Turnhout 1977, $1-109$.

La Passion anonyme de saint Maurice d'Agaune. Edition critique d'Eric Chevalley, Vallesia 45 (1990), 37-120 (96-110).

Magnus Felix Ennodius, Epistulae: Magni Felicis Ennodii opera omnia, rec. et commentario critico instr. Wilhelm Hartel, Wien 1882 (CSEL 6), 1-260.

Sophronius Eusebius Hieronymus, Commentarioli in psalmos: S. Hieronymi Presbyteri opera, pars 1, 1: Opera exegetica. Hebraicae quaestiones in libro Geneseos, Liber interpretationis Hebraicorum nominum. Commentarioli in psalmos. Commentarius in Ecclesiasten (CCSL 72), Turnhout 1959, 163-245 (ed. Germain Morin).

Sulpicius Severus, Vita Martini: Sulpice Sévère, Vie de Saint Martin. Introduction, texte, traduction et commentaire par Jacques Fontaine (SC 133-135), Paris 1967-1969.

\section{Littérature secondaire}

Blaise $\left({ }^{2} 1962\right)$ : Albert Blaise, Dictionnaire latin-français des auteurs chrétiens, Turnhout. Bruggisser (1984): Philippe Bruggisser, „Le Commentariolum petitionis, acte électoral?“, Les Etudes Classiques 52, 115-130.

Bruggisser (2004): Philippe Bruggisser, „Vltima necessitas. Tacite et la mort de Sénèque: la formule qui tue“, Mnemosyne 57, 489-492.

Bruggisser (2006a): Philippe Bruggisser, „Nobilis - nobilior: de la noblesse sociale à la noblesse spirituelle. A propos de la Passion des martyrs d'Agaune d'Eucher de Lyon“, Rivista di Storia e Letteratura Religiosa 42, 147-150.

Bruggisser (2006b): Philippe Bruggisser, „Vltima necessitas. De Sénèque à Eucher: l'évêque débiteur du philosophe“, in: Eugenio Amato, Alexandre Roduit et Martin Steinrück (eds.), Approches de la troisième sophistique. Mélanges en l'honneur de Jacques Schamp, Bruxelles, 406-419.

Bruggisser (2008a): Philippe Bruggisser, „Echos tardifs de Virgile et d'Ovide: la Passion des martyrs d'Agaune dans la version d'Eucher de Lyon“, Rivista di Storia e Letteratura Religiosa 44, 149-152.

Bruggisser (2008b): Philippe Bruggisser, „Un manuscrit fantôme de la Passion des martyrs d'Agaune d'Eucher de Lyon (A1* Krusch)“, Revue d'Histoire des Textes N.S. 3, 201-216.

Bruggisser (2010): Philippe Bruggisser, „Un conflit de conscience dans le métier des armes. Le plaidoyer des soldats thébains dans la Passion des martyrs d'Agaune selon Eucher de Lyon“, in: Lavinia Galli Milic et Nicole Hecquet-Noti (eds.), Historiae Augustae Colloquium Genevense in honorem F. Paschoud septuagenarii 'Les traditions historiographiques de l'Antiquité tardive: idéologie, propagande, fiction, réalité' (Genève, 1-4 mai 2008), Bari, 105-116.

Courcelle (1968): Pierre Courcelle, „Nouveaux aspects de la culture lérinienne“, Revue des Etudes Latines 46, 379-409.

Goetz (1894): Georg Goetz, „Agroecius (3)“, $R E$ 1, col. 902, Stuttgart.

Hellegouarc'h ( $\left.{ }^{2} 1972\right)$ : Joseph Hellegouarc'h, Le vocabulaire latin des relations et des partis politiques sous la République, $2^{\text {ème }}$ tirage revu et corrigé, Paris.

Holtz (2008): Louis Holtz, „La tradition lyonnaise d'Eucher de Lyon et le manuscrit Paris, BNF, Lat. 9550“, Revue d'Histoire des Textes N.S. 3, 135-200. 
Kaster (1988): Robert A. Kaster, Guardians of Language: The Grammarian and Society in Late Antiquity, Berkeley/Los Angeles/London.

Müller (2006): Gernot Michael Müller (ed.), Das ehemalige Kollegiatstift St. Moritz in Augsburg (1019-1803). Geschichte, Kultur, Kunst, Lindenberg.

Prost (2003): François Prost, „Cicero (Marcus Tullius)“, in: Richard Goulet (ed.), Dictionnaire des philosophes antiques, Supplément, Paris, 712-713.

Ratti (2009): Stéphane Ratti, Ecrire l'histoire à Rome, en collaboration avec Jean-Yves Guillaumin, Paul-Marius Martin et Etienne Wolff, Paris.

Schanz et al. (1920): Martin Schanz, Carl Hosius et Gustav Krüger, Geschichte der römischen Literatur bis zum Gesetzgebungswerk des Kaisers Justinian, t. IV.2, München.

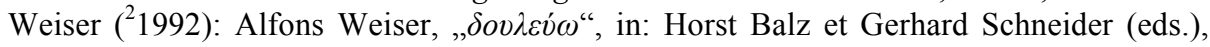
Exegetisches Wörterbuch zum Neuen Testament, Bd. 1, Stuttgart/Berlin/Köln, 844852.

Wermelinger et al. (2005): Otto Wermelinger, Philippe Bruggisser, Beat Näf et JeanMichel Roessli (eds.), Saint Maurice et la Légion Thébaine. Actes du colloque, Fribourg, Saint-Maurice, Martigny, 17-20 sept. 2003, Fribourg/Suisse.

Widmann (1968): Susanne Widmann, Untersuchungen zur Übersetzungstechnik Ciceros in seiner philosophischen Prosa, Diss., Tübingen. 


\section{VII.}

LITERARISCHE KOMMUNIKATION IM SPÄTANTIKEN GALLIEN ZWISCHEN UNIVERSALER BILDUNGSTRADITION

UND REGIONALISIERUNG 



\title{
Gallien als Literaturlandschaft
}

\author{
Zur Dezentralisierung und Differenzierung \\ lateinischer Literatur im 5. und 6. Jh.
}

Ulrich Eigler

Dass man mit der seit Caesar geographisch und organisatorisch als Gallien definierten Provinzengruppe ${ }^{1} \mathrm{ab}$ dem 4 . Jh. eine große Blüte der lateinischen Literatur verbinden darf, ${ }^{2}$ ist auch ein Resultat der zunehmenden Schwäche Roms als integrierendes literarisches Zentrum, seitdem es nicht mehr dauerhaft Kaisersitz war. ${ }^{3}$ Spricht man aber von Gallien als ,Literaturlandschaft', bedarf dies einer genaueren als nur verwaltungstechnischen Erklärung. Der Begriff umfasst sowohl die Literaturproduktion als auch -vermittlung bzw. -rezeption.

Zudem unterlag Gallien ab dem 5. Jh. politisch einer großen Dynamik. Verschiedene Germanenreiche bildeten sich auf seinem Boden, die kulturellen Unterschiede - gerade zwischen Nordost- und Südgallien - prägten sich nachhaltig aus. ${ }^{4}$ Diese Umwälzungen bescheren in der Folge dem geographischen Gallien als Ganzem eine besondere Stellung im Westen des Römischen Reiches. ${ }^{5}$ Zweifellos gilt gerade für Gallien und damit auch die dort entstehende lateinische Literatur spätestens seit dem 6. Jh. allgemein, was Stroheker feststellte: „Nach Justinian schreitet dann die Auflösung der Spätantike im Westen so weit voran, dass ein Urteil über das Gesamtbild kaum noch anders als von den Teilen möglich wird. “6 Es bilden sich lokal differenziert auch im Bereich der Literatur eigene Formen

1 Seit der Reform des Diokletian 293 umfasst das geographische Gallien zwei große Verwaltungssprengel, die Dioecesis Galliarum und die Dioecesis Viennensis. S. dazu die Liste der Diözesen und der jeweiligen Kaiser bei Barnes 1982, 199f. Zum früheren Status der Provinz in partes tres: Drinkwater 1983.

2 Wie die Person des Ausonius zeigt, stehen Dichtung, Rhetorik und Briefliteratur zwischen Bordeaux und Trier in besonderer Blüte. Zur Briefliteratur s. z.B. Zelzer 1997, 343.

3 Engels/Hofmann 1997, 59.

4 Angenendt 1990, 169ff.; zur stärkeren mediterranen Orientierung des Südens Galliens: Angenendt 1990, 201f., Gualandri ${ }^{2} 1993$, 502ff.

5 Scheibelreiter 1999, 17 betont: „Die Region des weströmischen Reiches, in der die genannten Einflüsse einander kreuzten, in der sie viele Voraussetzungen fanden und mehr Realität gewinnen konnten als anderswo, war Gallien.“

6 Stroheker 1965, 305. 
und Bedingungen sowohl der Produktion als auch der Vermittlung heraus. ${ }^{7} \mathrm{Zu}-$ gleich dauert für diese Region eine gewisse Verbindung zur mediterranen (Leit-) Kultur fort. Die daraus sich ergebende Dynamik ist bei der Verwendung des literaturwissenschaftlichen, aber auch bildungsgeschichtlichen Begriffs ,Literaturlandschaft ${ }^{\natural} \mathrm{zu}$ bedenken. ${ }^{8}$ Gerade für die Vermittlung, d.h. insbesondere für den Schulunterricht, scheint Gallien schon früh einen Raum gebildet zu haben, den man als Einheit auffassen kann. ${ }^{9}$

Zudem lässt sich im politischen Bereich bereits seit dem gallischen Sonderreich im 3. Jh. eine verstärkte Selbstwahrnehmung in Gallien feststellen. ${ }^{10} \mathrm{Im}$ Gefolge bildet sich ein besonderes Selbstverständnis der Elite heraus, das seine Bezeichnung als „gallorömisch“ rechtfertigt. Die Geschlossenheit dieser Gruppe belegt unter anderem die intensive Kommunikation der einzelnen Aristokraten untereinander, was zu einer besonderen Blüte der Briefkultur führte. ${ }^{11}$ Die Bedeutung Galliens als Literaturlandschaft drückt sich aber auch durch die in bestimmten Perioden erkennbare Pflege einzelner Literaturgattungen, wie der Rhetorik bzw. Panegyrik, Chronistik und Viten aus. Letztgenannte Gattung erhält mit der Martinsvita des Sulpicius Severus Anfang des 5. Jh.s einen entscheidenden Impuls und erlebt eine besondere Blüte im 6./7. Jh., ${ }^{12}$ während die Rhetorik besonders im 4. Jh. gepflegt wird.

Schon früh erkennt man in Werken, die in dem mit Gallien umschriebenen Raum entstanden sind, einen lokalpatriotischen Zug, der gleichsam eine implizite Wahrnehmung einer spezifischen Literaturlandschaft erahnen lässt und als bewusster „Provinzialismus“ charakterisiert wird. ${ }^{13}$ Das durch den Kaiser repräsen-

7 Dies hebt z.B. Brunhölzl 1975, 115 für Gallien im Gegensatz zur lateinischen Kultur der Pyrenäenhalbinsel hervor.

8 Isabella Gualandri (Gualandri $\left.{ }^{2} 1993,491-494,502-504\right)$ bespricht im Rahmen ihrer Überlegungen zu einer ,geografia della letteratura Latina“ die gallische Literatur der Spätantike in verschiedenen Zeitabschnitten. Der Begriff wird z.B. für das zweifellos kleinräumigere Bodenseegebiet im Frühmittelalter verwendet: Berschin 1987.

9 Vgl. die ältere Untersuchung von Haarhof 1920. Auf eine gewisse Wahrnehmung Galliens als Bildungsraum weist schon Ausonius in seinen 385/86 abgeschlossenen Professores, wobei er besonders Bordeaux herausstellt. Von dort gelangten Absolventen und Lehrer nach ganz Gallien: Gualandri ${ }^{2} 1993,491$.

10 Drinkwater 1987; König 1981.

11 S. dazu den Beitrag von Gernot Michael Müller in diesem Band und Zelzer 1997.

12 Berschin 1988, VII betont zu Recht: „Die reichste biographische Literaturlandschaft des frühen Mittelalters bildet Gallien. Der Schwerpunkt biographischer Produktion liegt im VII. Jahrhundert.“

13 Opelt 1978, 159-166 zum Carmen de laudibus Domini. In dem 317-323 verfassten Gedicht wird die Erweckung einer Toten im Häduerland beschrieben (1-35). Es schließt sich eine Darstellung des Jüngsten Gerichtes (36-142) an. Den Abschluss bildet eine laus Constantini (143ff.). Es wird damit eine besondere Beziehung zu dem aus Gallien stammenden Kaiser hergestellt. Neben der lokalen Orientierung steht aber damit nach wie vor die Reichsausrichtung. Zu diesem Werk zuletzt Schierl 2009. 
tierte Reich wird in Spannung zu dem lokalen gallischen Geschehen gesetzt, Provinzialität steht neben Universalität.

Es ist bemerkenswert, dass gerade durch spezifisch christliche Texte der Blick auf die eigene Umgebung gefördert wird, während die traditionelle Kultur und ihre christliche aristokratische Trägerschicht grundsätzlich global ausgerichtet bleiben. ${ }^{14}$ Im Zuge der politischen Veränderungen und Klerikalisierung dieser Schicht ${ }^{15}$ verstärkt sich allerdings gerade in Gallien gegen die Reichsorientierung die Gewichtung zugunsten der eigenen Umgebung. ${ }^{16}$ So ist in der Chronik von 452 eine deutliche Gallienorientierung zu erkennen, die sich in einer Idealisierung des gallischen Usurpators Magnus Maximus (383-388) gegenüber dem Kaiserhaus in Rom niederschlägt. ${ }^{17}$ Seine Leistung im Kampf gegen die Barbaren erfährt Würdigung, während die Vernachlässigung der Verteidigung Galliens durch Theodosius und insbesondere Honorius als Verrat empfunden wird. ${ }^{18}$ Das klar greifbare Ressentiment der Gallier gegenüber dem schwachen Regiment in Italien erklärt die Kaisererhebung des Galliers Avitus 455, wodurch sich ein gallischer Sonderweg andeutet. ${ }^{19}$

Der hier umrissene Vorgang, der Gallien als Literaturlandschaft eine besondere Stellung verschafft, ist also als langsamer und mit unterschiedlicher Dynamik ablaufender Ablösungsprozess von einer politischen und literarischen Leitkultur zu begreifen, die ihren visuellen Niederschlag ab der Mitte des 6. Jh.s in der Lösung von einer allgemeinen im Westen praktizierten Schrift und der Herausbildung eigener gallischer Schriftarten erhält. ${ }^{20}$

Im vorliegenden Beitrag behandeln wir mit Sidonius Apollinaris die mittlere Phase dieses Prozesses einer Neugewichtung der Spannung zwischen Reichsorientierung und Regionalität. Wir wollen zunächst (I.) diese Spannung grundsätzlich betrachten, ausgehend von einem Blick des Gregor von Tours auf Gallien, dessen Grenzen er klar vor Augen zu haben scheint, wenn er in der Vorrede seiner Frankengeschichte von nostri Galli spricht. Dann (II.) betrachten wir die Vil-

14 Prinz ${ }^{2}$ 1988, 449 bemerkte daher zur Anfang des 4. Jh.s noch traditionell ausgerichteten Aristokratie Galliens: „Diese spätantike, aristokratische Oberschicht hatte bisher die ,internationale" heidnisch-pluralistische Bildung wie selbstverständlich repräsentiert.“

15 Für Gallien s. Heinzelmann 1976. Krön 1997, 6 betont generell für die westlichen Führungsschichten: „Mitglieder westlicher Oberschichten erscheinen in den monastischen Quellen vom 4. bis zum 6. Jh. im Westen als entscheidende soziale Trägergruppe des entstehenden Mönchtums [...]."

16 Große Bedeutung kommt in diesem Zusammenhang auch den gallischen Konzilien zu.

17 Eine ähnliche Beurteilung bieten Sulp. Sev. dial. 2, 6, 2 und auch Oros. hist. 7, 34, 9; vgl. Muhlberger 1992, 34.

18 Muhlberger 1992, 34: „The chronicler felt that Rome's rulers had betrayed Gaul [...].“

19 Muhlberger 1992, 34. Muhlberger 1992, 30f. betont, dass in der früheren Chronik des Prosper der Blick auf das Zentrum in Italien noch wesentlich ausgeprägter ist. Auch die Kaiserherrschaft der Familie des Theodosius erscheint in positiverem Licht. Zentrum und Peripherie werden noch nicht in Spannung gesetzt.

20 Cencetti 1978, 64ff. spricht von einem ,particolarismo grafico medievale“ ab dem 6. Jh. auf dem Boden der ehemaligen Westprovinzen. 
lenkultur als Ort sozialer Kohärenz und Literaturvermittlung. Diese steht im 5. Jh. im Umbruch. ${ }^{21}$ Es erfolgt eine Transformation vom Adelssitz zu Inseln der Bildung, aber auch Orten der Umorientierung der Elite, die als Bischöfe oder Äbte ${ }^{22}$ neue Funktionen erhalten. Für die literarische Kultur bleibt dies nicht ohne Folgen. Sie erhält eine Ausrichtung im Sinne einer neuen Norm und neuer, oft regional geprägter Inhalte. Dem Versuch des Sidonius Apollinaris, die Veränderungen zu beschreiben, ist der nächste Abschnitt gewidmet (III.). Zwei koexistierende Literaturgruppen für die christliche Elite werden erkennbar: eine traditionelle und eine spezifisch christliche (libri religiosi), die sich von der globalen Reichskultur emanzipiert hat. ${ }^{23}$ Sidonius kann dafür noch keinen festen Kanon mitteilen. Wir gehen aber davon aus, dass es sich um spezifisch gallische Literatur handelt. Dies führt im Folgenden zu einer allgemeinen Behandlung der Frage nach Phänomenen und Kriterien einer spezifischen gallischen Literatur im 5. und 6. Jh. (IV.). Die Folgen der in dieser Zeit greifbaren Entwicklungen werden erst in karolingischer Zeit revidiert, als sich die gallofränkische Literatur und Kultur im Zuge der allgemeinen politischen Entwicklung im Zentrum der westeuropäischen literarischen Kultur wiederfindet. Dieser Dynamik seien die abschließenden Überlegungen unserer tour de force gewidmet (V.).

Nach Trier schrieb Sidonius Apollinaris ca. 475 einen Brief an den comes Arbogast: $^{24}$

Etsi apud limitem Latina iura ceciderunt, verba non titubant $[\ldots]{ }^{25}$

Obwohl an der Rheingrenze (apud limitem) die römische Herrschaft gefallen ist, wanken die Worte nicht [...].

Sidonius fährt fort:

21 Engels/Hofmann 1997, 59: „Ergänzend übernahmen die Privatbibliotheken der Gutsbesitzer vom 4. bis weit ins 7. Jahrhundert, solange eine gewisse politische und wirtschaftliche Struktur noch gewährleistet war, auch die Funktion von Seiten literarischer Produktion und Rezeption.“"

22 Heinzelmann 1976. S. auch den Beitrag von Steffen Diefenbach in diesem Band zur Entwicklung der Elite zu viri honorati (Laien) und Bischöfen.

23 Fontaine $1980 \mathrm{zu}$ dieser neuen Ausrichtung zu Zeiten des Fortbestands traditioneller, reichsorientierter Bildung.

24 S. auch Sidon. epist. 2, 10, 1; 5, 10, 1; 8, 6, 3.

25 Sidon. epist. 4, 17, 2. 
Quapropter [...] granditer laetor saltim in inlustri pectore tuo vanescentium litterarum remansisse vestigia, quae si frequenti lectione continuas, experire per dies, quanto antecellunt beluis homines tanto anteferri rusticis institutos.

Daher freue ich mich gewaltig, dass wenigstens in deiner großartigen Brust Spuren der schwindenden literarischen Bildung (vanescentium litterarum vestigia) verblieben sind. Wenn du diese durch beharrliche Lektüre weiterverfolgst, dann wirst du täglich erfahren, dass Gebildete sich vor den Ungebildeten auszeichnen wie Menschen vor den Tieren.

Sidonius schlägt mit der Klage drohenden literarischen Verfalls ein die gallische Literatur noch lange beherrschendes Thema an, das allerdings umso paradoxer anmutet, als es zu Zeiten höchster literarischer Produktivität erhoben wird. ${ }^{26}$ Es wird die Gefährdung einer im römischen Westen etablierten Bildungs- und Sprachnorm registriert und mit der aktuellen, eher regional greifbaren Verfallssituation kontrastiert. Arbogast hält in Sidonius' Augen noch die Reichsnorm aufrecht. Das Thema stiftet durch die Jahrhunderte eine gewisse Einheit unter den gallischen Autoren, deren Werke thematisch und stilistisch einem erkennbaren Wandel unterliegen. Immer mehr wird eine Lösung von den durch die kanonische, klassische Literatur vorgegebenen Themen und Lesevorlieben sichtbar, aber auch von einem allgemein verbindlichen durch die reichsweit ähnlich geartete grammatisch-rhetorische Bildung garantierten Stil. Global-reichsweite Maßstäbe geraten in Konkurrenz zu regionalen, spezifisch gallischen Themen und Sprachbesonderheiten. Sidonius ist als traditionell gallorömischer Aristokrat noch weitgehend reichsorientiert. Die frequens lectio gilt daher der kanonischen Schul- und Bildungsliteratur. ${ }^{27}$ Sie bewahrt Gallien als Teil des Reiches, garantiert einen Lebensraum als Leseraum. Sidonius' Benennung der Grenze zwischen Gallien und Barbaren erinnert an die spätere Bemerkung des Venantius Fortunatus, der den engeren Bereich Südgalliens vom barbarischen Rest abtrennt und sich dabei auch sprachlich-stilistischer Metaphorik bedient: hinc barbaries illinc Romania (Ven. Fort. carm. 6, 2, 7). Auch er bemüht sich, auf diese Weise Gallien als Literaturlandschaft zu umreißen.

Circa 200 Jahre früher waren unter Constantius Chlorus in Reaktion auf die Zerstörungen des 3. Jh.s von Trier aus Anstrengungen für die Literatur- bzw. besser: Bildungslandschaft Galliens unternommen worden. ${ }^{28}$ Der gallische Panegyriker Eumenius von Autun sah im Jahre 289 in der Unterstützung der Schule durch den Kaiser eine besondere Maßnahme zum Schutz Galliens nach den Beeinträchtigungen des 3. Jh.s. Die eruditi des Eumenius verteidigen Gallien wie die

26 Mathisen 1988, 47f.

27 Die gemeinsame Lektüre als identitätsstiftendes Merkmal der kulturellen Elite wird z.B. auch beschworen in Sidon. epist. 2, 10, 1; 5, 10, 1. In epist. 8, 6, 3 betont er die schwindende Kraft der artes in einem mundus senescens. S. auch zu dem homogenen Lebensstil der Elite und ihrer literarischen Praxis in Gallien Gualandri ${ }^{2} 1993,493$.

Eigler 2006, 65; Gualandri ${ }^{2}$ 1993, 491; Holtkamp 1969, 74 f. 
instituti des Sidonius gegen die Barbaren. Deutlich identifiziert sich der gallische Panegyriker mit seinen Landsleuten, wenn er von nostri Galli spricht:

Merentur et Galli nostri ut eorum liberis, quorum vita in Augustodunensium oppido ingenuis artibus eruditur [...] ut eorum indoli consulere cupiamus. ${ }^{29}$

Unsere Gallier verdienen es, dass wir den Kindern, die in Autun in den edlen Künsten ausgebildet werden, $[\ldots]$ dass wir deren Begabung besondere Pflege widmen wollen.

Als Gregor von Tours im Jahre 575 die praefatio seiner Historia Francorum verfasst, verwendet auch er den Topos vom Kulturverfall mit Blick auf Gallien, d. h. auf die urbes Gallicanae:

Decedente atque immo potius pereunte ab urbibus Gallicanis liberalium cultura litterarum, cum nonnullae res gererentur vel rectae vel inprobae [...] nec repperire possit quisquam peritus dialectica in arte grammaticus, qui haec aut stilo prosaico aut metrico depingeret versu: ingemescebant saepius plerique, dicentes: ,Vae diebus nostris, quia periit studium litterarum a nobis nec reperitur rhetor in populis, qui gesta praesentia promulgare possit in paginis. ${ }^{30}$

Da die Pflege der schönen Wissenschaften in den Städten Galliens in Verfall geraten, ja sogar im Untergang begriffen ist, hat sich kein in der Redekunst erfahrener Grammatiker gefunden, um in Prosa und Versen zu schildern, was sich unter uns zugetragen hat; und doch hat sich Vieles ereignet, Gutes wie Böses [...] So mancher hat oftmals den Mangel beklagt und gesprochen: „Wehe über unsere Tage, dass die Pflege der Wissenschaften bei uns untergegangen ist, und niemand im Volke sich findet, der das, was zu unseren Zeiten geschehen ist, zu Pergament bringen könnte! ‘31

Gregor beschreibt, wie die literarische Kultur sich regionalisiert und von einem allgemeinen kanonischen Standard gelöst hat. Ein peritus dialectica in arte grammaticus findet sich nicht mehr, wohl aber besteht eine lateinische Literatur eigenen Charakters auf dem Boden Galliens fort, ja erlebt eine große Blüte, so dass die kritische Bemerkung Gregors nur als Klage auf hohem Niveau bezeichnet werden kann. Wie aber ist die hier neu greifbare Literatur zu beschreiben, die eher gallischen als reichsrömischen Charakter besitzt, ja die alten Standards verletzt? ${ }^{32}$ Eine hypothetische Antwort soll von einem Versuch des Sidonius Apollinaris, die Literatur der Literaturlandschaft Gallien zu beschreiben, ausgehen.

29 Paneg. Lat. 9 (4), 14, 1.

30 Greg. Tur. Franc., praef. 1.

31 Übersetzung: Buchner.

$32 \mathrm{Zu}$ einem Überblick über die Literatur in Gallien im Übergang von der Spätantike zum Frühmittelalter vgl. Brunhölzl 1975, 115-155. 
II.

Im Jahre 465 beschreibt Sidonius einen für gallische Aristokraten typischen Besuch in der Villa des Ferreolus, des praefectus praetorio Galliarum von 451. Kaum eingetreten, ist er umgeben von Ball- und Würfelspielern (epist. 2, 9, 4). Schließlich gelangt er in die Bibliothek, in der sich mehrere Regale befinden. Unter diesen werden zwei hervorgehoben:

Huc libri adfatim in promptu (videre te crederes aut grammaticales pluteos aut Athenaei cuneos aut armaria exstructa bybliopolarum): sic tamen quod, qui inter matronarum cathedras codices erant, stilus his religiosus inveniebatur, qui vero per subsellia patrumfamilias, hi cothurno Latiaris eloquii nobilitabantur; licet quaepiam volumina quorumpiam auctorum servarent in causis disparibus dicendi parilitatem: nam similis scientiae viri, hinc Augustinus, hinc Varro, hinc Horatius, hinc Prudentius lectitabantur. Quos inter Adamantius Origenes Turranio Rufino interpretatus sedulo fidei nostrae lectoribus inspiciebatur; pariter et, prout singulis cordi, diversa censentes sermocinabamur $\left[\ldots . .{ }^{33}\right.$

Hier standen Bücher in Fülle zur Verfügung (man hätte glauben können, dass es sich um brusthohe Regale (plutei) wie bei einem Grammatiker, die keilförmigen Kästen (cunei) des Athenaeums oder die wohlgefüllten Schränke (armaria) von Buchhändlern handelt): ${ }^{34}$ Und es war so, dass in den Büchern (codices), die sich zwischen den Sitzen (cathedrae) der Frauen befanden, ein religiöser Stil (stilus religiosus) zu finden war, die aber, die bei den Sitzen (subsellia) der Herren standen, durch den hohen Stil lateinischer Sprache geadelt wurden (hi cothurno Latiaris eloquii nobilitabantur); [war es doch so, dass] jede Rolle beliebiger Autoren (licet quaepiam volumina), wenn auch in verschiedenen Angelegenheiten, den gleichen Stil (parilitatem dicendi) wahrte. Denn Autoren gleicher sprachlicher Gewandtheit (similis scientiae viri), Varro und Augustinus, Horaz und Prudentius wurden da gelesen. Unter diesen wurde fleißig von Lesern unseres Glaubens Origenes in der Übersetzung des Rufinus konsultiert. Obwohl unterschiedlicher Meinung, diskutierten wir in ausgeglichener Atmosphäre und wie dem Einzelnen der Sinn stand [...].

Die Gegenüberstellung scheint merkwürdig. Eine Gruppe von libri wird wegen ihres stilus religiosus hervorgehoben, aber auch optisch identifiziert durch die Codex-Form. Sidonius konstruiert einen Gegensatz. Er ist aufgeladen durch Metaphern und Symbole und voll von literatur- und kulturgeschichtlicher Semantik. Im Gendermodus werden die Geschlechter bestimmten Regalen, aber auch Sitzen zugeordnet. Mit cathedrae, dem im klassischen Latein üblichen Begriff für die Frauensessel, wird im Spätlatein das semantische Feld kirchlicher Lehre und Machtrepräsentation eröffnet. Die von den Herren eingenommenen subsellia

33 Sidon. epist. 2, 9, 5.

$34 \mathrm{Zu}$ den bibliothekstechnischen Begriffen vgl. Manguel 2000, 155. 
dagegen verweisen im klassischen Latein auf politisch-rhetorische Tätigkeit, da sie im Senat oder vor Gericht als Sitzgelegenheiten üblich waren. Wird mit diesen Symbolen bereits eine religiöse Sphäre von einer weltlich-laikalen separiert, so erfährt dies noch eine Verstärkung durch die suggestive Buchmetaphorik. Sidonius platziert die Frauen vor den codices und wählt damit für die ihnen zugeordneten Bücher eine Mediengestalt, die man mit christlicher Literatur assoziiert. ${ }^{35}$ Entsprechend werden die Männer vor volumina, d.h. Buchrollen gesetzt, die einen materiellen Kontrast konstituieren, der für diese Zeit bereits anachronistisch ist, ${ }^{36}$ da sich der Codex als Buchform schon generell durchgesetzt hat. Sidonius inszeniert eine Differenz traditionell-lateinischer und spezifisch christlicher Literatur.

Schließlich wendet er sich dem Inhalt der Regale zu, wobei er hinsichtlich der bei den Herren befindlichen Bücher sehr auskunftsfreudig ist. Dort befinden sich Autoren, die unabhängig von der Frage, ob nichtchristlich oder christlich, durch den gemeinsamen hohen Stil verbunden sind. Varro steht auf einer Stufe mit Augustinus, Prudentius mit Horaz. Prosa und poetische Sprache sind vertreten: $h i$ cothurno Latiaris eloquii nobilitabantur.

Der dort verwendete stilus adelt nicht nur die Autoren, sondern die Leser der Texte, also ein im Grammatik- und Rhetorikunterricht geschultes Publikum, das sich mit der traditionellen gallorömischen Aristokratie gleichsetzen lässt. Für sie ist literarische Bildung ein wichtiges soziales Distinktionsmerkmal, das auch die innere Geschlossenheit der sozialen Gruppe garantiert. Wir sehen hier die Identität von Sprachnorm und Lebensnorm. Adlige Lebensform und Sprache, Lebenswelt und Lesewelt konvergieren. Die für diese Leser bestimmten Autoren besitzen einen hervorragenden Platz und signalisieren dem Besucher Stand und Identität seines Besitzers. Er ist ein römischer nobilis, der sich der globalen, reichsweit üblichen grammatisch-rhetorischen Bildung verpflichtet fühlt.

Sidonius hat damit ein literaturkritisches Urteil abgegeben, aber auch eine kulturelle Standortbestimmung vorgenommen. ${ }^{37}$ Die im Herrenregal versammelten Bücher sind der kanonischen literarischen Kultur verpflichtet, die im Westen des Römischen Reiches etabliert ist und die die gemeinsame sprachliche Grundlage (parilitas dicendi) der Kirchenväterliteratur wie auch der Schulautoren bildet. ${ }^{38}$

35 Jochum 1999, 52 zum Zeichencharakter von Codex und Rolle in der Unterscheidung von christlicher und heidnisch-traditioneller Literatur; vgl. auch Katz 1945.

36 Roberts 1970, 57 geht davon aus, dass an der Wende vom 3. zum 4. Jh. 95\% der heidnischen Literatur in Codex-Form vorlag. Allgemein s. Cavallo 1999, 99-133.

37 Sidonius hat die in einer Villa üblichen Bibliotheksverhältnisse eindeutig überzeichnet. Der Hinweis auf einen Bereich professionellen Umgangs mit Büchern in der Schule (grammaticus), in öffentlichen Bibliotheken (Athenaeum) oder im Buchhandel (bibliopola) konstituiert eine amplificatio und zugleich eine Differenz. Bücher in einem derartigen Umfang sind in einem aristokratischen Ambiente unüblich. Der professionelle Zug fehlt dem Leben und Lesen in der Villa, auf ihn trifft man in von der Villa aus betrachtet externen Institutionen und Berufen. S. aber Santela 2000, 220-220, die in bibliopola einen Privatsekretär oder Bibliotheksbetreuer sehen will.

Zu Varro s. Piacente 1998, 195 f. 
De civitate dei steht auf einer Stufe mit Vergil oder Varro, enthält ja auch große Passagen aus beiden Autoren und liegt stilistisch auf höchstem Niveau. ${ }^{39}$ Ebenso gilt Prudentius wegen der steten Präsenz seines Vorbilds Horaz als christlicher Horaz und ist diesem gleichgestellt. ${ }^{40}$

Diesen steht im Frauenregal eine Gruppe von libri gegenüber, die einerseits wegen ihres stilus religiosus hervorgehoben, andererseits optisch durch die Codex-Form identifizierbar ist. Sidonius hat einen pointierten Gegensatz konstruiert, ansonsten aber keine Angaben über die dort enthaltenen Bücher gemacht. Wir müssen sie also e contrario erschließen.

\section{III.}

Wir können davon ausgehen, dass auch im Herrenregal Literatur für Christen enthalten ist, eine Unterscheidung der Regale nach heidnischen Klassikern und christlichen Büchern also zu kurz greift. ${ }^{41}$ Schließlich diskutieren gerade am Herrenregal christliche Laien (lectores fidei nostrae) über eine Origines-Übersetzung des Rufinus, also über einen Text, der sowohl christlicher Kirchenväterliteratur als auch klassischem Sprachstandard, dem cothurnus Latiaris eloquii, zuzuordnen ist. Im Sprachstil beruht denn auch, folgt man der antithetischen Ordnung, der Unterschied gegenüber den libri religiosi des Frauenregals. Es liegt nahe, dass der Stil der Bücher des Herrenregals für die eruditi oder instituti, also die durch Grammatik- und Rhetorikunterricht geprägten traditionellen Leser, bestimmt ist. Diese sind durch eine lectio unterwiesen, die die Kenntnis allgemein verbindlicher schriftsprachlicher Normen, mit diesen aber auch bestimmte Themen und Motive verbreitet und garantiert. Gerade die Literatur der Kirchenväter und Apologeten des 4. und 5. Jh.s ist mit dieser aufs engste verbunden und verdankt diesem Umstand ihre Wirksamkeit in der römischen Oberschicht. Diese wird hier durch die patresfamilias repräsentiert, deren konservative literarische Ausrichtung auch durch die besondere Materialiät ihrer Bücher als volumina betont ist. Ihre soziale und römische Identität definiert sich über die gemeinsame lectio, die ja auch Sidonius zu seiner Zufriedenheit bei Arbogast als letzte Maßnahme gegen die Barbarisierung registriert.

39 Der intensiven Bezugnahme auf Autoren der klassischen Bildungsliteratur scheint freilich der von Aug. civ. 3, 8, 10 erhobene Anspruch zu widersprechen, für einen homo Christianus litteris tantum ecclesiasticis eruditus zu schreiben. Vgl. Gemeinhardt 2007, 451.

$40 \mathrm{Zu}$ Prudentius und Horaz vgl. Ludwig 1977. Die Unterscheidung von Chadwick 1955, 275 ist dahingehend irreführend, als sie die Kirchenväter in das Frauenregal zu verlegen scheint, wenn sie das Herrenregal folgendermaßen beschreibt: ,[...] which contained the Roman classics on one side of the room, and the works of the Fathers of the Church on the opposite side [...]." Kirchenväter und Klassiker befinden sich vielmehr im gleichen Regal.

41 Insofern greift die Charakterisierung von Manguel 2000, $155 \mathrm{zu}$ kurz, der den Inhalt der beiden Regale als „lateinische Klassiker für Männer, Gebetbücher für Frauen“ charakterisiert. 
Denkt man in den Bahnen der von Sidonius angelegten bipolaren Argumentation weiter, so müssen die libri religiosi diesen gegenübergestellt werden, dem klassischen Kanon und seiner christlichen Transformation stilistisch und inhaltlich entgegengesetzt sein und der Voraussetzung grammatisch-rhetorischen Trainings, also des globalen professionellen Hintergrunds, entbehren.

Zunächst lässt sich an die Bibellektüre als Alternative denken, zumal die Sidoniusstelle dann eine direkte Parallele in einem Brief des Hieronymus an Marcella besäße (Hier. epist. 29, 1). Dort schreibt Hieronymus einem weiblichen Publikum, das sich mit Bibelfragen in der Abgeschiedenheit beschäftigt. Er begründet seinen flüchtigen und nicht der rhetorischen eloquentia verpflichteten Stil mit der Bibellektüre seiner Adressatinnen, die ja keine große Rhetorik verlange, sondern ganz der Sache zugewandt sei. Deutlich distanziert sich dabei auch er von einem globalen Kanon, der an das Herrenregal des Sidonius erinnert. Die Frauen richten ihren Sinn nicht auf die verba, sondern auf die sensus, die Deutung der Bibel in der schlichten Übersetzung des Hieronymus. Für den hohen Stil sind die Klassiker zuständig: ${ }^{42}$

[...] rem grandem celerius dicto quam debeo, licet de scripturis sanctis disputanti non tam necessaria sint verba quam sensus, quia si eloquentiam quaerimus Demosthenes legendus aut Tullius est, si sacramenta divina nostri codices, qui de Hebraeo in Latinum non bene resonant pervidendi.

[...] eine gewichtige Angelegenheit diktiere ich schneller als ich sollte, dürfen doch für jemanden, der über die Heiligen Schriften spricht, die Worte nicht so wichtig sein wie die Bedeutungen. Denn, wenn wir brillianten Stil wollen, dann müssen wir den Demosthenes oder den Tullius lesen, wenn es um die Heiligen Schriften geht, dann unsere Bücher (codices!), die nicht so gut vom Hebräischen ins Lateinische hinüberklingen.

Hieronymus stellt die codices der Bibel gleichsam als einzige Bibliothek ${ }^{43}$ dem $^{2}$ Kanon der Klassiker, vertreten durch Cicero und Demosthenes, explizit gegenüber, Sidonius dagegen lässt das ,Frauenregal' merkwürdig leer. Die Bibel wird nicht als Pendant genannt. So müssen wir weiter e contrario den möglichen Inhalt erschließen und können nicht umhin zu vermuten, dass es die stilistisch den Frauen zuzuordnenden biblischen Schriften enthält. Auf jeden Fall dürfte es sich um Schriften handeln, deren Inhalt sich unmittelbar erschließt und nicht Schulstoff,

42 Hieronymus berichtet andernorts (epist. 127, 8), dass sich Marcella 385 mit gleichgesinnten Frauen auf eines ihrer Landgüter zurückgezogen habe. Religiöse Frauenlektüre in aristokratischen Kreisen ist ein bekanntes Phänomen, wobei selten die Lektüre genau spezifiziert wird. Vgl. Ambr. virg. 3, 4, 37 zum Rückzug seiner Schwester aufs Land; Hier. epist. 1, 14, 2 zum gemeinsamen Leben von virgines in einer villula bei Vercelli.

43 Zur Zusammenfassung der biblischen Schriften als bibliotheca vgl. Isid. orig. 6, 3, 2 (bibliotheca Veteris Testamenti), die gesamthaft 22 Bücher umfasst. 
sei er grammatisch, sprachlicher oder inhaltlicher Natur, wie antike Geschichte oder Mythologie voraussetzt. ${ }^{44}$

Das hieße, an die Stelle globaler Einbindung würden Werke mit einem regionalen oder evidenten Stoffhorizont treten, die nur allgemein biblisches und eventuell regionales literarisches Vorwissen verlangen. Schulgestützte Lesevoraussetzungen wären dann ersetzt durch allgemeine Erfahrungen, die die Werke unmittelbar zugänglich machen. Stilistische Finessen treten zurück und sprachliche Einfachheit, die keinen Grammatikunterricht verlangt, dominiert. Für diese Deutung spräche, dass Sidonius keinen alternativen Kanon formuliert, das Frauenregal ist zu offen, die dortigen Codices nicht durch eine Institution kanonisch formuliert. Nur die Codex-Form verbindet. Um einen pointierten Gegensatz zu formulieren, bemüht Sidonius die Differenzierung nach Geschlechtern. Wir müssen also die Literatur des Frauenregals aus der sich im Gegensatz zur stilistischen Besonderheit der Herrenlektüre ergebenden besonderen Semantik des Begriffs religiosus im Zusammenhang mit Fragen der Bildung und der Lektüre erschlieBen.

Der Begriff begegnet z.B. in einem einleitenden Paratext, ${ }^{45}$ der sich zu Anfang der im 6. Jh. versifizierten actus apostolorum des Arator befindet und diese einführt. Der Verfasser dieses Vortextes betont nämlich in Kenntnis der 544 in Rom erfolgten Rezitation, dass zwischen einem gleichermaßen angesprochenen Publikum frommer Laien, die der Oberschicht entstammten, und der Schar einfacher Zuhörer zu unterscheiden gewesen sei:

In ecclesia beati Petri quae vocatur ad vincula religiosorum simul ac laicorum nobilium sed et e populo diversorum turba convenit. Atque eodem Aratore recitante distinctis diebus ambo libri quattuor vicibus sunt auditi.

In der Kirche, die St. Peter ad vincula genannt wird, kam eine Schar aus dem Kreise frommer und zugleich vornehmer Laien und eine Gruppe ganz verschiedener Leute aus dem Volk zusammen und, während Arator rezitierte, lauschte man den zwei Büchern an vier verschiedenen Tagen.

Die Lesung spricht ein doppeltes Publikum an, das sich in der ausschließlichen Konzentration auf die christliche Botschaft vereint. Die vornehmen Laien werden deswegen als religiosi charakterisiert, da sie von ihrer traditionellen wortorientierten Bildung absehen. Für das rezitierte Werk bedeutet dies, dass auf rhetorischen

44 Dies ist z. B. für Prudentius' allgorische Dichtungen und allemal für Horaz der Fall oder auch für Augustinus, der die Kenntnis von Livius, Varro, Sallust, Vergil und auch Cicero für das Verständnis von De civitate dei voraussetzt und sich deshalb auch im Herrenregal mit diesen Autoren befindet.

45 Arator act., $28 \mathrm{f}$. 
Schmuck verzichtet und der Schwerpunkt auf den Inhalt gelegt wurde. ${ }^{46}$ Die Verbindung eines doppelten Publikums unter der Priorität der religiösen Aussage sehen wir z.B. auch in der Rechtfertigung des einfachen Stils durch Sulpicius zu Beginn seiner 396 verfassten Martinsvita. Allerdings steht jetzt nicht die Bibel im Vordergrund sondern das exemplarische Leben eines Heiligen. Für die Vita gilt auch, was Sulpicius am Anfang seiner Chronik von 403 pointiert zusammenfasst, was aber bei Sidonius auf zwei Regale verteilt wird:

\section{[...] ut imperitos docerem et litteratos convincerem. ${ }^{47}$}

[Ich schrieb] dies, um diejenigen, die nicht literarisch gebildet sind, zu belehren, die literarisch Gebildeten aber zu überzeugen.

Das Frauenregal war, bliebe man bei der von mir gezogenen Analogie, eher für imperiti bzw. imperitae, bestimmt, die nicht über das formale Training des Grammatik- und Rhetorikunterrichts verfügten bzw. diese nicht für wichtig erachteten, gleichwohl aber zur Elite zu rechnen waren. Als laici religiosi interessierten sie sich für biblische und allgemein religiöse Stoffe unmittelbarer Evidenz ohne sprachlichen Schmuck.

Das Frauenregal brächte demnach das Konzept einer neuen spezifisch christlichen literarischen Bildung zum Ausdruck, könnte also neben der Bibel auch Heiligenviten wie die Martinsvita enthalten - und später z.B. auch den Arator aufgenommen haben. Im Frauenregal erhält die rhetorisch nicht geregelte Literatur ihren inhaltlich begründet legitimen Platz als libri religiosi und kann als normale Fortsetzung bzw. Ergänzung literarischer Kultur jenseits von Verfalls- und Dekadenzempfindungen angesehen werden.

Nun wäre dies keinesfalls eine in unserem Zusammenhang, in dem es um Gallien als Literaturlandschaft geht, wichtige Erkenntnis, ${ }^{48}$ wenn nicht die stilistische Einfachheit mit einer inhaltlichen Entglobalisierung einherginge. Das allgemeine Phänomen des Normenverfalls in der Literatur ermöglichte erst die Ausbildung von Literatur, die lokalem Stil und regionalen Themen verpflichtet war. Sehr schön ist dies zu erkennen in der Historia Francorum Gregors von Tours, bei dem die bewusste Inkaufnahme stilistischer Einfachheit mit einem stark gallischen Blickwinkel einhergeht, der auch das Interesse seines Publikums widerspiegelt. Dies betont der Autor selber in der praefatio, in der er über nostri Galli spricht und die Verwendung eines unrhetorischen Stils, eines incultus effatus, rechtfertigt, wobei er den Gedankengang mit einem Ausspruch abschließt: ,Philosophantem rhetorem intellegunt pauci, loquentem rusticum multi. 'Entsprechend bedeutet sein Geschichtswerk die Durchsetzung des Lokalen gegenüber

46 Zweifellos war Arator sehr gebildet, bediente sich aber eines ostentativ bescheidenen Stils: Herrin 1987, 84.

47 Sulp. Sev. chron. 1, 1, 4.

48 Eigler 2003, 114ff. 
dem Globalen, des lebensweltlichen anstelle des leseweltlichen Bezugs. ${ }^{49}$ Diese Entwicklung der Literatur besitzt ihre Entsprechung im Politischen, wo reichsbezogene Instanzen lokalen Machtverhältnissen weichen.

Um verschiedene Grade von Globalität bzw. Regionalität könnte es auch bei Sidonius' Darstellung der Bibliothek eines anderen Mitglieds der gallischen Aristokratie, des Claudianus Mamertus, gehen. Er hat sie in einen Nachruf auf den christlichen Aristokraten eingefügt. Claudianus habe eine triplex bibliotheca besessen:

Triplex Bybliotheca quo magistro,

Romana, Attica, Christiana fulsit. ${ }^{50}$

Eine dreigeteilte Bibliothek besaß er,

eine römische, griechische und eine christliche.

Gerade die bibliotheca Christiana dürfte die libri religiosi enthalten haben, während die bibliotheca Romana der globalen Ausrichtung des Herrenregals des Ferreolus entsprochen haben könnte. ${ }^{51}$ Die Annahme der griechischen Bibliothek unterstreicht die Globalität des Claudianus Mamertus, dürfte aber eher topische Bedeutung haben. Es geht vielmehr um Systematisierung, um Positionsklärung und nicht um konkrete Bücher.

Aristokratische Villen besaßen wohl durchweg derartige Bücherzusammenstellungen, immer mehr tritt allerdings im Zuge der Klerikalisierung der Elite das Frauenregal bzw. die bibliotheca Christiana und damit ein regionales Prinzip in den Vordergrund und verdrängt zunächst völlig das Herrenregal. Der global orientierte Schulbesuch beim Grammatiker oder Redelehrer tritt allein schon aufgrund der politischen und wirtschaftlichen Wirren in den Hintergrund und wird zudem von christlicher Seite abgelehnt. Beide Umstände bedingen eine Regionalisierung, die als allein richtige Orientierung des christlichen Gebildeten auch normativ eingefordert werden kann. Die Koexistenz der beiden Regale wird problematisch.

Im Jahre 601 schreibt Gregor der Große nämlich an den gallischen Bischof Desiderius. Dieser hatte sich - wir wollen im Bild unserer bisherigen Überlegungen bleiben - um beide Regale gekümmert und den Grammatikunterricht anhand der Klassikerhandschriften übernommen, zugleich aber als Bischof die libri religiosi gepflegt:

49 Buchner 1970, XIX nennt in der Einleitung seiner Ausgabe der Decem libri Historiarum „gallisches Heimatgefühl“ als einen der wichtigsten Faktoren in Gregors Denken. Zu vergleichen ist dies übrigens auch mit der Perspektive Bedas in seiner Historia ecclestiastica gentis Anglorum. Die fehlende Voraussetzung einer globalen Bildung bedingt eine Schrumpfung des sachlichen Interesses von Autor und Publikum auf das Regionale.

50 Sidon. epist. 4, 11, 6; vers. 4-5.

51 Vgl. Eigler 2003, $103 \mathrm{f}$. 
Sed post hoc pervenit ad nos, quod sine verecundia memorare non possumus, fraternitatem grammaticam quibusdam exponere. Quam rem ita moleste suscepimus ac sumus vehementius aspernati, ut ea quae prius dicta fuerant in gemitu et tristitia verteremus, quia in uno se ore cum Iovis laudibus Christi laudes non capiunt. Et quam grave nefandumque sit episcopo canere, quod nec laico religioso conveniat, ipse considera. $^{52}$

\begin{abstract}
Aber anschließend gelangte uns etwas zu Ohren, was wir nicht in Erinnerung rufen können, ohne uns dessen zu schämen, dass mein Bruder einigen Leuten Grammatik beibringt. Dies haben wir ziemlich unwillig aufgenommen und haben heftige Abscheu bekundet, so dass wir das, was [an Gutem] zuvor gesagt worden war, unter trauervollem Seufzen ins Gegenteil verkehren mussten, weil in einem Munde zusammen mit dem Lob Iupiters die Rühmung Christi keinen Platz findet. Mach dir doch selber klar, wie schwerwiegend und schrecklich es für einen Bischof ist zu singen, was schon einem frommen (religiosus!) Laien nicht ansteht.
\end{abstract}

Hier erkennen wir die Reste der Professionalisierung aristokratischer Lektüre, die nun aus ideologischen Gründen einer neuen Regel gegenübergestellt wird. Der Inhalt traditioneller Unterweisung passt nicht mehr zum klerikalen Selbstverständnis, damit aber auch nicht mehr der alte Stil. Lebensstil und Sprachstil werden unter dem Stichwort religiosus neu zugeordnet.

Gregor wusste, wovon er sprach, wenn er einen neuen Stil, einen stilus religiosus, für Bücher und Menschen verlangte. So schreibt er im Jahre 595 an den spanischen Bischof Leander, dem er seine Expositiones in Hiob zugesandt hatte. Dort betrachtet er die elementare Basis der Syntax:

Nam sicut huius quoque epistolae tenor enuntiat, non metacismi collisionem fugio. non barbarismi confusionem devito, situs modosque et praepositionum casus servare contemno, quia indignum vehementer existimo, ut verba caelestis oraculi restringam sub regulis Donati. ${ }^{53}$

Denn wie es auch der Stil dieses Briefes erkennen lässt, meide ich nicht die sich aus der häufigen Abfolge des Buchstaben $M$ ergebende Unstimmigkeit, ebenso nicht die Verwirrung durch Barbarismen. Wortstellung, Prosarhythmus verachte ich genauso, wie die entsprechenden Casus mit den jeweiligen Präpositionen zu verbinden, denn ich bin entschieden der Meinung, dass es unwürdig ist, die Worte der göttlichen Offenbarung unter die Regeln des Donat zu knechten.

Der globale, reichsorientierte Stil Donats passt nicht zum neuen Lebensstil und Glauben. Dieser ist regional geprägt, zumal in Gallien.

52 Greg. M. epist. 11, 34.

53 Greg. M. epist. 5, 53a. 
IV.

In Gallien setzt sich das alternative christliche Literaturkonzept durch, das den Stil einer reichsweit etablierten Schule nicht wünscht und damit eine spezifisch gallische Literatur freisetzt. In einfacher Sprache werden lokale Themen, insbesondere Heiligenleben, behandelt, man denke nur an die zahlreichen Nachfolger des Sulpicius Severus, die sich der Martinsthematik gewidmet haben. ${ }^{54}$ Auf diese Weise obsiegt der unmittelbare, lokale Sprachstil, aber auch der regionale Horizont von Autoren und Publikum.

Ein möglicher Inhalt für das Frauenregal wäre auch die Vita, die Constantius, der Lyoner Kleriker und Briefpartner des Sidonius Apollinaris, über den LérinsGründer Germanus ca. 478 geschrieben hat. Die Vita ist im niederen Stil der libri religiosi verfasst. ${ }^{55}$

Den niederen Stil fordert - ganz auf der Linie Gregors des Großen - auch Caesarius von Arles (470-542), ein gallischer Aristokrat, der 491 ins Kloster Lérins eingetreten, 502 Bischof von Arles geworden war und 512 dort ein Männerkloster gründete. Er selber hatte noch eine grammatisch-rhetorische Ausbildung bei dem Grammatiker Pomerius erhalten, lehnt diese aber nun ab. Um im Bild des Sidonius zu bleiben, distanziert er sich zugleich von den christlichen, patristischen Autoren des Herrenregals, die ja der globalen literarischen Kultur entstammen:

Si expositiones sanctarum scripturarum eo ordine et illo eloquio, quo a sanctis patribus sunt expositae, caritatis vestrae auribus voluerimus intimare, non nisi ad paucos scolasticos cibus doctrinae poterit pervenire, reliqua vero populi multitudo ieiuna remeabit; et ideo rogo humiliter, ut contentae sint eruditae aures verba rustica aequanimiter sustinere, dummodo totus grex domini simplici et, ut ita dixerim, pedestri sermone pabulum spirituale possit accipere. ${ }^{56}$

Wenn wir die Auslegungen der Heiligen Schriften in dieser Ordnung und jenem Stil, in dem dies die heiligen Väter getan haben, Euren geschätzten Ohren vermitteln wollen, dann wird die Speise des Wissens nur zu Wenigen, die Schulbildung genossen haben, gelangen, die übrige große Schar des Volkes wird hungrig davongehen; und darum bitte ich demütig, dass die gebildeten Ohren sich damit zufriedengeben, gleichmütig bäurische Worte zu ertragen, solange nur die ganze Herde des Herrn die geistliche Speise in einfachem und sozusagen Fußgängerstil aufnehmen kann.

54 Zwischen 460 und 470 verfasste Paulinus von Périgueux eine Versbearbeitung der Martinsvita, 576 tat dies nochmals Venantius Fortunatus. Das Leben Martins wird zu einem herausragenden regionalen gallischen Thema. S. auch Vielberg 2006.

55 Brunhölzl 1975, 484; Gualandri ${ }^{2}$ 1993, 503. Zu der sensationellen Zahl von in dieser Phase verfassten gallischen Heiligenviten s. allgemein Berschin 1988.

56 Caes. Arel. serm. 86, 1. 
Die Schriften der Kirchenväter zeichnen sich durch einen gebildeten, nur für die aures eruditae weniger Absolventen der Grammatikschule (scholastici) bewältigbaren Stil (eloquium) aus. Caesarius benennt damit die Rezipientenkreise, die Sidonius vor das Herrenregal gesetzt hatte. Wie Sidonius stellt Caesarius diesen eine andere Gruppe, die reliqua vero populi multitudo gegenüber, ohne dabei eine Geschlechterdifferenz zu konstruieren, von seinem gebildeten Publikum aber zu verlangen, im Interesse der Ungebildeten auf diesen Hintergrund zu verzichten. Beide gallischen Autoren bedienen sich derselben Dichotomie. Caesarius freilich privilegiert die Verwendung des niederen Stils (verba rustica, sermo pedestris), lehnt also zugunsten eines am unmittelbaren Publikum orientierten Stils den globalen Standard der Sprache, wie ihn die Schule vermittelt, ab. Dass damit ein Prozess benannt und nicht ein fester Zustand beschrieben wird, zeigen die Bemerkungen Gregors zum Ende des 6. Jh.s. Die Entscheidung ist bei Caesarius, obwohl er aus der alten Bildungswelt stammt, zugunsten des Frauenregals und der Regionalisierung gefallen. Es ist nicht zu unterschätzen, dass damit nicht nur die Wahl bestimmter Inhalte, sondern auch eine neue Intertextualität verbunden ist. Weiter ausgreifende Klassikerzitate und Anspielungen, wie sie z.B. bei den Kirchenvätern üblich sind, weichen der Restriktion zugunsten einer voraussetzungslosen, regional-provinziellen Lektüre und Kommunikation.

Wir schließen die Überlegungen zu Gallien als Literaturlandschaft, die auf der Annahme beruhen, dass gerade die Einschränkung auf libri religiosi diese als regional definierte Literatur besonders befördert hat, mit einem Blick auf die Fortsetzung von De viris illustribus des Hieronymus durch Gennadius von Marseille (ca. 480). ${ }^{57}$ Zweifellos hätten dessen Zusätze zum Frauenregal gepasst, eine besondere Gallienorientierung ist bei ihm allerdings nicht wahrnehmbar. Der übernächste Fortsetzer, Ildefons von Toledo, war dagegen ein entschiedener Lokalpatriot und betonte die spanischen Beiträge zur christlichen Literatur. Allerdings ergibt sich mit 18 Einträgen ein Schwerpunkt für Südgallien. Außerdem hat Gennadius für die Zeichnung einer „Literaturlandschaft Gallien“ dadurch einen Beitrag geleistet, dass er die Provenienz der Autoren nach dem Vorbild des Hieronymus mitteilte. Alle diese Bücher sind im Gegensatz zur Auswahl des Hieronymus libri religiosi und heben sich vom Kanon antiker Bildungsliteratur und Väterschriften ab. Das Herrenregal erhält keine Ergänzungen.

V.

Erst im 8. Jh. kehren die dort vertretenen Autoren gerade in Gallien im Zuge der ,karolingischen Renaissance' ins Zentrum des kulturellen Interesses zurück, nicht zuletzt angemahnt durch die wieder aktuelle Lektüre von Hieronymus' De viris illustribus und der Institutiones des Cassiodor. Damit ist die erneute Etablierung

57 Gennadius ergänzte Hieronymus' De viris illustribus um weitere 101 bzw. 103 Autoren. Zur Frage geographischer Vorlieben s. Barthold 2010, $127 \mathrm{f}$. 
eines grammatisch-rhetorischen Sprachstils und die Rückkehr spätantiken inhaltlichen Kulturwissens neben der etablierten lateinischen literarischen Kultur verbunden. Die alten Regalgenossen der ehemaligen christlichen Laienkultur aus dem Herrenregal werden von Klerikern zurückgeholt, ohne dass die einstigen sozialen Bedingungen wiederhergestellt würden. Pomerius, der von Caesarius verleugnete Grammatiklehrer, kommt in Klerikerkreisen wieder zu Ehren und die Nachfolger des Caesarius müssen sich seiner nicht schämen ${ }^{58}$ Zugleich kehren in der aktuellen literarischen Produktion wieder intertextuelle Bezüge mit antiken und patristischen Autoren, eine neue Themenvielfalt und auch eine rudimentäre römische historische Perspektive zurück. ${ }^{59}$ Der klassische Stil wird im Sinne einer neuen norma rectitudinis favorisiert. Das Kirchenväterstudium führt nämlich zum sprachlichen Hintergrund dieser klassisch gebildeten Autoren und damit zugleich zur Grammatikerlektüre unter anderem des von Gregor verachteten Donat. Dies verschafft Horaz, Vergil, Cicero und Terenz als Normautoren des klassischen Stils wieder ein Heimatrecht im karolingischen Wissens- und Lebenskosmos. Ständig wurden die Leser auf diese Garanten des kulturellen Hintergrunds der Kirchenväter hingewiesen. So schreibt Alcuin 799 in einem an Karl den Großen gerichteten Brief:

Legitur quendam veterum dixisse poetarum, cum de laude imperatorum Romani regni, si rite recordor, cecinisset, quales esse debuissent, dicens: Parcere subiectis et debellare superbos [Verg. Aen. 6, 853] quem versiculum beatus Augustinus in libro de civitate dei [Aug. civ. 1,6] multa laude exposuit. ${ }^{60}$

Man liest, dass einer der alten Dichter, als er, wenn ich mich recht erinnere, zum Ruhme der Kaiser des Römischen Reiches ein Gedicht verfasste, gesagt habe - er sprach nämlich darüber, wie sie sein sollten: Schonen die Unterworfenen und bekämpfen die Hochmütigen. Diesen Vers behandelte in großartiger Weise der Heilige Augustinus in einem Buch seines Werks De civitate dei.

Die Kirchenväter standen bei Sidonius im Herrenregal. Das wiedererwachte Interesse an ihnen kommt ihren Regalgenossen, den klassischen Bildungsautoren, zugute, die auf diese Weise in eine erweiterte gallisch-karolingische literarische Kultur reintegriert werden. Dies gilt auch für die Gemeinschaft verschiedener Autoren im Codex. ${ }^{61}$ Nebeneinander und in derselben Schrift, der karolingischen Minuskel, werden die römischen Autoren mit den christlichen abgeschrieben, ja in Miscellanhandschriften zusammengebunden. Auch kodikologisch wird die

58 Devisse 1970, 285-295.

59 Eigler 2003, $271 \mathrm{ff}$.

60 Alcuin epist. 178.

61 Bischoff 1975. 
Wiedergewinnung der Regalgemeinschaft dokumentiert. Die Regula Benedicti steht äußerlich in der Bibliothek von Tours genauso da wie die Aeneis Vergils. ${ }^{62}$

In der karolingischen Renaissance erlebt Gallien als Literaturlandschaft eine der Spätantike vergleichbare Blüte. Allerdings bedeutet diese Epoche zugleich auch das Ende der Literaturlandschaft Gallien. Die durch die Entwicklung der gallisch-karolingischen Schriftkultur zum europäischen Phänomen verbundene Entgrenzung macht nun die fränkische „Randkultur ${ }^{\text {“63 }}$,global“, kehrt also den Regionalisierungsprozess um. Der gallische Heilige Martin z.B. wird europaweit bekannt. Zugleich aber erfolgt ein wesentlicher Teil der Überlieferung regionaler Literatur aus anderen Räumen gerade im gallischen Bereich. Bedas, Gregors des Großen und Isidors Schriften verdanken ihre europaweite Prominenz der karolingischen Rezeption. Die europäische Karriere der gallischen Literaturlandschaft bedeutete auch deren Ende.

\section{Literaturverzeichnis}

\section{Primärliteratur}

Alcuinus, Epistulae: Epistolae Karolini aevi, Bd. 2, rec. Ernst Dümmler (MGH Epp. 4), Berlin 1895.

Ambrosius, De virginitate (liber unus): Sancti Ambrosii Mediolanensis episcopi opera omnia, accurante et denuo recognoscente Jacques-Paul Migne, Bd. 2 (PL 16), Paris $1882,266-302$.

Arator, De Actibus Apostolorum: Aratoris subdiaconi de actibus apostolorum, rec. Arthur Patch McKinlay (CSEL 72), Wien 1951.

Augustinus, De civitate Dei: Sancti Aurelii Augustini episcopi de civitae Dei libri XII, rec. Emanuel Hoffmann (CSEL 40/1-2), Wien u. a. 1899/1900.

Caesarius Arelatensis, Sermones: Sancti Caesarii Arelatensis sermones recogniti studio et diligentia Germain Morin OSB, 2 Bde. (CCSL 103-104), Turnhout ${ }^{2} 1953$.

Gregorius Magnus, Epistulae: Gregorii I papae registrum epistolarum, ed. Paul Ewald und Ludwig M. Hartmann, 2 Bde. (MGH Epp. 1-2), Berlin 1891-1899.

Gregorius Turonensis, Libri Historiarum decem (=Historia Francorum):

Gregorii episcopi Turonensis libri historiarum X, ed. Bruno Krusch und Wilhelm Levison (MGH SS rer. Merov. 1, 1), Hannover ${ }^{2} 1951$.

Gregor v. Tours, Historiarum libri decem - Zehn Bücher Geschichten. Auf Grund der Übersetzung W. Giesebrechts neu bearbeitet von Rudolf Buchner, Bd. 1 (Ausgewählte Quellen zur deutschen Geschichte des Mittelalters 2), Darmstadt, 1970.

Hieronymus, Sophronius Eusebius, Epistulae: Sancti Eusebii Hieronymi opera, Bd. 1, 1-3, ed. Isidor Hilberg (CSEL 54-56), Wien ${ }^{2} 1996$.

62 Nun konnte ein Kleriker tun, was Gregor dem Desiderius verwehrt hatte, nämlich zur gleichen Zeit Gott preisen und die Klassiker lesen. Lupus von Ferrières schrieb z.B. Cicero und Augustinus ab und kommentierte beide.

63 Hauck 1967. 
Isidor von Sevilla, Origines: Isidori Hispalensis episcopi etymologiarum sive originum libri XX, recogn. brevique adnotatione critica instr. Wallace M. Lindsay, Oxford 1987.

Orosius, Historia adversus paganos: Orose, Histoires (Contre les Païens). Texte établi et trad. par Marie-Pierre Arnaud-Lindet, Paris 1990-1991.

Sidonius Apollinaris, Carmina: Sidoine Apollinaire, Euvres, Bd. 1: Poèmes. Texte établi et traduit par André Loyen, Paris 1960.

Sidonius Apollinaris, Epistulae: Sidoine Apollinaire, Euvres, Bd. 2-3: Lettres. Texte établi et traduit par André Loyen, Paris 1970.

Sulpicius Severus, Chronica: Sulpicii Severi libri qui supersunt, rec. et commentario critico instr. Carolus Halm (CSEL 1), Wien 1866 (ND Hildesheim 1983), 3-105.

Ders., Dialogi: Sulpicii Severi libri qui supersunt, rec. et commentario critico instr. Carolus Halm (CSEL 1), Wien 1866 (ND Hildesheim 1983), 152-216.

Venantius Fortunatus, Carmina: Venance Fortunat, Euvres, Bd. 1-3: Poèmes. Texte établi et traduit par Marc Reydellet, Paris 1994-2004.

XII Panegyrici Latini, recogn. brevique adnotatione critica instr. Roger A. B. Mynors, Oxford 1964

\section{Sekundärliteratur}

Angenendt (1990): Arnold Angenendt, Das Frühmittelalter. Die abendländische Christenheit von 400 bis 900 , Stuttgart.

Banniard (1985): Michel Banniard, „Théorie et pratique de la langue et du style chez Alcuin: Rusticité feinte et rusticité masquée“, Francia 13, 579-601.

Barnes (1982): Timothy D. Barnes, The New Empire of Diocletian and Constantine, Cambridge/London.

Barthold (2010): Claudia Barthold, Hieronymus. De viris illustribus, Mülheim.

Berschin (1987): Walter Berschin, Eremus und Insula, St. Gallen und die Reichenau im Mittelalter. Modell einer lateinischen Literaturlandschaft, Wiesbaden.

Berschin (1988): Walter Berschin, Biographie und Epochenstil im lateinischen Mittelalter II. Merowingische Biographie. Italien, Spanien und die Inseln im frühen Mittelalter, Stuttgart.

Bischoff (1975): Berhard Bischoff, „Paläographie und Frühmittelalterliche Klassikerüberlieferung“, in: La cultura antica nell' occidente latino dal VII all'XI secolo. Settimane di studio del centro Italiano di studi sull' alto medioevo (14-18 aprile 1974), Spoleto, 59-87.

Brunhölzl (1975): Franz Brunhölzl, Geschichte der lateinischen Literatur des Mittelalters, München.

Cavallo (1978): Guglielmo Cavallo, „La circolazione libraria all'età di Giustiniano”, in: Gian G. Archi (Hg.), L'imperatore Giustiniano. Storia e mito (Giornate di studio a Ravenna, 14-16 ottobre), Mailand, 201-236.

Cavallo (1987): Guglielmo Cavallo, „Dallo scriptorium senza bibliotheca alla bibliotheca senza scriptorium“, in: Giovanni Pugliese Carratelli (Hg.), Dall'eremo al cenobio. La civiltà monastica in Italia dalle origini all'età di Dante, Mailand, 331-422.

Cavallo (1999): Guglielmo Cavallo, „Vom Volumen zum Codex. Lesen in der römischen Welt", in: Roger Chartier u. Guglielmo Cavallo (Hgg.), Die Welt des Lesens. Von der Schriftrolle zum Bildschirm, Frankfurt a. M./New York, 97-133.

Cencetti (1978): Giorgio Cencetti, Paleografia Latina, Rom (ND $\left.{ }^{2} 1958\right)$. 
Chadwick (1955): Nora K. Chadwick, Poetry and Letters in Early Christian Gaul, London.

Devisse (1970): Jean Devisse, „L'influence de Julien Pomère sur les clercs carolingiens“, RHEF 61, 285-295.

Drinkwater (1983): John F. Drinkwater, Roman Gaul. The Three Provinces, 58 BC-AD 260, London/Canberra.

Drinkwater (1987): John F. Drinkwater, The Gallic Empire. Separatism and Continuity in the North-Western Provinces of the Roman Empire A.D. 260-274, Stuttgart (Historia Einzelschriften 52).

Eigler (2003): Ulrich Eigler, Lectiones vetustatis. Römische Literatur und Geschichte in der lateinischen Literatur der Spätantike, München (Zetemata 115).

Eigler (2006): Ulrich Eigler, „Konstantin und die Literatur“, in: Alexander Demandt u. Joseph Engemann (Hgg.), Konstantin der Große. Geschichte - Archäologie - Rezeption, Trier (Schriftenreihe des Rheinischen Landesmuseums Trier 32), 61-67.

Engels u. Hofmann (1997): Lodewijk J. Engels u. Heinz Hofmann, „Literatur und Gesellschaft in der Spätantike“, in: Lodewijk J. Engels u. Heinz Hofmann (Hgg.), Neues Handbuch der Literaturwissenschaft 4: Spätantike, Wiesbaden, 29-88.

Ewig (1976): Eugen Ewig, Spätantikes und Fränkisches Gallien, München (Beihefte der Francia 3/1).

Fontaine (1980): Jacques Fontaine, „Valeures antiques et valeurs chrétiennes dans la spiritualité des grands proprietaires terriens à la fin du $\mathrm{IV}^{\mathrm{e}}$ siècle occidental", in: Jacques Fontaine, Etudes sur la poésie latine tardive d'Ausone à Prudence, Paris, 241-265.

Gemeinhardt (2007): Peter Gemeinhardt, Das lateinische Christentum und die antike pagane Bildung, Tübingen (Studien und Texte zu Antike und Christentum 41).

Gualandri ('1993): Isabella Gualandri, „Per una geografia della letteratura Latina“, in: Guglielmo Cavallo, Paolo Fedeli u. Andrea Giardina (Hgg.), Lo spazio letterario di Roma antica II. La circolazione del testo, Rom, 469-505.

Haarhof (1920): Theodore J. Haarhof, Schools of Gaul, Oxford.

Hauck (1967): Karl Hauck, „Von einer spätantiken Randkultur zum mittelalterlichen Europa“, Frühmittelalterliche Studien 1, 3-93.

Heinzelmann (1976): Martin Heinzelmann, Bischofsherrschaft in Gallien. Zur Kontinuität römischer Führungsschichten vom 4. bis zum 7. Jahrhundert. Soziale, prosopographische und bildungsgeschichtliche Aspekte, München (Francia Beihefte 5).

Herrin (1987): Judith Herrin, The Formation of Christendom, Princeton.

Holtkamp (1969): Dirk Holtkamp, Die Bildung der Herrscher im Urteil kaiserzeitlicher Historiker, Konstanz.

Jochum (1999): Uwe Jochum, Kleine Bibliotheksgeschichte, Stuttgart.

Katz (1945): Peter Katz, „The early christians' use of codices instead of rolls“, The Journal of Theological Studies 46, 63-65.

König (1981): Ingomar König, Die gallischen Usurpatoren von Postumus bis Tetricus, München (Vestigia 31).

Krön (1997): Martin Krön, Das Mönchtum und die kulturelle Tradition des lateinischen Westens, München.

Ludwig (1977): Walter Ludwig, „Die christliche Dichtung des Prudentius und die Transformation der klassischen Gattungen", in: Christianisme et formes littéraires de l'antiquité tardive en occident, Genf, 303-363 (Entretiens sur l'antiquité classique 23).

Manguel (2000): Alberto Manguel, Eine Geschichte des Lesens, Hamburg. 
Mathisen (1981): Ralph W. Mathisen, „Epistolography, Literary Circles and Family Ties in Late Roman Gaul", Transactions of the American Philological Association 111, 95-109 (wiederabgedruckt in: Mathisen 1991, 13-27).

Mathisen (1988): Ralph W. Mathisen, „The Theme of Literary Decline in Late Roman Gaul“, Classical Philology 83, 45-52 (wiederabgedruckt in: Mathisen 1991, 45-52).

Mathisen (1991): Ralph W. Mathisen, Studies in the History, Literature and Society of Late Antiquity, Amsterdam.

Muhlberger (1992): Steven Muhlberger, „Looking back from mid-century: The gallic Chronicler of 452 and the Crisis of Honorius' Reign“", in: John F. Drinkwater u. Hugh Elton (Hgg.), Fifth Century Gaul: A Crisis of Identity?, Cambridge, 28-37.

Opelt (1978): Ilona Opelt, „Das Carmen de laudibus Domini als Zeugnis des Christentums bei den Galliern“, Romanobarbarica 3, 159-166.

Piacente (1998): Luigi Piacente, „Sopravvivenze dei classici: i logistorici di Varrone”, Invigilata Lucernis 20, 191-199.

Prinz (1980): Friedrich Prinz, Askese und Kultur. Vor- und frühbenediktinisches Mönchtum an der Wiege Europas, München.

Prinz ( $\left.{ }^{2} 1988\right)$ : Friedrich Prinz, Frühes Mönchtum im Frankenreich, Darmstadt.

Riché (1976): Pierre Riché, Education and Culture in the Barbarian West, Columbia.

Roberts (1970): Colin H. Roberts, ,Books in the Graeco-Roman World and in the New Testament", in: The Cambridge History of the Bible I, Cambridge.

Santelia (2000): Stefania Santelia, „Sidonio Apollinare ed i bybliopolae“, in: Invigilata lucernis 22, 217-239.

Scheibelreiter (1999): Georg Scheibelreiter, Die barbarische Gesellschaft. Mentalitätsgeschichte der europäischen Achsenzeit 5.-8. Jh., Darmstadt 1999.

Schierl (2009): Petra Schierl, „Tu casti rectique tenax. Gottes- und Kaiserlob in den Laudes Domini “, in: Henriette Harich-Schwarzbauer u. Petra Schierl (Hgg.), Lateinische Poesie der Spätantike (Internationale Tagung Castelen bei Augst, 11.-13. Oktober 2007), Basel, 129-158.

Stroheker (1965): Karl Friedrich Stroheker, Germanentum und Spätantike, Zürich/Stuttgart.

Vielberg (2006): Meinolf Vielberg, Der Mönchsbischof von Tours im, Martinellus : Zur Form des hagiographischen Dossiers und seines spätantiken Leitbilds, Berlin (Untersuchungen zur spätantiken Literatur und Geschichte 79).

Zelzer (1997): Michaela Zelzer, „Die Briefliteratur“, in: Lodewijk J. Engels u. Heinz Hofmann (Hgg.), Neues Handbuch der Literaturwissenschaft 4: Spätantike, Wiesbaden, 321-353. 



\title{
Freundschaften wider den Verfall
}

\author{
Gemeinschaftsbildung und kulturelle Selbstverortung \\ im Briefwechsel des Ruricius von Limoges
}

\author{
Gernot Michael Müller
}

I.

Als er von seinem Lyoneser Mitbruder Constantius zur Herausgabe seiner Briefe aufgefordert worden sei, ${ }^{1}$ habe ihn dieser - offensichtlich um der Bitte an den Freund mehr Gewicht zu verleihen - an zwei große Vorbilder gemahnt, denen er bei der gebotenen Überarbeitung seiner Abschriften und deren anschließender Zusammenfassung zu einem Buch nacheifern solle. Richtschnur sollten ihm Quintus Symmachus und Gaius Plinius sein, an deren Stil und Kunstfertigkeit er sich orientieren möge. ${ }^{2}$ So beschreibt Sidonius Apollinaris ${ }^{3}$ zu Beginn seiner Briefsammlung ${ }^{4}$ deren Anlass und gewünschten Verständnishorizont, wobei er

1 Zur Biographie des Constantius von Lugdunum s. PLRE 4, 1 (1900), 1103f. (Jülicher) sowie Köhler 1995, 100f. In Sidon. epist. 3, 2, 3 wird er als religione venerabilis geehrt, in Sidon. epist. 2, 10, 3 als herausragender Dichter tituliert, der für eine neuerbaute Kirche in Lyon hexametrische Tituli für den Altar verfasst habe. Zudem hat er eine Biographie des um 448 verstorbenen Bischofs Germanus von Auxerre verfasst (Vita S. Germani Autisidoriensis). Ob er später Bischof von Lyon war, ist unsicher.

2 Zur Wertschätzung, die Sidonius Apollinaris, um den es hier geht, dem Symmachus und dessen Korrespondenz entgegengebracht hat, s. Matthews 1984, 64f. Die von Constantius vorgenommene Verbindung von Symmachus und Plinius d. J. stellt auch Macrobius her (vgl. ebd.). In der Tat hat Symmachus' Sohn die immense Briefsammlung seines Vaters postum in zehn Büchern herausgegeben, wobei das letzte Buch mit dessen Relationes öffentliche Korrespondenz enthält. Damit hat sich Symmachus' Sohn sichtlich die Korrespondenz des Plinius zum Vorbild genommen.

3 Zu Vita und Euvre des Sidonius Apollinaris s. die ältere Arbeit von Stevens 1933 sowie Gualandri 1979, 1-33 (zu seiner literarischen Technik ebd., 35-74); Kaufmann 1995, 4164 und vor allem Harries 1994, die Sidonius' Leben und literarisches Schaffen als paradigmatisch für die ereignis- und kulturgeschichtliche Entwicklung des 5. Jh.s präsentiert.

4 Zu Entstehung und Veröffentlichung von Sidonius' Briefsammlung s. die zusammenfassenden Bemerkungen in Köhler 1995, 8f. Allgemein wird angenommen, dass die Bücher 1 bis 7 vor Sidonius' Rückkehr aus dem Exil im Jahre 477 (s. dazu Harries 1994, 238-242), die Bücher 8 und 9 danach erschienen sind. Uneinigkeit besteht über die Edition des ersten 
zugleich mit dem Hinweis auf das Anliegen des Freundes und Mitbruders Constantius implizit zu erkennen gibt, dass er den von diesem gewünschten Wettbewerb mit den genannten Vorbildern auch tatsächlich aufzunehmen gedenkt. Denn mit dem Beginn seiner ersten Epistel spielt Sidonius in gekonnter Variation auf den Eingang des ersten Pliniusbriefs an Septicius an, so dass sein Widmungsschreiben an Constantius raffiniert Anspruch und dessen erste Einlösung gleichermaßen formuliert: ${ }^{5}$

Diu praecipis, domine maior, summa suadendi auctoritate, sicuti es in his quae deliberabuntur consiliosissimus, ut, si quae mihi litterae paulo politiores varia occasione fluxerint, prout eas causa, persona, tempus elicuit, omnes retractatis exemplaribus enucleatisque uno volumine includam, Quinti Symmachi rotunditatem, Gai Plinii disciplinam maturitatemque vestigiis praesumptuosis insecuturus.

Schon seit langem, verehrter Herr, schlagt Ihr mir mit stärkster Überzeugungskraft vor - denn Ihr seid ja im zur Verhandlung stehenden Gegenstand der beste Ratgeber -, ich solle von meinen Briefen, die aus unterschiedlichem Anlass entstanden sind, wie es Gegenstand, Person und Umstände erforderten, die ein wenig sorgfältiger geschriebenen, nachdem ich die Abschriften mir noch einmal vorgenommen und sie überarbeitet hätte, allesamt in einem Buch zusammenfügen; dabei solle ich der gerundeten Rede des Quintus Symmachus und der reifen Kunst des Gaius Plinius mit kühnen Schritten nacheilen.

Buches; die Auffassungen schwanken zwischen einer Frühdatierung um 469, mithin vor Antritt des Bischofsamts, und ebenfalls 477 wie die folgenden sechs Bücher. Auf jeden Fall geht aus dem oben folgenden Zitat (vgl. Anm. 5) hervor, dass Sidonius zunächst nur ein Buch ediert hat (uno volumine). Allerdings kündigt er am Ende des ersten Briefs an, dass er zügig weitere Bücher folgen lassen werde, wenn sich das erste Briefbuch als ähnlich erfolgreich wie seine Dichtungen erweisen sollten (Sidon. epist. 1, 1, 4: Porro autem super huiusmodi opusculo tutius conticueramus, contenti versuum felicius quam peritius editorum opinione, de qua mihi iam pridem in portu iudicii publici, post lividorum latratuum Scyllas enavigatas, sufficientis gloriae ancora sedet. Sed si et hisce deliramentis genuinum molarem invidia non fixerit, actutum tibi a nobis volumina numerosiora, percopiosis scaturientia sermocinationibus multiplicabuntur). In der Tat bilden die Bücher 1 bis 7 eine Einheit, welche dadurch angezeigt wird, dass der letzte Brief des siebten Buches ebenfalls eine Widmung an Constantius enthält, die Dedikation an diesen folglich eine Klammer um diese Buchfolge bildet. Dass Sidonius' Briefe eifrig gelesen wurden, bezeugt dieser selbst (vgl. etwa epist. 5, 1, 1). Auch Ruricius von Limoges, um den es im Folgenden vor allem gehen wird, gibt seine Achtung gegenüber Sidonius' Briefkunst deutlich zu erkennen (vgl. unten Anm. 18).

5 Sidon. epist. 1, 1, 1 (dieses und alle folgenden Zitate aus Sidonius' Briefen folgen der Ausgabe von Loyen 1970; die Übersetzungen dieses und des folgenden Zitats entstammen Köhler 1995). Vgl. hierzu Plin. epist. 1, 1, 1: Frequenter horatus es, ut epistulas, si quas paulo curatius scripsissem, colligerem publicaremque. Tatsächlich war Sidonius mit der späteren Erweiterung seiner Briefsammlung auf neun Bücher bemüht, diese auch kompositorisch der Korrespondenz des Plinius anzugleichen. Anders als Symmachus' Sohn und womöglich auch Ambrosius von Mailand (s. u. Anm. 64), die diesem auch durch ein zehntes Buch mit politischer Korrespondenz nacheiferten, hat sich Sidonius freilich nur an die neun Bücher Privatkorrespondenz des Plinius gehalten. 
Aber mehr noch: Sidonius baut den literarhistorischen Verweiszusammenhang, in dessen Horizont Constantius die Veröffentlichung seiner Briefe gestellt wissen will, selbst noch weiter aus, indem er mit Cicero und dem ansonsten nicht besser bekannten Iulius Titianus - offensichtlich einem Nachahmer des Marcus Cornelius Fronto - weitere Bezugsgrößen für seine Korrespondenz anführt. Während der erstgenannte Sidonius als der unerreichbare Gipfelpunkt briefstellerischen Schaffens gilt, ${ }^{6}$ muss der zweite als Beispiel dafür herhalten, wie man am Vorbild des großen Briefeschreibers aus Arpinum scheitern könne. Entsprechend dient ihm dieser als Negativfolie, um die eigene Unsicherheit und die Angst vor dem Scheitern bei der Herausgabe seiner Briefe wirkungsvoll zum Ausdruck zu bringen: ${ }^{7}$

Nam de Marco Tullio silere melius puto, quem in stilo epistulari nec Iulius Titianus sub nominibus inlustrium feminarum digna similitudine expressit; propter quod illum ceteri quique Frontonianorum utpote consectaneum aemulati, cur veternosum dicendi genus imitaretur, oratorum simiam nuncupaverunt. Quibus omnibus ego immane dictu est quantum semper iudicio meo cesserim quantumque servandam singulis pronuntiaverim temporum suorum meritorumque praerogatiuam.

Freilich, von Marcus Tullius sollte ich besser schweigen, dessen Briefe nicht einmal Iulius Titianus unter dem Namen berühmter Frauen mit angemessener Ähnlichkeit nachzubilden vermochte. Die übrigen Frontonianer, die natürlich in Konkurrenz zu ihrem Kollegen standen, nannten ihn dann auch deshalb, weil er sich nach ihrer Meinung einen hoffnungslos veralteten Stil zum Vorbild genommen habe, den Affen unter den Rednern. Es lässt sich kaum in Worte fassen, wie weit ich all diesen Männern nach meinem Urteil immer unterlegen war und wie sehr ich stets dafür plädiert habe, dass jedem einzelnen der Vorrang einzuräumen sei, der ihm nach seiner Epoche und nach seinen Verdiensten zukommt.

In Kombination von Erinnerung an die Ermahnungen des Freundes und eigener Rückschau auf einschlägige Vorgänger ruft Sidonius raffiniert die zentralen Eckpfeiler römischer Epistolographie auf und ordnet sein eigenes Editionsprojekt in die von diesen begründete Traditionslinie ein. Wenngleich diese Bezugnahme in der ostentativen Bescheidenheitsbekundung mündet, den genannten Briefstellern in keinster Weise gewachsen zu sein, bedeutet die Erwähnung der illustren Reihe Cicero, Plinius, Fronto - dieser über die Erwähnung seiner Nachahmer - und Symmachus doch mehr und dient auch der eigenen kulturellen Selbstverortung. ${ }^{8}$ Mit der Herausgabe seiner Briefsammlung beabsichtigt Sidonius nicht nur, Einblick in Themen und Adressaten seiner Korrespondenz zu geben. Sein Bestreben ist zudem, sich hierdurch als Erben und Fortsetzer einer bedeutenden römischen

6 Cicero, der seine Korrespondenz freilich nicht selbst herausgegeben, dies aber durchaus beabsichtigt hat, ist bereits für Plinius unerreichbares Vorbild für dessen Korrespondenz. Zu Plinius' eigener Selbstdarstellung in dessen Briefouvre, die Sidonius sichtlich kontinuiert, s. Krasser 1993; Ludolph 1997; Radicke 1997 und Gauly 2008.

7 Sidon. epist. 1, 1, 2 (Übersetzung aus Köhler 1995).

8 Vgl. Harries 1994, $207 f$. 
Tradition in Szene zu setzen. Und in dieser Zielsetzung weiß er sich ganz offensichtlich mit seinem Freund verbunden. ${ }^{9}$ Denn nach den Worten des Sidonius sei es ja Constantius gewesen, der die von jenem sodann bereitwillig aufgegriffene Bezugnahme auf die großen Namen der römischen Epistolographie zunächst angestoßen habe. ${ }^{10}$

Eine solche Übereinstimmung in der Bedeutung der literarischen Tradition als Referenzpunkt und Messlatte der eigenen Korrespondenz scheint Sidonius mit einem anderen, ihm gleichermaßen eng verbundenen Briefpartner, Ruricius von Limoges nämlich, ${ }^{11}$ nicht gefunden zu haben. ${ }^{12}$ Dabei zeugt ein Brief an diesen durchaus vom Optimismus des Sidonius, dass sich sein Adressat für eine vergleichbare Verortung seiner literarischen Kompetenz als empfänglich erweisen könnte, wie er diese in Verbindung mit Constantius für seine eigene Korrespondenz vorgenommen hatte. Ausgangspunkt des Schreibens ist Sidonius' Freude darüber, dass er sich mit Ruricius in der gemeinsamen Wertschätzung der Briefstellerei verbunden wissen dürfe, woraufhin er zu einer Würdigung der sprachlichen Gewandtheit seines Adressaten ansetzt. Der einzige Fehler, den sich Rurici-

9 Indem er ihn ehrend als consiliosissimus bezeichnet, qualifiziert Sidonius Constantius als literarischen Kenner, und dies nicht nur in Bezug auf die Literatur selbst, sondern offensichtlich auch im Hinblick auf die möglichen Funktionen ihrer Veröffentlichung.

10 Dass sich spätantike Autoren aus Gallien allgemein als Fortsetzer der literarischen Tradition inszenieren und sich dabei gerne in eine Linie mit den bedeutenden Autoren der klassischen Literatur stellen, bedeutet Mathisen 1988, 48; auf den kompetitiven Charakter dieses Rückgriffs verweist Egelhaaf-Gaiser 2010, 259.

11 Ruricius' Lebendaten sind nicht gesichert. Sie dürften aber zwischen den 440er Jahren und ca. 507 n. Chr. liegen. Bischof von Limoges wurde er Ende der 480er Jahre. Zu Ruricius' Vita und dessen Familie s. Hagendahl 1952, 5-7; Demeulenaere 1985, 305f. (Praefatio seiner Edition) und ausführlich Mathisen 1999, 19-49. Die jüngste Edition der Korrespondenz des Ruricius sowie der erhaltenen Briefe an diesen ist Demeulenaere 1985; dieser folgen die nachstehenden Zitate aus dem Ruricius-Briefwechsel. Eine englische Übersetzung der Briefe findet sich in Mathisen 1999.

12 Mathisen 1981 rekonstruiert für das Gallien des 5. und beginnenden 6. Jh.s zwei große Korrespondenznetzwerke, deren Mitglieder häufig durch enge verwandtschaftliche Beziehung verbunden waren (zu den familiären Bindungen zwischen den produktivsten Epistolographen der Epoche Sidonius, Avitus, Ruricius und Ennodius s. ebd., 97-104). Deren eines siedelt sich um Eucherius von Lyon an und besteht aus Briefpartnern, die wie dieser selbst für eine bestimmte Zeit in der Klostergemeinschaft von Lérins gelebt haben. Deren zweites findet seinen Mittelpunkt in Sidonius Apollinaris. Diesem gehört auch Ruricius von Limoges an (vgl. bes. ebd., 107; graphische Darstellung der familiären Beziehungen zwischen den wichtigsten Epistolographen im Gallien der besagten Zeit ebd., 109). In der Tat belegen neben dem im Folgenden zu besprechenden Brief weitere Schreiben den brieflichen Austausch zwischen Sidonius und Ruricius. Von der engen Verbindung zwischen den beiden zeugt auch, dass Sidonius das Epithalamium auf Ruricius' Hochzeit mit Hiberia verfasst hat (Sidon. carm. 11 mit der praefatio carm. 10). Hiberia stammte wahrscheinlich aus der gleichen gallorömischen Adelsfamilie, der Kaiser Eparchius Avitus (455-456 n. Chr.) angehörte. Damit wäre sie auch mit Sidonius Apollinaris verwandtschaftlich verbunden gewesen, da dieser mit Avitus' Tochter Papianilla verheiratet war (vgl. Mathisen 1999, 22f.). 
us erlaubt habe, sei inhaltlicher Natur gewesen, und zwar ein seiner Meinung nach unangemessenes Lob auf ihn. ${ }^{13}$ Indes vermag Sidonius auch diesen vermeintlichen Makel zugunsten seines Korrespondenzpartners umzudeuten. Hierzu wird er grundsätzlicher und belehrt diesen, dass es gerade Kennzeichen des herausragenden Redners sei, die Herausforderung schwieriger Gegenstände zu suchen. Denn nur diese böten die Gelegenheit, über sich hinauszuwachsen. Als Beleg für die Richtigkeit seiner Behauptung weiß Sidonius sodann mehrere exempla aus der römischen Literaturgeschichte anzuführen, nämlich Cicero, Plinius und Fronto. All diesen habe Ruricius erfolgreich nachgeeifert, indem er es im Vertrauen auf sein Können unternommen habe, einen so niedrigen Gegenstand wie ihn, Sidonius, lobend zu behandeln: ${ }^{14}$

Scaturrit mundus similibus exemplis: medicus in desperatione, gubernator in tempestate cognoscitur; horum omnium famam praecedentia pericula extollunt, quae profecto delitescit, nisi ubi probetur invenerit. Sic et magnus orator si negotium aggrediatur angustum, tunc amplum plausibilius manifestat ingenium. Marcus Tullius in actionibus ceteris ceteros, pro Aulo Cluentio ipse se vicit. Marcus Fronto cum reliquis orationibus emineret, in Pelopem se sibi praetulit. Gaius Plinius pro Attia Viriola plus gloriae de centumvirali suggestu domum rettulit, quam cum Marco Ulpio inconparabili principi conparabilem panegyricum dixit. Sic et ipse fecisti, qui, dum vis exercere scientiam tuam, non veritus es fore tibi impedimento etiam conscientiam meam. Quin potius supplicando meis medere languoribus neque per decipulum male blandientis eloquii aegrotantis adhuc animae fragilitatem gloriae falsae pondere premas. Sane cum tibi sermone pulchro uita sit pulchrior, plus mihi indulges, si mei causa orare potius uelis quam perorare. Vale.

Die Welt quillt über von derartigen Beispielen: Der Arzt gibt sich bei einer ausweglosen Krankheit, der Steuermann in einem Unwetter zu erkennen. Bestandene Gefahren steigern ihrer aller Ansehen, welches freilich im Verborgenen bleibt, wenn sich keine Gelegenheit findet, durch die es sich beweisen kann. So legt auch ein bedeutender Redner seine umfassende Begabung dann umso bewundernswerter an den Tag, wenn er sich einer intrikaten Aufgabe stellt. Marcus Tullius hat in seinen übrigen Gerichtsreden alle anderen, in jener für Aulus Cluentius hat er sich selbst übertroffen. Marcus Fronto ragte mit seinen übrigen Reden hervor, mit jener gegen Pelops hat er sich über sich selbst erhoben. Gaius Plinius brachte durch seine Verteidigung des Attia Viriola mehr Ruhm von der Rednertribüne des Centumviralgerichts nach Hause als durch seine Lobrede auf Marcus Ulpius [Traianus] und dies, obwohl diese dem Vergleich

13 Sidon. epist. 8, 10, 1 (= Epistulae ad Ruricium 9, 1-8): Esse tibi usui pariter et cordi litteras granditer gaudeo. Nam stilum vestrum quanta comitetur vel flamma sensuum vel unda sermonum, liberius assererem, nisi, dum me laudare non parum studes, laudari plurimum te vetares. Et quamquam in epistula tua servet caritas dulcedinem, natura facundiam, peritia disciplinam, in sola materiae tamen electione peccasti, licet id ipsum praedicari possit in voto, quod videris errasse in iudicio.

14 Sidon. epist. 8, 10, 2-4 (= Epistulae ad Ruricium 9, 17-29); die Übersetzungen dieses und der folgenden Zitate aus der Ruricius-Korrespondenz stammen vom Autor dieses Aufsatzes. 
mit dem unvergleichlichen Princeps standhielt. So hast es auch du getan: Um dein Können zu üben, hast du keine Bedenken getragen, dass dir mein schlechtes Gewissen hierfür hinderlich sein könnte. Vielmehr solltest du durch Gebete meine Schwachheit heilen und die Zerbrechlichkeit meiner krankenden Seele nicht durch die Last falscher Ruhmesbekundungen belasten, indem du sie durch eine unberechtigterweise schmeichelhafte Rede einfängst. Da dein Lebenswandel aber wahrlich noch schöner ist als deine Rede, würdest du meiner Sache mehr dienen, wenn du meinetwegen eher beten als reden wolltest. Leb wohl!

Zwar verweist Sidonius im Zusammenhang mit den drei von ihm erwähnten Autoren jeweils auf Reden, die diese gehalten haben. ${ }^{15}$ Dennoch sind mit diesen auch jene Briefsteller benannt, an denen er auf Einladung seines Freundes Constantius seine Korrespondenz gemessen wissen will. Und da Anlass für Sidonius' Verweis auf die drei herausragenden Reden ein Brief des Ruricius war, wird er mit diesem auch die durch die drei Namen verkörperte epistolographische Tradition im Blick gehabt haben. Nahegelegt wird eine solche Intention zudem dadurch, dass sogar eine Anspielung auf Symmachus nicht fehlt. Denn von diesem weiß Sidonius ein anderweitig nicht überliefertes Diktum zu referieren, durch das er Ruricius' Lob auf ihn einmal mehr als unangemessen erweisen kann: ${ }^{16}$

Ingentes praeconiorum titulos moribus meis applicas; sed si pudoris nostri fecisses utcumque rationem, Symmachianum illud te cogitare par fuerat: „Ut vera laus ornat, ita falsa castigat."

Unermessliche Lobesbekundungen zollst Du meinem Charakter; doch wenn Du unserem Schamgefühl Rechnung getragen hättest, hätte es dir gut angestanden, jenes Wort des Symmachus zu bedenken: „Wie wahres Lob eine Zierde ist, so kommt das falsche einem Tadel gleich.“

Zwar außerhalb der Reihe jener drei anderen Autoritäten erwähnt, denen sich Ruricius durch seinen Brief als ebenbürtig erwiesen habe, erweitert Symmachus diese dennoch auf jene vier Epistolographen, die sich Sidonius zusammen mit seinem Freund Constantius als Vorbilder für seine Briefsammlung erwählt hat. Damit liest er das von ihm kommentierte Schreiben des Ruricius im gleichen Horizont jener exempla römischer Briefkultur, die er zuvor für sich als verbindlich festgelegt hat. Die zu Beginn des Briefs an Ruricius zum Ausdruck gebrachte Verbundenheit mit diesem erschöpft sich für Sidonius offensichtlich nicht in einer allgemeinen Wertschätzung der Briefkommunikation als solcher. Darüber hinaus

15 Sidonius spielt auf Ciceros Rede Pro Cluentio aus dem Jahr 66 v. Chr. an, in der dieser Cluentius gegen den Vorwurf des Vatermordes verteidigte. Plinius berichtet von seiner Rede für Attia Viriola, welche von ihrem Vater enterbt worden war und die er vor den centumviri vertrat, in Plin. epist. 6, 33. Die andere angesprochene Rede des Plinius ist dessen berühmter Panegyricus auf Trajan. Die Pelops-Rede des Fronto wird ausschließlich an dieser Stelle erwähnt und kann daher nicht näher bestimmt werden.

16 Sidon. epist. 8, 10, 1 (= Epistulae ad Ruricium 9, 8-11). 
scheint er vom gemeinsamen Konsens über einen epistolographischen Traditionsrahmen auszugehen, vor dessen Hintergrund das Ruricius gespendete Lob erst seinen vollen Bedeutungsgehalt entfaltet.

Mit dieser Vermutung dürfte Sidonius jedoch ins Leere getroffen haben. Jedenfalls spielt Ruricius nirgendwo in seinem Briefwechsel auf das für dessen literarische Selbstverortung so grundlegende Quartett vorbildlicher Epistolographen an, wie er überhaupt darauf verzichtet, ein Referenzmodell für seine Korrespondenz zu benennen. ${ }^{17}$ An einer Inszenierung seines epistolographischen Schaffens als Fortsetzung einer ihm vorangehenden und durch bedeutende Namen geadelten literarischen Tradition scheint er im Gegensatz zu Sidonius generell nicht interessiert zu sein. ${ }^{18}$ Selbst sein von Sidonius hervorgehobenes stilistisches Können hat Ruricius für eine vergleichbare Indienstnahme ungenutzt gelassen. Zwar präsentieren sich seine Briefe durchweg als kunstvoll gestaltete Schriftstücke; ${ }^{19}$ auch zeigt er sich in einem Schreiben zufrieden darüber, dass seine Söhne eine gediegene rhetorische Ausbildung erhalten, und dokumentiert damit, dass er eine entsprechende Kompetenz für Menschen seines Standes als angemessen und notwendig erachtet. ${ }^{20}$ Für seine Selbstdarstellung zieht er daraus indes keine Konse-

17 Dieser Befund ist umso auffälliger, als Ruricius in seinen Briefen neben den zentralen christlichen Schriftstellern des 4. und beginnenden 5. Jh.s durchaus auch aus klassischen lateinischen Autoren zitiert (vgl. den Similienapparat in Demeulenaere 1985). Charakteristisch für Ruricius ist folglich, dass er sich in seiner Korrespondenz durchaus als literarisch hochgebildet präsentiert, daraus aber keine mit Sidonius' Selbststilisierung vergleichbare Programmatik ableitet. Auf Ruricius' Belesenheit verweisen die zahlreichen Nachrichten über den Austausch von Büchern in dessen Briefwechsel (vgl. Mathisen 1999, 54). Namentlich werden dort allerdings nur christliche Schriftsteller wie Cyprian, Augustinus, Ambrosius von Mailand und Hilarius von Poitiers genannt.

18 Freilich gibt Ruricius immer wieder zu erkennen, dass er Sidonius' Briefkunst selbst sehr schätzt. So zitiert er wiederholt aus dessen Briefen, beispielsweise in epist. 1, 4 an den Rhetor Hesperius (vgl. Anm. 20), dessen Beginn Sidon. epist. 4, 16, 1 wörtlich entspricht (vgl. Mathisen 1999, 53f. sowie den Similienapparat in Demeulenaere 1985, 318). Noch nach Sidonius' Tod hat Ruricius dessen Briefe eifrig gelesen und sich dabei eines eigenen Exemplars bedienen können, wie aus epist. 2, 36 an Sidonius' Sohn Apollinaris hervorgeht (vgl. Mathisen 1981, 108). Insofern erscheint Sidonius in Ruricius' Briefwechsel zumindest implizit als epistolographisches Modell und Vorbild (neben wenigen anderen wie etwa dem für Ruricius' spirituelle Entwicklung bedeutenden Faustus von Riez). Entscheidend ist jedoch, dass Ruricius diese Beziehung nicht ostentativ inszeniert und für eine literarische Standortbestimmung seiner Briefstellerei nutzt.

19 Zu Ruricius' Stil s. Mathisen 1999, 53-56 und Loyen 1943, 169-173. Die ausführlichste Untersuchung hierzu findet sich in Hagendahl 1952, freilich mit ähnlich pejorativen Wertungen wie bei Loyen. Hagendahl bewertet dabei Ruricius' wörtliche Übernahmen aus Briefen des Sidonius (vgl. Anm. 18) und des Faustus von Riez sowie aus anderen spätantiken Autoren in unhistorischer Weise als Plagiate (vgl. Hagendahl 1952, 12-31).

20 Die Rede ist von epist. 1, 3 an den Rhetoriker Hesperius, übrigens auch ein Vertrauter des Sidonius Apollinaris (vgl. Sidon. epist. 2, 10 und 4, 22), der einige Söhne des Ruricius wahrscheinlich Eparchius und Ommatius (vgl. Mathisen 1999, 105f.) - in der Redekunst unterrichtete. Ruricius betont dort, dass seine Söhne Gefahr liefen, ihren Adel zu verlieren, wenn sich diese Hesperius nicht zum Vorbild nähmen. Bei allem adulatorischen Unterton 
quenzen. Im Gegenteil grenzt er sich entschieden von einem Wirken durch guten Stil zugunsten gottgefälliger Werke ab und zeigt auf diese Weise an, dass er sich ganz bewusst von einem Selbstkonzept distanziert, wie es Sidonius ostentativ für sich reklamiert. ${ }^{21}$

In der Tat präsentiert sich Ruricius in seiner Korrespondenz zunächst ganz anders als sein älterer Bischofskollege aus dem benachbarten Clermont-Ferrand. ${ }^{22}$ Zwar ist zweifelhaft, ob die Anordnung der Briefe im einzigen Überlieferungsträ-

bezeugt diese Aussage für Ruricius doch deutlich ein ausgeprägtes aristokratisches Selbstverständnis, für das rhetorische und literarische Bildung offensichtlich von wesentlicher Bedeutung sind.

21 Vgl. etwa Ruric. epist. 2, 27 an Sidonius' Sohn Apollinaris. Anlass des Briefs ist Ruricius' Bitte an Apollinaris, dieser möge ihm schreiben, sooft sich ihm eine Gelegenheit dazu biete. Entsprechend verfahre Ruricius selbst, und dies, obwohl er lieber als anhänglich, aber ungebildet denn als witzig und beredt, aber ohne Glauben beurteilt werden möchte. Folglich beginnt der Brief (2, 27, 1-8): Quamlibet per diaconem Iustum non meruerim litteras benigni pectoris et facundi oris accipere, quibus et erudiretur ingenium et desiderium pasceretur, ego tamen, qui malo affectuosus rusticus, quam urbanus impius iudicari, scribendi opportunitatem mihi perire non passus sum, utpote qui mihi nolim, non dicam occasionem scribendi, sed nec videndi vos unius saltim horae spatium deperire. Immer wieder bezeichnet sich Ruricius in seinen Briefen als stilistisch wenig versierten Literaten, so beispielsweise auch zu Beginn der in Anm. 20 besprochenen Epistel 1, 3 an den Rhetor Hesperius, in der Ruricius die Bedeutung einer gediegenen rhetorischen Ausbildung für seine Söhne betont. Zwar handelt es sich hier zweifelsohne auch um Bescheidenheitstopik, durch die sich Ruricius selbst als rhetorisch höchst gebildet präsentiert. Aus der weiteren Rekurrenz solcher Aussagen im Briefœuvre des Ruricus lässt sich allerdings folgern, dass es diesem vor allem darum geht, ein entsprechendes Selbstbild von sich zu vermitteln. In diesen Kontext gehört auch, dass Ruricius seinen Bischofssitz Limoges gegenüber seinem Amtskollegen Caesarius von Arles als unbedeutende Stadt bezeichnet (vgl. Ruric. epist. 2, 33, 20-24). Damit beschreibt Ruricius einen zutreffenden Befund. Seine daran anschlieBende Bemerkung, es möge eher eine Stadt wegen ihres Bischofs bedeutend sein als umgekehrt, erweist sich aber einmal mehr als Plädoyer für ein Selbstkonzept, das gänzlich auf äußere Bedeutungszuschreibungen verzichtet: Erst deren Verzicht und eine diesbezügliche Bescheidenheit eröffnen die Möglichkeit, unmttelbar als Mensch und d. h. durch seine christliche Lebensführung zu wirken, welche ihn vor allem anderen für sein kirchliches Leitungsamt empfehlen sollen.

22 Zu Sidonius' Karriere als Bischof von Clermont s. Harries 1994, 169-242. Sidonius' Ordination hat freilich keinen Einfluss auf dessen literarisches Selbstbild. Mag auch der oben besprochene Brief 1, 1 vor seinem Aufstieg auf dortige Cathedra datieren, die anschließend verfasste Korrespondenz und nicht zuletzt Brief 9, 16, mit dem er sein Briefœuvre endgültig beschließt, bezeugen Sidonius' anhaltendes Interesse an einer ebenso intensiven wie wahrnehmbaren Beziehungsstiftung zwischen seinem Schreiben und der literarischen Tradition (zu den programmatischen intertextuellen Anspielungen von epist. 9, 16 an Plinius d. J., Statius und Horaz vgl. Egelhaaf-Gaiser 2010). Zwar deutlicher, aber dennoch einziger Reflex auf die Ordination in seinem Euvre ist seine Abkehr von der Dichtung, auf welche der Auftaktbrief in 1, 1, 4 (vgl. oben Anm. 4) anspielt. Vor diesem Hintergrund erscheint der Brief für Sidonius als adäquate Artikulationsform des Bischofs, um seinem literarischen Selbstverständnis weiterhin Ausdruck zu verleihen, ohne dieses auch nur in Ansätzen preisgeben zu müssen. 
ger auf ihn selbst zurückgeht. ${ }^{23}$ Somit ist die programmatische Hinwendung zu einer christlichen Lebensweise, von der Ruricius in den ersten zwei Briefen gegenüber seinem geistlichen Mentor Faustus von Riez Zeugnis ablegt, ${ }^{24}$ ebenso wie die das erste Buch abschließende Bestärkung des eigenen Sohnes Ommatius, seinen Glaubensweg vertiefend fortzusetzen, ${ }^{25}$ in ihrer herausgehobenen Positionierung innerhalb der Briefsammlung als Rahmen um das erste Buch womöglich nicht authentisch. Doch auch wenn diese nicht auf den Autorwillen zurückgeht, porträtiert die Korrespondenz des Ruricius trotz ihres weitgehend privaten Charakters in verschiedenen Briefen einen für das Amt eines Oberhirten vorbildlich geeigneten Christen, ${ }^{26}$ der in ostentativer Bescheidenheit die seelsorglichen Belange seiner Adressaten stets im Blick hat oder aber im vertrauten Austausch mit seinen Mitbrüdern auf den benachbarten Bischofsstühlen steht. ${ }^{27}$ Demgegenüber

23 Der Briefwechsel des Ruricius von Limoges ist allein in einem spätestens seit 1461 in St. Gallen befindlichen Kodex (Codex Sangallensis 190) überliefert, der im späten 8. oder beginnenden 9. Jh. im südwestdeutschen Raum geschrieben worden ist und ausschließlich Schriften aus dem südgallischen Raum enthält; zu diesem Kodex und der Überlieferung des Ruricius-Briefwechsels s. Demeulenaere 1985, 308f.; Mathisen 1998; Mathisen 1999, 63-76 mit Hinweisen zu weiterer Literatur und einschlägigen Bibliothekskatalogen und knapp Mathisen 2001, 104f. In 1999, 71-74 erschließt Mathisen als Vorlage für den Codex Sangallensis eine Sammlung von Ruricius-Briefen, die zunächst in dessen Familie zirkuliert habe, bevor sie Mitte des 7. Jh.s im Umfeld des Desiderius von Cahors (zu diesem s. den Beitrag von Ralph W. Mathisen in diesem Band) mit dessen Briefœuvre verbunden worden sei, das ebenfalls ausschließlich durch den besagten St. Galler Kodex überliefert ist. Zur Frage nach dem Interesse an der Ruricius-Korrespondenz in frühkarolingischer Zeit s. ebd., 74-76.

24 Faustus von Riez, ursprünglich aus Britannien stammend, wurde nach einem längeren Lebensabschnitt im Inselkloster Lérins, dessen Abt er seit 434 war, um 460 Bischof von Riez. Sidonius Apollinaris dichtete auf ihn ein Eucharisticon (Sidon. carm. 16). Zur Theologie des Faustus und deren Rezeption bis in die Neuzeit s. Tibiletti 1981; vgl. auch Tibiletti 1986 zu den theologischen Kontroversen zwischen Provençalen - unter ihnen Faustus von Riez - und afrikanischen Theologen in der Nachfolge des Augustinus; zu seinen Predigten s. Griffe 1960.

25 Ruricius' Sohn Ommatius ist vor 490 zum Priester ordiniert worden (vgl. Ruric. epist. 2, 28 und 2, 58f.). Der letzte Brief des ersten Buches scheint noch vor Ommatius' Eintritt in den Klerikerstand zu datieren; vgl. Mathisen 1999, 131.

26 Ruricius' Ordination zum Bischof von Limoges dürfte in die Zeit kurz nach dem Tod Eurics am 28. Dezember 484 fallen, nachdem Ruricius' spiritueller Förderer Faustus von Riez aus dem Exil (ca. 477-485) zurückkehren konnte und die vakanten Bischofssitze in Aquitanien wieder besetzt wurden. In einem Brief des Faustus an Ruricius, der kurz nach seiner Rückkehr aus dem Exil datiert, deutet dieser an, dass Ruricius in das Bischofsamt aufgestiegen ist (Fausti epistula ad Ruricium 5, 17). Ruricius' Eintritt in den Klerus dürfte um 477 erfolgt sein. Hiervon zeugt ein weiterer Brief des Faustus an Ruricius, diesmal aus der Zeit seines Exils, in welchem der verbannte Bischof von Riez seine Freude über diese Entscheidung zum Ausdruck bringt (Fausti epistula ad Ruricium 2, 17-20); vgl. hierzu Demeulenaere 1985, 305 und Mathisen 1999, 33f. Zur Vermutung, dass es Sidonius Apollinaris war, der Ruricius mit Faustus in Verbindung gebracht habe, nachdem dieser ein ernsthaftes Interesse am Eintritt in den geistlichen Stand entwickelt hatte, s. ebd., 87.

27 Ein Großteil von Ruricius' Korrespondenzpartnern waren Mitbrüder im bischöflichen 
äußert sich Sidonius nirgendwo in seinem Briefwechsel über seinen Weg zum Episkopat, geschweige denn über einen dahinterstehenden Glaubensweg, wie überhaupt pastorale Fragen in seiner Korrespondenz praktisch keinen Ort haben. ${ }^{28}$

Damit stehen sich in den Briefwechseln des Sidonius Apollinaris und des Ruricius von Limoges offensichtlich zwei gänzlich unterschiedliche Formen der Selbstmodellierung gegenüber, und dies, obwohl es sich bei beiden um Korrespondenzen zweier Bischofskollegen handelt, die zudem einander familiär und durch freundschaftliche Wertschätzung verbunden waren. Während Sidonius der Wechsel in das hohe geistliche Amt nicht daran hindert, sich in seinen Briefen weiterhin als gewandten Literaten zu inszenieren und sich darin als Erben einer vor allem vorchristlichen literarischen Tradition zu präsentieren, ${ }^{29}$ scheint Ruricius dieser offensichtlich keine Bedeutung mehr beizumessen. Seinen Bezugsrahmen scheint er allein in den Grundsätzen einer christlichen Lebensführung und infolgedessen in der Heiligen Schrift als deren Grundlegung zu erblicken.

Doch auch wenn Ruricius seinen Briefwechsel bewusst nicht in die für Sidonius so zentrale Reihe der bedeutendsten epistolographischen Modellautoren der heidnischen Antike einordnet, ist dieser trotzdem nicht gänzlich frei von beziehungsstiftenden Verweisen auf die zumal vorchristliche Vergangenheit. Diese artikulieren sich allerdings verhaltener als bei Sidonius und siedeln sich anders als bei diesem auf der Ebene einer bestimmten kommunikativen Funktion an, die Ruricius dem brieflichen Austausch zuweist und durch die er sich in einer letztlich ebenso lang zurückreichenden Kontinuität zu wähnen scheint wie Sidonius mit seinem Anschluss an die großen Vertreter der römischen Epistolographie. Diese im Folgenden zu kommentierenden Referenzen werden den Blick dafür freilegen, dass im spätantiken Gallien bereits die Pflege brieflichen Austauschs selbst als Bekenntnis zur römischen Tradition inszeniert werden kann. Als kulturelle Praktik der gelehrten Oberschicht, die spätestens seit dem 4. Jh. n. Chr. in unterschiedlicher Intensität in der christlichen Epistolographie ihre Fortsetzung findet, wird diese bei Ruricius somit als willkommene performative Strategie gegenseitiger Selbstvergewisserung im Kreis eines sich zunehmend verkleinernden und grobmaschiger werdenden Netzwerks gelehrter christlicher Aristokraten sichtbar werden, durch welche sich diese bereits ohne den offensichtlich nicht mehr durchweg akzeptierten ostentativen Gestus literarischer Traditionsbildung

Dienst der benachbarten Diözesen. Mehrere von diesen standen auch in brieflichem Austausch mit Sidonius Apollinaris, woraus einmal mehr die Affinität beider Korrespondenznetzwerke sichtbar wird; s. Mathisen 1999, 31-33 (vgl. Anm. 12); zu den Briefen, in denen sich Reflexe auf Ruricius' bischöfliche und seelsorgerliche Tätigkeiten finden, vgl. ebd., 34-36.

28 In ihrer Interpretation von epist. 9, 16 führt Egelhaaf-Gaiser 2010, $266 \mathrm{zu}$ Recht aus, dass das Bischofsamt in Sidonius' dortiger sphragishafter Selbstbeschreibung nur marginale Bedeutung hat.

29 Als Untersuchung über den Stil des Sidonius immer noch unersetzt ist Loyen 1943, der diesen freilich in abwertender Tendenz beschreibt. Vgl. auch Gualandri 1979, 75-181 und knapp und vor allem mit Blick auf das erste Buch der Korrespondenz Köhler 1995, 18-25. 
eines Sidonius als Repräsentanten römischer Kultur in einer von dieser immer weniger geprägten Umwelt zu positionieren suchen.

II.

Das zweite Buch der Ruricius-Korrespondenz, das deren erstes um mehr als das Vierfache übertrifft, ${ }^{30}$ beginnt mit einigen Schreiben an das befreundete Ehepaar Namatius und Ceraunia, mit welchem Ruricius durch die Heirat seines Sohnes mit dessen Tochter später sogar eine familiäre Verbindung unterhielt. ${ }^{31}$ Der erste dieser Briefe, der Auftaktbrief des zweiten Buches, ist nach Ruricius' Rückkehr von einem Besuch bei den beiden verfasst und thematisiert die Trennung von diesen. Diese habe dazu geführt, dass Ruricius sich selbst nicht mehr als vollständig empfinden könne, da er einen Teil seiner selbst bei den Freunden zurückgelassen zu haben vermeint. Und auch bei Namatius und Ceraunia vermutet er Ähnliches, habe er seit seiner Abreise doch den Eindruck, seinerseits einen Teil von diesen stets bei sich zu führen. Dieses Gefühl der wechselseitigen Unvollständigkeit, solange ein Wiedersehen mit dem befreundeten Ehepaar aussteht, begreift Ruricius dabei als Bestätigung antiker Lehren über das Wesen der Freundschaft, auf welche er zu Beginn des Briefs sentenzenhaft anspielt: ${ }^{32}$

Antiqui sapientes amicos duos unam animam habere dixerunt, quod valde verum esse ego praedico proboque. Nam postquam a vestra germanitate discessi, divisum esse me sentio partemque meam vobiscum resedisse cognosco nec absentibus vobis integer esse mi videor. Et cum me in me non inveniam, apud vos me ad vos reversus inquiro atque ibidem, quantum mei vobis reliquisse, tantum vestri mecum abstulisse conspicio.

Die Weisen des Altertums haben gesagt, dass zwei Freunde eine einzige Seele hätten. Dass dieses Wort ganz gewiss wahr ist, bestätige ich mit allem Nachdruck. Denn seitdem ich von euch, meinen innigen Freunden, abgereist bin, empfinde ich mich als geteilt und erkenne, dass ein Teil von mir bei Euch zurückgeblieben ist, und es scheint mir, dass ich nicht vollständig sein kann, solange ihr abwesend seid. Und da ich mich in mir nicht finden kann, kehre ich zu euch zurück und suche mich bei euch. Doch in gleicher Weise fällt mir auf, dass ich ebensoviel von euch mit mir mitgenommen, wie ich von mir bei euch zurückgelassen habe.

30 Im einzigen Überlieferungsträger der Ruricius-Korrespondenz, dem Codex Sangallensis 190, enthält das erste Buch 18, das zweite Buch je nach Zählung 64, 65 oder 66 Briefe. Hinzu kommen 12 Briefe, in denen Ruricius der Adressat ist. Zum Kodex und seiner Überlieferung s. die Literatur in Anm. 23.

31 Im Ruricius-Briefwechsel sind insgesamt acht Briefe an Namatius, Ceraunia oder wie im vorliegenden Beispiel an beide überliefert. Fünf von diesen bilden eine Gruppe am Anfang des zweiten Buches. Zur Prosopographie der beiden s. Mathisen 1999, 133.

32 Ruric. epist. 2, 1, 4-10. 
Mit der Erfahrung des partiellen Selbstverlusts infolge der Trennung von seinen Freunden eröffnet sich in der Korrespondenz des Ruricius ein Themenfeld, in dem dieser nun doch den Rückgriff auf die im Bereich von Stil und epistolographischen Vorbildern unbeachtet gelassene antike Tradition sucht. Diese reicht dabei mindestens so weit zurück wie Sidonius' Kette modellhafter Briefsteller. Denn unter die antiken Weisen, die Ruricius eher allgemein ins Feld führt, ist nicht zuletzt Cicero zu rechnen, auf dessen Laelius der Auftakt des Briefs an Namatius und Ceraunia indirekt anspielt. ${ }^{33}$ Ungeachtet seiner ansonsten auf christlicher Askese und einer untadeligen Ausübung seines Hirtenamts gründenden Selbstmodellierung scheint es Ruricius bei der Trennung von dem befreundeten Ehepaar darauf anzukommen, seine damit verbundenen Empfindungen explizit im Horizont eines Freundschaftskonzepts zu verorten, das gerade nicht auf ein christliches Modell zurückzuführen ist, sondern in der heidnischen Antike seinen Ursprung hat. ${ }^{34}$

Im Zusammenhang eines solchen Verständnisses von Freundschaft als Vereinigung zweier Seelen, welche bei einer Trennung notwendigerweise Schaden erleidet, eröffnet die Briefkommunikation den einander freundschaftlich Zugetanen nicht nur die Gelegenheit, sich über ihre seelische Versehrtheit Rechenschaft abzulegen. Darüber hinaus erweist sich diese für Ruricius auch als wirksames Heilmittel gegen die Folgen der Trennung. Denn im weiteren Verlauf seines Schreibens an die Freunde Namatius und Ceraunia bringt er zwar zum Ausdruck, dass die eheliche Verbindung zweier ihrer Kinder ein dauerhaftes Band zwischen

33 Vgl. als einschlägige Stelle Cic. Lael. 80f.: [...] Ipse enim se quisque diligit, non ut aliquam a se ipse mercedem exigat caritatis suae, sed quod per se sibi quisque carus est quod nisi idem in amicitiam transferetur, verus amicus numquam reperietur; est enim is, qui est tamquam alter idem. Quod si hoc apparet in bestiis, volucribus nantibus agrestibus, cicuribus feris, primum ut se ipsae diligant (id enim pariter cum omni animante nascitur), deinde ut requirant atque appetant, ad quas se applicent eiusdem generis animantes, idque faciunt cum desiderio et cum quadam similitudine amoris humani, quanto id magis in homine fit natura, qui et se ipse diligit, et alterum anquirit cuius animum ita cum suo misceat ut efficiat paene unum ex duobus. Zu Inhalt und Aufbau des Laelius bzw. zu Ciceros darin entwickeltem Freundschaftskonzept in Anschluss und Auseinandersetzung mit griechischen Vorstellungen s. Fürst 1996, 144-176 (zum Problem von Ideal und Wirklichkeit in Ciceros Argumentation s. ebd., 176-180). Zu weiteren Stellen in Ciceros' Euvre, in denen dieser das Thema Freundschaft behandelt, s. ebd., 181f. Im Hintergrund des von Cicero ausformulierten Freundschaftskonzepts der Seeleneinheit steht freilich die pythago-

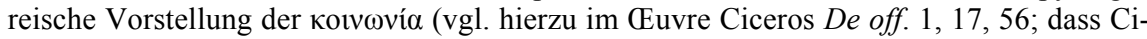
cero seinen Laelius als Ergänzung zu De officiis ansah, geht aus ebd., 2, 9 hervor). Vorlage

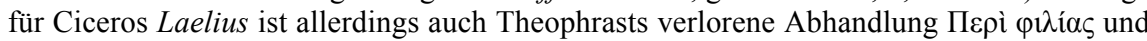
Panaitios: vgl. White 1992, 28-35; Konstan 1997, 131-135 sowie Pizzolato 1993, $106-$ 128 und Fiore 1997 zum Laelius sowie zum Freundschaftsdiskurs bei Cicero insgesamt; zur Thematisierung von Freundschaft im Euvre Ciceros insbesondere im Verhältnis zu Haltungen wie politischer Loyalität und Staatsraison s. ebd., 124-131 (freilich ist auch hier der Briefwechsel Ciceros zentrale Quelle).

34 Einen Überblick über antike Freundschaftskonzepte von der griechischen Archaik bis in die christliche Spätantike gewähren Pizzolato 1993 und Konstan 1997; für eine systematische Untersuchung des Freundschaftsbegriffs aus philosophischer Sicht s. Lemke 2000. 
ihnen stiften werde. Wirklich überwinden lässt sich jene für die eigene seelische Integrität so verhängnisvolle Trennung voneinander aber scheinbar allein im Medium des Briefs.

In der Tat erkennt Ruricius einem Briefwechsel das Potential zu, jene Präsenz zwischen zwei Menschen herzustellen, welche diesen in räumlicher Hinsicht verwehrt ist. Mehrere Schreiben deuten sogar an, dass er darin eine zentrale raison d'être brieflicher Kommunikation erblickt. Beispiel hierfür ist ein Brief an seinen Bischofskollegen von Auxerre Censorius, ${ }^{35}$ der Ruricius als veritabler Ersatz für eine Begegnung von Angesicht zu Angesicht gilt. Denn dieser erlaube es immerhin, dass sich beide im Geiste ansichtig würden und sie auf diese Weise miteinander ins Gespräch kämen: ${ }^{36}$

Litteras sanctitatis vestrae etsi per occasionem accepisse me gratulor. Non enim interest, utrum ex necessitate aut ex voluntate, dummodo inter se invicem, qui se diligunt, conloquantur et, quos corpore locorum intervalla discriminant, animorum ac sensuum conloquia fida coniungant, quia hoc nobis generale vel maximum virtus divinae pietatis indulsit, ut, qui nos aspectu carnali non possumus contueri, spiritali cernamus obtutu. Unde redeunte gerulo litterarum has, sicut iniunxistis, reddere procuravi, ut et sollicitudini vestrae et mutuae caritati pariter responderem.

Ich freue mich, dass ich einen Brief von Eurer Heiligkeit erhalten habe, auch wenn dies einem konkreten Anlass geschuldet ist. Es besteht nämlich kein Unterschied, ob ein Brief wegen eines bestimmten Grundes oder aus freien Stücken geschickt wird, wenn nur zwei Personen, die einander schätzen, miteinander im Gespräch sind und, obwohl sie durch räumliche Distanz körperlich voneinander getrennt sind, im kontinuierlichen vertrauensvollen Gespräch der Seele und der Gedanken untereinander stehen. Denn dieses ist das umfassendste und größte Geschenk, welches uns die göttliche Gnade gewährt hat, dass wir uns vor dem geistigen Auge sehen, wenn wir einander körperlich nicht ansichtig werden können. Daher habe ich dem Boten bei seiner Abreise ein Erwiderungsschreiben mitgeben lassen, wie ihr aufgetragen habt, damit ich gleichermaßen eurem Ansinnen antworte wie auch unserer gegenseitigen Zuneigung entspreche.

Angesichts der Gelegenheit, im Brief einander geistig zu begegnen, wird sogar jeder weitere Mitteilungsgrund, dem dieser seine Existenz verdankt, zu einem zweitrangigen Aspekt. Mehr noch: Aus Ruricius' einleitender Bemerkung, dass er sich über die Zeilen des Mitbruders aus Auxerre trotz des diesen zugrunde liegenden konkreten Anlasses freue (etsi per occasionem), lässt sich schließen, dass die Verwendung eines Briefs zum Informationsaustausch mit seiner Funktion als Freundschaftserweis und dementsprechend zur Generierung geistiger Präsenz

35 Censorius von Auxerre erscheint auch im Briefwechsel des Sidonius Apollinaris (s. Sidon. epist. 6, 10); vgl. Mathisen 1999, 222.

36 Ruric. epist. 2, 51, 1-11. Ein vergleichbares Beispiel aus der Korrespondenz des Sidonius Apollinaris findet sich in Sidon. epist. 1, 9, 7f.; allgemein zur Verwendung des Freundschaftsmotivs bei Sidonius Apollinaris s. Loyen 1943, 95-100. 
zwischen den Briefpartnern tendenziell sogar konfligiert. Letztlich vermag nur ein Brief, der jeder weiteren Zweckbestimmung entbehrt, dem Beweis gegenseitiger Verbundenheit zu dienen. Allein die zu Beginn seines Briefs geäußerte Gewissheit, einander ohnehin in tiefer Zuneigung verbunden zu sein, stellt sicher, dass Ruricius diesen als Bestätigung der gegenseitigen Freundschaft lesen kann, obwohl ihm ein Anliegen jenseits davon zugrunde liegt. ${ }^{37}$

Entsprechend finden sich in Ruricius' Korrespondenz Schreiben, deren einziger Zweck es ist, ihren Autor mit dessen Briefpartnern in der Gemeinschaft des Geistes zusammenzuführen. Besonders virtuos hat Ruricius darüber in einem weiteren Brief an den bereits erwähnten Namatius reflektiert, der denn tatsächlich auch kein anderes Thema hat. Ausgangspunkt für die sprachlich ebenso einfallsreiche wie elegante Hommage an die Briefkommunikation als Medium, das jede räumliche Trennung einander zugetaner Menschen zu überwinden vermag, ist die gemeinsame Ermahnung an sich und den Freund, keine Gelegenheit auszulassen, um dem jeweils anderen zu schreiben: ${ }^{38}$

Qui occasionem scribendi pro necessitudinis iure perquirimus, oblatam praetermittere non debemus, ut reddat nobis quandam praesentiae portionem sermo mediator, qui emittitur et non amittitur, tribuitur et habetur, videtur discedere nec recedit, a me dirigitur, a te suscipitur, a me scribitur, a te legitur nec tamen dividitur, cum quasi divisus integer utriusque corde teneatur, quia verbi more divini traditur et non egreditur, confertur indigenti et non aufertur auctori accipientis lucrum sine dispendio largientis, ditans inopem nec adtenuans possessorem.

Die wir eine Gelegenheit zu schreiben suchen, um damit unserer freundschaftlichen Verbindung gerecht zu werden, dürfen keine verstreichen lassen, wenn sie sich bietet, damit uns das Gespräch als Mittler gleichsam teilweise einander präsent macht, welches abgeschickt wird und nicht verloren geht, zugestellt und in Händen gehalten wird, davonzugehen und nicht wieder zurückzukehren scheint, das von mir auf den Weg gebracht und von dir empfangen wird, das von mir geschrieben, von dir gelesen und dennoch nicht zerteilt wird, da es eben nur scheinbar geteilt ist und als Ganzes von jedem von uns beiden im Herzen gehalten wird, weil es nach Art des göttlichen Wortes versandt wird und doch nicht gänzlich von dannen geht, weil es demjenigen, der danach verlangt, zugetragen und seinem Urheber doch nicht weggenommen wird, seinem Empfänger ein Gewinn ist, ohne seinem Spender einen Verlust zu bereiten, indem es denjenigen, der es nicht hat, bereichert, ohne denjenigen, der es in Händen hält, ärmer zu machen.

Die Rekurrenz, mit der Ruricius im zweiten Buch seiner Korrespondenz auf deren Potential zu sprechen kommt, geistige Präsenz zwischen abwesenden Freunden zu generieren, dokumentiert die hohe Bedeutung, die er dieser Funktion innerhalb

37 Kernbegriff ist voluntas: Im Horizont des hier zur Debatte stehenden Freundschaftskonzepts geht es also um das Schreiben aus eigenem Antrieb und nicht aus einem anderweitigen Anlass.

38 Ruric. epist. 2, 5. 
seines Briefwechsels zumisst. ${ }^{39}$ Damit verleiht Ruricius einer Zweckbestimmung besonderes Gewicht, die ein weiteres Mal auf vorchristliche Vorstellungen zurückweist. Denn nicht nur das gegenüber seinen Freunden Namatius und Ceraunia artikulierte Verständnis von Freundschaft als Vereinigung zweier Seelen, sondern auch die daran anknüpfende Vorstellung, dass ein Brief die räumliche Trennung von Freunden und damit das Gefühl seelischer Unvollständigkeit im Geiste aufzuheben vermag, kontinuiert gleichermaßen verbreitete antike Ansichten, die neben entsprechenden Bemerkungen in der griechischen Brieftheorie ${ }^{40}$ erneut bis auf Cicero und in diesem Falle sogar auf dessen eigene Briefpraxis zurückzuführen sind. ${ }^{41}$ Denn die Ansicht, dass ein Brief das unmittelbare Gespräch zwischen Anwesenden ersetzen könne, formuliert Cicero an zahlreichen Stellen seiner Korrespondenz. Beispiel wäre statt vieler ein Schreiben vom Juni 43 v. Chr. an Cornificius, in welchem Cicero den Briefkontakt als veritable Alternative zum gegenseitigen Austausch ante oculos bezeichnet: ${ }^{42}$

Aut quid mi iocundius quam, cum coram tecum loqui non possim, aut scribere ad te aut tuas legere litteras?

Oder was kann mir ein schöneres Vergnügen bereiten als dir zu schreiben oder einen Brief von dir zu lesen, wenn ich nicht mit dir persönlich sprechen kann?

Diese Auffassung hat auch bei Cicero zur Konsequenz, dass dieser einem Brief sogar zubilligt, den Eindruck unmittelbarer Präsenz des abwesenden Korrespondenzpartners erzeugen zu können. Entsprechend äußert er sich gegenüber C. Cassius im Januar 45 v. Chr.: ${ }^{43}$

39 Vgl. etwa ebd., 2, 16 und 2, 51. Im Briefœuvre des Sidonius Apollinaris wäre hier etwa Sidon. epist. 7, $11 \mathrm{zu}$ nennen; vgl. Mathisen 2001, $106 \mathrm{f}$.

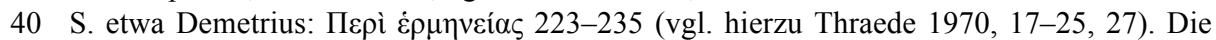
Brieftheorien leiten aus dieser Funktion freilich nicht ab, dass ein Brief in einer eher kolloquialen Sprache zu verfassen sei. Angesichts des Geschenkcharakters eines Briefs sei im Gegenteil besondere stilistische Sorgfalt geboten. Wenngleich der Brief dem literarischen Dialog als ähnlich bewertet wird, da er dessen eine Hälfte verkörpere, unterscheide er sich in dieser Hinsicht dennoch von diesem, da der Dialog ein Gespräch nachahme und daher tatsächlich in einem der Alltagssprache ähnlichen Idiom abgefasst werden müsse. Der Brief ist hingegen Gespräch Abwesender und Geschenk in einem. S. hierzu Demetrios:

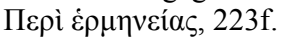

41 Zum Folgenden mit weiteren Beispielen als den hier angeführten s. Thraede 1970, 39-47.

42 Cic. fam. 12, 30, 1 (modifizierte Übersetzung nach Kasten 1959); zum Bief als colloquium amicorum absentium s. auch Cic. Phil. 2, 7 sowie Att. 9, 10, 1 und 12, 53.

43 Cic. fam. 15, 16, 1 (Übersetzung nach Kasten 1959); vgl. ähnlich dazu fam. 16, 16, 2 (Quintus an Marcus): te totum in litteris vidi oder fam. 15, 19, 1 (C. Cassius an Cicero): Non mehercule in hac mea peregrinatione quicquam libentius facio quam scribo ad te; videor enim cum praesente loqui et iocari. Indem es sich bei diesen Beispielen um Briefe anderer Personen an Cicero handelt, wird ersichtlich, wie verbreitet die Vorstellung von der anwesenheitsstiftenden Funktion des Briefs in dessen Korrespondenznetzwerk gewesen sein muss. 
Puto te iam suppudere quem haec tertia iam epistula ante oppressit quam tu scidam aut litteram. sed non urgeo; longiores enim (ex)spectabo, vel potius exigam. ego, si semper haberem cui darem, vel ternas in hora darem. fit enim nescio qui, ut quasi coram adesse videare, cum scribo aliquid ad te, [...].

Wahrscheinlich genierst Du Dich nachgerade ein wenig, dass Dich bereits dieser dritte Brief überrascht, ehe von Dir ein Zettelchen oder ein Buchstabe. Aber ich dränge nicht; dafür erwarte, nein, fordere ich einen ganz langen! Fände ich immer jemanden, dem ich einen mitgeben könnte, ich schriebe Dir wohl dreimal stündlich. Sonderbarerweise scheinst Du mir nämlich gleichsam gegenüberzusitzen, wenn ich an Dich schreibe, $[\ldots]$.

Bereits bei Cicero besitzt der Brief folglich eine Bedeutung, die sich jenseits des bloßen Informationsaustauschs ansiedelt und diesen als adäquates Medium empfiehlt, um die Trennung zwischen befreundeten Briefpartnern aufzuheben und diese unter dem Eindruck veritabler Präsenz im geistigen Gespräch über die räumliche Distanz hinweg zusammenzuführen.

Vor dem Hintergrund, dass Ruricius der heidnisch-antiken Tradition in seinen Briefen in der Regel mit Indifferenz begegnet, ist es durchaus bemerkenswert, dass er im Hinblick auf seine Vorstellung von Freundschaft den entschiedenen Anschluss an diese, namentlich an Cicero, sucht und mit seiner dazu komplementären Auffassung, dass ein Brief Präsenz zwischen getrennten Freunden herzustellen vermag, eine ebenso vom Arpinaten maßgeblich formulierte Ansicht über die Möglichkeiten der Briefkommunikation aufgreift. ${ }^{44}$ Seine Erklärung erhält dieser Befund jedoch im Horizont eines Briefs an den Abt Pomerius, ${ }^{45}$ in welchem Ruricius nochmals mit der gleichen sentenzenhaften Wortwahl wie im oben zitierten Brief an Namatius und Ceraunia und erneut an dessen Anfang Freundschaft als Einheit zweier Seelen definiert und diese Auffassung wiederum auf Ciceros Laelius bezieht, zusätzlich dazu aber noch einen zweiten und diesmal biblischen Referenztext benennt. Bestätigung fände diese nämlich auch in der Apostelgeschichte, wenn dort geschrieben stünde, dass die Gläubigen der Urgemeinde nach dem Pfingstereignis ein Herz und eine Seele gewesen seien: ${ }^{46}$

44 Demgegenüber wird dieses Potential der Briefkommunikation in den für die christliche Epistolographie grundlegenden Paulus-Briefen in spezifisch anderer Weise funktionalisiert: vgl. Thraede 1970, 95-106.

45 Die Abtswürde bezeugt für Pomerius nur Ruricius' Brief 1, 17. Iulianus Pomerius war ein Rhetor aus Nordafrika, der vor den Vandalen nach Arles floh, wo er zum Priester geweiht wurde. $\mathrm{Zu}$ seinen Schülern gehörte auch Caesarius von Arles. In seinen theologischen Ansichten zeigt er sich durch Faustus von Riez beeinflusst; vgl. Mathisen 1989, 242-244; Mathisen 1999, 129.

46 Ruric. epist. 2, 10, 4-13 mit Verweis auf Acta Apostolorum 4, 32: Multitudinis autem credentium erat cor unum et anima una: nec quisquam eorum, quae possidebat, aliquid suum esse dicebat, sed erant illis omnia communia. 
Sapientes saeculi amicos duos unam animam habere dixerunt, quod ego etiam ecclesiastico testimonio verum esse confirmo, quo ait: „Credentium autem erat anima et cor unum ", unum utique caritate, non numero, et fidei simplicitate, non singularitate personae. Hoc ego praedico proboque. Nam ex quo a vestra unanimitate discessi, divisum esse me sentio partemque meam vobiscum resedisse cognosco nec absentibus vobis integrum esse me credo et, cum me in me non inveniam, apud vos me ad vos regressus inquiro atque ibidem quantum mei vobis reliquisse, tantum vestri mecum abstulisse conspicio.

Die Weisen des Heidentums haben gesagt, dass zwei Freunde eine einzige Seele haben. Dass dieses Wort wahr ist, kann ich mit einem Schriftzeugnis bestätigen, in dem es heißt: „Die Gläubigen aber waren eine Seele und ein Herz,“ und zwar eines in der Liebe nicht an Zahl, in der Einheit des Glaubens und nicht in der Einzahl der Person. Dies kann ich nachdrücklich bestätigen. Denn nachdem ich von Euch, meinem in Eintracht verbundenen Mitbruder, abgereist bin, empfinde ich mich wie geteilt und ich erkenne, dass ein Teil von mir bei euch zurückgeblieben ist. So glaube ich, dass ich nicht mehr vollständig sein kann, solange ihr abwesend seid. Und da ich mich bei mir nicht finden kann, kehre ich zu euch zurück und suche mich bei euch. Doch ich erkenne gleichermaßen, dass ich soviel von euch mit mir mitgenommen habe, wieviel ich von mir bei euch zurückgelassen habe.

Somit beruft sich Ruricius mit seiner Vorstellung, dass Freundschaft als Einheit zweier Seelen zu verstehen sei, nicht nur auf Cicero und die heidnisch-antike Tradition, sondern er findet für diese auch ein Äquivalent in der Heiligen Schrift. Denn Ciceros Definition von Freundschaft, wie sie dieser im Laelius niedergelegt hat, korrespondiert seiner Meinung nach mit einer Erfahrung, welche die Apostelgeschichte für die Mitglieder der Urgemeinde überliefert und die Ruricius in spezifischer Ausweitung ihres dort vorrangig auf die Aspekte von Eintracht und Gütergemeinschaft bezogenen Bedeutungsgehalts als Beleg für die Existenz eines Gefühls freundschaftlicher Verbundenheit unter den vom Heiligen Geist erfüllten Urchristen deutet. ${ }^{47}$

Es sind ein solches Verständnis jener von der Apostelgeschichte überlieferten urchristlichen Gemeinschaft sowie die daraus resultierende Möglichkeit, das bei Cicero ausformulierte Freundschaftsideal mit einer vergleichbaren christlichen Realisation in Verbindung bringen zu können, welche Ruricius dazu bewogen haben dürften, einmalig den Umkreis eines rein christlichen Selbstverständnisses zu verlassen. Vor dem Hintergrund, dass sich Ruricius mit dem von ihm bemühten Zeugnis der Apostelgeschichte durchaus eine Gelegenheit geboten hätte, sein Freundschaftsideal allein aus der Bibel heraus zu begründen, profilieren sich die beiden programmatischen Sentenzen zu Beginn der Briefe 2, 1 und 2, 10 allerdings auch deutlich als bewusstes Ausgreifen auf das Feld außerchristlicher Tradition. Mithin scheint es Ruricius im zweiten jener beiden Schreiben vor allem

47 Zur Diskussion von Act 4, 32 im christlichen Freundschaftsdiskurs s. White 1992, 49f.; zu den Bezügen dieser Stelle zum antiken Hintergrund im Allgemeinen s. statt vieler Klauck 1989 und Mitchell 1997, 236-241. 
darum gegangen zu sein, einen für sein Selbstverständnis konstitutiven Rückbezug auf einen ursprünglich nichtchristlichen Diskurs gegenüber seinem Mitbruder zusätzlich glaubenskonform zu legitimieren, ohne dessen eigentlich andersartige Zielrichtung dabei zu verleugnen. Sein Anliegen im Brief 2, 10 ist folglich weniger, das in der Apostelgeschichte formulierte Idealbild der Urgemeinde zu propagieren, als vielmehr einen jenseits christlicher Begründungen angesiedelten Aspekt seines Selbstverständnisses durch entsprechende Korrespondenzen abzusichern.

Damit eignet Ruricius eine wesentlich integrativere Haltung gegenüber dem auf vorchristliche Traditionen zurückverweisenden Element seines Selbstbildes als Sidonius Apollinaris, dem in seiner Korrespondenz kaum daran gelegen ist, sein Bekenntnis zu einer nahezu ausschließlich von heidnischen Autoren repräsentierten literarischen Tradition mit seiner Rolle als Bischof zu harmonisieren, zumal letztere ohnehin kaum Gegenstand seines Briefwechsels ist. Andererseits wird aus jener in Brief 2, 10 vorgenommenen Engführung von christlicher und außerchristlicher Referenz Ruricius' Anliegen sichtbar, sein Freundschaftskonzept explizit in einer vorchristlichen Tradition zu verorten, zeigen doch die Zeilen an den Abt Pomerius an, dass er sich bei dessen Archäologie durchaus allein auf einen biblischen Ursprung hätte berufen können.

In seinem Selbstverständnis ist Ruricius somit nicht so weit von Sidonius entfernt, wie es zunächst scheinen möchte. Denn bei allem Gestus christlicher Bescheidenheit ist es auch für ihn von Bedeutung, sich in seinen Briefen als Erben und Fortsetzer einer vor das Christentum zurückreichenden antiken Tradition zu inszenieren. Freilich äußert sich dieses Bestreben nicht in der exaltierten literarischen Standortbestimmung eines Sidonius, sondern indem Ruricius mit dem Freundschaftsbrief lediglich einen Aspekt seiner epistolaren Praxis auf deren vorchristliche Ursprünge zurückführt. Mag sich dies auch als verhaltenere Strategie erweisen als jene seines älteren Amtsbruders, so nutzt Ruricius seine Korrespondenz dennoch ebenso als Artikulationsmedium eines Selbstverständnisses, das sich zumindest partiell über die Kontinuierung kultureller Verhaltensmuster definiert, welche nichtchristlicher Provenienz sind.

III.

In seiner Verbindung von vorrangig theologisch-spirituellem Austausch und gelegentlichem Freundschaftserweis steht Ruricius' Briefwechsel im Gallien des 5. Jh.s n. Chr. nicht allein da. ${ }^{48}$ Ein ähnliches thematisches Panorama findet sich

48 Allgemein zur Briefliteratur im spätantiken Gallien s. Chadwick 1955 sowie Mathisen 1981, der die Anzahl der von dort aus den einhundert Jahren zwischen 420 und $520 \mathrm{n}$. Chr. erhaltenen Briefe auf ca. 475 beziffert. Dass das Verfassen von Briefen zur produktivsten literarischen Betätigung der Spätantike zählt, betont Matthews 1984, 64f. - Zur Briefliteratur in der lateinischen Literatur insgesamt s. die ältere Arbeit von Peter 1901 (zur Episto- 
bereits in der Korrespondenz des Salvian von Marseille, die, zahlenmäßig schmaler als jene des Bischofs von Limoges, in die 20er Jahre des 5. Jh.s datiert. Während die meisten Schreiben in dieser pastoralen Fragen gelten, belegt immerhin ein Brief, dass der aus Trier oder Köln stammende und später in der Provence wirkende Geistliche der Briefkommunikation wie Ruricius die Funktion zuerkennt, Freundschaften zwischen räumlich getrennten Partnern zu bekunden und aufrechtzuerhalten. In ihm beklagt sich Salvian nämlich heftig bei Eucherius, dem Autor der Passio Acaunensium Martyrum und offensichtlich seit kurzem erst Bischof von Vienne, ${ }^{49}$ dass dieser durch einen Boten habe Grüße ausrichten lassen, anstatt ihm einen Brief zu übermitteln. Ursache dieser auf den ersten Blick außergewöhnlichen Beschwerde ist Salvians Argwohn, im Verzicht auf eine schriftliche Formulierung des Grußes artikuliere sich womöglich eine Abnahme seiner Wertschätzung bei seinem Mitbruder aus Vienne: ${ }^{50}$

Ursicinus alumnus tuus salutationem tuam proxime ad me detulit: si non iussus, laudo sapientiam, licet non probem falsitatem, si iussus, miror quod mandare amoris officium quam scribere maluisti, hoc est, per seruum potius quam per te dare. arguo itaque hoc et emendari uolo, si tamen neglegentiae est non superbiae. pedissequa enim plerumque novi honoris est adrogantia, licet in te nec generalis vitii opinio admittenda sit, quia prope singularis est mens ac benignitas tua. unde responderi a te antiquae existimationi meae etiam nunc iugiter cupio, ne, si in quibusdam officiorum tuorum mos discreparit, aliquid in te novis honoribus licuisse videatur.

Ursicinus, dein Zögling, hat mir kürzlich deinen Gruß übermittelt: wenn er's ohne deinen Auftrag tat, lobe ich mir seine Verständigkeit, wenn ich auch die Falschheit nicht billigen kann; tat er's in deinem Auftrag, muss ich mich wundern, dass du den Freundschaftsdienst lieber einem anderen übertragen hast, als zu schreiben, d. h. ihn lieber durch Vermittlung eines Dieners als in eigener Person zu leisten. Ein solches Benehmen muss ich deshalb tadeln und erwarte Besserung, wenn wirklich nur Nachlässigkeit, nicht etwa gar Hochmut die Ursache davon ist. Denn sehr häufig ist Überhebung eine unmittelbare Begleiterscheinung eines neuen Amtes; womit nicht gesagt sein soll, dass man den gebräuchlichen Maßstab für die Sünde auch an dich anlegen muss, da ja deine gütige Gesinnung einzig dasteht. Daher ist es mein sehnlichster Wunsch, du mögest auch jetzt meiner alten Meinung gerecht werden; sonst könntest du, wenn du die gute alte Sitte mit einigen deiner neuen Pflichten nicht in Einklang bringen kannst, den Verdacht erregen, du habest für die neuen Ehren etwas in dir verkauft.

lographie im spätantiken Gallien ebd., 149-168) sowie Cugusi 1983, der die christliche Literatur der Spätantike jedoch nicht miteinbezieht; vgl. zu dieser Stowers 1986; formale Besonderheiten des christlichen Briefs in lateinischer Sprache bespricht Bastiaensen 1964.

49 Zum Korrespondenznetz des Eucherius von Lyon, dem zahlreiche Geistliche aus Lérins angehörten, s. Mathisen 1981, 104-108.

50 Salv. epist. 2; Übersetzung aus Mayer 1935. 
Indem er mündlich ausgerichtete und schriftliche Zuneigungsbekundung einander gegenüberstellt und im Hinblick auf deren Aussagewert für den Adressaten zugunsten der Letzteren hierarchisiert, stellt Salvian nochmals deutlicher als Ruricius die eminente Bedeutung des Briefs als Medium zur Bekundung und Pflege von Freundschaften heraus. Ganz offensichtlich - so lässt sich aus Salvians Vorwurf an Eucherius schließen - erschöpft sich die Leistung eines Briefs für die Kommunikation zwischen Freunden nicht allein darin, dass sich diese über eine größere räumliche Distanz hinweg der gegenseitigen Verbundenheit vergewissern können. ${ }^{51}$ Denn eine solche Botschaft lässt sich wie im Falle des Eucherius auch mündlich durch einen Boten übermitteln. Wenn diese Art der Freundschaftsbekundung Salvian nicht ausreicht, dann liegt das vielmehr an der Materialität eines Briefs, die diesen zur dauerhaften Gabe des Absenders an den Adressaten macht. Zwar ändert dies nichts daran, dass auch ein Brief die beiden Korrespondenzpartner nur mittelbar in Kontakt zueinander bringt. Dennoch ist er Träger von Äußerungen und macht diese dem Adressaten unmittelbar ansichtig, welche - obgleich schriftlich formuliert und dabei womöglich von einem Sekretär verfasst - durch die Verwendung der Ich-Form vom Absender explizit als dessen eigene Worte markiert sind. Es ist diese gleichsam vermittelte Unmittelbarkeit, welche es dem Adressaten ermöglicht, sich in der Lektüre eines Briefs dessen Absender so zu vergegenwärtigen, als ob dieser selbst anwesend sei. ${ }^{52}$

Salvian und Ruricius bilden somit einen Zweig in der Briefkultur des spätantiken Gallien, in dem diese zwar nicht wie bei Sidonius und dessen Freund Constantius zur ostentativen Selbstverortung innerhalb der Tradition heidnischantiker Epistolographie instrumentalisiert wird, in dem aber die in der lateinischen Literatur bis auf Cicero zurückreichende Verwendung des Briefs als Freundschafterweis und -garant weiterhin ihren festen Platz hat. Damit kontinuieren sie eine Linie, die sich bis zu den christlichen Autoren des 4. Jh.s zurückverfolgen lässt. So haben vor allem Paulinus von Nola und Ambrosius von Mailand, aber auch Hieronymus und nicht zuletzt Augustinus ihre Korrespondenz dazu benutzt, um Freundschaften über eine längere Distanz zu pflegen und zu bewahren. ${ }^{53}$ Dabei greifen auch sie wiederholt auf jene von Cicero in der lateinischen

51 Vergleichbare Klagen über das Ausbleiben von Briefen, obwohl ein Bote zur Hand gewesen wäre, finden sich auch in den Korrespondenzen des Sidonius Apollinaris und bei Ruricius, z.B. Ruric. epist. 2, 27. Eine Liste von Schreiben, in denen Sidonius um Briefe bittet oder ungehalten darüber ist, dass er keine erhält, findet sich in Mathisen 2001, 107, Anm. 32.

52 Zu dieser Vorstellung der Anwesenheit sei nochmals auf Thraede 1970, 39-47 (zu Cicero) und 146-161 (zur christlichen Tradition) verwiesen.

53 Allgemein zum Freundschaftsverständnis der vier genannten Autoren s. White 1992, 111 163, 185-217 und Pizzolato 1993, 283-319; zur Verwendung des Freundschaftsbriefs bzw. der für diesen typischen Topik bei diesen s. White 1992, passim sowie die Beispiele bei Thraede 1970, 162-165. Ergänzend hierzu s. im Hinblick auf Paulinus von Nola Fabre 1949, 137-154; Trout 1999, 209-218 und ferner 200-209 über dessen weitverzweigtes Freundschaftsnetzwerk als Hintergrund seines Briefwechsels sowie Mratschek 2002 zum selben Themenfeld; zur Korrespondenz zwischen Paulinus und Hieronymus s. Canellis 
Epistolographie erstmals formulierte Auffassung zurück, dass ein Brief den Absender im Geiste ansichtig werden lasse und dieser somit die räumliche Trennung von Freunden zu überwinden verhelfe. ${ }^{54}$ Deutlich erkennbar wird dies in einem Brief des Ambrosius von Mailand an Sabinus, der hier stellvertretend für zahlreiche andere Beispiele aus den Briefwechseln der genannten Autoren stehen möge: ${ }^{55}$

Quoniam tibi quoque conplacuit nostrarum usus epistularum, in quibus quidam inter absentes praesentium sermo est, pergam frequentius te in meis scriptis, et cum solus sum, adloqui. Numquam enim minus solus sum, quam cum solus esse videor, nec minus otiosus, quam cum otiosus. Certe pro arbitrio accersio, quos volo, adque adiungo mihi, quos magis diligo aut quos aptiores arbitror; nemo interpellat, nemo interpolat. Tunc ergo te magis teneo et de scripturis confero et prolixiorem simul sermonem caedimus.

Da ja auch dir unsere Praxis des brieflichen Austauschs gefällt, in dem unter Abwesenden gleichsam ein Gespräch unter Anwesenden stattfindet, will ich regelmäßiger fortfahren, dich in meinen Schreiben anzusprechen, und dies auch, wenn ich alleine bin. Denn niemals bin ich weniger allein, als wenn ich allein zu sein scheine, und niemals weniger müßig, als wenn ich in Muße bin. Ganz wie es mir beliebt, rufe ich mir diejenigen herbei, die ich möchte, und ich geselle mich denjenigen zu, die ich ganz und gar schätze oder die ich gerade für passend halte; keiner darf unterbrechen, keiner darf verfälschen. Dann also habe ich dich ganz und gar bei mir, ich tausche mich mit dir über die heiligen Schriften aus und unser Gespräch zieht immer weitere Kreise.

Indem sie Freundschaft immer wieder zum Gegenstand ihrer Korrespondenz machen, stellen die christlichen Autoren des 4. Jh.s diese in den Dienst einer menschlichen Regung und Form der Gemeinschaftsbildung, welche in der christlichen Literatur bis dahin nur ausnahmsweise, etwa im Octavius des Minucius Felix, eine Rolle gespielt hat. ${ }^{56}$ In der Tat lässt sich im christlichen Kontext eine

2006; zu Augustinus' Freundschaftskonzept und zur Bedeutung von Ciceros Laelius für dieses s. Monagle 1971 und vor allem van Bavel 1987.

54 S. Thraede 1970, 125-132. Ambrosius hat diese Vorstellung analog zu Cicero in seinen Briefen auch theoretisch reflektiert (vgl. ebd., 183-185 zu Ambr. epist. 47 und 66; s. auch knapp Zelzer 1987, 204-206). Weiterhin zu nennen wären Ambr. epist. 33 und 48.

55 Ambr. epist. 33, 1 (Maur. 49); Übersetzung: G.M.M. Vgl. ähnlich statt vieler Hieronymus an Florentius aus dem Jahr 374 (s. Stowers 1986, 69) und Paulinus von Nola epist. 23 an Severus vom Jahre 400.

56 In Octavius 1, 3 rekurriert Minucius Felix auf die auch hier zur Debatte stehende Vorstellung, dass Freunde über eine gemeinsame Seele verfügten, wenn er sich rückblickend über sein Verhältnis zum verstorbenen Freund Octavius in sichtlicher Anlehnung an Cicero folgendermaßen äußert: nec inmerito discedens vir eximius et sanctus inmensum sui desiderium nobis reliquit, utpote cum et ipse tanto nostri semper amore flagraverit, ut et in ludicris et seriis pari mecum voluntate concineret eadem velle vel nolle: crederes unam mentem in duobus fuisse divisam (vgl. auch ebd., 4, 6; s. White 1992, 3f.; Pizzolato 1993, 244-246). 
ambivalente Haltung gegenüber der Freundschaft beobachten, welche sich aus deren tendenziell elitärem Charakter ableitet. ${ }^{57}$ Dieser gegenübergestellt wird die Menschenfreundlichkeit Jesu, welche der Christ jedem Menschen schulde, so fern dieser ihm auch stehen mag. ${ }^{58}$ Aus ihrer Perspektive musste die Kernbedeutung des antiken Freundschaftsbegriffs als Beziehung zwischen bewusst ausgewählten Personen zweifelsohne fragwürdig werden, zumal in der antiken Philosophie mehrfach empfohlen wird, bei der Bildung von Freundschaften äußerst restriktiv vorzugehen, da die einem Freund zustehende Aufmerksamkeit nur wenigen zuteilwerden könne, ohne an der notwendigen Intensität Schaden zu nehmen. ${ }^{59}$

Mit ihren Freundschaftsbriefen geben die genannten christlichen Autoren des 4. Jh.s folglich Einblick in Beziehungen, die im christlichen Denken zunächst keinen expliziten Ort haben, sondern eher ein vorchristliches Freundschaftsideal kontinuieren und dabei durchaus auch dessen elitäre Implikationen nicht aus den Augen verlieren. ${ }^{60}$ Und dementsprechend verwenden sie ihre Korrespondenz nicht nur zum freundschaftlichen Gedankenaustausch, sondern sie verstehen diese explizit auch als Möglichkeit, sich ihrer Freundschaft selbst zu versichern und

57 Zum Problemfeld s. ebd., 230-233.

58 Entsprechend bevorzugt das frühe Christentum den Begriff der Brüderlichkeit (s. Konstan 1997, 156f.). Die Termini pí $\lambda$ os und $\varphi \imath \lambda i ́ \alpha$ finden sich bereits im Neuen Testament eher selten, wenngleich Jesus in Joh 15, 13-15 seine Jünger als Freunde bezeichnet (vgl. auch 3 Joh 12, wo die Anrede „Freund“ das Mitglied der johanneischen Gemeinde meint; vgl. hierzu Mitchell 1997, 257-259); s. Stählin 1974, 159-169 zur Verwendung des Begriffs pí̉os im Neuen Testament; vgl. auch Klauck 1991; White 1992, 46-53; Pizzolato 1993, 228-238 (zur Stelle s. ebd., 233) und Mitchell 1997. Zur weiten Verwendung des Begriffs Freundschaft bezogen auf die gesamte Menschheit vgl. die Beispiele bei Konstan 1997,

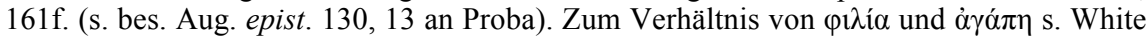
1992, 45 sowie in Bezug auf den spätantiken christlichen Brief, in welchem die beiden Termini allerdings immer wieder kovergieren, Thraede 1970, 125-146.

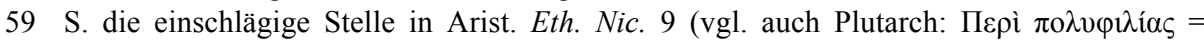
Moralia 93A-97B). Eine größere Anzahl von Freunden weist in Richtung von ó $\mu$ óvor $\alpha$, welche eher ein allgemeines gesellschaftliches Beziehungsgeflecht meint; vgl. zum Problemfeld White 1992, 26f. und Trout 1999, 209-211; zum Freundschaftsbegriff des Aristoteles s. knapp Schroeder 1997.

60 Dass sich Christen ab dem 4. Jh. intensiv mit dem Konzept der heidnischen Freundschaft auseinanderzusetzen beginnen, bedeutet White 1992, 4f. Insbesondere Ambrosius von Mailand hat sich in De officiis ministrorum 3, 125-138 dem Thema Freundschaft gewidmet und sich dabei eingehend mit Ciceros Laelius auseinandergesetzt; vgl. Sr. Mary 1948; Fürst 1996, 181f.; White 1992, 111-128 und Pizzolato 1993, 269-276. Allgemein zum Verständnis von Freundschaft in spätantiken christlichen Kreisen s. Konstan 1997, 149 173. Anstelle von amicitia wird in diesen vermehrt der Begriff der caritas verwendet, der Freundschaft in Christus und damit eine der heidnischen Variante überlegene Form meint (vgl. ebd., 157f.). Besonders deutlich wird dies bei Ambrosius von Mailand markiert, der insgesamt stark an jenem Freundschaftskonzept festhält, das im lateinischen Westen von Cicero festgeschrieben worden ist. Demgegenüber zeigen die anderen hier angesprochenen Autoren mehr oder weniger starke christliche Umdeutungen des Freundschaftsgedankens, die sich indes allein auf die Frage nach dem Ursprung von Freundschaft, nicht aber auf deren Wesen an sich bezieht. 
diese damit über die räumliche Distanz hinweg aufrechtzuerhalten. ${ }^{61}$ In ihrer gelegentlichen Verwendung des Briefs als Freundschaftserweis, welcher die räumliche Trennung im Geiste aufzuheben vermag, stehen bereits sie wie Salvian und Ruricius in einer Tradition, die ihren Ursprung in der heidnisch-antiken Briefkultur hat und in der christlichen Epistolographie bis dahin keine Parallele aufweist. $^{62}$

Somit vollziehen bereits die hier in aller Knappheit angesprochenen christlichen Briefsteller des 4. und beginnenden 5. Jh.s keinen radikalen Schnitt mit der vorchristlichen Briefpraxis. ${ }^{63}$ Zusammen mit den beiden gallischen Autoren Salvian von Marseille und Ruricius von Limoges repräsentieren sie eine christliche Briefkultur, die einerseits kein Interesse an der expliziten Bezugnahme auf die großen Namen der heidnisch-antiken Epistolographie hat, auf der anderen Seite aber grundlegende Aspekte der von diesen kodifizierten Briefpraxis kontinuiert. ${ }^{64}$ Damit erweisen sie sich durchaus als Erben einer vorchristlichen Kommunikationskultur, die sich nicht nur im Brief realisiert, sondern in diesem auch das zentrale Medium ihrer Stilisierung als wesentliches Element aristokratischer Lebensform findet. ${ }^{65}$

61 Die von christlichen Epistolographen der Spätantike gepflegten amicitia-Beziehungen machen an Glaubensgrenzen übrigens keinen Halt; vgl. Matthews 1984, 87-98 mit Blick auf Ambrosius von Mailand. Dass das Briefritual sogar die Kommunikation über religöse Konflikte hinweg ermöglichte, s. ebd., 91. Damit soll freilich nicht geleugnet werden, dass das Verhältnis zwischen Christen und Heiden im 4. Jh. insgesamt unproblematisch gewesen sei: vgl. statt vieler Thrams 1992.

62 Dass die heidnischen Epistolographen des 4. Jh.s die Freundschaftsepistel weiterführen, ist vor diesem Hintergrund selbstverständlich. $\mathrm{Zu}$ deren Verwendung bei Symmachus s. grundlegend Bruggisser 1993; allgemein zu Symmachus, dem produktivsten Briefsteller des Jahrhunderts, s. Matthews 1984, 62, 64 et passim; Matthews 1975, 1-12 sowie die Beiträge in Paschoud 1986; als tragischen Repräsentanten des untergehenden Heidentums zeichnet ihn Klein 1971.

63 Dass sich christliche Epistolographie selbstredend vor den allgemeinen sozialen und kulturellen Bedingungen der Spätantike situiert, betont Stowers 1986, 27-36 (eine exemplarische Sammlung von Freundschaftsbriefen heidnischer und christlicher Provenienz findet sich ebd., 58-70).

64 Dass insbesondere Ambrosius von Mailand den Anschluss an die vorchristliche Tradition des literarischen Privatbriefs sucht, bedeutet Thraede 1970, 190. Zelzer 1976, 15f. und Zelzer 1990 plädiert im Anschluss an den ersten modernen Editor der Ambrosius-Briefe Faller sogar dafür, dass deren Anordnung in zehn Büchern auf Ambrosius selbst zurückgehe, welcher damit die Briefsammlung des Plinius d. J. habe imitieren wollen (vgl. zu letzterem schon Zelzer 1987, die ebd., 206 freilich auch nahelegt, wie intensiv Ambrosius die Briefe Ciceros rezipiert hat); kritisch der These gegenüber, dass Ambrosius seine Briefe selbst in zehn Bücher eingeteilt habe, steht Mazières 1974; die Diskussion fasst zusammen Savon 1995, welcher der These einer bewussten Plinius-imitatio bei Ambrosius ebenfalls kritisch gegenübersteht.

65 In carm. 24, 481-483 gibt Paulinus von Nola an, dass Bildung und Herkunft grundlegende Statusmerkmale darstellen. An solcher Selbstbeschreibung wie auch daran, dass Paulinus seine Briefpartner im Kreis gebildeter Aristokraten findet, ändert sich nach seinem Umzug von Gallien ins Kloster nach Nola nichts: vgl. Mratschek 2002, 325. 
Charakteristisch für all diese Autoren ist folglich, dass sie ihre Korrespondenz zwar durchaus vorrangig für pastorale, spirituelle und theologische Anliegen einsetzen ${ }^{66}$ und sich damit im Horizont typisch christlicher Verwendungstraditionen des Briefs bewegen, wie sie von Paulus und der neutestamentlichen Epistolographie begründet ${ }^{67}$ und hierauf etwa durch Cyprian von Karthago für den Bereich episkopaler Korrespondenz modellhaft adaptiert wurden. ${ }^{68}$ Trotzdem setzen sie daneben typische Funktionsfelder vorchristlicher Briefkultur fort, welche neben dem gelehrten Austausch vor allem im Horizont elitärer Gemeinschaftsbildung anzusiedeln sind. Bei aller christlichen Prägung im Bereich von Inhalt ${ }^{69}$ und einer Selbstmodellierung, die im Absender den Hirten, Seelsorger oder allgemein den spirituell-gläubigen Menschen hervorhebt, ${ }^{70}$ weisen die christlichen Briefkorpora seit dem 4. Jh. ihre Autoren damit genau besehen als Träger zweier Kulturen aus: einer christlichen sowie jener traditionell römisch-aristokratischen, der diese allesamt von ihrer Herkunft her entstammen ${ }^{71}$ und die sich in deren Korrespondenz unter anderem über die Kontinuität der Freundschaftsepistel bemerkbar macht.

IV.

Vor diesem Hintergrund gilt es auf das Verhältnis zwischen Ruricius von Limoges und Sidonius Apollinaris zurückzukommen, das Ausgangspunkt der vorliegenden Überlegungen war. Auch wenn sich jener nicht daran interessiert zeigt, seine Korrespondenz wie dieser explizit mit den Autoritäten vorchristlicher Epistolographie in Beziehung zu setzen, wäre es verfehlt, zwischen den beiden eine Generation auseinanderliegenden Epistolographen den Abbruch einer an den klassischen Modellen orientierten Briefliteratur im spätantiken Gallien zu verorten. Vielmehr erweist sich Sidonius Apollinaris mit seinem programmatischen Anschluss an die großen Namen heidnischer Epistolographie bis auf Cicero als ein besonderer Fall innerhalb einer christlichen Briefliteratur, die jene zwar in der

66 Ambrosius verhandelt in seinen Briefen freilich auch zahlreiche (kirchen-)politische Themen; vgl. statt vieler Dassmann 1996 und Nauroy 2003, 9-244 sowie speziell zum zehnten Buch seiner Korrespondenz aus überlieferungsgeschichtlicher Sicht Klein 1970.

67 Zur andersartigen Verwendung der Vorstellung, dass der Brief Präsenz im Geiste erzeuge, in den paulinischen Episteln s. Thraede 1970, 95-106; allgemein zur Verwendung des Freundschaftsbegriffs bei Paulus s. Mitchell 1997, 236-236.

68 Vgl. Thraede 1970, 109-111. Allgemein zu Cyprian von Karthago, seiner Biographie und deren historischem und geographischem Kontext s. Brent 2010.

69 Mathisen 1981, 96 mit Anm. 8 weist freilich zu Recht darauf hin, dass in den meisten Briefwechseln spätantiker kirchlicher Würdenträger etwa die Hälfte der Korrespondenz weltlichen Angelegenheiten vorbehalten bleibt.

70 Zur Modellierung des Paulus als Modell eines spirituell ausgerichteten Lebens im Briefwechsel des Ambrosius s. Turek 1998.

71 Vgl. White 1992, 53f. und Eigler 2003, 124 sowie bes. 130-138. 
Regel nicht als ihre Vorläufer benennt, die aber, wie die Kontinuität der Freundschaftsepistel belegt, inhaltlich und funktional trotzdem einiges mit diesen gemeinsam hat. Indem ein Ruricius von Limoges oder ein Salvian von Marseille wie bereits die christlichen Briefsteller des 4. Jh.s vor ihnen sich nicht nur über christliche Themen austauschen, sondern sich bereits wie Cicero oder Plinius d. J. brieflich ihrer freundschaftlichen Verbundenheit mit ihren Briefpartnern versichern, bestätigen sie mit ihrer Korrespondenz einen Befund, der auf anderen Feldern spätantiker Kulturgeschichte bereits gut dokumentiert ist: Die christianisierte Oberschicht Galliens, aber auch anderer Regionen des weströmischen Reichs hält in vielfältiger Weise an traditionellen aristokratischen Lebensformen fest, und dies sogar dann, wenn sich deren Vertreter zu einer asketischen Lebensweise entschließen. $^{72}$

In einem Aspekt steht Ruricius seinem älteren Landsmann und bischöflichen Mitbruder Sidonius indes doch näher als die übrigen hier erwähnten Epistolographen. Denn anders als diese hat er explizit hervorgehoben, dass die Verwendung des Briefs als Freundschaftsbeweis auf vorchristliche Vorbilder zurückgeht. Während Ruricius' Vorgänger sich des Freundschaftsbriefs wie selbstverständlich bedienen, ohne sich darin eines besonderen Traditionsbezugs versichern zu müssen, scheint es Ruricius offensichtlich wichtig gewesen zu sein, wenigstens ganz allgemein darauf hinzuweisen, dass er mit seinem Freundschaftsverständnis und einer dementsprechenden Indienstnahme seiner Korrespondenz in einer langen, bis weit in vorchristliche Zeit zurückreichenden Linie steht. Dabei siedelt sich sein zweimaliger sentenzenhafter Verweis auf die antiqui sapientes gleich zu Briefbeginn, durch den er den Anschluss an ein Freundschaftsverständnis vollzieht, aus welchem der Freundschaftsbrief seinen Sinn erhält, trotz des unspezifischeren Charakters durchaus auf einer vergleichbar programmatischen Ebene an wie Sidonius' Erwähnung jener Briefautoren, in deren Horizont er seine Briefsammlung verstanden wissen will. Mag sich Ruricius einer solchen Bezugnahme enthalten haben, weil er in einer derartigen literaturgeschichtlichen Verortung seiner epistolographischen Praxis keinen Wert mehr erkannt hat, im Hinblick auf die Indienstnahme seiner Korrespondenz für Bestätigung und Erhalt seiner Freundschaftsbeziehungen war es für ihn dennoch von Bedeutung, diese explizit im Horizont eines bis auf Cicero zurückgehenden Freundschaftsverständnisses zu verorten.

Die Gründe dafür, dass Ruricius eine auch in der christlichen Epistolographie der Spätantike allgegenwärtige Verwendungsweise brieflicher Kommunikation so deutlich als eine althergebrachte Praxis markiert, mögen in den kulturellen Bedingungen an der Wende vom 5. zum 6. Jh. n. Chr. zu suchen sein. So schrieben die angesprochenen christlichen Autoren des 4. Jh.s und mit gewissen Einschränkungen auch noch Ruricius' Landsmann Salvian von Marseille in einem intakten römischen Kulturraum, in dem sie sich als Christen zwar neu zu positionieren

72 Am Beispiel der skulpturalen Ausstattung in gallischen Villen aufgezeigt von Balmelle 2001; vgl. auch Stirling 2005. 
trachteten, dessen grundlegende Mentalitäten und Verhaltensmuster sie aber dennoch teilten. Dabei scheinen Freundschaftspflege und eine entsprechende Indienstnahme ihrer Korrespondenz bei aller Ambivalenz des Freundschaftsbegriffs im christlichen Denken zu jenen identitätsbildenden Aspekten der gebildeten römischen Oberschicht gehört zu haben, welche ihnen nicht als problematisch galten bzw. die sie mit ihrem stets herausgehobenen Rang innerhalb der christlichen Hierarchie zu vereinbaren wussten. Auf diese Weise bezeugen ihre Briefwechsel, dass sie auch als Christen im Hinblick auf bestimmte kulturelle Praktiken weiterhin als Vertreter der römischen Oberschicht agierten und keinen grundlegenden Schnitt mit deren Lebensweise vollzogen. ${ }^{73}$ Im Horizont epistolographischer Selbstmodellierung besteht der Unterschied zu ihren heidnischen Standesgenossen vor allem darin, dass sie jene Themenfelder römischer Briefkultur, welche deren Träger bis dahin zur programmatischen Selbstbeschreibung heranzogen, für diese Zwecke zwar ungenutzt ließen, diese aber selbst nicht preisgaben.

Demgegenüber situiert sich Ruricius' Korrespondenz vor einem kulturellen Hintergrund, in dem es nicht mehr darum geht, sich als Christ innerhalb der römischen Oberschicht zu positionieren und deren Mentalität zu transformieren, sondern in dem die römische Kultur selbst existentiell in Frage gestellt ist. ${ }^{74}$ Im Umfeld einer inzwischen vollständig auf die umliegenden barbarischen regna übergegangenen politischen Ordnung und einer entsprechenden ethnischen Realität sind es dabei vor allem die christlichen Würdenträger, die als Repräsentanten römischer Kultur und Bildung übrigbleiben. ${ }^{75}$ Innerhalb dieser Kommunikations-

73 Eine weitere dieser kulturellen Praktiken ist der Austausch von Büchern, welchen auch der Briefwechsel des Ruricius bezeugt. Zum Bücherkult der Spätantike, der in der Regel mehr über ein bestimmtes Interesse der Selbstinszenierung denn über die Bildung der sammelnden Person aussagt, s. Mratschek 2000. Freilich verengt sich der Bücheraustausch zunehmend auf Titel christlicher Autoren (vgl. Mathisen 2001, 107f.). Charakteristisch für christliche Intellektuelle der Spätantike ist folglich eine inhaltliche Neuorientierung bei gleichzeitiger Beibehaltung traditioneller kultureller Praktiken.

74 Mathisen 2001 setzt Ruricius zu Recht ans Ende einer das gesamte 5. Jh. währenden Übergangszeit, welche mit der Barbareninvasion $406 \mathrm{n}$. Chr. beginnt und mit der Expansion der Franken nach Aquitanien ab dem beginnenden 6. Jh. endet (für einen knappen historischen Abriss Südgalliens vom 4. bis zum 6. Jh. s. Balmelle 2001, 23-37). In diesen gut einhundert Jahren musste sich die eingesessene gallorömische Oberschicht an gänzlich neue politische wie ethnische Rahmenbedingungen anpassen. Eine Antwort darauf sei die ostentative Beibehaltung traditioneller, die soziale Ordnung bestätigender Kommunikationsformen gewesen (ebd., 102). Zum Umgang gelehrter gallorömischer Aristokraten mit der neuen ethnographischen Situation s. Chadwick 1955, 122-141 (Kap. „The Last of the Classics“); zur Entwicklung der gallischen Aristokratie im betreffenden Jh. vor dem Hintergrund der wechselvollen Ereignisgeschichte s. Stroheker 1948, 43-105, für die Zeit bis 425 Matthews 1975 sowie umfänglich und grundlegend Mathisen 1993.

75 Alle Epistolographen aus dem Gallien des 5. und beginnenden 6. Jh.s n. Chr. waren Bischöfe; vgl. Mathisen 1981. Zum Phänomen der gallischen Bischofsherrschaften s. grundlegend Heinzelmann 1976; Mathisen 1993, 89-104 sowie Jussen 1998, der luzide die Gründe herausarbeitet, weshalb die gallorömische Oberschicht ab dem 4. Jh. das Bischofsamt für sich entdeckt und dieses auf der Grundlage ihrer traditionellen Mentalität gegen 
gemeinschaft, deren Mitglieder zudem ein immer weitmaschigeres Netz bilden, ${ }^{76}$ geht es längst nicht mehr um die Verhandlung konkurrierender Selbstmodellierungen im Spannungsfeld von Christentum und Heidentum, sondern um die gegenseitige Versicherung, neben dem christlichen Leitungsamt das Erbe einer als überlegen empfundenen römischen Kultur zu verkörpern. ${ }^{77}$

Vor diesem Hintergrund erhält Ruricius' Verweis, dass er mit seinem Freundschaftsverständnis in einer bis auf Cicero zurückreichenden Tradition steht, seine spezifische Bedeutung. Was im 4. und beginnenden 5. Jh. noch der Affirmation traditioneller heidnischer Identität im Angesicht des sich etablierenden Christentums diente, erhält angesichts der grundlegend veränderten kulturellen Situation an der Wende zum 6. Jh. die Funktion eines fundamentalen Bekenntnisses zur römischen Kultur überhaupt ${ }^{78}$ und dient damit als Standesmerkmal und Abgrenzung einer zunehmend kleiner werdenden Gruppe gebildeter Christen ${ }^{79}$ gegenüber

das Konzept des asketischen Bischofs zu einem aristokratischen Herrschaftsamt transformiert hat. Vgl. auch den Beitrag von Steffen Diefenbach in diesem Band. Zur mentalen Verarbeitung der Barbareninvasion im spätantiken Gallien s. Chadwick 1955, 122-141 und Mathisen 1993, 39-49.

76 Vgl. in Bezug auf Ruricius Mathisen 1999, 52f. Zur Klage gallischer Literaten, dass literarisch gebildete Personen eine immer kleiner werdende Gruppe bildeten, s. Mathisen 1988, 48f. $\mathrm{Zu}$ den Migrationen gallischer Aristokraten infolge der Barbareninvasionen seit dem Beginn des 5. Jh.s n. Chr. s. Mathisen 1984. Freilich zeigt Mathisen auf, dass nach einer Welle von Auswanderungen die Anzahl der in Gallien verbliebenen aristokratischen Familien ab ca. 460 stabil blieb. Lim 2008, 168-170 bringt die Funktion des Briefs in spätantiken christlichen Kommunikationsnetzwerken mit jener des literarischen Dialogs in Verbindung, indem beide der Selbstkonstruktion einer ebenso gelehrten wie elitären Gesprächsgemeinschaft dienten. Dass sich die gelehrten Christen der Spätantike für ihre Selbstdarstellung vorzugsweise des Briefs und nicht des literarischen Dialogs bedient hätten, läge daran, dass deren Kommunikationsnetz inzwischen so grobmaschig geworden sei, dass auch realiter ein regelmäßiges Treffen zum mündlichen Austausch nicht mehr möglich gewesen sei. In einem Schreiben an Aeonius von Arles betont Ruricius (epist. 2, 16), dass Briefe Freundschaften zwischen Menschen ermöglichen, die sich nie gesehen haben (vgl. auch epist. 2, 51 an Censorius von Auxerre).

77 Dass der Briefverkehr der sozialen und familiären Kohäsion diente, bedeutet Mathisen 1981, 106. - Komplementär zur Epistolographie ist der in Anm. 73 genannte rege Austausch von Büchern zu sehen, der ebenfalls der gegenseitigen Vergewisserung dient, einer intellektuellen Elite anzugehören; vgl. Chadwick 1955, 15 und Mathisen 1988, 51f. In diesem Zusammenhang ist auch bedeutsam, dass sich die Verachtung der gallischen Intellektuellen für die Barbaren nicht an der von diesen ausgehenden Gefahr für die politische Ordnung, sondern an deren Unkultur entzündete. Vor diesem Hintergrund lässt sich das Streben nach einer verfeinerten Lebenswelt spätantiker Aristokraten als Bollwerk gegen die Barbaren begreifen; s. Mratschek 2008; vgl. auch Eigler 2003, 127.

78 Neben dem Austausch von Büchern zur gegenseitigen Begutachtung gehört in diesen Zusammenhang die hohe Bedeutung des convivium mit Freunden und Bekannten als Bestandteil des sozialen Lebens, der in der Spätantike gegenüber der Kaiserzeit nochmals an Bedeutung gewann; vgl. Rossiter 1991.

79 Diese immer kleiner werdende Gruppe von Literaten misst sich freilich immer höhere Bedeutung für die Tradierung antiker Bildung zu; vgl. Mathisen 1988, 45-48. 
einer zunehmend von illiteraten Barbaren geprägten Gesellschaft. ${ }^{80}$ Dabei ist es nicht unerheblich, dass Ruricius seine Verbundenheit mit der römischen Tradition im Kontext einer epistolaren Praxis markiert, welche bereits die christlichen Autoren des 4. und beginnenden 5. Jh.s allesamt ganz selbstverständlich und unkommentiert gepflegt haben. Während Sidonius' expliziter Anschluss an eine entsprechende literarische Tradition und deren prominente vorchristliche Namen in einer Linie mit heidnischen Strategien der Selbstvergewisserung steht, führt Ruricius somit eine Verwendungsweise antiker Korrespondenz auf ihre vorchristlichen Ursprünge zurück, die im Kreis der führenden christlichen Intellektuellen des 4. und 5. Jh.s unangefochten fortgesetzt wurde.

Freilich vermochte Ruricius im Brief an den Abt Pomerius, in dem er zum zweiten Mal auf die vorchristlichen Ursprünge seines Freundschaftsverständnisses verwies, für dieses auch auf eine biblische Entsprechung verweisen. Bei allem Interesse, sich in eine alte römische Tradition zu stellen, ist es Ruricius dennoch wichtig, dass diese in Einklang mit seiner christlichen Vorstellungswelt und den diese begründenden Texten gebracht werden kann. Insofern verkörpert Ruricius die typische Haltung christlicher Intellektueller der Spätantike gegenüber der heidnisch-antiken Bildungstradition, welche dieser zwar affirmativ gegenüberstehen, aber darauf achten, nur solche Aspekte zu tradieren, die in Einklang mit christlichen Normen zu bringen sind. So sehr das römische Bildungs- und Kultur-

80 Dass angesichts des politischen und gesellschaftlichen Machtverlusts der gallorömischen Eliten literarische Betätigung als eine der traditionellen aristokratischen Möglichkeiten, das otium zu verwenden, zum wesentlichen Standesmerkmal wird, s. Mathisen 1988, 50 52 sowie Mathisen 1993, 50-57, 105-118. Als Möglichkeit, im weiteren Sinne politischen Einfluss auszuüben, blieb nur noch die Übernahme geistlicher Ämter (vgl. Mathisen 1984, 167f.). Hierdurch verschafften sich die römischen Aristokraten einen Modus Vivendi mit den neuen barbarischen Herrschern, die diese Art der Einflussnahme akzeptierten. - Dass das Briefritual bereits im 4. Jh. Halt in einer Zeit des Wandels und der Unsicherheit diente, zeigt am Beispiel des Symmachus Matthews 1984, 80-82 auf. Sidonius weist in epist. 8, 2, 2 darauf hin, dass nach Rückzug des Imperiums aus Gallien für die Aristokraten nur noch die Möglichkeit bestand, sich durch Bildung von der Masse abzugrenzen: Nam iam remotis gradibus dignitatum, per quas solebat ultimo a quoque summus quisque discerni, solum erit posthac nobilitatis iudicium litteras nosse. S. auch epist. 3, 3, 3, wo Sidonius davon berichtet, dass nur noch die gallische Nobilität die lateinische Literatursprache pflege, während sich ansonsten das Keltische breitmache. Vgl. Mathisen 1988, 50-52 sowie Eigler 2003, 122. Dennoch fehlt es nicht an brieflicher Kommunikation mit Barbaren, wenngleich diese nur ein Randphänomen bleibt. In Bezug auf das Euvre des Ruricius vgl. Mathisen 2001, 110-112. Freilich grenzten sich die spätantiken gallischen Aristokraten auch gegen die ungebildete Unterschicht im Allgemeinen ab. Am Beispiel der SidoniusKorrespondenz herausgearbeitet von Kaufmann 1995, 221-263; zur negativen Bewertung der Landarbeit und zur pejorativen Verwendung des Begriffs rusticus s. Amherdt 2004. Bereits Paulinus von Nola erkennt in Barbaren keine adäquaten Briefpartner. Seine ablehnende Haltung den Barbaren gegenüber artikuliert sich beispielsweise in carm. 21, in welchem er seine Freude über den Sieg des Stilicho über Radagaisus bei Faesulae im Jahre 406 zum Ausdruck bringt; vgl. Mratschek 2002, 63. Allgemein zur Korrespondenz spätantiker Epistolographen mit Barbaren s. Everschor 2007, speziell zu Ruricius ebd., 228-239; vgl. auch Ladner 1976. 
erbe dadurch nurmehr selektiv rezipiert wird, belegt das Beispiel der Praxis epistolarer Freundschaftspflege im Kreis christlicher Briefsteller bis in die Zeit des Ruricius und noch darüber hinaus indes doch, dass dieses gleichwohl prägend auf Identität und Selbstverständnis christlicher Eliten in der Spätantike gewirkt hat.

Vor dem Hintergrund, dass am Ausgang der Spätantike die Träger römischer Bildung und Kultur mit den christlichen Eliten an den Bischofssitzen und in den Klöstern in eins fielen, ${ }^{81}$ hat es Ruricius dabei für angezeigt gehalten, sich selbst und den Mitgliedern seines Korrespondenznetzwerkes ihrer Zugehörigkeit zu dieser sich sukzessive verkleinernden Bildungselite zu vergewissern, indem er sie daran erinnert hat, dass sie mit der brieflichen Freundschaftsbekundung eine uralte Tradition fortsetzen. ${ }^{82}$ An die Stelle der literarischen Traditionsstiftung im Sinne des Sidonius Apollinaris tritt bei Ruricius gleichsam eine Art performativer Alternative, die sich in bewusster Anknüpfung und Fortsetzung eines Rituals artikuliert, das just von jenen Autoren in lateinischer Sprache begründet und an die christlichen Epistolographen ab dem 4. Jh. weitergegeben worden ist, die von Sidonius ehrfürchtig als Gewährsleute seiner Korrespondenz angesprochen werden. ${ }^{83}$ Wenngleich Sidonius damit tatsächlich als der letzte lateinischsprachige Epistolograph der Spätantike erscheint, der seinen kulturellen Standort über eine literarische Tradition zu bestimmen suchte, funktionalisiert Ruricius seine Korrespondenz damit nicht grundsätzlich anders. Über ihre Freundschaftsbriefe bezeugt die Korrespondenz des Ruricius somit die Persistenz antiker Briefkultur als identitätsstiftendes Ritual der römisch sozialisierten Elite im spätantiken Gallien über den traditionsbewussten Literaten Sidonius hinaus. Ihr spätes Ende wird sie erst bei Desiderius von Cahors im frühen 7 . Jh. finden, ${ }^{84}$ bevor sie in der Karolingerzeit unter veränderten kulturellen Vorzeichen, aber in vergleichbarer Verwendung wieder zu neuer Blüte erwachen wird. ${ }^{85}$

81 S. Anm. 75; vgl. auch Mratschek 2002, 48 zur Bedeutung des Klerus für die Tradierung von Literatur und Bildung ab dem 5. Jh.

82 Demgegenüber verbinden die heidnischen Autoren des 4. Jh.s Bildung dezidiert noch mit der Zugehörigkeit zur alten Religion. Am Beispiel der Korrespondenz zwischen Symmachus und Nicomachus Flavianus aufgezeigt von Matthews 1984, 83-86.

83 In beiden Fällen geht es um kulturelle Bewahrung. Ähnliche Intention hat das Sammeln von Büchern. Vgl. Ruricius epist. 2, 17, in dem die Übertragung eines alten Papyruskodex auf Pergament als Akt der Zukunftssicherung von Bildung begründet wird.

84 S. den anschließenden Beitrag von Ralph W. Mathisen.

85 Vgl. hierzu Steckel 2011, 242-376. 


\section{Literaturverzeichnis}

\section{Primärliteratur}

Ambrosius von Mailand, Epistulae et acta: Sancti Ambrosii opera, pars X 1: Epistularum libri I-VI, rec. Otto Faller (CSEL 82,1), Wien 1968; Sancti Ambrosii opera, pars X 2: Epistularum libri VII-VIIII, rec. Michaela Zelzer (CSEL 82, 2), Wien 1990; Sancti Ambrosii opera, pars X 3: Epistularum liber decimus. Epistulae extra collectionem. Gesta concili Aquileiensis, rec. Michaela Zelzer (CSEL 82, 3), Wien 1982.

Minucius Felix, Octavius: M. Minucius Felix, Octavius. Lateinisch/Deutsch, hg. und übers. von Bernhard Kytzler, Stuttgart/Leipzig 1993.

Paulinus von Nola, Epistulae: Sancti Pontii Meropii Paulini Nolani opera, pars 1: Epistulae, rec. Wilhelm von Hartel (CSEL 29), Wien ${ }^{2} 1999$ ( $\left.{ }^{1} 1894\right)$.

Ruricius von Limoges, Epistulae: Foebadius, Victricius, Leporius, Vincentius Lerinensis, Evagrius, Ruricius, cura et studio Roland Demeulenaere (CCSL 64), Turnhout 1985, 303-415.

Salvianus von Marseilles, Epistulae: Salviani Presbyteri Massiliensis opera omnia, rec. et commentario critico instr. Franz Pauly (CSEL 8), Wien 1883, 201-223.

Sidonius Apollinaris, Carmina: Sidoine Apollinaire, Euvres, Bd. 1: Poèmes. Texte établi et traduit par André Loyen, Paris 1960 (ND Paris 2003).

Sidonius Apollinaris, Epistulae: Sidoine Apollinaire, Euvres, Bd. 2-3: Lettres. Texte établi et traduit par André Loyen, Paris 1970 (ND Paris 2003).

2. Übersetzungen (soweit nicht Bestandteil der oben genannten Editionen) und Kommentare

Kasten (1959): M. Tulli Ciceronis Epistularum ad familiares libri XVI - Marcus Tullius Cicero an seine Freunde, lateinisch-deutsch, hg. und übers. Von Helmut Kasten, München $1959\left({ }^{3} 1980\right)$.

Köhler (1995): Helga Köhler, C. Sollius Apollinaris Sidonius: Briefe, Buch 1. Einleitung Text - Übersetzung - Kommentar, Heidelberg (Bibliothek der klassischen Altertumswissenschaften N.F. 96).

Mayer (1935): Des Presbyters Salvianus von Massilia erhaltene Schriften. Von der Weltregierung Gottes. Vier Bücher an die Kirche. Briefe, aus dem lateinischen übersetzt und mit Einleitung versehen von Anton Mayer, München 1935 (Bibliothek der Kirchenväter, 2. Reihe, 11).

Mathisen (1999): Ruricius of Limoges and Friends. A Collection of Letters from Visigothic Gaul, translated with introduction, commentary and notes by Ralph W. Mathisen, Liverpool (Translated Texts für Historians 30).

\section{Sekundärliteratur}

Amherdt (2004): David Amherdt, „Rusticus politicus. Esprit de caste? L'agriculture et la politique chez Sidoine Apollinaire. Réalité et lieux communs“, Hermes 132, 373-387.

Balmelle (2001): Catherine Balmelle, Les demeures aristocratiques d'Aquitaine. Société et culture de l'Antiquité tardive dans le Sud-Ouest de la Gaule, Bordeaux/Paris (Aquitania, Supplément 10). 
Bastiaensen (1964): Anton A. R. Bastiaensen, Le cérémonial épistolaire des chrétiens Latins. Origine et premiers développements, Nijmegen (Graecitas et Latinitas Christianorum primaeva, Supplementa 2).

Brent (2010): Allen Brent, Cyprian and Roman Carthage, Cambridge.

Bruggisser (1993): Philippe Bruggisser, Symmaque ou le rituel épistolaire de l'amitié littéraire. Recherches sur le premier livre de la correspondance, Freiburg/Schweiz (Paradosis 35).

Canellis (2006): Aline Canellis, „Une amitié par lettres et ses aléas: la correspondance entre Paulin de Nole et Jérôme“, in: Patrick Laurence u. François Guillaumont (Hgg.), Epistulae antiquae IV. Actes du IV colloque international ,"l'épistolaire antique et ses prolongements européens " (Université François Rabelais Tours, 2-3 décembre 2004), Löwen/Paris, 215-232.

Chadwick (1955): Nora K. Chadwick, Poetry and Letters in Early Christian Gaul, London.

Cugusi (1983): Paolo Cugusi, Evoluzione e forme dell'epistolografia Latina nella tarda repubblica e nei primi due secoli dell'impero. Con cenni sull'epistolografia preciceroniana, Rom.

Dassmann (1996): Ernst Dassmann, „Die Kirchenpolitik des Ambrosius von Mailand“, in: Ernst Dassmann (Hg.): Kirchengeschichte, Bd. 2, 1: Konstantinische Wende und spätantike Reichskirche, Stuttgart/Berlin/Köln, 78-83.

Egelhaaf-Gaiser (2010): Ulrike Egelhaaf-Gaiser, „Bleibende Klänge: Das hymnische Briefsiegel des Bischofs Sidonius (epist. 9, 16)“, Millennium 7, 257-292.

Eigler (2003): Ulrich Eigler, Lectiones vetustatis. Römische Literatur und Geschichte in der lateinischen Literatur der Spätantike, München (Zetemata 115).

Everschor (2007): Britta Everschor, Die Beziehungen zwischen Römern und Barbaren auf der Grundlage der Briefliteratur des 4. und 5. Jahrhunderts, Bonn.

Fabre (1949): Pierre Fabre, Saint Paulin de Nole et l'amitié chrétienne, Paris (Bibliothèque des Écoles Françaises d'Athènes et de Rome 167).

Fiore (1997): Benjamin Fiore SJ: „The Theory and Practice of Friendship in Cicero“, in: Fitzgerald 1997, 59-76.

Fitzgerald (1997): John T. Fitzgerald (Hg.), Greco-Roman Perspectives on Friendship, Atlanta (Resources for Biblical Study 34).

Fürst (1996): Alfons Fürst, Streit unter Freunden. Ideal und Realität in der Freundschaftslehre der Antike, Stuttgart/Leipzig (Beiträge zur Altertumskunde 85).

Gauly (2008): Bardo Maria Gauly, „Magis homines iuvat gloria lata quam magna. Das Selbstlob in Plinius' Briefen und seine Funktion“, in: Alexander H. Arweiler u. Bardo M. Gauly (Hgg.), Machtfragen. Zur kulturellen Repräsentation und Konstruktion von Macht in Antike, Mittelalter und Neuzeit, Stuttgart, 187-204.

Griffe (1960): Elie Griffe, „Les sermons de Fauste de Riez. La ,Collectio Gallicana“ du Pseudo-Eusèbe“, Bulletin de la littérature ecclésiastique 61, 27-38.

Gualandri (1979): Isabella Gualandri, Furtiva lectio. Studi su Sidonio Apollinare, Mailand (Testi e documenti per lo studio dell'antichità 62).

Hagendahl (1952): Harald Hagendahl, La correspondance de Ruricius, Göteborg (Acta Universitatis Gotoburgensis 58, 3).

Harries (1994): Jill Harries, Sidonius Apollinaris and the Fall of Rome AD 407-485, Oxford. 
Heinzelmann (1976): Martin Heinzelmann, Bischofsherrschaft in Gallien. Zur Kontinuität römischer Führungsschichten vom 4. bis zum 7. Jahrhundert. Soziale, prosopographische und bildungsgeschichtliche Aspekte, München (Beihefte der Francia 5).

Jussen (1998): Bernhard Jussen, „Liturgie und Legitimation, oder: Wie die GalloRomanen das römische Reich beendeten“, in: Reinhard Blänkner u. Bernhard Jussen (Hgg.), Institutionen und Ereignis. Über historische Praktiken und Vorstellungen gesellschaftlichen Ordnens, Göttingen (Veröffentlichungen des Max-Planck-Instituts für Geschichte 138), 75-136.

Kaufmann (1995): Frank-Michael Kaufmann, Studien zu Sidonius Apollinaris, Frankfurt a.M. u.a. (Europäische Hochschulschriften, Reihe 3, 681).

Klauck (1989): Hans-Josef Klauck, „Gütergemeinschaft in der klassischen Antike, in Qumran und im Neuen Testament, in: ders., Gemeinde - Amt - Sakrament. Neutestamentliche Perspektiven, Würzburg, 69-99.

Klauck (1991): Hans-Josef Klauck, „Kirche als Freundesgemeinschaft? Auf Spurensuche im Neuen Testament", Münchener theologische Zeitschrift 42, 1-14.

Klein (1970): Richard Klein, „Die Kaiserbriefe des Ambrosius von Mailand. Zur Problematik ihrer Veröffentlichung“, Athenaeum 58, 335-271.

Klein (1971): Richard Klein, Symmachus. Eine tragische Gestalt des ausgehenden Heidentums, Darmstadt (Impulse der Forschung 2).

Konstan (1997): David Konstan, Friendship in the Classical World, Cambridge.

Krasser (1993): Helmut Krasser, „Claros colere viros oder über engagierte Bewunderung“, Philologus 137, 62-71.

Ladner (1976): Gerhart B. Ladner, „On Roman Attitudes Towards Barbarians in Late Antiquity“, Viator 7, 1-26.

Lemke (2000): Harald Lemke, Freundschaft. Ein philosophischer Essay, Darmstadt.

Lim (2008): Richard Lim, „Christians, dialogues and patterns of sociability in late antiquity“, in: Simon Goldhill (Hg.), The End of Dialogue in Antiquity, Cambridge, 151-172.

Loyen (1943): André Loyen, L'esprit précieux en Gaule aux derniers jours de l'empire, Paris.

Ludolph (1997): Matthias Ludolph, Epistolographie und Selbstdarstellung. Untersuchungen zu den ,Paradebriefen 'Plinius' des Jüngeren, Tübingen (Classica Monacensia 17).

Mathisen (1981): Ralph W. Mathisen, „Epistolography, Literary Circles and Family Ties in Late Roman Gaul", Transactions of the American Philological Association 111, 95-109 (wiederabgedruckt in: Mathisen 1991, 13-27).

Mathisen (1984): Ralph W. Mathisen, „Emigrants, Exiles and Survivors: Aristocratic Options in Visigothic Aquitania“, Phoenix 38, 159-170 (wiederabgedruckt in: Mathisen 1991, 1-12).

Mathisen (1988): Ralph W. Mathisen, „The Theme of Literary Decline in Late Roman Gaul", Classical Philology 83, 45-52 (wiederabgedruckt in: Mathisen 1991, 45-52).

Mathisen (1989): Ralph W. Mathisen, Ecclesiastical Factionalism and Religious Controversy in Fifth-Century Gaul, Washington.

Mathisen (1991): Ralph W. Mathisen, Studies in the History, Literature and Society of Late Antiquity, Amsterdam.

Mathisen (1993): Ralph W. Mathisen, Roman Aristocrats in Barbarian Gaul. Strategies for Survival in an Age of Transition, Austin. 
Mathisen (1998): Ralph W. Mathisen, „The Codex Sangallensis 190 and the Transmission of the Classical Tradition", International Journal of the Classical Tradition 5, 163194.

Mathisen (2001): Ralph W. Mathisen, „The Letters of Ruricius of Limoges and the Passage from Roman to Frankish Gaul", in: Ralph W. Mathisen u. Danuta Shanzer (Hgg.), Society and Culture in Late Antique Gaul. Revisiting the Sources, Aldershot u.a., $101-115$.

Matthews (1975): John Matthews, Western Aristocracies and Imperial Court A.D. 364425, Oxford.

Matthews (1984): John Matthews, „The Letters of Symmachus“, in: James W. Binns (Hg.), Latin Literature of the Fourth Century, London/Boston, 58-99 (wiederabgedruckt in: John Matthews, Political Life and Culture in Late Roman Society, London 1985 mit der gleichen Seitenzahl).

Mazières (1974): Jean-Pierre Mazières, „Un principe d'organisation pour le recueil des Lettres d'Ambroise de Milan", in: Yves-Marie Duval (Hg.), Ambroise de Milan. XVI Centenaire de son élection épiscopale, Paris, 199-218.

Mitchell (1997): Alan C. Mitchell, „,Greet the Friends by Name‘: New Testament Evidence for the Greco-Roman Topos on Friendship“, in: Fitzgerald 1997, 225-262.

Monagle (1971): John F. Monagle, „Friendship in St. Augustine's Biography. Classical Notion of Friendship“, Augustinian Studies 2, 81-92.

Mratschek (2000): Sigrid Mratschek, „Codices vestri nos sumus. Bücherkult und Bücherpreise in der christlichen Spätantike“, in: Andreas Haltenhoff u. Fritz-Heiner Mutschler (Hgg.), Hortus litterarum antiquarum. Festschrift für Hans Armin Gärtner zum 70. Geburtstag, Heidelberg (Bibliothek der klassischen Altertumswissenschaften N.F. 109), 369-380.

Mratschek (2002): Sigrid Mratschek, Der Briefwechesel des Paulinus von Nola. Kommunikation und soziale Kontakte zwischen christlichen Intellektuellen, Göttingen (Hypomnemata 134).

Mratschek (2008): Sigrid Mratschek, „Identitätsstiftung aus der Vergangenheit: Zum Diskurs über die trajanische Bildungskultur im Kreis des Sidonius Apollinaris", in: Therese Fuhrer (Hg.), Die christlich-philosophischen Diskurse der Spätantike: Texte, Personen, Institutionen, Stuttgart, 363-380.

Nauroy (2003): Gérard Nauroy, Ambroise de Milan. Ècriture et esthétique d'une exégèse pastorale, Bern u.a. (Recherches en littérature et spiritualité 3).

Paschoud (1986): François Paschoud (Hg.), Colloque genevois sur Symmaque à l'occasion du mille six centième anniversaire du conflit de l'autel de la Victoire, Paris.

Peter (1901): Hermann Peter, Der Brief in der römischen Literatur. Litterargeschichtliche Untersuchungen und Zusammenfassungen, Leipzig (ND Hildesheim 1965).

Pizzolato (1993): Luigi Pizzolato, L’idea di amicizia nel mondo antico classico e cristiano, Turin.

Radicke (1997): Jan Radicke, „Die Selbstdarstellung des Plinius in seinen Briefen“, Hermes 125, 447-469.

Rossiter (1991): Jeremy Rossiter, „Convivium and Villa in Late Antiquity“, in: William J. Slater (Hg.), Dining in a Classical Context, Ann Arbor, 199-214.

Savon (1995): Hervé Savon, „Saint Ambroise a-t-il imité le recueil de lettres de Pline le Jeune?", Revue des études Augustiniennes 41, 3-17.

Schroeder (1997): Frederic M. Schroeder, „Friendship in Aristotle and Some Peripatetic Philosophers“, in: Fitzgerald 1997, 35-57. 
Sr. Mary (1948): Sr. Mary Dorothea, „Cicero and Saint Ambrose On Friendship“, Classical Journal 43, 219-222.

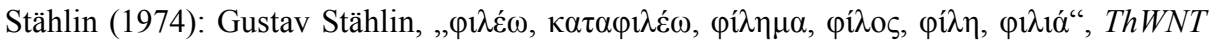
9, 112-169.

Steckel (2011): Sita Steckel, Kulturen des Lehrens im Früh-und Hochmittelalter. Autorität. Wissenskonzepte und Netzwerke von Gelehrten, Köln/Weimar/Wien (Norm und Struktur 39).

Stevens (1933): Courtenay E. Stevens, Sidonius Apollinaris and His Age, Oxford (ND Westport 1979).

Stirling (2005): Lea M. Stirling, The Learned Collector. Mythological Statuettes and Classical Taste in Late Antique Gaul, Ann Arbor.

Stowers (1986): Stanley K. Stowers, Letter Writing in Greco-Roman Antiquity, Philadelphia (Library of Early Christianity 5 ).

Stroheker (1948): Karl Friedrich Stroheker, Der senatorische Adel im spätantiken Gallien, Reutlingen (ND Darmstadt 1970).

Thraede (1970): Klaus Thraede, Grundzüge griechisch-römischer Brieftopik, München (Zetemata 48).

Thrams (1992): Peter Thrams, Christianisierung des Römerreiches und heidnischer Widerstand, Heidelberg.

Tibiletti (1981): Carlo Tibiletti, „Fausto di Riez nei giudizi della critica“, Augustinianum 21, 567-587.

Tibiletti (1986): Carlo Tibiletti, „Polemiche in Africa contro i teologi provenzali“, Augustinianum 26, 499-517.

Trout (1999): Dennis E. Trout, Paulinus of Nola. Life, Letters, and Poems, Berkeley/Los Angeles/London.

Turek (1998): Waldemar Turek, „Paolo maestro di vita spirituale nelle Lettere di Ambrogio“, in: Paolo Padovese (Hg.), Atti del V simposio di Tarso su S. Paolo Apostolo, Rom (Turchia: La Chiesa e la sua storia 12), 269-279.

van Bavel (1987): Tarsicius J. van Bavel, „The influece of Cicero's ideal of friendship on Augustine", in: Jan den Boeft u. Johannes van Oost (Hgg.), Augustiniana Traiectina (Communications présentées au Colloque International d'Utrecht, 13-14 novembre 1986), Paris, 59-72.

White (1992): Carolinne White, Christian Friendship in the Fourth Century, Cambridge.

Zelzer (1976): Michaela Zelzer, „Die Briefbücher des hl. Ambrosius und die Briefe extra collectionem", Anzeiger der Österreichischen Akademie der Wissenschaften. Philosophisch-historische Klasse 112 (1975), Wien, 7-23.

Zelzer (1987): Michaela Zelzer: „Ambrosius von Mailand und das Erbe der klassischen Tradition“, Wiener Studien 100, 201-226.

Zelzer (1990): Michaela Zelzer, „Zur Komposition der Briefsammlung des hl. Ambrosius“, Studia Patristica 18, 4, 212-217. 


\title{
Desiderius of Cahors: Last of the Romans
}

\author{
Ralph W. Mathisen
}

In the fifth century, the western Roman Empire crumbled and was replaced by barbarian kingdoms. During and after this process, many persons have been identified as having been especially active in attempts to preserve or restore the Roman political, social, and cultural heritage, and, as a consequence have been endowed with the title "Last of the Romans". Edward Gibbon, for example, suggested Boethius as "the last of the Romans whom Cato or Tully could have acknowledged for their countryman". ${ }^{1}$ Some recent novels nominate Fl. Aëtius, Romulus Augustus, and Belisarius ("the last Roman general"). ${ }^{2}$ The French version of a German film based on the novel by Felix Dahn, Der Kampf um Rom, ${ }^{3}$ nominates as "Le dernier des Romains" a certain "Cornelius Cethegus, Prefect of Rome" (perhaps referring to the caput senatus of the same name), whose ambition was to recreate the western Roman Empire. ${ }^{4}$ And a 1997 video documentary nominates Justinian, a theme reprised in a 2002 book, with Justinian as "the last Roman emperor". 5 Other suggestions for this sobriquet include Stilicho in the early fifth century, Syagrius, and Aurelius Ambrosius in the late fifth century. ${ }^{6}$ The latest of the generally cited candidates for this title, it seems, is Pope Gregory the Great (590-604). ${ }^{7}$

But exactly a century ago there was another, even later, suggested contender for the title "Last of the Romans", who has not made any of the current "top ten" lists. This candidate comes from Gaul, in the mid seventh century CE. In 1911, Anthyme Saint-Paul, in his Histoire monumentale de la France, nominated Desiderius, ${ }^{8}$ bishop of Cahors from 636 until 655, as "le dernier des Romains".

$1 \quad$ Gibbon 1776 [1860], 289.

2 Store 2007; Murdoch 2006; Hughs 2009; note also Sivan 2011.

3 Dahn 1876-1878.

4 http://www.peplums.info/pep29.htm.

5 "Justinian: Last of the Romans": http://www.allmovie.com/work/i-caesar-justinian-last-ofthe-romans-220404; Baker 2002.

6 For a list see http://en.wikipedia.org/wiki/Last_of_the_Romans.

7 Ibid.

8 For Desiderius' origin, see Vita Desiderii 1, 20, 30, 35-36: for the vita, see B. Krusch, ed., in: Monumenta Germaniae historica, Scriptores rerum Merovingicarum (= MGH SS rer. Merov.) 4, 547-602, reprinted in CCSL 117, 343-401; and Poupardin 1900.

9 "Le dernier des Romains": Saint-Paul 1911, 52. 
Now, Saint-Paul was speaking only from the perspective of Desiderius' building activities, but one also could make the case that Desiderius deserves the title "last of the Romans" for a much wider range of reasons, and in order to do so, this study will present evidence relating to Desiderius' family background, cultural credentials, and posterity.

\section{Desiderius and His Circle}

For someone living in this period, Desiderius' life is remarkably well documented. We have the good fortune to possess not only a collection of letters written by and to him, but also a vita written perhaps a century after his death that made use of documents from his personal archives. ${ }^{10}$ According to his vita, Desiderius was born, perhaps around 590, at "Obrege", an unidentified place that apparently was in the neighborhood of Albi. ${ }^{11}$ The name of his father, Salvius, suggests that he was descended from, perhaps a grandson of, Salvius, bishop of Albi c.574-584, ${ }^{12}$ who himself was succeeded by a Desiderius, ${ }^{13}$ which likewise suggests a family connection to Albi. In the first quarter of the seventh century, Desiderius and his two elder brothers Syagrius and Rusticus spent their youth at the court of King Chlothar II (584-629) in the company of the young prince Dagobert I (born ca. 603) and the scions of several other aristocratic families, including Paulus, Arnulphus, Eligius, and Audoenus. ${ }^{14}$ The ties that were formed there lasted a lifetime.

In 623, Dagobert became king of Austrasia, and on the death of Chlothar in 629 he became king of all of Francia, including Burgundy and Aquitaine. He thus became the most powerful Merovingian monarch of the seventh century and, indeed, the last one to hold real power. In 634, after a defeat by the Slavs, he was compelled to make his four-year-old son Sigebert III king of Austrasia, and Sigebert became king on Dagobert's death in $639 .{ }^{15}$ Dagobert went down in history as "good king Dagobert" and a bronze throne attributed to him was used as late as the reign of

10 The letters have been edited three times: (1) Canisius 1601, 461-523, repr. in PL 87, $247-$ 66; (2) Arndt, MGH Epp. 3, 191-214, repr. in CCSL 117, 309-342; and (3) Norberg 1961. The vita likewise has three editions: (1) Labbe 1657, repr. in PL 87, 219-46; (2) Poupardin 1900; and (3) B. Krusch, MGH SS rer. Merov. 4, 547-602, repr. in CCSL 117, 343-401.

11 Vita Desiderii 1, 1: "Igitur Desiderius Cadurcensis episcopus Obrege Galliarum oppido oriundus fuit"; Kirsch 1908 suggests a derivation of "Obrege" from the Antobroges, a Celtic people, but it may come from Nitiobriges, another local Celtic people; see also Cabie 1894.

12 Greg. Tur. Hist. 5, 45; see Duchesne 1907-15, 2, 43.

13 Greg. Tur. Hist. 8, 22: Post obitum sancti Salvii, hoc anno Desiderius Albigensibus episcopus datus est; see Duchesne 1907-15, 2, 43.

14 Vita Desiderii 2-3: Chlotharius autem pater inclyti Dagoberti monarchiam regni solus tenebat, a quo tres germani, id est Rusticus, Siagrius, et Desiderius, florentissime enutriti [...] Desiderius vero inter exercitatissimi palatii ministeria sedulo Deo vacans die noctuque orationibus insistebat [...] habebat enim amicos bonae fidei viros, Paulum scilicet, Arnulphum, Eligium, et Audoenum; see Vacandard 1897.

15 For the political history, see Wood 1994. 
Napoleon. Sigebert III, on the other hand, although he became a Christian saint, also became the first of the infamous rois fainéants.

Dagobert was known for having strong and generally dependable advisers around him from both secular and ecclesiastical backgrounds. Many of these were drawn from the friends of his youth, who not only served as advisers, government officials, and bishops, but also helped to counter the growing influence of powerful Mayors of the Palace. Many of these childhood friends became Merovingian VIPs in their own right, often finishing their careers as bishops. ${ }^{16}$ These included Audoenus Dado, first as referendarius of Dagobert and then as bishop of Rouen (640-684); ${ }^{17}$ Sulpicius as metropolitan bishop of Bourges (634-646) ${ }^{18}$ Eligius (588-60) first as royal moneyer and then as bishop of Noyon/Tournai; ${ }^{19}$ Arnulfus (c. 612-627) and his successor Abbo (c. 627-640) as bishops of Metz; and Paulus as bishop of Verdun († 648/9), not to mention Burgundofaro of Meaux (c. 630-675); and Wandregesilus (c. 570-667), who after serving at court founded the monastery that later bore his name. $^{20}$

Thus, from Desiderius' own family, Syagrius served as Count of Albi and patrician of Marseilles, Rusticus as bishop of Cahors, and Desiderius himself as thesaurarius ("treasurer") of both Chlothar and Dagobert. In 635, Syagrius died, and Desiderius was appointed to replace him at Marseilles. In the next year, 636, Rusticus was murdered, and Dagobert confirmed Desiderius as bishop of Cahors. ${ }^{21}$ As bishop, Desiderius put great efforts into the city infrastructure, restoring the walls, building and repairing churches and monasteries, and even repairing the water supply system with subterranean wooden pipes. ${ }^{22}$ While staying at his villa at Vuistrilingo ca. 655 , Desiderius fell ill and died; his body was interred in the church of St. Amantius at

16 Vita Desiderii 15: Habebat eo tempore plures Dominus Jesus in Galliis nobiles servos, Arverno Gallum, Bituricis Sulpitium, Rutena Verum, Agenno Salustium, Engolisma Ebargehenum, Petrogorico Austerium, Noviom[ag]o Eligium, Metis Arnulphum, Luco Austrasium, Mestarone Diodorum, Cadurca Desiderium.

17 Scheibelreiter 1989.

18 Vita Sulpicii: B. Krusch, ed., MGH SS rer. Merov. 4, 364-380.

19 See, e.g., Fouracre 1979.

20 See, e.g., Borias 1987.

21 Vita Desiderii 1, 4-5: Itaque honestissimo genitore Salvio, ut dictum est, iam defuncto, fratre quoque Siagrio in fascibus constituto, Rusticus germanus eius episcopatum Cadurcae urbis adipiscitur: decesserat enim ipso tempore Eusebius praefati municipii antistes, qui successor in episcopatum sanctae memoriae Ursicini fuerat [...] in anno autem septimo Dagoberti regis praedictus germanus eius Siagrius, dum Massiliae administrationem procuraret, deo iubente vitam finivit, pro quo rex Dagobertus gravi moerore percussus, solertissimum Desiderium loco praefecturae eius subrogare censuit. Rusticus episcopus cathedrae Cadurcinae praesidens, septimo autem et eo amplius anno pontificatus sui administrato, a perfidis et scelestis incolis interemptus est.

22 Desid. epist. 1, 13 (to Caesarius of Clermont): Praeterea credo, quod nec vobis lateat qualem egestatem de aqua quam fons praebeat in hac Cadurcina civitate habemus. Sed voluntas nobis inest, si possis permittit, ut per tubos ligneos subterraneo officio ad ipsam civitatem aquam ducere debeamus. proinde quia novimus, quod peritos ex hoc artifices haberes, precamur, ut compendium de ipsos faciatis. 
Cahors. In his extant will (649-650), Desiderius gave all his possessions, including his books, to the cathedral, the churches, and the monasteries of his episcopal city. ${ }^{23}$ So far, then, we have a typical Merovingian cursus honorum, a favored secular official who concluded his career as a bishop. ${ }^{24}$

Things become rather more interesting when we look at Desiderius' social circle. Later in life, Desiderius and the friends of his youth remembered their past times together. ${ }^{25}$ In one letter, Desiderius and Abbo of Metz reminded each other of the "good old days" at court: "In secular garb, we used to exchange stories in the company of the most serene prince Chlothar., ${ }^{26}$ And on another occasion Desiderius asked Audoenus Dado of Rouen to continue to grant to him "the one whom in the very flower of our early youth you once offered with a singular love", that is, Dado himself. ${ }^{27}$ Not to mention King Dagobert I himself, who also was part of this intimate circle of friendship and recollection, and whom Desiderius reminded of their "companionship, and the pleasure of the auspicious quality of youthfulness". ${ }^{28}$

\section{Literature, Culture, and Education}

What makes Desiderius circle of friends even more interesting is that they were bound together not just by shared personal and professional experiences, but also by shared cultural interests that were manifested in a literary circle that included an even wider range of Gallic ecclesiastics and bolsters the claims of Desiderius and his circle to be "the last of the Romans." And here, perhaps, one might smile and say, "Right, literary culture in the middle of seventh-century Gaul." For, unlike the fifth and even the sixth century, the seventh century did not produce a large number of surviving literary works of any genre, and those that were produced have not been admired for their Latinity; nor was there a Gallic literary renaissance parallel to the seventh-century burst of literary activity in Visigothic Spain. ${ }^{29}$ The literary culture of post-Roman Gaul in general and seventh-century Gaul in particular has not fared well in the eyes of modern-day critics. At best, the few writers whose works survive have been perceived as fighting a losing battle against an overwhelming tide of barbarism, soloecism, and stylistic infelicity. One is led to believe that the seventh cen-

23 Vita Desiderii 18-19.

24 See, e.g., Durliat 1979; Rey 1953; Sol 1936.

25 E.g., Desid. epist.1, 10.

26 Desid. epist. 1, 9 (to Abbo of Metz): Ut sicut nos sub saeculi habitu in contubernio serenissimi Chlothari principis mutuis solebamus revelare; and epist. 2.13, Abbo of Metz to Desiderius: Vos enim et in palatio regis, ubi innutriti fuistis, bene cogniti estis.

27 Desid. epist. 1.10 (to Audoenus Dado): "ut quem quondam in ipso flore primaevae juventutis unico mihi amore praebuisti, semper concedere digneris illum meum Dadonem."

28 Desid. epist. 1, 5 (to King Dagobert): Ipsa tamen recordatio contubernii, et dulcedo auspicatae indolis pubertatis.

29 Discussions of non-hagiographical aspects of seventh-century literature are rare, a few notable, albeit brief, exceptions being McKitterick 1981, and a 15-page chapter in Wood 1994. 
tury lies in the heart of the "Dark Ages", and that Roman cultural and especially literary traditions were far in the past. H.-I. Marrou, for example, stated baldly, "in the sixth century the darkness of barbarism descended, and culture declined in the West and threatened to disappear altogether [...] the Germanic invasions [...] destroyed Roman culture." ${ }^{, 30}$ Erich Auerbach asserted, "In Gaul, the last remnants of Roman culture collapsed" at the end of the sixth century. ${ }^{31}$ And speaking specifically of seventh-century Gaul, M.W. Laistner, disparagingly opined:

In truth, the literary output in Gaul between approximately 600 and 750 was deplorable both in quality and quantity. The notorious barbarism in style and language of Merovingian charters and other documents meets us also in the literary remains of that age. The hagiographical literature $[. .$.$] is exceedingly poor. { }^{32}$

One of the few to have anything good to say about seventh-century literature is Walter Goffart, who acknowledges Fredegarius as "a genuine historian, worthy of sustained study". 33 And Goffart also opines that the eighth-century Life of Desiderius of Cahors was of the same literary quality of Bede's Life of Wilfrid.

But before one condemns the seventh century out of hand, one might look at some redeeming factors. First of all, literary activity in seventh-century Gaul did not come to a complete halt. Liturgical collections include the so-called Gothic and Gallican missals. ${ }^{35}$ A few stray sermons and saints' lives, such as the late seventh century lives of Leudegarius of Autun and Eligius of Noyon, the Passio Leudegarii Augustodunensis and Vita Eligii Noviomensis, survive. ${ }^{36}$ At the same time, Defensor, a monk of Logiacum, compiled a Liber scintillarum, which was to become the medieval equivalent of a best seller. ${ }^{37}$ And works of a more secular nature include the "Fredegarius" Chronicle, ${ }^{38}$ not to mention Marculf's collection of formulae, if it is in fact to be dated to the late seventh century. ${ }^{39}$ And of course there were legal documents, canons of canons councils, and some very significant Libri canonum, such as the "Albi collection", which was created ca. 600 for bishop Dido of Albi by the

30 Marrou 1956, 443, 456-457.

31 Auerbach 1965, 262.

32 Laistner 1931, 138.

33 Goffart 1988, 12.

34 Goffart 1988, 289-90.

35 Griffe 1951; Morin 1941; van der Mensbrugghe 1959; Cabié 1972.

36 CCSL 117, 527-586; MGH SS rer. Merov. 4, 634-741.

37 CCSL 117, 1-234.

38 See Goffart 1988.

39 See Rio 2009. 
priest Perpetuus, ${ }^{40}$ who also might have been the writer of an unattributed Fragmentum mulomedicum preserved in Paris. ${ }^{41}$

Nor were educational opportunities quite as lacking or bad in the early seventh century as often has been thought. ${ }^{42}$ Bishop Sulpicius II (c. 620-640) of Bourges, for example, would have been a relative of the late sixth-century bishop Sulpicius I of Bourges, who was praised by Gregory of Tours: "He is in fact a man very noble and from the first-ranking senators of Gaul, well educated in rhetorical learning and, truly, in the metric arts second to none." ${ }^{43}$

Desiderius of Cahors's own cultural qualifications are stressed in his vita as if they still meant something:

Desiderius was raised with the greatest care by his parents; he was fully educated in literary studies; his diligence in these was augmented when after outstanding studies of literature and after Gallic eloquence, which are either most flourishing or exceptional, as a young man he assumed the dignities of a royal association, and then he gave attention to the investigation of Roman laws, so that the Roman gravity might temper the richness and splendor of Gallic speech. ${ }^{44}$

And if there was any doubt, in the next paragraph the author reiterates, "He was educated to the full in literature." ${ }^{, 45}$ In addition, the author of the vita clearly desired to connect Desiderius' educational experiences with the classical Roman past, for his account not only draws on the tradition of Gallic nobles being educated in Rome ${ }^{46}$ - something not likely to happen in the seventh century and which the author makes no claims did happen - but even quotes Jerome's letter about the education of the aristocratic Gallic monk Rusticus. ${ }^{47}$ Now, one might be tempted to dismiss the account of the vita as a mere topos, but in the context of

40 The original collection survives as the partially extant Codex Tolosanus 364, and is preserved entire in the Albi, Bibl. mun. 147 [olim 2]. See Ourliac 1978; Turner 1900-1901; Galabert 1933; le Bras 1929.

41 Archives nationales Ms.AB.XIX.1737 VII, Fragmentum mulomedicum; see McKitterick 1981, 176.

42 For educational opportunities, see Mathisen 2005.

43 Greg. Tur. Hist. 6, 39: Est enim vir valde nobilis et de primis senatoribus Galliarum, in litteris bene eruditus rhetoricis, in metricis vero artibus nulli secundus.

44 Vita Desiderii 1: Desiderius vero summa parentum cura enutritus, litterarum studiis ad plenum eruditus est, quarum diligentia auctus est ubi post insignia litterarum studia gallicanamque eloquentiam quae vel florentissima sunt vel eximia, contubernii regalis adulcisce indidit dignitatibus, ac deinde legum romanarum indagatione studium dedit, ut ubertatem eloquii gallici nitoremque sermonis gravitas romana temperaret.

45 Vita Desiderii 2: Ad plenum litteris fuerit eruditus.

46 E.g., Vita Germani Autissiodorensis 1: Ab ipsis infantiae rudimentis studiis liberalibus institutus, in quo doctrinae conlatio cum ingenii ubertate consentiens, eruditissimum duplicato bono... atque in eum perfectio litterarum plena conflueret, post auditoria gallicana intra urbem Romam iuris scientiam plenitudini perfectionis adiecit.

47 Jerome, epist. 125, 6: Post studia Galliarum, quae vel florentissima sunt, misit Romam, non parcens sumptibus, et absentiam filii, spe sustinens futurorum, ubertatem gallici nitioremque sermonis, gravitas romana condiret. 
this discussion one also might suggest that the very use of the topos validates the continuing importance of the classical tradition, and the importance that the vita's author attached to Desiderius' Roman identity.

Nor did the classical educational tradition stop there. Circa 640, the young aristocrat Bonitus of Clermont, whose mother's name, Syagria, recalls the name of Desiderius' brother, received a traditional classical education. According to his vita, "He was imbued with the elements of grammar and trained in the Theodosian decrees, and excelling the others of his age, he was examined by the sophistae ("sophists") and advanced". 48 The presence of sophists, schoolmates, and examinations, not to mention the teaching of grammar and law, suggests the presence of a secular school even in the seventh century. Bonitus then followed the same career trajectory as Desiderius and many of his friends, being made "princeps pincernarum" and then referendarius ("referendary") by Sigibert III (634-656), "praefectus Massiliae primae provinciae" by Theoderic III (673-698), and then, in 690, bishop of Clermont (c. 690-706) in succession to his brother Avitus (676-690), who likewise had been described in Bonitus' vita as "a man learned in wider studies and in sacred literature." 49

And at about the same time, Leudegarius, future bishop of Autun (660-679), according to his vita, was engaged "in the diverse studies that secular potentes are accustomed to study, he was fully polished in everything by the touchstone of discipline". 50 The monastic author of the vita may not have known exactly what these secular studies were, but he realized it was important to mention them.

\section{Epistolography and Classical Culture}

Furthermore, most modern study of the cultural climate of the seventh century has lacked any discussion of one of the most evocative and significant seventh-century literary genres: epistolography. This is most regrettable, for some of our best evidence for the continuity of classical culture in seventh-century Francia comes from Desiderius' letter collection. The collection survives in only a single manuscript, the Codex Sangallensis 190, which also preserves the only copy of the letters of Ruricius of Limoges, the only copies of some of the letters of Faustus of Riez, and originally included a collection of letters of Sidonius Apollinaris. ${ }^{51}$ Desiderius' letters are di-

48 Vita Boniti 1-2 (MGH SS rer. Merov. 6, 119-139): Inclita Bonitus progenie Arvernicae urbis oriundus fuit, cuius pater Theodatus, mater vero Syagria vocitata est, ex senatu Romano dumtaxat, nobili prosapia [...] postea vero cum natus adolevisset et esset praefata cum parentibus in urbe constitutus, gramaticorum inbutus iniciis necnon Theodosii edoctus decretis, ceterosque coetaneos ecellens, a sophistis probus atque praelatus est.

49 Vir exterioribus studiis eruditus sacrisque litteris, (ibid.). Riché 1976, 192, drops the last two words, and consequently masks the distinction between the two kinds of learning.

50 Vita Leudegarii 1 (CCSL 117, 529): Fuisset strenue enutritus et ad diversis studiis, quae saeculi potentes studire solent, adplene in omnibus disciplinae esse lima politus.

51 See Mathisen 1998. 
vided into two books, the first containing sixteen "Letters of lord Desiderius, bishop of Cahors, directed to diverse persons", and the second comprised of twenty-one "Letters of diverse persons sent to lord Desiderius." In addition, five other letters from Desiderius' archive, not included in the letter collection, are inserted into his vita. The earliest letter in the collection (Epist. 2, 2), dating to 629/630, goes back to Desiderius' days in the palace, where as thesaurarius he received a letter from the abbot Bertegyselus asking for help in a legal matter.

Seventh-century epistolographers such as Desiderius and his friends represent part of a long chain of ancient epistolography extending back to the Hellenistic period and before, and their topics of discussion present insights into the nature of contemporary literary culture that can be found nowhere else. The ties that Desiderius and his friends had formed in their youth bound them together in later life, and were manifested by their exchanges of letters, many of which came from this circle. In addition, as a result of the letter-exchange process, others were drawn into the circle, such as Constantius of Albi, who co-authored a letter to Desiderius with Audoenus Dado of Rouen, and Verus of Rodez, whose letter from Sulpicius of Bourges was included in Desiderius' collection along with two letters from Sulpicius to Desiderius himself.

In their letter exchanges these friends also mentioned each other, cementing the circle of friendship. ${ }^{52}$ In one letter, Desiderius recalled to Audoenus Dado their friendship with Eligius "in aula terreni principis", and, while regretting the loss of his brothers Rusticus and Syagrius, he rejoiced that they still also enjoyed the friendship of Paulus of Verdun and Sulpicius of Bourges. ${ }^{53}$ Desiderius' eighth-century vita mentions additional bishops who were included in the extended circle of friends, several of whom also were among Desiderius' correspondents. ${ }^{54}$ These friendships also appeared in other literary works connected with this circle; the late seventhcentury Vita Eligii, for example, mentioned Eligius' special friendships not only with Audoenus Dado but also with King Dagobert. ${ }^{55}$

52 E.g., Desid. epist. 2, 16 (Verus of Rodez to Desiderius): Accepimus una cum exemplari de litteris domni Sulpitii.

53 Desid. epist. 1, 10: Igitur debito obsequio humiliter exhibito, illud peculiarius peroro, ut quem quondam in ipso flore primaevae iuventutis unico mihi amore praebuisti, semper concedere digneris illum meum Dadonem. maneat pristina inter nos atque illum tuum, imo nostrum Eligium inconvulsa charitas [...] et licet de nostro collegio duos iam amiserim germanos, habemus pro his venerabilem Paulum, nec minus praedicabilem meritis Sulpicium.

54 Vita Desiderii 15: Habebat eo tempore plures Dominus Jesus in Galliis nobiles servos, Arverno Gallum, Bituricis Sulpitium, Rutena Verum, Agenno Salustium, Engolisma Ebargehenum, Petrogorico Austerium, Noviom[ag]o Eligium, Metis Arnulphum, Luco Austrasium, Mestarone Diodorum, Cadurca Desiderium.

55 Vita Eligii 8-9: Quod cum vir sanctus sodali suo Audoeno nomine, cognomento Dadoni, quem sicut animam suam diligebat, secretius enarrasset [...] mortuo interea Clotario rege Francorum, Dagobertus filius eius monarchiam regni solus obtinuit, a quo Eligius tanta familiaritate habitus est, ut plurimorum eius felicitas ingens gigneret odium. The vita sometimes is attributed to Audoenus himself. 
Another extant letter from the same period that can be connected to Desiderius' literary circle is found in the Codex Sangallensis 917, which preserves a fifteenthcentury copy of a lost manuscript, perhaps of Carolingian date, that contained a letter written ca. $620 / 650$ by the aristocrat Venerandus to Constantius, bishop of Albi, the same Constantius who appears in Desiderius' letter connection. ${ }^{56}$ Venerandus had founded a monastery at Altaripa, presumably in the territory of Albi, under the Rule of St. Benedict, and he forwarded to Constantius a copy of the rule - its earliest attested use in France - to be kept in the church of Albi. ${ }^{57}$ And here, one cannot but note the recurring role of Albi as a center of literary productivity at this period.

These letters were written at a time when other historical sources are few and far between. Briefly, one is transported back to the days of Sidonius Apollinaris, Ruricius of Limoges, and Avitus of Vienne, when Gallic aristocrats exchanged multitudes of letters. The fact that Desiderius' collection, like that of Ruricius of Limoges, includes letters written by Desiderius paired with letters written to him, indeed even a greater number of the latter, means that one has multiple perspectives on contemporary life. The seventh-century letters serve much the same purpose as those of the fifth and sixth. First and foremost, they provided a means for isolated Gallic aristocrats to maintain their ties of friendship with each other: A letter from Sulpicius of Bourges reflected on the role of epistolography, "Therefore, nothing is lost to absence because the present works in [your] presence. Your Beatitude always does its

56 Cod. Sangall. 917, p. 3: Domino reverendissimo et pontificali honore laudabiliter decorato Constantio papae Venerandus. Regulam sancti Benedicti abbatis Romensis, quam praesens continet liber, eatenus vestrae beatitudini in arce sanctae ecclesiae Albiensis recondendam pariterque habendam direximus, ut si quoquam tempore [non] aliter, quam in eadem scriptum dictumque inveneritis, monachi vel etiam quilibet abbas eorum, quos Altaripa in monasteriolo nostro adiuvante domino adunavimus, agere vel quidquam de his obviare temptaverint, vestris sanctis vestrorumque successorem coherceantur monitis. siquidem ante hos paucos annos noc mecum sanctae memoriae patruo vestro domino sancto Fibicio episcopo, ita ut facere debuissem, convenerat. (Venerandus to a lord most reverend and laudibly endowed with pontifical honor, the pope Constantius. I have sent into the possession of Your Beatitude the Rule of St. Benedict, abbot of Rome, which is contained in the proffered book to be preserved and likewise possessed in the altar of the blessed church of Albi, so that if any time the monks or even whoever may be abbot of whose whom we have gathered into our little monastery at Altaripa attempt to act otherwise or to violate any of them, let them be restrained by the holy admonishments of yourself and your successors. In fact, it happened a few years ago that I had to do this in this manner along with your uncle of blessed memory, the holy lord bishop Fibicius). See Traube 1910, 35-36, 87-88; and Pardessus $1849,2,193,240$.

57 Constantius' otherwise-unknown uncle Fibicius likely was his predecessor as bishop of Albi; this would have had to have been the case for Fibucius to have exercised any authority over the monastery. For Constantius, see Duchesne 1907-15, 2, 43-44. One notes that Benedictine monasteries seem to have been particularly active in the preservation of classical culture: see Bischoff 1994; and Lehmann 1960. 
duty in sending letters". ${ }^{58}$ The letters are rife with precious realia of seventh-century life that, briefly, allow Desiderius and his friends to speak directly to us. They are replete with the politesse and exchange of favors that greased the wheels of day-today existence: help in legal cases, support for travelers, assistance in the carrying out of administrative functions, the passing on of news (such as the date of the next church council), or just the general provision of good offices.

Writ large, Desiderius' collection also has much to say about the social world of seventh-century Gaul. In the corpora of Sidonius, Ruricius, and Avitus, one encounters only a sprinkling of persons with barbarian-looking names, and very few barbarians with any claim to literary learning. By the time of Desiderius, however, there is no indication of any divide, social or cultural, between Romans and barbarians. One now sees a completely integrated society. But that does not mean that old ways did not die hard. A look at the hard core of Desiderius' literary circle still shows a predominance of Roman sounding names, suggesting that, irrespective of what the actual ethnicity of these persons was, there still was a connection to the Roman past.

\section{The Case for Desiderius as Last of the Romans}

So far, the case for Desiderius as "last of the Romans" has been based on the ways in which he and his circle of friends continued to manifest aspects of the cultural traditions of the Roman past: literary circles comprised primarily of individuals who at least looked Roman, and attempts to preserve the literary traditions of the past. But what is significant for Desiderius in particular as "last of the Romans" are several circumstantial considerations. In addition to the geographical proximity of Cahors to Limoges and Clermont, it has been suggested that Desiderius had a family connection to the other epistolographers preserved in the Sangallensis 190, Sidonius Apollinaris and Ruricius of Limoges. ${ }^{59}$ For example, in the 530s, Sidonius' daughter and daughter-in-law, Alcima and Placidina, went into exile from Clermont to Cahors. ${ }^{60}$ And a sister of Desiderius was named Avita, suggesting a tie to the Aviti of Clermont, to whom Sidonius was at least doubly related. ${ }^{61}$ In addition, it may be significant that Ruricius' family property was located not in the territory of Limoges, but at Decaniacum, in the civitas of Cahors. ${ }^{62}$ Given these connections, one might propose that the letters to and from Ruricius, the letters of Sidonius, and the

58 Desid. epist. 2, 1: Ergo nihil perdet absentiam, quod praesentialiter laborabit praesentiam. semper in dirigendis apicibus beatitudo vestra solvit officium, ut plus debeat reddendum agminis famulatum, quam meritis consideret debitorem.

59 See Mathisen 1981 = Idem 1991, 13-27; also Mathisen 1999.

60 Greg. Tur. Hist. 3, 12.

61 For the interrelation among these families, see Mathisen 1979-1980, 260-273, 283-298, 463-464, 716; and Idem, "Epistolography". Desiderius' other sister was named Selina: Vita Desiderii 1: Sororibus aderant: quarum una Selina, alia vero dicebatur Avita.

62 See Mathisen 1999, 20, 47. 
letters to and from Desiderius formed part of an epistolographic collection preserved by the family and literary circles of first Ruricius and then Desiderius.

In addition, it would seem that these seventh century ecclesiastics were well aware of their heritage, and a continued value was attached to being able to speak the language of the past. Sulpicius of Bourges, for example, wrote to Desiderius, "But all virtue suddenly is lacking in my words; I, whom the material of such a great topic overcomes, and, when I weigh the immense studies of such great readings in the scales of my mind, I succumb, overcome, by the mass of its magnitude". ${ }^{3}$ But his use of the rare word "anagnostici" suggests that Sulpicius was not nearly as shy as he made out to be. ${ }^{64}$ On the other hand, Felix of Limoges, perhaps with greater cause, apologized for his lack of politesse: "It shames me to have expressed myself uncautiously in a sense less cultivated and a style of unpolished speech.",65

Paulus of Verdun, on the other hand, thanked Desiderius for sending him five amphorae of Falernian wine when he had asked only for one - and small matter that this Falernian most likely was only a Gallic ersatz for the Italian original. ${ }^{66}$ In another letter to Desiderius, Paulus casually dropped a Vergilian tag, from book six of the Aeneid. ${ }^{67}$ And on another occasion, Desiderius wrote to bishop Felix of Limoges ${ }^{68}$ in an attempt to clear up an unspecified enmity that had arisen between them, saying in one alliterative section, ${ }^{69}$

63 Desid. epist. 2, 1 (Sulpicius to Desiderius): Sed universa subito virtus defecit in verbis, quem exsuperavit tantae materia dictionis, et, dum inmensa tantarum anagnusticorum studia animo librante pensarem, ipsius magnitudinis molem victus subcubui.

64 For the word anagnostes as a reader or an educated slave, see Cic. Att. 1, 12, Fam. 5, 9, 2; Corn. Nep. Aristides 13, 14 ("pueri literatissimi”); Aul. Gell. 3, 19; 18, 5.

65 Desid. epist. 2, 21, from Felix of Limoges, Me tamen poenitet incaute et minus inculto sensu vel impolito sermone stylum exarasse.

66 Desid. epist. 2, 11, Paulus to Desiderius: Praeterea multiplices dominationi vestrae agimus gratias de eulogiis sanctis, de Falerno nobili, vel vasculis decem, quae nobis tanti habuistis dirigere [...] superexcrevit quidem, et superabundavit benedictio largitatis vestrae, adeo, ut dum nos unam Falerni amphoram deposcimus, vos eminentia vasa, et, ut usitatius dicam, tunnas decem eligantissimi Falerni tanti habuistis dirigere; for the "Falernian" wine of Dijon, see Greg. Tur. Hist. 3, 19: Vineisque repleti, quia tam nobile incolis Falernum porrigunt, ut respuant Cabillonum, nam veteres ferunt ab Aureliano hoc imperatore fuisse aedificatum; and cf. Salvian, Adv. avaritiam 6: Natant tricliniorum redundantium pavimenta vino; Falerno nobili lutum faciunt; mensae eorum ac toreumata mero jugiter madent, semper uda sunt.

67 Desid. epist. 2, 12: Caeterum ut ad vestra beneficia mentis oculos reflectam, nec si lingua clamet ferrea, ut quidam poeta ait, aut centena sonent spiramina, nullatenus potest quis tanta narrare dei magnalia, quantum eius in viscera vestra diffunditur gratia; cf. Verg. Aen. 6, 625-626: Non, mihi si linguae centum sint oraque centum, / ferrea uox, omnis scelerum comprendere formas.

68 The lemma to the letter reads, It(em) ep(istu)la domini Desideri ad Felicem Narbonae urbis ep(iscopum), but Arndt, MGH Epp. 3, 202 n. 1, and Norberg 1961, 40 n. 1, asserting that no Felix is known to have been bishop of Narbonne at this time, disregard the lemma and identify the addressee as the Felix who was bishop of Limoges ca. 650 (Duchesne 1907-15, 2, 52). Given Desiderius' connections to the area of Limoges, this is an attractive alternative, but it does not explain how such a fundamental error could have arisen. And 
Sin autem sueta me ambiunt accusatione vexare, contuendum censeo et a vestra censura opto fore cavendum ut aures vestras viperina venena ac velut Sirenarum canto letalis sibilus non infundat [...].

But if, however, the usual matters endeavor to vex me with accusation, I believe that it must be taken care of, and I choose to trust to your judgment that viperous poisons and the, so to speak, lethal hiss of the song of the Sirens do not overwhelm your ears $[\ldots]$.

In the mid seventh century, therefore, the Sirens continued to sing their seductive song, even in the presence of the "precepts of Christ".

We have here, therefore, a coterie of literary minded bishops with a shared educational background and political/ecclesiastical careers - looking very much like the aristocratic social-cultural coteries of the late Roman Empire. In their own way, these seventh century Gallic litterati kept the classical tradition flickering in Merovingian Gaul. Seventh-century writers knew that they were the representatives of an unbroken sequence of literary culture going back to Vergil and Homer, and their literary efforts, however imperfect they may seem in our eyes, reflect that conviction. But Desiderius and his circle were remarkably few in number. The sources refer over and over to the same people, a small circle constantly turning back in on itself, indicating that only a very few individuals were participating in seventh century literary society, and suggesting to us how very valuable that their contributions and efforts were in maintaining the tenuous chain connecting classical antiquity to the Middle Ages.

But Desiderius had no successors. No further line of family descent be identified - save for apocryphal documents such as the Genealogia domus carolingicae, which lists a Desiderius among the children of Gamardus cognomento Babo, which itself suggests the degree to which the late antique past had become the stuff of fable. ${ }^{70}$ And the path of continuous literary transmission likewise stopped here. With Desiderius' letter collection, we come to the end of an unbroken chain of not only literary style but also cultural and social connection that can be traced back to Cicero and before. This was the end of the line. Subsequent letter collections of the Carolin-

one also must note that the episcopal fasti of Narbonne for the seventh century are very imperfectly known: only two bishops, Sergius and Selva, are known for the entire period ca. 600-670 (Duchesne 1907-15, 1, 304-305). So one might not want to disregard out of hand the possibility that Felix was in fact bishop of Narbonne.

69 Desid. epist. $1,16$.

70 Genealogia domus carolingicae, in the Annales Altahenses, MGH SS 2, 308-312, lists among the children of Gamardus cognomento Babo, Godinus and Desiderius, and as the daughter of Godinus "domna Sigolina." One brother of Gamardus was Firminus, bishop of Uzès in the late sixth century, and another, Ansbertus, was married to Blithildis, daughter of the Frankish king Chlothar, which places Desiderius circa the early seventh century, and Sigolena shortly thereafter. According to the Vita Firmini, moreover, Firminus was preceded by a bishop "Roricius," and was the son of Ferreolus vir praefectorius, viz. Tonantius Ferreolus, Praetorian prefect of Gaul in the mid fifth century. 
gian period are marked not by direct continuity with their Merovingian predecessors, but by an antiquarian spirit lacking a direct, organic, and conceptual connection to any ancient models. For Gaul at least, then, Desiderius and his friends were the "last of the Romans", and it therefore is with good cause that we often say that this period also marks the end of Late Antiquity.

\section{Bibliography}

\section{Primary sources}

Desiderius Cadurcensis, epistulae:

Lectiones antiquae, ed. Henricus Canisius, vol. 5, Ingolstadt 1604, 461-523, repr. in PL 87, 247-266.

Epistolae Merowingici et Karolini aevi 1, ed. Ernst Dümmler et al. (MGH Epp. 3), Berlin 1892, 191-214 (ed. Wilhelm Arndt), repr. verbatim in CCSL 117, Turnhout 1957, 309-342.

Epistulae S. Desiderii Cadurcensis, ed. et commentario instr. Dag Norberg, Stockholm 1961.

Gellius, Noctes Atticae: A. Gellii Noctes Atticae, recogn. brevique adnotatione critica instr. Peter K. Marshall, Oxford 1968.

Hieronymus, Epistulae: Saint Jérôme, Lettres. Texte établi et traduit par Jérôme Labourt, Tome I-VIII, Paris 1949-1963.

Passio Leudegarii I: Passiones vitaeque sanctorum aevi Merovingici 3, ed. Bruno Krusch and Wilhelm Levison (MGH SS rer. Merov. 5), Hannover/Leipzig 1910, 282-362, repr. in CCSL 117, 527-586.

Vita Boniti: Passiones vitaeque sanctorum aevi Merovingici 4, ed. Bruno Krusch and Wilhelm Levison (MGH SS rer. Merov. 6), Hannover/Leipzig 1913, 110-139.

Vita Desiderii Cadurcensis:

Nova bibliotheca manuscriptorum 1, opera ac studio Philippe Labbé, Paris 1657, 699716, repr. in $P L 87,219-46$.

La vie de Saint Desiderius, Evêque de Cahors (630-655), publiée d'après les manuscrits de Paris et de Copenhague par René Poupardin, Paris 1900.

Passiones vitaeque sanctorum aevi Merowingici 2 (MGH SS rer. Merov. 4), ed. Bruno Krusch, Hannover/Leipzig 1902, 547-602, repr. in CCSL 117, 343-401.

Vita Eligii: Passiones vitaeque sanctorum aevi Merowingici 2 (MGH SS rer. Merov. 4), ed. Bruno Krusch, Hannover/Leipzig 1902, 634-741.

Vita Sulpicii Bituricensis: Passiones vitaeque sanctorum aevi Merowingici 2 (MGH SS rer. Merov. 4), ed. Bruno Krusch, Hannover/Leipzig 1902, 364-380.

Constantius Lugdunensis, Vita s. Germani episcopi Autessiodorensis:

Constance de Lyon, Vie de Saint Germain d'Auxerre. Introduction, traduction, texte critique et notes par René Borius (SC 112), Paris 1965.

Passiones vitaeque sanctorum aevi Merowingici 5, ed. Bruno Krusch u. Wilhelm Levison (MGH SS rer. Merov. 7), Hannover/Leipzig 1920, 225-283.

Genealogia domus carolingicae: Scriptores rerum Sangallensium. Annales, chronica et historiae aevi Carolini, ed. Georg H. Pertz (MGH SS 2), Hannover 1829, 308-312. 
Georgius Florentius/Gregorius Turonensis, Historiae: Gregorii episcopi Turonensis libri historiarum X, ed. Bruno Krusch und Wilhelm Levison (MGH SS rer. Merov. 1, 1), Hannover ${ }^{2} 1951$.

Salvian, Adversus avaritiam (= Timothei ad ecclesiam libri IV): Salviani presbyteri Massiliensis opera omnia, recogn. et commentario critico instr. Franciscus Pauly (CSEL 8), Wien 1883, 224-316.

\section{Secondary sources}

Auerbach (1965): E. Auerbach, Literary Language and its Public in Late Antiquity and the Middle Ages, London.

Baker (2002): G. P. Baker, Justinian: The Last Roman Emperor, Cooper Square.

Bischoff (1994): B. Bischoff, "Benedictine Monasteries and the Survival of Classical Literature," in: Michael M. Gorman (ed.), Manuscripts and Libraries in the Age of Charlemagne, Cambridge, 134-160.

Borias (1987): André Borias, "Saint Wandrille et la crise monothélite", Revue Bénédictine 97, 42-67.

Cabie (1894): R. Cabie, "Rapports de S. Desiderius, eveque de Cahors, et de S. Desiderius, eveque d'Auxerre, avec l'Albigeois", Annales du Midi, Toulouse, 407ff.

Cabié (1972): R. Cabié, "Les letters attribuées à saint Germain de Paris et les origines de la liturgie gallicane", BLE 73, 183-192.

Canisius (1601): H. Canisius, Lectiones antiquae, Bd. 5, Ingolstadt.

Dahn (1876-1878): Felix Dahn, Ein Kampf um Rom, 3 Bde., Leipzig.

Duchesne (1907-15): Louis Duchesne, Fastes épiscopaux de l'ancienne Gaule, 3 Bde., (2nd ed.), Paris.

Durliat (1979): Jean Durliat, "Les attributions civiles des évèques mérovingiens: L’exemple de Desiderius, évèque de Cahors (630-655)", Annales du midi 91, 237-254.

Fouracre (1979): Paul Fouracre, "The Work of Audoenus of Rouen and Eligius of Noyon in Extending Episcopal Influence from the Town to the Country in Seventh-Century Neustria", in: Derek Baker (ed.), The Church in Town and Country, Oxford (Studies in Church History 16), 77-91.

Galabert (1933): Fr. Galabert, "Notice sur deux manuscrits des bibliothêques de Toulouse et d'Albi", Annales du Midi 45, 353-372.

Gibbon (1776 [1860]): Edward Gibbon, The History of the Decline and Fall of the Roman Empire, repr. Harper (1860).

Goffart (1988): Walter Goffart, The Narrators of Barbarian History (A.D. 550-800). Jordanes, Gregory of Tours, Bede and Paul the Deacon, Princeton.

Griffe (1951): E. Griffe, “Aux origines de la liturgie gallicans”, BLE 52, 17-43.

Hughes (2009): Ian Hughes, Belisarius: The Last Roman General, Westholme.

Kirsch (1908): J.P. Kirsch, The Catholic Encyclopedia, vol. 4, Appleton.

Labbe (1657): P. Labbe, Nova bibliotheca manuscriptorum, vol. 1, Paris.

Laistner (1931): M. W. Laistner, Thought and Letters in Western Europe, A.D. 500 to 900, London.

le Bras (1929): G. le Bras, "Richesses méconnues de la bibliothèque d'Albi", Revue historique de droit français et étranger $8,767-775$.

Lehmann (1960): Paul Lehmann, "The Benedictine Order and the Transmission of the Literature of Ancient Rome in the Middle Ages", Erforschung des Mittelalters 3, 173-183.

Marrou (1956): H.-I. Marrou, A History of Education in Antiquity, G. Lamb tr., New York. 
Mathisen (1979, 1980): R. W. Mathisen, The Ecclesiastical Aristocracy of Fifth-Century Gaul: A Regional Analysis of Family Structure, diss., Univ. of Wisconsin, Ann Arbor: Univ. Microfilms.

Mathisen (1981): R. W. Mathisen, „Epistolography, Literary Circles, and Family Ties in Late Roman Gaul“, Transactions of the American Philological Society 111, 95-109.

Mathisen (1991): R. W. Mathisen, Studies in the History, Literature, and Society of Late Antiquity, Amsterdam, 13-27.

Mathisen (1998): R. W. Mathisen, "The Codex Sangallensis 190 and the Transmission of the Classical Tradition", International Journal of the Classical Tradition 5, 163-194.

Mathisen (1999): R. W. Mathisen, Ruricius of Limoges and Friends: A Collection of Letters from Visigothic Aquitania, Liverpool.

Mathisen (2005): R. W. Mathisen, "Bishops, Barbarians, and the 'Dark Ages': The Fate of Late Roman Educational Institutions in Early Medieval Gaul", in: R. Begley and J. Koterski (eds.), Medieval Education, Fordham, 1-27.

McKitterick (1981): R. McKitterick, "The scriptoria of Merovingian Gaul: A Survey of the Evidence", in: H. Clark and M. Brennan (eds.), Columbanus and Medieval Monasticism, Oxford, 173-207.

Morin (1941): G. Morin, "Sur la provenance du 'missale gothicum'”, RHE 37, 24-30;

Murdoch (2006): Adrian Murdoch, The Last Roman: Romulus Augustulus and the Decline of the West, Sutton.

Norberg (1961): D. Norberg, Epistulae S. Desiderii Cadurcensis, Stockholm.

Ourliac (1978): P. Ourliac, "Le manuscrit toulaisain de la collection d'Albi", Revue de droit canonique 28, 223-238.

Pardessus (1849): J. M. Pardessus, Diplomata, Chartae, Epistolae, Leges aliaque instrumenta ad res Gallo-Francicas spectantia, Paris.

Poupardin (1900): R. Poupardin, La vie de Saint Didier, Evêque de Cahors (630-655), Paris.

Rey (1953): Raymond Rey, "Un grand batisseur au temps du roi Dagobert: s. Desiderius, évêque de Cahors", Annales du Midi 65, 287-293.

Rio (2009): Alice Rio, Legal Practice and the Written Word in the Early Middle Ages: Frankish Formulae, c. 500-1000, Cambridge.

Saint-Paul (1911): Anthyme Saint-Paul, Histoire monumentale de la France, Nouvelle edition, Paris.

Scheibelreiter (1989): Georg Scheibelreiter, “Audoin von Rouen. Ein Versuch über den Charakter des 7. Jahrhunderts", in: Hartmut Atsma (ed.), La Neustrie: Les pays au nord de la Loire de 650 à 850, Sigmaringen, 195-216.

Sivan (2011): Hagith Sivan, Galla Placidia: The Last Roman Empress, Oxford.

Sol (1936): E. Sol, "Saint Desiderius, eveque de Cahors (636-655)", Bulletin de la Societe des études litteraires, scientifiques et artistiques du Lot 57, 536-551.

Store (2007): Paul V. Store, Aëtius and the Augusta: The Last of the Romans, Trafford.

Traube (1910): L. Traube, Textgeschichte der Regula s. Benedicti, Munich.

Turner (1900-1901): C. H. Turner, "A Group of mss. of Canons at Toulouse, Albi, and Paris", Journal of Theological Studies 2, 435-441.

Vacandard (1897): E. Vacandard, "La Schola du palais merovingien", Revue des questions historiques 61, 490-502.

van der Mensbrugghe (1959): A. van der Mensbrugghe, "L'Expositio missae gallicanae estelle de saint Germain de Paris", Messager de l'Exarchat du Patriarche russe in Europe occidentale 32, 217-249.

Wood (1994): Ian Wood, The Merovingian Kingdoms 450-751, London. 



\section{Orts- und Namenregister}

Aachen 240

Abbo v. Metz 457f.

Adalgudis 316-318

Aegidius 60, 64, 68f.

Aeneas 336, 338-340, 344, 358, 362, 365, 366 A., 369, 371-373

Aeonius v. Arles 447 A.

Aetherius v. Lyon 132 A.

Aëtius, Fl. 25, 35-41, 63, 65, 261f., 361f., 455

Afrika 28, 35, 40, 45-47, 52-54, 65, 67, 84-86, 102 A., 103, 159, 288, 357 A., 362-364, 366-368, 370, 436 A.

Agaune (Saint-Maurice en Valais) 379f., 389

Agde 117, 118 A.

Agen (Aginnum) 160 A., 165 A.

Agroecius v. Sens 390f.

Ägypten 102 A.

Aigatheus 316-318

Aix-en-Provence 103 A., 202f., 205 (fig. 2), 206, 212 (fig. 7), 213, 227

Alarich I. 25, 27, 30, 82f., 87, 368 A., $371 \mathrm{~A}$

Alarich II. 88

Albi 456-460, 462f.

Alcima, Tochter des Sidonius Apollinaris 464

Alcimus Ecdicius Avitus s. Avitus v. Vienne

Alcuin 415

Alexander v. Aphrodisias 343

Alpes Maritimae 211, 218

Altaripa 463

Amantius, Märtyrer 457

Ambrosius Aurelius 455

Ambrosius v. Mailand 131 A., 422 A., 427 A., 440-443

Amida (Diyabarkir) 287

Amiens (Samarobriva) 158 A., 160 A., 226 A.

Anaolsus 36

Andelot 223-225, 233, 239, 243

Andemantunum $s$. Langres
Anianus, vir spectabilis 88

Anianus v. Orléans 132 A.

Antalas 288

Anthemius, F1. Procopius, röm. Kaiser 6265 A., 69, 356f., 371-373

Antibes 209

Antonius, M. 393

Apollinaris, Großvater des Sidonius Apollinaris 26

Apollinaris, Sohn des Sidonius Apollinaris 61, 427 A., 428 A.

Apollinaris Sidonius $s$. Sidonius Apollinaris, C. Sollius

Apollinaris v. Valence 114 A.

Aprunculus v. Langres 184 A.

Apt 203

Aquae $s$. Dax

Aquae Sextiae 202

Aquitanien 27f., 33-35, 50, 66, 79, 86, 97, 105, 153f., 156 A., 158 A., 162 A., 176, 177 A., 218, 238, 266, 269, 429 A., 446 A.

Aquitania I 153f., 170 A.

Aquitania II 27, 34, 153f., 169 A.

Arator 409, 410

Arbogast v. Chartres 59, 402f., 407

Arborius 61

Arelate $s$. Arles

Arelatensis provincia 218

Argelliers 218

Aristoteles 343, 442 A.

Arles (Arelate) 27, 34, 36, 62, 67, 103 A., 107 A., 108 A., 109, 136 A., 153, 154 A., 202f., 205f., 209, 210 (fig. 5), 213, 218, 226f., 229 A., 413, 428 A., 436 A., 447 A.

Armorica 255 A., 258, 261f., 270

Arnulf v. Metz 456f.

Arpinum 423

Arvandus 64, 87

Arvernia 357, 370

Athaulf, König der Westgoten 25-29, 31, 64, 83 
Attalus, Priscus, röm. Kaiser 27-29, 34, 69

Attia Viriola 425f.

Auch 165 A.

Audoenus/Dado v. Rouen 115 A., 456458,462

Augsburg 55

Augst (Colonia Augusta Raurica) 161 A.

Augustinus v. Hippo 72, 103 A., 120, 129 A., 337, 405f., 409 A., 415, 427 A., 429 A, $440 f$.

Augustodunum $s$. Autun

Augustoritum $s$. Limoges

Augustus, röm. Kaiser 69, 153, 158 A., 207

Aulus Cluentius 425

Aurelianus, röm. Kaiser 184

Ausonius, Decimus Magnus 69-71, 73, 176f., 185-188, 331-349, 399f. A.

Austrasien 237f.

Autun (Augustodunum) 168 A.

Auvergne 61, 65

Auxerre 103f. A., 242

Avignon 209

Avita, Schwester des Desiderius of Cahors 464

Avitus, Fl. Eparchius, röm. Kaiser 38-40 $60,62,64,66,69,86,356-358$, 363 A., 368, 370, 373 A., 401, 424 A.,

Avitus v. Clermont 461

Avitus v. Vienne 60f., 65, 87, 424 A., 463f.

Bacaudae/Bagaudae 59, 73, 255-259, 261-263, 266-273

Baetica 30

Bagacum $s$. Bavay

Barcelona 40, 105

Bavay (Bagacum) 159f. A.

Bazas 28

Beda Venerabilis 411 A., 416

Belgica 155 A., 160 A., 162 A.

Belgica I $155 \mathrm{~A}$.

Belgica II 155 A., 163 A., 164 A., 286

Belisarius, F1. 455

Berimund 37

Bero 322

Bertegyselus 462

Bliesbruck $161 \mathrm{~A}$.

Blithildis, Großmutter des Arnulf v. Metz $466 \mathrm{~A}$.

Boethius, Anicius Manlius Severinus 307 A., 455

Bonifatius 84
Bonitus v. Clermont 461

Bordeaux (Burdigala) 28, 70, 159 A., 165 A., 170 A., $172-177,181$ A., 187f., 202, 207, 331, 399 A., 400 A.

Bourges 91f., 100, 164f. A., 215, 318 A.

Bretagne 60

Britannien 429 A.

Brunhild 223f.

Burdigala $s$. Bordeaux

Burgund 231, 237f., 240

Burgundofaro v. Meaux 457

Burgus 61

Cadolaicus 321

Caelestinus v. Rom 109

Caesar, C. Iulius 153, 399

Caesarius v. Arles 107 A., 114 A., 117, 135f. A., 205, 413-415, 428 A., $436 \mathrm{~A}$.

Caesarodunum $s$. Tours

Cahors 457f., 464

Calminius 61

Candidus, Märtyrer der thebäischen Legion 380

Caper, Fl. 390-392

Capo Don 218

Carausius, M. Aurelius, röm. Kaiser 68

Carcassonne 209

Cassianus, Johannes 71

Cassiciacum $120 \mathrm{~A}$.

Cassiodorus, Fl. Magnus Aurelius 46f., 414

Cassius, C. 435

Castinus 84

Castrum Rauracense $s$. Kaiseraugst

Catilina 393

Cato d.Ä. 392

Cato d.J. 392

Catullinus 280

Censorius v. Auxerre 433

Ceraunia 431f., $435 \mathrm{f}$.

Chalkedon $108 \mathrm{~A}$.

Charibert I. 223f.

Charibert II. 223, 238

Châteaudun $231 \mathrm{~A}$.

Châteauneuf-de-Grasse 218

Childebert II. 223f., 238

Childebert III. 318 A., 322-324

Childerich I. 282, 284-287

Childerich II. 238 A., 323

Chilperich I. 118, 223, 239

Chlodocharius (i.e. Chlodwig III. oder Chlothar IV.) 323

Chlodwig I. 53, 103 A.

Chlodwig II. 323 
Chlodwig III. s. Chlodocharius

Chlotharius (i.e. Chlothar I. oder Chlothar II.) 223, $466 \mathrm{~A}$.

Chlothar II. 224, 235f., 238, 240, 456, 458

Chlothar IV. s. Chlodocharius

Chrocus, König der Alamannen 68, 162 A., 163 A., 174 A.

Cicero, M. Tullius 384f, 387, 390-393, 408, 409 A., 415, 416 A., 423, 425f., 432, 435-437, 440-442, 444f., 447

Cicero, Qu. Tullius 392f.

Cimiez 206

Cimitile 105, 106 A., 108, 111 A.

Claudianus Mamertus 411

Claudianus, Cl. 284f., 368 A., 370 A., 371

Clermont (Augustonemetum/Arverni) 60, 62, 65, 67, 162f. A., 164f. A., 166, 167 (Abb. 2), 174 A., 183, 184 A., 188, 203, 215, 216 (fig. 10), 229, 230 A., 232 A., 242, 464

Clichy 240

Clos-de-la-Lombarde 215

Col de Panissars 32

Colonia Agrippinensis $s$. Köln

Colonia Augusta Raurica $s$. Augst

Compiègne $319 \mathrm{~A}$.

Consentius, Schwiegervater des Iovinus 26

Consentius, Sohn des Consentius 186

Consorannorum civitas s. Saint-Girons und Saint-Lizier

Constantinus I., röm. Kaiser 70f., 73, 226, $400 \mathrm{~A}$.

Constantinus (III.), Fl. Claudius, röm. Kaiser 26, 31f., 60, 64, 68, 83, 103 A.

Constantius Chlorus, röm. Kaiser 403

Constantius III., röm. Kaiser 27-32, 34f., $50,65,83 \mathrm{f}$.

Constantius v. Lyon 110 A., 257, 261f., 413, 421-424, 426, 440

Constantius v. Albi 462f.

Cornelius Cethegus 455

Convenarum civitas $s$. Saint-Bertrand-deComminges

Cornificius, Qu. 435

Cularo $s$. Grenoble

Cyprian v. Karthago 427 A., 444

Dagobert I. 74, 240, 456-458, 462

Dalheim (vicus Ricciacum) 162 A.

Dalfinus v. Saint-Denis 321-323

Damasus v. Rom 332

Dardanus, Cl. Postumus 27, 61

Dax (Aquae) 165f. A.

Decaniacum 464
Decimus Rusticus 26

Defensor v. Ligugé 459

Demosthenes 408

Desiderius v. Cahors 74, 135 A., 239, 241, 429 A., 449, 455-467

Desiderius v. Vienne 411, 416 A.

Desiderius v. Albi 456

Dido v. Albi 459

Die 202, 209

Dijon (Divio) 183-185, 186 A.

Diocletianus, röm. Kaiser 164, 226, 307, 399 A.

Domitianus v. Angers 132 A.

Domnicius 282

Donatus, Aelius 412, 415

Divio $s$. Dijon

Draguignan 218

Drogo, Sohn Pippins II. 306 A., 312 A.

Dynamius patricius 115 A., 132 A., 224, 239

Éauze 165 A., 203, 209

Ebroin 242, 322

Eligius v. Noyon 115 A., 121 A., 242, 456f., 459, 462

Ennodius, Magnus Felix 130 A., 424 A.

Entremont 206

Eparchius, Sohn des Ruricius v. Limoges $427 \mathrm{~A}$

Ermelinus 313 A.

Eucherius v. Lyon 71, 107 A., 379-394, 424 A., $439 f$.

Eudoxius, Anführer der Bagaudae 262

Eufronius v. Tours 131 A., 134 A.

Eumenius, gallischer Panegyriker 403

Euplutius 30

Eurich, König der Westgoten 66, 87, $429 \mathrm{~A}$.

Eusebius v. Vercelli 103 A.

Eutropius v. Orange 114 A., 133, 134 A.

Exsuperius v. Toulouse $131 \mathrm{~A}$.

Exsuperius, Märtyrer der thebäischen Legion 380

Faesulae 448 A.

Faustus v. Riez 108 A., 427 A., 429, 436 A., 461

Felix, Fl. 84

Felix v. Nola 104f., 106 A.

Felix v. Limoges 465

Ferreolus, Tonantius, Prätorianerpräfekt v. Gallien 405, 411, 466 A.

Firminus v. Uzès $466 \mathrm{~A}$.

Florentius $441 \mathrm{~A}$.

Francia 230f., 235, 238 A., 240 
Fredegar 238, 240, 459

Friedrich, Sohn Theoderichs I. 84, 86f.

Fréjus 212 (fig. 7), 213

Fronto, M. Cornelius 423, 425, 426 A.

Fundi 332

Gaius, römischer Jurist 304-306, 307 A.

Galla Placidia 27f., 30f., 36, 38, 84

Gallaecia 83

Galliarum provinciae $36,39,79,153,157$, $159,225,267,270$

s. auch Alpes Maritimae, Aquitania, Belgica, Narbonensis, Novempopulana Viennensis

Gallien 25-29, 41, 45, 48, 50f., 53f., 5967, 71f., 74f., 80f., 83, 85f., 88, 92 94, 96f., 99-102, 103 A., 106 A., 107-110, 116-123, 125, 127 A., 129 A., 130, 132, 135f., 156f., 158 A., 159 A., 161 A., 162-164, 166 A., 168 A., 174-176, 181, 185, 187, 190f., 201, 212, 215, 218, 225234, 243, 255, 256 A., 257 A., 258, 261f., 269, 273, 277-279, 286-288, 307, 331-349, 357 A., 358, 363 A., 364 A., 394, 399-401, 403f., 410, 412-414, 416, 424 A., 430, 438, 440, 444f., 446 A., 447 A., 449, 458-460, 464, 466f.

Gallienus, röm. Kaiser 162 A.

Galswinth 223f.

Gammo 316-318

Gap 202, 209

Garonne 66

Geiserich, König der Vandalen 40, 52, 357f., 361-364, 368

Genf (Genava) 178f. mit Abb. 8, 180 A., 202, 209, 211 (fig. 6), 212

Gennadius v. Marseille 414

Genovefa 111 A., 117 A.

Germanicus 99 A., 283

Germanus v. Auxerre 103f. A., 107 A., 109, 110 A., 111f., 132 A., 261f., 413, $421 \mathrm{~A}$.

Germanus v. Paris 132 A.

Gerontius 26

Gildo 371

Gimbercthus 322

Glycerius, röm. Kaiser 86f.

Goar, König der Alanen 26

Gordianus III., röm. Kaiser 159 A.

Gratianus, röm. Kaiser 331

Gregor v. Langres 114, 184
Gregor v. Tours 68 A., 74f., 93 A., 95 A., 97, 98 A., 99 A., 115, 129 A., 131 A., 136 A., 154 A., 157 A., 163 A., 174 A., 183-185, 186 A., 188f., 207, $209,215,218,223-225,227,229$, 232-238, 242, 401, 404, 410, 411 A., 460

Gregor der Große 411f., 413-416, 455

Grenoble (Cularo) 164, 202, 209, 214

Grimoald 312f., 315, 320-323

Gundahar, König der Burgunder 26

Gundioch, König der Burgunder 86

Gundobad, König der Burgunder 86

Guntram I., König der Franken 223f.

Guntram Boso 224

Hagenbach 162 A.

Heraclianus 28

Heros v. Arles 103 A.

Hesperius 427 A., 428 A.

Hiberia, Gattin des Ruricius v. Limoges $424 \mathrm{~A}$.

Hieronymus 105 A., 121, 408, 414, 440, $441 \mathrm{~A}$.

Hilarius v. Poitiers 427 A.

Hilarius v. Arles 103f. A., 107 A., 109112, 114 A., 128f. A., 131 A.

Hippo 103 A.

Hispanien $s$. Spanien

Honoratus v. Arles 107 A., 109, 131 A., 135 A., 235 A.

Honorius, röm. Kaiser 26-28, 30f., 66, 84, 371 A., 401

Horatius Flaccus, Qu. 405-407, 409 A., $415,428 \mathrm{~A}$.

Hydatius 26, 30, 33, 36-39, 256 A., 257

Ildefons v. Toledo 414

Illyricum 102 A.

Iovinus, röm. Kaiser 25-28, 32, 64

Isidor v. Sevilla 416

Italien 25, 27f., 35, 45-48, 50f., 53f., 64f., 67f., 79f., 85-87, 102 A., 103, 154 A., 201, 231 A., 240 A., 261f., 300 A., 349, 357, 365f., 368 A., 370, 371,401

s. auch Ligurien, Kampanien

Iulius Nepos, röm. Kaiser 65

Iulius Titianus 423

Johannes, grammaticus 74

Jordanes 26, 31-33, 37, 39f.

Justinian I., röm. Kaiser 65, 399, 455 
Kaiseraugst (Castrum Rauracense) 161 A. Kampanien 105

Karl der Große 240, 415

Karthago 28, 40, 360-362, 365-372

Köln (Colonia Agrippinensis) 156 A., 159 A., 439

Konstantinopel 26, 32f., 40, 66, 73

Langres (Andemantunum/Lingonica urbs) 114

Latiniacus $321 \mathrm{f}$.

Lazarus v. Aix 103 A.

Leander v. Sevilla 412

Le Mans 170 A., 171 A., 242

Leo, consiliarius der Westgotenkönige 87

Leo I., röm Kaiser 357, 372

Lérins 103, 107, 108 A., 109, 112f., 120f., 413, 424 A., 429 A., 439 A.

Leudegarius v. Autun 459

Ligurien 218

Limoges (Augustoritum/urbs Lemovica) 156 A., 158, 182, 428 A., 464

Limonum $s$. Poitiers

Litorius 37-39, 85, 261

Livia, Gattin des Augustus 207

Livius, Titus $409 \mathrm{~A}$.

Loire 83 A., 85, 88, 97 A., 99, 104 A., 201

Lugdunum $s$. Lyon

Lugdunum Convenarum $s$. Saint-Bertrandde-Comminges

Lucanus, M. Annaeus 337 A.

Lupus v. Troyes 61, 107 A., 109, 110 A.

Lupus, dux 224

Lupus v. Ferrières $416 \mathrm{~A}$.

Lusitania 30

Luzarches 319 A.

Lyon 62, 66f., 71, 79, 132 A., 214, 363, $421 \mathrm{~A}$.

Mâcon 118 A.

Macrobius, Ambrosius Theodosius 339, $421 \mathrm{~A}$.

Magnentius, Fl. Magnus, röm. Kaiser 32, 68

Magnus Maximus, röm. Kaiser 68, 129 A., 401

Mainz 242

Maiorianus, Fl. Iulius Valerius, röm. Kaiser 62-64, 69, 86f., 356f., 363f., 366-369

Mamacas $s$. Montmacq

Mamertinus, lateinischer Panegyriker 255, 257

Mamertus v. Vienne 110f.

Marcella 408
Marmoutier 103 A., 104, 106, 108, 111

Maroveus v. Poiters 236 A.

Marseille 27, 212f., 214f., 239

Martialis v. Limoges $182 \mathrm{~A}$.

Martin v. Tours 100-112, 120 A., 121 A., 129 A., 131 A., 134 A., 236, 322, 413,416

Massiliensis provincia 218

Masuna, rex gentium Maurorum et Romanorum 288

Mauritius, Märtyrer der thebäischen Legion $379 f$.

Maximianus, röm. Kaiser 164, 255, 380, 389

Maximus, Sohn des Gerontius und röm. Kaiser 26

Maximus v. Lérins 108 A.

Maximus v. Riez 115 A., 132 A., 209

Mediolanum $s$. Saintes

Melania d. Ä. 102 A., 121

Merobaudes, F1. 255 A., 262, $361 f$.

Merowech II. 118

Metz 164 A., 229 A., 242

Minucius Felix 441

Montmacq (Mamacas) 319 A., 321-324

Namatius, Feldherr im Dienst der Westgoten 61

Namatius, Schwager des Ruricius v. Limoges (möglicherweise identisch mit dem Vorigen) 431f., 434-436

Narbo $s$. Narbonne

Narbonensis 26, 32, 109 A., 153 A., 202, 209

Narbonensis I 209

Narbonensis II 202, 209

Narbonne (Narbo) 27f., 37-39, 62, 185187, 201, 209

Neustrien 237f.

Nicetas v. Remesiana 102 A.

Nicetius v. Lyon 114, 132 A.

Nicetius v. Trier 130 A.

Nicomachus Flavianus 449 A.

Nîmes 203, 207, 209

Nola 102 A., 104f., 443 A.

Notre-Dame-du-Brusc 218

Novempopulana 153, 154 A., 155 A., 165, 166 A., 203, 207, 208 (fig. 4), 211

Odoaker, König von Italien 45, 53, 54 A., 69

Olybrius, Fl. Anicius, röm. Kaiser 86f.

Olympiodoros v. Theben 27f., 30

Ommatius, Sohn des Ruricius v. Limoges 427 A., 429 
Oppedette 218

Orestes 47, 54

Orosius, Paulus 26, 30, 33

Ovidius Naso, P. 335, 341, 345

Palatin 359

Panaitios 432 A.

Papianilla, Gattin des Sidonius Apollinaris $424 \mathrm{~A}$.

Paris 60, 66, 111 A., 164 A., 174 A., 178 A., 180 A., 240, 242, $323 f$.

Pascentius v. Poitiers 132 A.

Paulinus v. Nola 102, 104-107, 120f., 331f., 349, 440, 443 A., 448 A.

Paulinus v. Périgueux 413 A.

Paulus, Apostel 105 A., 332, 436 A., 444

Paulus, comes 59, 71

Paulus v. Verdun 456f., 462, 465

Pausanias 334

Pelagia, Gattin des Aetius 40

Périgueux 165 A., 169, 178 A., 207

Petrus, Apostel 105 A., 332

Petronius, Fl. Maximus, röm. Kaiser 357

Placidina, Schwiegertochter des Sidonius Apollinaris 464

Platon 384, 392

Plinius d. J., C. Caecilius Secundus 348, 387, 421-423, 425, 426 A., 428 A., 443 A., 445

Poitiers (Limonum) 156 A., 165 A., 166, 178 A., 181 A., 215, 232 A., 234 A.

Pomerius, Iulianus 413, 415, 436

Pontius Leontius 61

Postumus, röm. Kaiser 62

Pouan 284

Primuliacum 104f., 106 A., 108, 111 A., $331,332 \mathrm{~A}$.

Priscillianus v. Avila 105

Priscus v. Lyon 132 A.

Proculus Gregorius 332

Prokopios v. Caesarea 47 A., 54

Prosper Tiro 30, 34, 36-38, 72, 85, 401 A.

Prosper v. Orléans 132 A.

Provence 97, 218, 227, 231, 233 A., 439

Prudentius, Aurelius Clemens 405-407. $409 \mathrm{~A}$.

Pyrenäen 26, 32f., 35

Radagaisus 82

Ravenna 305 A., 307 A.

Reims 66, 164 A., 172 A., 176 A., 178 A., 180 A., 182 A., 183 A.

Rhone, Rhoneraum 97, 107, 120 A., 202, 203

Ricimer 65, 86
Riez 209

Rigofredus, 314 A., 321-223

Riothamus 59

Rodez 170 A.

Rom 66, 70-72, 102 A., 105 A., 187 A., 357f., 360-366, 368-372, 409

Romulus Augustus 455

Roujan 218

Rufinus v. Aquleia 121, 405, 407

Ruricius v. Limoges 230, 422 A., 424 $440,443-449,461,463-465$

Rusticus v. Narbonne 187, 460

Rusticus v. Cahors, Bruder des Desiderius of Cahors 456f., 462

Rutilius Namatianus, Cl. 59, 64, 69, 255 $257 \mathrm{~A}$.

Sabinus v. Piacenza 441

Sagittarius v. Gap 98 A.

Saint-Bertrand-de-Comminges (Lugdunum Convernarum/civitas Convenarum) 35, 155 A., 165 A., 177 A., 203, 207f., 213

Saint-Césaire (Arles) 213

Saint-Denis 239 A., 310f., 313-315, 319322

Saintes (Mediolanum) 158 A., 160 A., 165 A., 169 A., 170 A., 171 (Abb. 4), 202, 207

Saint-Germain-des-Prés 316-318

Saint-Girons 165 A.

Saint-Hermentaire (bei Draguignan) 218

Saint-Just (Lyon) 214

Saint-Laurent (Grenoble) 214

Saint-Lizier 35, 165 A.

Saint-Maurice en Valais $s$. Agaune

Saint-Maximin (bei Draguignan) 218

Saint-Victor (Marseille) 214

Sallustius, C. Crispus 409 A.

Salonius v. Genf 107 A.

Salonius v. Embrun 98 A.

Salvian v. Marseille 39, 72f., 255-273, 439f., 443, 445

Salvius v. Albi 456

Samobriva $s$. Amiens

Sapaudia 41

Sarus 83

Saturninus v. Toulouse 207

Scipio Africanus, P. Cornelius 393

Sebastianus, röm. Kaiser 27, 37, 39f.

Seneca, Lucius Annaeus 381 A., 384

Septicius, C. Clarus 422

Septimania 231

Seronatus 65

Servius 339 
Severus, Fl. Libius, röm. Kaiser 87

Sidonius Apollinaris, C. Sollius 38-40, 60-63, 65f., 69, 73, 91f., 99 A., 107f., 108 A., 110 A., 111 A., 113, 118 A., 132 A. ,186f., 229f., 255 A., 262 A., 280-284, 288, 355-373, 401-415, 421-431, 433 A., 435 A., 438, 440, 444f., 448f., 461, 463f.

Sigerich, König der Westgoten 83

Sigibert I. 223, 231 A.

Sigibert III. 456f.

Sigismer 282-285, 287

Silius Italicus 337 A., 348, 368 A.

Simplicius v. Bourges 91

Sisteron 202

Soissons 60, 242

Spanien 25f., 29-35, 38, 40, 53, 80, 83, 105f., 159 A., 234 A., 255, 256 A., 258, 267, 349, 458

s. auch Baetica, Lusitania, Tarraconensis

Statius, P. Papinius 335, 337 A., 428 A.

Stilicho, Fl. 83, 284f., 448 A., 455

Sulpicius Severus 102, 104-107, 111 A., 120f., 129 A., 331f., 400, 410, 413, $441 \mathrm{~A}$.

Sulpicius I. v. Bourges 460

Sulpicius II. v. Bourges 457, 460, 462f., 465

Syagria, Mutter des Bonitus of Clermont 461

Syagrius, Sohn des Aegidius 59f., 68f., 455

Syagrius patricius, Bruder des Desiderius v. Cahors 456f., 462

Symmachus, Qu. Aurelius 421-423

Tacitus 381 A., 383 A.

Tarraconnensis 33

Theoderich I., König der Westgoten 36$40,66,83,85$

Theoderich II., König der Westgoten 66, 86,357

Theoderich d. Gr., König der Ostgoten 45, 53

Theodor v. Fréjus 108 A.

Theodor v. Marseille 239

Theodosius I., röm. Kaiser 31, 33, 209, 401

Theophrast 432 A.

Theopolis 61

Theuderich III. 323

Tibatto, Anführer der Bagaudae 261f., 269

Timotheus, comes unter den Westgoten 88
Toulouse (Tolosa) 33f., 37, 39f., 86, 114 A., 131 A., 153, 154 A., 168 A., 203, 204 (fig. 1), 207, 213, 229 A.

Tour de Vésone 207

Tournai (Turnacum) 163 A., 284

Tourraine 97

Tours (Caesarodunum) 103f., 111, 115 A., 131 A., 160 A., 162 A., 164 A., 172 A., 176 A., 178, 182, 226 A., 227, 228 A., 229 A., 234f

Traianus, M. Ulpius, röm. Kaiser 358, $387,426 \mathrm{~A}$.

Trier 62f., 66, 79, 153, 154 A., 226, 227 A., 331f., 333 A., 399 A., 402f., 439

Trinquetaille 202

Turnacum $s$. Tournai

Uernus 321f.

Urbicus von Riez 132 A.

Ursicinus 439

Vadomarius, König der Alamannen 83

Valenciennes 319 A.

Valentine 177

Valentinian I., röm. Kaiser 285

Valentinian III., röm. Kaiser 38, 84, 261, 357

Valerianus, röm. Kaiser 162 A.

Valerianus v. Cimiez 386

Valerius Flaccus, C. 334

Varro, M. Terentius 405-407, 409 A.

Venantius Fortunatus, Honorius Clementianus 114 A., 115, 130 A., 131 A., 132 A., 134 A., 135 A., 403, 413 A.

Venerandus 463

Veranus v. Vence 107 A.

Vercelli 408 A.

Verecundus, grammaticus 120 A.

Vergilius, P. Maro 69, 281, 333, 335, 336342, 345f., 362, 365 A., 407, 409 A., $415 f$., 466

Verus v. Rodez 462

Verus v. Orange 114 A., 133

Vetranio, röm. Kaiser 68

Victor v. Vita 47 A., $51 \mathrm{f}$.

Victorius 61

Vienne 66, 207, 209

Viennensis 109 A.

Vincentius 61

Vitericus 37, 40

Vivianus v. Saintes 114 A.

Vuistrilingo 457 
Wallia, König der Westgoten 30, 32, 83

Wandregisel, Klostergründer von Fontenelle 457
Zenon, röm. Kaiser 69

Zosimos 59, 255 A., 256 A 


\section{Stellenregister}

ACta Apostolorum

4,32

$436 \mathrm{~A}$.

Agroecius

gramm.

7,113,1-114,6 390 A.

AlkuIN

epist.

178

$415 \mathrm{~A}$.

Ambrosius von MAILAND

epist.

33

33,1

47

48

66

Hel.

13,46

off.

$3,125-138$

virg.

$3,4,37$

AmMianus MarCELlinUs

$15,8,13$

$16,2,1$

$19,6,7$

ARATOR

act.

$1,244-245$

$28 \mathrm{f}$.
283 A.

442 A.

$408 \mathrm{~A}$.

441 A.

441

441 A.

441 A.

$441 \mathrm{~A}$.

$382 \mathrm{~A}$.

$168 \mathrm{~A}$.

$287 \mathrm{~A}$.

$385 \mathrm{~A}$.

409 A.
ARISTOTELES

Eth. Nic.

9

442 A.

sens.

438b8f. $\quad 343$

Augustinus

civ.

$1,6 \quad 415$

$3,8,10 \quad 407 \mathrm{~A}$.

conf.

$1,13,20-21 \quad 337$ A.

epist.

149,13 $366 \mathrm{~A}$

$10^{*} \quad 272 \mathrm{~A}$.

24* 129 A.

Aulus Gellius

$3,19 \quad 465 \mathrm{~A}$.

$18,5 \quad 465 \mathrm{~A}$.

AURELIUS VICTOR

Caes.

39,17-20 $255 \mathrm{~A}$.

AUSONIUS

ephem.

8,24 f. $\quad 340 \mathrm{~A}$.

$8,25 \quad 348 \mathrm{~A}$.

hered.

29-32 177 A. 


\begin{tabular}{|c|c|c|c|}
\hline \multicolumn{2}{|l|}{ epist. } & \multicolumn{2}{|c|}{ DE BELLO ALEXANDRINO } \\
\hline $4,19-24$ & $188 \mathrm{~A}$. & 69,1 & $382 \mathrm{~A}$. \\
\hline \multirow[t]{2}{*}{$4,19-28$} & $70 \mathrm{~A}$. & & \\
\hline & & \multicolumn{2}{|c|}{ BERTRAM VON LE MANS } \\
\hline \multicolumn{2}{|l|}{ ordo } & \multicolumn{2}{|c|}{ Testamentum } \\
\hline 20 & $78 \mathrm{~A}$. & 24 & $240 \mathrm{~A}$. \\
\hline $82-90$ & $177 \mathrm{~A}$. & 25 & $240 \mathrm{~A}$. \\
\hline $120-123$ & $185 \mathrm{~A}$. & 30 & $240 \mathrm{~A}$. \\
\hline \multirow[t]{2}{*}{$128-168$} & $187 \mathrm{~A}$. & 36 & $240 \mathrm{~A}$. \\
\hline & & 71 & $240 \mathrm{~A}$. \\
\hline \multicolumn{4}{|l|}{ prof } \\
\hline praef. & 349 A. & $\begin{array}{l}\text { CAESA } \\
c i v .\end{array}$ & \\
\hline \multicolumn{2}{|l|}{ Cupid. Cruc. } & $2,6,1$ & $381 \mathrm{~A}$. \\
\hline praef. & 332 A., 336 & $2,7,1$ & $381 \mathrm{~A}$. \\
\hline 1 & 348 & & \\
\hline $1-12$ & 340 & \multicolumn{2}{|c|}{ CAESARIUS VON ARLES } \\
\hline $1-44$ & 333 & \multicolumn{2}{|c|}{ serm. } \\
\hline 2 & 342 & 86,1 & $413 \mathrm{~A}$. \\
\hline $3-4$ & 333 & 236,1 & $103 \mathrm{~A}$. \\
\hline 5 & $336,341,342$ & & \\
\hline 6 & 341 & \multicolumn{2}{|c|}{ CAPITULARIA MEROWINGICA } \\
\hline 7 & 343 & 8,11 & $236 \mathrm{~A}$ \\
\hline 8 & 342 & \multirow[t]{2}{*}{9,8} & $235 \mathrm{~A}$. \\
\hline 10 & 341 & & \\
\hline 11 & 341 & \multicolumn{2}{|c|}{ CARTULARIUM LANGOBARDORUM } \\
\hline 18 & 342 & \multirow[t]{2}{*}{17} & \multirow[t]{2}{*}{299 A. } \\
\hline $22-23$ & 342 & & \\
\hline 40 & 341 & \multicolumn{2}{|c|}{ CASSIANUS } \\
\hline 42 & 342 & \multirow{2}{*}{$\begin{array}{l}\text { conf. } \\
14,12\end{array}$} & \multirow[b]{2}{*}{$71 \mathrm{~A}}$. \\
\hline 43 & 342 & & \\
\hline $45-55$ & $333,343 f$ & \multirow{2}{*}{\multicolumn{2}{|c|}{ CASSIODOR }} \\
\hline 54 & 346 & & \\
\hline 55 & 347 & \multicolumn{2}{|c|}{ var. } \\
\hline 56 & 347 & $2,16,5$ & $47 \mathrm{~A}$. \\
\hline $56-98$ & 333 & 2,5 & $51 \mathrm{~A}$. \\
\hline $57-58$ & 333 & 3,40 & $51 \mathrm{~A}$. \\
\hline $62-63$ & 348 & 3,42 & $51 \mathrm{~A}$. \\
\hline $72-74$ & 347 & 4,13 & $51 \mathrm{~A}$. \\
\hline 77 & 347 & 5,9 & $51 \mathrm{~A}$. \\
\hline $88-96$ & $\begin{array}{l}34 / \\
334\end{array}$ & 5,26 & $51 \mathrm{~A}$. \\
\hline $99-103$ & 334 & 6,22 & $51 \mathrm{~A}$. \\
\hline 103 & 334 & 10,18 & $51 \mathrm{~A}$. \\
\hline & & 13,16 & $51 \mathrm{~A}$. \\
\hline $\begin{array}{l}\text { Avitus } \\
\text { hom. }\end{array}$ & & CASSIL & \\
\hline 6 & $134 \mathrm{~A}$. & 76,10 & $257 \mathrm{~A}$. \\
\hline 24 & $228 \mathrm{~A}$. & & \\
\hline
\end{tabular}


Chartae Latinae

Pardessus $355 \quad 242 \mathrm{~A}$.

Pardessus $406 \quad 240$ A.

Pardessus $442 \quad 317$ A.

Tjäder $20 \quad 305 \mathrm{~A}$.

Tjäder $29 \quad 307 \mathrm{~A}$.

Tjäder 31 305 A., 307 A.

Tjädar 31-33 $305 \mathrm{~A}$.

Tjäder 32 307A.

Tjäder $37 \quad 305 \mathrm{~A}$.

Chronica Gallica A. 452

$\begin{array}{ll}117 & 85 \text { A., } 255 \text { A., } 256 \text { A., } \\ & 261 \\ 119 & 255 \text { A., } 261 \\ 123 & 261 \\ 127 & 85 \text { A. } \\ 133 & 255 \text { A., } 261\end{array}$

Cicero, M. Tullius

ad Q. fr.

$1,2,7$

393 A.

Arch.

28

$382 \mathrm{~A}$.

Att.

1,12

$9,10,1$

12,53

$465 \mathrm{~A}$.

$435 \mathrm{~A}$.

$435 \mathrm{~A}$.

Brut.

313

Cluent.

11

off.

$1,17,56$

2,9

3,2

fam.

$5,9,2$

$12,30,1$

$15,16,1$

$15,19,1$

$16,16,2$

$432 \mathrm{~A}$.

$432 \mathrm{~A}$.

$435 \mathrm{~A}$.

$435 \mathrm{~A}$.

$435 \mathrm{~A}$. fin.

2,79

$381 \mathrm{~A}$.

5,18

5,67

$384 \mathrm{~A}$.

382 A.

Lael.

$80 \mathrm{f}$.

432 A.

Manil.

36-38

393 A

Phil.

2,7

$435 \mathrm{~A}$

Tim.

26

384 A.

Tusc.

3,1

3,16

390 A.

387 A.

Verr.

1,34 392 A

2,3,21 $392 \mathrm{~A}$.

2,3,217 $392 \mathrm{~A}$.

Cicero, Qu. Tullius

pet.

$8393 \mathrm{~A}$.

$13 \quad 393$ A.

CIL

XII $2229 \quad 164 \mathrm{~A}$

XII $4355 \quad 186$ A.

XII $5336 \quad 187 \mathrm{~A}$

XIII $128 \quad 177$ A.

XIII $633 \quad 174 \mathrm{~A}$.

XIII $7918 \quad 156$ A.

$390 \mathrm{~A}$.

Claudian

Gild.

$17 \mathrm{ff} . \quad 358 \mathrm{~A}$.

134ff. $363 \mathrm{~A}$

161ff. $363 \mathrm{~A}$.

Codex Euricianus

276

$53 \mathrm{~A}$.

277

$52 \mathrm{~A}$. 
Codex JUSTINIANUS

8,53,11 $307 \mathrm{~A}$.

Codex Theodosianus

$7,6,1$

$8,8,6$

$8,15,5,3$

$9,35,2$

$9,35,6$

$10,17,3$

$11,1,3$

$11,1,14$

$11,7,4$

$11,7,16$

$11,7,17$

$11,7,20$

$11,16,4$

$11,26,2$

$11,28,10$

$12,1,171$

$12,1,79$

$12,3,2$

$12,6,20$

$12,6,22$

$12,10,1$

$13,11,10$

$13,11,13$

$14,10,2-3$

$16,8,3$

264 A.

$265 \mathrm{~A}$.

$264 \mathrm{~A}$.

$264 \mathrm{~A}$

264 A.

$264 \mathrm{~A}$.

264 A.

$264 \mathrm{~A}$.

264 A., 265 A.

264 A., 265 A.

$265 \mathrm{~A}$.

$264 \mathrm{~A}$.

$264 \mathrm{~A}$.

264 A.

266

264 A.

264 A.

$264 \mathrm{~A}$.

$264 \mathrm{~A}$.

264 A., 265 A.

$265 \mathrm{~A}$.

$264 \mathrm{~A}$.

$50 \mathrm{~A}$.

$283 \mathrm{~A}$.

$156 \mathrm{~A}$.

Concilia Galliae

Conc. Agath. c. 20118 A.

Conc. Mat.I c. 5118 A.

\section{CONSTANTIUS VON LYON}

vita Germ.

4110 A., 115 A.

$6104 \mathrm{~A}$.

$12131 \mathrm{~A}$.

$19262 \mathrm{~A}$.

24113 A., 262 A.

28

32

40

255 A., 261 A., 262 A.

110 A.,112 A., 113 A.

255 A., 261 A, 262 A.

CuRTIUs Rufus

$4,2,10$

$4,6,6$
391 A.

$381 \mathrm{~A}$.
143

149

153

155

156

157

DESIDERIUS VON CAHORS

1,5

$458 \mathrm{~A}$.

$1,9 \quad 458 \mathrm{~A}$.

$1,10 \quad 458$ A., 462 A.

$1,11 \quad 239 \mathrm{~A}$.

$1,13 \quad 457 \mathrm{~A}$.

2,1 464 A., 465 A.

$2,2 \quad 462$

$2,11465 \mathrm{~A}$.

$2,12465 \mathrm{~A}$.

$2,16 \quad 462 \mathrm{~A}$.

$2,21 \quad 465 \mathrm{~A}$.

DiPLOMATA KAROLINORUM

$6315 \mathrm{~A}$.

Diplomata MEROVINGICORUM (BRÜHL/KÖLZER)

22

25

$310 \mathrm{~A}$.

$311 \mathrm{~A}$.

$310 \mathrm{~A}$.

$310 \mathrm{~A}$.

$310 \mathrm{~A}$.

297 A., 302 A., 319 A.

297 A., 302 A.

297 A., 302 A.

297 A., 302 A.

297 A., 302 A.

297 A.

297 A.

297 A., 301 A.,

302 A., 319 A.

297 A., 302 A.

298 A., 302 A., 312 A.

297 A., 302 A.,

303 A., 320 A.,

297 A., 302 A.,

303 A., 306 A., 318 A., 319 A.

298 A.

297 A., 302 A.,

306 A., 312 A.

298 A., 299 A.,

302 A., 303 A.,

306 A., 316-318

$298 \mathrm{~A}$.

297 A., 302 A.,

313 A., 314f., 321 A., 322-324

297 A., 302 A.,

306 A., 313-315, 319

322

158

298 A., 305 A. 
167

187

297 A., 302 A. 313 A.

298 A., 302 A.

DYNAMIUS VON MARSEILLE

vita Maxim.

15

16

$115 \mathrm{~A}$.

$115 \mathrm{~A}$.

\section{ENNODIUS}

epist.

7,13

$385 \mathrm{~A}$.

vita Epiph.

$13 \mathrm{f}$.

$113 \mathrm{~A}$.

EPISTUlAe ARELATENSES

8

$84 \mathrm{~A}$.

\section{EPISTUlAe Austrasicae}

5

$136 \mathrm{~A}$.

EUAGRIOS SCHOLASTIKOS

4,28

$134 \mathrm{~A}$.

EUCHERIUS VON LYON

cont.

36-40

36-72

42-47

802-805

form.

690

instr.

1,295-302 $388 \mathrm{~A}$.

1,387-391 389 A.

laud. her.

31-32

42

pass. Acaun.

2

3

9

10

11
389 A.

$390 \mathrm{~A}$.

$103 \mathrm{~A}$.

$386 \mathrm{~A}$.

$390 \mathrm{~A}$.

$386 \mathrm{~A}$.

$388 \mathrm{~A}$.

$380 \mathrm{~A}$.

$390 \mathrm{~A}$.

$382 \mathrm{~A}$.

$380 \mathrm{~A}$.

$380 \mathrm{~A}$.
15

$380 \mathrm{~A}$.

EUSEBIUS VON CAESAREA

hist. eccl.

9,8,15-9,1 $71 \mathrm{~A}$.

EUSEBIUS HISTORICUS

Frg. 2,5

$162 \mathrm{~A}$.

EUSEBIUS GALLICANUS

$51(60), 9 \quad 131 \mathrm{~A}$.

$72(72), 2 \quad 131 \mathrm{~A}$

EUTROP

$9,17,1 \quad 162 \mathrm{~A}$.

$9,20,3 \quad 255 \mathrm{~A}$.

FAUSTUS V. RIEZ

epist. ad Ruricium

2,17-20 429 A.

$5,17 \quad 429 \mathrm{~A}$.

FLORUS

1 praef. $2 \quad 382 \mathrm{~A}$.

$1,22,47 \quad 391 \mathrm{~A}$.

FoRMULAE ANDECAVENSES

1307 A., 309 A.

$32 \quad 309$ A.

$47 \quad 301 \mathrm{~A}$.

$53 \quad 301 \mathrm{~A}$.

Formulae SALicAe BignONIANAE

10 306A.

Fomulae Salicae Merkelianae

21 306A.

33 306A.

34 306A.

FormulaE TURONENSES

$2307 \mathrm{~A}$.

$3307 \mathrm{~A}$.

FREDEGAR

$3,29238 \mathrm{~A}$.

$3,55238 \mathrm{~A}$.

$3,80 \quad 238 \mathrm{~A}$.

3,82f. $238 \mathrm{~A}$.

$4,57 \quad 238 \mathrm{~A}$. 


\begin{tabular}{|c|c|c|c|}
\hline 4,58 & $240 \mathrm{~A}$. & 5,17 & $240 \mathrm{~A}$. \\
\hline 4,73 & $237 \mathrm{~A}$. & 5,18 & $238 \mathrm{~A}$. \\
\hline 4,87 & $237 \mathrm{~A}$. & 5,28 & $235 \mathrm{~A}$. \\
\hline \multirow[t]{2}{*}{4,90} & $240 \mathrm{~A}$. & 5,34 & $235 \mathrm{~A}$. \\
\hline & & 5,45 & $456 \mathrm{~A}$. \\
\hline \multicolumn{2}{|l|}{ cont. } & 5,48 & $232 \mathrm{~A}$. \\
\hline 46 & $238 \mathrm{~A}$. & 6,11 & $232 \mathrm{~A}$. \\
\hline \multirow[t]{2}{*}{48} & $240 \mathrm{~A}$. & 6,25 & $117 \mathrm{~A}$. \\
\hline & & 6,27 & $240 \mathrm{~A}$. \\
\hline \multicolumn{2}{|l|}{ GAIUS } & 6,39 & $460 \mathrm{~A}$. \\
\hline \multicolumn{2}{|l|}{ inst. } & 7,2 & $233 \mathrm{~A}$. \\
\hline 1,119 & 304 A. & $7,12-13$ & $234 \mathrm{~A}$. \\
\hline 2,24 & 304 A., 305 A., 306 A. & 7,15 & $236 \mathrm{~A}$. \\
\hline 4,16 & $304 \mathrm{~A}$ & 7,17 & $231 \mathrm{~A}$. \\
\hline \multirow[t]{2}{*}{4,5} & $305 \mathrm{~A}$. & 7,24 & $234 \mathrm{~A}$. \\
\hline & & $7,34-35$ & $155 \mathrm{~A}$. \\
\hline \multicolumn{2}{|c|}{ GENNADIUS } & 8,21 & $232 \mathrm{~A}$. \\
\hline \multicolumn{2}{|c|}{ vir. ill. } & 8,22 & $456 \mathrm{~A}$. \\
\hline 19 & $104 \mathrm{~A}$. & 8,30 & $238 \mathrm{~A}$. \\
\hline \multirow[t]{2}{*}{70} & $112 \mathrm{~A}$. & 8,31 & $232 \mathrm{~A}$. \\
\hline & & $9,8-11$ & $224 \mathrm{~A}$. \\
\hline \multicolumn{2}{|c|}{ GREGORIUS MAGNUS } & 9,11 & $223 \mathrm{~A}$ \\
\hline \multicolumn{2}{|c|}{ epist. } & 9,20 & 223 A., 224 A., 238 A. \\
\hline $5,53 a$ & $412 \mathrm{~A}$. & 9,30 & $236 \mathrm{~A}$ \\
\hline \multirow[t]{2}{*}{11,34} & $412 \mathrm{~A}$. & 10,7 & $236 \mathrm{~A}$. \\
\hline & & 10,16 & $232 \mathrm{~A}$. \\
\hline \multicolumn{2}{|c|}{ GREGOR VON TOURS } & 10,28 & 224 A. \\
\hline \multicolumn{4}{|c|}{ Franc. } \\
\hline praef.1 & $404 \mathrm{~A}$. & glor. conf. & \\
\hline 1,30 & $182 \mathrm{~A}$ & 12 & $135 \mathrm{~A}$. \\
\hline 1,32 & 162 A., 174 A. & 27 & $182 \mathrm{~A}$ \\
\hline 1,33 & 189 A., 215 & 28 & 115 A., 182 A. \\
\hline 2,23 & 184 A., 232 A. & 40 & $238 \mathrm{~A}$ \\
\hline 2,33 & $238 \mathrm{~A}$. & 58 & $232 \mathrm{~A}$. \\
\hline 2,37 & $61 \mathrm{~A}$ & 60 & $232 \mathrm{~A}$. \\
\hline 3,12 & $464 \mathrm{~A}$ & 78 & $228 \mathrm{~A}$. \\
\hline 3,19 & 183 A., 207,465 A. & 86 & $127 \mathrm{~A}$. \\
\hline 3,29 & $228 \mathrm{~A}$ & 88 & $115 \mathrm{~A}$ \\
\hline 3,36 & $236 \mathrm{~A}$. & 93 & 115 A., 128 A. \\
\hline 4,14 & $238 \mathrm{~A}$. & 94 & $115 \mathrm{~A}$ \\
\hline 4,16 & $238 \mathrm{~A}$. & 108 & $229 \mathrm{~A}$. \\
\hline 4,22 & $240 \mathrm{~A}$ & & \\
\hline 4,42 & 98 A., 238 A. & glor. mart. & \\
\hline 4,43 & $232 \mathrm{~A}$ & 12 & $134 \mathrm{~A}$. \\
\hline 5,1 & $240 \mathrm{~A}$. & 83 & $238 \mathrm{~A}$. \\
\hline 5,11 & $189 \mathrm{~A}$. & & \\
\hline 5,13 & $238 \mathrm{~A}$ & Iul. & \\
\hline 5,14 & 118 A., 238 A. & 9 & $127 \mathrm{~A}$. \\
\hline
\end{tabular}




\begin{tabular}{|c|c|c|c|}
\hline $\begin{array}{l}\text { Mart. } \\
1,26\end{array}$ & $238 \mathrm{~A}$. & $\begin{array}{l}\text { HILARUS VON } \\
\text { epist. }\end{array}$ & \\
\hline 1,36 & $238 \mathrm{~A}$. & 8 & $85 \mathrm{~A}$. \\
\hline 3,53 & $129 \mathrm{~A}$. & & \\
\hline 4,20 & $127 \mathrm{~A}$. & HistORIA Au & \\
\hline 4,29 & $238 \mathrm{~A}$. & vita Prob. & \\
\hline & & $13,5-7$ & $162 \mathrm{~A}$. \\
\hline vit. patr. & & 15,3 & $162 \mathrm{~A}$. \\
\hline 4,2 & $228 \mathrm{~A}$. & & \\
\hline 7 & 114 A. & HOMER & \\
\hline 8,2 & $114 \mathrm{~A}$. & Od. & \\
\hline 8,4 & $115 \mathrm{~A}$. & $11,198-222$ & 345 \\
\hline 17,4 & $228 \mathrm{~A}$. & $11,206-208$ & 345 \\
\hline & & $11,235 \mathrm{ff}$. & $341 \mathrm{~A}$. \\
\hline HERODIA & & $19,562 \mathrm{ff}$. & 340 A. \\
\hline $1,10,1-7$ & $257 \mathrm{~A}$. & & \\
\hline & & HORAZ & \\
\hline HIERONY & & carm. & \\
\hline chron. & & $3,30,6-7$ & 349 A. \\
\hline a. 2303 & $255 \mathrm{~A}$. & & \\
\hline epist. & & $\begin{array}{l}\text { HYDATIUS } \\
\text { chron. }\end{array}$ & \\
\hline $1,14,2$ & $408 \mathrm{~A}$. & 56 & $28 \mathrm{~A}$. \\
\hline $7,17,2$ & $131 \mathrm{~A}$. & 60 & $30 \mathrm{~A}$. \\
\hline 29,1 & 408 & 69 & $34 \mathrm{~A}$. \\
\hline 52 & $106 \mathrm{~A}$. & 117 & $255 \mathrm{~A}$. \\
\hline 58 & $105 \mathrm{~A}$. & 120 & $255 \mathrm{~A}$. \\
\hline 123,15 & $131 \mathrm{~A}$. & $133 \mathrm{f}$. & $255 \mathrm{~A}$. \\
\hline 125 & $106 \mathrm{~A}$. & 150 & $255 \mathrm{~A}$. \\
\hline 125,6 & $460 \mathrm{~A}$. & & \\
\hline 125,20 & $106 \mathrm{~A}$. & ILCV & \\
\hline 127,8 & $408 \mathrm{~A}$. & $1062 b$ & $112 \mathrm{~A}$. \\
\hline & & 1065 & $114 \mathrm{~A}$. \\
\hline in psalm. & & & \\
\hline 138,16 & $385 \mathrm{~A}$. & $\begin{array}{l}\text { ISIDOR VON S } \\
\text { diff. }\end{array}$ & \\
\hline HILARIUS & TIERS & 1,321 & 366 A. \\
\hline hymn. & & 437 & $366 \mathrm{~A}$. \\
\hline $2,33-34$ & $385 \mathrm{~A}$. & & \\
\hline & & orig. & \\
\hline HILARIUS & & $2,21,4$ & 393 A. \\
\hline vita Hon. & & $6,3,2$ & $408 \mathrm{~A}$. \\
\hline 8 & $113 \mathrm{~A}$. & & \\
\hline 9,4 & $107 \mathrm{~A}$. & IUSTIN & \\
\hline $12-14$ & $122 \mathrm{~A}$. & epit. & \\
\hline 20 & $235 \mathrm{~A}$. & $12,4,10$ & $382 \mathrm{~A}$. \\
\hline 37 & $131 \mathrm{~A}$. & & \\
\hline 39,2 & $134 \mathrm{~A}$. & & \\
\hline
\end{tabular}




\begin{tabular}{|c|c|c|c|}
\hline \multirow{2}{*}{$\begin{array}{l}\text { IUVENCU } \\
2,190\end{array}$} & \multirow{3}{*}{$385 \mathrm{~A}}$. & $34,1,1$ & $391 \mathrm{~A}$. \\
\hline & & $34,13,10$ & 383 \\
\hline & & $37,45,11$ & 383 \\
\hline \multicolumn{2}{|c|}{ JONAS VON BOBBIO } & $38,17,1$ & 383 \\
\hline \multicolumn{2}{|c|}{ Vita Columb. } & $38,23,11$ & $382 \mathrm{~A}$. \\
\hline \multirow[t]{2}{*}{2,10} & $242 \mathrm{~A}$. & $38,47,1$ & 383 \\
\hline & & $39,27,4$ & $382 \mathrm{~A}$. \\
\hline \multicolumn{2}{|c|}{ JORDANES } & $39,40,10$ & $392 \mathrm{~A}$. \\
\hline \multicolumn{2}{|c|}{ Get. } & $40,11,10$ & $381 \mathrm{~A}$. \\
\hline $32,164 f$. & $31 \mathrm{~A}$. & & \\
\hline 32,165 & $32 \mathrm{~A}$. & LUCAN & \\
\hline \multirow{2}{*}{34,177} & $37 \mathrm{~A}$. & $6,419-434 a$ & $337 \mathrm{~A}$. \\
\hline & & $6,588-603$ & $337 \mathrm{~A}$. \\
\hline \multicolumn{2}{|l|}{ Rom. } & $6,720 \mathrm{ff}$. & $337 \mathrm{~A}$. \\
\hline \multicolumn{2}{|r|}{$31 \mathrm{~A}}$. & $6,777 \mathrm{ff}$. & $337 \mathrm{~A}$. \\
\hline \multicolumn{2}{|l|}{ JULIAN } & MACROBIUS & \\
\hline \multicolumn{2}{|l|}{ Caes. } & somn. & \\
\hline $314 \mathrm{~A}-\mathrm{B}$ & $162 \mathrm{~A}$. & $1,3,6 \mathrm{ff}$ & $340 \mathrm{~A}$. \\
\hline \multicolumn{2}{|c|}{ JULIAN VON ECLANUM } & MARCULF & \\
\hline \multicolumn{2}{|c|}{ in $I o b$} & 1,12 & 309 A., 311 A. \\
\hline \multirow[t]{2}{*}{3,15} & $385 \mathrm{~A}$. & 1,13 & 309 A., 311 A. \\
\hline & & 1,21 & 309 A. \\
\hline \multicolumn{2}{|c|}{ LEX RIBUARIA } & 1,25 & 297 A., 298 A. \\
\hline 50 & $309 \mathrm{~A}$. & 1,26 & 297 A. \\
\hline \multirow{3}{*}{62} & $309 \mathrm{~A}$. & 1,27 & 297 A., 320 A. \\
\hline & 309 A. & 1,28 & 297 A. \\
\hline & & 1,29 & 297 A. \\
\hline & 1,31 & $311 \mathrm{~A}$. \\
\hline 25,3 & LEX SALICA & 1,35 & $311 \mathrm{~A}$. \\
\hline 44 & $309 \mathrm{~A}$. & 1,36 & $301 \mathrm{~A}$ \\
\hline 46 & $309 \mathrm{~A}$. & 1,37 & 239 A., 297 A., 298 A. \\
\hline 47 & $309 \mathrm{~A}$. & 1,38 & 297 A., 297 A., 298 A. \\
\hline 60 & 309 A. & 2,37 & 307 A. \\
\hline 67 & $305 \mathrm{~A}$ & 2,38 & $307 \mathrm{~A}$. \\
\hline \multirow[t]{2}{*}{100} & 305A., 309 A. & & \\
\hline & & supp. & \\
\hline \multicolumn{2}{|c|}{ LEX VISIGOTHORUM } & 2 & $298 \mathrm{~A}$. \\
\hline $10,1,16$ & 52 & & \\
\hline $10,1,8$ & $52 \mathrm{f}$. & $\begin{array}{l}\text { MEROBAUDES } \\
\text { paneg. poet. }\end{array}$ & \\
\hline \multicolumn{2}{|l|}{ LiviUS } & $8-15$ & $262 \mathrm{~A}$. \\
\hline $5,47,8$ & $391 \mathrm{~A}$. & $8-22$ & $255 \mathrm{~A}$. \\
\hline $9,30,5$ & $391 \mathrm{~A}$. & $148-186$ & $255 \mathrm{~A}$. \\
\hline $21,43,8$ & $382 \mathrm{~A}$. & $24 \mathrm{ff}$. & 361 \\
\hline $25,31,7$ & $382 \mathrm{~A}$. & & \\
\hline $30,34,1$ & $391 \mathrm{~A}$. & & \\
\hline
\end{tabular}


Minucius Felix

1,3

441 A.

CORNELIUS NEPOS

Arist.

13,14

$465 \mathrm{~A}$.

OLYMPIODOR VON THEBEN

frg. 22, 1-2 28

frg. 30

$30 \mathrm{~A}$.

ORIGENES

Cels. 2,30

$71 \mathrm{~A}$.

Orosius

hist.

$7,34,9$

$7,40,10$

$7,42,12$

$7,42,14$

$7,43,1$

$7,43,11-12$

$401 \mathrm{~A}$.

26

$28 \mathrm{~A}$.

$28 \mathrm{~A}$.

$28 \mathrm{~A}$.

$30 \mathrm{~A}$.

OvID

met.

$3,39-510$

341

3,253-312 342

10,57

$345 \mathrm{~A}$.

10,162-219 341

10,298ff. $\quad 347$

$11,7,15 \quad 341$

15,875-79 349 A.

PANEGYRICI LATINI

9 (4), 14,1 $404 \mathrm{~A}$.

$10(2), 4,3 \quad 255 \mathrm{~A}$.

PASSIO LEUDEGARII

$2241 \mathrm{~A}$.

$7238 \mathrm{~A}$.

$9 \quad 240 \mathrm{~A}$.

Passio Praeiecti

$\begin{array}{ll}11 & 235 \mathrm{~A} . \\ 12-14 & 241 \mathrm{~A} . \\ 13 & 232 \mathrm{~A} .\end{array}$

PAULINUS VON MAILAND

vita Ambr.

$1,3 \quad 131 \mathrm{~A}$.

PAULINUS VON NOLA

carm.

$15106 \mathrm{~A}$.

$16106 \mathrm{~A}$.

24,481-483 443 A.

epist.

29,6 102 A.

29,14 $102 \mathrm{~A}$.

$23441 \mathrm{~A}$.

$32,3 \quad 331 \mathrm{~A}$.

$32,6 \quad 332 \mathrm{~A}$.

$32,17 \quad 332 \mathrm{~A}$.

PAUSANIAS

$10,28,1 \quad 334 \mathrm{~A}$.

10,29,3-8 334 A.

10,29,3-9 335 A.

Philostorgios

$12,4 \quad 34 \mathrm{~A}$.

Platon

Tim.

36d-e 384 A.

PLINIUS D. Ä.

nat.

$3,4 \quad 201$

2,24 391 A.

7,7 391 A.

PliniUs D. J.

epist.

$1,1,1 \quad 422 \mathrm{~A}$.

3,7,14-15 348 A.

$6,33 \quad 426 \mathrm{~A}$.

paneg.

49,3 387 A.

PROKOPIOS VON CAESAREA bell. Goth.

1,1,4-5 $48 \mathrm{~A}$. 
Prosper Tiro von AQUiTANIEN carm. de ingrat.

481f.

$385 \mathrm{~A}$.

chron.

1259, A. 416

$31 \mathrm{~A}$.

1271, A. 419

1337

1338

$37 \mathrm{~A}$

37 A., 85 A.

PSEUdo PRosPer

vocat. gent.

2,16 $72 \mathrm{~A}$.

RURICIUS VON LIMOGES

epist.

1,3

1,4

1,17

$2,1,4-10$

2,5

$2,10,4-13$

2,12

2,16

2,17

$2,27,1-8$

2,27

2,28

2,33

$2,33,20-24$

2,36

$2,51,1-11$

2,51

$2,58 \mathrm{f}$.

Querolus

30

RUTILIUS Claudius NAMATIANUS

$1,141-154$

$1,213-216$

SALLuST

Catil.

12,1

54,6
$255 \mathrm{~A}$.

$64 \mathrm{~A}$.

59 A., 255 A.

427 A.

$427 \mathrm{~A}$.

$436 \mathrm{~A}$.

$431 \mathrm{~A}$.

$434 \mathrm{~A}$.

$436 \mathrm{~A}$.

$129 \mathrm{~A}$.

435 A., 447 A.

449 A.

$428 \mathrm{~A}$.

$440 \mathrm{~A}$.

$429 \mathrm{~A}$.

$230 \mathrm{~A}$.

$428 \mathrm{~A}$.

$427 \mathrm{~A}$.

$433 \mathrm{~A}$.

$435 \mathrm{~A}$.

$429 \mathrm{~A}$.

393 A.

392 A. hist.

$1,76 \quad 382$

SALVIAN

epist.

2

439 A.

gub.

1,10-12 260 A., 272 A.

3,22

$3,50-55$

$4,29-31$

4,54

$4,71-77$

$5,1-14$

5,17

$5,17-45$

5,18

5,19-26

5,21

5,21-23

5,21-24

5,21-26

5,22

5,22-24

5,23

5,23-24

5,24

5,24-25

5,25

5,25-26

5,26

5,28

5,28-36

5,29-35

5,30-31

5,33

5,34-35

5,36-37

5,37

5,37-38

5,38-39

5,38-45

5,42

5,43

5,45

5,52-61
$260 \mathrm{~A}$.

$261 \mathrm{~A}$.

$261 \mathrm{~A}$.

$260 \mathrm{~A}$.

261

$263 \mathrm{~A}$.

263, 265

259 A., 263

$263 f$.

263

$263,266,269,270$

270

266

255 A., 259 A.

266f., 269, 270, 271,

272

269 A.

$269 f$.

$267 f$.

263, 271

265

263, 265 A., 268

263

263, 268, 271

264, 270

263

268

263, 265 A.

$263 f$.

263

263, 266

268, 270

268

263

263, 268, 271

263

264

269

263 A. 


$\begin{array}{ll}6,10-38 & 261 \\ 6,50-52 & 260 \text { A., } 272 \text { A. } \\ 6,68-9 & 261 \\ 6,98-99 & 260 \text { A., 272 A. } \\ 7,2 & 260 \text { A., 272 A. } \\ 7,39-45 & 261 \\ 7,91-93 & 261 \text { A. } \\ 7,94 & 261\end{array}$

SCIPIO AFRICANUS MINOR, P. CORNELIUS or. frg.

32

393 A.

\begin{tabular}{|c|c|}
\hline $\begin{array}{l}\text { SENECA } \\
\text { brev. vit. } \\
1,3\end{array}$ & $381 \mathrm{~A}$. \\
\hline \multicolumn{2}{|l|}{ epist. } \\
\hline 17,9 & $381 \mathrm{~A}$. \\
\hline 70,5 & $381 \mathrm{~A}$. \\
\hline \multicolumn{2}{|l|}{ SERVIUS } \\
\hline $\begin{array}{l}\text { Aen. } \\
6,893\end{array}$ & 339 A. \\
\hline \multicolumn{2}{|c|}{$\begin{array}{l}\text { SIDONIUS APOLLINARIS } \\
\text { carm. }\end{array}$} \\
\hline 2 & 64 A., 356 \\
\hline $2,348 \mathrm{ff}$. & 372 \\
\hline 2,351 & 362 A. \\
\hline 5 & 356,363 \\
\hline $5,53 \mathrm{ff}$. & 364 \\
\hline $5,53-55$ & $363 \mathrm{~A}$. \\
\hline $5,56 \mathrm{ff}$. & $363 \mathrm{~A}$. \\
\hline $5,85 \mathrm{ff}$. & 364 \\
\hline $5,98 \mathrm{ff}$. & 367 \\
\hline $5,101-102$ & 368 \\
\hline 5,102 & 367 \\
\hline $5,102-103$ & 368 \\
\hline $5,102 \mathrm{ff}$. & 368A. \\
\hline $5,347-349$ & 365 \\
\hline 5,348 & $368 \mathrm{~A}$. \\
\hline $5,354-363$ & $62 \mathrm{~A}$. \\
\hline $5,529-532$ & $372 \mathrm{~A}$. \\
\hline 5,600 & $362 \mathrm{~A}$. \\
\hline 7 & $356-359$ \\
\hline 7,139 & 369 \\
\hline $7,139-140$ & $70 \mathrm{~A}$. \\
\hline
\end{tabular}

7,139ff.

7,246-248

7,306-315

7,441-451

$7,444 f$ f.

$7,478 \mathrm{f}$.

7,585-598

7,588

10 , praef.

11

12,1-19

16

23,37-47

23,59-62

23,256

epist.

$1,1,1$

$1,1,2$

$1,1,4$

$1,9,7 \mathrm{f}$.

$1,11,5$

$2,1,4$

$2,9,4$

$2,9,5$

2,10

$2,10,1$

$2,10,3$

$3,1,2$

$3,2,3$

$3,3,3$

3,3,3-6

3,9

$4,9,5$

$4,11,6$

$4,13,1$

$4,16,1$

$4,17,2$

4,20,1-3

4,22

$4,24,3 f$.

$4,24,4$

$5,1,1$

$5,10,1$

$5,14,2$

6,10

7,9

7,11
$370 \mathrm{~A}$.

255 A., 262 A.

$39 \mathrm{~A}$.

359

368

$38 \mathrm{~A}$.

$64 \mathrm{~A}$.

363 A., 370

$424 \mathrm{~A}$.

$424 \mathrm{~A}$.

$280 \mathrm{~A}$.

429 A.

$186 \mathrm{~A}$.

$186 \mathrm{~A}$.

$362 \mathrm{~A}$.

$422 \mathrm{~A}$.

$423 \mathrm{~A}$.

$422 \mathrm{~A}$.

$433 \mathrm{~A}$.

$230 \mathrm{~A}$.

$65 \mathrm{~A}$.

405

$405 \mathrm{~A}$.

$427 \mathrm{~A}$.

402 A., 403 A.

$421 \mathrm{~A}$.

$166 \mathrm{~A}$.

$421 \mathrm{~A}$.

448 A.

$61 \mathrm{~A}$.

$59 \mathrm{~A}$.

$108 \mathrm{~A}$.

$411 \mathrm{~A}$.

99 A., 283 A.

$427 \mathrm{~A}$.

$402 \mathrm{~A}$.

$282 \mathrm{~A}$.

$427 \mathrm{~A}$.

$113 \mathrm{~A}$.

$113 \mathrm{~A}$.

$422 \mathrm{~A}$.

402 A., 403 A.

$111 \mathrm{~A}$.

$433 \mathrm{~A}$.

$91 \mathrm{~A}$.

$435 \mathrm{~A}$. 


\begin{tabular}{|c|c|c|c|}
\hline 7,14 & $92 \mathrm{~A}$. & $3,4,2$ & $176 \mathrm{~A}$ \\
\hline $7,16 \mathrm{f}$. & $91 \mathrm{~A}$. & $3,6,2$ & 104 A., 129 A. \\
\hline 7,17 & 369 & $3,17,4$ & $102 \mathrm{~A}$ \\
\hline $7,17,2$ & $131 \mathrm{~A}$ & $3,11,5$ & $105 \mathrm{~A}$. \\
\hline $8,2,2$ & 74 A., 229 A., 448 A. & & \\
\hline $8,6,3$ & 402 A., 403 A. & vita Mart. & \\
\hline $8,10,1$ & 225 A., 226 A. & 9,3 & $103 \mathrm{~A}$ \\
\hline $8,10,2-4$ & $225 \mathrm{~A}$ & 10,2 & 106 A., 391 A. \\
\hline 8,15 & 110 A., 132 A. & 10,3 & $104 \mathrm{~A}$ \\
\hline $9,3,4$ & $108 \mathrm{~A}$ & 10,4 & $104 \mathrm{~A}$. \\
\hline $9,9,13$ & $108 \mathrm{~A}$ & 10,6 & $111 \mathrm{~A}$. \\
\hline \multirow[t]{2}{*}{9,16} & 428 A., 430 A. & $10,8 \mathrm{f}$ & $103 \mathrm{~A}$. \\
\hline & & $12-15$ & $104 \mathrm{~A}$. \\
\hline \multicolumn{2}{|l|}{ SiLIUS ITALICUS } & 20 & $130 \mathrm{~A}$. \\
\hline $7,487-491$ & $368 \mathrm{~A}$. & 20,1 & $103 \mathrm{~A}$. \\
\hline $13,523 \mathrm{ff}$. & $337 \mathrm{~A}$. & 27,3 & $103 \mathrm{~A}$. \\
\hline $13,806-830$ & $337 \mathrm{~A}$. & & \\
\hline $13,831-850$ & $337 \mathrm{~A}$. & $\begin{array}{l}\text { TACITUS } \\
A g r .\end{array}$ & \\
\hline SimPLiCIUS & & 29,4 & 383 \\
\hline \multicolumn{4}{|l|}{ Phys. } \\
\hline \multirow[t]{2}{*}{24,26} & $346 \mathrm{~A}$. & ann. & \\
\hline & & $1,58,1$ & 383 \\
\hline \multicolumn{2}{|l|}{ SOZOMENOS } & $2,71,1$ & 383 \\
\hline \multicolumn{2}{|l|}{ hist. eccl. } & $3,50,1$ & 383 \\
\hline \multirow[t]{2}{*}{$9,8,7$} & $28 \mathrm{~A}$. & $3,52,3$ & 383 \\
\hline & & $3,65,3$ & 383 \\
\hline \multicolumn{2}{|l|}{ Statius } & $4,34,2$ & 383 \\
\hline \multicolumn{2}{|l|}{ Theb. } & $12,10,1$ & 383 \\
\hline $4,473 \mathrm{ff}$ & $337 \mathrm{~A}$. & $12,19,1$ & 383 \\
\hline $4,519-578$ & $337 \mathrm{~A}$. & $12,36,3$ & 383 \\
\hline \multirow[t]{2}{*}{$4,741-742$} & 336 & $14,42,2$ & 383 \\
\hline & & $15,61,4$ & $381 \mathrm{~A}$. \\
\hline \multicolumn{4}{|c|}{ STATUTA ECCLESIAE ANTIQUA } \\
\hline \multirow[t]{2}{*}{25 f. (XLIVf.) } & $118 \mathrm{~A}$. & Germ. & \\
\hline & & 18,3 & $382 \mathrm{~A}$. \\
\hline \multicolumn{4}{|c|}{ SULPICIUS SEVERUS } \\
\hline \multicolumn{2}{|c|}{ chron. } & hist. & \\
\hline $1,1,4$ & $410 \mathrm{~A}$. & $1,15,1$ & 383 \\
\hline \multirow[t]{2}{*}{$2,50,1$} & $105 \mathrm{~A}$. & $1,29,2$ & 383 \\
\hline & & $2,96,2$ & 383 \\
\hline dial. & & $4,57,3$ & 383 \\
\hline $1,23,4$ & $102 \mathrm{~A}$. & $4,64,1$ & 383 \\
\hline $1,23,5 \mathrm{f}$ & $102 \mathrm{~A}$. & $4,65,1$ & 383 \\
\hline $1,24,3$ & $103 \mathrm{~A}$. & & \\
\hline $2,1,2$ & $104 \mathrm{~A}$. & TERTULLIAN & \\
\hline $2,4,1$ & $104 \mathrm{~A}$. & apol. & \\
\hline $2,6,2$ & $401 \mathrm{~A}$. & $30,4 \mathrm{f}$. & $71 \mathrm{~A}$. \\
\hline
\end{tabular}




\begin{tabular}{|c|c|c|c|}
\hline \multicolumn{2}{|c|}{ THEODORET VON KYRRHOS } & 6,439 & 342 \\
\hline \multicolumn{2}{|c|}{ hist. rel. } & $6,440 f$. & 336 \\
\hline \multirow[t]{2}{*}{1,11} & $134 \mathrm{~A}$. & $6,440-476$ & 338 \\
\hline & & $6,445 \mathrm{ff}$ & 341 A. \\
\hline \multicolumn{2}{|l|}{ URANIUS } & 6,451 & 336,341 \\
\hline \multirow[t]{2}{*}{3} & $122 \mathrm{~A}$. & $6,452-454$ & 342 \\
\hline & & 6,462 & 342 \\
\hline \multicolumn{2}{|c|}{ VELLEIUS PATERCULUS } & 6,473 & 342 \\
\hline \multirow[t]{2}{*}{$2,122,2$} & $382 \mathrm{~A}$. & $6,477-547$ & 338 \\
\hline & & $6,494-497$ & 338 \\
\hline \multicolumn{2}{|c|}{ VENANTIUS FORTUNATUS } & $6,517 f$ & 341 \\
\hline \multicolumn{2}{|c|}{ carm. } & $6,548-558$ & 338 \\
\hline $3,1,3$ & 131 A., 134 A. & $6,548-627$ & 338 \\
\hline $3,2,5$ & $131 \mathrm{~A}$. & $6,625 f$ & $465 \mathrm{~A}$. \\
\hline $3,3,23 \mathrm{f}$ & $131 \mathrm{~A}$. & $6,640 \mathrm{f}$. & 339 \\
\hline 3,11 & $130 \mathrm{~A}$. & $6,677 f$ & 339 \\
\hline 10,19 & $156 \mathrm{~A}$. & $6,700-702$ & 339,344 \\
\hline \multirow[t]{2}{*}{$6,2,7$} & 403 & $6,713-715$ & 339 \\
\hline & & 6,851 & 372 \\
\hline \multicolumn{2}{|l|}{ vita Germ. } & $6,852-853$ & $69 \mathrm{~A}$. \\
\hline \multirow[t]{2}{*}{6} & $116 \mathrm{~A}$. & 6,853 & 415 \\
\hline & & 6,887 & 348 \\
\hline & $6,893-898$ & 339 \\
\hline $\begin{array}{l}\text { vita Hil. } \\
12(44)\end{array}$ & $116 \mathrm{~A}$. & $12,244-258$ & 345 \\
\hline \multicolumn{2}{|l|}{ VERGIL } & ecl. & \\
\hline \multicolumn{2}{|l|}{ Aen. } & 10,69 & 347 \\
\hline 1,8 & 341 & & \\
\hline $1,8 \mathrm{ff}$. & 369 & \multicolumn{2}{|c|}{ VICTOR VON VITA } \\
\hline $1,12-14$ & 366 & 1,13 & $52 \mathrm{~A}$. \\
\hline $1,19-22$ & 367,369 & \multirow[t]{2}{*}{1,22} & $52 \mathrm{~A}$. \\
\hline 1,22 & 367 & & \\
\hline $1,257 \mathrm{ff}$. & 370 & \multicolumn{2}{|c|}{ Vita AUdoInI Rotomagensis } \\
\hline $1,278-279$ & $69 \mathrm{~A}$. & \multicolumn{2}{|c|}{$3 \quad 115 \mathrm{~A}}$. \\
\hline 1,367 & 362 & & \\
\hline $4,230 f$ & 373 & \\
\hline $4,365 \mathrm{ff}$ & 372 & \multicolumn{2}{|c|}{5} \\
\hline $4,607 \mathrm{ff}$ & 360 & & \\
\hline 4,621 & $366 \mathrm{~A}$. & \multicolumn{2}{|c|}{ VITA BONITI ARVERNI } \\
\hline $4,624 \mathrm{ff}$ & 365 & $1-2$ & $461 \mathrm{~A}$. \\
\hline 4,625 & 365 & 40 & $243 \mathrm{~A}$. \\
\hline 4,629 & 366 & & \\
\hline 6,327 & 342 & VITA CAESAI & ELATENSIS \\
\hline 6,417 & 342 & 1,24 & $129 \mathrm{~A}$. \\
\hline $6,426 \mathrm{f}$ & 342 & 1,46 & $113 \mathrm{~A}$. \\
\hline $6,426-429$ & 338 & $2,16 f$ & $115 \mathrm{~A}$. \\
\hline $6,430-433$ & 338 & $2,20 \mathrm{f}$. & $115 \mathrm{~A}$. \\
\hline $6,434-439$ & 338 & 2,29 & $115 \mathrm{~A}$. \\
\hline
\end{tabular}




\begin{tabular}{|c|c|c|c|}
\hline 2,35 & $113 \mathrm{~A}$. & \multicolumn{2}{|c|}{ VITA HILARII ARELATENSIS } \\
\hline \multirow[t]{2}{*}{2,42} & $114 \mathrm{~A}$. & 7 & $103 \mathrm{~A}$ \\
\hline & & 10 & 103 A., 107 A., 113 A. \\
\hline \multicolumn{2}{|c|}{ VITA DESIDERII CADURCENSIS } & 11 & $112 \mathrm{~A}$. \\
\hline 1 & 460 A., 464 A. & 15 & $112 \mathrm{~A}$ \\
\hline 1,1 & $456 \mathrm{~A}$. & 16 & 128 A., 129 A. \\
\hline $1,4-5$ & $457 \mathrm{~A}$. & 18 & $110 \mathrm{~A}$ \\
\hline 2 & $460 \mathrm{~A}$. & 19 & $112 \mathrm{~A}$. \\
\hline $2-3$ & $456 \mathrm{~A}$. & & \\
\hline 15 & 457 A., 462 A. & \multicolumn{2}{|c|}{ VITA IUSTI LuGDUNENSIS } \\
\hline $18-19$ & $458 \mathrm{~A}$ & $2-5$ & $122 \mathrm{~A}$. \\
\hline \multicolumn{2}{|c|}{ ViTA ELIGII NOVIOMAGENSIS } & \multicolumn{2}{|c|}{ Vita LuPI TRECENSIS } \\
\hline 1,12 & $115 \mathrm{~A}$. & 7 & $110 \mathrm{~A}$. \\
\hline 1,17 & $242 \mathrm{~A}$. & & \\
\hline \multirow[t]{2}{*}{$8-9$} & $462 \mathrm{~A}$. & \multicolumn{2}{|c|}{ VITA NiCETII LUGDUNENSIS } \\
\hline & & 4 & $114 \mathrm{~A}$ \\
\hline \multicolumn{4}{|c|}{ VITA EUTROPII AURISICANI } \\
\hline p. $52 \mathrm{f}$. & $133 \mathrm{~A}$. & \multicolumn{2}{|c|}{ Vita ViVIANi SANTONENSIS } \\
\hline p. 56f. & $114 \mathrm{~A}$. & 4 & $114 \mathrm{~A}$. \\
\hline \multirow[t]{2}{*}{ p. 64} & $134 \mathrm{~A}$. & \multirow{2}{*}{\multicolumn{2}{|c|}{ Zosimos }} \\
\hline & & & \\
\hline \multicolumn{2}{|c|}{ Vita GenOVEFAe PaRisiensis } & 1,67 & $162 \mathrm{~A}$. \\
\hline 12 & $111 \mathrm{~A}$. & $5,6,1$ & 134 A. \\
\hline 30 & $117 \mathrm{~A}$. & $6,2,5$ & $255 \mathrm{~A}$ \\
\hline
\end{tabular}



